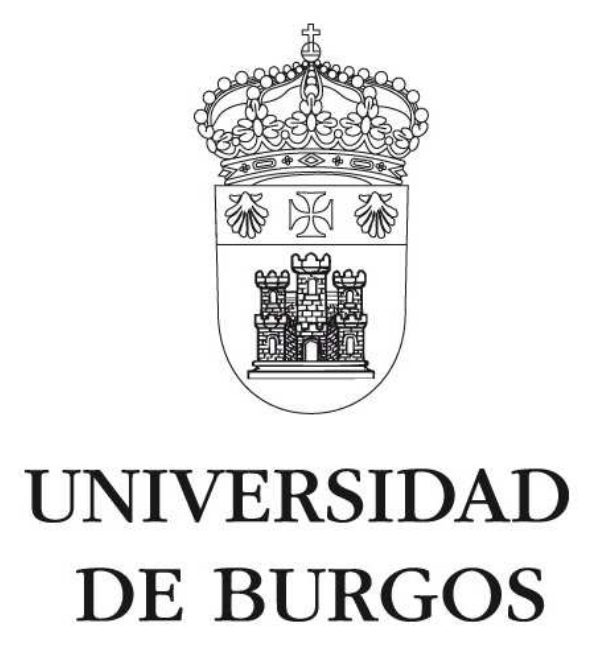

TESIS DOCTORAL

\title{
RELACIÓN ENTRE LA DISTRIBUCIÓN DEL TIEMPO Y LAS NUEVAS TECNOLOGÍAS EN LOS ADOLESCENTES
}

Doctoranda : Leyre de Miguel Tapia

Director: Dr. Ignacio Fontaneda González

Codirectora: Dra. Beatriz Nuñez Angulo

Burgos, 2015 



\section{AGRADECIMIENTOS}

A Nacho por confiar en mí. Por transmitirme la inquietud por la investigación con profesionalidad y paciencia. Por haber tenido la habilidad de encadenar retos, inevitablemente atractivos, que han tomado forma en este trabajo. Gracias por tu implicación y dedicación. Gracias por tu tiempo.

A Bea, que se unió a este proyecto aportando la visión que nos complementaba, por tu compromiso en este trabajo y por tener una palabra de apoyo en los momentos más complicados.

A los centros educativos que nos han abierto sus puertas, permitiéndonos recoger la información que necesitábamos.

A mi familia, a mis padres y a mi hermano, por demostrar su confianza en mí, transmitiéndome constantemente que la constancia me hace capaz de conseguir los objetivos propuestos. A mi abuela, que pelea con sus limitaciones y me demuestra su amor, al introducir la palabra estudiar en todas sus frases.

A Javi por mostrarme su apoyo incondicional en todas mis aventuras. 



\section{INDICE}

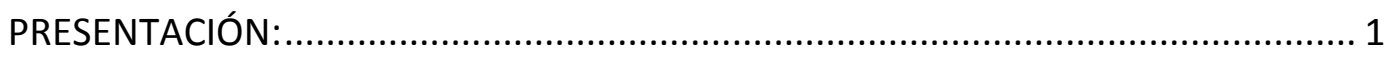

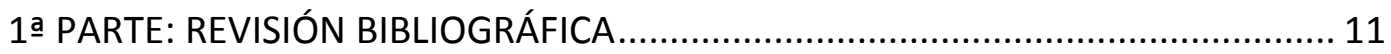

Capítulo 1.- USO DEL TIEMPO DE LOS ADOLESCENTES: .......................................11

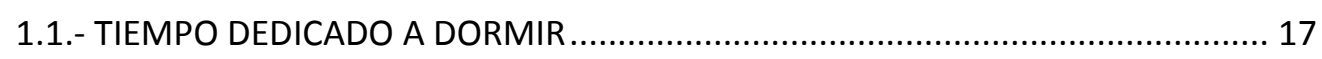

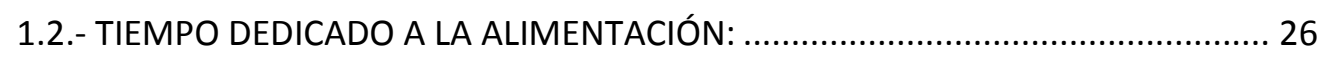

1.3.- TIEMPO DEDICADO A LA HIGIENE Y EL CUIDADO PERSONAL: .......................... 27

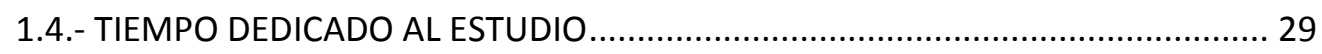

1.5.- TIEMPO DEDICADO A ACTIVIDADES EXTRAESCOLARES: .................................. 32

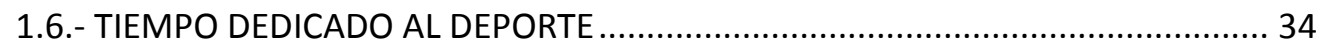

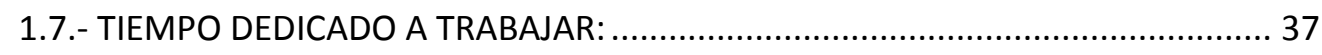

1.8.- TIEMPO DEDICADO AL TRABAJO DOMÉSTICO ................................................ 41

1.9.- TIEMPO LIBRE Y TIEMPO DEDICADO AL OCIO: .................................................. 43

1.10.- TIEMPO DEDICADO A LAS NUEVAS TECNOLOGÍAS DE INFORMACIÓN Y

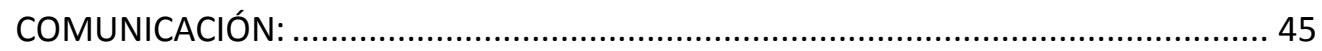

Capítulo 2.- ADOLESCENTES Y NUEVAS TECNOLOGÍAS:.......................................49

2.1.- NATIVOS DIGITALES VERSUS INMIGRANTES DIGITALES: LA BRECHA DIGITAL. 50

2.2.- LA RELACIÓN DE LOS ADOLESCENTES CON LAS NUEVAS TECNOLOGÍAS:........ 51

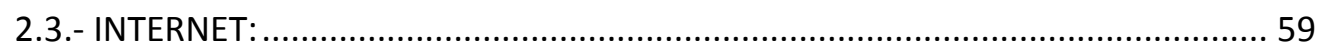

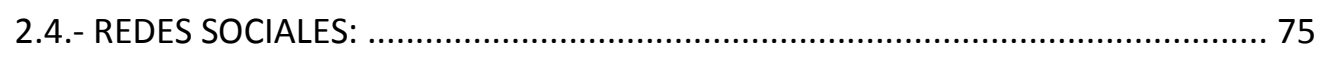

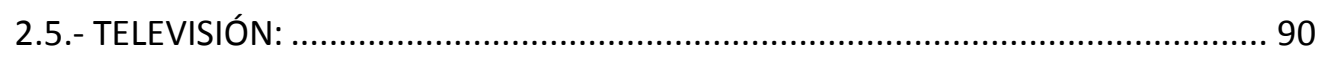

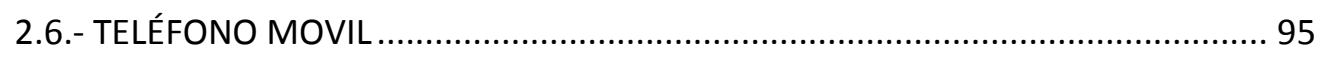

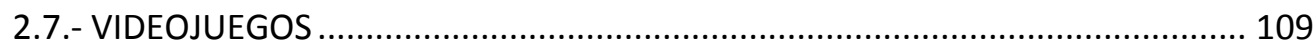

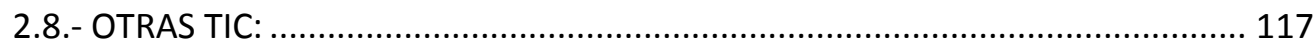

2.9.- EDUCAR A LOS ADOLESCENTES EN LAS NUEVAS TECNOLOGÍAS:................... 118 
2a PARTE: DESARROLLO DE LA INVESTIGACIÓN ........................................... 127

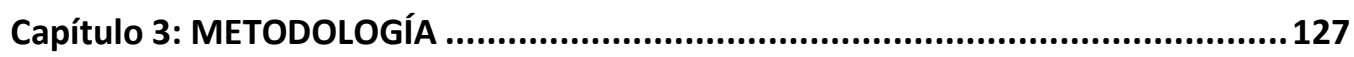

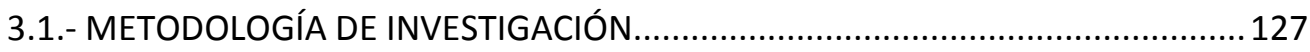

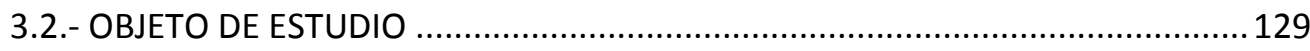

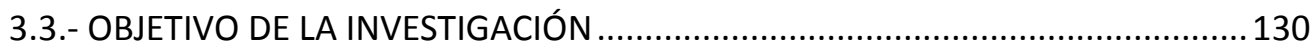

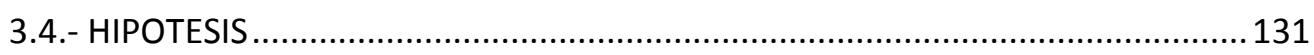

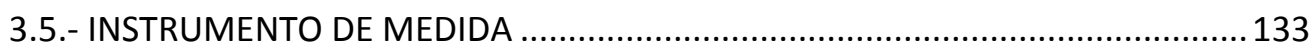

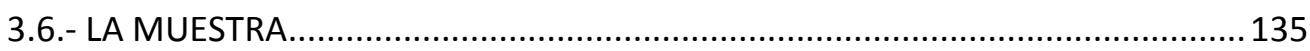

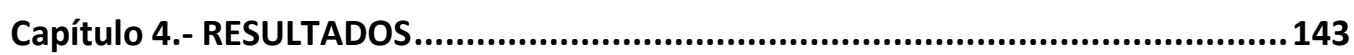

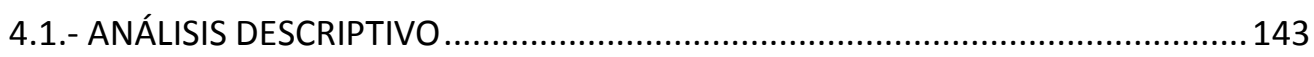

4.2.- ANÁLISIS DEL USO DEL TIEMPO DE LOS ADOLESCENTES:..............................155

4.3.- LA RELACIÓN DE LOS ADOLESCENTES CON LAS NUEVAS TECNOLOGÍAS: .......229

4.4.- USO DEL TIEMPO Y NUEVAS TECNOLOGÍAS ................................................... 275

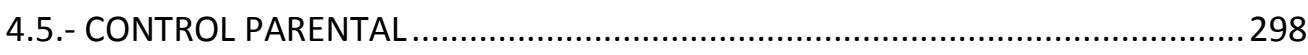

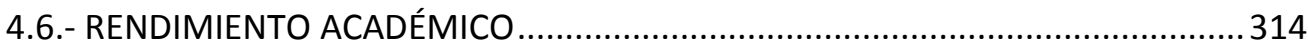

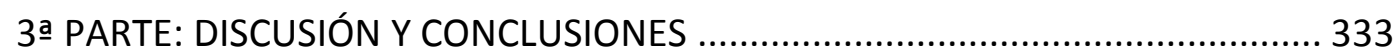

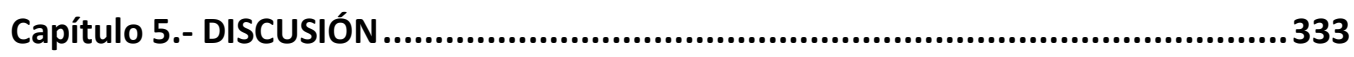

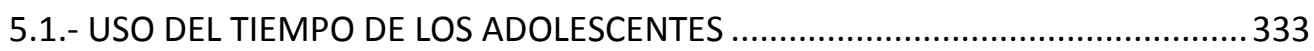

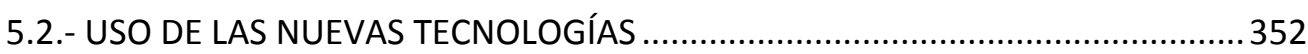

5.3.- SATISFACCIÓN ACADÉMICA Y BIENESTAR PERSONAL: ....................................376

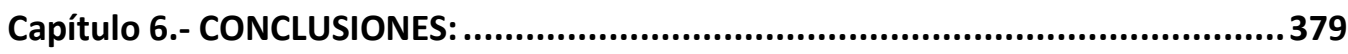

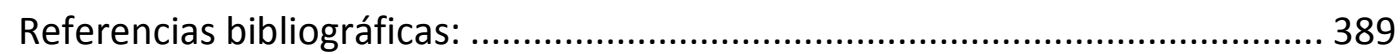

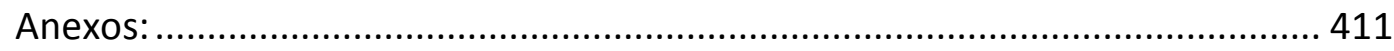

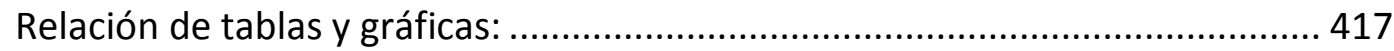




\section{PRESENTACIÓN:}

El estudio del uso del tiempo es actualmente un tema de gran importancia en el ámbito de la investigación. El interés existente en conocer el tiempo que los distintos miembros de la sociedad destinamos a realizar las distintas actividades cotidianas (dormir, trabajar, ocio, estudiar o cuidado personal) es creciente. La realidad evidente es que el día tiene 24 horas, por lo que el tiempo es un bien escaso. El aumento del tiempo dedicado a una actividad, conlleva la disminución de horas dedicadas a otra (Robinson, 1999). Por sentido común, el patrón de distribución del tiempo está ligado a la obtención de diferentes resultados de lo que deriva, alcanzar el éxito y la satisfacción personal, que es la razón que justifica nuestro interés por el tema.

La adolescencia es un periodo de exploración en el uso del tiempo en esta etapa varía notablemente con respecto a otros momentos de la vida (Shanahan \& Flaherty, 2001). Nos planteamos, con suma inquietud, si los adolescentes, regidos en algunos casos por cargados horarios ajustados al milímetro, invierten el tiempo en actividades que les preparan para ser adultos en la sociedad global del siglo XXI. Del mismo modo, nos interesamos por posicionarnos en el otro extremo y preguntarnos: ¿puede darse la circunstancia de que estemos proponiendo un elevado número de actividades a los adolescentes, que limitan su tiempo libre necesario para pensar, desarrollarse interiormente, descubrirse a sí mismos y crecer?, o ¿puede considerarse el tiempo libre un riesgo, por lo tanto es conveniente estructurar el tiempo de los adolescentes?

La gestión del tiempo de un adolescente, influenciado por familiares, educación o entorno, tiene una fuerte relación con su desarrollo, puesto que le permite entablar diferentes relaciones sociales e ir definiendo la línea que guiará su futuro.

Por otro lado, las nuevas tecnologías de la información y comunicación (TIC), están ligadas al uso del tiempo de los adolescentes. Las nuevas tecnologías han irrumpido en la vida cotidiana de manera contundente. Los ciudadanos recibimos a diario multitud de mensajes. De hecho, carecemos de tiempo material para poder procesarlos todos. Esta situación desencadena que ciertos estratos de la sociedad, experimenten niveles de 
aturdimiento. Se ha acuñado, en los últimos años, un nuevo término para definir la faceta tóxica del exceso de información denominado infoxicación.

En el pasado, la llegada de forma masiva de los aparatos, como la televisión a los hogares significó un cambio en los hábitos del uso del tiempo de las familias. Nos planteamos la siguiente pregunta: ¿veían más la televisión los adolescentes de los años 90 que los de los años 70? El sentido común parece respondernos afirmativamente. Pero ahora bien, ¿ven más la televisión los adolescentes actuales que los de los años 90 ? Esta pregunta nos genera incertidumbre. ¿Cómo las nuevas tecnologías, a las que los adolescentes han tenido acceso de forma masiva en el siglo XXI, han modificado los hábitos de su uso del tiempo? La llegada de los ordenadores, teléfonos móviles, consolas y otros dispositivos digitales significó una revolución, pero ¿qué ha supuesto la accesibilidad de internet en todos estos dispositivos en la vida cotidiana de los adolescentes?

Actualmente, internet se ha convertido en una herramienta cultural y social que no conoce fronteras. Internet y las redes sociales, han revolucionado nuestra manera de vivir, de comunicarnos y de socializar y, queremos matizar que han llegado para quedarse. 17 años después de la fundación de Google, 11 años después del nacimiento de Facebook, 10 años después del primer video de YouTube, 8 años después del primer smartphone de pantalla táctil, casi 6 años después del lanzamiento del primer ipad, tenemos acceso a equipamientos y servicios que ni tan siquiera podíamos imaginar hace unos años.

Navegar por internet, las redes sociales, los videojuegos online o los smartphones han supuesto un cambio radical en la forma de gestionar nuestra vida y nuestras relaciones con las demás personas (Munoz-Miralles et al., 2014). Este cambio es palpable principalmente en los adultos, puesto que lo han experimentado en primera persona en los últimos años (inmigrantes digitales). No podemos decir lo mismo para los niños y adolescentes, ya que en muchos casos, han vivido rodeados de estas nuevas tecnologías desde su nacimiento (nativos digitales). 
La elaboración de esta investigación viene suscitada por el interés sobre el uso del tiempo de los adolescentes y su relación con las nuevas tecnologías, además de vislumbrar cómo las nuevas tecnologías afectan al reparto de su tiempo, que constituye el objeto del presente trabajo. El fin último nos llevará a tratar de identificar relaciones entre el uso del tiempo y la gestión de las nuevas tecnologías, el triunfo académico y la satisfacción personal.

Por lo tanto, nos vamos a encontrar en este estudio dos líneas de investigación, que son motivo de nuestro interés:

1. el uso del tiempo por parte de los adolescentes: analizamos el soporte teórico que versa sobre el uso del tiempo de los adolescentes en diferentes países, con el objetivo de analizar y comparar la cantidad de tiempo que destinan a realizar cada actividad. Profundizamos en el estudio de los factores sociodemográficos que establecen diferencias en el uso del tiempo de cada una de las actividades analizadas (Hilbrecht, Zuzanek \& Mannell, 2008). Una de las conclusiones que entendemos es de interés general para la sociedad actual es obtener información sobre las actividades que pueden influir positivamente en el desarrollo del adolescente, con el objetivo de fomentar su realización. Las distintas alternativas del uso del tiempo, pueden definir ciertas pautas en su comportamiento en la etapa de adultos (Dumais, 2008) que, a su vez, pueden influir en su éxito académico y potenciar sus actitudes y habilidades que orienten su futuro.

2. el uso y la gestión de las nuevas tecnologías por los adolescentes: profundizamos en el estudio del uso de las TIC por los adolescentes, actividad coloquialmente conocida como "tiempo frente a una pantalla". Los objetivos principales en este apartado son los siguientes:

a) identificar el tipo y preferencias de TIC que utilizan.

b) cuantificar el tiempo que dedican cada una de ellas.

En este punto, al igual que en el anterior, consideramos vital incidir sobre la importancia de las fechas de los estudios analizados. La sociedad de la 
información avanza a velocidad vertiginosa, principalmente en los países desarrollados. Por esta razón, los estudios tienden a quedarse obsoletos en cortos periodos de tiempo.

c) analizar las consecuencias, tanto las positivas como las negativas, del uso de las nuevas tecnologías en el proceso de maduración del adolescente.

d) Determinar el control ejercido por los padres y las normas sobre el uso correcto de las nuevas tecnologías.

Dentro de las nuevas tecnologías debemos destacar las redes sociales y la conectividad a internet de los smartphones. Es necesario que hagamos mención especial a la aplicación estrella del momento: el WhatsApp. Durante la realización de esta investigación, hemos visitado en numerosas ocasiones las bibliotecas burgalesas, con el objetivo de tener visibilidad sobre los hábitos de estudio de los adolescentes actuales. Tras experimentar este contacto, se nos hace difícil plantearnos los métodos que deben seguir los adolescentes para concentrarse a la hora del estudio, siendo conscientes de que tienen a su alcance un dispositivo electrónico que le permite estar constantemente conectados con el exterior. Observamos que las miradas a la pantalla, en algunos casos, son constantes. Del mismo modo, nos planteamos la dificultad encontrada actualmente por los adolescentes para asegurar la calidad del sueño que puede verse perturbada por la accesibilidad a estos dispositivos durante la noche. El insomnio de uno de los participantes en un grupo de WhatsApp puede provocar una reacción en cadena, que impida dormir al resto de participantes que no hayan tomado la precaución de apagar su dispositivo móvil. Es una realidad.

Existe un soporte teórico importante sobre las relaciones entre las nuevas tecnologías, los medios de comunicación y los adolescentes. Algunos están orientados a reforzar su uso para obtener mayor satisfacción y bienestar en los adolescentes. Sin embargo, otros estudios anticipan la enorme carga de trabajo pendiente por desempeñar en este campo, puesto que el uso de nuevas tecnologías por parte de los adolescentes, el mal uso y/o abuso de las nuevas tecnologías y de los medios de comunicación pueden 
afectar negativamente al adolescente y contribuir a desarrollar en ellos comportamientos de riesgo (Cookingham \& Ryan, 2015).

El cerebro humano, en la etapa de la adolescencia, es aún moldeable, por lo que la irrupción de las nuevas tecnologías en su vida cotidiana puede modificar el patrón del uso de su tiempo, de manera más marcada que en etapas posteriores de la vida. El tiempo dedicado al uso de las nuevas tecnologías por parte de los adolescentes representa una parte tan importante de su actividad diaria que probablemente esté marcando un nuevo estilo de vida (Munoz-Miralles et al., 2014).

La adolescencia es un período durante el cual los jóvenes orientan su futuro y lo encaminan hacia una dirección determinada dependiendo, entre otros factores, de las experiencias vividas en relación a su uso del tiempo (Shanahan \& Flaherty, 2001).

Estamos especialmente interesados en analizar los efectos positivos o negativos tanto de los hábitos del uso del tiempo como de la gestión de las nuevas tecnologías. Actualmente, el papel de expertos tecnológicos en los hogares lo tienen los más jóvenes. Los adolescentes son conocedores de su supremacía puesto que conocen las limitaciones en este campo de los inmigrantes digitales (existe una evidente brecha digital) y creen saberlo todo. Pueden llegar a pecar de exceso de confianza. Además, el hecho de que en muchos ámbitos, los responsables de la educación (padres, profesores y educadores) no posean conocimientos suficientes para aconsejar a los menores sobre uso apropiado de las nuevas tecnologías, provoca que se afiancen aún más en su papel de expertos. Por esta razón, es importante concienciar de la necesidad de establecer barreras en el uso del tiempo y la gestión de las nuevas tecnologías. El control parental, junto con la educación en medios, desempeña un papel decisivo para convertir el uso de las nuevas tecnologías y su interrelación en la vida cotidiana de los adolescentes en una ventaja competitiva para ellos. 

$1^{\text {a Parte: }}$

\section{REVISIÓN}

\section{BIBLIOGRÁFICA}





\section{Capitulo 1:}

\section{Uso del tiempo de los}

adolescentes 



\section{1a PARTE: REVISIÓN BIBLIOGRÁFICA}

\section{Capítulo 1.- USO DEL TIEMPO DE LOS ADOLESCENTES:}

El estudio del uso del tiempo en niños y adolescentes es un tema de debate público desde los años 20 (Larson, 2001) y que ha ganado protagonismo con los años. Según el autor citado anteriormente, ha sido en el siglo XXI, cuando ha saltado una alarma en la sociedad de Estados Unidos por el escaso tiempo que los jóvenes norteamericanos pasan con sus padres y dedican a realizar las tareas del colegio. Sin embargo, dedican demasiado tiempo a ver la televisión y a jugar a videojuegos o navegar por internet.

El control de los padres en el uso del tiempo de sus hijos está relacionado con una dedicación mayor a actividades estructuradas con objetivos educativos por parte de los adolescentes (Bae \& Wickrama, 2014).

En Estados Unidos, las horas libres tras el colegio, se han convertido para los adolescentes en un tiempo de riesgo, puesto que es un tiempo sin supervisión (Larson, 2001). Pero, ¿se puede afirmar que las pautas del uso del tiempo son similares en el resto de países desarrollados?

Se ha tratado de comprobar si la relación entre el uso del tiempo de los adolescentes y el éxito, al menos académico, puede traducirse en un modelo. Dos de los modelos propuestos son los siguientes:

- La teoría de la Reproducción (Bourdieu, 1973).

- La teoría de la Movilidad (DiMaggio, 1982).

La Teoría de la Reproducción de Bourdieu (1973) establece que la desigualdad social se reproduce por el sistema educativo y el uso del tiempo, es decir, los estudiantes pertenecientes a un alto nivel socioeconómico tienen más posibilidades de destinar su tiempo a realizar actividades que les encaminen a la obtención de éxitos escolares. Esto puede proporcionarles una cultura rica, que les ayude a posicionarse en lugares más privilegiadas en un futuro. Este sociólogo mantiene que los adolescentes de entornos 
10 Parte

Capítulo 1: Uso del tiempo de los adolescentes

privilegiados poseen mejor cultura que los adolescentes con menos posibilidades. Esta cultura, generalmente ha sido heredada de sus padres y los adolescentes podrán dejársela de herencia a sus hijos.

Son varios los autores que apoyan, con sus investigaciones, este modelo. En algunos casos manifiestan que los hijos de universitarios participan en más actividades extraescolares y tienen más opciones de llegar a la universidad que los hijos de padres no universitarios (Aschaffenburg \& Maas, 1997). Los progenitores de clase media son más proclives que los de clase trabajadora a involucrar a sus hijos, desde primaria, en múltiples actividades como futbol, clase de piano o boy-scouts (Lareau, 2003).

Sin embargo, igualmente consideramos necesario prestar atención a la Teoría de la Movilidad (DiMaggio, 1982) que defiende el modelo de movilidad cultural. Éste comprobó empíricamente que la participación en actividades extraescolares culturales son más beneficiosas para los estudiantes (masculinos, según su estudio) de bajo nivel socioeconómico. La participación en actividades culturales puede llegar a ser un trampolín para que los adolescentes puedan, con el tiempo, saltar de un estatus socioeconómico bajo a otro más alto e incrementar sus posibilidades de futuro.

Encontramos más evidencias sobre el modelo de movilidad cultural, en autores que han investigado el desarrollo de adolescentes de diferentes razas o etnias. Los africanos americanos utilizan las actividades extraescolares culturales como una estrategia para mejorar su nivel socioeconómico (Kalmijn \& Kraaykamp, 1996). Dumais (2002) apoya, aunque ligeramente, la teoría de la movilidad, concluyendo que los estudiantes de menor nivel económico obtienen más beneficios con la realización de actividades extraescolares relacionadas con el ámbito educativo.

Tras estudiar las dos corrientes, podemos concluir que la Teoría la Reproducción y de la Movilidad pueden ser compatibles. Los adolescentes de bajo nivel socioeconómico tienen más dificultades, por su herencia cultural, a acceder a actividades que puedan reportarles beneficios en un futuro. Sin embargo, en el caso de que tengan la 
oportunidad de realizar estas actividades, obtienen de ellas un mayor rendimiento que puede ayudarles a cambiar su estatus socioeconómico futuro.

Estados Unidos es uno de los países donde más esfuerzos se realizan para estudiar el uso del tiempo, como bien demuestra por ejemplo, el número de encuestas sobre este tema realizadas en este país. Algunas de las más relevantes y populares son:

a) American Time Use Survey (ATUS): encuesta realizada anualmente por el Bureau of Labor Statistics. Esta encuesta ha sido cumplimentada por aproximadamente 136.000 personas desde el año 2003 hasta el 2012. Los resultados de estas encuestas, representan de manera estimada cómo, dónde y con quién utilizan su tiempo los ciudadanos norteamericanos de todas las edades. De ella, se puede obtener información sobre el uso del tiempo de los adolescentes estadounidenses escolarizados de entre 15 y 19 años, disgregado en una serie de actividades (educación, trabajo, dormir, tiempo libre y ocio, deportes y juego, actividades religiosas y voluntariado) con el objetivo de obtener conclusiones al respecto.

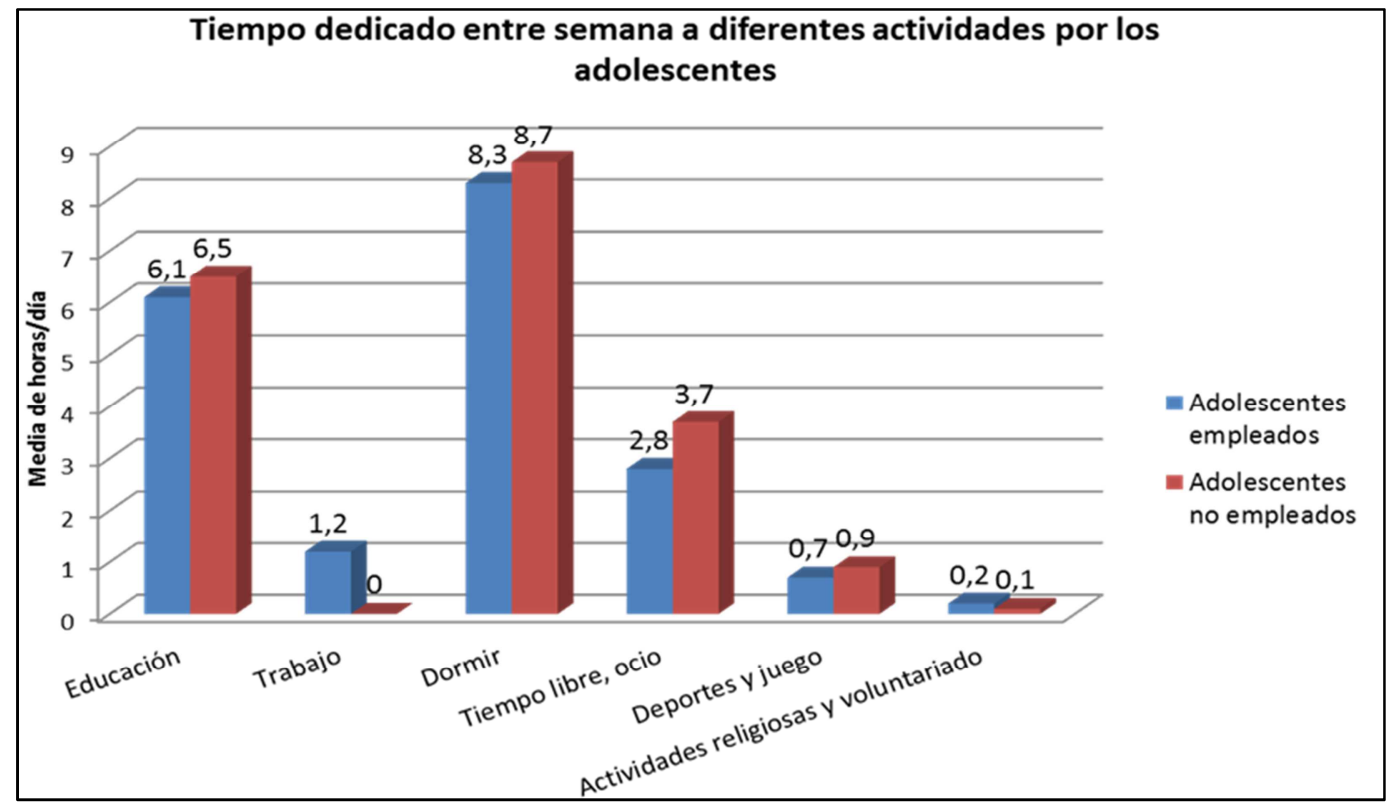

Gráfico 1: tiempo dedicado por los adolescentes entre semana a diferentes actividades. Fuente: Bureau of Labor Statistics. American Time Use Survey (media de horas al día 2008-2010) 
Se consideran sólo los datos aportados para los días entre semana de las semanas que no pertenecen al periodo vacacional, es decir, de Enero a Mayo y de Septiembre a Diciembre. Como puede observarse en el gráfico 1, en Estados Unidos se estudia por separado el uso del tiempo de los adolescentes que tienen un empleo y de los que no lo tienen, puesto que el porcentaje de adolescentes que tienen un empleo es importante. Puede observarse que los adolescentes que dedican tiempo a trabajar, se ven obligados a dedicar menos tiempo a realizar otras actividades.

b) Current Population Survey (CPS): encuesta mensual realizada por la oficina del censo de Estados Unidos a 60.000 hogares que recoge información sobre el uso del tiempo.

c) Monitoring the Future (MTF): encuesta anual realizada por el Institute of Survey Research, Universidad de Michigan. El número de alumnos encuestados es de entre 14.000 y 18.000 pertenecientes al $12^{\circ}$ grado. La encuesta se realiza entre 125 y 140 colegios, tanto públicos como privados.

En España, es relevante en este campo, la encuesta de empleo del tiempo, realizada por el Instituto Nacional de Estadística (INE). Esta encuesta incluye en un mismo grupo de población a las personas entre 0 y 25 años, por lo que el resultado obtenido no es referido exclusivamente a nuestro grupo de estudio, los adolescentes. Sin embargo, los resultados de esta encuesta nos aportan una visión general del uso del tiempo del segmento poblacional español comprendido entre 0 y 25 años.

Como se puede observar en el gráfico 2, la distribución estimada del tiempo de los menores de 25 años en España según la encuesta de empleo del tiempo 2009-2010 realizada por el INE, es la siguiente:

$\checkmark 12$ horas al día dedicados a cuidados personales (dormir, comer e higiene personal)

$\checkmark$ menos de 1 horas al día dedicado a trabajo remunerado

$\checkmark$ 3:13 horas al día dedicado al estudio 
$\checkmark$ ligeramente más de 1 horas al día destinado al hogar y familia

$\checkmark$ menos de 30 minutos/día dedicado trabajo voluntario y reuniones

$\checkmark$ prácticamente 2 horas al día destinadas a la vida social y diversión)

$\checkmark$ menos de 1 horas al día deportes y actividades al aire

$\checkmark \quad$ 1:23 horas al día para aficiones e informática (casi el doble que en 2002-2003)

$\checkmark$ más de 2 horas a los medios de comunicación

$\checkmark$ menos de 1 horas al día a trayectos y empleo del tiempo no especificado.

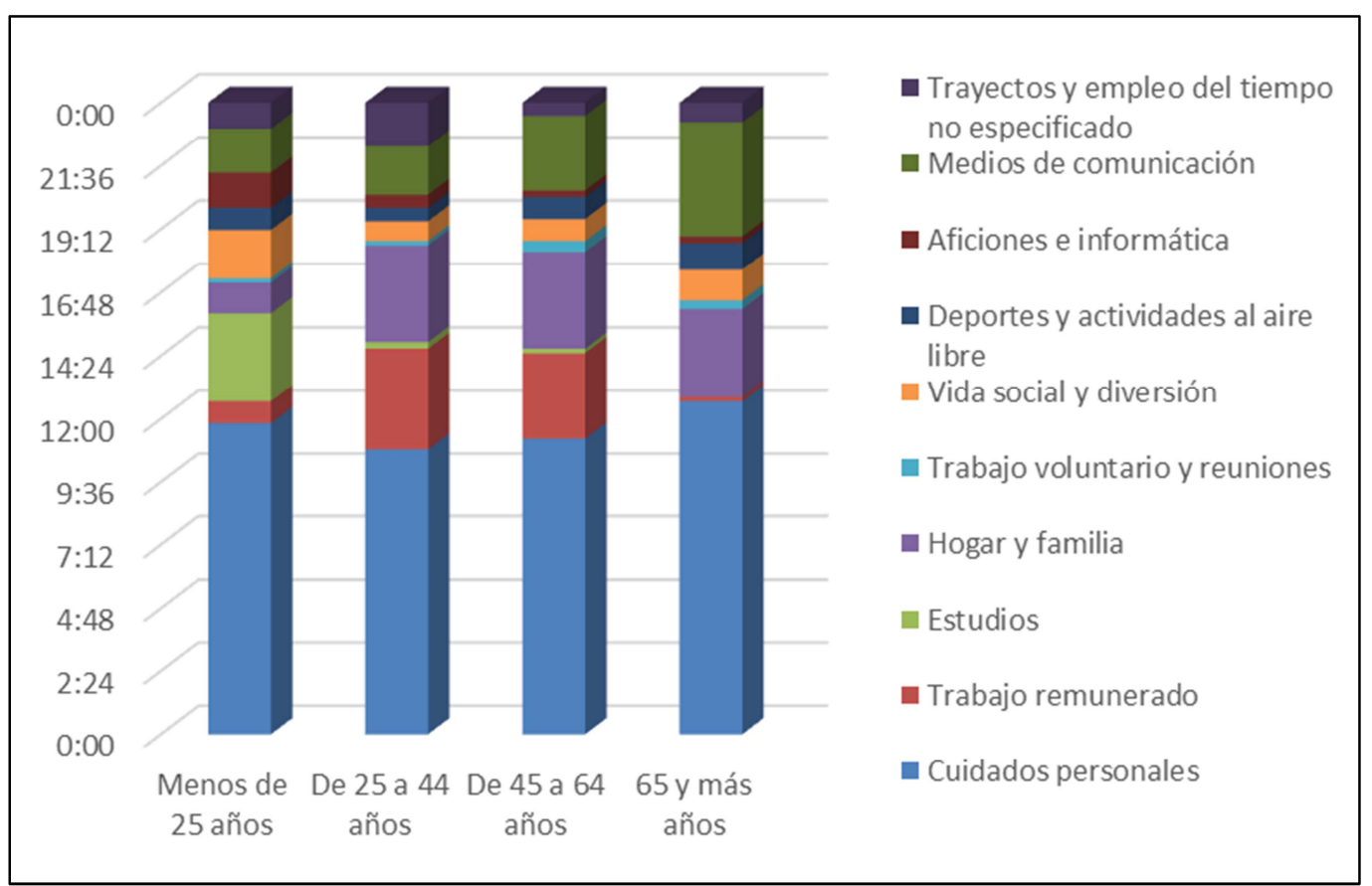

Gráfico 2: distribución de actividades por grupo de edad, 2009-2010. Fuente: datos obtenidos en la Encuesta de Empleo del Tiempo realizada por el INE 2009-2010

El Instituto de la Juventud es otra organización que dedica esfuerzos a estudiar los hábitos de distribución del tiempo por parte de los jóvenes en España. En la tabla 1, podemos observar el listado de actividades realizadas por los adolescentes y jóvenes españoles en 5 años diferentes, comprendidos entre el año 1982 y el año 2007. La tabla 1 muestra el ranking de actividades preferidas por los jóvenes españoles, ordenadas de mayor frecuencia de ejecución a menor, es decir, las actividades colocadas en la posición 1 son las que más frecuentemente realizan mientras que las situadas en la posición 10 son realizan de manera menos repetida. 


\begin{tabular}{|c|c|c|c|c|c|c|}
\hline & & 1982 & 1992 & 1999 & 2002 & 2007 \\
\hline & 1 & \begin{tabular}{|c} 
Salir - \\
Reunirse con \\
amigos
\end{tabular} & $\begin{array}{c}\text { Salir - } \\
\text { Reunirse con } \\
\text { amigos }\end{array}$ & $\begin{array}{c}\text { Salir - } \\
\text { Reunirse con } \\
\text { amigos }\end{array}$ & $\begin{array}{l}\text { Escuchar } \\
\text { música }\end{array}$ & $\begin{array}{l}\text { Escuchar } \\
\text { música }\end{array}$ \\
\hline & 2 & Ver TV & Ver TV & Ver TV & $\begin{array}{l}\text { Salir - } \\
\text { Reunirse con } \\
\text { amigos }\end{array}$ & $\begin{array}{c}\text { Salir - } \\
\text { Reunirse con } \\
\text { amigos }\end{array}$ \\
\hline & 3 & Ir al cine & Oír la radio & $\begin{array}{l}\text { Escuchar } \\
\text { música }\end{array}$ & Ver TV & Ver TV \\
\hline & 4 & $\begin{array}{l}\text { Escuchar } \\
\text { música }\end{array}$ & $\begin{array}{l}\text { Charlar con } \\
\text { la familia }\end{array}$ & $\begin{array}{c}\text { Hacer } \\
\text { deporte }\end{array}$ & $\begin{array}{l}\text { Leer } \\
\text { periódicos/ } \\
\text { revistas }\end{array}$ & $\begin{array}{l}\text { Usar el } \\
\text { ordenador }\end{array}$ \\
\hline $1=$ & 5 & Ir a bailar & Ir a bailar & Ir al cine & Oír la radio & Oír la radio \\
\hline 产 & 6 & Leer libros & $\begin{array}{c}\text { Leer } \\
\text { periódicos }\end{array}$ & Leer libros & Ir al cine & $\begin{array}{c}\text { Ir de } \\
\text { compras }\end{array}$ \\
\hline & 7 & Oír la radio & Fumar & Dormir & $\begin{array}{c}\text { Descansar - } \\
\text { no hacer } \\
\text { nada }\end{array}$ & $\begin{array}{c}\text { Estar con la } \\
\text { pareja }\end{array}$ \\
\hline & 8 & $\begin{array}{c}\text { Hacer } \\
\text { deporte }\end{array}$ & Leer revistas & $\begin{array}{c}\text { Descansar - } \\
\text { no hacer } \\
\text { nada }\end{array}$ & $\begin{array}{l}\text { Usar el } \\
\text { ordenador }\end{array}$ & $\begin{array}{c}\text { Leer } \\
\text { periódicos/ } \\
\text { revistas }\end{array}$ \\
\hline & 9 & $\begin{array}{c}\text { Ir de } \\
\text { excursión }\end{array}$ & $\begin{array}{c}\text { Hacer } \\
\text { deporte }\end{array}$ & Viajar & Leer libros & $\begin{array}{c}\text { Descansar - } \\
\text { no hacer } \\
\text { nada }\end{array}$ \\
\hline & 10 & - & - & - & Ir a bailar & Ir al cine \\
\hline & EDAD & $15-20$ & $15-29$ & $15-29$ & $15-29$ & $15-29$ \\
\hline
\end{tabular}

Tabla 1: Actividades de ocio por frecuencia (1982-2007). Fuente: Instituto de la Juventud (INJUVE) 2000

Las investigaciones analizadas ponen de manifiesto que el estudio del uso del tiempo es una práctica habitual en otros muchos países del mundo. Con este fin, los distintos países desarrollan sus encuestas propias que distribuyen a nivel estatal. Algunas de las más destacadas y con más relevancia son nombradas en el listado siguiente: Australia (Australian Bureau of Statistics), Canadá (General Social Survey), Finlandia (Time Use Survey; Statistics Finland), Nueva Zelanda (Time Use Survey), Sudáfrica (A Survey of Time Use; Statistics South Africa), Tailandia (Time Use; National Statistical Office Thailand), Reino Unido (The Time Use Survey, National Statistics), Japón ("NHK Public Opinion Research Division. Japanese time use in 1995," 1996) y México (Encuesta Nacional sobre Uso del Tiempo realizada por el INEGI).

A continuación, vamos a abordar la primera parte de esta investigación que recoge la revisión bibliográfica del uso del tiempo de los adolescentes. El objetivo es recopilar y 
analizar la documentación existente sobre el uso del tiempo por los adolescentes con el fin de, posteriormente, descubrir en qué medida las diferentes actividades o hábitos ocupan el tiempo de los adolescentes y obtener una serie de conclusiones. Comenzaremos por la identificación y análisis del tiempo dedicado a realizar actividades personales (dormir, alimentación e higiene y cuidado personal) para, a continuación, proseguir con el tiempo dedicado al estudio y a las actividades extraescolares. Continuaremos analizando el tiempo dedicado por los adolescentes a realizar deporte, a las nuevas tecnologías de la información y comunicación, al trabajo remunerado y al trabajo doméstico. Para finalizar, estudiaremos el tiempo libre y el ocio.

\section{1.- TIEMPO DEDICADO A DORMIR}

Para comenzar el análisis del tiempo dedicado por los adolescentes a las diferentes tareas diarias, empezamos por una de las actividades importantes en el reparto del uso del tiempo de los adolescentes: el tiempo dedicado a dormir. Una de las razones por las cuáles esta actividad es importante, es por su peso específico, puesto que como veremos a continuación, va a ocupar aproximadamente una media de un tercio del tiempo diario disponible por el adolescente.

Otro de los motivos de la relevancia del estudio de esta actividad radica en la influencia que los hábitos de dormir muestran tener en la capacidad del pensar, comportarse y sentirse del adolescente durante el día (Wolfson \& Carskadon, 1998).

Dormir alimenta el cerebro. Estudios recientes demuestran que puede existir una posible asociación entre la falta de sueño y los siguientes comportamientos:

$\checkmark$ Posibles alteraciones físicas y psicológicas como falta de atención, deterioro de la memoria, disminución de la creatividad y el aprendizaje (Gozal \& KheirandishGozal, 2007; O'Brien \& Gozal, 2004).

$\checkmark$ Problemas motores (Kuriyama, Stickgold \& Walker, 2004).

$\checkmark$ Hiperactividad y desórdenes de humor (Blunden, Hoban \& Chervin, 2006). 
$\checkmark$ Peor rendimiento escolar (Salcedo Aguilar et al., 2005).

$\checkmark$ Ansiedad y depresión (Johnson, Roth \& Breslau, 2006), aumento de las emociones negativas y pobre funcionamiento socioemocional (Kirmilgray, Eagleston, Gibson \& Thoresen, 1984), problemas de ajuste emocional y conductual (Oliva Delgado, Reina Flores, Pertegal Vega \& Antolin-Suarez, 2011), conducta agresiva y comportamiento antisocial (O'Brien \& Mindell, 2005; Wong, Brower, Fitzgerald \& Zucker, 2004), mayor prevalencia de los trastornos psiquiátricos (Blader, Koplewicz, Abikoff \& Foley, 1997), incluso pensamientos suicidas (Gangwisch et al., 2010; Roberts, Roberts \& Duong, 2009; Wolfson \& Carskadon, 1998).

$\checkmark$ Participación en accidentes de tráfico (Danner \& Phillips, 2008), fumar o consumir sustancias (Albares Tendero, Estivill Sancho, Pascual Domenech \& Roure Miro, 2008; Choi, Patten, Gillin, Kaplan \& Pierce, 1997; Holmen, BarrettConnor, Holmen \& Bjermer, 2000; Sivertsen, Skogen, Jakobsen \& Hysing, 2015).

$\checkmark$ Problemas de salud y sobrepeso (Eisenmann, Ekkekakis \& Holmes, 2006; Landhuis, Poulton, Welch \& Hancox, 2008).

Debido a los posibles efectos que hemos descrito anteriormente, derivados de la carencia o falta de calidad del sueño, consideramos de vital importancia investigar más a fondo sobre los hábitos de sueño de los adolescentes de las diferentes sociedades actuales. Del mismo modo, encontramos necesario destacar la importancia de establecer un plan pedagógico sobre hábitos y rutinas de sueño para los adolescentes.

Empezamos esta investigación por realizar una recopilación de los estudios existentes que elaboran recomendaciones sobre el número de horas que deben dedicar a dormir los adolescentes. Hemos encontrado investigaciones, que datan del siglo pasado, que ya afirmaban que los adolescentes deben de dormir al menos el mismo tiempo que en el periodo de pre-adolescencia, es decir, entre 8:30 a 9:15 horas al día (Carskadon et al., 1980). La fundación National Sleep Foundation (2006), recomendaba a los adolescentes dormir 8 horas al día. Cuatro años más tarde, la misma fundación (National Sleep Foundation, 2010) aumentaba el número de horas de dormir recomendadas para los 
adolescentes entre 8:30 y 9:15 horas al día. Carskadon, Acebo \& Jenni (2004) recomiendan a los adolescentes dormir 9 horas al día. Sin embargo, en algunos casos adelantan que aunque el tiempo recomendado que deben dormir los adolescentes sea de al menos 9 horas al día, pocos adolescentes lo cumplen (Yang, Kim, Patel \& Lee, 2005).

Una vez, analizadas las recomendaciones, procedemos a realizar el estudio de los artículos que versan sobre el número de horas que realmente duermen los adolescentes. Como regla general, se puede afirmar que la media de tiempo dedicado a dormir por los adolescentes de todo el mundo es de entre 7 y 9 horas al día, durmiendo más tiempo los adolescentes más jóvenes que los más mayores (Albares Tendero et al., 2008; Carskadon, 1990; Flammer \& Alsaker, 1999).

El día de la semana es un factor que influye en el tiempo dedicado por el adolescente a dormir. Olds, Blunden, Petkov \& Forchino, (2010) afirma, como parece lógico que los adolescentes duermen más tiempo los días festivos que los días lectivos.

Además del día de la semana, son varios los factores que pueden influir en el número de horas que duermen los adolescentes como por ejemplo, el género, la edad, el país y el estatus socioeconómico al que pertenecen.

A continuación, procedemos a analizar si existe relación entre cada uno de estos factores y la cantidad de horas dedicadas a dormir por los adolescentes.

\subsection{1.- Nacionalidad:}

Sobre este tema, destacamos un estudio realizado sobre el tiempo dedicado a dormir por adolescentes de 23 países diferentes elaborado por Olds, Blunden, et al. (2010). En este estudio global, los autores concluyen que las pautas relacionadas con los hábitos de dormir de los adolescentes de los países estudiados, siguen modelos similares. A grandes rasgos, los adolescentes de Australia, Canadá, Francia y Suiza duermen prácticamente las mismas horas. Los países del resto de Europa no nombrados en este 
10 Parte

Capítulo 1: Uso del tiempo de los adolescentes

grupo duermen menos horas. Los adolescentes americanos duermen menos horas que los europeos.

Como muestra la tabla 2, Hilbrecht et al. (2008) afirman que los adolescentes canadienses de Ontario dedican a dormir entre semana una media de entre 8:28 horas al día los adolescentes más jóvenes (entre 12 y 14 años) y 7:21 horas los adolescentes más mayores (entre 15 a 19 años).

Encontramos también estudios sobre los hábitos de sueño de niños y adolescentes en Australia (Olds, Maher, et al., 2010). Estos autores recopilaron información sobre cómo 4.023 jóvenes australianos de edades entre 9-18 años habían empleado las 48 horas anteriores a realizar la encuesta. Tras analizar los resultados, concluyeron que los adolescentes australianos de edades comprendidas entre 16 y 17 años duermen una media de 9:00 horas los días lectivos y entre 9:30 y 10:00 horas al día los días no lectivos.

Los adolescentes de las regiones chinas de Wuhan y Hunan (China) duermen una media de 7:52 horas al día los días lectivos (Jaung, 2008). Los adolescentes de instituto del este asiático normalmente dedican menos tiempo a dormir, puesto que invierten mucho tiempo en preparar los exámenes de acceso a la universidad (Lee, 1994). Es interesante remarcar que el 10,8\% tiene problemas para dormirse, el 3,5\% se despierta por la noche y tiene problemas para volver a dormir y el $4,6 \%$ tiene a menudo pesadillas.

En España, de igual manera, encontramos numerosos estudios que versan sobre el tiempo dedicado a dormir por los adolescentes de las distintas regiones españolas. La mayoría de los adolescentes de Cuenca (España) manifiestan dormir 8:00 horas al día o más entre semana, aunque más de una cuarta parte $(31,3 \%)$ afirma dormir sólo entre 6:00 y 7:00 horas al día (García-Jiménez et al., 2004). Los adolescentes de la zona de Andalucía Occidental (España) duermen una media de 7:36 horas al día los días lectivos, y sólo el 56,3\% duermen 8:00 horas al día o más (Oliva Delgado et al., 2011). Sin embargo, el 81,9\% duerme más de 9:00 horas al día los fines de semana. 
Capítulo 1: Uso del tiempo de los adolescentes

\begin{tabular}{|c|c|c|c|c|c|}
\hline PAÍS & ESTUDIO & Edad & Entre semana & Fin de semana & Comentarios \\
\hline $\begin{array}{l}\text { Cuenca } \\
\text { (España) }\end{array}$ & $\begin{array}{c}\text { García-Jiménez et } \\
\text { al., } 2004\end{array}$ & & $\begin{array}{l}\text { 8:00 } \\
\text { o más }\end{array}$ & & $\begin{array}{c}\text { 31,3\% duerme } \\
\text { entre } 6: 00 \text { y 7:00 } \\
\text { horas/día }\end{array}$ \\
\hline \multirow{2}{*}{$\begin{array}{l}\text { Ontario } \\
\text { (Canadá) }\end{array}$} & \multirow{2}{*}{$\begin{array}{l}\text { Hilbrecht et al., } \\
2008\end{array}$} & 12-14 años & $8: 28$ & & \\
\hline & & 15-19 años & $7: 21$ & & \\
\hline $\begin{array}{l}\text { Wuhan y } \\
\text { Hunan (China) } \\
\end{array}$ & $\begin{array}{c}\text { Jaung, } \\
2008\end{array}$ & & $7: 52$ & & \\
\hline Australia & $\begin{array}{c}\text { Olds, Maher et al., } \\
2010\end{array}$ & 16-17 años & $9: 00$ & $9: 30-10: 00$ & \\
\hline $\begin{array}{l}\text { Andalucía } \\
\text { Occidental } \\
\text { (España) } \\
\end{array}$ & $\begin{array}{l}\text { Delgado et al., } \\
2011\end{array}$ & & $7: 36$ & $\begin{array}{c}81,9 \% \text { más de } \\
9: 00\end{array}$ & $\begin{array}{c}56,3 \% \text { duermen } \\
\text { 8:00 horas al día o } \\
\text { más }\end{array}$ \\
\hline
\end{tabular}

Tabla 2: estudios sobre el tiempo que dedican los adolescentes a dormir por nacionalidad

En países económicamente menos potentes algunos adolescentes manifiestan problemas para dormir lo que requerido por circunstancias físicas que no les permiten hacerlo. Por ejemplo, cabe destacar que los niños y adolescentes que viven en las calles de Colombia y duermen en las puertas de los comercios, duermen poco por la inseguridad existente y porque la actividad desarrollada en la calle comienza muy temprano (Aptekar, 1988).

\subsection{2.- Género:}

En Ontario (Canadá), las adolescentes duermen menos tiempo que los chicos, aproximadamente 0:20 horas al día menos en sus años más jóvenes y 0:09 horas al día menos entre los 15 y 19 años (Hilbrecht et al., 2008).

Sin embargo, las chicas australianas manifiestan dormir más tiempo que los chicos, principalmente los días no lectivos (Olds, Maher, Blunden \& Matricciani, 2010). Según la literatura encontrada, uno de los motivos puede ser la afición de los chicos australianos a hacer deporte durante el fin de semana.

La tabla 3 muestra además, que esta misma tendencia se encuentra en España. Las adolescentes de la ciudad de Cuenca duermen durante más tiempo el fin de semana que los chicos (García-Jiménez et al., 2004). 
10 Parte

Capítulo 1: Uso del tiempo de los adolescentes

\begin{tabular}{|lc|cc|}
\hline PAís & ESTUDIO & $\begin{array}{c}\text { Género que más } \\
\text { duerme }\end{array}$ & Observaciones \\
\hline $\begin{array}{l}\text { Cuenca } \\
\text { (España) }\end{array}$ & $\begin{array}{c}\text { García-Jiménez et al., } \\
2004\end{array}$ & femenino & en fin de semana \\
\hline $\begin{array}{l}\text { Ontario } \\
\text { (Canadá) }\end{array}$ & $\begin{array}{c}\text { Hilbrecht et al., } \\
\mathbf{2 0 0 8}\end{array}$ & masculino & $0: 20$ más de 12 a 14 años \\
\hline Australia & $\begin{array}{c}\text { Olds, Maher, et al., } \\
\mathbf{2 0 1 0}\end{array}$ & femenino & 0:09 más 15 a 19 años \\
\hline
\end{tabular}

Tabla 3: estudios sobre el tiempo dedicado por los adolescentes a dormir por género

\subsection{3.- Edad:}

Otro de los factores que pueden influir en el número de horas destinadas a dormir por los adolescentes es la edad. Se observa en varios de los países estudiados que existe una disminución paulatina de las horas de sueño con el crecimiento de los adolescentes (Albares Tendero et al., 2008; Olds, Blunden, et al., 2010).

Investigaciones ponen de manifiesto que los adolescentes pasan de dormir aproximadamente 9:00 horas al día a la edad de 13 años a 7:00 horas al día a la edad de 18 años (Albares Tendero et al., 2008) por lo que puede apreciarse que existe una diferencia de 2:00 para ese periodo de edad.

En Ontario (Canadá), los adolescentes también duermen menos tiempo con la edad. La diferencia de tiempo dedicado a dormir entre los más jóvenes (entre 12 y 14 años) y los adolescentes más mayores (entre 15 a 19 años) oscila en 1:08 y 0:39 horas al día (Hilbrecht et al., 2008).

El tiempo dedicado a dormir por los adolescentes australianos disminuye también con los años, aproximadamente 12 minutos por año los días lectivos y 4 minutos por año los días no lectivos (Olds, Maher, et al., 2010).

Oliva Delgado et al. (2011) afirman que el número de horas dedicadas a dormir por los adolescentes de Andalucía Occidental (España) sufren un decremento con la edad. Concluyen además que esta disminución de tiempo es más notable en el género femenino que en el masculino. 
Varios investigadores han estudiado sobre las posibles causas que provocan la disminución de tiempo dedicado a dormir por los adolescentes con los años (Dahl \& Lewin, 2002; Griffiths, 2005). A continuación enumeramos las causas más relevantes encontradas: la menor supervisión de los padres de la hora de acostarse, la mayor autonomía de los adolescentes, el incremento de tareas escolares y la práctica de un gran número de actividades estimulantes como navegar por la red, jugar a videojuegos y ver la televisión cuya interrelación con el número de horas de dormir ha sido estudiada por varios investigadores (Calamaro, Mason \& Ratcliffe, 2009; Ortega et al., 2010; Shochat, Flint-Bretler \& Tzischinsky, 2010) y veremos en capítulos posteriores de esta tesis.

\subsection{4.- Entorno familiar:}

Otro factor que puede mostrar diferencias en cuanto al tiempo dedicado por los adolescentes a dormir es el nivel socioeconómico al que pertenecen. En España, no se aprecia diferencia en el número de horas dedicadas a dormir de los adolescentes andaluces por el nivel socioeconómico (Oliva Delgado et al., 2011).

Tampoco se encuentran evidencias de relación entre el nivel socioeconómico de los adolescentes australianos y la cantidad de tiempo dedicado a dormir (Olds, Maher, et al., 2010).

\subsection{5.- Otros factores:}

En Australia, los adolescentes no duermen lo mismo todos los días ni en todas las estaciones ( 8 min más en invierno que en otoño). También hay ligeras diferencias por la localización geográfica (Olds, Maher, et al., 2010).

En España, se aprecia diferencia en el número de horas dedicadas a dormir por el tamaño de la localidad en la que residen (Oliva Delgado et al., 2011). Este estudio afirma además, que entre semana, los adolescentes de las zonas rurales declaran dormir más que los de las zonas urbanas. Sin embargo, en fin de semana, duermen más los de las zonas urbanas. 
10 Parte

Capítulo 1: Uso del tiempo de los adolescentes

Los hábitos de sueño en España reproducen lo descrito por otros autores en otras partes del mundo. Por ejemplo, la modificación de los horarios durante el fin de semana, ocasiona que los adolescentes duerman mal la noche del domingo. Los adolescentes duermen menos de lo que se considera adecuado a su edad, por lo que tienden a dormir más durante el fin de semana para recuperar el tiempo de dormir perdido (GarcíaJiménez et al., 2004).

Una de las medidas para incrementar las horas dedicadas a dormir por los adolescentes radica en aumentar el control parental (Gangwisch et al., 2010; Randler, Bilger \& DíazMorales, 2009). Otra de las medidas planteadas para mitigar el déficit de sueño de los adolescentes consiste en atrasar la hora de comienzo de las clases en los institutos (Owens, Belon \& Moss, 2010). Este experimento consistió en atrasar la hora de entrada desde las 8:00 hasta las 8:30 en un instituto de Rhode Island (EEUU) con el objetivo de analizar el impacto en el sueño, el humor y el comportamiento de los adolescentes. La American Academy of Pediatrics (AAP) recomendó a los institutos norteamericanos en nota de prensa en 2014 retrasar el comienzo de la actividad lectiva de las 7:30 a las 8:30 de la mañana o más tarde. Se han realizado varios experimentos en EEUU y los resultados han sido satisfactorios, puesto que han supuesto una mejora en el tiempo que duerme el adolescente. Es importante remarcar las bondades de esta experiencia debido a que la hora de acostarse no se ha retrasado (Boergers, Gable \& Owens, 2014).

Consideramos este último comentario importante, puesto que las horas de sueño son consecuencia de la hora a la que los adolescentes se han acostado y dormido, y la hora a la que se han levantado. Por esta razón, estudiamos estos dos puntos más en profundidad.

\subsection{6.- Hora de acostarse:}

En todos los casos estudiados, la hora de acostarse depende del día de la semana. Normalmente, es 0:34 minutos más tardía los días no lectivos que los lectivos, no apreciándose diferencias notables por género (Olds, Maher, et al., 2010). Los 
adolescentes australianos se acuestan más tarde con el paso de los años (aumenta 0:17 horas al día por año en días lectivos y 0:16 horas al día en días no lectivos).

Según los estudios realizados por Garitaonandia, Fernández y Oleaga (2005), existe una regla fija en los hogares españoles que los adolescentes de 15-16 años aceptan y respetan en relación a la hora de acostarse: la hora de acostarse en días lectivos es de media las 23:15.

Los adolescentes de Cuenca, España, se acuestan de media, los días lectivos, a las 23:00. Los fines de semana, sin embargo, retrasan la hora de acostarse hasta la 01:00 de la madrugada (García-Jiménez et al., 2004), porque suelen salir por la noche (el 15,6\% afirma que sale siempre y el $48,8 \%$ a veces).

El 76,5\% de los adolescentes de Andalucía Occidental se acuestan antes de medianoche entre semana (Oliva Delgado et al., 2011). Sólo un 19,2\% se acuesta entre las 00:00 y la 01:00 de la madrugada. En este estudio, no se aprecian diferencias notables por género. Los chicos se acuestan ligeramente más tarde que las chicas. Tampoco se muestran diferencias por el nivel socioeconómico de la familia; pero sí por la zona de residencia. Los adolescentes de entornos rurales se acuestan más temprano entre semana pero más tarde los fines de semana, que los de entornos urbanos (Oliva Delgado et al., 2011).

La hora de acostarse los fines de semana es notablemente más tardía que la de los días lectivos (una media de 2:30 horas), retrasándose más con los años. Esta diferencia hace que los adolescentes desarrollen desajustes que les pueden provocar somnolencia en los primeros días de la semana escolar e insomnio e incluso consecuencias negativas para la salud (Crowley, Acebo \& Carskadon, 2007). Existe una relación entre la hora de acostarse de los adolescentes andaluces y ciertos problemas experimentados, quedando patente la relación entre la hora de acostarse los fines de semana y el consumo de sustancias (Oliva Delgado et al., 2011).

Puede existir una relación entre el mayor uso de dispositivos electrónicos y la hora cada vez más tardía de acostarse de los adolescentes (Van den Bulck, 2004). 
10 Parte

Capítulo 1: Uso del tiempo de los adolescentes

\subsection{7.- Hora de levantarse:}

Al igual que la hora de acostarse, la hora de levantarse está condicionada por el día de la semana. Los adolescentes australianos se levantan una media de 82 minutos más tarde los días no lectivos. No hay diferencias en la hora de levantarse por género entre semana, pero sí en días no lectivos, donde las adolescentes se levantan una media de 15 minutos más tarde (Olds, Maher, et al., 2010).

Los adolescentes de Cuenca (España), se levantan de media a las 7:59 entre semana y a las 11:42 los fines de semana (García-Jiménez et al., 2004). El adelanto de la hora de comienzo de las clases en secundaria hace que los adolescentes duerman menos horas los días lectivos. Esto ocurre en varios países además de España (Crowley et al., 2007).

Una vez analizados los estudios relativos al tiempo dedicado por los adolescentes a dormir, pasamos a estudiar la siguiente actividad, también parte del cuidado personal, que es el tiempo dedicado a su propia alimentación.

\section{2.- TIEMPO DEDICADO A LA ALIMENTACIÓN:}

A continuación analizamos la bibliografía encontrada en relación al tiempo dedicado por los adolescentes a su alimentación.

\subsection{1.- Nacionalidad}

Son numerosas las investigaciones que se centran en los adolescentes en el mundo. Los adolescentes estadounidenses dedican entre 0:48 y 1:12 horas al día de media a comer (Bianchi \& Robinson, 1997; Duckett, Raffaelli \& Richards, 1989). Estudios reflejan que las familias americanas cada vez se sientan a comer todos juntos en menos ocasiones. Los adolescentes comen rápidamente porque tienen muchas actividades que les impiden realizar una comida de manera tranquila (Hofferth \& Sandberg, 2001).

Los adolescentes canadienses de Ontario dedican una media de 0:40 horas al día a comer entre semana (Hilbrecht et al., 2008). 
Encontramos del mismo modo, información relativa al tiempo dedicado a las comidas por los adolescentes europeos. En Francia, los adolescentes dedican más tiempo a comer (media de 1:54 horas al día) que el resto de los adolescentes europeos (media de 1:12 horas al día). Los adolescentes que menos tiempo dedican a comer son los húngaros (0:58 horas al día de media).

Los adolescentes belgas dedican aproximadamente 1:00 hora al día comer entre semana, cuando comen en casa. Los fines de semana dedican más tiempo, casi 1:15 horas cuando comen en casa. No se aprecia diferencia en el tiempo dedicado a comer entre semana y el fin de semana por los adolescentes holandeses. Dedican cualquier día de la semana alrededor de 1:00 hora al día (Stevens, Van Den Broek \& Vandeweyer, 2003).

\subsection{2.- Género}

Se encuentran evidencias de diferencias en el tiempo dedicado por los adolescentes a la alimentación. Los adolescentes canadienses de Ontario dedican más tiempo a la alimentación que las adolescentes (Hilbrecht et al., 2008).

\subsection{3.- Entorno familiar:}

Cabe destacar que los adolescentes norteamericanos, cuyas madres no trabajan, no muestran la misma celeridad en las comidas que el resto de adolescentes (Hofferth \& Sandberg, 2001).

\section{3.- TIEMPO DEDICADO A LA HIGIENE Y EL CUIDADO PERSONAL:}

Los adolescentes canadienses de Ontario manifiestan dedicar más tiempo a la higiene y cuidado personal entre semana que el fin de semana (Hilbrecht et al., 2008).

\subsection{1.- Nacionalidad:}

Un estudio realizado en 12 países (Bulgaria, antigua Checoslovaquia, Finlandia, Francia, Alemania, Hungría, Polonia, Rusia, Suiza, Estados Unidos, Noruega y Rumania) puso de 
10 Parte

Capítulo 1: Uso del tiempo de los adolescentes

manifiesto que el tiempo medio dedicado por los adolescentes a su cuidado personal es de entre 0:30 y 0:48 horas al día (Flammer \& Alsaker, 1999).

La literatura existente hace visible la existencia de similitudes en el uso del tiempo dedicado al cuidado personal por los adolescentes americanos, coreanos y japoneses (Duckett et al., 1989). Del mismo modo, concluye que el tiempo dedicado por los adolescentes europeos a su cuidado personal no varía en exceso dependiendo del país al que pertenecen.

No se encuentran grandes diferencias en el tiempo destinado a esta actividad por los adolescentes de Holanda y Bélgica, países vecinos geográficamente. Los adolescentes belgas dedican aproximadamente 0:45 horas al día, mientras que los holandeses dedican ligeramente más tiempo a esta actividad, llegando a 1:00 hora al día en el fin de semana (Stevens et al., 2003).

\subsection{2.- Género:}

Las adolescentes que pertenecen a países desarrollados dedican más tiempo al cuidado personal que los chicos, principalmente en esta etapa que nos ocupa que es la adolescencia (Carpenter, Huston \& Spera, 1989; Duckett et al., 1989; Flammer \& Alsaker, 1999).

Se puede apreciar que existen diferencias significativas por género en cuanto al tiempo que dedican los adolescentes de Ontario (Canadá) entre semana a su cuidado personal. En esta investigación se observa que las chicas dedican 17 minutos al día más que los chicos a esta actividad (Hilbrecht et al., 2008). Este estudio, pone de manifiesto igualmente, que durante el fin de semana, las chicas dedican más tiempo a esta actividad que los chicos.

La tabla 4 muestra que tanto en Bélgica como en Holanda, las adolescentes dedican más tiempo al cuidado personal que los chicos, aproximadamente una media de 12 minutos al día (Stevens et al., 2003). 
Capítulo 1: Uso del tiempo de los adolescentes

\begin{tabular}{|lc|cc|}
\hline PAís & ESTUDIO & $\begin{array}{c}\text { Dedican más tiempo a } \\
\text { higiene personal }\end{array}$ & $\begin{array}{c}\text { Tiempo que } \\
\text { dedican más }\end{array}$ \\
\hline Bélgica y Holanda & $\begin{array}{c}\text { Stevens et al., } \\
\mathbf{2 0 0 3}\end{array}$ & femenino & $0: 12$ \\
\hline Canadá (Ontario) & $\begin{array}{c}\text { Hilbrecht et al., } \\
\mathbf{2 0 0 8}\end{array}$ & femenino & $0: 17$ \\
\hline
\end{tabular}

Tabla 4: estudios del tiempo dedicado por los adolescentes a su higiene personal por género

\subsection{3.- Edad:}

El tiempo dedicado por los adolescentes canadienses de Ontario al cuidado personal no varía con la edad. Prácticamente las cifras son las mismas para el grupo de edad entre 12 y 14 años que para los adolescentes de entre 15 y 19 años (Hilbrecht et al., 2008). Podemos observar, sin embargo, un aumento con la edad en el tiempo que dedican los adolescentes a su cuidado personal durante el fin de semana. Este aumento es mayor en los chicos que en las chicas (donde la cifra prácticamente se mantiene).

\section{4.- TIEMPO DEDICADO AL ESTUDIO}

A continuación nos adentramos en el estudio del tiempo dedicado por los adolescentes a realizar las tareas escolares y a estudiar.

Ceci y Williams (1997) afirman que el tiempo invertido por los adolescentes en su educación está relacionado con el conocimiento que adquirirán en el futuro, el desarrollo de su inteligencia y los ingresos en su época de adulto. Según esta corriente, el tiempo dedicado a estudiar está relacionado incluso, a nivel global, con el crecimiento económico de la sociedad a la que pertenecen.

Por lo tanto, visto desde diferentes prismas, incluido el económico, el salto dado por los adolescentes desde dedicar el grueso de su tiempo a trabajar con el fin único de subsistir, a destinarlo a estudiar, implica un cambio positivo para ellos (Larson, 2001). 
10 Parte

Capítulo 1: Uso del tiempo de los adolescentes

No podemos, sin embargo, pasar por alto el factor calidad de la educación. Una hora dedicada a realizar las tareas escolares o a estudiar, puede tener más consistencia educativa en un entorno, sociedad o país que en otros. Creemos interesante conocer los motivos que han ocasionado que los resultados de los test realizados a los adolescentes americanos sean bajos. Es importante saber si este hecho puede hacer que estos adolescentes se encuentren en desventaja con respecto al resto de los estudiantes de países postindustriales en un mercado global competitivo.

Estudios de principio de siglo indican que la media de tiempo dedicado a hacer tareas escolares está cuantificada en 0:49 horas al día (Kalenkoski \& Pabilonia, 2012).

Estudios más actuales ponen de manifiesto que el tiempo de estudio mínimo recomendado para alcanzar el éxito académico está estipulado en 5 horas a la semana (Cooper \& Valentine, 2001).

Encontramos estudios que ponen de manifiesto que el tiempo empleado por los adolescentes norteamericanos en realizar las tareas del colegio ha disminuido considerablemente en las últimas décadas. Estudios afirman que el tiempo dedicado a realizar las tareas del colegio por los adolescentes norteamericanos no es suficiente (Fuligni \& Stevenson, 1995; Juster, Ono \& Stafford, 2003). Sin embargo, el tiempo dedicado al estudio después del colegio por los adolescentes canadienses de Ontario en días lectivos aumenta con los años (Hilbrecht et al., 2008).

\subsection{1.- Nacionalidad:}

Los adolescentes americanos dedican menos tiempo a realizar las tareas del instituto que los jóvenes de otros países industrializados (Larson, 2001). Estudios del pasado, clasificaban a los adolescentes por nacionalidad en relación al tiempo medio dedicado al estudio: los adolescentes americanos dedican aproximadamente entre 3 y 4:30 horas por semana en hacer la tarea, los europeos entre 4 y 5:30 horas por semana y los asiáticos entre 5:30 horas y 7:30 horas semanales, considerando la semana de 7 días (Larson \& Verma, 1999). 
Los adolescentes norteamericanos dedican menos tiempo a actividades relacionadas con los estudios que los adolescentes chinos y japoneses, lo cual se traduce en un nivel por ejemplo en matemáticas inferiores (Fuligni \& Stevenson, 1995; Juster et al., 2003).

En Argentina, los resultados de una encuesta sobre el uso del tiempo realizada a 6790 adolescentes argentinos, obtuvieron como resultado que la cantidad de tiempo dedicada al estudio es bastante preocupante. Más de la mitad de los adolescentes argentinos no invierte un sólo minuto en estudiar los fines de semana (Kornblit, Diz \& Adaszko, 2006).

En días lectivos, los adolescentes belgas dedican más tiempo a realizar las tareas del colegio que los holandeses (Stevens et al., 2003).

\subsection{2.- Género:}

Las adolescentes canadienses de Ontario dedican más tiempo a estudiar que los chicos. Entre semana, las adolescentes de 12 a 14 años dedican 0:23 horas al día más, mientras que entre las adolescentes de 15 a 19 años la diferencia se reduce a 0:10 horas al día (Hilbrecht et al., 2008).

Encontramos esta misma tendencia con respecto al género en las adolescentes afroamericanas, quienes manifiestan realizar la tarea del colegio más a menudo que los chicos, afirmando éstas la poca satisfacción que les produce asistir a clase sin tener la tarea hecha (Xu, 2010). En línea con esta afirmación, las adolescentes norteamericanas de 9o a 12 grado dedican más tiempo a realizar la tarea del colegio que los chicos (Gager, Cooney \& Call, 1999; Wight, Price, Bianchi \& Hunt, 2009; Shanahan \& Flaherty, 2001).

\subsection{3.- Edad:}

El tiempo dedicado al estudio por los adolescentes norteamericanos aumenta entre 9o grado y $12 \circ$ grado (Gager et al., 1999). 
10 Parte

Capítulo 1: Uso del tiempo de los adolescentes

\section{5.- TIEMPO DEDICADO A ACTIVIDADES EXTRAESCOLARES:}

Diversos estudios han demostrado que los adolescentes dedican una parte importante de su tiempo a la realización de actividades extraescolares relacionadas con su educación. Desde Coleman (1961) con su estudio The Adolescent Society hasta fechas actuales, se aprecia un interés creciente por encontrar la relación entre la participación en actividades extraescolares y el éxito o fracaso académico. Farb y Matjasko (2012) publican un artículo que recopila varias líneas de investigación relacionadas con la práctica de actividades extraescolares y el desarrollo del adolescente. Se pretende estudiar el impacto del tiempo invertido por el adolescente en realizar actividades extraescolares en los resultados académicos y posterior éxito o fracaso en la vida.

Normalmente, la participación en actividades extraescolares y la inquietud por el autoaprendizaje, son precursores de consecuencias positivas en la educación futura: reduce el abandono escolar, el comportamiento criminal, la posibilidad de ser madre/padre adolescente, fumar y consumir drogas y alcohol (Wight et al., 2009). La participación en actividades extraescolares ayuda al adolescente a mejorar su lenguaje y a desarrollar competencias reconocidas en el sistema educativo (Lareau, 2003).

La participación en actividades extraescolares, permite al adolescente hacerse partícipe de la cultura educativa e interiorizar la importancia de la disciplina, la perseverancia y la responsabilidad (Eitle, 2005; Jordan, 1999).

Estudios comprueban que los alumnos que forman parte de grupos musicales en la escuela, al igual que los que participar en delegación de alumnos (por ejemplo, ser delegado de la clase) obtienen mejores notas en inglés y matemáticas (Broh, 2002). Las clases de música desarrollan el capital cultural que es reconocido por los profesores (Kaufman \& Gabler, 2004). La mayoría de los estudiantes americanos son conscientes de que para entrar en la universidad de prestigio deben demostrar que son completos, y en muchos caso se acredita justificando su participación en actividades extraescolares varias (Dumais, 2008). 
Los estudiantes que participan en clubs de hobbies del colegio tienen más posibilidades de acceder universidades de élite en Estados Unidos (Kaufman \& Gabler, 2004).

Existe una clara asociación entre la realización de actividades culturales (por ejemplo, visitar museos) y la nota obtenida en lectura y matemáticas (Eitle \& Eitle, 2002).

\subsection{1.- Nacionalidad:}

Los adolescentes americanos dedican una media de 15 minutos al día a realizar actividades extraescolares no deportivas (Larson \& Verma, 1999). Según Larson, Richards, Sims, y Dworkin (2001) el origen de los adolescentes influye en el tiempo dedicado a realizar actividades extraescolares. Los adolescentes norteamericanos de origen africano dedican a actividades extraescolares 10 minutos al día. Los de origen europeo dedican, sin embargo, una media de 15 minutos diarios. Mahoney, Harris \& Eccles (2006) afirma que los adolescentes norteamericanos entre 15 y 18 años dedican una media de 5 horas semanales a realizar actividades extraescolares.

Los adolescentes europeos dedican más tiempo a practicar música que los americanos. Como ejemplo, los adolescentes alemanes concretamente, dedican una media de 20 minutos diarios a la música mientras que los americanos sólo 5 minutos (Flammer, Alsaker \& Noack, 1999). Los adolescentes asiáticos, dedican menos horas a actividades artísticas, hobbies o relacionadas con organizaciones que los americanos y europeos (Lee, 1994).

Según los estudios, la relación entre la práctica de actividades extraescolares culturales y el aumento del capital cultural del adolescente es más relevante en Francia que en Estados Unidos (Kingston, 2001).

\subsection{2.- Género:}

Con respecto al género, los adolescentes norteamericanos de secundaria dedican más tiempo a realizar actividades extraescolares y actividades de ocio que las adolescentes, principalmente durante el $12^{\circ}$ grado (Gager et al., 1999; Shanahan \& Flaherty, 2001). 
10 Parte

Capítulo 1: Uso del tiempo de los adolescentes

\subsection{3.- Nivel socioeconómico de los padres - entorno familiar:}

Puede existir una relación entre el nivel económico al que pertenecen los padres y las actividades realizadas por los adolescentes (Lareau, 2003). Los padres de clase media deciden apuntar a sus hijos a más actividades extraescolares que los de clase baja, con el objetivo de fomentar su desarrollo cultural. Los estudiantes pertenecientes a los niveles socioeconómicos más altos, suelen participar en más actividades extraescolares relacionadas con su educación, verificando este comportamiento la teoría de la reproducción de Bordieu (Dumais, 2008). En este estudio, tras analizar sus datos, la autora afirma que la realización de actividades extraescolares estructuradas tiene un efecto positivo en la educación futura del alumno. Esta teoría es apoyada por otros autores que manifiestan que la participación en actividades extraescolares se traduce en beneficios educativos, porque puede desarrollar el capital cultural del adolescente (Broh, 2002; Feldman \& Matjasko, 2005). Sin embargo, estos estudios, no dejan de señalar que el tiempo es limitado. Por lo tanto, el tiempo empleado en realizar actividades extraescolares, no se invierte en realizar la tarea del colegio o estudiar, lo cual puede considerarse un riesgo notable para la consecución de logros académicos futuros.

El aumento del tiempo destinado a realizar actividades extraescolares por los adolescentes, se puede interpretar como un esfuerzo de los padres para supervisar, controlar y racionalizar el tiempo libre (Larson \& Verma, 1999).

\section{6.- TIEMPO DEDICADO AL DEPORTE}

No debemos olvidarnos de otro tipo de actividad extraescolar, no relacionada con el ámbito académico, pero muy popular entre los adolescentes: practicar deporte.

Hacer deporte ayuda a desarrollar la personalidad del adolescente, enseña a respetar las normas, permite aprender a trabajar en equipo, promover la competición sana y la perseverancia (Smoll \& Smith, 1996). 
Realizar deporte es una de las actividades más divertidas para los adolescentes, que les aporta aspectos positivos como sentirse bien físicamente, mejorar la autoestima, confianza, independencia y canalizar la energía (Broh, 2002). En Estados Unidos, la participación en actividades deportivas está asociada con alcanzar estudios universitarios y a bajos niveles de abandono escolar (Eitle, 2005).

La participación en actividades deportivas hace que el adolescente promueva su compromiso con su propia educación y su autoconfianza (Jordan, 1999). Este autor defiende, tras analizar los datos de la encuesta National Educational Longitudinal Study (1998), que existe una relación positiva entre la realización de actividades deportivas y la consecución de logros académicos.

\subsection{1.- Nacionalidad:}

Como ya hemos comentado, en Estados Unidos, los adolescentes deben demostrar que son completos para acceder a la universidad (Dumais, 2008) y por esta razón, es uno de los países en que los adolescentes dedican más tiempo a realizar actividades deportivas.

El tiempo dedicado por los adolescentes asiáticos a las actividades deportivas es inferior al de los europeos y norteamericanos. Los adolescentes de Corea de $12 \circ$ grado dedican al día sólo 7 minutos a realizar deporte (Lee, 1994). En Japón, los chicos de 10 a 15 años dedican 30 minutos al día mientras que las chicas sólo 10 minutos al día.

En Europa, es Noruega quien está a la cabeza de la lista de países en que los adolescentes de entre 10 y 16 años, dedican más tiempo a realizar actividades deportivas. La media de tiempo aproximadamente es de 1:26 horas al día (Flammer \& Alsaker, 1999). Este mismo estudio estima que los adolescentes alemanes dedican 0:52 horas al día a esta actividad y los búlgaros sólo 0:21 horas diarias.

\subsection{2.- Género:}

En general, son varios los estudios que demuestran la influencia del género en la práctica de deportes (Carpenter et al., 1989; Lee, 1994; NHK Public Opinion Research Division, 1996). 
10 Parte

Capítulo 1: Uso del tiempo de los adolescentes

Encontramos diferencias por género en el tiempo dedicado a realizar deporte. Los chicos norteamericanos de entre 12 y 17 años dedican 1:13 horas al día de media a realizar deporte mientras que las chicas dedican 0:53 horas diarias (Robinson \& Bianchi, 1997).

Las adolescentes de Estados Unidos dedican a realizar deporte entre 12 y 17 minutos al día menos que los chicos (Larson \& Verma, 1999).

Estudios más recientes concluyen que los adolescentes norteamericanos de entre $15 \mathrm{y}$ 17 años, según los datos de la ATUS 2003-2004, dedican a realizar ejercicio y practicar deportes una media de 0:59 horas al día. El tiempo dedicado por las adolescentes es inferior, siendo la media de 0:29 horas al día las chicas.

Se aprecia un incremento en el tiempo dedicado a practicar deporte los fines de semana, tanto en los chicos como las chicas. Los chicos hacen deporte los fines de semana 20 minutos/día más y las chicas 10 minutos/día que entre semana (Wight et al., 2009).

Los chicos canadienses de Ontario también hacen más actividad física que las chicas, sobre todo los fines de semana (Hilbrecht et al., 2008).

El comportamiento en relación a la actividad deportiva con respecto al género es el mismo en Alemania (Bucksch, Inchley, Hamrik, Finne \& Kolip, 2014) que en el resto de países analizados, es decir, los chicos realizan deporte durante más tiempo (tabla 5).

\begin{tabular}{|c|c|c|c|c|c|c|}
\hline PAÍS & ESTUDIO & $\begin{array}{c}\text { Género más tiempo } \\
\text { a hacer deporte }\end{array}$ & $\begin{array}{l}\text { Tiempo me } \\
\text { Femenino }\end{array}$ & $\begin{array}{r}\text { dio deporte } \\
\text { Masculino }\end{array}$ & $\begin{array}{l}\text { Diferencia } \\
\text { por género }\end{array}$ & Observaciones \\
\hline EEUU & $\begin{array}{c}\text { Robinson \& } \\
\text { Bianchi, } 1997\end{array}$ & masculino & $0: 53$ & $1: 13$ & $0: 20$ & $\begin{array}{c}\text { entre } 12 \text { y } 17 \\
\text { años }\end{array}$ \\
\hline Mundial & $\begin{array}{c}\text { Larson \& Verma, } \\
1999\end{array}$ & masculino & & & $0: 12-0: 17$ & \\
\hline $\begin{array}{l}\text { Canadá } \\
\text { (Ontario) }\end{array}$ & $\begin{array}{c}\text { Hilbrecht, } \\
\text { Zuzanek, \& } \\
\text { Mannell, 2008 }\end{array}$ & masculino & & & & $\begin{array}{l}\text { diferencia } \\
\text { mayor durante } \\
\text { el fin de }\end{array}$ \\
\hline EEUU & Wight et al., 2009 & masculino & $0: 29$ & $0: 59$ & $0: 30$ & $\begin{array}{l}\text { entre } 15-17 \\
\text { años }\end{array}$ \\
\hline Alemania & $\begin{array}{l}\text { Bucksch, Inchley, } \\
\text { Hamrik, Finne \& } \\
\text { Kolip, } 2014\end{array}$ & masculino & & & & \\
\hline
\end{tabular}

Tabla 5: estudios sobre el tiempo dedicado por los adolescentes a hacer deporte por género 


\subsection{3.- -Edad:}

Robinson y Bianchi (1997) afirman que se aprecia un incremento del tiempo dedicado a realizar deporte con los años. En Japón existe un evidente descenso con la edad, en el tiempo dedicado a realizar deporte por los adolescentes. Los chicos de 10 a 15 años practican deporte durante 0:30 horas diarias mientras que entre 16 y 19 años, solamente 7 minutos al día. También se evidencia el descenso con la edad en las chicas, que pasan de dedicar una media de 10 minutos al día con 10-15 años a sólo 3 minutos al día con 16-19 años (NHK Public Opinion Research Division, 1996).

\section{7.- TIEMPO DEDICADO A TRABAJAR:}

Existe una corriente de investigación que afirma que los estudiantes que conjugan estudios y trabajo tienen menos posibilidades de llegar a la Universidad por sufrir abandono escolar (Marsh, 1991). Esta corriente trata de demostrar que compaginar los estudios de secundaria con un trabajo, trae consigo un empeoramiento de las notas obtenidas por el adolescente (Kalenkoski \& Pabilonia, 2012). Dedicar tiempo a trabajar durante la etapa de la adolescencia puede entrañar un bajo nivel de compromiso con los estudios. Los adolescentes que trabajan durante la secundaria tienen menos tiempo para desarrollar actividades que puedan ser beneficiosas para su futuro (Steinberg \& Cauffman, 1995). Según el análisis realizado de los datos de la National Education Longitudinal Survey of 1988 (cuarta ola), se puede concluir que compaginar el trabajo con los estudios en secundaria, tiene efectos negativos en la educación postsecundaria a nivel de elección de los cursos, aspiraciones educacionales y ocupacionales y asistencia a la universidad (Marsh \& Kleitman, 2005). Según estos autores, el único beneficio que obtienen los estudiantes de secundaria que trabajan es obtener remuneración económica para ir a la universidad.

Sin embargo, existe otra corriente en la que padres, educadores e investigadores consideran que trabajar durante la etapa de adolescencia contribuye a forjar el carácter del adolescente, enseñándoles a adoptar comportamientos necesarios para tener éxito 
10 Parte

Capítulo 1: Uso del tiempo de los adolescentes

en su educación. El tiempo que dedican a trabajar, no lo emplean en actividades con dudosos beneficios a largo plazo, como ver la televisión (Schoenhals, Tienda \& Schneider, 1998). En la misma línea, investigaciones afirman que los alumnos que obtienen mejores notas en matemáticas suelen emplear más tiempo a trabajar (Porterfield \& Winkler, 2007).

Del mismo modo, encontramos estudios que apoyan ambas teorías. El aumento de las horas de trabajo, disminuye las horas dedicadas a hacer la tarea o a asistir a actividades extraescolares, pero también disminuye el tiempo frente a una pantalla (sobre todo los fines de semana) el cuál se considera tiempo improductivo académicamente (Kalenkoski \& Pabilonia, 2012).

Además de conocer el porcentaje de estudiantes adolescentes que trabajan, consideramos necesario estudiar dos factores relevantes que hacen que trabajar durante la adolescencia pueda influir en el futuro del estudiante: la cantidad de horas trabajadas y la calidad del trabajo.

Con respecto a la cantidad de trabajo realizado, encontramos estudios que cifran en 20 horas/semana de trabajo como cantidad límite para que el trabajo no afecte al rendimiento académico del adolescente ni le ponga en riesgo, pudiendo entrañar conductas negativas en el colegio, delincuencia y consumo de sustancias (Mortimer, Harley \& Aronson, 1999).

Como hemos anticipado, además de la cantidad de trabajo realizado es necesario analizar la calidad del trabajo desempeñado por el adolescente. Los adolescentes pueden enfrentarse a puestos de trabajo que les aporten beneficios y les permita conseguir interiorizar contenidos importantes para su futuro.

\subsection{1.- Género:}

Los estudios corroboran que las adolescentes trabajan más que los chicos. Statistics Canada (2006) publicó que durante el curso 2005-2006, el 34,3\% de las chicas y el 28,3\% de los chicos canadienses entre 15 y 17 años tenían un trabajo. Lo mismo ocurre en 
Ontario (Canadá) puesto que las adolescentes de entre 15 y 19 años dedican más tiempo a trabajar entre semana que los chicos aunque la diferencia es muy poco reseñable (Hilbrecht et al., 2008).

Según los datos de la CPS recogidos en 2003 y 2004, tanto en 9o como en 12ํgrado, las adolescentes estadounidenses dedican más tiempo a desempeñar un trabajo que los chicos, especialmente en 9o grado donde trabajan el doble de tiempo (Gager et al., 1999).

En contraposición, Vernon (2005) no encuentra una excesiva diferencia en cuanto al tiempo destinado a trabajar por los jóvenes de 15-19 años por género. Donde sí se aprecia una diferencia notable por género es en el tipo de empleo. Según Statistics Canada (2002), las adolescentes suelen desempeñar trabajos de venta al público y de servicios mientras que los chicos trabajan en la industria, comercio, transporte y construcción. No se realizaron encuestas a menores de 14 años, aunque se conoce por otras fuentes (Ontario Ministry of Labour 2006) que normalmente trabajan de babysitting, repartiendo periódico y ayudando en los negocios familiares.

\subsection{2.- Edad:}

Los jóvenes dedican poco tiempo a actividades que reportan ingresos (Larson \& Verma, 1999), aunque aumenta el tiempo trabajado por los adolescentes más mayores. Según los datos de la CPS recogidos en 2003 y 2004, el porcentaje de adolescentes que tienen un trabajo a los 18 años es mayor que a los 16 años, siendo ligeramente mayor el porcentaje en las chicas que en los chicos.

\subsection{3.- Nacionalidad:}

La tasa de empleo en los adolescentes varía mucho dependiendo del país. En Estados Unidos, aproximadamente el $80 \%$ de los adolescentes, en el momento de su graduación, manifiesta haber trabajado alguna vez durante su época de instituto (Greenberger \& Steinberg, 1986). Sin embargo, la tasa de empleo de los adolescentes norteamericanos ha disminuido desde el año 2000 hasta el 2005. Según los datos recogidos por el Bureau 
10 Parte

Capítulo 1: Uso del tiempo de los adolescentes

of Labor Statistics, la tasa de empleo adolescente en Estados Unidos en el año 2005 era del 36,5\%, siendo la tasa más baja en los últimos 35 años. Esta disminución podría deberse al aumento del porcentaje de adolescentes que estudian (Porterfield \& Winkler, 2007). Según los datos de la CPS, se ha observado también una disminución en el porcentaje de adolescentes que asisten al colegio, que tienen un empleo entre el año 1995 y el 2004. La tasa de empleo en países subdesarrollados es bastante superior a la encontrada en países desarrollados, sobre todo en los adolescentes más mayores (Larson \& Verma, 1999).

El 25\% de los adolescentes de la Ciudad de Buenos Aires trabaja además de estudiar. Este porcentaje es algo más alto que en el resto de las ciudades de Argentina, probablemente debido a que en la capital los adolescentes tienen más posibilidades de encontrar un empleo a tiempo parcial (Kornblit et al., 2006).

El tiempo dedicado por los adolescentes estadounidenses de entre 14 y 16 años a trabajar es de 0:48 horas al día (Flammer \& Alsaker, 1999). En Corea, se ha constatado que los adolescentes de entre 14 y 16 años no trabajan, puesto que han declarado dedicar 0 minutos/día a desempeñar un trabajo (Lee, 1994).

\subsection{4.- Entorno familiar:}

Nivel económico:

No se puede obviar que el estatus socioeconómico familiar al que pertenece el adolescente es influyente para que el adolescente destine parte de su tiempo a trabajar. La mayoría de los adolescentes de Buenos Aires que trabajan mientras estudian, pertenecen a clases sociales bajas (Kornblit et al., 2006). Los adolescentes pertenecientes a niveles socioeconómicos más bajos trabajan además, más cantidad de horas (Dumais, 2008).

Nivel de estudios de los padres:

Del mismo modo, el nivel educativo alcanzado por los padres también es un factor que incide en la decisión de trabajar por parte del adolescente (Porterfield \& Winkler, 2007). 
Cuanto menor es el nivel educativo alcanzado por los padres, mayor número de horas trabajan los hijos adolescentes. La evidencia es que encontramos mayor cantidad de adolescentes trabajando más de 20 horas semanales en los hogares cuyos padres no han terminado el bachillerato.

\section{8.- TIEMPO DEDICADO AL TRABAJO DOMÉSTICO}

El tiempo medio destinado por los adolescentes norteamericanos de entre 12 y 17 años a realizar trabajos del hogar está estimado en 0:36 horas al día (Robinson \& Bianchi, 1997).

\subsection{1.- Nacionalidad:}

Estudios del siglo pasado situaban la media de tiempo dedicado al trabajo doméstico por los estudiantes estadounidenses de 9o grado en 0:24 horas al día (Duckett et al., 1989).

En Corea del Sur, los adolescentes de $12^{\circ}$ grado dedican una media de 6 minutos diarios al trabajo doméstico (Lee, 1994).

En Europa, los datos son similares. Los adolescentes europeos entre 10 y 16 años dedican entre 12 y 42 minutos al día esta actividad (Flammer \& Alsaker, 1999).

No se encuentran estudios que verifiquen que los adolescentes de países desarrollados dediquen más de 1 hora/día a las labores del hogar (Larson \& Verma, 1999).

Los adolescentes de países subdesarrollados destinan notablemente más tiempo a realizar trabajos del hogar que los adolescentes de países más desarrollados. En la mayoría de los casos, se trata de jóvenes sin escolarizar, que dedican la mayor parte de su tiempo a esta actividad. Como ejemplo, las adolescentes de entornos rurales en Nepal de 15 a 19 años dedican hasta 9:12 horas diarias a labores del hogar (Larson \& Verma, 1999). Uno de los motivos principales que justifican esta gran cantidad de 
10 Parte

Capítulo 1: Uso del tiempo de los adolescentes

tiempo, es que viven en un entorno donde las labores domésticas como recoger agua o cuidar de los animales, requieren una elevada inversión de tiempo.

\subsection{2.- Género:}

Al igual que ocurre en la etapa de adulto, las tareas del hogar se distribuyen entre los adolescentes por género, siendo normalmente mayor la carga de tareas del hogar asignadas a las adolescentes y aún más a las adolescentes cuyas madres trabajan fuera de casa (Larson \& Verma, 1999).

Del mismo modo, Gager et al. (1999) encuentran estas diferencias durante la niñez, siendo más relevante el tiempo destinado a realizar las tareas del hogar por las niñas norteamericanas que por los niños. Esta diferencia por género, sigue incrementándose durante la secundaria (Gager et al., 1999). Además, estos autores, diferencian las tareas realizadas generalmente por el género femenino, por el masculino o tareas que pueden considerarse neutras. Las tareas del hogar que recaen generalmente sobre las adolescentes y a las cuáles dedican más tiempo que los jóvenes masculinos son las siguientes: cocinar, poner la mesa, lavar los platos, planchar, limpiar, cuidar a los niños pequeños y ancianos de la familia y hacer las compras. Las tareas a las que los adolescentes dedican más tiempo son: cortar el césped, quitar la nieve y sacar la basura. Se consideran tareas neutras limpiar la propia habitación y cuidar a las mascotas.

La Youth Development Study (YDS) pone de manifiesto que las tareas del hogar asociadas al género femenino de 9o y 12으 grado de Estados Unidos requieren más tiempo que las designadas a los hombres, lo cual crea una diferencia importante en el tiempo dedicado a las labores de la casa desde la adolescencia (Gager et al., 1999).

\subsection{3.- Edad:}

El tiempo dedicado a las labores del hogar realizado por los adolescentes norteamericanos disminuye con los años (Shanahan \& Flaherty, 2001). El tiempo dedicado a las labores del hogar disminuye durante los años de adolescencia un $25 \%$ en las chicas y hasta un $40 \%$ en los chicos (Gager et al., 1999). 


\subsection{4.- Entorno familiar:}

Nivel económico:

Los adolescentes pertenecientes a hogares en los que hay una única fuente de ingresos, dedican más tiempo a desempeñar trabajo doméstico (Larson \& Verma, 1999).

\section{9.- TIEMPO LIBRE Y TIEMPO DEDICADO AL OCIO:}

El tiempo destinado a realizar actividades de ocio por los adolescentes refleja sus intereses. La utilización del tiempo libre a realizar unas u otras actividades puede tener efectos positivos o negativos en el desarrollo de los adolescentes.

Las actividades realizadas durante el tiempo libre pueden conllevar concentración y motivación por lo que pueden ser oportunidades positivas para el crecimiento del adolescente. Estas actividades pueden estar asociadas con el desarrollo de la identidad del adolescente, la iniciativa, disminuir el riesgo de practicar la delincuencia y tener efectos positivos en la etapa adulto (Lee $\&$ Larson, 2000). Aunque se considera necesario profundizar más en este tema, se puede concluir que las actividades estructuradas aportan experiencias únicas para el desarrollo (Larson, 2001).

Sin embargo, Larson (2001) también afirma que existen otras líneas de investigación que indican que los adolescentes no necesitan mucho tiempo libre sin estructurar para explorar por sí mismos y fomentar su creatividad. Pasar mucho tiempo sin estructurar con los amigos puede predecir problemas de comportamiento (Larson \& Verma, 1999). Es dependiente del contenido de la interacción, de las disposiciones individuales y de numerosos factores.

Estudios más actuales confirman que pasar muchas horas con los amigos o viendo la televisión hace disminuir las notas en matemáticas (Porterfield \& Winkler, 2007). 
10 Parte

Capítulo 1: Uso del tiempo de los adolescentes

\subsection{1.- Nacionalidad:}

Los adolescentes americanos cuentan con más tiempo libre que los del resto de países (Larson \& Verma, 1999). Estudios que datan desde el año 1920 manifiestan que el 40$50 \%$ del tiempo libre de los adolescentes americanos se dedica a actividades discrecionales. Esta cifra es ligeramente más baja en Europa, siendo el 35-45\% y solamente el $25-35 \%$ en el este de Asia. En días lectivos, los estudiantes belgas tienen más tiempo libre que los (Stevens et al., 2003). Dependiendo de la actividad a la que destinen este tiempo libre, puede ser considerado una ventaja o una amenaza.

Los jóvenes norteamericanos utilizan casi todo su tiempo libre no estructurado en jugar, hablar por teléfono y estar con amigos. Los más jóvenes dedican el mismo tiempo a jugar que los japoneses y taiwaneses, aunque hay que señalar que, en Asia, el tiempo dedicado a esta tarea disminuye más rápido con la edad (Larson \& Verma, 1999).

\subsection{2.- Género:}

Se aprecian diferencias en el uso del tiempo libre por género. Entre semana, los adolescentes canadienses de Ontario disfrutan de más tiempo libre que las adolescentes, siendo más notable esta diferencia en los primeros años de adolescencia (hasta 0:42 minutos entre 12 y 14 años y disminuyendo a 0:25 minutos en los adolescentes entre 15 y 19 años). Esta disminución puede ser debida a que los adolescentes más mayores dedican más tiempo a desempeñar un trabajo. El tiempo libre el fin de semana aumenta, existiendo igualmente una diferencia importante por género (hasta 1:27 horas diarias en los adolescentes más jóvenes), y al igual que entre semana, también disminuye con la edad (Hilbrecht et al., 2008). Según este estudio, las adolescentes socializan más que los chicos tanto entre semana como el fin de semana.

Stevens et al. (2003) manifiestan que las diferencias por género en el uso del tiempo libre son poco pronunciadas en la etapa de la adolescencia.

Es reseñable que el porcentaje de adolescentes que dedican parte de su tiempo libre a la escritura creativa ha aumentado en los últimos años, principalmente en adolescentes que pertenecen a familias con bajo nivel cultural. Uno de los motivos de esta práctica 
puede ser por la participación en blogs, al tratarse de una tendencia muy reciente (Porterfield \& Winkler, 2007).

\subsection{0.- TIEMPO DEDICADO A LAS NUEVAS TECNOLOGÍAS DE INFORMACIÓN Y} COMUNICACIÓN:

Actualmente los adolescentes encuentran a su alcance una gran variedad de dispositivos electrónicos (televisión, teléfono móvil, ordenador, tablets y consolas). En los últimos 15 años, el despliegue de internet ha crecido de manera muy evidente, permitiendo a los adolescentes tener la posibilidad de estar permanentemente conectados a la red, mediante numerosos dispositivos (ordenador, teléfono móvil o tablets). Por lo tanto, es interesante estudiar cómo ha afectado y afecta la expansión de los nuevos dispositivos electrónicos y medios de comunicación a la organización del tiempo de los jóvenes (Garitaonandia et al., 2005) y analizar si su uso ha restado tiempo a otro tipo de actividades.

Puesto que consideramos que la investigación sobre el uso de las nuevas tecnologías por los adolescentes es un punto clave en nuestro estudio, hemos tomado la decisión de dedicar el capítulo 2 de esta revisión bibliográfica a recopilar la información referida a este tema. 



\section{Capítulo 2:}

\section{Adolescentes y}

nuevas tecnologias 



\section{Capítulo 2.- ADOLESCENTES Y NUEVAS TECNOLOGÍAS:}

En esta segunda parte de la revisión bibliográfica de trabajo, vamos a centrarnos en analizar los distintos estudios que investigan sobre la relación entre las nuevas tecnologías y los adolescentes.

Nos interesa estudiar el uso por parte de los adolescentes de los diferentes dispositivos tecnológicos y de las tecnologías de la información y comunicación además de conocer cuáles son sus medios preferidos y el tiempo que dedican a cada uno de ellos, tratando de encontrar diferencias significativas, si las hubiese, por factores sociodemográficos.

Del mismo modo, analizaremos cuáles son los posibles efectos positivos y negativos que el uso de las nuevas tecnologías y dispositivos digitales puede provocar en los adolescentes.

Finalmente, examinaremos los artículos encontrados que hablan sobre el control parental en relación a la gestión de las nuevas tecnologías por parte de los adolescentes.

Cabe destacar el aumento de dispositivos o aparatos tecnológicos disponibles en los hogares españoles. En el gráfico 3, confeccionado a partir de los datos obtenidos en la encuesta "Equipamiento de los hogares españoles en algunos productos de tecnologías de información y comunicación" realizada por el INE en 2014, se puede apreciar la evolución entre el año 2013 y 2014. Este gráfico muestra el porcentaje de hogares españoles que dispone de cada uno de los diferentes dispositivos electrónicos.

Se puede apreciar que prácticamente, en todos los hogares españoles hay televisión y teléfono móvil. Las cifras muestran estabilidad entre el año 2013 y 2014, excepto para el caso del libro electrónico, cuya presencia en los hogares españoles en el último año ha aumentado de manera notable. Del mismo modo, es destacable la disminución del porcentaje de hogares que cuentan con DVD y similar y con video. 


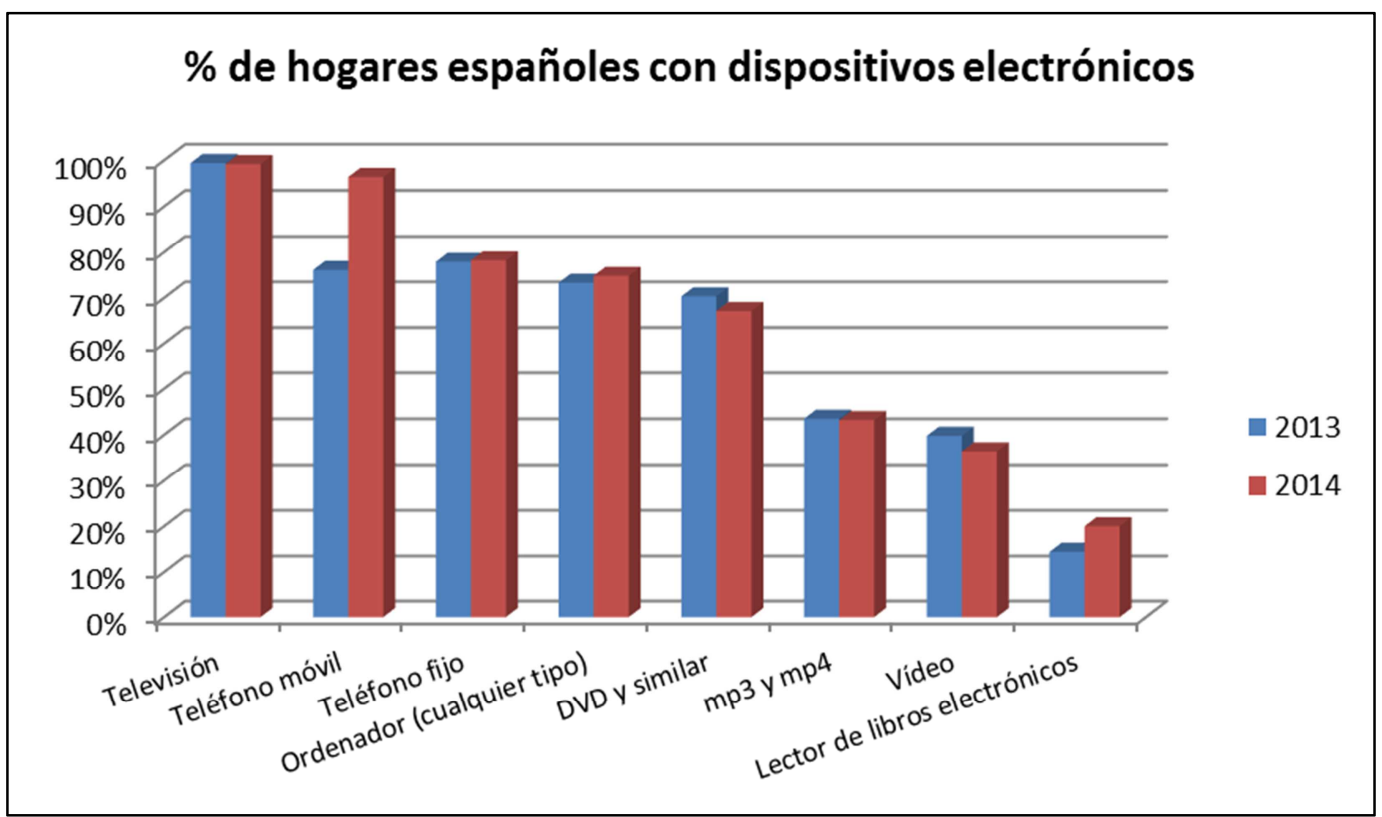

Gráfico 3: hogares españoles que disponen de cada dispositivo electrónico. Fuente: Encuesta sobre Equipamiento y Uso de Tecnologías de Información y Comunicación en los Hogares (2014)

\section{1.- NATIVOS DIGITALES VERSUS INMIGRANTES DIGITALES: LA BRECHA DIGITAL}

Recientemente se ha creado el término usuarios "nativos de las TIC" o "nativos digitales" para designar a los niños y jóvenes que han nacido y crecido rodeados de los nuevos soportes, plataformas tecnológicas y contenidos digitales. La relación de estos niños y jóvenes con la tecnología difiere enormemente de la experimentada por sus padres y abuelos. Estos tienen distinto grado de relación con las TIC, dependiendo principalmente del momento en que hayan comenzado a experimentar con ellas y el grado de manejo (Navarro, González \& Massana, 2014).

Manteniendo la jerga anteriormente utilizada para los niños y adolescentes, se utiliza el término "inmigrantes digitales" para dirigirnos a los padres y a los abuelos de los nativos digitales. Del mismo modo, se utiliza el término "brecha digital", para señalar la diferencia existente entre los nativos y los inmigrantes digitales (Munoz-Miralles et al., 2014). 


\section{2.- LA RELACIÓN DE LOS ADOLESCENTES CON LAS NUEVAS TECNOLOGÍAS:}

Los adolescentes se sienten fascinados por la tecnología y son proclives a tener cuanta más mejor.

En este capítulo, para la revisión bibliográfica, hemos prestado especial atención a las fechas de las que datan cada uno de los artículos estudiados, puesto que la velocidad a la que las nuevas tecnologías penetran en nuestra vida y evolucionan en sí mismas es tan rápida que la foto de la realidad está en constante transformación.

Estos cambios vertiginosos provocan que los hábitos de los adolescentes, grupo de edad que se adapta rápidamente a estos cambios, se modifiquen y con ello su relación con las nuevas tecnologías. Es por esta razón, que los estudios realizados sobre las nuevas tecnologías y los adolescentes corren el riesgo de quedarse obsoletos en breves periodos de tiempo. Vamos, por lo tanto, a utilizar la bibliografía más reciente encontrada para configurar este estado del arte relacionado con los adolescentes y las nuevas tecnologías.

\subsection{1.- Edad de inicio en las nuevas tecnologías:}

En la actualidad, nos encontramos a menudo frente a la imagen de niños, de muy corta edad, utilizando con destreza distintos dispositivos tecnológicos como ordenadores, smartphones o tablets con acceso a internet. En algunos casos, disponen desde muy pequeños de sus propios dispositivos.

La edad a la cual se considera conveniente que un niño utilice y/o tenga en propiedad estas nuevas tecnologías es muy a menudo, motivo de debate. Cánovas (2015) afirma que los adolescentes que no hayan podido acceder a las TIC y familiarizarse con ellas hasta los 13-14 años, estarán en clara desventaja respecto a los demás. La adolescencia es un mal momento para iniciarles en las TIC, puesto que los adolescentes son reacios a permitir que sus padres les supervisen. Sin embargo, los niños de 9 a 12 años interactúan mucho más con los padres y son especialmente receptivos a los consejos y recomendaciones. 
Los niños actuales acceden a las TIC, cada vez, a una edad más temprana (MunozMiralles et al., 2014). Un estudio reciente americano indica que los actuales estudiantes de universidad (adolescentes menores de 20 años), accedieron $s$ a internet con una edad promedio de 9 años (Li, O’Brien, Snyder \& Howard, 2015).

La edad de inicio en las nuevas tecnologías, en la actualidad, no se sitúa en los adolescentes. Ni tan siquiera en los niños. Estudios recientes, afirman que los bebés de pocos meses de edad pasan 1 hora diaria viendo la televisión. Los niños, empiezan a los 2 años a jugar con smartphones y tablets (Genc, 2014).

Con respecto a la edad de iniciación de los jóvenes en las redes sociales, cada vez es más temprana. Los adolescentes catalanes de menos de trece años consumen redes sociales (Navarro et al., 2014).

En Norteamérica, el 93\% de los adolescentes tiene ordenador o tiene acceso en casa al ordenador (Madden, Lenhart, Duggan, Cortesi \& Gasser, 2013). En España, la encuesta sobre Equipamiento y Uso de Tecnologías de Información y Comunicación en los Hogares realizada por el INE en 2014 , pone de manifiesto que el $74,8 \%$ de los hogares españoles tienen algún tipo de ordenador.

\subsection{2.- Tiempo dedicado por los adolescentes a las nuevas tecnologías:}

En la última década, las nuevas tecnologías se han convertido en una parcela cada vez más importante de la vida de los adolescentes.

Estudios concluyen que los adolescentes pasan más tiempo utilizando nuevas tecnologías que en el colegio. De hecho, se ha convertido en la actividad a la que más tiempo destinan los adolescentes, después de dormir (Strasburger, Jordan \& Donnerstein, 2010).

En el año 2004, en Estados Unidos, los jóvenes de edades comprendidas entre 11 y 14 años ya afirmaban dedicar a las nuevas tecnologías una media de 6:30 horas al día. En ese año, esta cifra ya era superior al tiempo que pasaban en el colegio (Roberts \& Foehr, 
2004). En los últimos 10 años ha habido un aumento del consumo de tecnologías por los jóvenes (Rideout, Foehr \& Roberts, 2010). Por esta razón los adolescentes de este principio de siglo son denominados en el idioma anglosajón "media generation". Según el estudio mencionado anteriormente, los adolescentes en Estados Unidos dedicaban en 2009 más de 7:30 horas diarias de media (contando los 7 días de la semana) a las nuevas tecnologías, cualquiera que ésta sea (tabla 6):

\begin{tabular}{|l|ccc|}
\cline { 2 - 4 } \multicolumn{1}{c|}{} & $\mathbf{2 0 0 9}$ & $\mathbf{2 0 0 4}$ & $\mathbf{1 9 9 9}$ \\
\hline Contenido TV & $4: 29$ & $3: 51$ & $3: 47$ \\
\hline Música/audio & $2: 31$ & $1: 44$ & $1: 48$ \\
\hline Ordenador & $1: 29$ & $1: 02$ & $0: 27$ \\
\hline Videojuegos & $1: 13$ & $0: 49$ & $0: 26$ \\
\hline Imprimir & $0: 38$ & $0: 43$ & $0: 43$ \\
\hline Películas & $0: 25$ & $0: 25$ & $0: 18$ \\
\hline Total TICS & $10: 45$ & $8: 34$ & $7: 29$ \\
\hline$\%$ multitarea & $6: 57$ & $6: 14$ & $3: 50$ \\
\hline Total TICS & $7: 38$ & $6: 21$ & $6: 19$ \\
\hline
\end{tabular}

Tabla 6: tiempo medio de exposición a las TIC de los adolescentes norteamericanos entre 8 y 18 años Fuente: Rideout et al. (2010)

Dos de los organismos referentes en esta materia, la AAP y la Canadian Society of Pediatrics (CSP), recomiendan no exponer a los niños de menos de dos años a las tecnologías. A partir de los 3 años y hasta los 5 años, se recomienda que como máximo estén expuestos durante una hora al día. Desde los 6 hasta los 18 años la recomendación es de no sobrepasar las 2:00 horas diarias de consumo de nuevas tecnologías (Strasburger et al., 2013).

En Australia, el $45 \%$ de los niños de 8 años y el $80 \%$ de los adolescentes de 16 años exceden las 2:00 horas diarias frente a una pantalla recomendado por la AAP (Houghton et al., 2015)

En Norteamérica, un estudio pone de manifiesto que los niños de entre 8 y 10 años dedican una media de 8:00 horas al día en los diferentes medios de comunicación. Esta 
cifra, aumenta con la edad, puesto que la media de tiempo dedicado por los adolescentes más mayores supera las 11 horas diarias (Rideout et al., 2010).

El tiempo medio de un adolescente estadounidense frente a una pantalla es superior a 7 horas diarias (Strasburger, 2014).

En Noruega, el tiempo destinado frente a una pantalla también excede las 2:00 horas diarias recomendadas (Overby, Klepp \& Bere, 2013), aunque pone de manifiesto que ha habido una reducción del tiempo frente a la pantalla de los adolescentes noruegos de 10 a 12 entre el año 2001 y 2008. Esto se debe a un incremento en el esfuerzo en transmitir a los adolescentes los beneficios de realizar actividad física y los efectos negativos de una vida sedentaria. Este incremento ha sido más notable en los adolescentes de 6으 grado y en aquellos cuyos padres alcanzaron titulación universitaria.

Tanto los niños como los jóvenes dedican a las nuevas tecnologías 4 o 5 veces más del tiempo recomendado por la AAP (Rideout et al., 2010; Tremblay et al., 2012).

Esta media de tiempo dedicada a las nuevas tecnologías, puede llegar a alcanzar las 11 horas diarias entre los adolescentes que cuentan con nuevas tecnologías disponibles en su habitación (Strasburger, 2014).

\subsection{3.- Beneficios o efectos positivos del uso de las TIC:}

Para la mayoría de los adolescentes de los Estados Unidos, la utilización de las nuevas tecnologías y de los medios de comunicación es una parte muy relevante de su vida diaria. Los adolescentes españoles comparten este mismo pensamiento. Las TIC se han convertido para ellos en un elemento de comunicación, relación, aprendizaje y ocio imprescindible en sus vidas (Munoz-Miralles et al., 2014).

La llegada de internet ha acercado y puesto a disposición la información y mejorado la comunicación en todo el mundo, pero es importante resaltar que también puede provocar un impacto negativo en el bienestar social de muchos de sus usuarios adolescentes (Cookingham \& Ryan, 2015). 
La implantación de las nuevas tecnologías en la rutina diaria de los adolescentes, ha permitido, en algunos casos, mejorar su calidad de vida. Mediante las nuevas tecnologías, los adolescentes pueden relacionarse, aprender, comunicarse y satisfacer sus necesidades de ocio y diversión. Les permite:

- Conectarse con otras personas con intereses compartidos. Las nuevas tecnologías ofrecen realmente a los adolescentes la posibilidad de descubrir e incluir en sus amistades a otras personas de diversos ambientes. Esta comunicación es un punto muy importante para que los adolescentes tengan la oportunidad real de relacionarse con personas de otras culturas y aprender a respetar, tolerar e incrementar su diálogo (O'Keeffe, Clarke-Pearson \& Council, 2011).

- Disponer de los recursos necesarios para su formación académica (O’Keeffe et al, 2011).

- Mejorar la creatividad individual y colectiva. Materializar ideas mediante la creación de blogs, podcasts, videos y aplicaciones de juegos.

- Compartir esfuerzos artísticos y musicales.

- Obtener acceso online a información sobre sus preocupaciones de manera sencilla y anónima. Existen una serie de recursos en la red con información disponible sobre los intereses de los adolescentes, como enfermedades de transmisión sexual, reducción de estrés o signos de depresión ( $O^{\prime}$ Keeffe et al, 2011).

- Los contenidos prosociales disponibles en las nuevas tecnologías pueden influenciar en los adolescentes. Ciertos programas en los medios pueden enseñar a los adolescentes a empatizar, a ser tolerantes con otras razas y etnias y toda una variedad de habilidades interpersonales (Hogan \& Strasburger, 2008).

- Oportunidad de participar en acontecimientos de la comunidad a través de voluntariados para eventos locales, eventos políticos y filantrópicos o pedir dinero para caridad. 


\subsection{4.- Riesgos o efectos negativos del uso de las TIC:}

La mayoría de los jóvenes tiene un alto nivel de conciencia en relación a los riesgos y posibles resultados de su comportamiento en línea (Bryce \& Fraser, 2014).

Son numerosos los posibles riesgos asociados al mal uso de las nuevas tecnologías como el aislamiento, la pérdida de las habilidades sociales o la adicción (Munoz-Miralles et al., 2014). El tiempo frente a una pantalla representa un factor de riesgo de ansiedad y depresión en los adolescentes canadienses (Maras et al., 2015). Según la literatura encontrada, los principales riesgos o efectos negativos de la práctica del mal uso de las TIC son los siguientes:

\subsubsection{1.- Riesgo de perder la privacidad:}

La identidad digital se corresponde a la información de un individuo expuesta en los medios. Está formada por información personal, fotografías, videos, noticias, comentarios y preferencias entre otros datos. Por lo tanto, la identidad digital es lo que la red dice que cada individuo es para los demás. Al igual que en la vida real tenemos una identidad, en internet tenemos la identidad digital.

La identidad digital de cada individuo, por lo tanto, nace en blanco. Se va conformando con el paso de los años, mediante la información aportada por el propio individuo o por terceras personas.

El riesgo aparece cuando el individuo es consciente de que en la red hay más información disponible sobre su persona de la que hubiese deseado. Puede ser que el joven haya expuesto cierta información sobre sí mismo que a posteriori, no quisiese que hubiese quedado grabada en internet. El problema se agrava, si además esta información resulta ser falsa. Cualquier persona puede colgar información sobre otra en la red. Cualquiera puede publicar información que contenga datos sobre terceros, que puedan no haber consentido esa publicación. La reputación online actualmente es muy importante. 


\subsubsection{2.- Problemas de somnolencia y calidad del sueño:}

El uso en exceso de medios electrónicos por los adolescentes antes de acostarse o durante la noche se relaciona con tener dificultades para dormir y muestra un impacto negativo en la duración del sueño (Cain \& Gradisar, 2010).

Estudios puntualizan que los efectos más negativos del uso de las TIC son los relacionados con las dificultades para conciliar el sueño. La duración del sueño está afectada por el uso de las nuevas tecnologías, pero no de manera tan contundente (Lemola, Perkinson-Gloor, Brand, Dewald-Kaufmann \& Grob, 2015).

El 90\% de los artículos analizados en la realización de un estudio por Hale \& Guan (2015), ratifican la existencia de una asociación negativa entre el tiempo pasado frente a una pantalla por el adolescente y la calidad del sueño. También afectan a la cantidad de tiempo destinado a dormir y al tiempo necesario a dormirse.

El uso frecuente de los dispositivos tecnológicos se asocia significativamente a un tiempo destinado a dormir deficiente. Las consecuencias de utilizar los dispositivos electrónicos antes de dormirse entre semana pueden ser numerosas, y dependen del tipo de tecnología utilizada (Arora, Broglia, Thomas \& Taheri, 2014). Los adolescentes que utilizan los teléfonos móviles, videojuegos y redes sociales antes de dormirse tienen más dificultades para conciliar el sueño

- Los adolescentes que escuchan música antes de dormirse corren el riesgo de padecer pesadillas frecuentes.

- Los adolescentes que ven la televisión antes de acostarse son cuatro veces más propensos a reportar mayor frecuencia de sonambulismo.

Arora et al (2014) afirman que el menor uso de dispositivos electrónicos antes de acostarse aumenta la calidad del sueño.

El uso de los medios electrónicos también está relacionado con padecer síntomas de depresión (Lemola et al., 2015). 


\subsubsection{3.- Riesgo de reducir su actividad física:}

La práctica de actividad física (moderate-to-vigorous physical activity MVPA) y el tiempo frente a una pantalla (ordenador, tablet, televisión, etc...), están asociadas con una serie de resultados sobre la salud. Los resultados de un estudio realizado a adolescentes alemanes destacan la necesidad de establecer estrategias dirigidas a reducir el tiempo frente a una pantalla y a promocionar la inversión de tiempo en actividades físicas (Bucksch et al., 2014).

Según Cánovas (2015), el 40\% de los adolescentes entre 8 y 18 años están desarrollando lesiones de espalda propias de personas de 50 años, debido a la alta exposición a las TIC. También problemas de vista y hasta tendencia a la obesidad, por la falta de actividad física.

\subsubsection{4.- Riesgo de sufrir adición}

Uno de los aspectos más controvertidos y que mayor alarma social ha creado, es el potencial uso adictivo de las nuevas tecnologías, especialmente entre los adolescente. Por esta razón, se ha tratado de investigar sobre la adicción y la medición de la adición a los medios (Labrador, Villadangos, Crespo \& Becoña, 2013).

\subsection{5.- Control parental:}

Las cifras barajadas sobre el porcentaje de adolescentes que utiliza las TIC y el tiempo que las dedican son elevadas, por lo que es interesante adentrarse en la literatura para tratar de ver qué control o pautas educativas establecen principalmente los padres y educadores sobre el uso de estas tecnologías por los adolescentes.

Lam (2015) afirma que el control parental sobre el uso de las TIC por sus hijos es bajo y además, disminuye con la edad. Los adolescentes, al hacerse mayores tienen más independencia y esto dificulta el control de su uso de las TIC. La asociación entre bajo rendimiento escolar y falta de control paterno del uso TIC debe considerarse como una oportunidad educativa, puesto que el consejo paterno en la etapa de la adolescencia es muy importante para hacerles aprender a utilizar las TIC de manera responsable. EI 
control por parte de los padres del uso de las TIC se asocia a mejor rendimiento escolar por parte de los adolescentes.

Los padres no deben pretender que sus hijos sean ajenos a las nuevas tecnologías por el hecho de que ellos no las tuviesen a su edad (Cánovas, 2015). Las circunstancias de los adolescentes actuales son diferentes a las que tenían sus padres, y sus necesidades también. Margaret Mead lo confirma de la siguiente manera: "Han llegado los tiempos en que debemos enseñar a nuestros hijos lo que nadie sabía ayer, y preparar las escuelas para lo que nadie sabe todavía hoy".

Con el objetivo de profundizar en la bibliografía existente relacionada con las nuevas tecnologías y los adolescentes, procedemos a análisis de los estudios referidos a las TIC y los adolescentes y en relación con los diferentes dispositivos electrónicos y aplicaciones, estructurado en los siguientes puntos:

- internet

- Redes sociales

- Televisión

- Teléfono móvil

- Videojuegos

\section{3.- INTERNET:}

El nacimiento y principalmente la popularización de internet ha significado una revolución tecnológica, que ha cambiado la vida a los miembros de la sociedad. No es sencillo concretar la fecha exacta en que se creó internet, puesto que ha sido un fenómeno en constante evolución desde los años 60. Lo que sí se puede afirmar es que la popularización de internet comenzó hace un cuarto de siglo. Es un descubrimiento por lo tanto, relativamente joven. Sin embargo, los adolescentes actuales han nacido ya en esta "nueva era" y han crecido rodeados de estas tecnologías (Barrio Fernández, 2014). 
10 PARTE

Capítulo 2: Adolescentes y nuevas tecnologías

\subsection{1.- Cifras de adolescentes conectados a internet}

El aumento del ancho de banda y una mejor funcionalidad han mejorado la accesibilidad a internet y lo ha mostrado más atractivo. Por esta razón, podemos observar en los estudios mencionados a continuación, que la evolución del uso de internet por parte de los adolescentes, ha sido muy importante en los últimos años.

Shapira, Goldsmith, Keck, Khosla y McElroy (2000) afirman, ya a principio de este siglo, que dedicar entre 20 y 28 horas semanales al uso de Internet puede comenzar a causar dificultades en el adolescente.

En el Reino Unido, el 70\% de los menores se conectaba a internet desde su propia casa (Livingstone \& Bober, 2004). Según los estudios realizados por la AIMC (Asociación para la Investigación en Medios de Comunicación) en 2006, en España, el 75\% de los adolescentes afirmaba usar internet. Según la Asociación Mexicana de internet (AMIPCI), en 2008, el $48 \%$ de los adolescentes mexicanos se conectaba desde su hogar; el $35 \%$ desde lugares públicos y el resto desde otros lugares como su lugar de trabajo, en la escuela, etc. La tabla 7 muestra que en Grecia, en 2008 , el $70,8 \%$ de los adolescentes tenía acceso a internet (Siomos, Dafouli, Braimiotis, Mouzas \& Angelopoulos, 2008).

En Estados Unidos, el 84\% de los adolescentes tienen acceso a internet, a menudo, de alta velocidad. Un tercio de ellos tiene acceso a internet en su propio dormitorio (Strasburger et al., 2013).

\begin{tabular}{|cc|c|}
\hline PAís & ESTUDIO & $\begin{array}{c}\text { \%ADOLESCENTES } \\
\text { CONEXIÓN A INTERNET EN } \\
\text { CASA }\end{array}$ \\
\hline Grecia & Siomos, Dafouli et al., 2008 & $70,8 \%$ \\
\hline EEUU & Strasburger, Hogan, et al 2013 & $84,0 \%$ \\
\hline España & $\begin{array}{c}\text { encuesta sobre Equipamiento y Uso de } \\
\text { Tecnologías de Información y Comunicación } \\
\text { en los Hogares INE, 2014 }\end{array}$ & $74,5 \%$ \\
\hline
\end{tabular}

Tabla 7: estudios sobre el porcentaje de adolescentes que tienen conexión a internet en sus hogares 
El uso de internet por los adolescentes australianos se ha incrementado notablemente en estos últimos años (Usher et al., 2014).

En España, el gráfico 4 mostrado a continuación, refleja claramente la evolución de la presencia de ordenadores, internet y conexión de banda ancha en los hogares españoles en los últimos 8 años. Los datos han sido obtenidos de las Encuestas sobre Equipamiento y Uso de Tecnologías de Información y Comunicación en los Hogares, realizadas por el INE en sucesivos años.

En el año 2014, el 74,8\% de los hogares españoles tienen algún tipo de ordenador. El $74,4 \%$ tienen conexión a internet y el 73\% disponen de conexión de banda ancha.

Como puede observarse en el gráfico 4, la evolución es notable, principalmente en la presencia de conexión de banda ancha en los hogares, que ha multiplicado su cifra por 2,6 en los últimos 8 años.

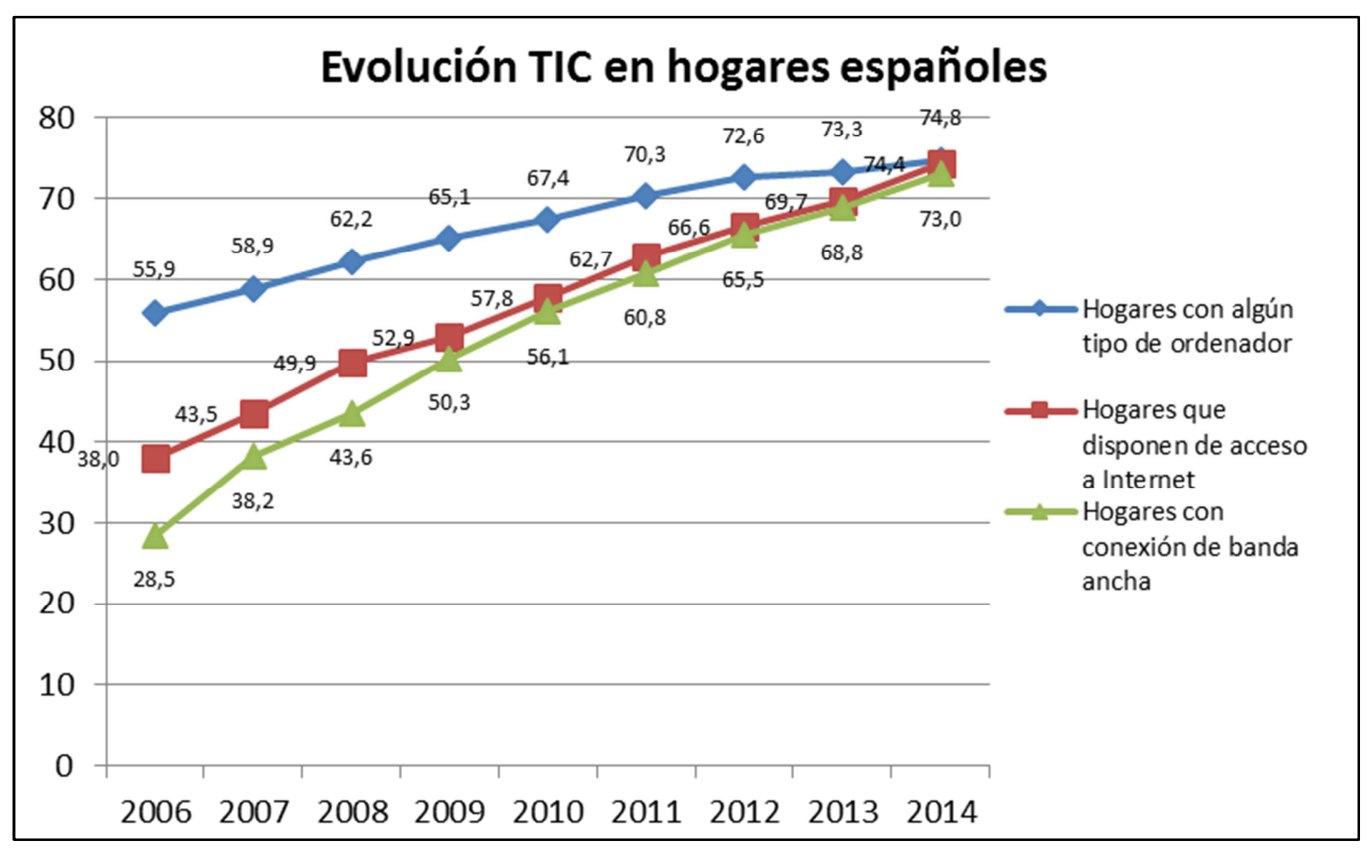

Gráfico 4: Evolución del equipamiento TIC en los hogares. Total nacional (\% hogares). Fuente: Encuesta sobre Equipamiento y Uso de Tecnologías de Información y Comunicación en los Hogares (2006-2014) 
Capítulo 2: Adolescentes y nuevas tecnologías

Internet es una herramienta de uso habitual entre los jóvenes en España. En el año 2003-2005, el 39\% de los adolescentes vascos de entre 14 y 18 años disponían de acceso a red en su hogar (de la Piscina, Zarandona, Basterretxea \& Idoiaga, 2011), cifra que está en línea con la información mostrado en el gráfico 4.

El estudio elaborado por la OCU en el año 2013, con motivo del Día de internet, recogió las respuestas realizadas a 400 padres y madres sobre los hábitos de uso de internet de sus hijos. El 95\% de los padres manifestó que sus hijos adolescentes de entre 10 y 16 años, usa internet.

La encuesta sobre Equipamiento y Uso de Tecnologías de Información y Comunicación en los Hogares realizada por el INE en el año 2014, concluye que en España la media de jóvenes de 10 a 15 años que utiliza el ordenador es de $93,8 \%$. El 92\% de los adolescentes españoles de edades comprendidas entre 10 y 15 años son usuarios de internet.

Con respecto al tiempo que dedican los adolescentes a conectarse a internet, según Bercedo Sanz et al. (2005) los adolescentes españoles se conectaban a internet entre semana una media de 0:49 horas/día y de 1:09 horas/día el fin de semana.

En 2009, la mitad de los menores accedía a diario a internet y navegaba de media 1:12 horas/día, con mayor intensidad el fin de semana que los días de diario. El $75 \%$ de los menores declaraba que conectarse a internet le gusta mucho o bastante más que otras cosas (Observatorio INTECO, 2009).

El estudio de Munoz-Miralles et al. (2014) afirma que el 44,8\% de los adolescentes barceloneses se conecta a internet durante 2 o más horas al día.

Casi el $72 \%$ de los chicos y el $80 \%$ de las chicas adolescentes de la Comunidad Autónoma de Cantabria, manifiestan utilizar internet para estudiar entre semana durante menos de 2:00 horas al día (Noriega et al., 2015). 
La encuesta sobre Equipamiento y Uso de Tecnologías de Información y Comunicación en los Hogares realizada por el INE durante el año 2014, pone de manifiesto que entre los adolescentes españoles no se encuentran diferencias significativas en el uso de internet por género.

Según Bercedo Sanz et al. (2005), los adolescentes cántabros masculinos prefieren navegar y descargarse juegos de la red, mientras que las adolescentes chatean y envían más correos electrónicos (Bercedo Sanz et al., 2005).

La encuesta sobre Equipamiento y Uso de Tecnologías de Información y Comunicación en los Hogares realizada por el INE en el año 2014 afirma que el porcentaje de adolescentes usuarios de internet en España aumenta con la edad, llegando a ser de un 95,2\% para los adolescentes de 15 años.

Noriega et al. (2015) concluyen igualmente que el porcentaje de adolescentes cántabros que utilizan internet como herramienta de ocio entre semana aumenta con la edad, haciéndose más significantes a los 16 y 17 años.

\subsection{2.- Dispositivos de acceso a internet:}

Los principales dispositivos utilizados por los adolescentes para navegar por la red son: el ordenador, tablets o el teléfono móvil. Un 74\% de los adolescentes de entre 12 y 17 años, manifiesta conectarse a internet en el teléfono móvil, tablet u otros dispositivos móviles, al menos de manera ocasional. Uno de cada dos adolescentes de Estados Unidos es usuario de internet desde su smartphone (Madden et al., 2013). Este estudio afirma también que el porcentaje de adolescentes norteamericanos que tiene acceso a dispositivos electrónicos donde conectarse a internet muy elevado. El 93\% de los adolescentes tiene ordenador o tiene acceso en casa al ordenador. En Norteamérica, uno de cada cuatro adolescentes (23\%) posee una tablet, porcentaje similar al de los adultos.

En Cataluña, casi la totalidad de los adolescentes menores de trece años, se conectan a internet tanto en ordenador de sobremesa como en portátil en casa y en el colegio 
(Navarro et al., 2014). El 98\% de los adolescentes de Barcelona tiene ordenador en casa y el $98,6 \%$ de ellos accede a internet (Munoz-Miralles et al., 2014).

La encuesta sobre Equipamiento y Uso de Tecnologías de Información y Comunicación en los Hogares, realizada por el INE en el año 2014, ha destacado la aparición de un fenómeno nuevo en España en relación a los medios utilizados para conectarse a internet. Ha sido la primera vez en que, se contabilizan más usuarios de internet $(76,2 \%)$ que de ordenador (73,3\%). El 77,1\% de los internautas accedieron a internet mediante el teléfono móvil.

El 60\% de los menores españoles de entre 11 y 14 años navega y busca información a través de internet desde sus smartphones (Cánovas, García de Pablo, Oliaga San Atilano, Aboy Ferrer \& Protégeles, 2014).

Entre los jóvenes catalanes más mayores (edades comprendidas entre 14 y 29 años) la conexión a internet mediante el teléfono móvil gana importante relevancia (Navarro et al., 2014).

Se observa que existe una diferencia por género entre los adolescentes norteamericanos, puesto que el porcentaje de chicas que se conectan a internet desde el móvil es mayor al de chicos (34\% las chicas frente a $24 \%$ los chicos). Entre los adolescentes más mayores, el $55 \%$ de las chicas con smartphone manifiesta conectarse a internet desde el móvil (Madden et al., 2013).

\subsection{3.- Utilidades de internet}

Son variados los usos a los cuales, los distintos miembros de esta sociedad, destinamos el tiempo dedicado a internet. Como muestra, el gráfico 5 refleja el porcentaje de personas que han utilizado los diferentes servicios que ofrece internet en 2013.

Los adolescentes, lo utilizan principalmente para los dos puntos que se exponen a continuación: 


\subsubsection{1.- Internet como apoyo en sus estudios}

Los adolescentes catalanes menores de 13 años, afirman utilizar internet para estudiar y como soporte en el desempeño de sus tareas del colegio. Lo prefieren para hacer los deberes y más en su versión portátil, porque se pueden llevar el aparato a todas partes. Utilizan páginas como Google y Wikipedia como apoyo para realizar sus tareas. En el hogar, el ordenador está situado en su habitación o en una habitación/estudio (Navarro et al., 2014).

El 81\% de los adolescentes de Barcelona (España) considera que los contenidos de la red son de su interés, y les sirven, entre otros, para realizar los trabajos de clase (Castellana Rosell, Sánchez-Carbonell, Graner Jordana \& Beranuy Fargues, 2007).

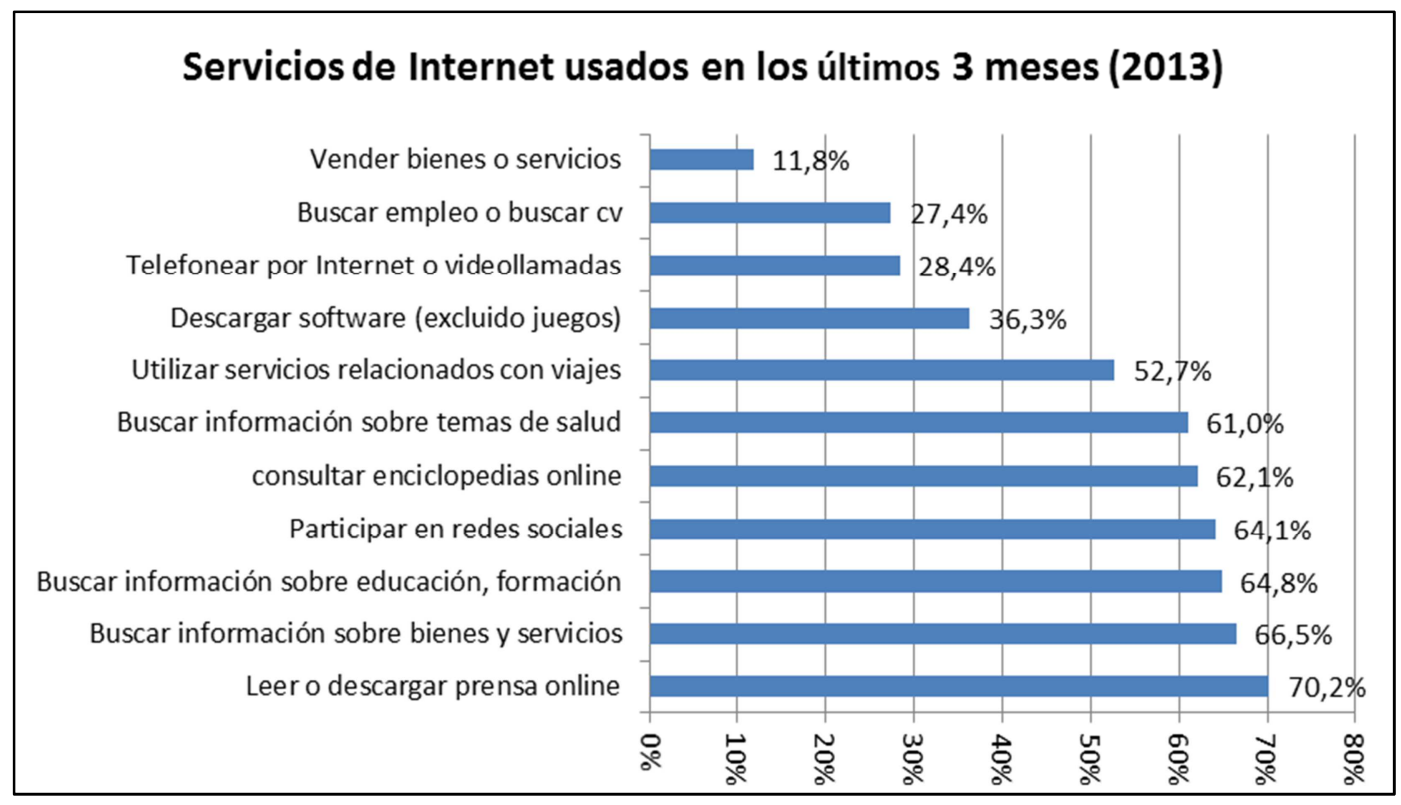

Gráfico 5: Servicios de internet usados en los últimos 3 meses (2013). Fuente: Encuesta sobre el Equipamiento y Uso de Tecnologías de la Información y Comunicación en los Hogares y Encuesta de uso de TIC y comercio electrónico en las empresas (INE)

\subsubsection{2.- Internet para ocio y para relacionarse:}

Los adolescentes utilizan internet como herramienta de comunicación, principalmente para reforzar las relaciones existentes, tanto con sus amigos como con sus parejas. También para establecer nuevas relaciones sociales e interaccionar con extraños en 
línea (práctica no tan común como lo fue durante los primeros años de existencia de internet). Esta práctica puede aportar beneficios al adolescente, como aliviar la ansiedad social pero también le enfrenta a diferentes riesgos (Subrahmanyam \& Greenfield, 2008).

Según los estudios realizados por la AIMC (Asociación para la Investigación en Medios de Comunicación) en 2006, en España, el 75\% de los adolescentes usa internet, de los cuáles el $67 \%$ lo utiliza para ocio, para entretenerse, para chatear, para jugar y para buscar música (por orden de importancia).

El tiempo destinado por los adolescentes a navegar en internet por ocio, ha aumentado durante los últimos años (Rey-López et al., 2010). Las causas principales de este hecho son el aumento de puntos de conexión a internet y la popularización de las redes sociales (Noriega et al., 2015).

El $47 \%$ de los adolescentes de 10 y 11 años de Cantabria (España), utilizan internet como herramienta de ocio entre semana. El fin de semana, esta cifra aumenta hasta casi un $86 \%$ en los chicos y un $88 \%$ en las chicas. Estos datos evolucionan con la edad, haciéndose más significantes a los 16 y 17 años (Noriega et al., 2015).

El $64,3 \%$ de los adolescentes gallegos manifiesta utilizar internet para su propio ocio; principalmente para descargarse contenidos digitales, tanto música como películas (Gómez Salgado, Rial Boubeta, Brana Tobio, Varela Mallou \& Barreiro Couto, 2014).

Los adolescentes catalanes de entre 14 y 29 años (grupo de edad que incluye los adolescentes más mayores) manifiestan utilizar la conexión a internet tanto en el ordenador como en el teléfono móvil principalmente para distraerse y tener una actividad que les sirve para pasar entretenidos los tiempos perdidos (Navarro et al., 2014). 


\subsection{4.- Efectos positivos y negativos del uso de internet en los adolescentes:}

Con respecto al uso de internet, se sabe poco aún sobre los impactos del uso de internet en el desarrollo del adolescente puesto que la práctica constante del uso de internet data de pocos años atrás. Existe un debate constante en torno a esta cuestión.

Tanto el propio uso de internet como los contenidos publicado por los adolescentes pueden ser tanto positivos como negativos para los adolescentes (Bryce \& Fraser, 2014).

El uso de internet por los adolescentes preocupa cada vez más a investigadores e instituciones. Problemas de conducta, aislamiento social, fracaso escolar y problemas familiares son algunas de las consecuencias del impacto a nivel psicológico y conductual que puede producir en ellos (Gómez Salgado et al., 2014).

Por otro lado, es del mismo modo importante, hacer referencia a los beneficios y los efectos positivos que el uso de internet puede producir en los adolescentes.

\subsubsection{1.- Efectos positivos y ventajas:}

Mientras que el grueso de los estudios llevados a cabo durante los años noventa indicaban que la utilización de internet era perjudicial (detrimento de la vida social, posibilidad de socializar con extraños, etc..), actualmente, nos encontramos estudios que afirman que la posibilidad de disponer en la actualidad de internet, puede otorgar a los adolescentes una serie de oportunidades o ventajas (Valkenburg \& Peter, 2009), por lo que puede considerarse el uso de internet positivo para el adolescente. A continuación analizamos algunas de ellas.

Otros estudios encuentran también beneficioso el acceso a internet por los adolescentes. Los jóvenes pueden obtener todo tipo de información, permitirles relacionarse con gente, aprender habilidades que pueden ser útiles para los trabajos futuros e incluso hasta abrir empresas, independiente de la edad, el género, la raza y el estatus socioeconómico (Larson, 2001).

Gross (2004) afirma no encontrar relación entre el bienestar entre el uso de internet por los adolescentes y su bienestar. 
a.- Internet como herramienta de apoyo a la educación:

Existen estudios para valorar las consecuencias de la incorporación de tecnologías de información y comunicación en la educación.

Algunas investigaciones hacen especial mención a la necesidad de continuar estudiando y profundizando sobre este tema (Cabero Almenara, Cairncross, Schramm, Millerson \& Fuenzalida, 2007; Hernández et al, 2010).

El uso de las TIC en el aula puede servir de apoyo a la explicación del profesor. Su utilización, puede además convertir las clases en sesiones más prácticas, con consigan aumentar la motivación del adolescente. Además, permite al adolescente familiarizarse con las TIC, necesidad sobresaliente puesto que se prevé que sea una herramienta omnipresente en su futuro.

En algunos casos, el profesorado manifiesta que las TIC son una gran herramienta para la educación. El uso de las TIC aporta beneficios muy positivos para la comunidad escolar. La incursión de las TIC en la educación de los adolescentes ha mejorado la satisfacción personal del profesor, el rendimiento en su trabajo y la relación con el alumnado. Los profesores que están en contacto con las nuevas tecnologías son más optimistas que aquellos que no están tan familiarizados con ellas (Valmaña \& GarcíaMartínez, 2009). Sin embargo, el estudio anterior pone de manifiesto la existencia de opiniones de profesores que manifiestan que el uso de las TIC como soporte en el aula les requiere realizar un trabajo extra en el momento de preparar las clases.

Actualmente, internet es una herramienta de apoyo a la educación además en otro sentido. Tanto los jóvenes como sus padres utilizan internet para comunicarse con los compañeros de clase con el objetivo de aclarar cuestiones que les surgen durante el estudio o confirmar temario. Anteriormente, se utilizaban las llamadas de teléfono, pero actualmente mediante el uso de internet, la comunicación es mucho más ágil además de versátil. 
b.- Internet como herramienta de socialización:

Bryce y Fraser (2014) sugieren que los beneficios para el adolescente asociados a la divulgación en los medios de su información personal y la interacción en línea con extraños pueden ser mayores que los riesgos asociados con estas conductas. Esto es debido a la importancia de entablar relaciones sociales y explorar su identidad durante la etapa de la adolescencia.

Internet permite a los adolescentes mantener contacto con sus conocidos y amigos; por lo tanto de conservar su vida social (Valkenburg \& Peter, 2009).

Como ya hemos comentado, la comunicación mediante internet puede reforzar la conexión con los amigos o compañeros de clase. En algunos casos, la comunicación con los padres, puede verse perjudicada por el uso de internet que les deja al margen, por lo que les resta tiempo y calidad de comunicación con sus hijos (Subrahmanyam \& Greenfield, 2008).

\subsubsection{2.- Efectos negativos y riesgos:}

El uso de internet puede entrañar riesgos, principalmente provocados por el mal uso o por el exceso de tiempo dedicado a esta actividad.

Es importante remarcar las múltiples amenazas a las que se enfrentan los adolescentes al utilizar internet. Es por esta razón que proliferan en la investigación las líneas de trabajo dedicadas a estudiar las consecuencias del abuso o mal uso de internet, tanto a nivel psicológico como de conducta entre los adolescentes (Gómez Salgado et al., 2014; Fuster et al., 2012; Durkee et al., 2012).

Entre las posibles consecuencias que puede entrañar el abuso de internet se encuentran las alteraciones en la conducta, pérdida de control, fracaso escolar, asilamiento social e incremento de los conflictos familiares (Gómez Salgado et al., 2014; Cao \& Su, 2007; Holtz \& Appel, 2011; Sánchez-Martinez \& Otero Puime, 2010; Tonioni et al., 2012). 
a.- Pérdida de privacidad y relación con extraños:

En algunos casos, los adolescentes consideran que la divulgación de su información personal en los medios es importante para el desarrollo de las relaciones online.

Sin embargo, también pueden hacer un uso irresponsable de internet, por ejemplo colgando vídeos o imágenes comprometidas en las redes sociales o contactando con desconocidos. De esta manera, se ponen en riesgo. Se debaten las distintas estrategias para la evaluación de la confianza y la verificación de la identidad.

Según un estudio realizado en Cataluña, todos los niños menores de trece años entrevistados son conocedores y conscientes de los riesgos existentes en la red. Saben que entablar contacto con desconocidos, es un riesgo puesto que se lo han explicado sus profesores. Sin embargo, dicho estudio no encuentra constancia de que sus padres o tutores igualmente se lo hayan explicado (Navarro et al., 2014).

\section{b- Acceso a contenidos inapropiados / mensajes existentes en la red:}

Aunque los adolescentes encuentran información muy valiosa en la web, también pueden encontrarse con mensajes de odio, racistas o con contenidos sexuales no acordes con su edad (Subrahmanyam \& Greenfield, 2008).

El 20,4\% de los adolescentes gallegos admite visitar páginas web con contenidos no apropiados para su edad (Gómez Salgado et al., 2014).

\section{c.- Adicción a internet:}

La tristeza, la depresión, el aburrimiento y el estrés son comúnmente factores desencadenantes del uso intensivo de internet (Li et al., 2015).

El mal uso o uso intensivo de internet puede provocar numerosas consecuencias negativas en los adolescentes. Desde la creación del término internet Addiction Disorder (IAD), atribuido a (Goldberg, 1996) hasta la fecha, se discute si se debe reconocer la adicción de los adolescentes a las nuevas tecnologías, principalmente a internet y al 
teléfono móvil, como una enfermedad (Young, 1998; Echeburúa, Labrador \& Becoña, 2009; Rial, Gómez, Braña \& Varela, 2014).

Estudios proponen utilizar el término Adicción a internet o Uso Patológico de internet (Durkee, et al, 2012; Tsitsika, Tzavela, Mavromati \& Consortium, 2012). La adición a internet (IA) se puede llegar a definir como un problema de salud mental grave en muchos países (Brand, Laier \& Young, 2014). También se usan términos similares en el contexto asiático, donde se ha creado el concepto CIAl (Huang, Wang, Qian, Zhong \& Tao, 2007) y conceptos similares para referirse a la adicción a internet (Ko, Yen, Chen, Chen \& Yen, 2005). Del mismo modo se puede afirmar que no existen herramientas de medición "estándar" para la adición a internet (Greydanus \& Greydanus, 2012).

La investigación de la Doctora Kimberly S. Young es considerada como uno de los principales referentes sobre la adicción a internet. En su estudio desarrolló, en 1996, la herramienta IAS (Young's internet Addiction Scale). Este instrumento es y sigue siendo la herramienta más utilizada para analizar el uso adictivo de internet. La herramienta en sí es un cuestionario de 20 preguntas con opción única de respuesta cerrada. El resultado reporta tres posibles niveles de adicción a internet: nivel leve, moderado o severo.

Se han llevado a cabo numerosos estudios para tratar de confirmar si la adicción a internet (IA) de los adolescentes de debe considerar como cualquier otro trastorno o enfermedad. Este tema sigue siendo investigando con firmeza, puesto que es un tema de actualidad.

Algunos de estos estudios, han creado y propuesto metodologías para tratar de definir la Adición a internet por los adolescentes e incluso escalas para medirla. Tal y como se muestra en la tabla 8, la trayectoria del estudio de la adicción a internet en España se remonta desde el siglo pasado y sigue estando vigente en la actualidad (Pichel Mira, 2014). 
10 PARTE

Capítulo 2: Adolescentes y nuevas tecnologías

\begin{tabular}{|c|c|c|c|}
\hline AÑO & PAís & AUTOR/ES & HERRAMIENTA \\
\hline 1999 & España & Echeburúa & Test de adicción a Internet \\
\hline 2002 & España & De Gracia, Vigo et al & Problemas relacionados con Internet (PRI) \\
\hline 2002 & EEUU & Caplan & Problematic Internet use (PIU) \\
\hline 2007 & España & Jenaro, Flores et al. & Internet over-use scale (IOS) \\
\hline 2008 & Irán & $\begin{array}{l}\text { Ghassemzadeh, } \\
\text { Shahraray, \& Moradi }\end{array}$ & Internet addiction (IA) \\
\hline 2008 & China & Lu & Internet dependence \\
\hline 2009 & España & $\begin{array}{l}\text { Beranuy, Chamarro } \\
\text { et al. }\end{array}$ & $\begin{array}{l}\text { Cuestionario de experiencias } \\
\text { relacionadas con Internet (CERI) }\end{array}$ \\
\hline 2009 & Holanda & $\begin{array}{l}\text { Meerkerk, Van Den } \\
\text { Eijnden, Vermulst, \& }\end{array}$ & Compulsive Internet Use Scale (CIUS) \\
\hline 2013 & España & $\begin{array}{l}\text { López-Fernández, } \\
\text { Freixa-Blanxart et al. }\end{array}$ & $\begin{array}{l}\text { Problematic Internet Entertainment. Use } \\
\text { sacle for adolescents (PIEUSA) }\end{array}$ \\
\hline 2013 & España & $\begin{array}{l}\text { Labrador, } \\
\text { Villadangos et al. }\end{array}$ & $\begin{array}{c}\text { Cuestionario de uso problemático de } \\
\text { nuevas tecnologías (UPNT) }\end{array}$ \\
\hline 2014 & España & Gómez, Rial et al. & $\begin{array}{c}\text { Screening scale of problematic Internet } \\
\text { use in adolescents }\end{array}$ \\
\hline 2015 & Worldwide & $\begin{array}{l}\text { Śkařupová, } \\
\text { Ólafsson, \& Blinka }\end{array}$ & Excessive Internet Use (EIU) \\
\hline
\end{tabular}

Tabla 8: estudios relacionados con la Adicción a internet desde el año 1999

Ante la incertidumbre, Zhu, Zhang \& Tian (2015) aseguran que es necesario continuar con esta investigación, para determinar los cambios específicos en el cerebro adicto a internet, así como sus implicaciones para el comportamiento y la cognición.

Sin embargo, aunque se trate de un tema de creciente importancia, no se llega a un consenso. Actualmente, las instituciones no consideran la adicción a internet como una enfermedad patológica. Sin embargo, sí está reconocida como enfermedad la adicción a los videojuegos.

\section{Resultados de los test de adicción a internet:}

Los resultados obtenidos en diversos test sobre adicción a internet realizados a los adolescentes en Hong Kong, sugieren la necesidad de llevar a cabo tareas de detección precoz y tratamiento de la adicción a internet en los adolescentes (Shek \& Yu, 2012). 
EU NET ADB (2012) afirma que el 0,9\% de los adolescentes alemanes está desarrollando conductas adictivas en internet, aunque el porcentaje de adolescentes que está en riesgo por el uso inadecuado de internet y las TIC es del 9,7\%. En este país, tanto los padres como los adolescentes de entre 14 y 17 años manifiestan percibir un uso excesivo de internet, principalmente por el género masculino (Wartberg et al, 2015).

En España, ya en la década pasada, el 18,5\% de los adolescentes de Barcelona se consideraban adictos a internet. El 43\% de la ellos reconocía haber perdido la noción del tiempo en internet en algún momento de su vida. El $21,1 \%$ ha restringido el uso de internet alguna vez en su vida, probablemente han sido los padres quienes lo han hecho (Graner, Fargues, Sánchez-Carbonell, Lusar \& Rosell, 2007). Según el estudio EU NET ADB (2012), el 1,5\% de los menores de 14 a 17 años está desarrollando conductas adictivas a internet. Según esta investigación, el 21,3\% de los adolescentes en España está en riesgo de desarrollo de adicción debido a un uso inadecuado de internet.

\section{d.- Riesgo de empeorar la calidad del sueño del adolescente:}

Los adolescentes que mayor uso hacen de internet, muestran hábitos problemáticos a la hora de dormir y problemas en relación al sueño. Es por esta razón, que los padres y educadores deben preocuparse por el posible impacto del uso en exceso de internet en los hábitos de dormir de los adolescentes (Ekinci, Celik, Savas \& Toros, 2014).

Interesa estudiar si los adolescentes tienen conexión a internet en sus habitaciones. Bercedo Sanz et al. (2005) ya afirmaba que el $52 \%$ de los adolescentes de Cantabria (España) tenían conexión a internet en su habitación. Chaput et al. (2014) afirman que la presencia de conexión a internet en las habitaciones de los adolescentes canadienses de Otawa, representan un riesgo ante la calidad o eficiencia del sueño del mismo.

e-Dificultades de la introducción de las TIC en el entorno educativo:

Aunque internet ha sido aclamado como el salvador de la educación, ésta actualmente trata de controlar los usos perjudiciales y de distracción que la tecnología provoca en las 
aulas. El reto para las escuelas es el de eliminar los usos perjudiciales de internet en los centros educativos, preservando sus importantes contribuciones a la educación y a la conexión social (Subrahmanyam \& Greenfield, 2008).

En algunos casos, los profesores ponen de manifiesto los inconvenientes del uso de internet en la educación como la dispersión, falta de concentración, dificultad a la hora de reflexionar o la pérdida de tiempo tratando de encontrar la información requerida. En algunos casos, los adolescentes aprovechan el uso de internet durante las clases para navegar en otros contenidos diferentes a los tratados en clase o simplemente para jugar (Valmaña \& García-Martínez, 2009).

\subsection{5.- Control parental}

En China, Yang, Lu, Wang \& Zhao (2014) demuestran que el control parental sobre el uso de internet de los estudiantes de secundaria, disminuye significativamente la adicción a internet. La vigilancia de los padres sobre el uso de sus hijos de internet, controla el carácter exploratorio de los jóvenes.

El 54\% de los adolescentes gallegos afirman que sus padres no les controlan el uso de internet. Hasta tal punto que el $77,9 \%$ de ellos, manifiesta nunca o casi nunca haber discutido con sus padres debido a internet (Gómez Salgado et al., 2014).

El 98,6\% de los adolescentes de Barcelona accede a internet. El 47,2\% de ellos manifiesta conectarse a internet sin control paterno (Munoz-Miralles et al., 2014).

Según el "Observatori de la Societat de la Informació de les Illes Balears», dos tercios de los jóvenes de 15 y 16 años navegan solos por internet y el 62,2\% no tienen en casa normas para acceder internet (Sureda et al, 2008).

Sorbring, Hallberg, Bohlin \& Skoog, (2015) han observado que el control y las actitudes de los padres difieren según el género de los padres y el género y la edad del adolescente. 


\section{4.- REDES SOCIALES:}

El uso de las redes sociales en la web es una de las actividades más comúnmente realizadas por los adolescentes actuales. Cualquier página web que permita interactuar socialmente con otros, se considera una red social. Las redes sociales ofrecen a los adolescentes muchas posibilidades para conectarse con amigos, compañeros de estudios o personas con intereses comunes.

Las redes sociales están desempeñando un papel muy importante en el desarrollo de la identidad de los menores (Cánovas, 2015).

Las redes sociales son un servicio de internet que permite a cualquier cibernauta construirse un perfil dentro de un sistema gestionado por un tercero. En este perfil se comparten relaciones, experiencias o fotos con una lista de otros contactos que, normalmente cada dueño de perfil confecciona (Ellison, 2007).

\subsection{1.- Cifras de adolescentes conectados a redes sociales}

Porcentaje de adolescentes que se conectan a las redes sociales:

En el año 2011, en Estados Unidos, más de la mitad de sus adolescentes tenían creado un perfil en una red social de internet (Mazur \& Richards, 2011). En el año 2015, un estudio pone de manifiesto que el $92 \%$ de los adolescentes afirma participar a diario en redes sociales (Lenhart, 2015).

En España, el estudio elaborado por la OCU en el año 2013, con motivo del Día de internet, recogió las respuestas realizadas a 400 padres y madres sobre los hábitos de uso de internet de sus hijos. El $84 \%$ de los padres manifestó que sus hijos adolescentes de entre 10 y 16 años, participa en redes sociales.

La encuesta sobre Equipamiento y Uso de Tecnologías de Información y Comunicación en los Hogares realizada por el INE en el año 2014, pone de manifiesto que ha sido en ese año cuando el número de usuarios de redes sociales ha sido superior a la mitad de la población (51,1\%). El VI Estudio Redes Sociales de IAB Spain, recogió información en Diciembre de 2014 sobre el uso de redes sociales de los adolescentes españoles de 
edades comprendidas entre 14 y 17 años. Los resultados de este estudio, afirman que el $97 \%$ de los adolescentes españoles tiene algún perfil en alguna red social.

Cánovas (2015) afirma que más del 90\% de los jóvenes europeos de entre 14 y 17 años forman parte de al menos una red social.

Tiempo dedicado a las redes sociales:

Las redes sociales ocupan una gran parte del tiempo que los adolescentes dedican a internet. De hecho, casi el 70,7\% del tiempo invertido por los adolescentes andaluces de entre 10 y 18 años a navegar por internet, está destinado a las redes sociales (Bringué \& Sádaba, 2009). El 71\% de los adolescentes de 16 años tienen varios perfiles en más de una red social (Bravo \& Rasco, 2013).

Desde el año 2006 hasta la actualidad se ha incrementado notablemente el número de preadolescentes y adolescentes que utilizan las redes sociales. James (2009) manifiesta que más del 50\% de los adolescentes acceden a las redes sociales más de 1 vez al día y el $22 \%$ de los mismos accede diariamente más de 10 veces.

Se encuentran diferencias en las actividades realizadas en las redes sociales dependiendo del género. Las chicas, que tienen perfil social en Facebook, principalmente lo utilizan para chatear, ver fotos y hacer comentarios (Navarro et al., 2014).

\subsection{2.- Dispositivos de acceso a las redes sociales}

Encontramos, en la literatura existente, artículos que confirman que los adolescentes acceden a las redes sociales principalmente desde sus teléfonos móviles (Lenhart, Ling, Campbell \& Purcell, 2010). En Estados Unidos, el 24\% de los adolescentes que se conecta a diario a redes sociales, manifiesta hacerlo "casi constantemente", y principalmente desde su smartphone (Lenhart, 2015).

En España, el 72\% de los usuarios de edades comprendidas entre 11 y 14 años accede a redes sociales con su smartphone (Cánovas et al., 2014). El 69,2\% de los adolescentes 
andaluces utilizan su teléfono móvil para conectarse, a diario, a las redes sociales (Bravo \& Rasco, 2013).

El VI Estudio Redes Sociales de IAB Spain (2015), puso de manifiesto que el 97\% de los adolescentes españoles de edades comprendidas entre 14 y 17 años se conecta a las redes sociales desde el ordenador, el $83 \%$ desde el móvil y el $28 \%$ desde una tablet.

\subsection{3.- Redes sociales utilizadas por los adolescentes:}

En la actualidad, podemos encontrar en el mercado digital una amplia oferta de redes sociales. Según un estudio realizado en el año 2014 por Webempresa20.com, las 30 redes sociales más utilizadas a nivel mundial son las que podemos encontrar en la tabla 9 mostrada a continuación.

En Estados Unidos, la institución Pew Research Center's Teens Relationships Survey realizó un estudio a 1060 adolescentes estadounidenses de entre 13 y 17 años, desde Septiembre de 2014 a Marzo 2015, con el objetivo de obtener información en relación a su uso de redes sociales (Lenhart, 2015). Los resultados del estudio se recogen en el gráfico 6. Según este estudio, la red social más utilizada por adolescentes de entre 13 y 17 sigue siendo, con diferencia, Facebook, seguida de Instagram y Snapchat (aplicación móvil similar a WhatsApp en la que las fotos son destruidas pasado un tiempo tras su lectura).

La tabla 10 mostrada a continuación, refleja el porcentaje de adolescentes españoles que tienen, al menos, un perfil creado en las diferentes redes sociales (Jiménez, de Ayala López \& García, 2013). Se pueden distinguir los porcentajes dependiendo del género y de la clase social. Los porcentajes en negrita muestran las diferencias significativas a un nivel de significación 0,05. Según este estudio, los adolescentes tienen perfil social principalmente en Tuenti, independientemente de la edad, del género o de la clase social. 
Capítulo 2: Adolescentes y nuevas tecnologías

\begin{tabular}{|c|c|}
\hline RANKING MUNDIAL & RED SOCIAL \\
\hline 1 & Facebook \\
\hline 2 & YouTube \\
\hline 3 & $Q Q$ \\
\hline 4 & Qzone \\
\hline 5 & WeChat \\
\hline 6 & Twitter \\
\hline 7 & Whats App \\
\hline 8 & SinaWeibo \\
\hline 9 & $\mathrm{Hi} 5$ \\
\hline 10 & Tagged \\
\hline 11 & Google+ \\
\hline 12 & Line \\
\hline 13 & Linkedln \\
\hline 14 & Habbo \\
\hline 15 & Tumblr \\
\hline 16 & Ortsbo \\
\hline 17 & Badoo \\
\hline 18 & Soundhound \\
\hline 19 & Renren \\
\hline 20 & Instagram \\
\hline 21 & DailyMotion \\
\hline 22 & Friendster \\
\hline 23 & Netlog \\
\hline 24 & VK \\
\hline 25 & Kik \\
\hline 26 & Match \\
\hline 27 & QuePasa \\
\hline 28 & Flickr \\
\hline 29 & Pinterest \\
\hline 30 & Reddit \\
\hline
\end{tabular}

Tabla 9: ranking de 30 redes sociales más utilizadas en el mundo. Fuente: Webempresa20 (2014) 


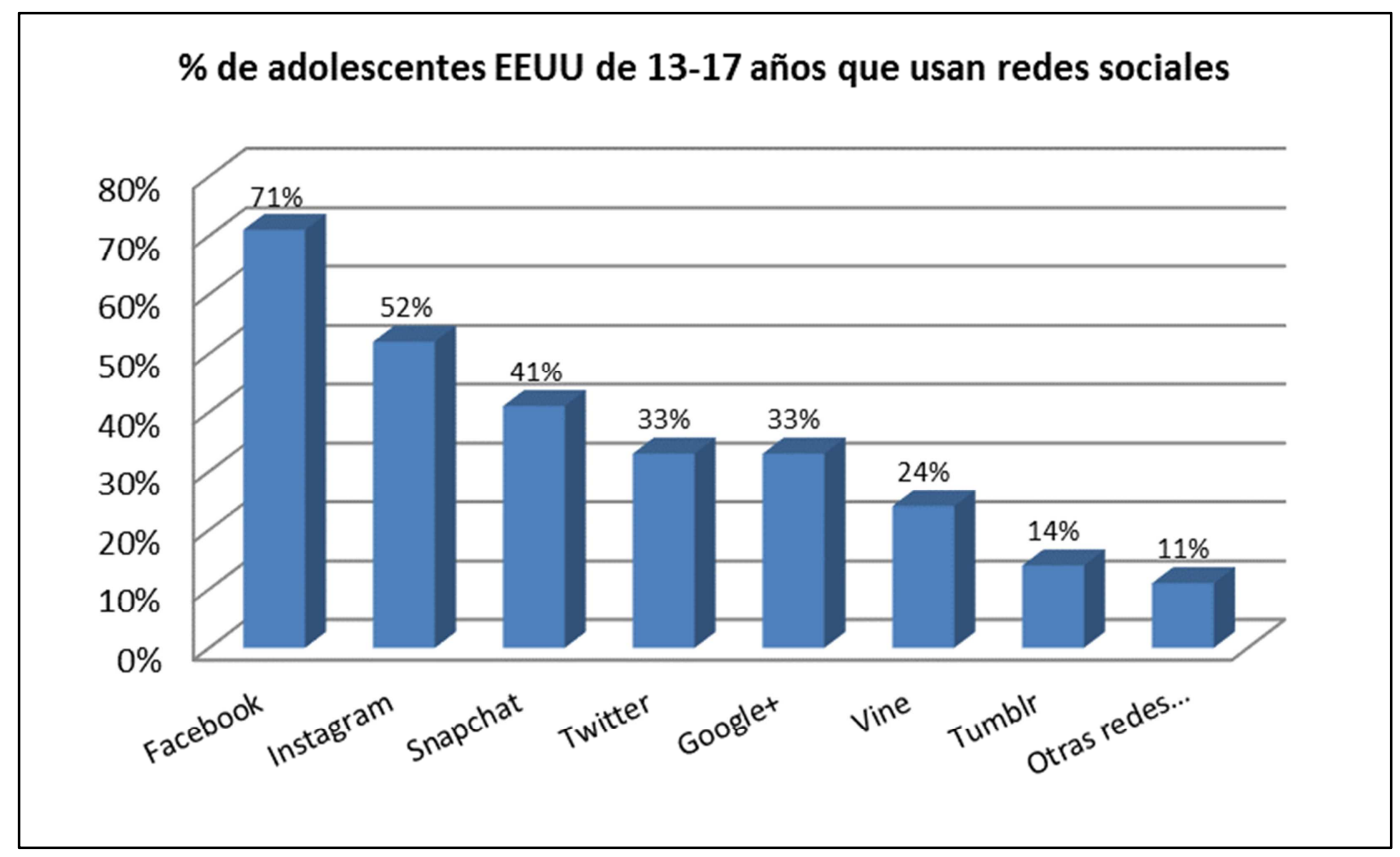

Gráfico 6: utilización de las redes sociales por los adolescentes estadounidenses de 13 a 17 años Fuente: Lenhart (2015)

\begin{tabular}{|c|c|c|c|c|c|c|c|}
\hline & \multicolumn{2}{|c|}{ De 12 a 14 años } & \multicolumn{2}{|c|}{ De 15 a 17 años } & \multicolumn{3}{|c|}{ Clase social } \\
\hline & Hombre & Mujer & Hombre & Mujer & Alta & Media & Baja \\
\hline My Space & $7,2 \%$ & $5,0 \%$ & $9,2 \%$ & $11,3 \%$ & $8,6 \%$ & $6,3 \%$ & $8,4 \%$ \\
\hline Facebook & $60,2 \%$ & $56,3 \%$ & $72,0 \%$ & $79,5 \%$ & $71,5 \%$ & $64,5 \%$ & $65,8 \%$ \\
\hline Tuenti & $71,5 \%$ & $72,5 \%$ & $83,9 \%$ & $86,9 \%$ & $78,3 \%$ & $81,0 \%$ & $84,0 \%$ \\
\hline Twitter & $25,0 \%$ & $26,3 \%$ & $38,9 \%$ & $43,9 \%$ & $37,5 \%$ & $32,4 \%$ & $36,0 \%$ \\
\hline Fotolog & $4,2 \%$ & $4,8 \%$ & $8,4 \%$ & $13,9 \%$ & $7,8 \%$ & $8,0 \%$ & $6,1 \%$ \\
\hline
\end{tabular}

Tabla 10: redes sociales en que los adolescentes tienen un perfil por grupo de edad, género y clase social. Fuente: Jiménez et al. (2013)

El VI Estudio Redes Sociales de IAB Spain, recoge información sobre el uso de redes sociales de los adolescentes españoles de edades comprendidas entre 14 y 17 años. Los resultados de este estudio, que fueron recogidos en Diciembre de 2014, se han plasmado en el gráfico 7. Según este estudio, la red preferida por los adolescentes es Facebook (con un 35\%), seguida de Twitter y de Instagram. El gráfico 8 muestra las redes sociales utilizadas por los adolescentes y el porcentaje de adolescentes que utiliza cada una de ellas. 


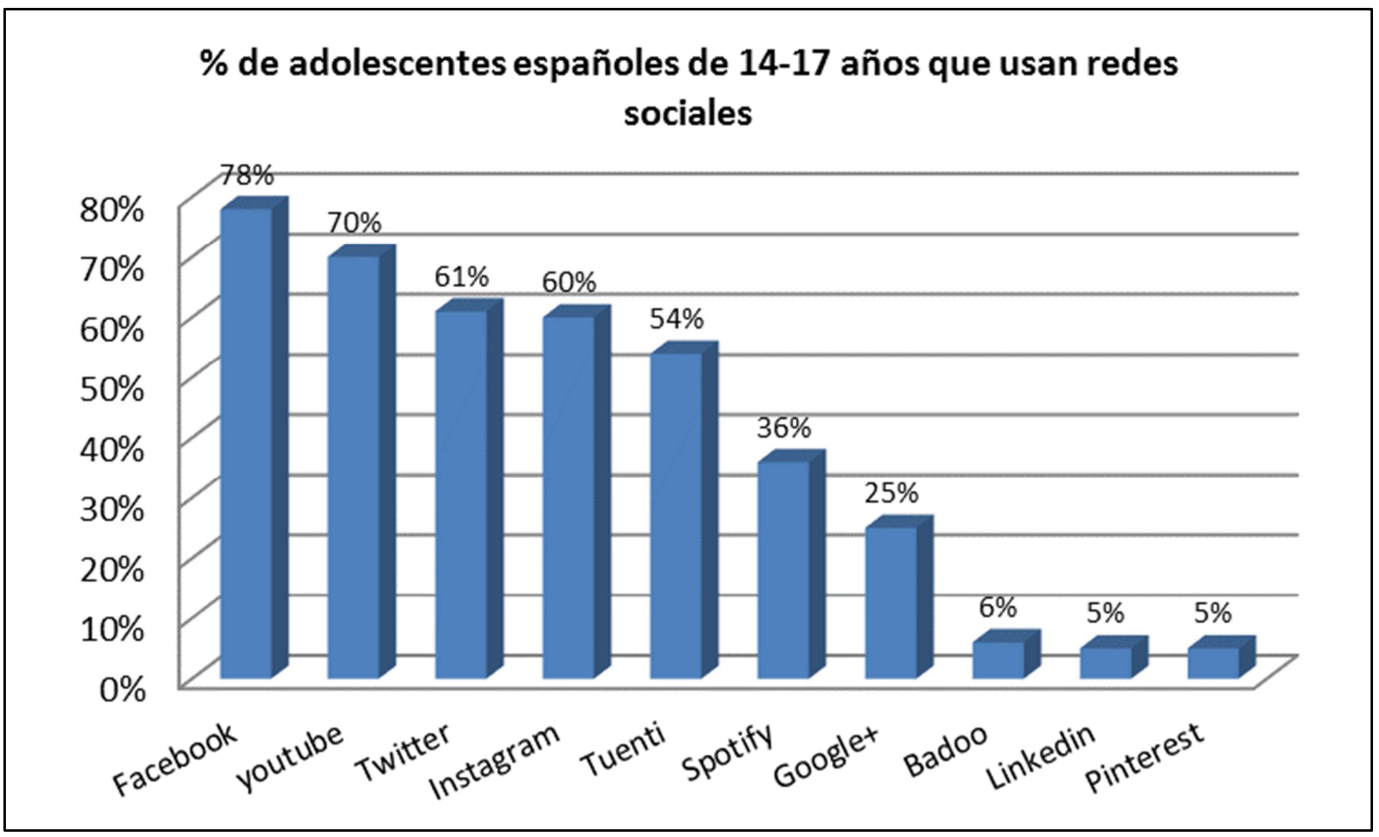

Gráfico 7: redes sociales usadas por los adolescentes españoles de 14 a 17 años. Datos obtenidos en Diciembre 2014. Fuente: VI Estudio Redes Sociales de IAB Spain

El análisis realizado por Navarro (2015), tomando como referencia los datos Cristian Monroy, de Global Web Index sobre las preferencias de los jóvenes de 16 a 19 años en el uso de redes sociales, dibuja el top 10 de redes sociales con más cuentas y con más usuarios activos.

Tal y como puede observarse en el gráfico 8, la red social que tiene mayor número de cuentas de usuarios adolescentes es Facebook (el 82\% de los adolescentes tiene cuenta en Facebook), aunque es importante señalar que el $44 \%$ de esas cuentas no están activas. La segunda red social más popular es Youtube (el $72 \%$ de adolescentes tiene cuenta en Youtube), con un 33\%de usuarios activos. En tercera posición encontramos Google+ (con un $70 \%$ de adolescentes teniendo cuenta) y usado por un $28 \%$ de usuarios activos. Google+ tiene más usuarios que Twitter (70\% frente a $62 \%$ ) aunque este último tiene más usuarios activos ( $30 \%$ de Twitter frente a $28 \%$ de Google+). Le siguen, tanto por porcentaje de cuentas creadas como por porcentaje de uso de las mismas, Instagram, Tumblr, Pinterest, LinkedIn, MySpace y Reddit. 


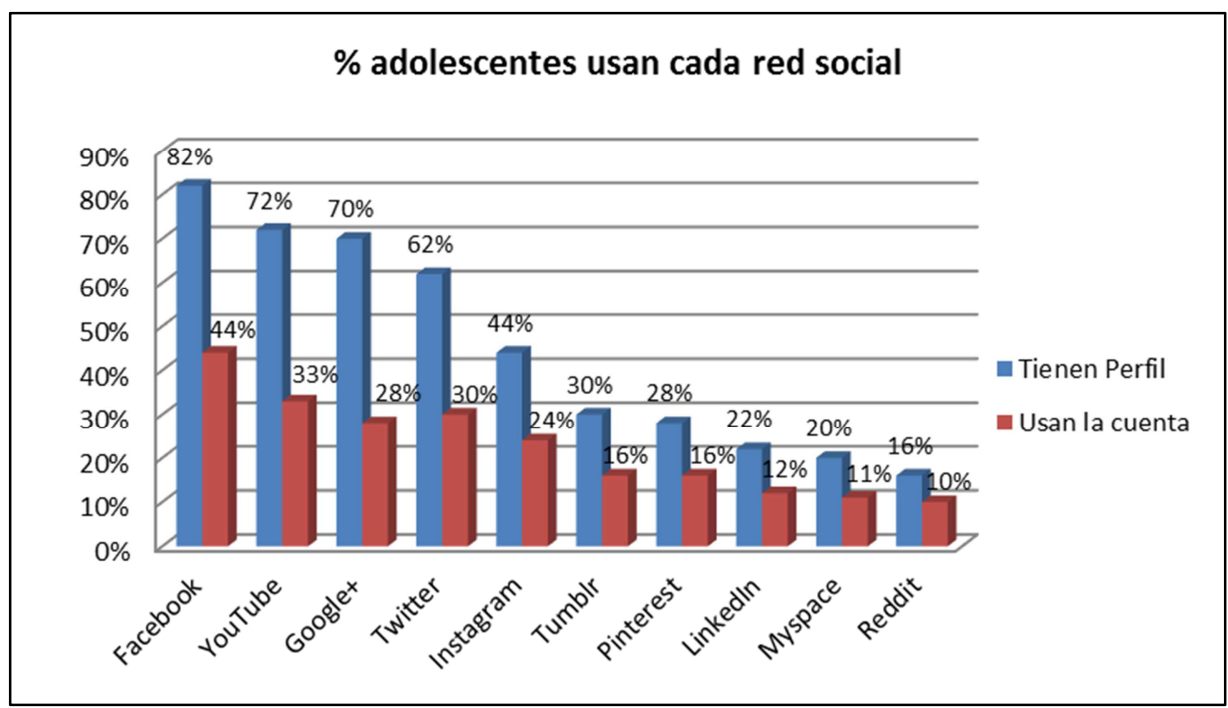

Gráfico 8: jóvenes entre 16 y 19 años que tienen perfil y que usan la cuenta en las distintas redes sociales. Fuente: Emprendemanía (2015)

Los adolescentes andaluces menores de 20 años prefieren Tuenti seguida de Facebook (Bravo \& Rasco, 2013). La edad media a la que los adolescentes andaluces de edades comprendidas entre 13 y 19 años, se crean su primer perfil en una red social es de 12 años.

El 40,2\% de los adolescentes gallegos sube fotos a Facebook o a Tuenti (Gómez Salgado et al., 2014).

\begin{tabular}{|c|c|c|c|c|c|c|c|c|c|c|c|}
\hline \multirow[b]{2}{*}{ PAís } & \multirow[b]{2}{*}{ ESTUDIO } & \multicolumn{10}{|c|}{ Rankingde redes sociales más utilizadas por los adolescentes } \\
\hline & & 1 & 2 & 3 & 4 & 5 & 6 & 7 & 8 & 9 & 10 \\
\hline España & $\begin{array}{c}\text { Jiménez, de } \\
\text { Ayala López, } \\
\text { et al., } 2013\end{array}$ & Tuenti & Facebook & Twitter & My Space & Fotolog & & & & & \\
\hline $\begin{array}{l}\text { Andalucía } \\
\text { (España) }\end{array}$ & $\begin{array}{c}\text { Bravo y } \\
\text { Rasco, 2013 }\end{array}$ & Tuenti & Facebook & & & & & & & & \\
\hline $\begin{array}{l}\text { Cataluña } \\
\text { (España) }\end{array}$ & $\begin{array}{c}\text { Navarro, } \\
\text { González et } \\
\text { al., } 2014\end{array}$ & Facebook & & & & & & & & & \\
\hline Mundial & $\begin{array}{c}\text { Webempres } \\
\text { a20.com } \\
(2014)\end{array}$ & Facebook & Youtube & QQ & Qzone & WeChat & Twitter & Whats App & SinaWibo & $\mathrm{Hi} 5$ & Tagged \\
\hline España & $\begin{array}{l}\text { VI Estudio } \\
\text { Redes } \\
\text { Sociales de } \\
\text { IAB Spain, } \\
2014\end{array}$ & Facebook & Youtube & Twitter I & Instagram & Tuenti & Spotify & Google+ & Badoo & Linkedln & Pinterest \\
\hline USA & $\begin{array}{l}\text { Lenhart, } \\
2015\end{array}$ & Facebook & Instagram & Snapchat & it Twitter & Google+ & Vine & Tumblr & & & \\
\hline Internacional & $\begin{array}{c}\text { Navarro, } \\
2015\end{array}$ & Facebook & Youtube & Google+ & Twitter & Instagram & Tumblr & Pinterest & Linkedln $\Lambda$ & My Space & Reddit \\
\hline
\end{tabular}

Tabla 11: estudios que definen un ranking de redes sociales preferidas por los adolescentes 
Tal y como muestra la tabla 11, la red social más popular entre los adolescentes catalanes más mayores es Facebook (Navarro et al., 2014).

Los adolescentes catalanes, utilizan en algunos casos la aplicación Skype para hacer videollamadas. Sin embargo, no es una práctica muy extendida, puesto que la mayoría reconoce que le gusta más hablar en persona que por las redes sociales (Navarro et al., 2014).

\subsection{4.- Efectos positivos y negativos del uso de las redes sociales}

Los estudios demuestran que las redes sociales ofrecen oportunidades pero también riesgos potenciales a los jóvenes usuarios (O’Keeffe et al, 2011).

\subsubsection{1.- Efectos positivos y ventajas:}

Las redes sociales ofrecen diariamente oportunidades para conectarse con amigos, compañeros de estudios o personas con intereses comunes. Las aplicaciones de comunicación y socialización en las nuevas tecnologías permiten a los adolescentes conseguir online varias de las tareas que son importantes en su vida: estar conectados con los compañeros y amigos, hacer nuevas amistades, compartir fotos, impresiones e intercambiar ideas. La participación en las redes sociales puede aportarles beneficios que se extienden a ellos mismos, a toda la comunidad y al mundo en general (O'Keeffe et al, 2011).

\section{a) Comunicarse y socializar:}

Las redes sociales permiten a los adolescentes relacionarse con otras personas. Son, para ellos, una nueva forma de socialización. En definitiva, una ventana al mundo, sin barreras. Los adolescentes se sirven de las redes sociales para encontrar amistades con afinidades comunes y establecer relaciones de amistad o amorosas. Algunos acumulan una serie de amigos, que en ciertos casos no conocen en persona (Navarro et al., 2014).

Las redes sociales son importantes porque son una herramienta de ayuda en el proceso de búsqueda de amistad (Mazur \& Richards, 2011). Pertenecer y participar en una red social es una actividad rutinaria que permite al adolescente mejorar su comunicación, conexión social e incluso su capacidad técnica (Ito \& al, 2008). 
Con las redes sociales no existen barreras comunicativas. Es por esta razón que el motivo principal por el que los adolescentes utilizan las redes sociales es para comunicarse y chatear (Barker, 2009).

Los adolescentes catalanes de entre 14 y 29 años (grupo de edad que incluye los adolescentes más mayores) utilizan las redes sociales, principalmente Facebook y Messenger tanto para ocio como para relacionarse. También para pasar los tiempos muertos (Navarro et al., 2014).

Las redes sociales son también un elemento de reconocimiento social, puesto que contabilizan el número de personas interesadas en un perfil concreto, denominadas seguidores (Bravo \& Rasco, 2013). El 51\% de los adolescentes andaluces manifiesta su interés en conocer la opinión de sus amigos sobre los comentarios que hacen y las fotos que suben. Quieren saber si están bien valorados por sus amistades, puesto que según afirman, en las redes sociales los adolescentes son más sinceros que en el cara a cara.

La sensación de pertenencia que genera el ser miembro de una red social, es otro de los motivos por los cuales los adolescentes son seguidores de estas aplicaciones (Morales, 2011).

Entre los jóvenes se ha extendido el uso de las redes sociales como sustitutos de las llamadas telefónicas. Es el caso de los jóvenes catalanes de entre 14 y 29 años, que aprovechan las redes sociales para quedar con los amigos. Entre el género femenino, prácticamente todo el mundo tiene Facebook, por lo que ven como casi una obligación hacerse una cuenta. Llegan a confirmar que tienen cierta presión social por tener cuenta en las redes sociales (Navarro et al., 2014).

\section{b) Estar informado:}

Las redes sociales dan respuesta a la necesidad de los adolescentes de estar informados a tiempo real, lo cual les permite estar presentes ante lo que ocurra en cualquier momento y en cualquier entorno (Bringué \& Sádaba, 2009). 
c) Soporte académico:

Los adolescentes, se sirven de las redes sociales, además de los usos mencionados anteriormente, para hablar con sus compañeros sobre las tareas y trabajos de clase (Ellison, 2007).

Hemos decidido introducir los blogs dentro del grupo de las redes sociales. Consideramos interesante comentar que muchos institutos utilizan blogs para colgar los temas que se están enseñando en las aulas, proponer ejercicios y tratar temas escolares (Borja, 2005).

\subsubsection{2.- Efectos negativos y riesgos}

a) Riesgo de perder la noción del tiempo:

Los adolescentes tienen la sensación de perderse algo importante si no están constantemente conectados a las redes sociales. En ocasiones, este tiempo que pasan conectados se considera excesivo. Pierden la noción del tiempo y se olvidan del resto de sus planes por estar conectados a las redes sociales (Navarro et al., 2014).

b) Riesgo de distraerse sus tareas:

Los adolescentes utilizan los dispositivos tecnológicos como apoyo para realizar los deberes y trabajos escolares. Esto hace que corran el riesgo de terminar conectados a las redes sociales mientras están estudiando. En este caso, suelen dejar de prestar atención a los deberes para finalmente focalizarse en las redes sociales. Las adolescentes catalanas, reconocen realizar ambas actividades a la vez, incluso en algún caso a escondidas de sus padres (Navarro et al., 2014).

c) Riesgo de atrasar la hora de dormirse:

Según el estudio realizado utilizando el Bergen Facebook Addiction Scale (BFAS), los altos niveles de utilización de Facebook están asociados con una hora más tardía de dormirse y también de levantarse (Andreassen, Torsheim, Brunborg \& Pallesen, 2012). 
d) Riesgo de perder la privacidad:

Aun conocida la creciente utilización de los adolescentes de las redes sociales, son pocos los estudios que se han documentado y han estudiado sobre las políticas o comportamientos para proteger la privacidad en las redes sociales. Un estudio, trata de investigar sobre el nivel de preocupación de los adolescentes sobre su privacidad en las redes. Para ello, ha utilizado los datos de Facebook. Los padres se preocupan por el mantenimiento de la privacidad de sus hijos en las redes sociales. Las mismas redes sociales tratan de concienciar a los adolescentes sobre la importancia de la privacidad e impulsan a los adolescentes a adoptar estrategias de privacidad como pasar sus perfiles de Facebook a privado (Feng \& Xie, 2014).

Casi el $85 \%$ de los adolescentes andaluces conocen la importancia de gestionar los permisos de acceso a sus perfiles de sociales y dan mucha importancia a la privacidad y la seguridad. Sólo el 4,4\% de los adolescentes andaluces reconoce tener su perfil de red social abierto a todos los usuarios, es decir, no restringen el acceso a su perfil a sus seguidores (Bravo \& Rasco, 2013).

e) Riesgo de sufrir adicción:

Consideramos necesario definir herramientas capaces de detectar el riesgo de adicción a las redes sociales en los adolescentes. En un estudio realizado en Perú a adolescentes de edades comprendidas entre 14 y 18 se concluyó que se podían medir 7 dimensiones de la adicción a las redes sociales: pérdida de control, síndrome de abstinencia, disminución del rendimiento académico, modificación estado de ánimo, dependencia, pérdida de interés en otras actividades y conflictos en el ámbito social (Vilca \& Vallejos, 2015).

Los varones de entre 16 y 17 años cuyos progenitores tienen un nivel educativo mediobajo son quienes tienen más posibilidades de desarrollar estos trastornos, que se caracterizan por una tendencia a la ruptura de las relaciones habituales, mientras que aumenta el tiempo que se dedica a internet, y la falta de comunicación en el entorno familiar (Cánovas, 2015). 
10 PARTE

Capítulo 2: Adolescentes y nuevas tecnologías

f) Ciberacoso. Tipos de ciberacoso:

Las redes sociales, en algunos casos, son utilizadas para enviar mensajes dañinos a otras personas. La intimidad de las personas queda al descubierto con las redes sociales.

El nuevo Código Penal, en base a la redacción contemplada en los artículos 1974 bis, 510.1 . b) y 510.3 recoge el concepto ciberacoso, a modo de premisa conceptual como quienes utilicen las tecnologías de la información para lesionar la dignidad de las personas mediante acciones que entrañen humillación, menosprecio o descrédito, revelando información a terceros sin consentimiento del titular y menoscabando gravemente la intimidad personal, haciendo accesible ese acoso a un elevado número de personas, se enfrentan a un reproche penal traducible en la imposición de multas y penas privativas de libertad.

Se entiende además por ciberacoso el acto agresivo e intencionado llevado a cabo de manera repetida y constante a lo largo del tiempo, mediante el uso de formas de contacto electrónicas por parte de un grupo o de un individuo contra una víctima que no puede defenderse fácilmente (Smith \& Collage, 2006). Estas prácticas son muy graves y se consideran delito.

Actualmente, se catalogan tres tipos de ciberacoso:

\section{i. Ciberbullying}

El Estudio sobre "hábitos seguros en el uso de las TIC por los menores" (Observatorio INTECO, 2009) el ciberbullying es el acoso entre iguales en el entorno de las TIC. EI acosador es un niño o adolescente, al igual que el acosado. Las víctimas son objeto de amenazas, humillaciones insultos, vejaciones y chantajes. No es un acoso sexual. Una de las prácticas más repetidas del ciberbullyng es la creación por parte del acosador de un perfil falso de la persona acosada en una red social, con el objetivo de colgar información incierta que humille y perjudique a la persona acosada. En otros casos, pueden colgar rumores inciertos sobre el acosado. 
Debido a todas estas razones, el ciberbullying es uno de los principales problemas entre los adolescentes por la gravedad de sus consecuencias y la dificultad de intervención (debido al anonimato del acosador).

La incidencia del ciberbullying varía significativamente en los diferentes países. Se han evidenciado porcentajes superiores de victimización, tanto ocasional como sistemática, en Estados Unidos y Asia (55\%), frente al resto de los países americanos (22\%), Canadá (25\%), Oceanía (25\%), o Europa (30\%) (Garaigordobil, 2011). El estudio europeo EU NET ADB (2012) ha cuantificado el porcentaje de adolescentes europeos que han sufrido ciberbullying en las siguientes cifras: $15,5 \%$ de los adolescentes holandeses, $21,5 \%$ de los adolescentes polacos, $21,9 \%$ de los adolescentes españoles de 14 a 17 años y $24,3 \%$ de los adolescentes alemanes.

En España, el porcentaje de adolescentes que sufren ciberbullying está creciendo notablemente. La cifra ha crecido en los últimos años. En el año 2009, se situaba en el 5,9\% (Observatorio INTECO, 2009). Según el estudio europeo EU NET ADB (2012), el $21,9 \%$ de los adolescentes españoles de 14 a 17 años ha sufrido ciberbullying en alguna ocasión.

Ante este incremento del porcentaje de adolescentes que sufren ciberbullying, la asociación Pantallas Amigas ha recuperado la campaña "Seis recomendaciones para la prevención del Ciberbullying", realizada en 2014 junto con Telefónica y en la que colaboraron Cuerpo Nacional de Policía (CNP), la Organización de Estados Iberoamericanos para la Educación, la Ciencia y la Cultura (OEI),Tuenti y Red.es. En esta campaña, se hace hincapié sobre seis puntos importantes para concienciar al adolescente sobre el ciberbullying:

- ¿Conoces los efectos del Ciberbullying?

- ¿Alguien te está molestando en la Red?

- ¿Te has parado a pensar lo que subes a la Red?

- ¿Estás tranquilo compartiendo tu vida con todo el mundo?

- ¿Qué informaciones no publicarías de otros?

- ¿Con qué tipo de gente compartes la Red? 


\section{ii. Grooming}

El concepto grooming se circunscribe a la acción de un adulto como acosador. El adulto establece lazos de amistar con el menor mediante las TIC con el objetivo de lograr satisfacción sexual mediante el intercambio de fotos o incluso mediante un encuentro físico. Sin embargo, se comienza a considerar grooming la relación entre dos menores con diferencia de edad considerable (uno de 17 años que acose a un menor de 12 años).

Según la guía de actuación contra el ciberacoso elaborada en España por red.es y Ministerio de Industria, Energía y Turismo, un $60 \%$ de los padres considera el ciberacoso sexual como el más preocupante. La incidencia de este tipo de acoso en la red no es, afortunadamente, muy alta (el $1 \%$ de los menores manifiesta haber padecido grooming). Algo más de la mitad de los padres y menores entrevistados son conscientes de que existe el riesgo de sufrir acoso sexual en el uso de las TIC, y son más los padres que los hijos los que manifiestan conocer la amenaza. En el caso de los menores, existe un conocimiento de este riesgo significativamente más alto entre las niñas $(62,2 \%)$ que entre los niños $(39,7 \%)$. Un $2,1 \%$ de los padres y un $1,3 \%$ de los hijos afirman que los menores han estado expuestos a situaciones que identifican como grooming o acoso sexual.

\section{iii. Sexting}

El Instituto Nacional de Ciberseguridad (INCIBE) define el sexting como la difusión o publicación de contenidos (principalmente fotografías o vídeos) de tipo sexual, producidos por el propio remitente, utilizando para ello las TIC.

La falta de cultura de privacidad entre los adolescentes y la menor consciencia sobre los riesgos que esto conlleva, representan una serie de circunstancias que determinan la especial vulnerabilidad de los adolescentes en relación con el sexting.

Según el Observatorio INTECO (2011) estudio sobre hábitos seguros en el uso de smartphones por los niños y adolescentes españoles, los menores son más conscientes de los riesgos asociados al sexting pasivo que al sexting activo (39\% frente a $30,8 \%$ ). El $4,3 \%$ de los menores reconoce haber recibido imágenes sugerentes de personas de su 
entorno (sexting pasivo), y un 1,5\% reconoce haberse hecho a sí mismo fotografías de carácter sexy (sexting activo). En ambos casos, la percepción de los adultos es inferior a la manifestada por sus hijos. El sexting activo es más practicado por chicas $(2,2 \%)$ que por chicos $(0,9 \%)$. Ocurre lo contrario en relación al sexting pasivo $(5,1 \%$ de los chicos frente a $3,3 \%$ en el caso de las chicas). En cualquier caso, el conocimiento de ambos comportamientos se incrementa con la edad.

El 4\% de los menores entre 10 y 16 años confiesa hacerse fotos o vídeos en postura sexy para posteriormente subirla a una red social. Más alto, hasta el $8,1 \%$, es el porcentaje de adolescentes que afirman haber recibido vídeos o fotografías en esta actitud INCIBE, 2011).

El ciberacoso tiene un grado superior en las chicas de entre 13 y 16 años que en los chicos (12\% frente a 2\%). En Europa, un $12 \%$ de los adolescentes entre 9 y 16 años manifiesta haber acosado a otros menores. La tasa en España es menor, puesto que se sitúa en el 9\% (Garmendia, Garitaonandia, Martínez \& Casado, 2011). Este estudio obtiene las mismas conclusiones que el trabajo de la red EU Kids Online realizado en el marco del Safer internet Programme de la Comisión Europea, afirmando que el porcentaje de menores que han sufrido ciberacoso escolar es de un $5 \%$.

\section{g) Riesgo de iniciación en redes sociales muy temprana:}

Actualmente, la edad de acceso a las redes sociales es menor de la legalmente definida por los propios servicios de internet (Bravo \& Rasco, 2013).

\section{h) Bajo control parental:}

Según los resultados obtenidos tras el análisis de los datos que estudian las prácticas de los jóvenes andaluces con las redes sociales, se puede concluir que los adolescentes no muestran restricciones en el uso y el control parental es bastante escaso (Bravo \& Rasco, 2013).

El estudio elaborado por OCU en 2013, con motivo del Día de internet encontró que, de los 400 padres y madres a los que encuestaron, el $27 \%$ admitió no tener información sobre el uso que sus hijos de entre 10 y 16 años hacen de las redes sociales. 
1ㅇ PARTE

Capítulo 2: Adolescentes y nuevas tecnologías

\section{5.- TELEVISIÓN:}

La introducción de las nuevas tecnologías en la sociedad, han cambiado radicalmente el panorama de los medios. Sin embargo, la TV sigue siendo el medio predominante (de la Piscina et al., 2011).

\subsection{1.- Cifras de adolescentes y televisión}

La tabla 12 recoge diversos estudios que analizan el tiempo dedicado por los adolescentes a ver la televisión. Los adolescentes norteamericanos ven la televisión una media diaria de tiempo superior a 4 horas (Strasburger et al., 2013).

Los adolescentes de entre 15 y 19 años del Sureste de Brasil, manifestaron entre los años 2001 y 2011, una reducción significativa en el tiempo dedicado a ver la televisión. Se puede predecir que el motivo de esta reducción de tiempo destinado a esta actividad es debido al aumento del tiempo que dedican al uso del ordenador, teléfonos móviles y/o jugar a videojuegos (Lopes et al., 2014).

En España, la televisión sigue siendo el medio de comunicación más consumido por los adolescentes. Los adolescentes catalanes menores de trece años así lo manifiestan (Navarro et al., 2014). Los adolescentes vascos ven la televisión durante más de 4 horas al día. Sin embargo, se observa una variación en el dispositivo tecnológico sobre el cuál ven la televisión, utilizando también el ordenador, la tablet o el teléfono móvil (de la Piscina et al., 2011; Samaniego, Barandiaran \& Navarro, 2010) afirman que los adolescentes vascos ven la televisión entre 2:15 y 2:30 horas/día entre semana y como media casi 7 horas/día los fines de semana.

Durante los días lectivos, los adolescentes cántabros cumplen en un $86 \%$ las recomendaciones indicadas por la AAP. Sin embargo, los días de fin de semana, el número de horas que los adolescentes dedican a ver la televisión es superior a lo recomendado (Noriega et al., 2015). Otros estudios, han llegado a la misma conclusión y asocian este aumento de tiempo frente a la televisión, entre otros motivos, a la incorporación de la televisión en la habitación del adolescente (Bercedo Sanz et al., 2005). 
Capítulo 2: Adolescentes y nuevas tecnologías

\begin{tabular}{|c|c|c|c|}
\hline PAís & ESTUDIO & $\begin{array}{l}\text { Horas diarias TV entre } \\
\text { semana }\end{array}$ & $\begin{array}{c}\text { Horas diarias TV fin de } \\
\text { semana }\end{array}$ \\
\hline España & Gabelas, 2005 & $3: 30$ & \\
\hline España & Bercedo Sanz et al., 2005 & $3: 00$ & $3: 12$ \\
\hline $\begin{array}{l}\text { Ontario } \\
\text { (Canadá) }\end{array}$ & Hilbrecht et al., 2008 & $1: 12$ y $1: 30$ & $2: 24$ y $3: 00$ \\
\hline $\begin{array}{l}\text { País Vasco } \\
\text { (España) }\end{array}$ & $\begin{array}{c}\text { Samaniego, Barandiaran, \& } \\
\text { Navarro, } 2010\end{array}$ & $2: 15$ y $2: 30$ & 7:00 \\
\hline $\begin{array}{l}\text { País Vasco } \\
\text { (España) }\end{array}$ & $\begin{array}{l}\text { De la Piscina, Zarandona et al., } \\
2011\end{array}$ & más de 4:00 & \\
\hline USA & Strasburger et al., 2013 & más de 4:00 & \\
\hline $\begin{array}{l}\text { Cantabria } \\
\text { (España) }\end{array}$ & $\begin{array}{c}\text { Borge, Canser, Pablos, Lanza, } \\
\text { Guerra, Ruiz \& Rivas, } 2015\end{array}$ & $\begin{array}{l}86 \% \text { de los adolescentes } \\
2: 00\end{array}$ & \\
\hline
\end{tabular}

Tabla 12: adolescentes y televisión

Se ha encontrado una diferenciación por género en cuanto al número de horas de visualización de televisión por parte del adolescente. El género femenino dedica, independientemente del día de la semana, menos horas a ver la televisión que el masculino (Noriega et al., 2015).

El porcentaje de adolescentes que ven la televisión durante más de 2 horas diarias aumenta con la edad, excepto para el intervalo entre 16 y 17 años donde decrece levemente (Noriega et al., 2015). Estos resultados son ligeramente superiores a otros trabajos previos (Jago, Sebire, Gorely, Cillero \& Biddle, 2011) y muestran un menor consumo de televisión que otras poblaciones estudiadas (Biddle, Gorely, Marshall \& Cameron, 2009; Loucaides, Jago \& Theophanous, 2011).

\subsection{2.- Usos de la televisión por los adolescentes:}

En Estados Unidos, casi un tercio de la programación de televisión que visualizan los adolescentes es vista en plataformas alternativas: ordenadores iPads, teléfonos o teléfonos móviles (Strasburger et al., 2013).

Se observan diferencias importantes en cuanto a las preferencias de contenidos consumidos en televisión por género. Los chicos adolescentes prefieren contenidos deportivos, mientras que las chicas se inclinan más hacia series y programas musicales (de la Piscina et al., 2011). 
Capítulo 2: Adolescentes y nuevas tecnologías

Los adolescentes catalanes menores de trece años manifiestan ver la televisión por ocio. Los programas que prefieren ver son los de dibujos animados. Los chicos, prefieren ver programas de deportes. Las preferencias con respecto a los contenidos y también con respecto a los dispositivos en los que se ve la televisión, cambian con la edad. Los jóvenes catalanes de entre 14 y 29 años prefieren ver programas, series de televisión e incluso las películas en internet (principalmente para evitar los cortes publicitarios). Incluso en algún caso, la respuesta emitida por los jóvenes confirmaba que ven películas en el teléfono móvil. Los jóvenes de edades comprendidas entre 14 y 29 años $\sin$ estudios universitarios prefieren ver programas de entretenimiento, series, telenovelas y reality shows. También utilizan el servicio de televisión a la carta, siempre y cuando se han perdido algún programa que deseaban ver (Navarro et al., 2014).

Con respecto al hábito de ver la televisión, es importante destacar la práctica del zapping entre los adolescentes.

En cuanto a las preferencias, los adolescentes prefieren charlar con los amigos antes que ver la televisión tanto entre semana como el fin de semana. Sin embargo, prefieren ver la televisión antes que hablar con la familia, sobre todo los fines de semana (de la Piscina et al., 2011).

\subsection{3.- Televisión en la habitación}

En Estados Unidos, el 54\% de los niños de entre 8 y 10 años tiene televisión en su habitación. Esta cifra aumenta, entre 11 y 18 años, hasta el 76\%. De media, el 71\% de los adolescentes estadounidenses tienen TV en su habitación (Rideout et al., 2010; Zamorano, Abad, Torres, Hernández \& Puerta, 2014).

En Europa, el 40\% de los jóvenes tiene televisión en la habitación. El porcentaje es mayor en países como Hungría (que se eleva hasta el 65\%) y disminuye notablemente en países como Bélgica, Eslovenia y España (donde el porcentaje ronda el 28\%) (Cameron et al, 2013). 
En los últimos años, se ha corroborado la tendencia de los adolescentes a consumir televisión sin compañía. Casi un cuarto de los adolescentes vascos tiene televisión en su habitación (de la Piscina et al., 2011).

\subsection{4.- Efectos positivos y negativos de ver la televisión}

\subsubsection{1.- Efectos positivos y ventajas}

Tras revisar la literatura existente, no se han encontrado estudios que pongan de manifiesto las ventajas que tiene ver la televisión para el adolescente.

\subsubsection{2.- Efectos negativos y riesgos}

a) Riesgos asociados a tener televisión en la habitación:

Según los estudios realizados, se han encontrado evidencias claras que demuestran que tener televisión en la habitación aumenta considerablemente las posibilidades de perder el control del tiempo de visionado (tanto los padres como los mismos adolescentes), disminuir las horas de sueño, disminuir la actividad física, consumir sustancias y las posibilidades de exposición a contenidos sexuales no apropiados para la edad del adolescente (Gilbert-Diamond, Li, Adachi-Mejia, McClure \& Sargent, 2014; Chaput et al., 2014). Los principales riesgos ante los que se encuentran los adolescentes que tienen televisión en su habitación son los siguientes:

\section{a.1) Riesgo de aumentar el tiempo dedicado a ver la televisión:}

Los adolescentes que tienen televisión en su habitación dedican más tiempo a esta actividad. Este hecho, además de la posibilidad de ver la televisión en otras plataformas, como son el ordenador o las tablets han propiciado un cambio de un patrón familiar o social a un patrón individual (Zamorano al, 2014).

Cameron et al, (2013) recomiendan a los adolescentes limitar el tiempo que dedican a ver la televisión en su habitación.

a.2) Riesgo de empeorar la eficiencia y calidad del sueño:

El número de horas que duermen los adolescentes canadienses de Otawa no está relacionado con la presencia o no de pantallas en su habitación. Sin embargo, se 
comprueba que este hecho sí que afecta a la eficiencia o calidad del sueño, que es perjudicada por la presencia de estos dispositivos en la habitación del joven (Chaput et al, 2014).

Van den Bulck (2004) manifiesta que los jóvenes que tienen televisión en la habitación, se van a dormir más tarde que los que no la tienen, tanto entre semana como durante el fin de semana.

a.3) Riesgo de padecer sobrepeso y reducir la actividad física:

Son numerosos los autores que, tras el análisis de sus estudios, relacionan el tiempo frente al televisor con un mayor riesgo de padecer obesidad o sobrepeso (VicenteRodríguez et al., 2008; Noriega et al., 2015).

Los menores canadienses de Otawa (Canadá), que manifiestan tener televisión en su habitación, tienen un porcentaje más alto de obesidad que los adolescentes que no la tienen. Estos adolescentes que tienen televisión en la habitación afirman pasar más tiempo frente a ella. Sin embargo, es importante resaltar que el tiempo total sin realizar actividad física es prácticamente el mismo que el de un adolescente que no posee estos dispositivos en su habitación (Chaput et al, 2014).

\section{b) Riesgo de sufrir depresión:}

Según el estudio realizado a los adolescentes del noreste de USA, ver la televisión puede contribuir a desarrollar síntomas depresivos. El hecho de implementar reglas en el hogar sobre la duración y el contenido visionado en la televisión, puede ayudar a reducir la depresión en los adolescentes (Bickham, Hswen \& Rich, 2015).

Sin embargo, ver la televisión no está asociado a depresión en los adolescentes canadienses (Maras et al, 2015).

\section{c) Riesgo de acceder a contenidos violentos o sexuales en la televisión:}

Muchos preadolescentes y adolescentes ven programas, ya sea en la televisión, online o en cine, que contienen contenidos inadecuados para ellos (Strasburger et al., 2010). 
Los que, con frecuencia, ven películas con contenidos sexuales y violentos se desensibilizan ante ello. Un estudio realizado en Estados Unidos demuestra que los padres normalizan las escenas de violencia y el sexo en las películas y se vuelven insensibles a ellas. Esto puede contribuir a la creciente permisibilidad de acceso de estos contenidos a sus hijos adolescentes (Romer et al., 2014).

Encontramos evidencias que demuestran la existencia de un vínculo potencial entre la exposición a contenido sexual en la televisión y experimentar un embarazo antes de los 20 años. Limitar la exposición de los adolescentes a contenido sexual en la televisión e informar mediante los medios de comunicación sobre las posibles consecuencias negativas de acceder a ciertos contenidos de adultos, podrían reducir el riesgo de embarazo en la adolescencia. Ver la televisión de manera controlada por los padres y hablar sobre el contenido sexual, puede reducir la influencia de estos contenidos en los adolescentes (Chandra et al., 2008).

\subsection{5.- Control parental:}

Cameron et al, (2013) recomiendan a los padres interesarse en conocer las consecuencias de colocar una televisión en la habitación de sus hijos adolescentes.

\section{6.- TELÉFONO MOVIL}

El teléfono móvil ha irrumpido en la vida cotidiana de los adolescentes de manera muy notable en los últimos años. Son para ellos, una parte integral de sus vidas (Briere et al., 2012).

Actualmente, ocupa un lugar dominante en la sociedad de los más jóvenes. Ya desde principio de esta década, el teléfono móvil estaba considerado como el nuevo canal de comunicación preferido por los adolescentes norteamericanos (Lenhart, Ling, et al., 2010).

Sin embargo, los hábitos de utilización del teléfono móvil han evolucionado en los últimos años con la llegada masiva de los smartphones, teléfonos inteligentes con 
10 PARTE

Capítulo 2: Adolescentes y nuevas tecnologías

capacidad de, entre otras muchas, acceder a internet y a las redes sociales, además de disponer de aplicaciones de mensajería instantánea. El uso de los móviles en los adolescentes tiene un evidente componente lúdico, pero se demuestra que prima en su uso el factor comunicativo, como lo demuestra el hecho de que los mensajes y las llamadas sean los aspectos más valorados por los adolescentes (Garitaonandia et al., 2005). El 92,5\% de los adolescentes españoles entre 11 y 14 años se descarga aplicaciones en el móvil (Cánovas, 2015), aunque el 90\% se descarga sólo aplicaciones gratuitas.

Davie, Panting \& Charlton (2004) revelan en su estudio que los teléfonos móviles representan, para los adolescentes, un medio que les permite comunicarse sin ser vigilados por los padres, tutores y profesores.

El estudio realizado por Bercedo Sanz et al. (2005) afirmaba que el 87,2 \% de los adolescentes de Cantabria (España) ya tenían teléfono móvil. Bercedo Sanz et al. (2005) Además afirma que el $46,4 \%$ de los adolescentes llevan móvil al instituto y refieren que hay una media de tres móviles por familia.

\subsection{1.- Cifras de adolescentes y teléfono móvil}

\subsubsection{1.- Edad de posesión del primer teléfono móvil:}

La edad a la que los niños disponen de su primer teléfono móvil ha disminuido notablemente en los últimos años (Zheng et al., 2015). En el año 1998 sólo el 8\% de los adolescentes tenía teléfono móvil. Sin embargo, ya en el 2007 este porcentaje llegó hasta el 94\% (Briere et al., 2012).

Los estudios mencionados a continuación ponen de manifiesto que la edad de inicio en las nuevas tecnologías disminuye con los años. En España, según Bercedo Sanz et al. (2005), la edad estimada a la que los adolescentes cántabros conseguían su primer teléfono móvil era a los 13 años. Chóliz, Villanueva \& Chóliz, (2009) afirmaban que a los 12 años de edad, el $85,2 \%$ de los menores ya tenían teléfono móvil. Según el Instituto Nacional de Tecnologías de la Comunicación (2011), la edad media de acceso al primer 
teléfono móvil es de 11,2 años. El $30 \%$ de los niños españoles de 10 años tiene su propio teléfono móvil, el $70 \%$ a los 12 años y el $83 \%$ a los 14 años (INE).

El 45,6\% de los adolescentes de Barcelona confirma haber tenido su primer móvil antes de los 12 años (Munoz-Miralles et al., 2014). Bravo y Rasco (2013) afirman que el 80\% de los adolescentes andaluces se han iniciado en el uso del teléfono móvil entre los 8 a los 12 años.

Según datos de un estudio realizado por INTECO y Fundación Orange en 2013 en España, la edad de inicio en el uso de teléfonos móviles tradicionales es de 11 años y de 13 en teléfonos inteligentes o smartphone.

En 2005-2006, el 74,1\% de los adolescentes de Barcelona (España), afirmaba tener teléfono móvil desde hacía más de 2 años (Graner et al 2007).

Los niños de 2 y 3 años utilizan de forma habitual los teléfonos móviles y tablets de los padres (Cánovas, 2015). Acceden principalmente a juegos, aplicaciones para pintar o series infantiles. Los juegos, aplicaciones de TV y Youtube son las aplicaciones con las que se inician los niños en el uso del smartphone.

\subsubsection{2.- Porcentaje de adolescentes que posee teléfono móvil:}

A continuación seleccionamos una serie de estudios existentes con el objetivo de obtener una visión cronológica del uso del teléfono móvil por parte de los adolescentes:

a) Año 2004: sólo el 45\% de los adolescentes estadounidenses tiene un teléfono móvil (Lenhart, 2012).

b) Año 2009: el 75\% de los adolescentes estadounidenses confirmaba tener un teléfono móvil (Lenhart, 2012).

c) Año 2010: En el año 2010 el 75\% de los adolescentes de entre 12 y 17 años de Estados Unidos tenía teléfono móvil propio (Lenhart, Ling, et al., 2010). 
d) Año 2011: el 77\% de los adolescentes estadounidenses confirmaba tener un teléfono móvil (Lenhart, 2012).

e) Año 2011: en España se cumplen pautas semejantes. El teléfono móvil es la estrella entre los adolescentes del País Vasco (de la Piscina et al., 2011). El $88 \%$ de los adolescentes de entre 14 y 18 años tienen teléfono móvil propio.

f) Año 2012 el 31\% de los adolescentes norteamericanos de entre 14 y 17 años, tenía un smartphone. Este porcentaje no se ve afectado por la raza, etnia o los ingresos del adolescente. Los adolescentes cuyos padres han estudiado en la universidad, son más partidarios de que sus hijos adolescentes tengan un smartphone (Lenhart, 2012).

g) Año 2013: la tabla 13 muestra que en Norteamérica, el 78\% de los adolescentes de entre 12 y 17 años poseen teléfono móvil, de los cuáles el 47\% poseen un smartphone. No se aprecian diferencias por género (Madden et al., 2013).

h) Año 2014: Estudios más actuales, como el realizado a los adolescentes de la Comunidad Autónoma de Cantabria (España), apuntan que el 92,9\% de los adolescentes tienen teléfono móvil (de los cuáles, el 80,9\% tienen smartphone). Un 7,0\% de los adolescentes encuestados, afirmaba no poseer teléfono móvil (Barrio Fernández, 2014).

i) Año 2015: Las cifras de posesión de smartphone entre los adolescentes crecen a un buen ritmo. Más de la mitad de los adolescentes estadounidenses de edades comprendidas entre 13 y 17 años tiene un smartphone, el $30 \%$ tiene un teléfono móvil convencional y sólo un $12 \%$ manifiesta no tener teléfono móvil (Lenhart, 2015)

Según Cánovas (2015), la penetración de los teléfonos inteligentes en España es la mayor de Europa, con una media dle 66\%. La media en países como Inglaterra, Italia, Francia o Alemania es del 57\%. 
Vista la evolución tecnológica y social, se prevé que en un futuro muy próximo la totalidad de los adolescentes disponga de su propio smartphone (Barrio Fernández, 2014).

\begin{tabular}{|lc|ccc|}
\hline ESTUDIO & PAís & $\begin{array}{c}\text { \%tiene teléfono } \\
\text { móvil }\end{array}$ & $\begin{array}{c}\text { \%tiene } \\
\text { smartphone }\end{array}$ & $\begin{array}{c}\text { \% no tiene } \\
\text { teléfono móvil }\end{array}$ \\
\hline EEUU & $\begin{array}{c}\text { Madden, Lenhart et al. } \\
\text { (2013) }\end{array}$ & $78,0 \%$ & $47,0 \%$ & \\
\hline $\begin{array}{l}\text { Cantabria } \\
\text { (España) }\end{array}$ & $\begin{array}{c}\text { Barrio Fernández } \\
\text { (2014) }\end{array}$ & $92,9 \%$ & $80,9 \%$ & $7,1 \%$ \\
\hline
\end{tabular}

Tabla 13: adolescentes y telefonía móvil

\subsubsection{3.- Uso del teléfono móvil en relación a los distintos factores sociodemográficos:}

También se encuentran diferencias en este campo por etnia. En Estados Unidos, el 85\% de adolescentes afroamericanos tienen smartphone. La cifra para los blancos e hispanos ronda el $71 \%$ de los adolescentes (Lenhart, 2015).

Sánchez-Martinez \& Otero Puime (2010) concluyen que los adolescentes que más utilizan el teléfono móvil cumplen los siguientes patrones: pertenecen al género femenino, al medio rural, son de entornos de alto nivel económico, fuman tabaco, consumen alcohol, tienden a la depresión y al fracaso escolar.

Estudios analizados reflejan que existe un factor género en el uso del teléfono móvil. Según la encuesta sobre Equipamiento y Uso de Tecnologías de Información y Comunicación en los Hogares realizada por el INE en el año 2014, demuestra que la disponibilidad de teléfono móvil en las chicas supera en más de tres puntos a la de los chicos.

Estudios demuestran que la dependencia del teléfono móvil es más alta en la población femenina (Flynn, 2014). Las chicas jóvenes son más dependientes del teléfono móvil y lo utilizan para combatir momentos de soledad o de aburrimiento (Montañés \& Silvestre, 2011; Barrio Fernández, 2014).

Madden et al. (2013) afirma, sin embargo, que entre los adolescentes estadounidenses, no se aprecian diferencias por género. 
1ㅇ PARTE

Capítulo 2: Adolescentes y nuevas tecnologías

Los estudios que se comentan a continuación, han encontrado diferencias del uso del teléfono móvil en cuanto al género. Las adolescentes normalmente hablan más por teléfono y utilizan la mensajería instantánea más que los chicos (Ohannessian, 2009). Garitaonandia et al. (2005) afirman también que las chicas utilizan más el servicio de mensajes que los chicos. Las adolescentes valencianas, siguen el mismo patrón, puesto que envían más mensajes de texto. Además hicieron más "Ilamadas perdidas" y, generalmente, pasan más tiempo utilizando sus teléfonos móviles que los chicos. No se observan diferencias en las llamadas (Chóliz, Villanueva \& Chóliz, 2009).

Las adolescentes de Barcelona manifiestan un uso del teléfono móvil más enfocado a las relaciones sociales, mientras que los chicos lo utilizan principalmente para para jugar. El $68,4 \%$ de ellos juegan a videojuegos, el $36,5 \%$ de los cuales juega durante 3 o más horas a la semana. Además, el 66,8\% afirma jugar a videojuegos en el móvil sin ningún tipo de control parental (Munoz-Miralles et al., 2014). Chóliz et al. (2009) alcanzan la misma conclusión y afirman que las adolescentes utilizan más el teléfono móvil como un dispositivo de comunicación interpersonal y como un instrumento para hacer frente a estados emocionales desagradables. Los chicos utilizan más las funciones tecnológicas de los teléfonos como por ejemplo, los juegos, las descargas de internet y la conexión a dispositivos electrónicos (Chóliz et al., 2009).

La encuesta sobre Equipamiento y Uso de Tecnologías de Información y Comunicación realizada a los Hogares por el INE en el año 2014, manifiesta que el $23,9 \%$ de los niños de 10 años poseía teléfono móvil, el 64,3\% de los de 12 años y el 85,6\% de los de 14 años y el $90,3 \%$ de los de 15 años.

\subsection{2.- Evolución del teléfono móvil y actuales usos:}

El uso que hacen los adolescentes del teléfono móvil es, en cierta medida, diferente al del resto de los grupos de la sociedad.

El uso tradicional del teléfono, hacer y recibir llamadas, ha quedado desplazado por nuevas utilidades. Los adolescentes hablan menos por el teléfono móvil que los adultos (Lenhart, Ling, et al., 2010). De hecho, sólo un 29\% de los adolescentes de entre 11 y 14 
años usa su smartphone para hacer llamadas, cifra ligeramente superior al porcentaje de adolescentes que nunca realiza llamadas (25\%). El 45\% de ellos, sólo lo usa en alguna ocasión (Cánovas et al., 2014)

\subsubsection{1.- smartphone:}

El smartphone o teléfono inteligente ha hecho furor entre los adolescentes y lo consideran su principal pantalla. Barrio Fernández (2014) afirma que los adolescentes viven "pegados" a su smartphone.

Además de las funciones propias de un teléfono, el smartphone dispone de otras capacidades. Las utilidades que les dan los menores de 11 a 14 años son las siguientes: escuchar música (80\%), conectarse a redes sociales (72\%), navegar por internet (60\%), acceder a videojuegos (52,5\%), recibir correos electrónicos (38\%) y sacar fotografías (Cánovas et al., 2014).

\subsubsection{2.- Mensajes de texto - WhatsApp:}

El teléfono móvil se ha convertido en una herramienta indispensable puesto que se utiliza para enviar y recibir mensajes, que es el canal de comunicación preferido entre los adolescentes y sus amigos.

La tecnología avanza tan rápidamente, que las aplicaciones utilizadas para intercambiar los mensajes también han evolucionado notablemente en los últimos años. A principio de este siglo, los mensajes de texto eran el canal de comunicación más utilizado por la juventud en Estados Unidos (superando a las llamadas de teléfono, socialización cara a cara, etc..). En ese momento, pudo apreciarse un vertiginoso crecimiento de esta actividad desde 2008. En 2007, el servicio más usado del teléfono móvil entre los adolescentes de Barcelona (España) era el de realizar llamadas, seguido por el envío y recepción de mensajes de texto, conocidos comúnmente como SMS. Estudios posteriores aportaban cifras que reflejan la evolución del uso de los mensajes de texto en Estados Unidos: 
a) En Febrero de 2008, el 38\% de los adolescentes utilizaba mensajes de texto (Lenhart, Ling, et al., 2010).

b) En Septiembre de 2009 lo hacía el 54\% (Lenhart, Ling, et al., 2010).

c) En 2010 , el $72 \%$ de los adolescentes (el $88 \%$ de los usuarios de teléfono móvil), utilizaban los mensajes de texto. Dos tercios de los adolescentes que enviaban mensajes de texto, ya reconocían utilizar más el teléfono móvil para mensajes de texto que para hablar por teléfono El $15 \%$ de los adolescentes que utilizaban mensajes de texto, enviaban más de 200 mensajes al día y más de 6000 mensajes al mes (heavy users) (Lenhart, Ling, et al., 2010).

d) En los 3 primeros meses de 2011, los adolescentes de entre 13 y 17 años enviaron una media de 3364 mensajes de texto al mes. La mitad de los adolescentes que utilizaban mensajes de texto enviaban 50 o más mensajes de texto al día y un tercio de ellos más de 100 al día (Lenhart, Ling, et al., 2010).

e) En Estados Unidos, el $90 \%$ de los adolescentes de edades comprendidas entre 13 y 17 años se comunican a través de mensajes de textos. Un adolescente, envía y recibe de media diariamente 30 mensajes. Las aplicaciones más utilizadas para este tipo de comunicación son Kik o WhatsApp (Lenhart, 2015).

Las compañías de teléfono tomaron nota del uso de los SMS y ofertaron paquetes de telefonía móvil con un número de SMS gratuitos o incluso ilimitados, lo cual produjo un aumento mayor del uso de los mismos. Sin embargo, la mensajería instantánea mediante WhatsApp ha prácticamente sustituido a los SMS. Esto se ha visto reflejado en los ingresos de las operadoras de telefonía móvil, que han caído en España entre 2012 y 2013 en un 66,7\% (Cánovas, 2015).

Estudios apuntan que los adolescentes, además de para comunicarse, utilizan el teléfono móvil para otra serie de usos como navegar por internet, localizador, reloj, cámara de fotos, grabadora o despertador (Garitaonandia et al., 2005). Del mismo 
modo, este estudio puntualiza que el teléfono móvil es utilizado actualmente por los adolescentes como agenda puesto que ha sustituido al papel. Es por esta razón, que este dispositivo se ha convertido en un elemento muy importante en su vida cotidiana. Entre los adolescentes catalanes de 13 años, el teléfono móvil está sustituyendo tanto al reproductor de MP3/MP4 para escuchar música como a las cámaras fotográficas digitales (Navarro et al., 2014).

\section{WhastsApp:}

El fenómeno más llamativo en la actualidad, en cuanto a aplicaciones de comunicación, es el WhatsApp. Actualmente, puede considerarse la aplicación estrella del smartphone. Es utilizada a nivel mundial y permite comunicarse, tanto con un individuo como con un grupo de ellos, de manera instantánea.

Esta aplicación permite enviar y recibir mensajes al instante, fotos, videos y mensajes de voz de manera inmediata. Requiere tener conexión a internet.

WhatsApp es una aplicación de muy fácil manejo y prácticamente gratuita (puede tener un coste de 1,99\$(año). Es la aplicación más utilizada por los adolescentes españoles de entre 11 y 14 años y ha desbancado a los SMS. El 76\% de los adolescentes lo utiliza habitualmente y el 65\% participa en grupos (Cánovas et al., 2014).

Por su reciente implantación en la sociedad, no hemos encontrado una extensa bibliografía sobre WhatsApp y aplicaciones de mensajería instantánea similares, sin embargo, sí que podemos aportar algunas cifras que hemos obtenido del blog oficial de WhatsApp (https://blog.WhatsApp.com/). WhatsApp fue creada en enero de 2009. Su segunda versión, que data de junio de 2009, logró tener 250.000 usuarios. En Abril de 2014 el número de usuarios era de aproximadamente 500 millones. En los últimos meses de 2014, el número de usuarios ha crecido de manera increíblemente notable, principalmente en países como Brasil, India, México y Rusia. En Septiembre de 2014, el número de usuarios alcanzó los 600 millones. Según datos actualizados a Abril de 2015, el número de usuarios activos de WhatsApp ya supera los 800 millones. Cada día se registra en WhatsApp 1 millón de usuarios nuevos. El 21 de enero de 2014, WhatsApp 
alcanzó la cifra de 54 millones de mensajes circulando en un solo día. En Abril de 2014, se envían 700 millones de fotos y 100 millones de vídeos cada día.

En Enero del 2015, se sobrepasaron los 30 billones de mensajes de WhatsApp enviados y recibidos por día. Se comparten diariamente una media de 200 millones de mensajes de voz. Un usuario medio envía y recibe al mes una media de 1000 mensajes de WhatsApp, chequea esta aplicación una media de 23 veces al día y dedica a la semana una media de 3:15 horas. Como dato de interés, añadir que WhatsApp se vendió a Facebook por 19 billones de dólares.

En España, el 76\% de los niños y adolescentes de 11 a 14 años usa WhastsApp y el $65 \%$ de los ellos participa en grupos de WhatsApp. Como media diaria, cada usuario de WhatsApp envía 42 mensajes y recibe 75 mensajes. Además, adjunta fotos a diario (Cánovas, 2015). Sólo el 2,5\% de los menores de entre 11 y 14 años utiliza exclusivamente una aplicación de mensajería diferente a WhatssApp.

El WhatsApp, bien usado, es enormemente útil. Mal empleado puede causar mucho daño.

\subsubsection{3.- Conexión a internet desde el smartphone:}

El smartphone se ha convertido en el principal motor de acceso a internet por parte de los adolescentes. Se demuestra que los adolescentes que no tienen smartphone se conectan con menor frecuencia a internet que los que sí que lo tienen. El $68 \%$ de los adolescentes se conectan a internet desde sus dispositivos móviles como mínimo una vez al día (Lenhart, 2015).

Según Cánovas (2015), el 23\% de los menores de 11 a 14 años publica fotos y videos en internet desde su teléfono móvil. Aunque el teléfono móvil tenga conexión a internet, sólo el $38 \%$ de los adolescentes lo utilizan para descargar y contestar correos electrónicos. Según comentan, el correo electrónico ha sido sustituido por WhatsApp. Otro de los usos del teléfono móvil es escuchar música. Casi el $80 \%$ de los adolescentes 
afirma escuchar música habitualmente en su smartphone. El hecho de estar conectado a internet le permite acceder a la música disponible en la red.

\subsection{3-Riesgos del uso del teléfono móvil:}

El uso abusivo o mal uso del teléfono móvil por parte de los adolescentes, puede provocar distintas situaciones de riesgo como son dependencia del teléfono, padecer tensión en lugares sin cobertura, irritabilidad si no tienen el teléfono móvil, fatiga, gastos excesivos, etc. Del mismo modo, puede ser una herramienta discriminativa, puesto que pueden sentirse apartados si no tienen teléfono móvil, si no son incluidos en los grupos o si no reciben tantos mensajes como el resto de sus amigos o compañeros (Graner et al 2007).

\subsubsection{1.- Riesgo de sufrir trastorno del sueño:}

Encontramos, en el análisis de la bibliografía referente a esta cuestión, una línea de investigación importante sobre la utilización del teléfono móvil por parte de los adolescentes después de irse a la cama (coloquialmente denominado después de "apagar las luces"). Esta actividad es realizada muy frecuentemente y se asocia a niveles de agotamiento preocupantes en el adolescente durante el día. En Bélgica en 2005, más del 55\% de los adolescentes envían y/o reciben mensajes de texto después de "apagar las luces, por lo cual reportan mayores niveles de cansancio, incluso durante las clase. Van den Bulck (2007) no consigue encontrar una cifra que represente el tiempo de seguridad de uso del teléfono móvil después de haber "apagado las luces" que no induzca a efectos negativos en el adolescente.

Los adolescentes suelen tener problemas para ponerse límites y en algunos casos lo utilizan por las noches, restando horas al sueño (Brunborg et al., 2011; Dijk, 2014). Los adolescentes que juegan en el móvil o lo utilizan para navegar por internet o enviar/recibir mensajes pueden padecer insomnio y problemas para madrugar (Fossum, Nordnes, Storemark, Bjorvatn \& Pallesen, 2014). El 27\% de los adolescentes de entre 11 y 14 años afirma no apagar nunca su teléfono móvil (Cánovas, 2015). Esta cifra aumenta con la edad, puesto que entre los adolescentes de 13 y 14 años, aumenta el porcentaje a 
un 33\%. Sólo el 30\% afirma apagarlo antes de dormirse. El $43 \%$ lo apaga después de haberse acostado, a cualquier hora.

El 62,9 \% de los adolescentes de entre 12 y 20 años se lleva el teléfono móvil a la cama y el $56.8 \%$ lo tiene conectado mientras duerme. El $45,7 \%$ lo utiliza como alarma. El $36.7 \%$ envío al menos un mensaje por el móvil después de haberse ido a la cama. Casi el $8 \%$ de los adolescentes manifiesta haber sido despertado durante dos o más veces por semana por un mensaje del móvil (Adachi-Mejia, Edwards, Gilbert-Diamond, Greenough \& Olson, 2014).

Según el análisis de los datos recogidos en encuestas realizadas a adolescentes españoles en 2009 , se podía concluir que el $80 \%$ de los adolescentes no apagaba el teléfono móvil para dormir (Chóliz et al., 2009).

Los adolescentes que tienen un smartphone, usan más las tecnologías antes de dormirse que los adolescentes que tienen teléfonos convencionales y se duermen más tarde. Lo utilizan principalmente para llamar, enviar y recibir mensajes y estar en línea. Sin embargo, el estudio de Lemola et al. (2015) no encontró relación entre la posesión de un smartphone y el hecho de padecer trastornos del sueño o síntomas de la depresión.

Se observa que, en los niños, existe una asociación significativa entre el uso consistente del teléfono móvil y la fatiga. Se reclama más investigación en profundidad para explorar los posibles efectos del uso de teléfonos móviles en la salud de los niños (Zheng et al., 2015).

Por lo tanto, se recomienda educar en los riesgos del uso del teléfono móvil durante la noche y en la calidad del sueño.

\subsubsection{2.- Riesgo de perder comunicación con la familia:}

La comunicación con la familia puede verse afectada por el uso en exceso del teléfono móvil. Cuando los adolescentes usan constantemente el smartphone, por ejemplo sin 
restricciones durante la comida, la comunicación con la familia queda perjudicada.

\subsubsection{3.-Riesgo de sufrir depresión:}

Según el estudio realizado a los adolescentes del noreste de USA, un mal uso del teléfono móvil puede contribuir a desarrollar síntomas depresivos (Bickham et al., 2015).

\subsubsection{4.-Riesgo de sufrir adicción:}

El teléfono móvil es uno de los dispositivos tecnológicos más utilizados por los adolescentes. Se comprueba que aparecen distintos síntomas en los adolescentes en relación al uso del teléfono móvil, que hacen plantearnos si pueden sufrir adicción al mismo: utilización en exceso, problemas con los padres o dificultad para controlar el uso. Son variados los métodos utilizados para detectar adicción al teléfono móvil como el Test of Mobile Phone Dependence (TMP) (Chóliz, 2012).

Foerster, Roser, Schoeni \& Röösli (2015) afirman que los adolescentes suizos con síntomas de adicción al teléfono móvil, presentan cuatro comportamientos comunes: pérdida del control, abstinencia, ansia y consecuencias negativas en la vida. Promulgan además que existe un quinto factor, que es la dependencia, que refleja el componente social.

WhatsApp tiene tanto atractivo para los adolescentes, que éstos pueden correr el riesgo de volverse dependientes del mismo. En algunos casos, los adolescentes están constantemente pendientes del teléfono móvil, pendientes de un sonido o de un zumbido que indica que ha se ha registrado actividad. Forman parte de numerosos grupos, lo cual implica que pueden encontrar con facilidad otra persona dispuesta a chatear o a enviar fotos, vídeos, o cualquier información, por poco relevante que sea. WhatsApp les permite pertenecer a un grupo, lo cual es muy importante en la etapa de adolescente (Barrio Fernández, 2014). 
El $26,1 \%$ de las estudiantes y el $13 \%$ de los estudiantes de secundaria de Madrid (España) son dependientes de su teléfono móvil (Sánchez-Martinez \& Otero Puime, 2010).

Los adolescentes, independientemente del lugar donde se encuentren, dedican una mirada a la pantalla, cada poco de tiempo. Sufren ansiedad si no tienen con ellos su teléfono móvil, principalmente porque piensan que se están perdiendo información (Barrio Fernández, 2014). Antiguos estudios ya revelan que el 38\% de los adolescentes manifestaba encontrarse intranquilo y padecer ansiedad si no tenía consigo el teléfono móvil (Cánovas, 2015).

\subsubsection{5.-Riesgo de empeorar el rendimiento académico y la satisfacción personal:}

El teléfono móvil es un aparato que ofrece al adolescente una enorme distracción. El hecho de tener el teléfono móvil encima de la mesa en la que están haciendo las tareas escolares, suele implicar estar pendiente de él (aunque se pongan medidas como poderlo en silencio), y esto se traduce en descuidar el estudio. El $60 \%$ de los adolescentes de 11 a 14 años lleva su smartphone al colegio, y afirma no tenerlo apagado (Cánovas, 2015).

Existe un debate sobre el uso del teléfono móvil por el estudiante, y si el aumento del uso puede impactar negativamente en los resultados académicos, la salud mental, en el bienestar y la felicidad. Estudios demuestran que el uso de teléfonos móviles y de los mensajes de texto no está relacionado con el rendimiento académico, pero sí con la ansiedad. A su vez, el resultado académico sí está relacionado con la satisfacción personal del adolescente, mientras que la ansiedad no está vinculada a dicha satisfacción (Lepp, Barkley \& Karpinski, 2014).

Ciertos análisis estadísticos demostraron que no existía relación entre el uso del teléfono móvil y atención prestada por el adolescente. Sin embargo, profesores y maestros en algunos casos, tienen una opinión diferente, principalmente cuando un estudiante utiliza su teléfono durante la clase (Flynn, 2014). 


\subsubsection{6.- Riesgo de empobrecer su lenguaje escrito:}

Uno de los riesgos asociados al uso de los móviles por niños y jóvenes es que el lenguaje sintético que usan en los mensajes de texto, que tienden a empobrecer su lenguaje (Garitaonandia et al., 2005).

\subsection{4.- Control parental:}

Las campañas realizadas por los operadores de teléfono, poniendo a disposición paquetes de datos de internet en teléfono móvil a costes asequibles, han hecho llegar los teléfonos móviles a casi todos los estratos sociales. Los adolescentes utilizan generalmente tarifas de prepago. De esta manera, sus padres o responsables pueden controlar sus gastos (Navarro et al., 2014).

\section{7.- VIDEOJUEGOS}

Los videojuegos, como hecho cultural, nos han cogido por sorpresa. La progresión de los videojuegos es imparable en nuestra sociedad (Munoz-Miralles et al., 2014). En España, el Congreso de los Diputados en 2009 aprobó una proposición no de ley que considera a los videojuegos como una industria cultural y lo equipara al cine y a la música. Los videojuegos son dispositivos electrónicos de ocio muy populares en todas las edades, aunque son los adolescentes los que hacen un uso más intenso (Lorenci, 2012).

En los videojuegos tradicionales, el adolescente jugaba contra la máquina. Sin embargo, la novedad de los videojuegos más actuales es que son interactivos y permiten interactuar en línea con otros jugadores (Chamarro et al., 2014).

\subsection{1.- Cifras de adolescentes y videojuegos:}

Según Munoz-Miralles et al (2014), el 64,4\% de los adolescentes de Barcelona juegan a videojuegos.

Con respecto al tiempo que dedican a jugar, Pasquier, Buzzi, D'Haenens \& Sjöberg (1998) anunciaba ya en el siglo pasado que los adolescentes belgas dedican a jugar en el 
ordenador 0:20 horas diarias durante la semana, y 0:30 horas diarias durante el fin de semana. Los holandeses dedican hasta 0:46 horas diarias en fines de semana a juegos de ordenador.

Alrededor del $64 \%$ de los adolescentes ingleses juegan a videojuegos una media de una 0:45 horas al día (Livingstone \& Bovill, 1999).

En España, Munoz-Miralles et al. (2014) concluye que el 36,5\% de los adolescentes de Barcelona juegan a videojuegos durante 3 o más horas a la semana. El 36\% de los adolescentes cántabros encuestados juegan a videojuegos en el ordenador durante 6 o menos horas a la semana, el $3 \%$ entre 7 y 9 horas por semana y el $4,3 \%$ más de 10 horas a la semana (Barrio Fernández, 2014).

Los adolescentes cántabros, afirman haber comenzado a jugar a los videojuegos de promedio a la edad de 8,8 años (Bercedo Sanz et al., 2005).

El tiempo dedicado a jugar a videojuegos por los adolescentes de 15 a 19 años del Sureste de Brasil se ha incrementado desde el año 2001 hasta el 2011, principalmente en los días entre semana (Lopes et al., 2014).

El $85 \%$ de los adolescentes de Ontario (Canadá) manifestaron haber jugado a videojuegos durante el año 2011. El 18\% declaró haber jugado diariamente (Turner et al., 2012).

El $64,4 \%$ de los adolescentes de Barcelona juegan a videojuegos. El $36,5 \%$ lo hace durante 3 o más horas a la semana (Munoz-Miralles et al., 2014).

Cabe preguntarse si existe diferencia en el tiempo utilizado para jugar a videojuegos por género. A continuación comentamos algunos de los estudios que concluyen que los adolescentes de género masculino dedican más tiempo a jugar a videojuegos que los de género femenino. Hilbrecht et al. (2008) afirman que los adolescentes canadienses de Ontario, dedican más cantidad de tiempo a jugar videojuegos que las adolescentes, tanto entre semana como el fin de semana y en todas las edades de la adolescencia. 
Incluso anuncian que una de las razones puede ser porque, la acción de jugar a los videojuegos, reproduce los estereotipos masculinos como acción, aventura y dominio.

Esta pauta misma pauta en el uso de los videojuegos por género se cumple también en el caso de los adolescentes belgas y holandeses (Stevens et al., 2003).

Ohannessian (2009) afirma que los chicos juegan más a menudo a videojuegos que las chicas

En España, el estudio llevado a cabo por Barrio Fernández (2014) afirma que el impacto de los videojuegos en la vida cotidiana de los chicos es mucho mayor que en la de las chicas, tanto en porcentaje de usuarios de videojuegos como en el tiempo invertido en dicha actividad.

En el caso de los adolescentes de Barcelona, las diferencias por género son muy notables. El 75,7\% los chicos manifiestan jugar a videojuegos frente a 31,3\% las chicas (Munoz-Miralles et al., 2014).

Entre el $90 \%$ y el $95 \%$ de las adolescentes cántabras juegan a videojuegos durante menos de 1 hora al día, cifra inferior a la encontrada para el género masculino (Noriega et al., 2015).

Conocidas las evidencias sobre el diferente uso de los videojuegos por género, puede resultar interesante analizar las corrientes que señalan que el uso equitativo del ordenador e internet entre hombres y mujeres, conllevará menos diferencias en el futuro entre ellos (DiMaggio, Hargittai, Neuman \& Robinson, 2001; Haythornthwaite, 2001; Tyler, 2002).

Con respecto a la edad, estudios demuestran que el tiempo dedicado a jugar a videojuegos por los jóvenes de género masculino, de edades comprendidas entre $10 \mathrm{y}$ 17 años de Cantabria, aumenta con la edad. En el género femenino se aprecia, sin embargo, el efecto contrario. Las chicas, dedican menos tiempo a jugar con los años (Noriega et al., 2015). 
Otros estudios ponen de manifiesto que, entre los adolescentes de Barcelona, el tiempo dedicado a jugar a los videojuegos disminuye con la edad (Munoz-Miralles et al., 2014).

Además, Dumais (2008) afirma que otro de los factores que afectan en el tiempo dedicado por los adolescentes a jugar a videojuegos es el estatus socioeconómico del entorno del adolescente. De este modo, los adolescentes ingleses de estatus socioeconómico medio dedican menos horas a jugar a videojuegos que los de clase trabajadora. Es por esta razón, que en este caso se demuestra que al disminuir el nivel socioeconómico del adolescente, aumenta el tiempo dedicado a esta actividad (Livingstone \& Bovill, 1999).

\subsection{2.- Dispositivos de acceso a videojuegos:}

Los dispositivos tecnológicos desde los que los adolescentes juegan a videojuegos son variados. Actualmente, acceden a los videojuegos desde el ordenador, la videoconsola, la tablet o el smartphone. Sin embargo, los dispositivos más utilizados para jugar a videojuegos son el ordenador y la videoconsola (Connolly, Boyle, MacArthur, Hainey \& Boyle, 2012). En la comunidad autónoma de Cantabria (España), el 71,5 \% de los adolescentes tienen videoconsola (Bercedo Sanz et al., 2005). Se observan diferencias por género en el uso de la consola, puesto que el porcentaje de adolescentes masculinos que la utilizan es del $87 \%$, frente al 57,2 \% de las adolescentes (Bercedo Sanz et al., 2005).

El 52,5\% de los menores de 11 a 14 años de edad españoles juega habitualmente con sus dispositivos móviles (Cánovas et al., 2014).

Las videoconsolas han evolucionado mucho en los últimos años, al igual que el resto de la tecnología. Su capacidad para conectarse a internet le confiere una gran versatilidad. Los catalanes menores de 13 años usan una amplia gama de videoconsolas. No es muy elevado el porcentaje de adolescentes femeninas de entre 14 y 29 años que dispone de videoconsola propia (Navarro et al., 2014). 
El $87,3 \%$ de los adolescentes de ESO y 10 de $\mathrm{BACH}$ de la Comunidad Autónoma de Cantabria tiene videoconsola (Barrio Fernández, 2014). Los usos que le dan a la videoconsola son varios:

- $78,11 \%$ la utilizan para juegos

- $33,40 \%$ para juegos con control de movimiento

- $26,61 \%$ para ver películas

- $8,27 \%$ para hacer chat o videochat

- $7,25 \%$ ve la TV a la carta o similar a través de la videoconsola

- $3,75 \%$ la utiliza para informarse de noticias

- 4,13 para otros fines sin especificar.

Resulta interesante destacar el tiempo que los adolescentes destinan a jugar a videojuegos en el ordenador. El $36 \%$ de los adolescentes encuestados juegan a videojuegos en el ordenador durante 6 o menos horas a la semana, el $3 \%$ entre 7 y 9 horas por semana y el 4,3\% más de 10 horas a la semana (Barrio Fernández, 2014).

\subsection{3.- Temática de los videojuegos:}

Los videojuegos existentes en el mercado son de diversas temáticas y pueden estar catalogados como videojuegos de aventura, estrategia, simulación o deporte (Chamarro et al., 2014).

Los adolescentes catalanes más mayores prefieren juegos de acción y de deporte (Navarro et al., 2014).

Bercedo Sanz et al. (2005) encuentran diferencias por género en cuanto a la temática de los videojuegos: los chicos prefieren invertir su tiempo en jugar a videojuegos de disparos, lucha, deporte y conducción mientras que las chicas eligen videojuegos de aventuras. 
Capítulo 2: Adolescentes y nuevas tecnologías

\subsection{4.- Videojuegos/consolas en la habitación}

Los jóvenes que tienen videoconsola en su habitación se van a dormir más tarde los fines de semana que los que no las tienen, y pasan menos horas en la cama (Van den Bulck, 2004).

\subsection{5.- Efectos positivos y negativos del uso de videojuegos}

Al igual que para el resto de las tecnologías, el uso de videojuegos puede tener efectos positivos y negativos en los adolescentes.

\subsubsection{1.-Efectos positivos y ventajas}

Estudios existentes en la bibliografía actual, se focalizan en estimular el interés que precede a la realización de nuevas investigaciones que examinen los efectos positivos de los videojuegos en el desarrollo de los adolescentes (Blumberg, Blades \& Oates,, 2013).

El uso de videojuegos puede ser un factor de positiva influencia en el aprendizaje del adolescente. Por esta razón, sus pautas de uso deben ser estudiadas (Blades, Blumberg \& Oates, 2015).

Los videojuegos de buena calidad, instructivos y con capacidad de retar las habilidades del adolescente, pueden estimular el aprendizaje de manera agradable y eficaz (Durkin, Boyle, Hunter \& Conti-Ramsden, (2015).

Garitaonandia et al. (2005) afirman que los juegos de ordenador ayudan a la mayoría de los niños a desarrollar destrezas en la resolución de problemas. Del mismo modo, queremos resaltar que una tercera parte de los niños estudiados en dicha investigación se sienten agresivos después de jugar con el ordenador.

El éxito consiste en seguir 2 pautas: seleccionar el videojuego correctamente y controlar el tiempo destinado a jugar. De esta manera, este tiempo le puede permitir al adolescente madurar psicológicamente y fomentar su creatividad (Barrio Fernández, 2014). 
Además, el uso de videoconsolas es un precursor de la interactividad y de la socialización entre los adolescentes que dedican tiempo a este tipo de juegos online (Sanz ,2008).

\subsubsection{2.- Efectos negativos y riesgos}

Los riesgos ante los que se encuentran los adolescentes que practican un mal uso o uso en exceso de los videojuegos son los siguientes:

\section{a) Riesgo de sufrir adicción:}

Una de las preocupaciones principales relacionadas con el uso de videojuegos es su posible capacidad adictiva (King, Delfabbro \& Griffiths, 2013).

Griffiths (2005) trata de determinar si el exceso de tiempo dedicado a jugar a los distintos videojuegos puede tener consecuencias negativas. Aunque se evidencia la necesidad de realizar estudios más exhaustivos en el tema, se puede sugerir que el exceso de tiempo dedicado a los videojuegos puede ser potencialmente adictivo y que, además, puede afectar principalmente a individuos con comportamientos compulsivos o adictivos.

El mayor peligro de adicción a internet entre los adolescentes griegos se encuentra entre aquellos que juegan a videojuegos principalmente en cibercafés (Siomos et al., 2008).

\section{b) Riesgo de sufrir ansiedad, aislamiento o sedentarismo.}

Según los estudios, los adolescentes canadienses que juegan a videojuegos pueden presentar síntomas severos de ansiedad (Maras et al., 2015).

En algunos casos, la práctica de videojuegos puede entrañar riesgos como aislamiento social, pérdida de la noción del tiempo, sedentarismo, problemas físicos por posturas incorrectas o abandono de las obligaciones escolares (Barrio Fernández, 2014). 
1ㅇ PARTE

Capítulo 2: Adolescentes y nuevas tecnologías

\section{c) Riesgo de fomentar comportamientos violentos:}

Jugar a videojuegos violentos en general es una actividad muy popular entre los adolescentes canadienses. Se demuestra que existe una relación negativa significativa entre la cantidad de tiempo que los adolescentes destinan a jugar a juegos violentos durante el día y su madurez socio-moral (Bajovic, 2013).

Por esta razón, uno de los puntos de actualidad con respecto al uso de los videojuegos, es estudiar la relación entre los patrones de comportamiento de adolescentes jugadores de videojuegos violentos, sus hábitos y actitudes y sus niveles de razonamiento moral. Interesa saber si existe una relación (tanto a corto como a largo plazo), entre la violencia en los videojuegos y la confianza del individuo (Rothmund, Gollwitzer, Bender \& Klimmt, 2015).

Interesa conocer los efectos en la confianza y sensibilidad del adolescente que provoca, a largo plazo, la exposición frecuente a la violencia de videojuegos. El análisis de Cross-lagged muestra que el aumento de la frecuencia de juego reduce la confianza interpersonal en un periodo de 12 meses, particularmente en los jugadores más sensibles. Estos resultados sugieren que la desconfianza interpersonal es un resultado relevante a largo plazo de la exposición frecuente a la violencia de los videojuegos (Rothmund et al., 2015).

Otros estudios relacionan el uso problemático de los videojuegos principalmente con el género masculino (Labrador \& Villadangos, 2010; Fuster et al., 2012). Este estudio pone de manifiesto además, que este efecto se desarrolla con más virulencia en la etapa de la preadolescencia.

El Cuestionario de Experiencias Relacionadas con los Videojuegos (CERV) es una herramienta útil cuyo objetivo radica en detectar los problemas de los adolescentes relacionados con el uso de videojuegos. Está compuesta por 17 ítems relacionados principalmente con la preocupación, negación, aumento de la tolerancia, efectos negativos, reducción de actividades, pérdida de control, evasión y deseo de jugar (Chamarro et al., 2014). 


\subsection{6.- Control parental:}

Sobre el consumo de videojuegos por los adolescentes, aparentemente existe cierto control en los hogares. Los padres dosifican su práctica en el tiempo libre y después de otras actividades extraescolares (Navarro et al., 2014).

Otros estudios afirman lo contrario. El $66,8 \%$ de los adolescentes de Barcelona encuestados para un estudio, manifiesta que juega a videojuegos sin control paterno (Munoz-Miralles et al., 2014).

El principal problema es que los padres se encargan de comprar el mecanismo pero no realizan una vigilancia sobre el tipo de juegos que utilizan (Muñoz, 2009; Barrio Fernández, 2014).

\section{8.- OTRAS TIC:}

\subsection{1- LIBRO DIGITAL:}

Otra de las nuevas tecnologías utilizada por los adolescentes es el libro digital, tanto en el ordenador como en otros dispositivos.

Los adolescentes consideran el libro digital muy cómodo, rápido, y sobre todo versátil. Los jóvenes de entre 14 y 29 años piensan que el libro está viviendo su momento de evolución. Valoran la versatilidad del formato libro electrónico, el no gasto de papel y lo efímero frente a la materialidad del libro tradicional. Pese a todos estos argumentos, Las chicas de entre 14 y 29 prefieren el libro físico. Los adolescentes consideran que el libro en papel tiene un ritual insustituible: sofá, cigarrillo, rincón de lectura o tranquilidad (Navarro et al., 2014).

De cualquier manera, el análisis de los datos recogidos en estudios recientes, concluye que los adolescentes vascos leen libros con muy poca frecuencia (de la Piscina et al., 2011). 


\subsection{2.- DISPOSITIVOS/APLICACIONES PARA ESCUCHAR MÚSICA:}

Los adolescentes catalanes menores de trece años escuchan música mediante el programa Spotify y la descargan en línea del programa Ares. Una vez descargada, la pasan al teléfono móvil o al reproductor de MP3/MP4. Las chicas de entre 14 y 29 años escuchan música en la red con Spotify (Navarro et al., 2014).

Casi el $80 \%$ de los menores de 11 a 14 años escucha habitualmente música en su smartphone (Cánovas et al., 2014).

\section{9.- EDUCAR A LOS ADOLESCENTES EN LAS NUEVAS TECNOLOGÍAS:}

Se denomina alfabetización audiovisual al conocimiento, las habilidades y las competencias que se requieren para interpretar los medios (Buckingham, 2005).

La educación en nuevas tecnologías y comunicación, conocida en algunos foros como Educomunicación, pretende dotar al ciudadano de las herramientas necesarias para poner en orden el maremagno al que se enfrentan. Es una herramienta imprescindible para toda persona que aspire a considerarse audiovisualmente alfabetizada (de la Piscina et al., 2011).

Los adolescentes, al igual que el resto de los ciudadanos, necesitan ser educados en comunicación. El incremento de exposición ante los medios y las nuevas tecnologías no ha traído consigo un aumento en la alfabetización audiovisual. Es necesario explicar a los adolescentes, que al igual que hay ciertos comportamientos que no son admisibles en la vida cotidiana, otros comportamientos no lo son en los medios. Las normas en el uso de los medios deben estar en sintonía con la educación fuera de las nuevas tecnologías. Se trata de aplicar los conceptos que se utilizan en la vida real, a la vida virtual.

La educación en medios es, por lo tanto, una necesidad. Estudios realizados en Estados Unidos, afirman que ni los padres, ni los educadores ni los gobiernos, están dando la importancia que tiene a los efectos de las nuevas tecnologías en los adolescentes (Strasburger, 2014). La Educomunicación, debe enseñarse como garantía para formar 
personas audiovisualmente alfabetizadas, y debe ser transmitida tanto en la escuela, como en la familia, en las instituciones y en los medios, que deben ser responsables socialmente. A continuación, analizamos los estudios que investigan sobre la aportación de cada uno de estos grupos a la educación en medios de los adolescentes, sus fortalezas y sus debilidades.

Además, los medios pueden ser utilizados como plataforma para impartir educación sexual o programas de prevención de consumo de drogas, por lo que puede utilizarse como plataforma educativa (Strasburger, 2014).

Una vez argumentada la necesidad de educar a los adolescentes, es necesario definir quiénes son los actores encargados de dicha educación.

\subsection{1.- Control parental y educación por parte de los padres:}

Los padres que controlan la actividad de sus hijos en las TIC, manifiestan tener influencia sobre el tiempo que dedican a dormir, sobre su rendimiento escolar, sobre su salud física y sobre sus comportamientos prosociales o agresivos. El tiempo que pasan frente a la pantalla, expuestos a contenidos delicados, puede influir en la aparición de los síntomas enumerados anteriormente. Si el control ejercido por los padres es adecuado, es posible mitigar estos síntomas (Gentile, Reimer, Nathanson, Walsh \& Eisenmann, 2014).

Se demuestra que el control parental sobre el uso de las nuevas tecnologías por sus hijos, tiene influencia en su rendimiento escolar. Se concluye que está asociado con una mejora en el mismo (Munoz-Miralles et al., 2014).

\subsubsection{1.- Educación de los padres en nuevas tecnologías:}

En algunos casos, los padres usan las mismas nuevas tecnologías que sus hijos. Por ello, se sienten cómodos y capaces de utilizar los programas y aplicaciones que sus hijos adolescentes manejan. Sin embargo, otros padres encuentras dificultades de conocer el uso que sus hijos adolescentes le dan a las nuevas tecnologías. Algunos no entienden las nuevas formas de socialización. Frecuentemente no tienen habilidades técnicas o el 
1ㅇ PARTE

Capítulo 2: Adolescentes y nuevas tecnologías

tiempo necesario para emplearlo en adaptarse a los cambios constantes de internet (Palfrey \& Gasser, 2010). De igual modo, desconocen en muchos casos, los riesgos a los que se pueden enfrentar sus hijos con respecto a las nuevas tecnologías y a los medios. Por ejemplo, no conciben el hecho de que sus hijos puedan ser engañados en internet o que puedan recibir mensajes o correos electrónicos que no son reales. Tampoco entienden que exista la posibilidad de que personas adultas puedan suplantar la identidad de jóvenes para engañarlos o que físicamente, les puedan activar la Webcam de sus dispositivos sin que los adolescentes lo autoricen o sean conscientes.

No hemos encontrado una amplia bibliografía sobre la antigüedad en el uso de internet por parte de los padres. Solo un estudio que data del año 2009 que manifiesta que el $51,3 \%$ de los padres utilizaba internet hacía 1-2 años, 27\% 3-4 años, 7,2\% 5-6 años. El 9,8\% de los padres manifestó no usar internet o utilizarlo hacía menos de un año (INTECO, 2009).

Los padres no entienden que la vida online de los adolescentes es, en resumidas cuentas, una extensión de su vida real. El resultado final es, a menudo, una brecha importante en el conocimiento y capacidades técnicas entre los padres y los jóvenes, el cual crea desconexión en cómo los padres y la juventud participan juntos en el mundo online (Jenkins, 2009).

Los padres deben educarse en nuevas tecnologías. Es verdaderamente importante que los padres conozcan el funcionamiento de las TIC. Es la única manera de que puedan educar a sus hijos en este campo. En algunos casos, se ha detectado una falta de interés o de preocupación por parte de los padres en saber sobre las actividades relacionadas con las nuevas tecnologías en las que sus hijos invierten su tiempo (Strasburger, 2014).

\subsubsection{2.- Inculcar a los adolescentes el concepto de privacidad:}

Es necesario que los menores y adolescentes entiendan el riesgo de exponer sus datos personales, fotos o vídeos públicamente y que sean conscientes de la perdurabilidad de la información en la red. Deben lograr entender el concepto de privacidad. Es necesario 
transmitirles que la facilidad con la que emiten comentarios, suben fotografías o videos a internet, se convierte una gran dificultad a la hora de tratar de borrarlos.

2.9.1.3.- Controlar y restringir el tiempo dedicado a las nuevas tecnologías:

Es papel de los padres controlar el tiempo que pasan sus hijos frente a una pantalla. Como ya hemos apuntado en este estudio, la recomendación de la AAP sobre el tiempo que deben pasar los adolescentes frente a una pantalla es de máximo 2 horas diarias (Strasburger, 2014).

El tiempo medio de un adolescente estadounidense frente a una pantalla es superior a 7 horas diarias. El hecho de limitar este tiempo puede beneficiar la salud del adolescente enormemente (Strasburger, 2014). 

$2^{a}$ Parte:

\section{DESARROLLO}

\section{DE LA INVESTIGACIÓN}



Capítulo 3:

\section{Metodologia}





\section{2a PARTE: DESARROLLO DE LA INVESTIGACIÓN}

\section{Capítulo 3: METODOLOGÍA}

En este capítulo explicaremos la metodología seguida en la investigación y los elementos tenidos en cuenta para el diseño del cuestionario de recogida de datos.

El diseño de investigación establece el marco de referencia para el estudio de las relaciones entre las variables, indica en cierto sentido qué observaciones hay que hacer, cómo hacerlas y cómo realizar las representaciones cuantitativas de las investigaciones (Kerlinger, 2001, 404).

El objetivo de nuestra investigación es analizar los factores que intervienen en el uso del tiempo de los adolescentes y su relación con las nuevas tecnologías, además de estimar los resultados académicos y de satisfacción relacionados con esos usos del tiempo y de las nuevas tecnologías.

\section{1.- METODOLOGÍA DE INVESTIGACIÓN}

La investigación que se lleva a cabo se caracteriza como no experimental, ex post facto, descriptiva y correlacional, inductiva, de campo, transversal. Explicamos cada uno de los términos reseñados:

- No experimental en el que se pretende observar la realidad tal y como se produce en su ambiente habitual sin un control sobre las variables y el entorno que se podría llevar a cabo en un laboratorio. Se consulta, por medio de cuestionario, a los adolescentes que asisten a clase entre primero de Educación Secundaria Obligatoria (ESO) y segundo de Bachillerato (BACH).

- Ex post-facto ya que lo que hacemos es recoger información sobre las variables a estudiar (uso del tiempo y nuevas tecnologías) y buscar factores anteriores en el tiempo, que no podemos manipular, que tengan 
relación con las variables estudiadas. La principal debilidad de este tipo de investigación consiste en que por falta de control sobre los factores no podemos establecer causalidad aunque constatemos relación. No hay manipulación de variables, estas se observan y se describen tal como se presentan en su ambiente natural.

- Descriptiva en cuanto describe las principales variables objeto de estudio. Determinaremos las principales actividades en las que usan el tiempo los adolescentes de Burgos y qué nuevas tecnologías usan y cuánto las usan.

- Correlacional que estudia relaciones entre variables dependientes e independientes, es decir, se estudia la correlación entre dos variables por medio de análisis de regresión o influencia de unas variables independientes sobre otras dependientes por medio de herramientas estadísticas (ANOVA, t-Student en caso de comparación de medias entre dos grupos o chi-cuadrado para tablas de contingencia para determinar la posible relación entre variables cualitativas).

- Inductiva: ya que vamos de lo particular a lo general, tratando de sacar conclusiones generales partiendo del análisis de datos de una muestra, analizando los datos de manera sistemática.

- De campo: el estudio se lleva a cabo en varios centros educativos de la provincia de Burgos, hasta los que nos desplazamos para recoger los cuestionarios.

- Transversal: en los que se mide el fenómeno en un momento dado en el tiempo (no a los mismos sujetos en distintos momentos en el tiempo). Por lo que se confunden e interaccionan los efectos edad y cohorte. En el caso de nuestro estudio tiene especial incidencia en el efecto cohorte los aspectos relacionados con las nuevas tecnologías, ya que en 6 años que van desde 10 de ESO a 20 de BACH los cambios tecnológicos son amplios. 


\section{2.- OBJETO DE ESTUDIO}

Delimitamos nuestro objeto de estudio basándonos en los estudios previos revisados en la bibliografía, partiendo de los siguientes supuestos:

- El tiempo que los adolescentes emplean en distintas actividades varía con el paso de los años (con la misma edad se hacen distintas cosas en distintas épocas).

- El tiempo empleado en las distintas actividades está relacionado con las tecnologías disponibles, en momento y situación.

- Hay distintos factores personales y sociales que influyen en el uso del tiempo y el empleo de las nuevas tecnologías: la edad, el género, la influencia de los padres, hermanos y compañeros o/ y amigos.

- Los resultados académicos y el grado de satisfacción pueden verse afectados por el uso del tiempo y las nuevas tecnologías.

- La supervisión y control de los padres del uso de las nuevas tecnologías afecta a la distribución del tiempo de los adolescentes.

Nuestro trabajo tiene como objeto determinar el modo y factores que influyen en los adolescentes de Burgos, que cursan estudios desde 1을 de ESO hasta 20 de BACH.

El problema de investigación, como nos comenta Pérez Juste $(2009,20)$ se ha de ajustar a los siguientes criterios:

- Viabilidad: posibilidad de resolución del problema. El investigador debe cuestionarse si el problema se adecua al contexto y se puede abordar con los medios posibles, a nivel personal y material. La investigación se realiza con adolescentes de 1 으 de la ESO a 20 de $\mathrm{BACH}$ y versa sobre su uso de TIC en el tiempo libre.

- Interés: que tiene el tema para el investigador, es decir la implicación personal en la problemática abordada, además de la implicación para la sociedad y la comunidad científica. El uso del tiempo de los adolescentes y su acceso a las nuevas tecnologías determina su presente, marcará su futuro y el futuro de la 
sociedad en su conjunto, lo que hace de este campo de investigación un campo interesante.

- Relevancia teórica y práctica: la información suministrada en el trabajo y su análisis, puede conducir a tomar decisiones de mejora que repercuten en las personas y la sociedad. La información resultante de nuestra investigación nos permitirá conocer mejor a los adolescentes, detectar antes problemas por excesivo uso de las nuevas tecnologías y determinar patrones de actuación para su educación.

- Adecuación: situar el problema en el contexto en el que se va a realizar. La investigación se sitúa en los Centros de Educación Secundaria de Burgos.

- Otros aspectos: presentación minuciosa de la investigación, lenguaje claro y conciso, sin adornos externos, y enmarcada en ámbitos concretos de actuación. La investigación se puede llevar a cabo por la facilidad en el acceso a los alumnos y por tanto en la recogida de información y datos.

\section{3.- OBJETIVO DE LA INVESTIGACIÓN}

El objetivo de la investigación es determinar los usos del tiempo de los adolescentes burgaleses en relación a las nuevas tecnologías, considerando factores diversos (sexo, curso, edad, etc.).

Se pretende relacionar estos usos del tiempo con los usos del tiempo de los adolescentes en otras localizaciones geográficas y relacionar estos usos con las principales recomendaciones al respecto de la comunidad científica.

Consideramos que el uso del tiempo es uno de los determinantes de los resultados conseguidos y de la satisfacción vital propia y de quienes comparten ese tiempo.

Podemos concluir que, como objetivo general de esta investigación, nos proponemos mostrar el perfil de los adolescentes burgaleses en cuanto a uso del tiempo y acceso a las nuevas tecnologías. 
Se pretenden lograr los siguientes objetivos específicos:

- Elaborar y validar un cuestionario para la medida y recogida de datos del uso del tiempo de los adolescentes, su acceso a las nuevas tecnologías y algunos factores que influyen.

- Describir el uso del tiempo de los adolescentes y determinar el tiempo empleado en las principales actividades: dormir, asistir a clase, cuidado personal, tiempo en actividades extraescolares, uso de nuevas tecnologías, deporte, trabajo y ocio.

- Describir la forma y circunstancias del acceso a las nuevas tecnologías de los adolescentes y las plataformas empleadas para hacerlo de manera regular a estas tecnologías.

- Determinar la relación, si existe, entre el uso del tiempo y el acceso a las nuevas tecnologías.

- Analizar y cuantificar las diferencias en el uso del tiempo y en el acceso a las nuevas tecnologías según distintos factores relevantes:

$\checkmark$ Género

$\checkmark$ Edad

$\checkmark$ curso

$\checkmark$ Tipología de Centro educativo

$\checkmark$ Nacionalidad

$\checkmark$ Entorno familiar

- Determinar la influencia del uso del tiempo y de las nuevas tecnologías con los resultados académicos y de satisfacción de los adolescentes.

\section{4.- HIPOTESIS}

En palabras de Mc Millan y Schumacher (2010) las hipótesis de investigación son un enunciado provisional de la relación esperada entre dos o más variables, así mismo, podemos considerarlas como una explicación en forma de suposición, de un fenómeno que se acepta o se rechaza por una evidencia experimental. 
Para Bunge (1981) es importante tener en cuenta tres requisitos en la formulación de hipótesis:

$\checkmark$ Tiene que ser bien formulada y significativa

$\checkmark$ Fundamentada en conocimientos previos.

$\checkmark$ Ha de ser empíricamente contrastable mediante diferentes procedimientos.

Las hipótesis que nos planteamos son:

1. Existen diferencias significativas de género en la distribución del uso del tiempo, según el tipo de actividades que se realizan.

2. Existen diferencias significativas en función de la edad en la distribución del uso del tiempo y en el tipo de actividades que se realizan.

3. La nacionalidad es una variable que proporciona diferencias significativas en relación al uso del tiempo y tipo de actividades.

4. La tipología de centro educativo aporta diferencias significativas en función del tipo de actividad y distribución del tiempo.

5. Existen diferencias significativas en función del control y supervisión del uso del tiempo realizada por los padres o/y tutores en relación al tipo de actividades realizadas.

6. Existen diferencias significativas en el uso del tiempo en función del acceso a las nuevas tecnologías y su disponibilidad en la habitación.

7. El género proporciona diferencias significativas en el acceso a redes, plataformas y nuevas tecnologías.

8. Existen diferencias significativas en función de la edad en el acceso a las nuevas tecnologías y en las plataformas que se emplean para ello.

9. La tipología de Centro Educativo aporta diferencias significativas en relación a las diferentes redes y plataformas de acceso. Existen diferencias en función del 
centro educativo en el acceso a las nuevas tecnologías y en las plataformas que se emplean para ello.

10. Existen diferencias significativas en función de las características de los padres y de su supervisión en el acceso a las nuevas tecnologías y en las plataformas que se emplean para ello.

11. Existen diferencias significativas en función de la nacionalidad en relación a las diferentes redes y plataformas de acceso.

\section{5.- INSTRUMENTO DE MEDIDA}

La posible metodología a utilizar para estudiar el uso del tiempo de los adolescentes y su interacción con las nuevas tecnologías es diversa. Uno de los métodos, que consideramos que pudiese arrojar resultados más fiables, es la observación directa del uso del tiempo del encuestado. Sin embargo, este método muestra principalmente dos inconvenientes. Por un lado, es un método económicamente poco viable, puesto que es muy costoso. Por otro lado, la intrusión de un observador dentro del entorno del adolescente podría provocar que el adolescente modificase su comportamiento natural, por lo que los datos recogidos no serían veraces (Robinson, 1985).

Otra metodología a utilizar para la obtención de información referente al uso del tiempo es la realización de encuestas/cuestionario. La encuesta se materializa en nuestro caso, como un listado cerrado de actividades, en las que los encuestados cumplimentan la frecuencia de realización y el tiempo invertido en cada una de ellas. La debilidad de este método radica en la dificultad de definir un listado de actividades adecuado y completo, que no excluya ninguna actividad, y que no sea ambigua su cumplimentación (Robinson, 1985). En algunos casos, puede ocurrir que para conseguir mayor riqueza de datos, el listado de actividades es tan pormenorizado, que el volumen de cuestiones hace que el encuestado lo encuentre aburrido y no ponga toda la atención requerida en cumplimentarlo. 
El diario, es otro de los métodos existentes para la recogida de datos sobre uso del tiempo y uso de nuevas tecnologías. Esta metodología consiste en recoger en un diario, de manera secuencial las actividades realizadas durante las 24 horas siguiente o en las últimas 24 horas, incluyendo la hora de comienzo y la hora de finalización de cada actividad (Robinson, 1985). Además hace una relación de las actividades en las que se utilizan las nuevas tecnologías. La ventaja principal de los diarios de uso del tiempo es que comprenden un periodo determinado de tiempo, y además permite que cada encuestado utilice sus propias palabras para definir las actividades, aunque su posterior codificación implica dificultades a la hora de estandarizar las respuestas recogidas.

Otro método empleado, aprovechando las nuevas tecnologías es el descrito por Csikszentmihalyi (2011) dónde aleatoriamente en el tiempo se manda un mensaje al sujeto que responde en que actividad se encuentra involucrado. Se establece una media de mensajes predeterminada, por ejemplo 12 al día y manteniendo el sistema durante un periodo se puede estimar el tiempo dedicado a cada actividad.

La metodología elegida, para llevar a cabo este estudio, es la elaboración, validación e implementación de un cuestionario. Son dos los motivos principales que han propiciado la elección de la encuesta como metodología para la recogida de datos sobre el uso y la gestión del tiempo de los adolescentes y su interacción con las nuevas tecnologías. La primera razón es meramente económica, reflejada en el bajo coste económico que conlleva este método. La segunda razón viene definida por la posibilidad existente de acceder a centros de Educación secundaria que están dispuestos a colaborar en la obtención de datos a partir del cuestionario.

Por lo tanto, para identificar los factores que se relacionan con el uso del tiempo y las nuevas tecnologías, se emplea como técnica la encuesta y como instrumento el cuestionario compuesto por 59 items agrupados en cinco bloques:

- Items de 1 a 9: incluye variables sociodemográficas como el género, la edad, la nacionalidad; tipo de centro y el curso; cuestiones relativas al entorno familiar 
como el número de hermanos, con quién viven y los estudios de los padres y estado sentimental.

- Items de 10 a 15: esta parte del cuestionario está destinada a recabar información sobre el uso del tiempo de los adolescentes. Para ello, se ha definido un listado de actividades desempeñadas propiamente por ellos, y se ha requerido que cumplimenten el número de horas y minutos que dedican a cada una de las actividades, tanto entre semana como durante el fin de semana. Se hace especial hincapié en la cuestión del sueño, cuál es su percepción propia sobre la sensación de descanso.

- Items de 16 a 36: bloque de preguntas para obtener información sobre el uso de nuevas tecnologías en relación a:

- posesión de dispositivos electrónicos y uso en entorno educativo.

- edad de inicio de uso/pertenencia de dispositivos electrónicos.

- uso de dispositivos utilizados tras haberse acostado.

- utilización de internet (redes sociales) y posibles adiciones.

- Items 37 a 49: referidos a la gestión de las nuevas tecnologías y redes sociales.

- Items 50 a 59: relativos a los resultados académicos y satisfacción del adolescente y de su entorno próximo.

\section{6.- LA MUESTRA}

Al construir un instrumento de medición, como un cuestionario, se han de realizar una serie de análisis para la investigación que requieren un número mínimo de sujetos, con la finalidad de dar la mayor objetividad, estabilidad, validez y fiabilidad de los datos.

Como criterio general, es preferible y recomendable tener más sujetos que menos, para que los resultados de los análisis sean más estables, mientras que si son pocos, es más 
probable que los resultados tengan menor posibilidad de determinar diferencias significativas.

La representatividad es un aspecto esencial a la hora de seleccionar la muestra. Ante el objetivo de extrapolar los resultados a la población representada hay que considerar: el tipo de muestra y el número de sujetos que la componen, es decir, la muestra.

El tamaño de la muestra tiene que ver con los márgenes de error al extrapolar de la muestra a la población. Los límites o características de la población los determina y define el investigador, que ha de explicar los tipos de muestreo y describir las características de la muestra para poder valorar esta representatividad.

Las muestras podemos dividirlas en dos grandes categorías según sean o no sean muestras probabilísticas o aleatorias; ambos términos (probabilísticas o aleatorias) expresan lo mismo. Siguiendo a Morales (2011) podemos señalar:

- Aleatoria o probabilística es aquella en la que todos los sujetos de la población han tenido la misma probabilidad de ser escogidos. Son en principio los tipos de muestra más profesionales.

- No probabilística o determinístico cuando la muestra está disponible. Se utilizan para estudios específicos. El cálculo del tamaño y selección de la muestra se basan en juicios y criterios subjetivos y no es posible establecer la precisión respecto a niveles de confianza predefinidos. No obstante representa una alternativa viable, ya sea cuando la aplicación del muestreo probabilístico resulta demasiado costosa; cuando no es posible disponer de un marco de muestreo o cuando existe seguridad en que la información recabada bajo este tipo de muestreo es suficientemente útil para los fines de la investigación.

En nuestro caso es una muestra no probabilística ya que se eligieron los centros y los individuos de la muestra. La muestra se realizó en centros con los que existía una relación previa y que, a criterio de los investigadores, pueden ser representativos de la 
población general (criterio subjetivo y por lo tanto una de las debilidades del estudio) pásalo a limitaciones.

Otro aspecto relevante es el tamaño de la muestra para que nuestros resultados sean suficientemente fiables. Para determinar el tamaño de muestra el investigador necesita tener en cuenta las siguientes variables:

- El nivel de confianza (grado o nivel de seguridad) o riesgo que aceptamos de equivocarnos al presentar nuestros resultados: lo que deseamos es que en otras muestras semejantes los resultados sean los mismos o muy parecidos. El nivel de confianza habitual es de $0.05(\alpha=0.05)$, que quiere decir que aceptamos un $5 \%$ de probabilidades de error al rechazar la Hipótesis Nula (de no diferencia). Se trata de minimizar el denominado error Tipo I (aceptamos pocas probabilidades de equivocarnos cuando afirmamos una diferencia o una relación).

- La varianza estimada en la población. Diversidad de opinión en la población que si la conociéramos (cuántos van a decir que sí y cuántos van a decir que no) no necesitaríamos hacer la encuesta. A mayor diversidad esperada, se necesita un mayor número de sujetos en la muestra. El error Tipo I (decir sí cuando habría que decir que no hay diferencia, relación, etc.) es más serio que el error Tipo II (decir no cuando podríamos haber dicho que sí), de ahí la práctica generalizada de utilizar unos niveles de confianza muy estrictos, como son 0,05 ó 0,01, con el fin de tener muy pocas probabilidades de equivocarnos cuando afirmamos una diferencia. Si establecemos un nivel de significación muy estricto (un valor de $\alpha$ muy bajo) es muy improbable que cometamos el error Tipo I. Con un valor muy bajo de a podemos caer en el error Tipo II, es decir, que no rechacemos la Hipótesis Nula aunque sea falsa, debido al estricto nivel de confianza que nos hemos marcado. En la práctica hay que sopesar ambos tipos de error I y II. El minimizar el error Tipo I no significa que no tengamos que prestar atención al error Tipo II. 
- El margen de error que estamos dispuestos a aceptar. Se necesitarán muestras mayores si queremos que el margen de error o de oscilación de muestra a muestra de los resultados sea muy pequeño. El resultado exacto lo tendríamos si respondiera el $100 \%$ y la muestra coincidiera con la población. Solemos denominar tamaño del efecto. El término efecto no implica causalidad, sino simplemente el grado en que un fenómeno (diferencia, relación, etc.) está presente. Lo normal es buscar resultados (diferencias, relaciones,) estadísticamente significativos y no tanto pensar en qué magnitud podríamos estar interesados. La implicación de la magnitud en el tamaño de la muestra es obvia: cuando las diferencias son grandes, nos bastan pocos sujetos para detectarlas, pero cuando son muy pequeñas necesitamos muchos sujetos; si solamente nos interesan diferencias grandes, necesitaremos muchos menos sujetos.

El tamaño de la muestra será mayor según sea mayor el nivel de confianza y la varianza esperada en la población (numerador en la fórmula) y según sea menor el margen de error que estamos dispuestos a admitir (denominador en la fórmula).

En el caso de respuestas dicotómicas (tiene o no tiene Tablet) el margen de error viene expresado por la fórmula $n=\frac{z^{2} P(1-P)}{E^{2}}$ dónde:

- $\quad \mathrm{n}:$ Tamaño de la muestra.

- z: Número de unidades de desviación estándar de la distribución normal que producirá el grado de confianza que deseamos.

- P: Proporción de población que posee la característica de interés. La varianza en la distribución binomial viene dada por Px(1-P).

- E: error o máxima diferencia entre la población muestral y la proporción de la población que estamos dispuestos a aceptar en el nivel de confianza que señalamos. 
En nuestro caso consideramos:

- Un nivel de confianza del $95 \%(\alpha=0,05)$ corresponde a $Z=1,96$ sigmas o errores típicos.

- Como la varianza de la población P la desconocemos, ponemos la varianza mayor posible ya que a mayor varianza hará falta una muestra mayor. $\mathrm{P}=$ proporción de respuestas en una categoría $(1-P)$ = proporción de repuestas en la otra categoría. Este valor de $\mathrm{Px}(1-\mathrm{P})=0,25$, es válido para calcular el tamaño de la muestra, aun cuando las preguntas no sean dicotómicas.

- E: Error muestral (e). Es el margen de error que aceptamos. Aceptaremos un error del $5 \%$

$$
n=\frac{z^{2} P(1-P)}{E^{2}}=\frac{1,96^{2} \times 0,5 \times(1-0,5)}{0,05^{2}}=384,16 \Rightarrow 385
$$

En el caso de variables cuantitativas (tiempo dedicado a dormir) el margen de error viene expresado por la fórmula $n=\frac{z^{2} \sigma^{2}}{E^{2}}$ dónde:

- $\mathrm{n}$ : Tamaño de la muestra.

- z: Número de unidades de desviación estándar de la distribución normal que producirá el grado de confianza que deseamos.

- $\sigma$ : desviación típica estimada de la población para la variable medida.

- E: error o máxima diferencia entre la población muestral y la proporción de la población que estamos dispuestos a aceptar en el nivel de confianza que señalamos.

En nuestro caso este será el error a tener en cuenta en el caso de diferencias en el tiempo dedicado a las diferentes actividades. Suponiendo una desviación típica de 30 minutos (lo que supondría que en el intervalo de \pm 60 minutos estarían el $95 \%$ de los datos) y aceptando un error de 2 minutos:

$$
n=\frac{1,96^{2} 30^{2}}{2^{2}}=864,36 \Rightarrow 865
$$


Al ser esté tamaño mayor que el anterior será el que nos marca el tamaño de la muestra necesaria (865).

En nuestro caso nos sirve para valorar como adecuado el tamaño de la muestra que hemos tomado, ya que realizaron la encuesta 1.448 alumnos de 5 centros de secundaria de la provincia de Burgos. Además podemos garantizar que no hay sesgos muestrales por falta de respuesta, ya que todos los alumnos a los que se les pasó la encuesta la contestaron.

Este mayor tamaño de la muestra puede permitirnos resultados fiables en los casos de comparar más de dos grupos (con una ANOVA) o incluso si la desviación típica poblacional fuese más desfavorable.

El periodo de tiempo en el que se realizó la encuesta a los adolescentes está comprendido entre el 24 de Marzo de 2015 hasta el 30 de Mayo de 2015.

Para el análisis estadístico se ha utilizado el programa IBM SPSS Statistics versión 22.

En el siguiente capítulo de resultados comenzaremos por un análisis descriptivo de la muestra, que nos permitirá analizar con la suficiente objetividad y precisión las diferencias relevantes encontradas. 
Capítulo 4:

Resultados 



\section{Capítulo 4.- RESULTADOS}

Para la elaboración del análisis de los datos de esta tesis doctoral, como ya hemos anticipado en el capítulo anterior de metodología, hemos utilizado el programa estadístico IBM SPSS Statistics versión 22. Mediante este programa, hemos creado una base de datos que recoge todos los resultados obtenidos en las encuestas y que nos ha servido para realizar todos los análisis que hemos considerado necesarios.

\section{1.- ANÁLISIS DESCRIPTIVO}

\subsection{1.- Género}

Como puede apreciarse en la tabla 14, el género femenino predomina en nuestra muestra, puesto que el porcentaje de chicas $(53,2 \%)$ es ligeramente superior al de chicos $(46,8 \%)$.

\begin{tabular}{|l|cc|}
\cline { 2 - 3 } \multicolumn{1}{c|}{} & Frecuencia & Porcentaje \\
\hline Femenino & 771 & $53,2 \%$ \\
\hline Masculino & 677 & $46,8 \%$ \\
\hline Total & 1448 & $100,0 \%$ \\
\hline
\end{tabular}

Tabla 14: género

\subsection{2.- Edad}

Según los datos recogidos en la encuesta, el rango de edades de los estudiantes encuestados está comprendido entre los 12 y los 20 años, estando concentrado el grueso de las respuestas entre 12 y 17 años (tabla 15). 56 de los estudiantes encuestados tiene 18 años, 9 tiene 19 años y 1 de ellos 20 años. Debido al bajo número de muestras de adolescentes de 18, 19 y de 20 años y a que estos jóvenes ya son mayores de edad (con lo que esto implica a nivel de obligaciones y derechos que pueden afectar al control parental) hemos decidido marcar como perdidas las respuestas aportadas por los adolescentes de entre 18 y 20 años incluidos, y no vamos a considerarlas en los análisis de inferencia realizados posteriormente. 


\begin{tabular}{|l|cc|c|}
\cline { 2 - 4 } \multicolumn{1}{c|}{} & Frecuencia & Porcentaje & Porcentaje válido \\
\hline $\mathbf{1 2}$ & 201 & $13,9 \%$ & $14,5 \%$ \\
\hline 13 & 272 & $18,8 \%$ & $19,7 \%$ \\
\hline 14 & 244 & $16,9 \%$ & $17,7 \%$ \\
\hline 15 & 237 & $16,4 \%$ & $17,1 \%$ \\
\hline 16 & 241 & $16,6 \%$ & $17,4 \%$ \\
\hline Total & 187 & $12,9 \%$ & $13,5 \%$ \\
\hline 18 & 1382 & $95,4 \%$ & $100,0 \%$ \\
\hline 19 & 56 & $3,9 \%$ & \\
\hline $\mathbf{2 0}$ & 9 & $0,6 \%$ & \\
\hline Total & 1 & $0,1 \%$ & \\
\hline
\end{tabular}

Tabla 15: edad

\subsection{3.- Curso}

Se ha administrado esta encuesta a alumnos de todos los cursos impartidos en un centro de secundaria, es decir, desde 1 o de ESO hasta 20 de $\mathrm{BACH}$. En la tabla 16 se puede observar la frecuencia y el porcentaje de alumnos de cada uno de estos cursos que han respondido a nuestra encuesta. Aún con las dificultades encontradas para realizar las encuestas en los cursos superiores, principalmente $2 \stackrel{0}{ }$ de BACH (por la carga de trabajo que soportan los adolescentes durante el último año de bachiller), hemos conseguido obtener una muestra suficientemente significativa. El porcentaje mayor corresponde a alumnos de 1 을 de ESO y el porcentaje menor a alumnos de $2 \circ$ de $\mathrm{BACH}$.

\begin{tabular}{|l|cc|}
\cline { 2 - 3 } \multicolumn{1}{c|}{} & Frecuencia & Porcentaje \\
\hline 1 SO & 327 & $22,6 \%$ \\
\hline 20 ESO & 289 & $20,0 \%$ \\
\hline 3 ESO & 281 & $19,4 \%$ \\
\hline 4 ESO & 187 & $12,9 \%$ \\
\hline 1 BACH & 218 & $15,1 \%$ \\
\hline 20 BACH & 146 & $10,1 \%$ \\
\hline Total & 1448 & $100,0 \%$ \\
\hline
\end{tabular}

Tabla 16: curso 
En la tabla 17, se efectúa la relación entre la edad del adolescente y el curso académico que están cursando. Se puede ver en ella, el porcentaje de adolescentes que, por su edad, no están en el curso que les corresponde, principalmente porque han repetido algún año.

\begin{tabular}{|c|c|c|c|c|c|c|c|}
\hline & $1^{\circ}$ ESO & 20 ESO & 3 ESO & $4^{\circ} \mathrm{ESO}$ & 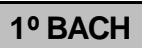 & $2^{\circ} \mathrm{BACH}$ & Total \\
\hline 12 & $61,5 \%$ & $0,0 \%$ & $0,0 \%$ & $0,0 \%$ & $0,0 \%$ & $0,0 \%$ & 201 \\
\hline 13 & $34,9 \%$ & $54,7 \%$ & $0,0 \%$ & $0,0 \%$ & $0,0 \%$ & $0,0 \%$ & 272 \\
\hline 14 & $3,7 \%$ & $37,4 \%$ & $43,8 \%$ & $0,5 \%$ & $0,0 \%$ & $0,0 \%$ & 244 \\
\hline 15 & $0,0 \%$ & $6,9 \%$ & $40,9 \%$ & $54,5 \%$ & $0,0 \%$ & $0,0 \%$ & 237 \\
\hline 16 & $0,0 \%$ & $1,0 \%$ & $12,5 \%$ & $38,0 \%$ & $60,6 \%$ & $0,0 \%$ & 241 \\
\hline 17 & $0,0 \%$ & $0,0 \%$ & $2,8 \%$ & $7,0 \%$ & $34,9 \%$ & $61,6 \%$ & 187 \\
\hline 18 & $0,0 \%$ & $0,0 \%$ & $0,0 \%$ & $0,0 \%$ & $4,6 \%$ & $31,5 \%$ & 56 \\
\hline 19 & $0,0 \%$ & $0,0 \%$ & $0,0 \%$ & $0,0 \%$ & $0,0 \%$ & $6,2 \%$ & 9 \\
\hline 20 & $0,0 \%$ & $0,0 \%$ & $0,0 \%$ & $0,0 \%$ & $0,0 \%$ & $0,7 \%$ & 1 \\
\hline Total & 327 & 289 & 281 & 187 & 218 & 146 & 1448 \\
\hline
\end{tabular}

Tabla 17: edad-curso

\subsection{4.- Nacionalidad}

La cuestión 3 de la encuesta, requiere a los adolescentes que indiquen cuál es su nacionalidad. Como puede apreciarse en la tabla 18, los adolescentes encuestados pertenecen a 18 nacionalidades diferentes. La mayoría de ellos (el 97,4\%) son de nacionalidad española. Las siguientes nacionalidades predominantes entre los encuestados son, por mayor frecuencia: rumana, moldava, brasileña, búlgara y ecuatoriana.

Con el objetivo de facilitar los posteriores análisis de los datos con respecto a la nacionalidad, decidimos crear una nueva variable que agrupe todos los casos de adolescentes encuestados de nacionalidad distinta a la española. Esta nueva variable agrupa todas las nacionalidades distintas a la española bajo la etiqueta "Extranjera". En el gráfico 9 podemos observar, por lo tanto, que el porcentaje de adolescentes de nacionalidad española de nuestra encuesta es de $97,58 \%$ frente a un $2,42 \%$ de adolescentes de nacionalidad extranjera. 


\begin{tabular}{|l|cc|}
\cline { 2 - 3 } \multicolumn{1}{c|}{} & Frecuencia & Porcentaje \\
\hline argelí & 1 & $0,1 \%$ \\
\hline brasileña & 3 & $0,2 \%$ \\
\hline búlgara & 3 & $0,2 \%$ \\
\hline camerunés & 1 & $0,1 \%$ \\
\hline colombiana & 2 & $0,1 \%$ \\
\hline cubana/alemana & 1 & $0,1 \%$ \\
\hline ecuatoriana & 3 & $0,2 \%$ \\
\hline española & 1413 & $97,6 \%$ \\
\hline francesa & 1 & $0,1 \%$ \\
\hline hondureño & 1 & $0,1 \%$ \\
\hline marroquí & 1 & $0,1 \%$ \\
\hline moldava & 4 & $0,3 \%$ \\
\hline pakistaní & 1 & $0,1 \%$ \\
\hline rumana & 10 & $0,7 \%$ \\
\hline rusa & 1 & $0,1 \%$ \\
\hline togolés & 1 & $0,1 \%$ \\
\hline ucrania & 1 & $0,1 \%$ \\
\hline Total & 1448 & $100,0 \%$ \\
\hline
\end{tabular}

Tabla 18: nacionalidad

\section{Porcentaje de alumnos por nacionalidad agrupada}

$2,42 \%$

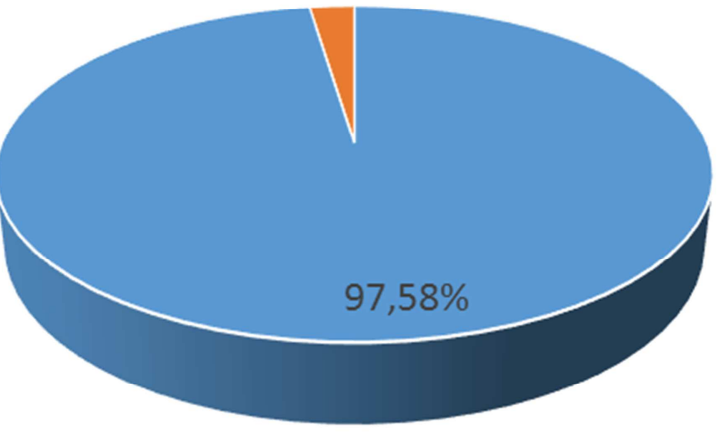

- Española

- Extranjera

Gráfico 9: nacional - extranjero 


\subsection{5.- Centro educativo}

Se ha realizado la encuesta en 5 centros de educación secundaria situados en la provincia de Burgos. La distribución de centros por su ubicación y tipo de centro puede verse en la tabla 19:

\begin{tabular}{|l|cc|}
\cline { 2 - 3 } \multicolumn{1}{c|}{} & Público/privado & Entorno \\
\hline Privado urbano 1 & privado & urbano \\
\hline Privado urbano 2 & privado & urbano \\
\hline Público urbano 1 & público & urbano \\
\hline Público urbano 2 & público & urbano \\
\hline Público rural & público & rural \\
\hline
\end{tabular}

Tabla 19: Clasificación de los centros

En conclusión, 4 centros en entorno urbano ( 2 públicos y 2 privados) y 1 centro en el entorno rural.

El gráfico 10 muestra el porcentaje de alumnos que ha cumplimentado la encuesta por cada uno de los centros educativos. Como se puede observar el porcentaje mayor de adolescentes corresponde al centro público urbano $1(48,2 \%)$, seguido del centro privado urbano $2(27,6 \%)$. El centro privado urbano 1 representa el $15 \%$ de la muestra. El 5,4\% corresponden adolescentes del centro público rural y el 3,9 al centro público urbano 2 (centro con menor representación).

\section{Porcentaje de encuestas respondidas por centro}

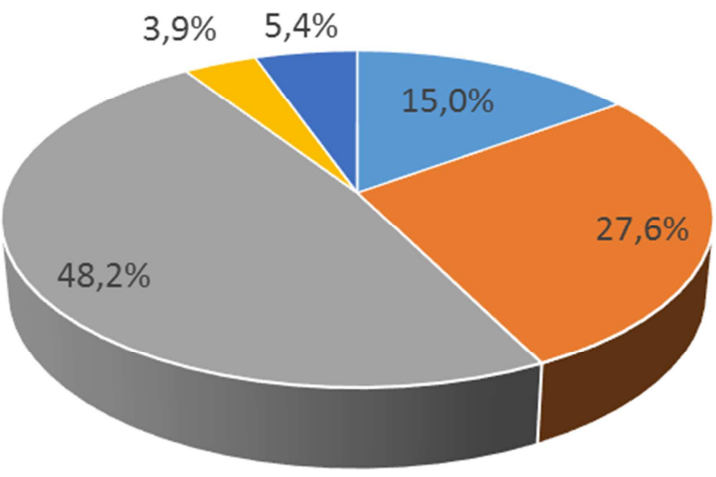

- Privado urbano 1

- Privado urbano 2

- Público urbano 1

- Público urbano 2

- Público rural

Gráfico 10: centro educativo 
Con el objetivo de obtener más información sobre los adolescentes encuestados de cada uno de los centros educativos, procedemos a analizar la composición de la muestra de cada centro en relación al género, curso y nacionalidad.

En la tabla cruzada 20 puede observarse que prácticamente existe paridad en los centros privado urbano 1 y público urbano 1 . Sin embargo, en el centro privado urbano 2 casi el $60 \%$ es alumnado femenino, mientras que en público rural y en público urbano 2, el porcentaje de alumnado masculino es superior al femenino.

\begin{tabular}{|l|cc|c|}
\cline { 2 - 4 } \multicolumn{1}{c|}{} & Femenino & Masculino & Total \\
\hline Privado urbano 1 & $50,7 \%$ & $49,3 \%$ & 217 \\
\hline Privado urbano 2 & $59,9 \%$ & $40,1 \%$ & 399 \\
\hline Público urbano 1 & $52,7 \%$ & $47,3 \%$ & 698 \\
\hline Público urbano 2 & $37,5 \%$ & $62,5 \%$ & 56 \\
\hline Público rural & $42,3 \%$ & $57,7 \%$ & 78 \\
\hline Total & 771 & 677 & 1448 \\
\hline
\end{tabular}

Tabla 20: Centro de estudios - Género

Según se puede apreciar en la tabla 21, el nivel de significación es inferior a 0,05, lo cual indica que sí existen diferencias significativas por género dependiendo del centro.

\begin{tabular}{|l|ccc|}
\cline { 2 - 4 } \multicolumn{1}{c|}{} & Valor & gl & $\begin{array}{c}\text { Sig. asintótica } \\
\text { (2 caras) }\end{array}$ \\
\hline Chi-cuadrado de Pearson & $17,068^{\mathrm{a}}$ & 4 & 0,002 \\
\hline
\end{tabular}

Tabla 21: chi-cuadrado Centro de estudios - Género

Del mismo modo, realizamos de nuevo una tabla cruzada para estudiar la distribución de los alumnos por centro y curso. Como puede observarse en la tabla 22, existe representación de todos los cursos en todos los centros (excepto para el centro público urbano 2 puesto que sólo se ha realizado la encuesta a alumnos de 30 ESO, 1으 y 2 은 $\mathrm{BACH})$. Por esta razón, estudiaremos de manera particular estos datos en los análisis posteriores. 


\begin{tabular}{|l|cccccc|c|}
\cline { 2 - 8 } \multicolumn{1}{c|}{} & $\mathbf{1 0}$ ESO & 20 ESO & 30 ESO & 40 ESO & 10 BACH & 20 BACH & Total \\
\hline Privado urbano 1 & $27,2 \%$ & $20,3 \%$ & $21,7 \%$ & $9,7 \%$ & $11,5 \%$ & $9,7 \%$ & 217 \\
\hline Privado urbano 2 & $26,3 \%$ & $20,1 \%$ & $13,5 \%$ & $16,0 \%$ & $10,0 \%$ & $14,0 \%$ & 399 \\
\hline Público urbano 1 & $22,2 \%$ & $20,9 \%$ & $20,5 \%$ & $13,2 \%$ & $17,0 \%$ & $6,2 \%$ & 698 \\
\hline Público urbano 2 & $0,0 \%$ & $0,0 \%$ & $37,5 \%$ & $0,0 \%$ & $44,6 \%$ & $17,9 \%$ & 56 \\
\hline Público rural & $10,3 \%$ & $24,4 \%$ & $20,5 \%$ & $12,8 \%$ & $11,5 \%$ & $20,5 \%$ & 78 \\
\hline Total & 327 & 289 & 281 & 187 & 218 & 146 & 1448 \\
\hline
\end{tabular}

Tabla 22: centro de estudios - curso

Según se puede apreciar en la tabla 23 , el factor de significación es de 0,000 por lo que se puede afirmar que el curso sí define diferencias significativas con respecto al centro educativo.

\begin{tabular}{|l|ccc|}
\cline { 2 - 4 } \multicolumn{1}{c|}{} & Valor & gl & $\begin{array}{c}\text { Sig. asintótica } \\
\text { (2 caras) }\end{array}$ \\
\hline Chi-cuadrado de Pearson & 136,523 & 20 & 0,000 \\
\hline
\end{tabular}

Tabla 23: chi-cuadrado centro de estudios - curso

A continuación, analizamos el número de estudiantes de nacionalidad extranjera que ha cumplimentado la encuesta por centro educativo, con el objetivo de observar si la nacionalidad es un factor representativo en alguno de los centros. Para ello, la tabla 24 muestra una imagen del porcentaje de alumnos extranjeros en relación al total de alumnos que ha participado en la encuesta por centro educativo. La primera conclusión que podemos obtener es que el porcentaje de adolescentes extranjeros en los centros públicos es mayor (entre 3,2 y $6,4 \%$ ) que en los privados (el máximo es 1,3\%). Del mismo modo observamos que el porcentaje mayor de adolescentes extranjeros lo encontramos en el entorno rural.

\begin{tabular}{|l|cc|c|}
\cline { 2 - 4 } \multicolumn{1}{c|}{} & Española & Extranjera & Total \\
\hline Privado urbano 1 & $99,5 \%$ & $0,5 \%$ & 217 \\
\hline Privado urbano 2 & $98,7 \%$ & $1,3 \%$ & 399 \\
\hline Público urbano 1 & $96,8 \%$ & $3,2 \%$ & 698 \\
\hline Público urbano 2 & $96,4 \%$ & $3,6 \%$ & 56 \\
\hline Público rural & $93,6 \%$ & $6,4 \%$ & 78 \\
\hline Total & 1413 & 35 & 1448 \\
\hline
\end{tabular}

Tabla 24: centro de estudios - nacionalidad 
Tras calcular la chi-cuadrado observamos que el valor obtenido para el nivel de significaciones es de 0,011 .

\subsection{6.- Entorno familiar:}

Analizamos, mediante las respuestas obtenidas en la pregunta 4, el número de hermanos que tienen los adolescentes encuestados. La pregunta está formulada de la siguiente manera: "número de hermanos (inclúyete)". La respuesta es una casilla en blanco donde el alumno encuestado escribe el número de hermanos que tiene, incluyéndose a sí mismo. Como ejemplo, los adolescentes que han respondido 1 son hijos únicos.

Como puede apreciarse en el gráfico 11 , más de la mitad de los adolescentes $(61,1 \%)$ manifiesta tener 1 hermano.

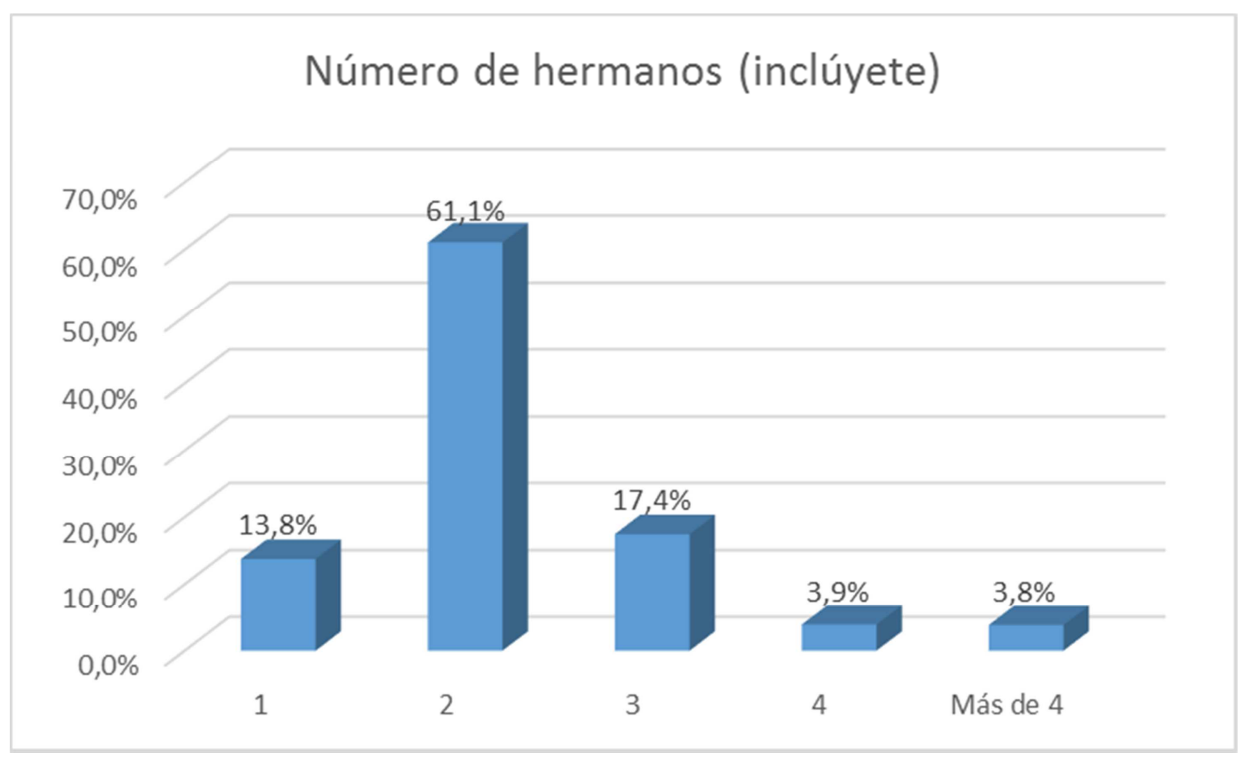

Gráfico 11: número de hermanos

Las opciones en cuanto a quien ejerce la tutela del adolescente pueden ser: padre, madre, ambos, tutor u otros. Como podemos observar en el gráfico 12 , de los 1421 adolescentes que han respondido a esta pregunta, el 86,4\% afirma vivir con su padre y su madre (ambos a partir de ahora). El 11,0\% vive con su madre y el $1,7 \%$ con su padre. 


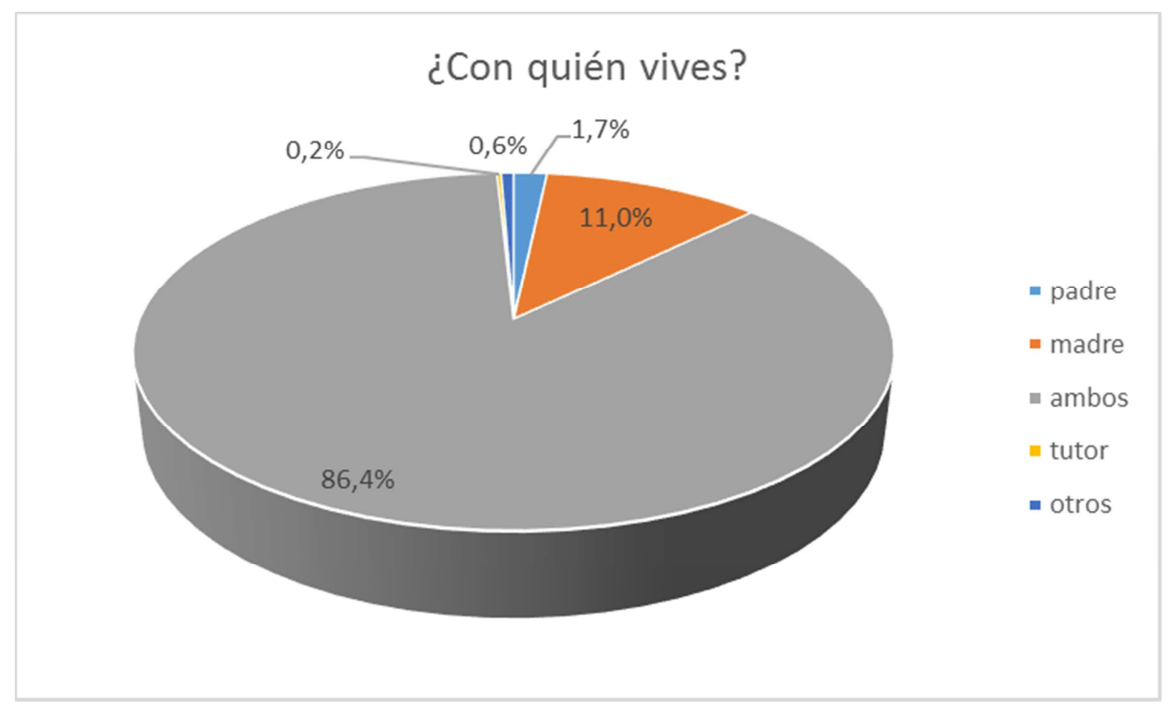

Gráfico 12: personas con las que vive el adolescente.

El gráfico 13 muestra que el 44,4\% de los adolescentes está acompañado por las tardes exclusivamente por su madre, por lo que podemos afirmar que la figura de la madre como responsable del cuidado del adolescente sigue siendo importante. Sin embargo, el $36,5 \%$ de ellos afirman pasar las tardes acompañados por ambos. Menos del 10\% está acompañado por las tardes exclusivamente de la figura paterna. Cerca del $7 \%$ de los adolescentes burgaleses encuestados afirma pasar las tardes sin la compañía de un adulto.

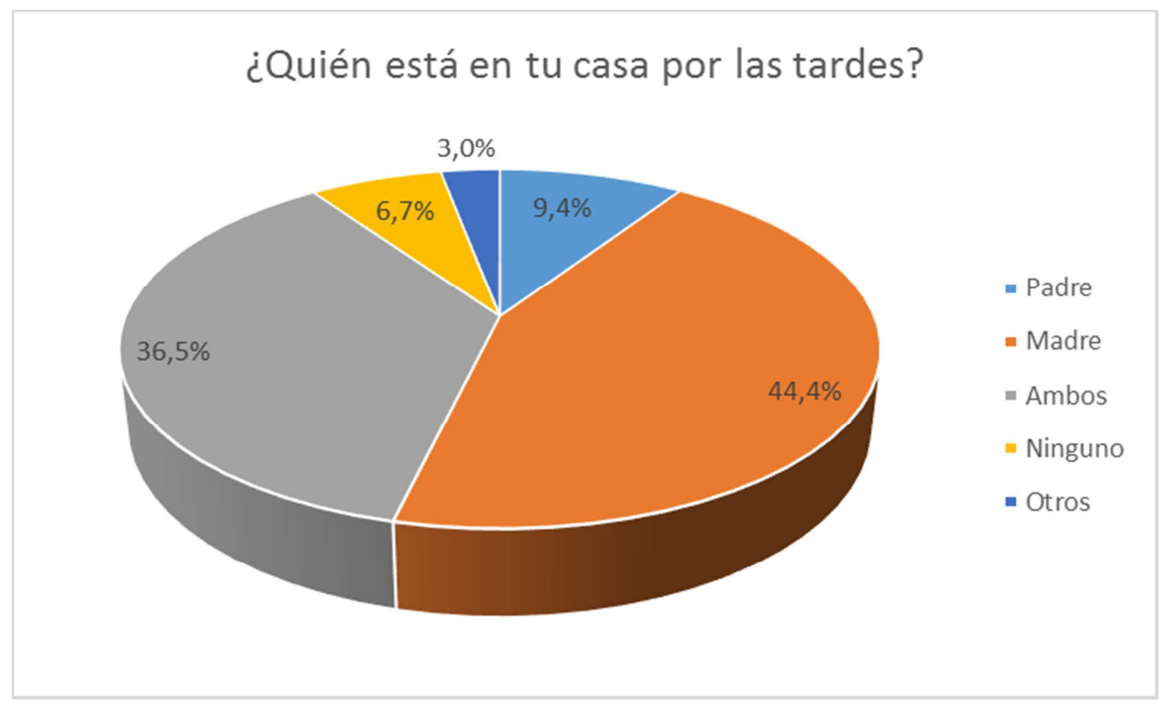

Gráfico 13: personas que acompañan al adolescente por las tardes 
El gráfico 14 muestra el nivel de estudios que han alcanzado tanto el padre como la madre. Como se puede observar, el porcentaje de adolescentes cuyo padre ha cursado estudios básicos y de formación profesional es superior al porcentaje de adolescentes cuyas madres han alcanzado este nivel de estudios. Sin embargo, el porcentaje de adolescentes con madres universitarias es mayor que el de adolescentes con padres con estudios superiores.

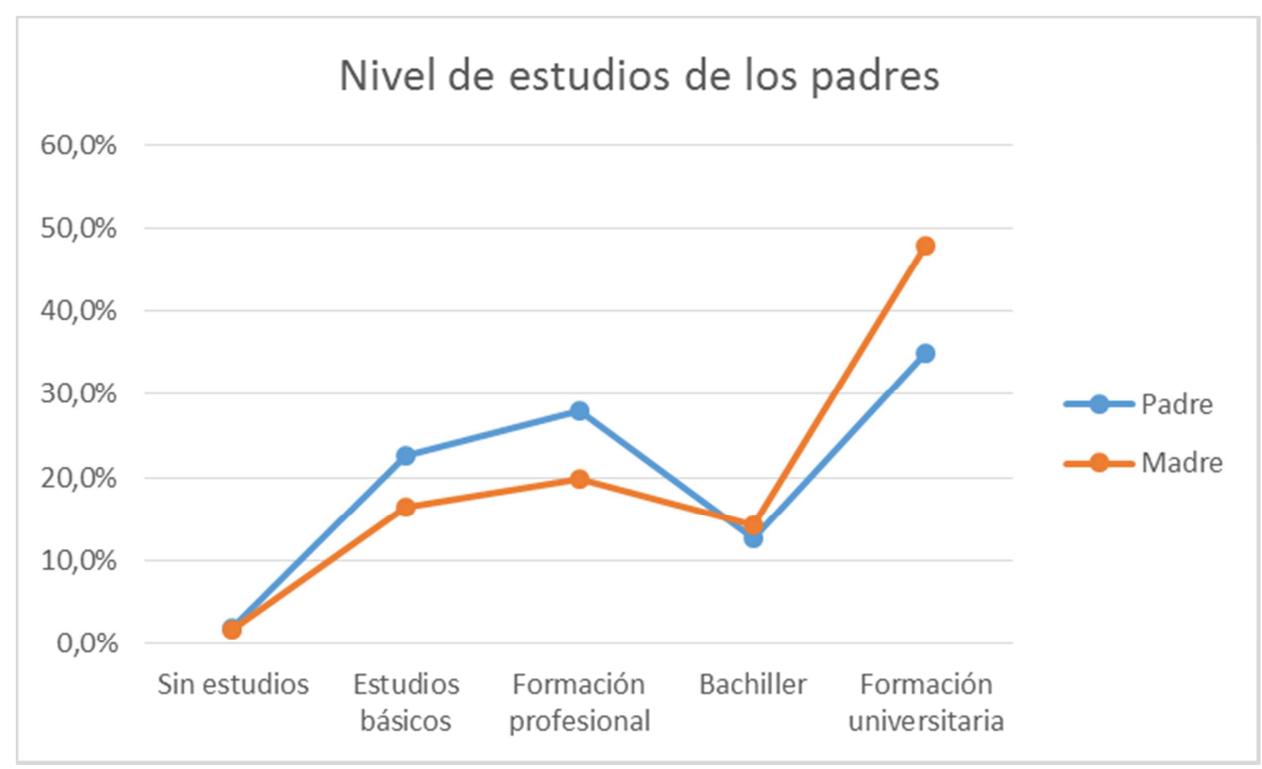

Gráfico 14: nivel de estudios del padre y de la madre

\subsection{7.- Pareja}

La cuestión 9 de la encuesta pregunta directamente al alumno si tiene pareja en el momento en que responde a la misma. Nos interesa estudiar si este factor puede afectar al uso del tiempo del adolescente y también a su relación con las nuevas tecnologías.

Como muestra el gráfico 15 , el $80,2 \%$ de los adolescentes afirman no tener pareja actualmente mientras que el $14,2 \%$ de la muestra manifiesta sí tenerla. El 5,7\% de los adolescentes no ha contestado a esta pregunta. 


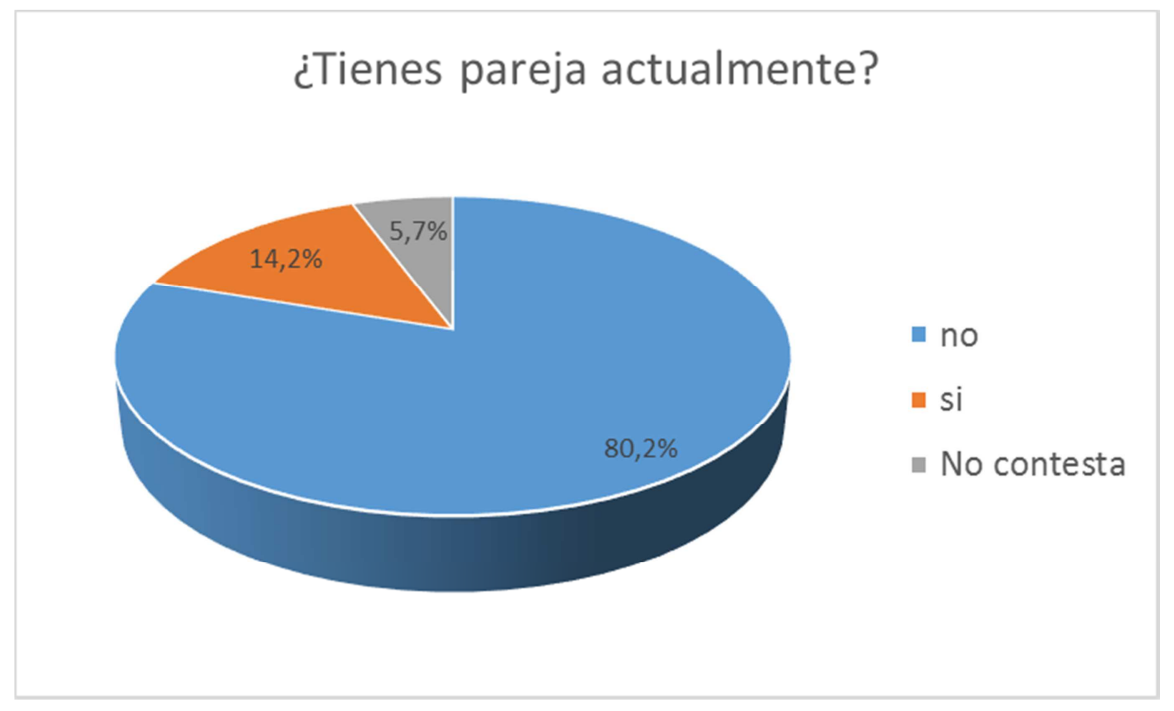

Gráfico 15: adolescentes con pareja

Si analizamos esta cuestión con respecto al género mediante una tabla cruzada, podemos observar que aparentemente el porcentaje de chicas que afirma tener pareja es superior al de chicos, aproximadamente un $16,1 \%$ con respecto a un $13,8 \%$ (tabla 25).

\begin{tabular}{|l|cc|c|}
\cline { 2 - 4 } \multicolumn{1}{c|}{} & No & \multicolumn{1}{c}{ Si } & Total \\
\hline Femenino & $83,9 \%$ & $16,1 \%$ & 728 \\
\hline Masculino & $86,2 \%$ & $13,8 \%$ & 638 \\
\hline Total & 1161 & 205 & 1366 \\
\hline
\end{tabular}

Tabla 25: adolescentes con pareja por género

Si calculamos la chi-cuadrado de la tabla cruzada anterior, podemos observar que el valor del nivel de significación que obtenido es del 0,239. Es por esta razón que no podemos afirmar que el género del adolescente afecte en el hecho de tener pareja (tabla 26).

\begin{tabular}{|l|ccc|}
\cline { 2 - 4 } \multicolumn{1}{c|}{} & Valor & gl & $\begin{array}{c}\text { Sig. asintótica } \\
\text { (2 caras) }\end{array}$ \\
\hline Chi-cuadrado de Pearson & 1,384 & 1 & 0,239 \\
\hline
\end{tabular}

Tabla 26: chi-cuadrado adolescentes con pareja por género 
En la tabla 27 mostramos el porcentaje de adolescentes que tiene pareja en relación a la edad. Los resultados ratifican las hipótesis iniciales y la tabla muestra que el porcentaje de adolescentes burgaleses encuestados que tiene pareja crece con la edad. El porcentaje mayor lo alcanzan los adolescentes de 17 años, donde más de 1 de cada 4 adolescentes encuestados afirma tener pareja en el momento en el que hemos realizado la encuesta.

\begin{tabular}{|l|cc|c|}
\cline { 2 - 4 } \multicolumn{1}{c|}{} & No & Si & Total \\
\hline 12 & $96,4 \%$ & $3,6 \%$ & 192 \\
\hline 13 & $92,0 \%$ & $8,0 \%$ & 251 \\
\hline 14 & $87,3 \%$ & $12,7 \%$ & 237 \\
\hline 15 & $85,0 \%$ & $15,0 \%$ & 214 \\
\hline 16 & $77,3 \%$ & $22,7 \%$ & 229 \\
\hline Total & $73,2 \%$ & $26,8 \%$ & 179 \\
\hline
\end{tabular}

Tabla 27: adolescentes con pareja por edad

El valor del nivel de significación es menor que 0,05 por lo que se puede afirmar que la edad sí marca diferencias significativas con respecto al hecho de que el adolescente tenga pareja (tabla 28).

\begin{tabular}{|l|ccc|}
\cline { 2 - 4 } \multicolumn{1}{c|}{} & Valor & gl & $\begin{array}{c}\text { Sig. asintótica } \\
\text { (2 caras) }\end{array}$ \\
\hline Chi-cuadrado de Pearson & $61,852^{\mathrm{a}}$ & 5 & 0,000 \\
\hline
\end{tabular}

Tabla 28: chi-cuadrado pareja por edad

Una vez analizadas las características de nuestra muestra en relación a los factores anteriormente descritos, proseguimos con el estudio adentrándonos, en el siguiente punto, en la investigación sobre el uso del tiempo de los adolescentes burgaleses encuestados. 


\section{2.- ANÁLISIS DEL USO DEL TIEMPO DE LOS ADOLESCENTES:}

A continuación, nos adentramos en el estudio del uso del tiempo de los adolescentes. La parte de la encuesta destinada a recoger información referida a este tema, corresponde al segundo bloque de cuestione. Esta parte comprende las preguntas de la 10 a la 15 incluidas y se puede dividir en 3 grupos:

i. Preguntas 10, 11 y 12: destinadas a obtener información sobre la hora a la que se acostaron y durmieron los adolescentes la noche antes de rellenar la encuesta y la hora a la que se han levantado el día que hacen la encuesta.

ii. Preguntas 13 y 14: solicitan al adolescente información con respecto a si duerme la siesta y/o si se encuentra cansado.

iii. Pregunta 15: pregunta cuántas horas y minutos dedican los adolescentes a realizar las diferentes actividades, tanto entre semana (S), como durante el fin de semana (F). Las actividades por las que se les preguntan son las siguientes:

$\begin{array}{ll}\text { - Dormir } & \text { - Consolas } \\ \text { - Asistir a clase } & \text { - Deporte } \\ \text { - Actividades extraescolares } & \text { - Trabajo doméstico } \\ \text { - Estudio } & \text { - Trabajo remunerado } \\ \text { - Lectura } & \text { - Higiene personal } \\ \text { - Redes sociales } & \text { - Alimentación } \\ \text { - Internet (no redes) } & \text { - Salir con amigos } \\ \text { - TV } & \text { - Desplazamientos } \\ \text { - Hablar por teléfono } & \end{array}$

Al realizar el primer análisis de los datos, podemos observar que existen valores que precisan un análisis. Como ejemplo nombraremos los resultados que indican que el tiempo dedicado por los adolescentes a realizar cierta actividad es superior a 24 horas. Con el fin de evitar que estos datos extremos puedan sesgar los resultados e influir en la 
media y en el resto de los estadísticos, hemos tomado la decisión de eliminarlos de la muestra y considerarles como perdidos. La regla que hemos seguido para eliminar estos datos ha sido considerar el $2,5 \%$ de los valores extremos superiores y el $2,5 \%$ de los valores extremos inferiores de cada una de las actividades. De esta forma, eliminamos de la muestra el $5 \%$ de los valores extremos. Puesto que nuestra muestra consta de 1448 casos, hemos tomado la decisión de eliminar los 72 resultados de los extremos (36 datos superiores y 36 datos inferiores) de cada actividad. Sin embargo, observamos ciertos casos que nos han exigido realizar una reflexión adicional para tomar otras medidas:

- En algunas variables existen puntos de acumulación (varias respuestas de adolescentes que coinciden en el mismo valor) y por esto tomamos la decisión de no eliminar los 36 datos extremos correspondientes.

- En otros casos, por ejemplo en la variable "tiempo dedicado a realizar actividades extraescolares", no podemos eliminar ningún resultado que indique 00:00, aunque sea el extremo inferior puesto que puede darse la situación de que el adolescente no invierta nada de tiempo en realizar actividades extraescolares, y por esta razón el tiempo sea 0:00. De hecho, el volumen de datos con la misma cantidad revela que es un punto de acumulación.

Por lo tanto, no siempre hemos eliminado los 36 resultados superiores y los 36 inferiores. En la tabla 29, podemos observar el número de resultados que hemos suprimido de la base de datos, tanto por la parte superior como por la parte inferior de la misma.

Una vez depurados los datos de la base de datos en SPSS, procedemos a realizar el análisis del uso del tiempo. 


\begin{tabular}{|c|c|c|c|}
\hline Horas que dedicas a... & $\begin{array}{c}\text { № eliminados } \\
\text { extremo inferior }\end{array}$ & $\begin{array}{c}\text { № eliminados } \\
\text { extremo superior }\end{array}$ & $\begin{array}{c}\text { Intervalo de valores } \\
\text { aceptados }\end{array}$ \\
\hline Dormir S & 36 & 16 (p.a.) & de 5:30 a 10:00 (p.a.) \\
\hline Dormir F & 36 & 35 (p.a.) & de 5:00 a 12:00 (p.a.) \\
\hline Asistir a clase $\mathrm{S}$ & 21 (р.a.) & 16 (р.a.) & de 5:30 (p.a.) a 7:00 (p.a.) \\
\hline Asistir a clase F & 0 (p.a.) & 9 & de 0:00 (p.a.) a 0:00 \\
\hline Actividades extraesc. S & 0 (p.a.) & 36 & de 0:00 (p.a.) a 7:00 \\
\hline Actividades extraesc. F & 0 (p.a.) & 36 & de 0:00 (p.a.) a 4:00 \\
\hline Estudio S & 0 (p.a.) & 36 & de 0:00 (p.a.) a 7:00 \\
\hline Estudio F & 0 (p.a.) & 15 & de 0:00 a 8:00 (p.a.) \\
\hline Whatsapp S & 0 (p.a.) & 36 & de $0: 00$ a $11: 00$ \\
\hline Whatsapp F & 0 (p.a.) & 36 & de 0:00 a 14:00 \\
\hline Redes sociales S & 0 (p.a.) & 36 & de $0: 00$ a 9:00 \\
\hline Redes sociales $F$ & 0 (p.a.) & 36 & de 0:00 a 12:00 \\
\hline Internet S & 0 (p.a.) & 36 & de $0: 00$ a 5:00 \\
\hline Internet F & 0 (p.a.) & 36 & de $0: 00$ a $6: 00$ \\
\hline Videojuegos/consolas S & 0 (p.a.) & 9 (p.a.) & de 0:00 a 7:00 (p.a.) \\
\hline Videojuegos/consolas F & 0 (p.a.) & 15 (p.a.) & de 0:00 a 8:00 (p.a.) \\
\hline Televisión S & 0 (p.a.) & 19 (p.a.) & de 0:00 a 7:00 (p.a.) \\
\hline Televisión F & 0 (p.a.) & 19 (p.a.) & de 0:00 a 8:00 (p.a.) \\
\hline Teléfono S & 0 (p.a.) & 8 (p.a.) & de 0:00 a 5:00 (p.a.) \\
\hline Teléfono F & 0 (p.a.) & 8 (p.a.) & de 0:00 a 5:00 (p.a.) \\
\hline Deporte S & 0 (p.a.) & 36 & de $0: 00$ a $6: 40$ \\
\hline Deporte F & 0 (p.a.) & 36 & de 0:00 a 5:00 \\
\hline Trabajo doméstico S & 0 (p.a.) & 17 (p.a.) & de 0:00 a 3:30 (p.a.) \\
\hline Trabajo doméstico F & 0 (p.a.) & 11 (p.a.) & de 0:00 a 4:00 (p.a.) \\
\hline Trabajo remunerado S & 0 (p.a.) & 0 (p.a.) & de $0: 00$ a $5: 00$ \\
\hline Trabajo remunerado $\mathrm{F}$ & 0 (p.a.) & 0 (p.a.) & de $0: 00$ a $9: 30$ \\
\hline Lectura S & 0 (p.a.) & 36 & de $0: 00$ a $4: 00$ \\
\hline Lectura F & 0 & 8 (p.a.) & de 0:00 a 5:00 (p.a.) \\
\hline Higiene personal S & 36 & 28 (p.a.) & de 0:05 a 5:00 (p.a.) \\
\hline Higiene personal F & 36 & 20 (p.a.) & de 0:00 a 5:00 (p.a.) \\
\hline Alimentación S & 36 & 36 & de $0: 15$ a $6: 00$ \\
\hline Alimentación F & 36 & 36 & de $0: 00$ a 5:00 \\
\hline Amigos S & 0 (p.a.) & 36 & de 0:00 a 5:02 \\
\hline Amigos F & 0 (p.a.) & 16 (p.a.) & de 0:00 a 10:00 (p.a.) \\
\hline Desplazamientos S & 0 (p.a.) & 36 & de $0: 00$ a 5:00 \\
\hline Desplazamientos F & 0 (p.a.) & 33 (p.a.) & de 0:00 a 5:00 (p.a.) \\
\hline Salir con pareja S & 0 (p.a.) & 15 (p.a.) & de 0:00 a 5:00 (p.a.) \\
\hline Salir con pareja F & 0 (p.a.) & 12 (p.a.) & de 0:00 a 6:00 (p.a.) \\
\hline
\end{tabular}

Tabla 29: Número de valores extremos superiores e inferiores eliminados (p.a.: punto de acumulación) 
Para comenzar, realizaremos el análisis de las primeras cuestiones de este bloque tratando de obtener información sobre la hora media a la que los adolescentes se acostaron y durmieron el día previo a la cumplimentación de esta encuesta y la hora a la que se habían levantado dicho día (tabla 30).

\begin{tabular}{|l|ccccc|}
\cline { 2 - 6 } \multicolumn{1}{c|}{} & N & Mínimo & Máximo & Media & $\begin{array}{c}\text { Desviación } \\
\text { estándar }\end{array}$ \\
\hline ¿ A que hora te acostaste ayer $?$ & 1416 & $19: 57$ & $4: 00(+1)$ & $23: 25$ & $0: 59$ \\
\hline ¿A qué hora te dormiste ayer? & 1405 & $20: 05$ & $5: 00(+1)$ & $23: 56$ & $1: 03$ \\
\hline ¿ A qué hora te levantaste hoy? & 1407 & $4: 30$ & $9: 30$ & $7: 20$ & $0: 27$ \\
\hline
\end{tabular}

Tabla 30: hora de acostarse, dormirse y levantarse

Los adolescentes, se acostaron de media, el día previo a la cumplimentación de la encuesta a las 23:25. La hora, sin embargo, a la que manifiestan haberse dormido es a las 23:56, lo cual quiere decir que tardaron 31 minutos en dormirse. Los adolescentes se levantaron de media a las 7:20.

La tabla 31 muestra las medias de cada una de las actividades segmentadas por género. Como se puede observar, la hora de acostarse y de dormirse es prácticamente la misma por género. De hecho, el nivel de significación pone de manifiesto que no se puede asegurar que existan diferencias significativas. Sin embargo, se puede apreciar en la tabla que existen diferencias significativas en la hora de levantarse por género, puesto que el nivel de significación es de 0,000, valor inferior a 0,05 (sombreado en rojo).

\begin{tabular}{|l|ccc|}
\cline { 2 - 4 } \multicolumn{1}{c|}{} & Femenino & Masculino & Sig. (bilateral) \\
\hline ¿ A que hora te acostaste ayer ? & $23: 25$ & $23: 26$ & 0,734 \\
\hline ¿A qué hora te dormiste ayer? & $23: 57$ & $23: 54$ & 0,305 \\
\hline ¿ A qué hora te levantaste hoy? & $7: 18$ & $7: 23$ & 0,000 \\
\hline
\end{tabular}

Tabla 31: hora de acostarse, dormirse y levantarse por género

A continuación, analizaremos los principales datos estadísticos de cada una de las actividades en las que los adolescentes invierten su tiempo. Para ello, realizaremos un análisis de frecuencias en SPSS solicitando que muestre el número de valores válidos y perdidos, la media, la desviación típica, el mínimo y el máximo (tabla 32). 
2a PARTE

Capítulo 4.- Resultados

\begin{tabular}{|c|c|c|c|c|c|c|}
\hline & $\mathbf{N}$ & Perdidos & Mínimo & Máximo & Media & $\begin{array}{l}\text { Desviación } \\
\text { estándar }\end{array}$ \\
\hline Dormir S & 1342 & 106 & $5: 30$ & $10: 00$ & $7: 44$ & $0: 53$ \\
\hline Dormir F & 1293 & 155 & 5:00 & $12: 00$ & $9: 33$ & $1: 15$ \\
\hline Asistir a clase $\mathrm{S}$ & 1351 & 97 & $5: 30$ & $7: 00$ & $6: 08$ & $0: 14$ \\
\hline Asistir a clase $\mathrm{F}$ & 1324 & 124 & $0: 00$ & $0: 00$ & $0: 00$ & $0: 00$ \\
\hline Actividades extraescolares $\mathrm{S}$ & 1093 & 355 & $0: 00$ & 7:00 & $1: 48$ & $1: 30$ \\
\hline Actividades extraescolares $\mathrm{F}$ & 1052 & 396 & $0: 00$ & $4: 00$ & $0: 41$ & $0: 57$ \\
\hline Estudio S & 1348 & 100 & $0: 00$ & 7:00 & $2: 23$ & $1: 20$ \\
\hline Estudio F & 1339 & 109 & $0: 00$ & $8: 00$ & $2: 31$ & $1: 46$ \\
\hline Whatsapp S & 1325 & 123 & $0: 00$ & $11: 00$ & $1: 47$ & $1: 50$ \\
\hline Whatsapp F & 1299 & 149 & $0: 00$ & $14: 00$ & $2: 45$ & $2: 28$ \\
\hline Redes sociales S & 1326 & 122 & $0: 00$ & 9:00 & $1: 05$ & $1: 20$ \\
\hline Redes sociales F & 1290 & 158 & $0: 00$ & $12: 00$ & $1: 36$ & $1: 47$ \\
\hline Internet S & 1311 & 137 & $0: 00$ & $5: 00$ & $0: 53$ & $0: 54$ \\
\hline Internet F & 1273 & 175 & $0: 00$ & $6: 00$ & $1: 15$ & $1: 15$ \\
\hline Videojuegos/consolas S & 1339 & 109 & $0: 00$ & $7: 00$ & $0: 28$ & $0: 58$ \\
\hline Videojuegos/consolas F & 1310 & 138 & $0: 00$ & $8: 00$ & $1: 01$ & $1: 28$ \\
\hline Televisión S & 1352 & 96 & $0: 00$ & $7: 00$ & $1: 25$ & $1: 14$ \\
\hline Televisión F & 1317 & 131 & $0: 00$ & $8: 00$ & $2: 06$ & $1: 35$ \\
\hline Teléfono S & 1232 & 216 & $0: 00$ & $5: 00$ & $0: 21$ & $0: 39$ \\
\hline Teléfono F & 1201 & 247 & $0: 00$ & $5: 00$ & $0: 30$ & $0: 51$ \\
\hline Deporte S & 1334 & 114 & $0: 00$ & $6: 40$ & $1: 49$ & $1: 24$ \\
\hline Deporte F & 1309 & 139 & $0: 00$ & $5: 00$ & $1: 31$ & $1: 12$ \\
\hline Trabajo doméstico S & 1332 & 116 & $0: 00$ & $3: 30$ & $0: 38$ & $0: 38$ \\
\hline Trabajo doméstico F & 1317 & 131 & $0: 00$ & $4: 00$ & $0: 50$ & $0: 48$ \\
\hline Trabajo remunerado S & 1247 & 201 & $0: 00$ & $5: 00$ & $0: 06$ & $0: 32$ \\
\hline Trabajo remunerado $\mathrm{F}$ & 1233 & 215 & $0: 00$ & $8: 00$ & $0: 10$ & $0: 46$ \\
\hline Lectura S & 1309 & 139 & $0: 00$ & 4:00 & $0: 40$ & $0: 47$ \\
\hline Lectura F & 1313 & 135 & $0: 00$ & $5: 00$ & $0: 50$ & $1: 03$ \\
\hline Higiene personal S & 1288 & 160 & $0: 05$ & $5: 00$ & $1: 11$ & $1: 02$ \\
\hline Higiene personal F & 1271 & 177 & $0: 00$ & $5: 00$ & $1: 13$ & $0: 54$ \\
\hline Alimentación S & 1262 & 186 & $0: 15$ & $6: 00$ & $1: 44$ & $1: 10$ \\
\hline Alimentación F & 1235 & 213 & $0: 00$ & 5:00 & $1: 45$ & $1: 04$ \\
\hline Amigos S & 1306 & 142 & $0: 00$ & $5: 02$ & $1: 11$ & $1: 28$ \\
\hline Amigos F & 1327 & 121 & $0: 00$ & $10: 00$ & $3: 33$ & $2: 21$ \\
\hline Desplazamientos S & 1263 & 185 & $0: 00$ & $5: 00$ & $0: 45$ & $0: 47$ \\
\hline Desplazamientos F & 1234 & 214 & $0: 00$ & $5: 00$ & $0: 58$ & $1: 04$ \\
\hline Salir con pareja S & 1252 & 196 & $0: 00$ & $5: 00$ & $0: 12$ & $0: 43$ \\
\hline Salir con pareja F & 1228 & 220 & $0: 00$ & $6: 00$ & $0: 26$ & $1: 14$ \\
\hline
\end{tabular}

Tabla 32: Valores estadísticos principales del uso del tiempo por parte de los adolescentes 
Una vez mostrada en la tabla 32 una visión general del tiempo dedicado por los adolescentes a realizar cada una de las actividades, procedemos a realizar un análisis en detalle de las medias de tiempo dedicado a cada actividad, diferenciando entre días lectivos y fin de semana.

En el gráfico 16 puede verse reflejado el tiempo medio dedicado por los adolescentes a realizar las distintas actividades entre semana. La actividad a la que los adolescentes dedican más tiempo entre semana es a dormir (media de 7:44), seguida de asistir a clase (media de 6:08) y de estudiar (media de 3:33).

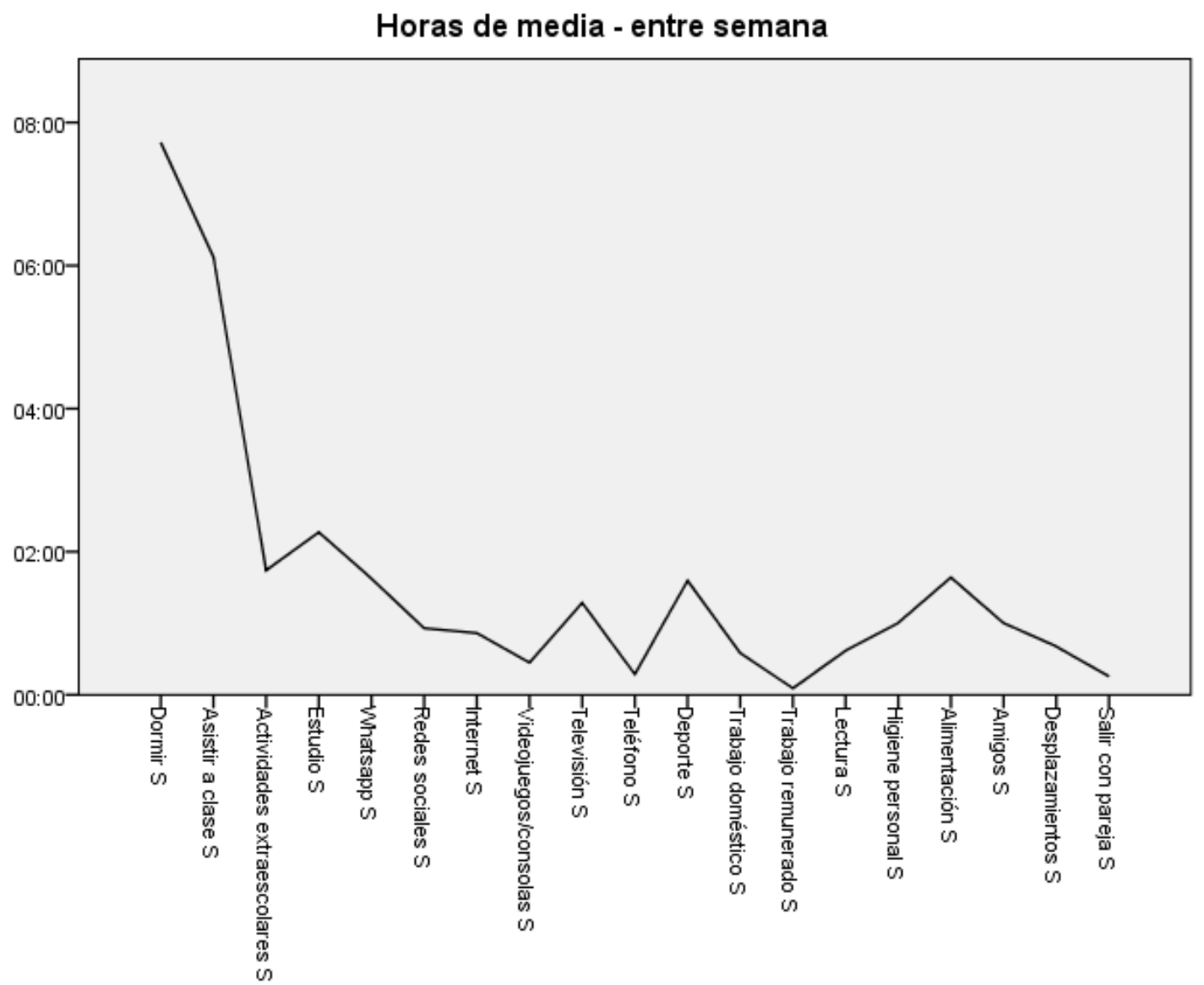

Gráfico 16: Media de tiempo dedicado por los adolescentes burgaleses entre semana

Del mismo modo, el gráfico 17 muestra la media de tiempo que dedican los adolescentes a realizar las diferentes actividades estudiadas durante el fin de semana. 
La actividad a la cual dedican más tiempo en fin de semana es a dormir (media de 9:33), seguida de salir con los amigos (media de 3:33) y de uso del WhatsApp (media de 2:45). Como dato relevante los adolescentes dedican durante el fin de semana más tiempo a estar conectados a WhatsApp (media de 2:45) que a estudiar (media de 2:31).

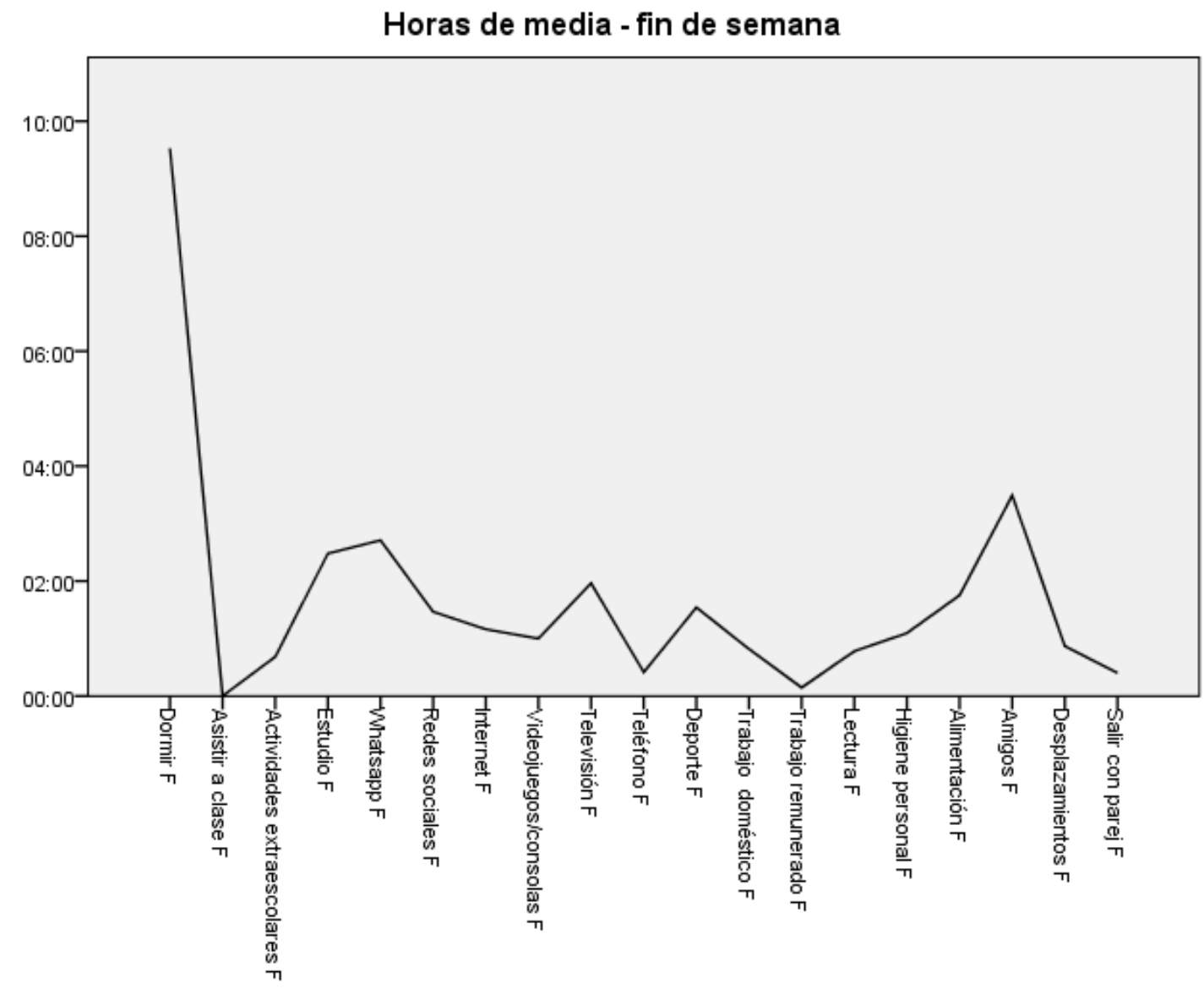

Gráfico 17: Media de tiempo dedicado por los adolescentes burgaleses el fin de semana

\section{Tiempo que tardan en dormirse:}

En esta encuesta, se ha preguntado a los adolescentes por el tiempo que duermen de media tanto entre semana como durante el fin de semana. También estudiamos el tiempo que los adolescentes tardan en dormirse.

Nuestra inquietud principal sobre este punto radica en investigar sobre el tiempo que los adolescentes tardan en dormirse para, en caso de ser relevante, proceder a analizar 
si existe relación entre este tiempo y la disponibilidad y uso de aparatos electrónicos tras haberse acostado.

Para ello, hemos incluido 2 cuestiones en nuestra encuesta relacionadas con este tema, que preguntan por la hora de acostarse (pregunta 10) y de dormirse (pregunta 11) del día previo a responder a esta encuesta. De esta manera, no preguntamos por la hora media a la que realizan estas 2 actividades, sino de un día en concreto.

Para analizar el tiempo que tardan en dormirse, hemos utilizado 2 variables de la base de datos de SPSS:

- ¿A qué hora te acostaste ayer? $\rightarrow$ HoraDeAcostarse

- ¿ ¿A qué hora te dormiste realmente ayer? $\rightarrow$ HoraDeDormiseAyer

Con las respuestas a estas 2 preguntas, hemos creado una nueva variable en SPSS denominada "tiempoendormirse" que recoge la diferencia de tiempo entre estas 2 cuestiones. Se han descartado los 10 valores inferiores obtenidos para esta variable, puesto que eran valores negativos que indicaban que el adolescente se había dormido antes de acostarse. Por la incoherencia de estos resultados, se ha procedido a eliminarlos.

Como puede observarse en la tabla 33, el tiempo medio que los adolescentes tardan en dormirse es de 30 minutos.

\begin{tabular}{|l|cccccc|}
\cline { 2 - 7 } \multicolumn{1}{c|}{} & Válido & Perdidos & Media & $\begin{array}{c}\text { Desviación } \\
\text { estándar }\end{array}$ & Mínimo & Máximo \\
\hline Tiempo en dormirse ayer & 1393 & 55 & $0: 30$ & $0: 33$ & $0: 00$ & $5: 00$ \\
\hline
\end{tabular}

Tabla 33: tiempo que tardan los adolescentes en dormirse

En este estudio del uso del tiempo, analizaremos por lo tanto esta nueva variable (tiempo en dormirse ayer) al mismo tiempo que el resto de actividades.

Una vez analizados los valores estadísticos generales del uso del tiempo de los adolescentes, vamos a proceder a realizar el estudio del uso del tiempo en función de los diferentes factores que hemos estudiado en la estadística descriptiva. 


\subsection{1.- Género:}

Para comenzar este análisis, realizaremos un primer estudio cuyo objetivo de analizar si existen diferencias significativas en el uso del tiempo por género. Para este fin, utilizaremos la prueba t-Student para muestras independientes. Consideramos que no se asumen varianzas iguales. El resultado de este cálculo puede verse en la tabla 34 . En la columna Sig. (bilateral) se puede observar, resaltado sobre fondo rojo, las actividades que presentan diferencias significativas por género, es decir, aquellas cuyo nivel de significación es inferior a 0,05.

- La gráfica 18 muestra que las chicas dedican más tiempo que los chicos a:

- Estudiar:

$\checkmark$ Entre semana: las chicas 19 minutos más de media

$\checkmark \quad$ Fin de semana: las chicas 38 minutos más de media

- WhatsApp:

$\checkmark$ Entre semana: las chicas 32 minutos más de media

$\checkmark \quad$ Fin de semana: las chicas 1:01 horas más de media

- Redes sociales:

$\checkmark$ Entre semana: las chicas 23 minutos más de media

$\checkmark$ Fin de semana: las chicas 35 minutos más de media

- Teléfono:

$\checkmark$ Entre semana: las chicas 12 minutos más de media

$\checkmark$ Fin de semana: las chicas 20 minutos más de media

- Trabajo doméstico:

$\checkmark$ Entre semana: las chicas 4 minutos más de media

$\checkmark \quad$ Fin de semana: las chicas 10 minutos más de media

- Leer:

$\checkmark$ Entre semana: las chicas 19 minutos más de media

$\checkmark \quad$ Fin de semana: las chicas 27 minutos más de media

- Higiene personal:

$\checkmark$ Entre semana: las chicas 17 minutos más de media

$\checkmark$ Fin de semana: las chicas 27 minutos más de media 


\section{2a PARTE}

Capítulo 4.- Resultados

- Tiempo en dormirse ayer:

$\checkmark$ Las chicas tardaron 4 minutos más en dormirse que los chicos.

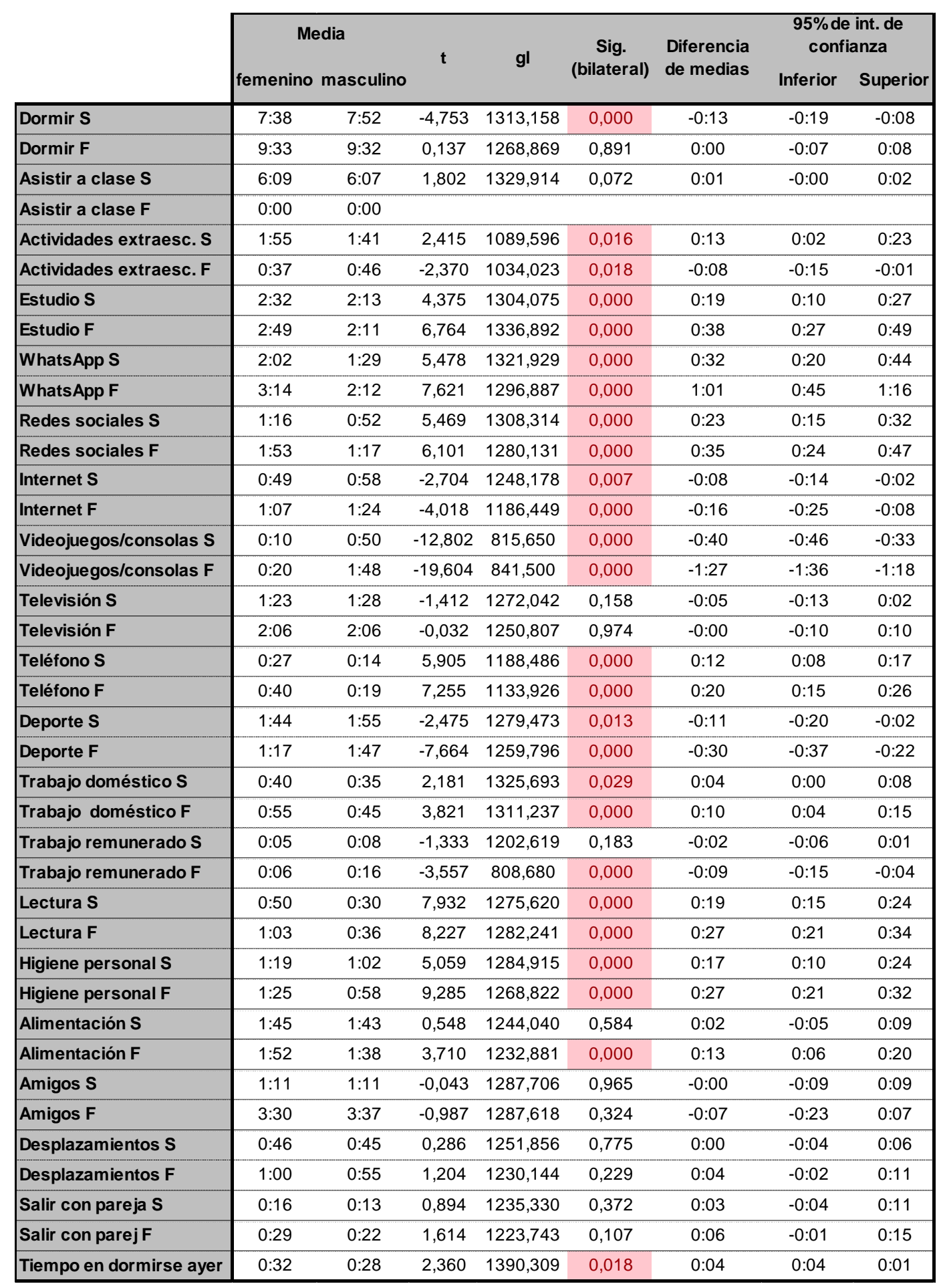

Tabla 34: Análisis t-Student del uso del tiempo con respecto al género 
El uso del tiempo de las actividades que se exponen a continuación, han mostrado la existencia de diferencias significativas por género:

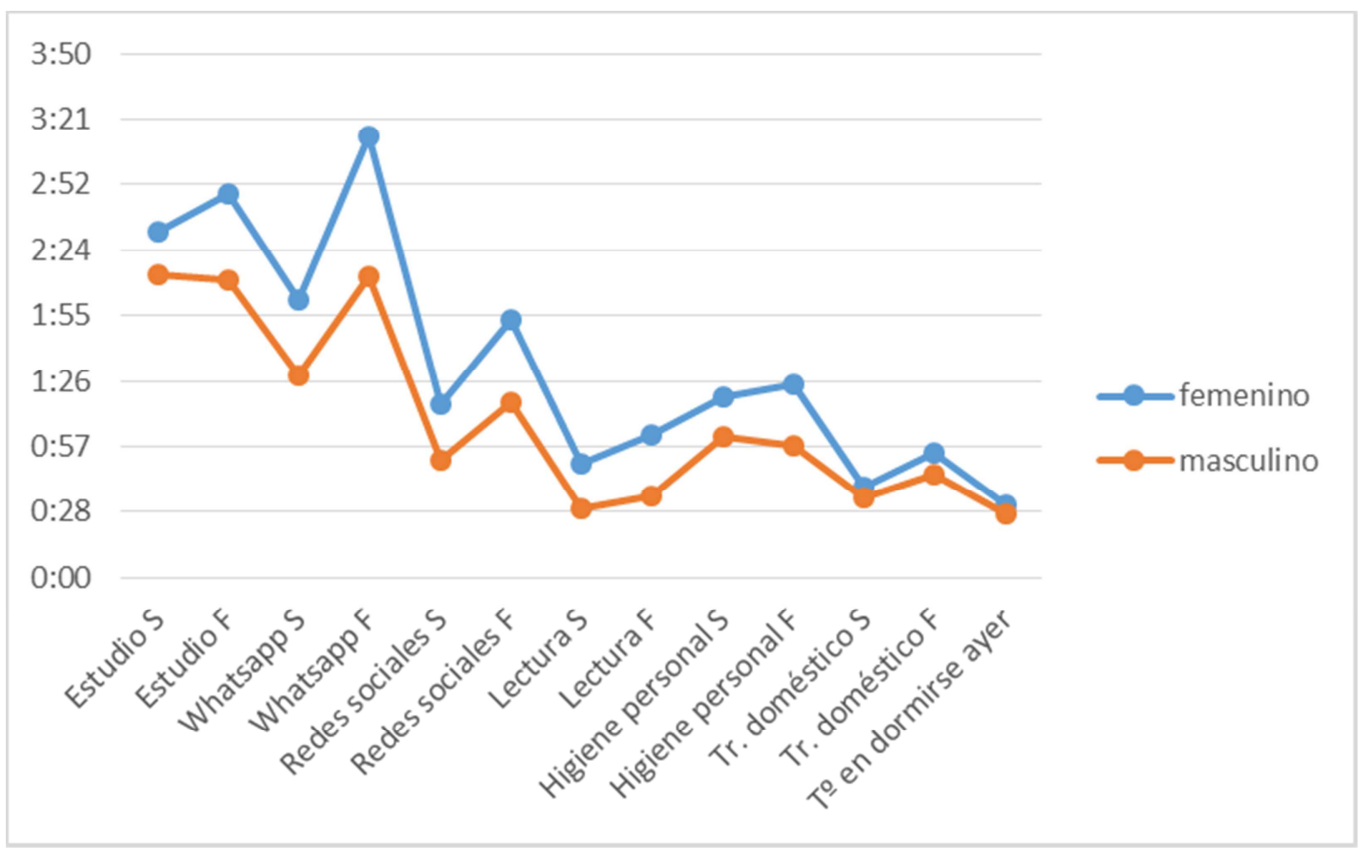

Gráfico 18: Tiempo dedicado a diferentes actividades -chicas dedican más tiempo que chicos

- Los chicos dedican más tiempo que las chicas a las siguientes actividades (gráfica 19):

- Internet:

$\checkmark \quad$ Entre semana: los chicos 8 minutos más de media.

$\checkmark$ Fin de semana: los chicos 16 minutos más de media.

- Videojuegos/consolas:

$\checkmark$ Entre semana: los chicos 40 minutos más de media.

$\checkmark$ Fin de semana: los chicos 1:27 horas más de media.

- Deporte:

$\checkmark$ Entre semana: los chicos 11 minutos más de media.

$\checkmark \quad$ Fin de semana: los chicos 30 minutos más de media. 


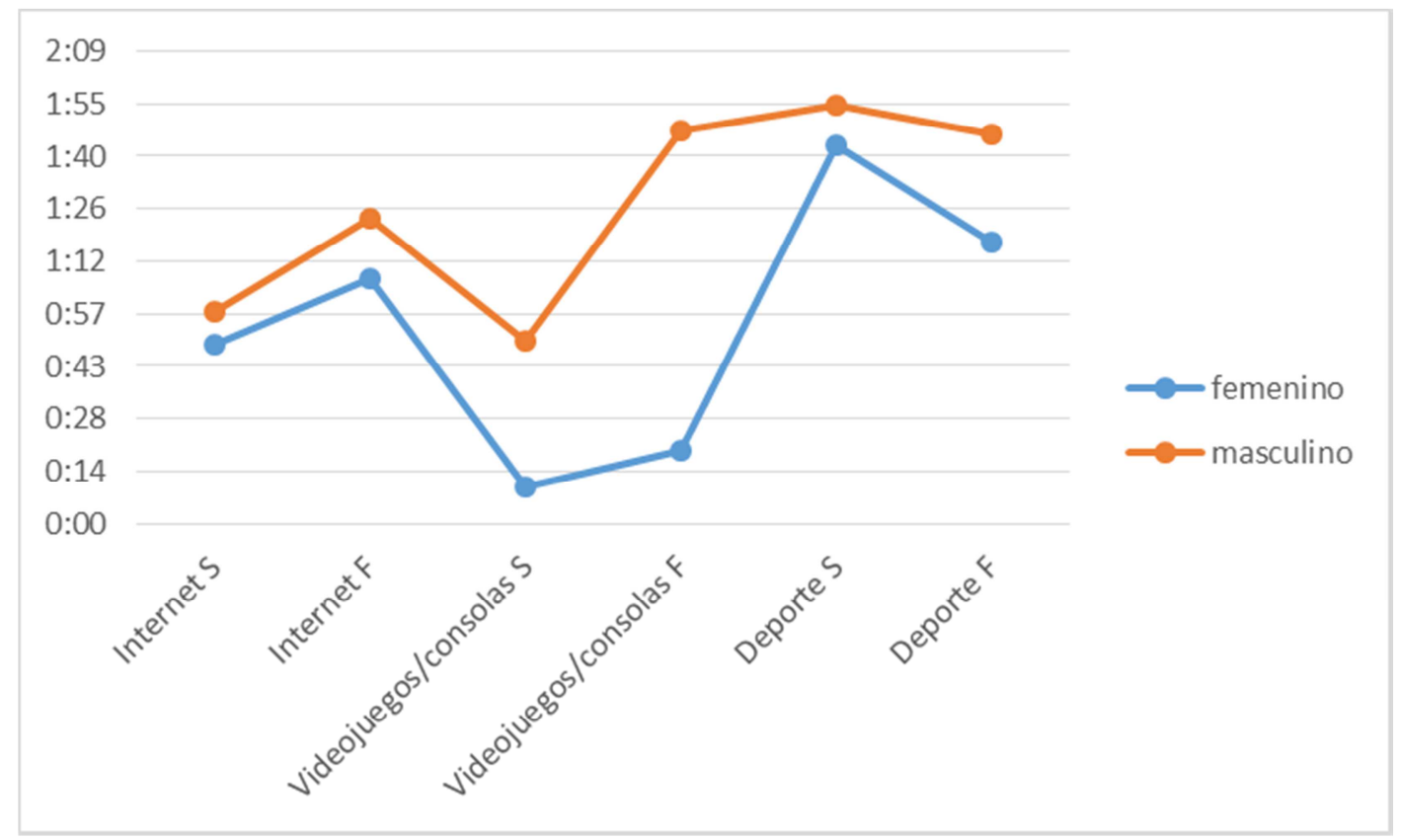

Gráfico 19: Tiempo dedicado a diferentes actividades-chicos dedican más tiempo que chicas

Se han encontrado diferencias significativas, aunque no tanto para días lectivos como para festivos, para el uso del tiempo de las siguientes actividades:

- Dormir entre semana: los chicos duermen 13 minutos más de media.

- Asistir a extraescolares:

$\checkmark$ Entre semana: las chicas asisten 13 minutos más de media

$\checkmark$ Fin de semana: los chicos asisten 8 minutos más de media.

- Trabajo remunerado fin de semana: los chicos emplean 9 minutos más de media.

- Alimentación fin de semana: las chicas dedican 13 minutos más de media que los chicos.

Por lo tanto, no podemos afirmar que existan diferencias significativas por género en el uso del tiempo de las siguientes actividades:

- Horas que duermen el fin de semana.

- Horas que asisten a clase entre semana. 
- Horas que ven la televisión durante la semana y el fin de semana.

- Horas que emplean en un trabajo remunerado durante la semana.

- Horas que emplean en la alimentación durante la semana.

- Horas que emplean en salir con los amigos durante la semana y el fin de semana.

- Horas que emplean en desplazamientos durante la semana y el fin de semana.

- Horas que emplean en salir con su pareja durante la semana y el fin de semana.

\subsection{2.- Edad}

Hemos decidido eliminar las respuestas de los adolescentes de edades comprendidas entre 18 y 20 años (incluidos), puesto que los adolescentes son mayores de edad y el número de respuestas de estas edades era reducido por lo que era difícil encontrar diferencias significativas.

Utilizamos para realizar este cálculo la ANOVA de un factor, y calculamos la HSD de Tukey (Diferencia Honestamente Significativa de Tukey). De esta manera podemos constatar si la influencia de la edad genera diferencias significativas en el tiempo dedicado por los adolescentes a realizar las diferentes actividades.

En la tabla 35 podemos ver el resultado de esta ANOVA en relación al listado de actividades de uso del tiempo que estamos analizando. Todas las actividades resaltadas sobre fondo rojo son aquellas en las que hemos encontrado diferencias significativas. EI motivo por el cual podemos hacer esta afirmación es debido a que su nivel de significación es inferior a 0,05. 


\section{2a PARTE}

Capítulo 4.- Resultados

\begin{tabular}{|c|c|c|c|c|c|c|c|}
\hline & 12 & 13 & 14 & 15 & 16 & $\overline{17}$ & Sig. \\
\hline Dormir S & $8: 16$ & $7: 58$ & $7: 48$ & $7: 32$ & $7: 39$ & $7: 13$ & 0,000 \\
\hline Dormir F & $9: 48$ & $9: 40$ & $9: 36$ & $9: 30$ & $9: 38$ & 9:08 & 0,000 \\
\hline Asistir a clase $\mathrm{S}$ & $6: 06$ & 6:09 & $6: 07$ & $6: 08$ & $6: 07$ & $6: 10$ & 0,127 \\
\hline Asistir a clase F & $0: 00$ & $0: 00$ & $0: 00$ & $0: 00$ & $0: 00$ & $0: 00$ & \\
\hline Actividades extr. $\mathrm{S}$ & $1: 44$ & $1: 47$ & $1: 56$ & $1: 50$ & $1: 49$ & $1: 48$ & 0,899 \\
\hline Actividades extr. F & $0: 44$ & $0: 43$ & $0: 43$ & $0: 46$ & $0: 41$ & $0: 37$ & 0,912 \\
\hline Estudio S & $2: 31$ & $2: 27$ & $2: 15$ & $2: 20$ & $2: 05$ & $2: 41$ & 0,000 \\
\hline Estudio F & $2: 12$ & $2: 14$ & $2: 08$ & $2: 36$ & $2: 33$ & $3: 25$ & 0,000 \\
\hline WhatsApp S & $1: 00$ & $1: 23$ & $1: 44$ & $2: 24$ & $2: 13$ & $1: 53$ & 0,000 \\
\hline WhatsApp F & $1: 55$ & $2: 22$ & $2: 51$ & $3: 12$ & $3: 08$ & $3: 01$ & 0,000 \\
\hline Redes sociales S & $0: 37$ & $0: 55$ & $1: 01$ & $1: 32$ & $1: 15$ & $1: 13$ & 0,000 \\
\hline Redes sociales F & $1: 01$ & $1: 22$ & $1: 37$ & $2: 11$ & $1: 48$ & $1: 33$ & 0,000 \\
\hline Internet S & $0: 45$ & $0: 52$ & $0: 59$ & $1: 05$ & $1: 00$ & $0: 43$ & 0,000 \\
\hline Internet F & $1: 03$ & $1: 11$ & $1: 26$ & $1: 26$ & $1: 26$ & $1: 04$ & 0,000 \\
\hline Videojuegos/consolas S & $0: 30$ & $0: 25$ & $0: 33$ & $0: 26$ & $0: 35$ & $0: 22$ & 0,148 \\
\hline Videojuegos/consolas F & $1: 04$ & $1: 02$ & $1: 07$ & $0: 59$ & $1: 04$ & $0: 51$ & 0,572 \\
\hline Televisión S & $1: 17$ & $1: 28$ & $1: 29$ & $1: 33$ & $1: 21$ & $1: 20$ & 0,232 \\
\hline Televisión F & $1: 58$ & $2: 07$ & $2: 14$ & $2: 14$ & $2: 03$ & $1: 52$ & 0,153 \\
\hline Teléfono S & $0: 17$ & $0: 21$ & $0: 24$ & $0: 27$ & $0: 22$ & $0: 15$ & 0,061 \\
\hline Teléfono F & $0: 25$ & $0: 30$ & $0: 37$ & $0: 35$ & $0: 31$ & $0: 22$ & 0,074 \\
\hline Deporte S & $1: 59$ & $1: 53$ & $2: 02$ & $1: 58$ & $1: 43$ & $1: 28$ & 0,000 \\
\hline Deporte F & $1: 32$ & $1: 46$ & $1: 30$ & $1: 36$ & $1: 27$ & $1: 11$ & 0,000 \\
\hline Trabajo doméstico S & $0: 42$ & $0: 37$ & $0: 39$ & $0: 41$ & $0: 38$ & $0: 32$ & 0,201 \\
\hline Trabajo doméstico F & $0: 46$ & $0: 51$ & $0: 47$ & $0: 58$ & $0: 54$ & $0: 44$ & 0,067 \\
\hline Trabajo remunerado S & $0: 06$ & $0: 05$ & $0: 09$ & $0: 05$ & $0: 07$ & $0: 07$ & 0,877 \\
\hline Trabajo remunerado F & $0: 08$ & $0: 10$ & $0: 11$ & $0: 09$ & $0: 10$ & $0: 12$ & 0,967 \\
\hline Lectura S & $0: 55$ & $0: 51$ & $0: 47$ & $0: 39$ & $0: 32$ & $0: 22$ & 0,000 \\
\hline Lectura F & $1: 01$ & $1: 03$ & $0: 54$ & $0: 48$ & $0: 43$ & $0: 32$ & 0,000 \\
\hline Higiene personal S & $1: 01$ & $1: 22$ & $1: 14$ & $1: 13$ & $1: 11$ & $1: 02$ & 0,007 \\
\hline Higiene personal F & $1: 07$ & $1: 13$ & $1: 17$ & $1: 18$ & $1: 13$ & $1: 08$ & 0,258 \\
\hline Alimentación S & $2: 03$ & $1: 46$ & $1: 43$ & $1: 46$ & $1: 39$ & $1: 30$ & 0,000 \\
\hline Alimentación F & $1: 56$ & $1: 43$ & $1: 44$ & $1: 47$ & $1: 41$ & $1: 44$ & 0,276 \\
\hline Amigos S & $1: 07$ & $1: 13$ & $1: 14$ & $1: 23$ & $1: 18$ & $0: 50$ & 0,009 \\
\hline Amigos $\mathrm{F}$ & $2: 21$ & $2: 51$ & $3: 41$ & $4: 29$ & $4: 13$ & $3: 49$ & 0,000 \\
\hline Desplazamientos S & $0: 51$ & $0: 48$ & $0: 48$ & $0: 47$ & $0: 46$ & $0: 36$ & 0,058 \\
\hline Desplazamientos F & $1: 10$ & $1: 05$ & $0: 59$ & $0: 55$ & $0: 56$ & $0: 43$ & 0,001 \\
\hline Salir con pareja S & $0: 01$ & $0: 08$ & $0: 19$ & $0: 19$ & $0: 21$ & $0: 17$ & 0,035 \\
\hline Salir con pareja F & $0: 04$ & $0: 11$ & $0: 26$ & $0: 16$ & $0: 40$ & $0: 53$ & 0,000 \\
\hline Tiempo en dormirse ayer & $0: 29$ & $0: 27$ & $0: 28$ & $0: 34$ & $0: 32$ & $0: 32$ & 0,189 \\
\hline
\end{tabular}

Tabla 35: media de tiempo por edad y nivel de significación 
.Las diferencias significativas se encuentran en las siguientes actividades:

- Dormir entre semana y en el fin de semana: en la gráfica 20 mostramos las medias de tiempo dedicado a dormir tanto entre semana como el fin de semana por los adolescentes, diferenciando por edades.

Como puede observarse en ellas, los adolescentes duermen menos tiempo de media según se van haciendo mayores, tanto entre semana como durante el fin de semana. Cabe remarcar una única diferencia en esta tendencia: los adolescentes de 16 años dedican más tiempo de media a dormir que aquellos de 15 años, existiendo un decremento entonces aún más notable en el tiempo dedicado de media a dormir por aquellos de 17 años.
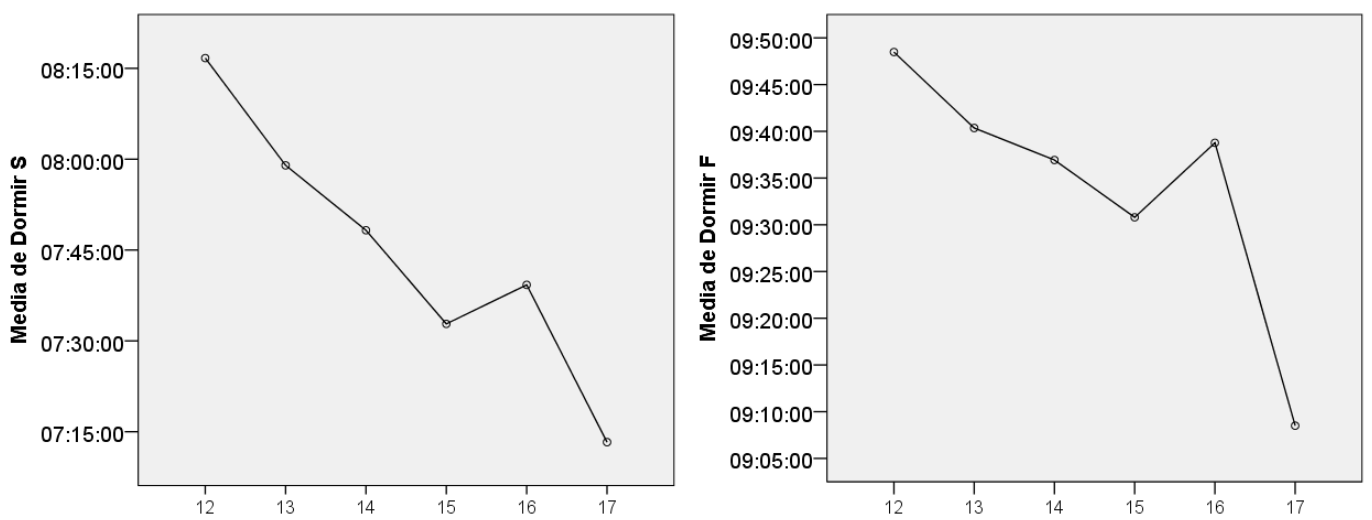

Gráfica 20: media de horas dedicadas a dormir por edad (entre semana y fin de semana)

\begin{tabular}{|c|c|c|c|c|c|c|c|}
\hline & & 12 años & 13 años & 14 años & 15 años & 16 años & 17 años \\
\hline \multirow{6}{*}{ Dormir S } & 12 años & & $0: 17^{*}$ & $0: 28^{*}$ & $0: 43^{*}$ & $0: 37^{*}$ & $1: 03^{*}$ \\
\hline & 13 años & $-0: 17^{*}$ & & $0: 10$ & $0: 26^{*}$ & $0: 19^{*}$ & $0: 45^{*}$ \\
\hline & 14 años & $-0: 28^{*}$ & $-0: 10$ & & $0: 15^{\star}$ & 0:09 & $0: 34^{*}$ \\
\hline & 15 años & $-0: 43^{*}$ & $-0: 26^{*}$ & $-0: 15^{*}$ & & $-0: 06$ & $0: 19^{*}$ \\
\hline & 16 años & $-0: 37^{*}$ & $-0: 19^{*}$ & $-0: 09$ & $0: 06$ & & $0: 25^{*}$ \\
\hline & 17 años & $-1: 03^{*}$ & $-0: 45^{*}$ & $-0: 34^{*}$ & $-0: 19^{*}$ & $-0: 25^{*}$ & \\
\hline \multirow{6}{*}{ Dormir F } & 12 años & & $0: 08$ & $0: 11$ & $0: 17$ & $0: 09$ & $0: 39^{*}$ \\
\hline & 13 años & $-0: 08$ & & $0: 03$ & $0: 09$ & $0: 01$ & $0: 31^{*}$ \\
\hline & 14 años & $-0: 11$ & $-0: 03$ & & $0: 06$ & $-0: 01$ & $0: 28^{*}$ \\
\hline & 15 años & $-0: 17$ & $-0: 09$ & $-0: 06$ & & $-0: 07$ & $0: 22$ \\
\hline & 16 años & $-0: 09$ & $-0: 01$ & $0: 01$ & $0: 07$ & & $0: 30^{*}$ \\
\hline & 17 años & $-0: 39^{*}$ & $-0: 31^{*}$ & $-0: 28^{*}$ & $-0: 22$ & $-0: 30^{*}$ & \\
\hline
\end{tabular}

Tabla 36: diferencia de medias del tiempo dedicado a dormir en fin de semana 
Las diferencias más importantes se observan a la edad de 12 y de 17 años entre semana y a los 17 años en fin de semana donde, como puede apreciarse en la tabla 36, existen diferencias significativas casi con la totalidad del resto de edades.

Observamos además que el tiempo dedicado a dormir, disminuye en mayor medida con la edad en el género femenino (tabla 37). La diferencia marca una tendencia analizando por años consecutivos. Si analizamos, sin embargo, los resultados a nivel global, hallando la diferencia entre el tiempo dedicado a dormir a los 17 y a los 12 años, los resultados son más contundentes. Observamos que las chicas duermen 1:16 menos entre semana frente a 0:45 que duermen menos los chicos. El fin de semana, la diferencia es de 0:59 para las chicas y de 0:17 para los chicos.

\begin{tabular}{|l|cc|cc|cc|c|c|}
\cline { 2 - 8 } \multicolumn{1}{c|}{} & \multicolumn{3}{c|}{ tiempo dormir ENTRE SEMANA } & \multicolumn{4}{c|}{ tiempo dormir FN DE SEMANA } \\
\cline { 2 - 9 } \multicolumn{1}{c|}{} & femenino diferencia & masculino diferencia & femenino diferencia & masculino diferencia \\
\hline $\mathbf{1 2}$ años & $8: 14$ & & $8: 18$ & & $9: 57$ & & $9: 38$ & $0: 19$ \\
\hline $\mathbf{1 3}$ años & $7: 55$ & $0: 19$ & $8: 03$ & $0: 15$ & $9: 38$ & $9: 42$ & $0: 04$ \\
\hline $\mathbf{1 4}$ años & $7: 37$ & $0: 18$ & $7: 58$ & $0: 05$ & $9: 29$ & $0: 09$ & $9: 43$ & $0: 01$ \\
\hline $\mathbf{1 5}$ años & $7: 26$ & $0: 11$ & $7: 40$ & $0: 18$ & $9: 42$ & $0: 13$ & $9: 16$ & $0: 27$ \\
\hline $\mathbf{1 6}$ años & $7: 33$ & $0: 07$ & $7: 45$ & $0: 05$ & $9: 43$ & $0: 01$ & $9: 34$ & $0: 18$ \\
\hline $\mathbf{1 7}$ años & $6: 58$ & $0: 35$ & $7: 33$ & $0: 12$ & $8: 58$ & $0: 45$ & $9: 21$ & $0: 13$ \\
\hline $\mathbf{1 7}$-12 años & $1: 16$ & & $0: 45$ & & $0: 59$ & & $0: 17$ & \\
\hline
\end{tabular}

Tabla 37: dormir por género y edad

- Estudio entre semana y en el fin de semana: podemos ver las gráficas 21 la media de tiempo dedicada a estudiar por los adolescentes con respecto a su edad. Podemos observar que, entre semana, los adolescentes estudian menos con el paso de los años, hasta los 14 años, puesto que se observa un aumento a los 15 años del tiempo dedicado al estudio.

A los 16 años se observa una disminución en el tiempo de estudio importante, que posteriormente aumenta notablemente a los 17 años. Durante el fin de semana, se observa en general un aumento en la media de tiempo dedicado a 
estudiar por los adolescentes con la edad, siendo notablemente más significativo el tiempo que estudian con 17 años.
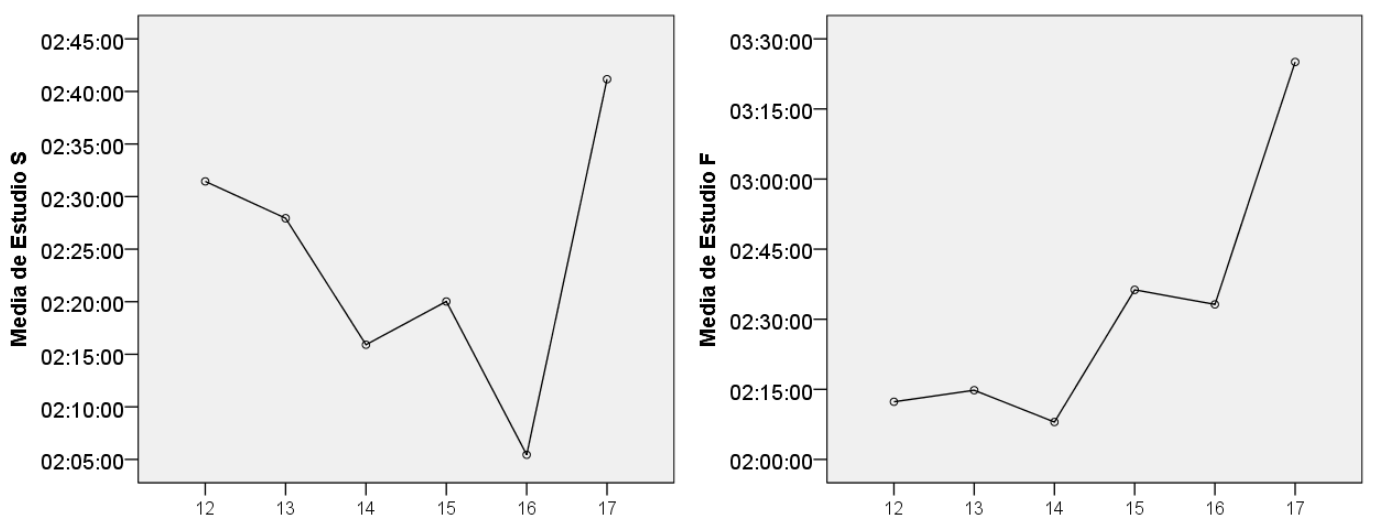

Gráfica 21: media de tiempo dedicado a estudiar por edad (entre semana y fin de semana).

En la tabla 38 podemos apreciar la diferencia de medias de tiempo dedicado a estudiar tanto entre semana como durante el fin de semana. Volvemos a encontrar las mayores diferencias significativas en el fin de semana y para 17 años.

\begin{tabular}{|c|c|c|c|c|c|c|c|}
\hline & & 12 años & 13 años & 14 años & 15 años & 16 años & 17 años \\
\hline \multirow{6}{*}{ Estudio S } & 12 años & & $0: 03$ & $0: 15$ & $0: 11$ & $0: 26^{*}$ & $-0: 09$ \\
\hline & 13 años & $-0: 03$ & & $0: 12$ & $0: 07$ & $0: 22^{*}$ & $-0: 13$ \\
\hline & 14 años & $-0: 15$ & $-0: 12$ & & $-0: 04$ & $0: 10$ & $-0: 25^{*}$ \\
\hline & 15 años & $-0: 11$ & $-0: 07$ & $0: 04$ & & $0: 14$ & $-0: 21$ \\
\hline & 16 años & $-0: 26^{*}$ & $-0: 22^{*}$ & $-0: 10$ & $-0: 14$ & & $-0: 35^{*}$ \\
\hline & 17 años & 0:09 & $0: 13$ & $0: 25^{\star}$ & $0: 21$ & $0: 35^{*}$ & \\
\hline \multirow{6}{*}{ Estudio F } & 12 años & & $-0: 02$ & $0: 04$ & $-0: 23$ & $-0: 20$ & $-1: 12^{*}$ \\
\hline & 13 años & $0: 02$ & & $0: 06$ & $-0: 21$ & $-0: 18$ & $-1: 10^{*}$ \\
\hline & 14 años & $-0: 04$ & $-0: 06$ & & $-0: 28$ & $-0: 25$ & $-1: 17^{*}$ \\
\hline & 15 años & $0: 23$ & $0: 21$ & $0: 28$ & & $0: 03$ & $-0: 48^{*}$ \\
\hline & 16 años & $0: 20$ & $0: 18$ & $0: 25$ & $-0: 03$ & & $-0: 51^{*}$ \\
\hline & 17 años & $1: 12^{*}$ & $1: 10^{*}$ & $1: 17^{*}$ & $0: 48^{*}$ & $0: 51^{*}$ & \\
\hline
\end{tabular}

Tabla 38: diferencia de medias de tiempo dedicado a estudiar 
- WhatsApp entre semana y en el fin de semana: en la gráfica 22 mostramos la media de tiempo dedicada por los adolescentes a utilizar el WhatsApp. Como puede observarse, la media de tiempo dedicada a esta actividad aumenta desde los 12 años hasta los 15. A partir de esta edad, el tiempo destinado al WhatsApp decrece aunque sigue manteniéndose en valores elevados a los 17 años.
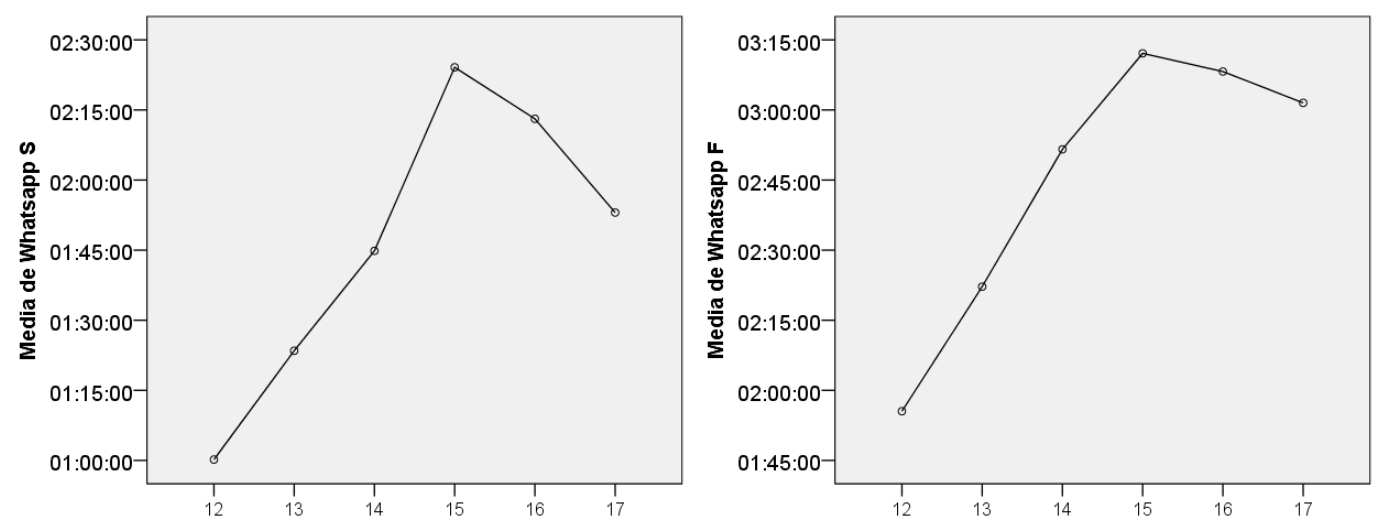

Gráfica 22: media de tiempo dedicado a WhatsApp por edad (entre semana y fin de semana).

Como se puede observar en la tabla 39, las diferencias significativas más importantes con respecto al tiempo utilizado por los adolescentes al uso del WhatsApp se encuentran a la edad de 12 años (tanto entre semana como el fin de semana).

\begin{tabular}{|c|c|c|c|c|c|c|c|}
\hline & & 12 años & 13 años & 14 años & 15 años & 16 años & 17 años \\
\hline \multirow{6}{*}{ Whatsapp S } & 12 años & & $-0: 23$ & $-0: 44^{*}$ & $-1: 23^{*}$ & $-1: 12^{*}$ & $-0: 52^{*}$ \\
\hline & 13 años & $0: 23$ & & $-0: 21$ & $-1: 00^{*}$ & $-0: 49^{*}$ & $-0: 29$ \\
\hline & 14 años & $0: 44^{*}$ & $0: 21$ & & $-0: 39^{*}$ & $-0: 28$ & $-0: 08$ \\
\hline & 15 años & $1: 23^{*}$ & $1: 00^{*}$ & $0: 39^{*}$ & & $0: 11$ & $0: 31$ \\
\hline & 16 años & $1: 12^{*}$ & $0: 49^{*}$ & $0: 28$ & $-0: 11$ & & $0: 20$ \\
\hline & 17 años & $0: 52^{*}$ & $0: 29$ & $0: 08$ & $-0: 31$ & $-0: 20$ & \\
\hline \multirow{6}{*}{ Whatsapp F } & 12 años & & $-0: 26$ & $-0: 56^{*}$ & $-1: 16^{*}$ & $-1: 12^{*}$ & $-1: 05^{*}$ \\
\hline & 13 años & $0: 26$ & & $-0: 29$ & $-0: 49^{*}$ & $-0: 46^{*}$ & $-0: 39$ \\
\hline & 14 años & $0: 56^{*}$ & $0: 29$ & & $-0: 20$ & $-0: 16$ & $-0: 09$ \\
\hline & 15 años & $1: 16^{*}$ & $0: 49^{*}$ & $0: 20$ & & $0: 03$ & $0: 10$ \\
\hline & 16 años & $1: 12^{*}$ & $0: 46^{*}$ & $0: 16$ & $-0: 03$ & & $0: 06$ \\
\hline & 17 años & $1: 05^{*}$ & $0: 39$ & $0: 09$ & $-0: 10$ & $-0: 06$ & \\
\hline
\end{tabular}

Tabla 39: diferencia de medias del tiempo dedicado al WhatsApp 
- $\quad$ Redes sociales entre semana y en el fin de semana: el tiempo invertido por los adolescentes a las redes sociales aumenta hasta los 15 años, edad en la que comienza a observarse un descenso importante (gráfica 23) en el tiempo dedicado a esta actividad. Como puede observarse, las gráficas obtenidas para el uso de WhatsApp y de redes sociales son muy similares.
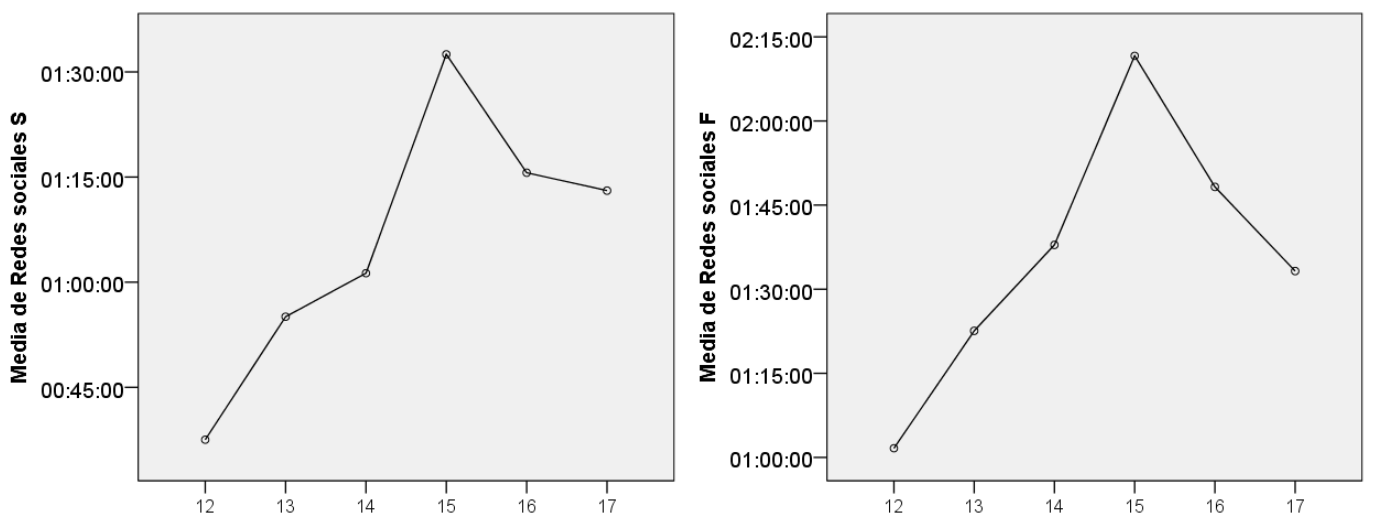

Gráfica 23: media de tiempo dedicado a redes sociales por edad

- Internet entre semana y en el fin de semana: en la gráfica 24 podemos observar una tendencia al aumento del tiempo dedicado a navegar por internet por los adolescentes hasta los 15 años. A partir de esa edad, esta media de tiempo disminuye drásticamente, llegando a bajar a los 17 años a valores similares a los obtenidos a los 12 años.
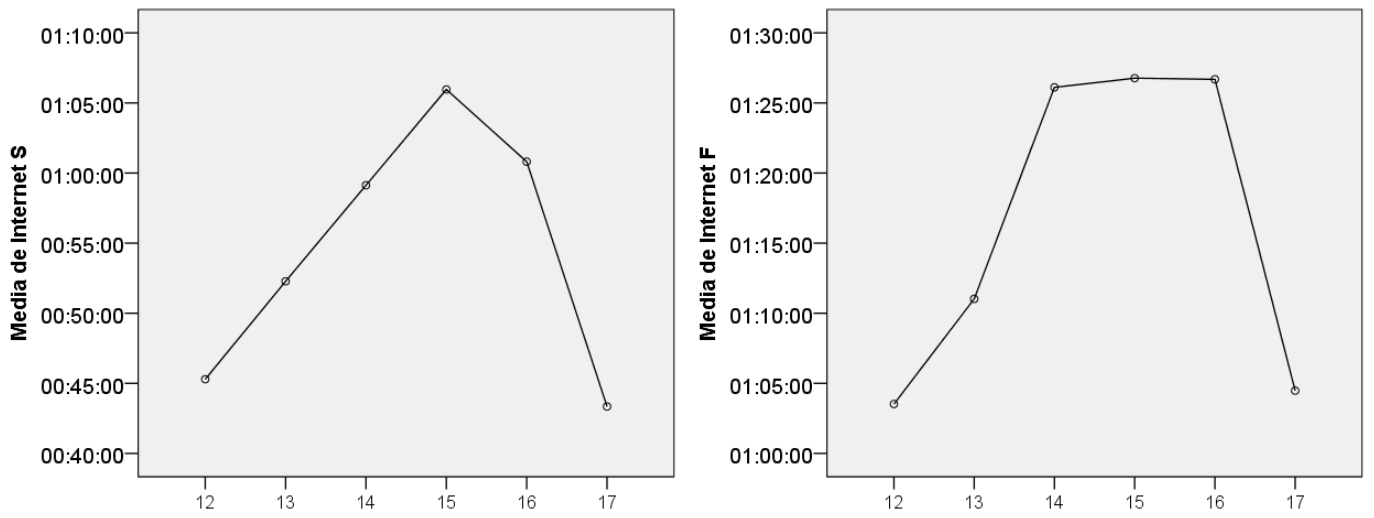

Gráfica 24: media de horas dedicadas a Internet por edad (entre semana y fin de semana). 
- Deporte entre semana y en el fin de semana: en la gráfica 25 se puede observar que el tiempo dedicado por los adolescentes a hacer deporte disminuye con los años. La diferencia de tiempo dedicado a esta actividad es importe: 34 minutos más a los 14 años que a los 17 entre semana y 35 minutos más a los 13 años que a los 17 durante el fin de semana.
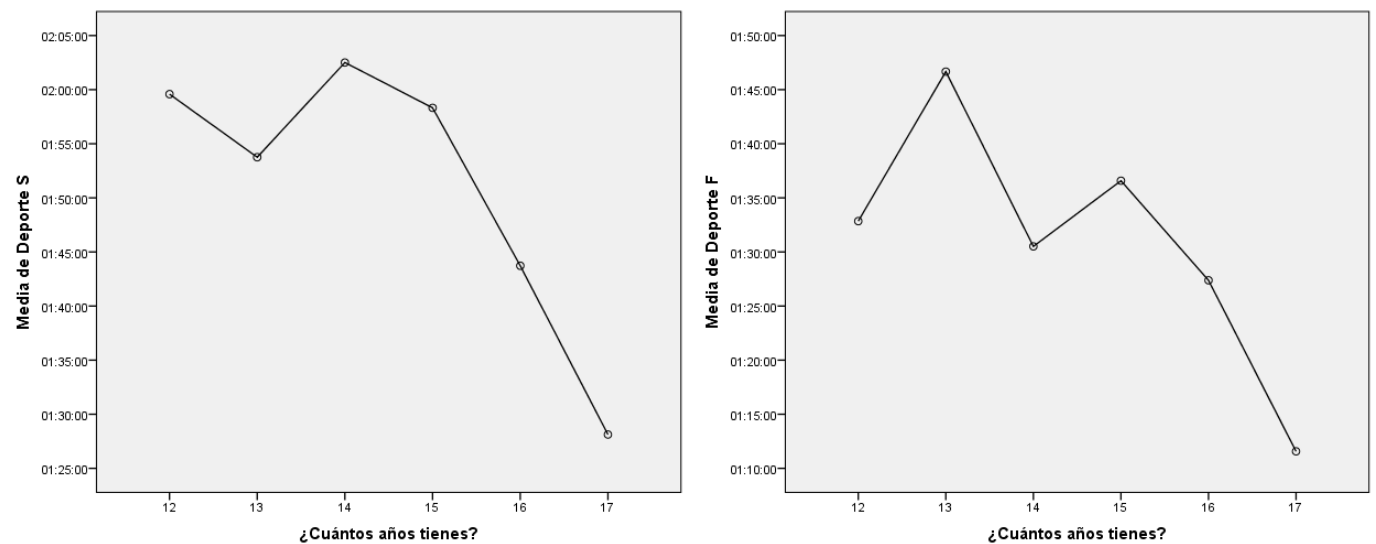

Gráfica 25: media de horas dedicadas al deporte por edad.

- Lectura entre semana y en el fin de semana: en la gráfica 26 se puede observar la tendencia a disminuir en el tiempo dedicado a la lectura con el paso de los años. Las diferencias son importantes. Los adolescentes burgaleses encuestados leen 33 minutos menos al día entre semana y 29 minutos menos el fin de semana a los 17 que a los 12 años.
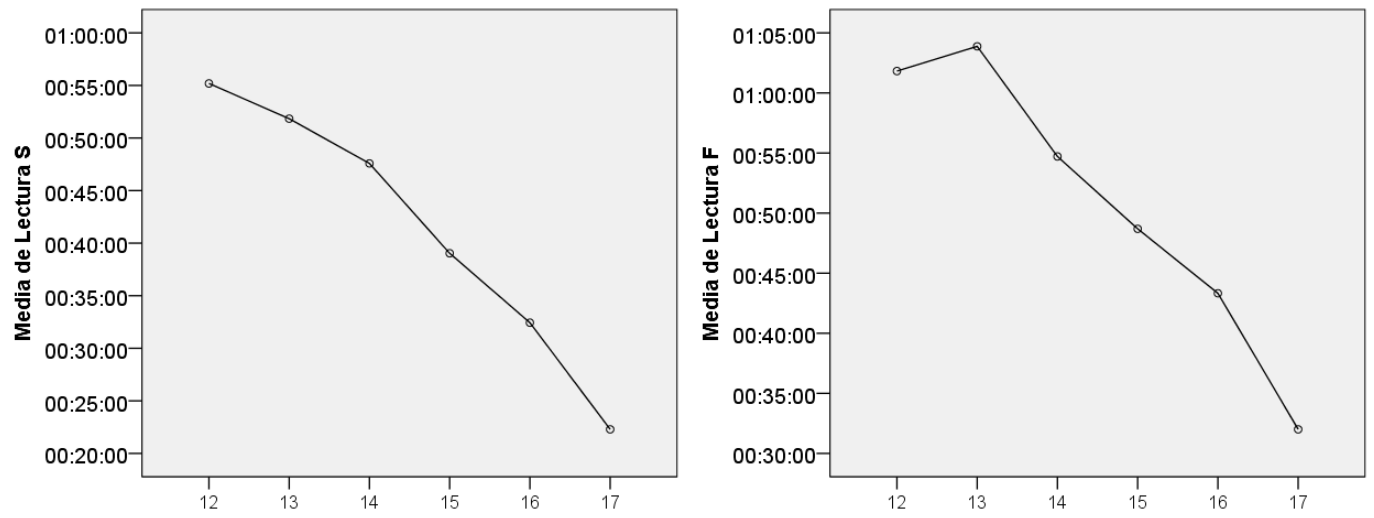

Gráfica 26: media de tiempo dedicado a la lectura por edad (entre semana y fin de semana). 
- Higiene personal entre semana: la gráfica 27 muestra las medias de tiempo dedicadas a realizar esta actividad. Se puede apreciar que el tiempo dedicado a la higiene personal aumenta notablemente entre los 12 y los 13 años. Sin embargo, a partir de los 13 años comienza a decrecer paulatinamente hasta llegar a los 17 años a valores semejantes que los encontrados para los adolescentes de 12 años.

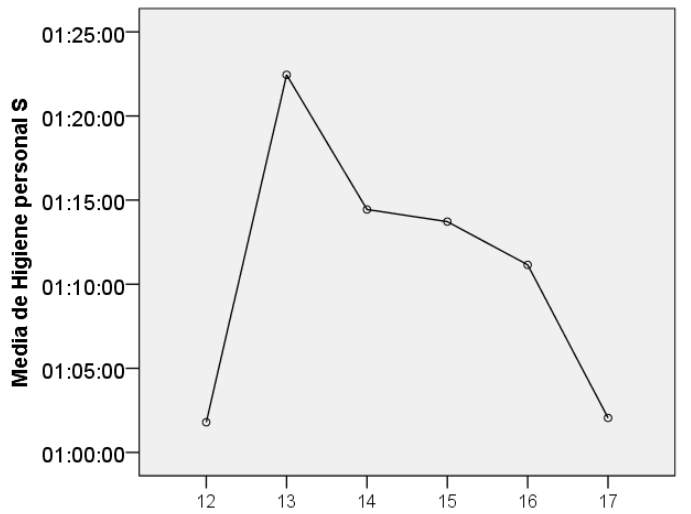

Gráfico 27: media de tiempo dedicado a la higiene personal por edad entre semana

- Alimentación entre semana: el gráfico 28 muestra la evolución de las medias del tiempo que los adolescentes dedican a su alimentación en días lectivos. No se puede afirmar que existan diferencias significativas en el fin de semana. El tiempo que dedican a esta actividad decrece con la edad, llegando a encontrarse diferencias entre los 12 años y los 17 años de 33 minutos.

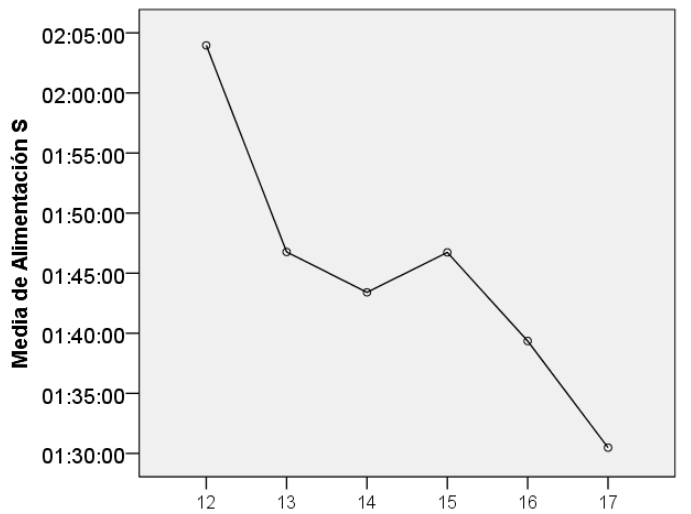

Gráfica 28: media de tiempo dedicado a la alimentación por edad entre semana 
- Amigos entre semana y en el fin de semana: el gráfico 29 muestra el tiempo medio dedicado por los adolescentes a salir con los amigos con respecto a la edad. Se observa una tendencia ascendente hasta los 15 años, que es la edad en la que los adolescentes dedican más tiempo a salir con los amigos (según la gráfica).

A partir de la edad de 15 años, el tiempo dedicado a esta actividad decrece notablemente. Entre semana los adolescentes salen menos tiempo a los 17 años (aproximadamente 33 minutos menos que a los 15 años). Durante el fin de semana, los adolescentes de 15 años salen 2:08 más que los de 12 años. En fin de semana, el tiempo dedicado a salir con los amigos decrece con relación a los 15 años, pero se mantiene siempre en cifras superiores a los adolescentes más jóvenes.
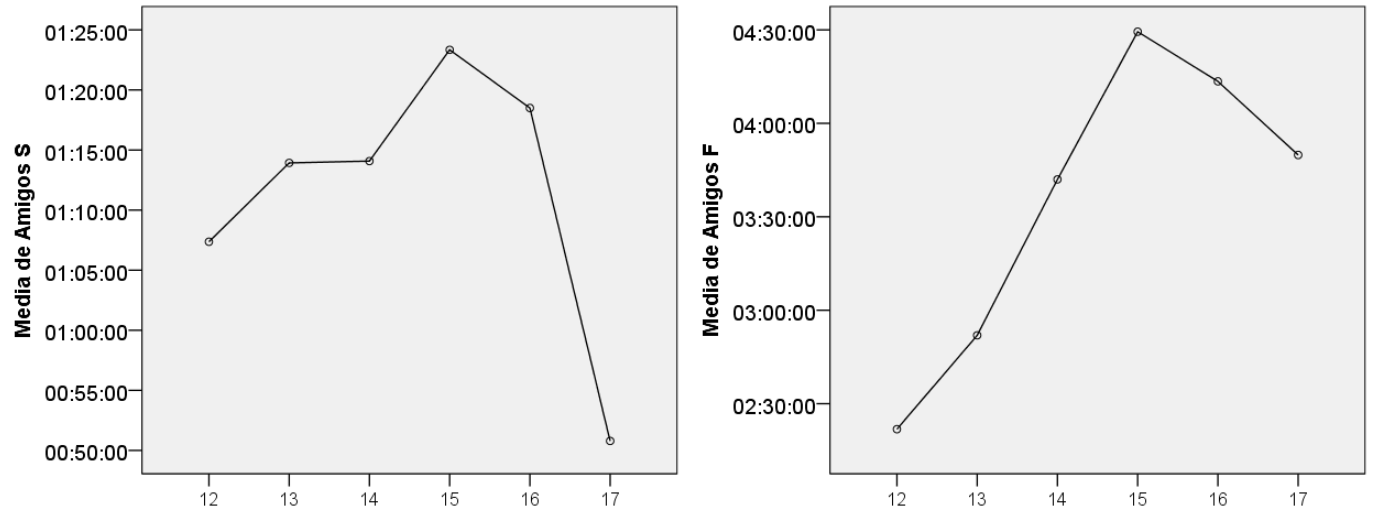

Gráfica 29: media de horas dedicadas a salir con los amigos con la edad

- Salir con pareja entre semana y en el fin de semana: el tiempo que los adolescentes dedican a salir con su pareja aumenta con la edad. Principalmente se puede observar durante el fin de semana, donde el aumento de tiempo dedicado a esta actividad por los adolescentes más mayores es más relevante (gráfico 30). 

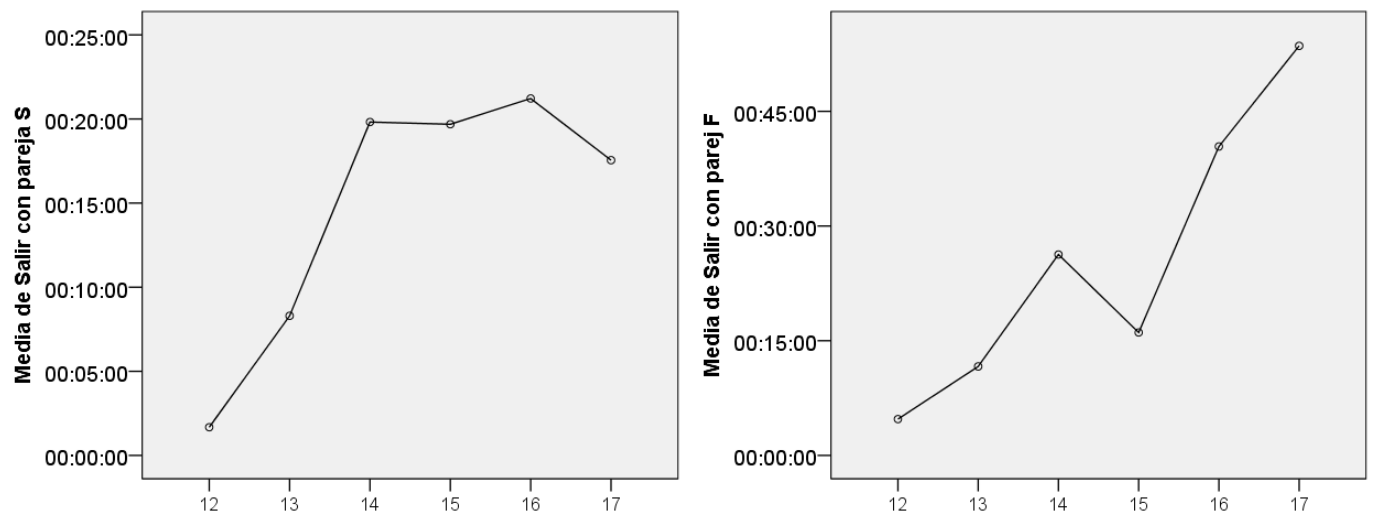

Gráfico 30: media de horas dedicadas a salir con la pareja con la edad

- Tiempo que tardan en dormirse: podemos observar en la gráfica 31 la evolución del tiempo medio que los adolescentes tardan en dormirse en relación a la edad. En general, tardan más tiempo en dormirse con la edad, pero el análisis de Tukey pone de manifiesto que no se puede asegurar que existan diferencias significativas, puesto que el valor de significación es bastante superior a 0,05.

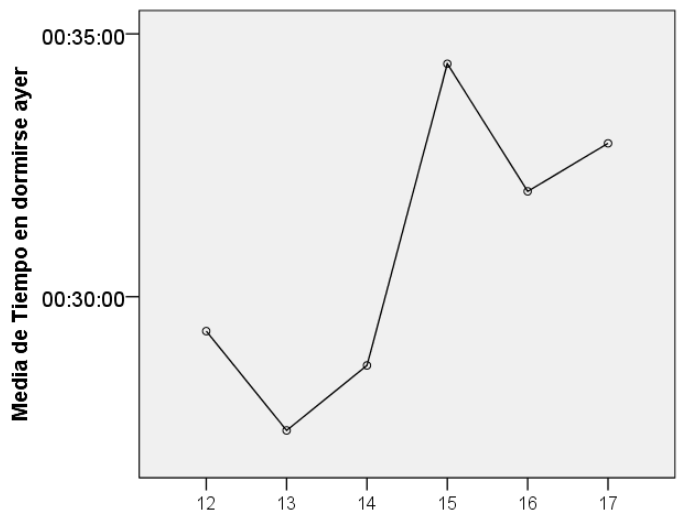

Gráfico 31: media de tiempo hasta dormirse el día previo a la realización de la encuesta

Comentar que no se encuentran diferencias significativas en cuanto al tiempo dedicado a videojuegos/consolas con la edad. El resultado de la ANOVA pone de manifiesto que no se puede asegurar que existan diferencias significativas en el tiempo dedicado a jugar a videojuegos/consolas ni durante la semana ni durante el fin de semana (tabla 40). 


\begin{tabular}{|c|c|c|c|c|c|c|c|}
\hline & & 12 años & 13 años & 14 años & 15 años & 16 años & 17 años \\
\hline \multirow{6}{*}{$\begin{array}{c}\text { Videojuegos/consolas } \\
\text { Entre semana }\end{array}$} & 12 años & & 0,938 & 0,991 & 0,984 & 0,953 & 0,764 \\
\hline & 13 años & 0,938 & & 0,597 & 1,000 & 0,391 & 0,995 \\
\hline & 14 años & 0,991 & 0,597 & & 0,786 & 1,000 & 0,368 \\
\hline & 15 años & 0,984 & 1,000 & 0,786 & & 0,608 & 0,984 \\
\hline & 16 años & 0,953 & 0,391 & 1,000 & 0,608 & & 0,217 \\
\hline & 17 años & 0,764 & 0,995 & 0,368 & 0,984 & 0,217 & \\
\hline \multirow{6}{*}{$\begin{array}{l}\text { Videojuegos/consolas } \\
\text { fin de semana }\end{array}$} & 12 años & & 1,000 & 0,999 & 0,993 & 1,000 & 0,727 \\
\hline & 13 años & 1,000 & & 0,993 & 0,999 & 1,000 & 0,797 \\
\hline & 14 años & 0,999 & 0,993 & & 0,942 & 1,000 & 0,501 \\
\hline & 15 años & 0,993 & 0,999 & 0,942 & & 0,986 & 0,960 \\
\hline & 16 años & 1,000 & 1,000 & 1,000 & 0,986 & & 0,652 \\
\hline & 17 años & 0,727 & 0,797 & 0,501 & 0,960 & 0,652 & \\
\hline
\end{tabular}

Tabla 40: niveles de significación de las diferencias dos a dos

\subsection{3.- Curso}

Además de la edad, el curso puede ser otro de los factores en que se manifiestan diferencias en el uso del tiempo del adolescente, posiblemente y entre otras causas, debido a la carga de trabajo asociada a cada curso escolar.

Para llevar a cabo este estudio, como para la edad analizada en el punto anterior, vamos a realizar de nuevo la comparativa de medias en SPSS, utilizando la ANOVA de un factor para conocer en qué actividades de uso del tiempo encontramos diferencias significativas con relación al curso.

Mostramos el resultado en la tabla 41, sombreando en rojo aquellas actividades en las que hemos encontrado diferencias significativas puesto que su factor de significación es inferior a 0,05. Como se puede observar en la figura, el curso establece diferencias significativas en el uso del tiempo de prácticamente todas las actividades estudiadas. 
2a PARTE

Capítulo 4.- Resultados

\begin{tabular}{|c|c|c|c|c|c|c|c|}
\hline & $1^{\circ} \mathrm{ESO}$ & $2 \circ$ ESO & 3 ESO & $4 \%$ ESO & $1^{\circ} \mathrm{BACH}$ & $2 \circ \mathrm{BACH}$ & Sig. \\
\hline Dormir S & $8: 12$ & $7: 52$ & $7: 39$ & $7: 35$ & $7: 27$ & $7: 13$ & 0,000 \\
\hline Dormir F & $9: 45$ & 9:39 & 9:32 & $9: 41$ & 9:29 & $8: 49$ & 0,000 \\
\hline Asistir a clase $\mathbf{S}$ & $6: 07$ & $6: 10$ & $6: 07$ & $6: 11$ & 6:04 & $6: 12$ & 0,000 \\
\hline Asistir a clase $\mathrm{F}$ & $0: 00$ & $0: 00$ & $0: 00$ & $0: 00$ & $0: 00$ & $0: 00$ & \\
\hline Actividades extr. S & $1: 39$ & $1: 51$ & $1: 45$ & $2: 06$ & $1: 55$ & $1: 27$ & 0,014 \\
\hline Actividades extr. F & $0: 43$ & $0: 40$ & $0: 40$ & $0: 55$ & $0: 40$ & $0: 27$ & 0,023 \\
\hline Estudio S & $2: 26$ & $2: 24$ & $2: 13$ & $2: 20$ & $2: 04$ & $3: 07$ & 0,000 \\
\hline Estudio F & $2: 04$ & $2: 10$ & $2: 11$ & $2: 53$ & $2: 35$ & $4: 19$ & 0,000 \\
\hline WhatsApp S & $1: 08$ & $1: 32$ & $2: 19$ & $1: 57$ & $2: 19$ & $1: 43$ & 0,000 \\
\hline WhatsApp F & $2: 04$ & $2: 32$ & $3: 17$ & $2: 59$ & $3: 14$ & $2: 43$ & 0,000 \\
\hline Redes sociales S & $0: 44$ & $1: 04$ & $1: 16$ & $1: 14$ & $1: 26$ & $0: 54$ & 0,000 \\
\hline Redes sociales F & $1: 07$ & $1: 36$ & $1: 49$ & $2: 01$ & $1: 51$ & $1: 19$ & 0,000 \\
\hline Internet S & $0: 51$ & $0: 49$ & $1: 07$ & $0: 57$ & $0: 59$ & $0: 31$ & 0,000 \\
\hline Internet F & $1: 09$ & $1: 12$ & $1: 29$ & $1: 20$ & $1: 25$ & $0: 54$ & 0,000 \\
\hline Videojuegos/consolas S & $0: 30$ & $0: 29$ & $0: 32$ & $0: 26$ & $0: 35$ & $0: 11$ & 0,006 \\
\hline Videojuegos/consolas F & $1: 05$ & $1: 06$ & $1: 11$ & $0: 52$ & $1: 03$ & $0: 33$ & 0,002 \\
\hline Televisión S & $1: 26$ & $1: 29$ & $1: 29$ & $1: 27$ & $1: 22$ & $1: 16$ & 0,518 \\
\hline Televisión F & $2: 02$ & $2: 08$ & $2: 17$ & $2: 08$ & $1: 57$ & $2: 01$ & 0,352 \\
\hline Teléfono S & $0: 17$ & $0: 26$ & $0: 29$ & $0: 18$ & $0: 17$ & $0: 12$ & 0,000 \\
\hline Teléfono F & $0: 25$ & $0: 39$ & $0: 38$ & $0: 26$ & $0: 24$ & $0: 22$ & 0,001 \\
\hline Deporte S & $2: 01$ & $1: 53$ & $2: 01$ & $1: 53$ & $1: 36$ & $1: 12$ & 0,000 \\
\hline Deporte F & $1: 40$ & $1: 31$ & $1: 44$ & $1: 25$ & $1: 19$ & $1: 08$ & 0,000 \\
\hline Trabajo doméstico S & $0: 39$ & $0: 41$ & $0: 43$ & $0: 39$ & $0: 32$ & $0: 27$ & 0,000 \\
\hline Trabajo doméstico F & $0: 47$ & $0: 51$ & $0: 55$ & $0: 55$ & $0: 49$ & $0: 41$ & 0,081 \\
\hline Trabajo remunerado S & $0: 08$ & $0: 05$ & $0: 05$ & $0: 04$ & $0: 09$ & $0: 07$ & 0,572 \\
\hline Trabajo remunerado $\mathrm{F}$ & $0: 14$ & $0: 04$ & $0: 10$ & $0: 12$ & 0:09 & $0: 15$ & 0,207 \\
\hline Lectura S & $0: 55$ & $0: 47$ & $0: 43$ & $0: 30$ & $0: 31$ & $0: 21$ & 0,000 \\
\hline Lectura F & $1: 04$ & $0: 54$ & $0: 51$ & $0: 43$ & $0: 42$ & $0: 34$ & 0,000 \\
\hline Higiene personal S & $1: 12$ & $1: 18$ & $1: 14$ & $1: 06$ & $1: 11$ & $0: 58$ & 0,076 \\
\hline Higiene personal F & $1: 07$ & $1: 20$ & $1: 17$ & $1: 11$ & $1: 14$ & $1: 03$ & 0,017 \\
\hline Alimentación S & $1: 57$ & $1: 47$ & $1: 45$ & $1: 33$ & $1: 40$ & $1: 25$ & 0,000 \\
\hline Alimentación F & $1: 48$ & $1: 47$ & $1: 45$ & $1: 41$ & $1: 46$ & $1: 41$ & 0,804 \\
\hline Amigos S & $1: 11$ & $1: 13$ & $1: 23$ & $1: 19$ & $1: 07$ & $0: 42$ & 0,001 \\
\hline Amigos $\mathrm{F}$ & $2: 32$ & $3: 16$ & $4: 21$ & 4:07 & $4: 17$ & $3: 13$ & 0,000 \\
\hline Desplazamientos S & $0: 49$ & $0: 51$ & $0: 45$ & $0: 43$ & $0: 45$ & $0: 32$ & 0,010 \\
\hline Desplazamientos F & $1: 11$ & $0: 58$ & $0: 59$ & $0: 52$ & $0: 54$ & $0: 40$ & 0,000 \\
\hline Salir con pareja S & $0: 05$ & $0: 07$ & $0: 27$ & $0: 21$ & $0: 17$ & $0: 14$ & 0,006 \\
\hline Salir con pareja F & 0:09 & $0: 14$ & $0: 31$ & $0: 33$ & $0: 39$ & $0: 43$ & 0,000 \\
\hline Tiempo en dormirse ayer & $0: 28$ & $0: 26$ & $0: 32$ & $0: 31$ & $0: 35$ & $0: 33$ & 0,047 \\
\hline
\end{tabular}

Tabla 41: media de tiempo por curso y nivel de significación 
A continuación, analizamos de manera individualizada, la evolución de las medias de tiempo dedicado a cada una de las actividades por curso, en los casos en los que se han encontrado diferencias significativas:

- Dormir entre semana y en el fin de semana: como puede observarse en el gráfico 32 el tiempo dedicado a dormir por los adolescentes tanto entre semana como en fin de semana, disminuye al aumentar de curso, durmiendo de hecho 58 minutos menos en 20 de $\mathrm{BACH}$ que en 10 de ESO entre semana y 55 minutos menos el fin de semana.
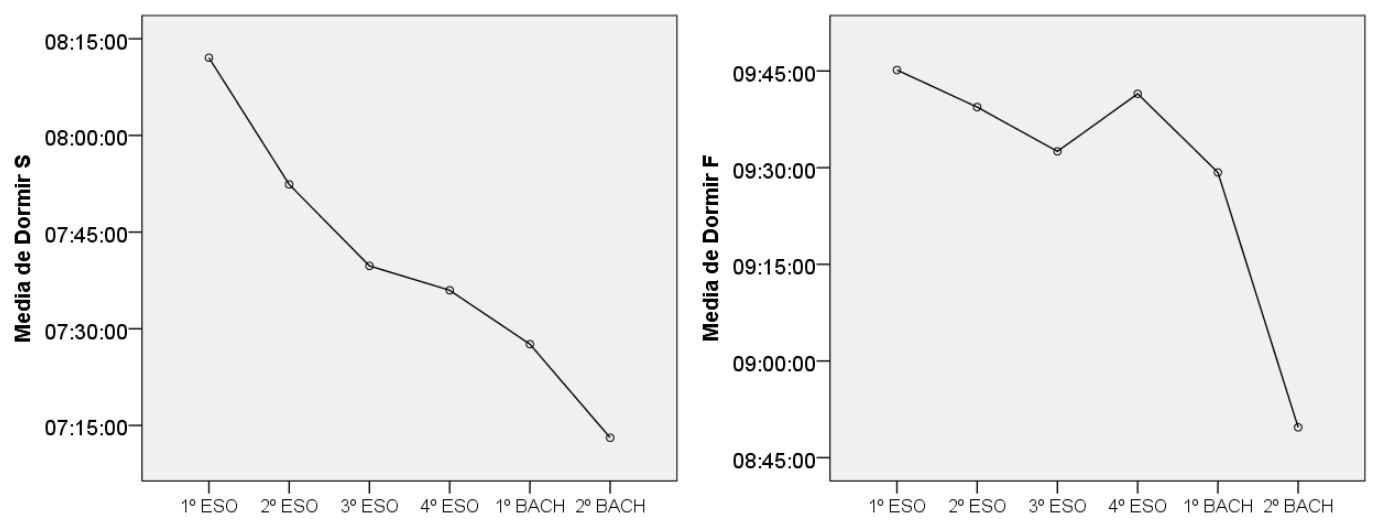

Gráfico 32: media de horas dedicadas a dormir por curso (entre semana y fin de semana)

- Estudiar entre semana y en el fin de semana: como puede observarse en el gráfico 33 , los adolescentes de 2 o de $\mathrm{BACH}$ dedican una cantidad de su tiempo a estudiar bastante mayor que la dedicada por los adolescentes de otros cursos. Entre semana, los adolescentes de 20 de $\mathrm{BACH}$ dedican 40 minutos más a estudiar que los de $1^{\circ}$ de ESO.

Es reseñable la disminución del tiempo dedicado al estudio por parte de los adolescentes de 1으 de $\mathrm{BACH}$, disminuyendo hasta una media de 2:04. Durante el fin de semana, la diferencia de tiempo medio dedicado al estudio entre adolescentes de $2 \circ$ de $\mathrm{BACH}$ y 10 de ESO es muy notable, aproximadamente de 2:14. 

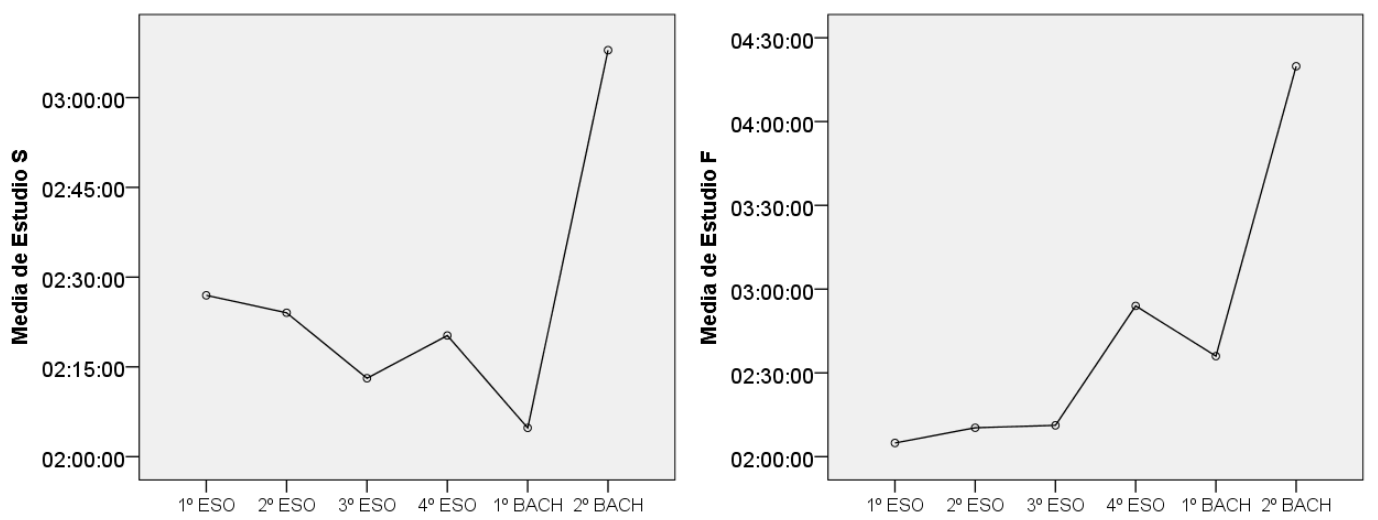

Gráfico 33: media de horas dedicadas a estudiar por curso (entre semana y fin de semana).

- Uso del WhatsApp entre semana y en el fin de semana: los perfiles mostrados en las gráficas 34 ponen de manifiesto que el consumo de tiempo medio dedicado al uso de la aplicación WhatsApp por curso escolar es el mismo tanto entre semana como el fin de semana.

La tendencia indica que el tiempo dedicado a esta actividad aumenta hasta 3o de ESO, para disminuir en 40 de ESO, volver a aumentar en 10 de $\mathrm{BACH}$ y terminar disminuyendo en 20 de $\mathrm{BACH}$. Los valores mínimos se localizan en adolescentes de 1을 de ESO .Los valores máximos se encuentran en 3으 de ESO y en 10 de $\mathrm{BACH}$.
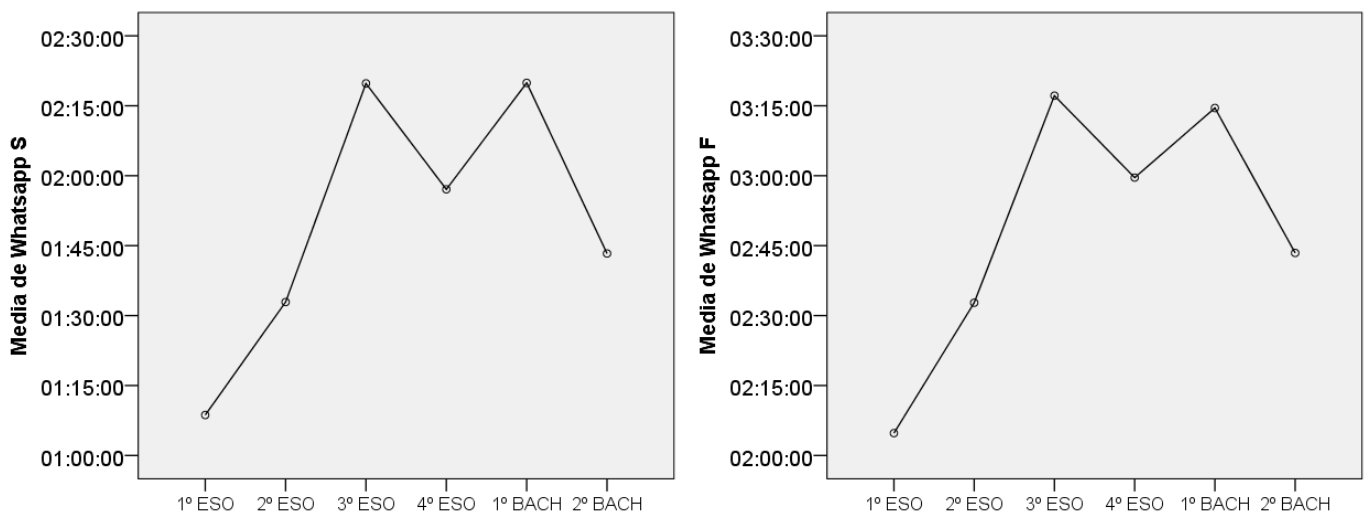

Gráfico 34: media de horas a uso del WhatsApp por curso (entre semana y fin de semana). 
- Uso de redes sociales entre semana y en el fin de semana: al igual que con el uso del WhatsApp se observa una disminución del tiempo medio de uso en los cursos superiores, principalmente un descenso notable en $2 \stackrel{\circ}{ }$ de $\mathrm{BACH}$, donde el tiempo dedicado al WhatsApp se acerca de nuevo a las cifras de 10 de ESO (gráfico 35).
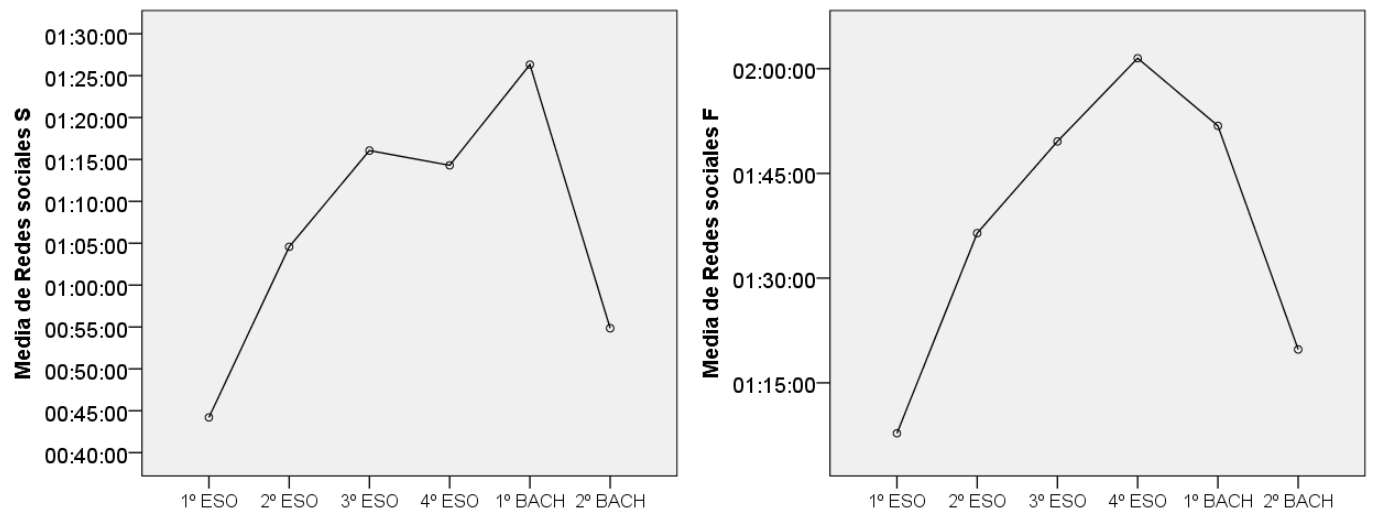

Gráfico 35: media de horas a uso de redes sociales por curso (entre semana y fin de semana).

- Uso de internet entre semana y en el fin de semana: obtenemos un resultado semejante a los anteriores en 20 de $\mathrm{BACH}$ el número de horas que los adolescentes dedican a navegar por internet es bastante inferior al de 10 de ESO (gráfico 36).
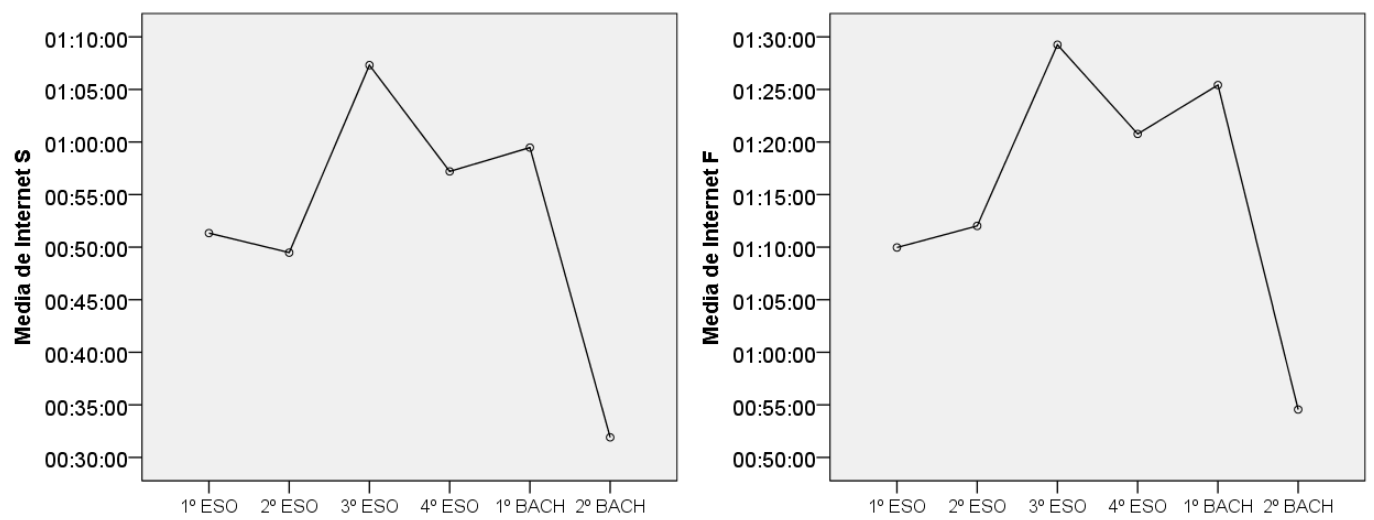

Gráfico 36: media de horas dedicadas a internet por curso (entre semana y fin de semana). 
- Uso de videoconsolas entre semana y en el fin de semana: el gráfico 37 muestra un decremento muy notable en el tiempo de uso de videojuegos por parte de los adolescentes en 20 BACH.
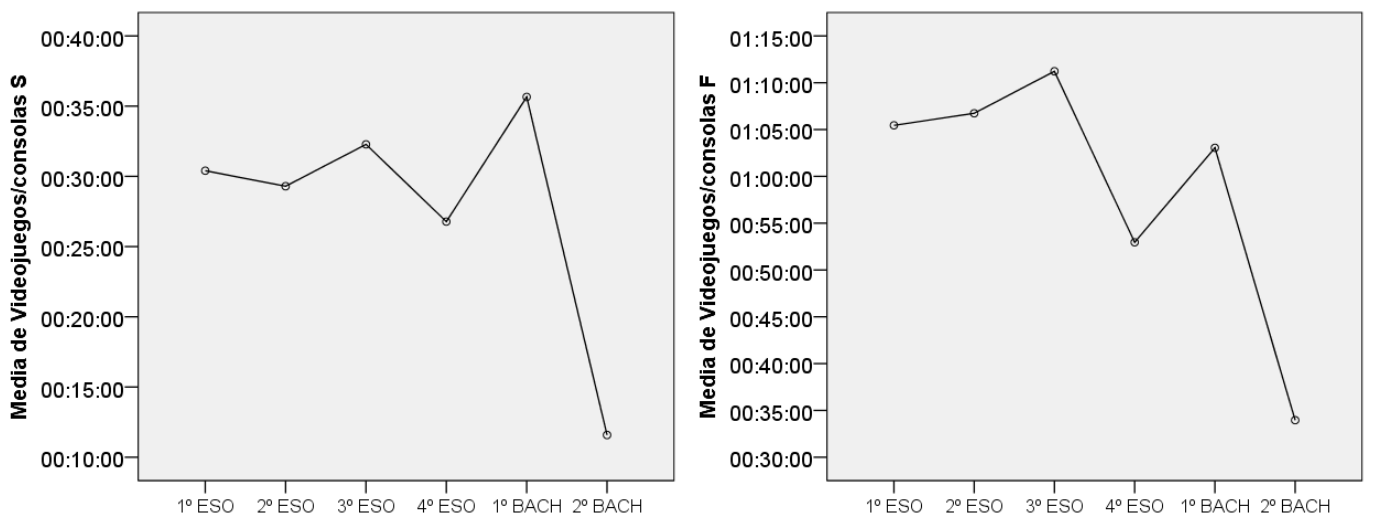

Gráfica 37: media de horas dedicadas a videojuegos y consolas por curso

- Teléfono semana y en el fin de semana: la gráfica 38 muestra un aumento en el tiempo dedicado a utilizar el teléfono móvil durante los primeros años de secundaria del adolescente. Sin embargo, a partir de 30 de ESO, el tiempo dedicado al uso del teléfono móvil desciende notablemente, hasta llegar a los valores más bajos en 2 de $\mathrm{BACH}$, valores inferiores a los encontrados para $1 \stackrel{0}{\mathrm{o}} \mathrm{de}$ ESO.
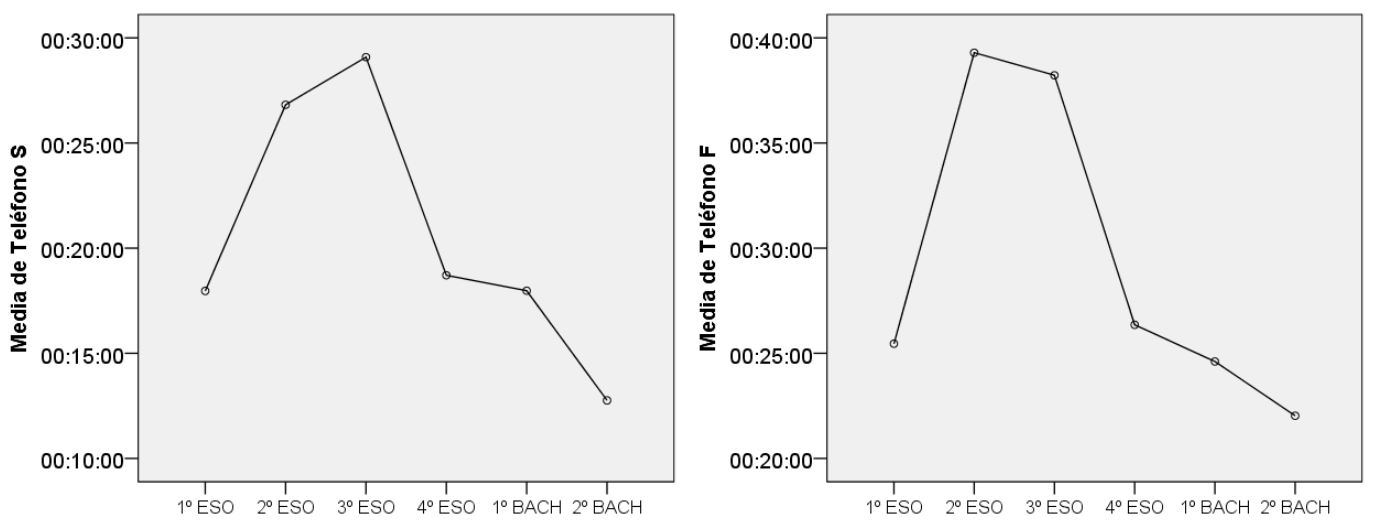

Gráfico 38: media de horas dedicadas al teléfono por curso 
- Deporte entre semana y en el fin de semana: como puede observarse en la gráfica 39, el tiempo medio dedicado por los adolescentes a realizar deporte decrece, desde $3 \circ$ de ESO, cada año. Los adolescentes de 20 de BACH dedican 49 minutos menos entre semana y 38 minutos menos el fin de semana a realizar deporte que los de 1 으 de ESO.
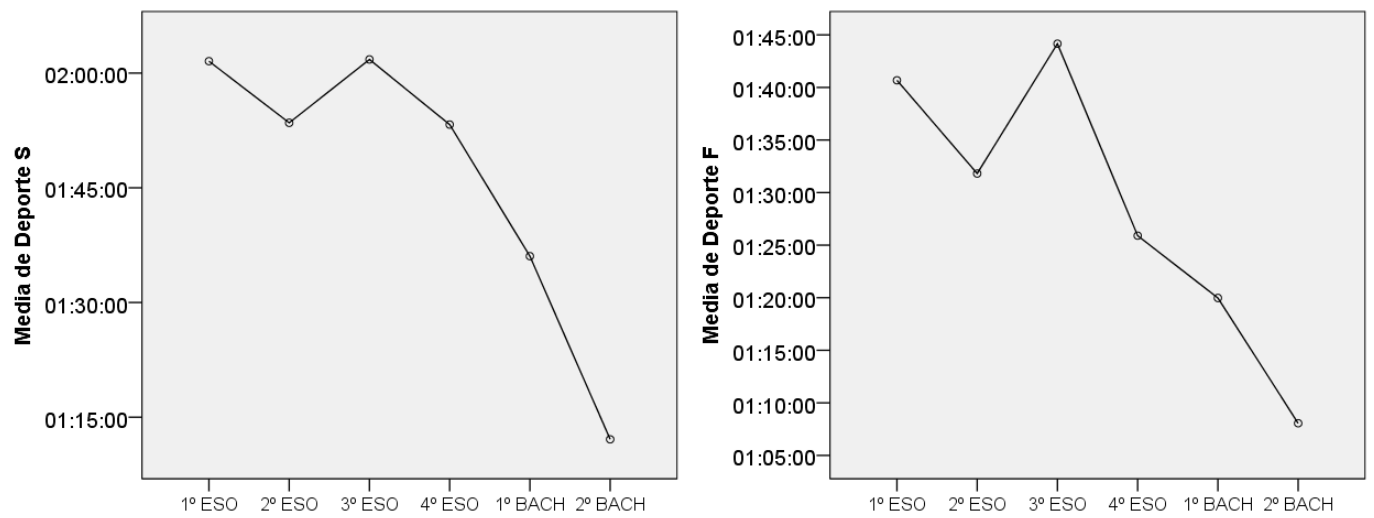

Gráfico 39: media de horas dedicadas al deporte por curso

- Lectura entre semana y en el fin de semana: la gráfica 40 muestra que el tiempo dedicado por los adolescentes a la lectura tanto entre semana como durante el fin de semana decrece notablemente con la edad, tomando sus valores más bajos en $2 \stackrel{\circ}{\circ}$ de $\mathrm{BACH}$.
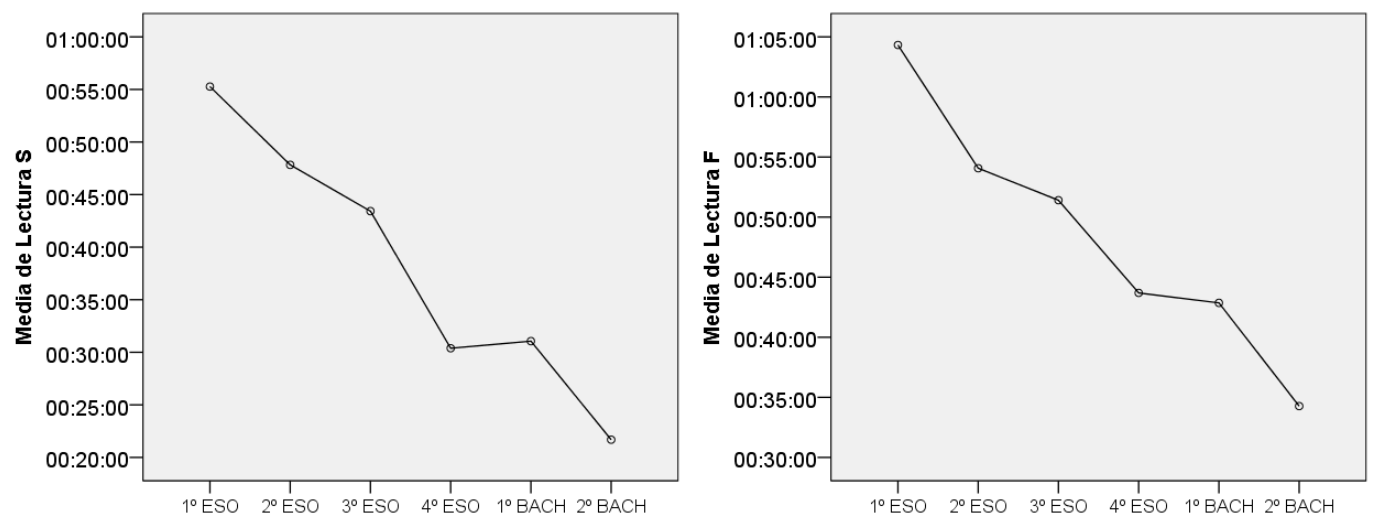

Gráfico 40: media de horas dedicadas al deporte por curso 
- Alimentación entre semana: se aprecian diferencias significativas en el tiempo dedicado por los adolescentes a la alimentación durante la semana. La diferencia entre 10 de ESO y $2^{\circ}$ de $\mathrm{BACH}$, como puede verse en la gráfica 41 , es de 32 minutos.

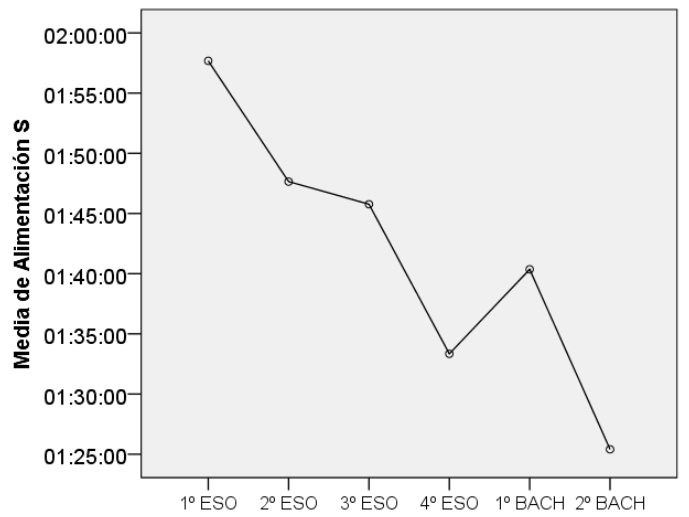

Gráfico 41: media de tiempo dedicado a la alimentación entre semana.

- Salir con amigos entre semana y fin de semana: existe diferencias significativas por curso en cuanto al tiempo destinado por los adolescentes a salir con los amigos. Como puede verse en la gráfica 42 , la media de tiempo dedicado a esta actividad aumenta hasta 30 de ESO (tanto entre semana como durante el fin de semana). A partir de 30 de ESO empieza a disminuir drásticamente hasta 41 minutos menos en $2^{\circ}$ de $\mathrm{BACH}$ que en $3^{\circ}$ de ESO entre semana y 68 minutos en fin de semana.
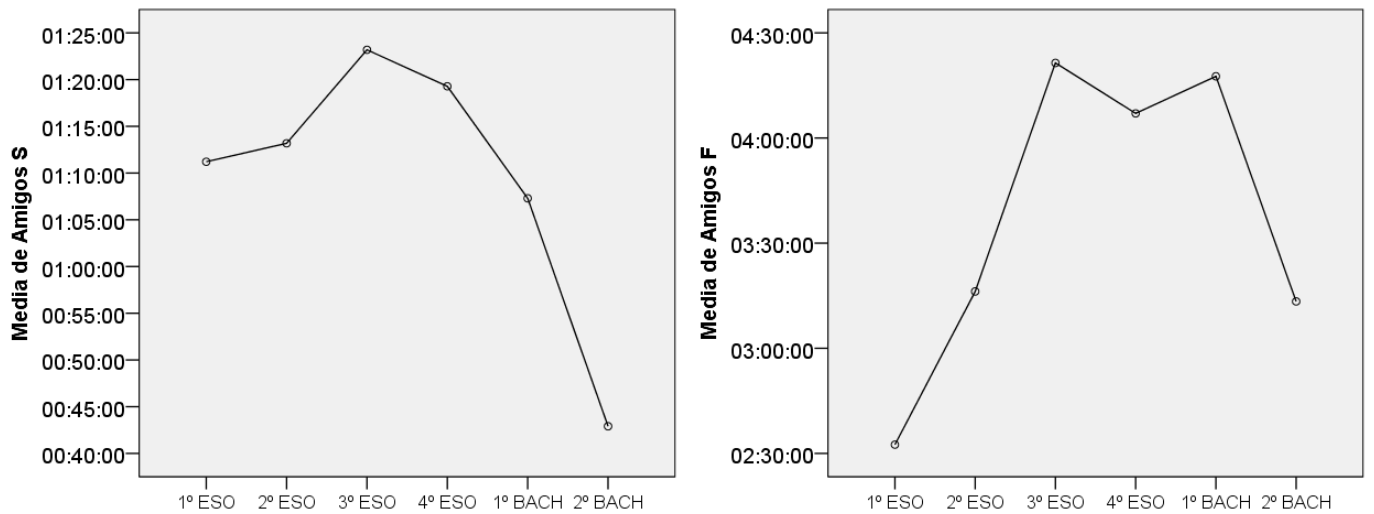

Gráfico 42: media de tiempo dedicado a la salir con los amigos entre semana. 
- Tiempo que tardan en dormirse: del mismo modo, vamos a analizar si existen diferencias en el tiempo que tardan en dormirse por curso. En la gráfica 43 podemos ver cuál es la tendencia por curso. Podemos concluir que los adolescentes tardan más tiempo en dormirse con el curso.

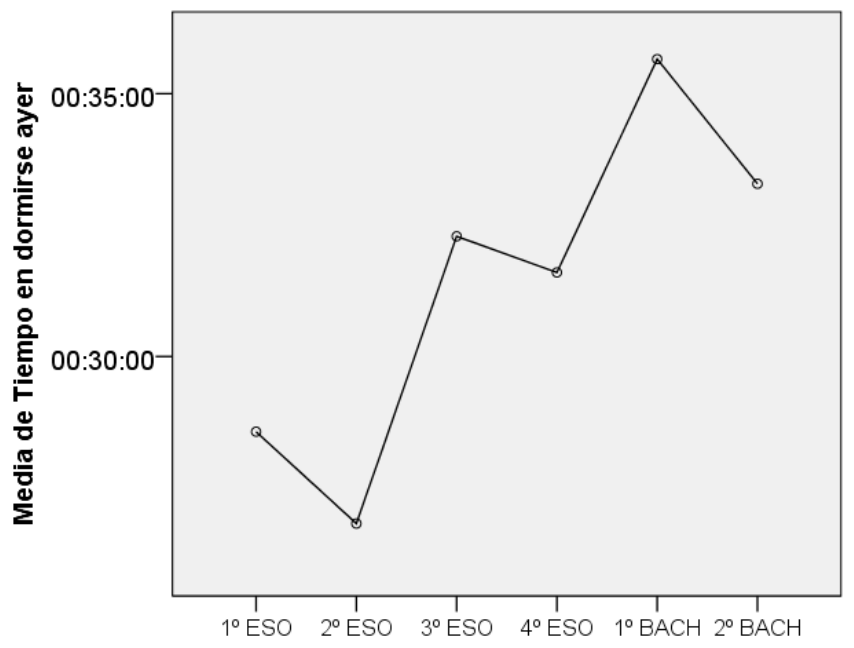

Gráfica 43: tiempo medio que los adolescentes tardan en dormirse por curso

El grado de significación global es de 0,047, lo que quiere decir que existen diferencias significativas por curso en el tiempo que tardan en dormirse. Si analizamos el grado de significación por cursos, podemos ver que sólo existen diferencias significativas entre 20 de ESO y 10 de BACH (tabla 42).

\begin{tabular}{|c|c|c|c|c|c|c|}
\hline & $1^{\circ} \mathrm{ESO}$ & 2o ESO & 3으 ESO & $4 \div$ ESO & 10 BACH & $2{ }^{\circ} \mathrm{BACH}$ \\
\hline $11^{\circ}$ ESO & & 0,988 & 0,773 & 0,926 & 0,160 & 0,726 \\
\hline $2^{\circ}$ ESO & 0,988 & & 0,410 & 0,664 & 0,043 & 0,412 \\
\hline 3으 ESO & 0,773 & 0,410 & & 1,000 & 0,887 & 1,000 \\
\hline $4^{\circ}$ ESO & 0,926 & 0,664 & 1,000 & & 0,836 & 0,998 \\
\hline $10 \mathrm{BACH}$ & 0,160 & 0,043 & 0,887 & 0,836 & & 0,986 \\
\hline $2{ }^{\circ} \mathrm{BACH}$ & 0,726 & 0,412 & 1,000 & 0,998 & 0,986 & \\
\hline
\end{tabular}

Tabla 42: diferencias significativas de tiempo que tardan en dormirse por curso

Podemos apuntar que no se encuentran diferencias significativas en el tiempo que los adolescentes dedican a ver la televisión (independientemente del día de la semana). 
Tampoco se encuentran diferencias en el tiempo dedicado a desempeñar trabajo remunerado cualquier día de la semana ni en el tiempo invertido en trabajo doméstico durante el fin de semana. No hay diferencias en el tiempo dedicado a la higiene personal entre semana, ni a la alimentación durante el fin de semana según el curso.

\subsection{4.- Nacionalidad}

Como hemos explicado en el punto 5.1.4 del análisis descriptivo, hemos agrupado todas las nacionalidades no españolas bajo la etiqueta de "extranjera"; lo cual nos ha permitido analizar las diferencias del uso del tiempo de los adolescentes por nacionalidad mediante la t-Student en SPSS.

Los resultados obtenidos de la t-Student ponen de manifiesto que existen 8 actividades en las que se pueden apreciar diferencias significativas en el uso del tiempo por nacionalidad (celdas marcadas en rojo en tabla 43).

A continuación analizamos más en detalle las 8 actividades que muestran diferencias significativas en relación a la nacionalidad:

- Los adolescentes españoles dedican más tiempo que los adolescentes de nacionalidades extranjeras a las siguientes actividades (gráfico 44):

- Actividades extraescolares entre semana: los adolescentes españoles dedican a asistir a clases extraescolares 1:50 frente a 0:49 los extranjeros (1:00 hora más de media).

- Estudiar el fin de semana: Los adolescentes españoles dedican a estudiar el fin de semana 2:32 mientras que los extranjeros sólo 1:55 (37 minutos más).

- WhatsApp el fin de semana: los adolescentes españoles dedican 2:46 frente a las 1:58 de los extranjeros (47 minutos más de media).

- Lectura el fin de semana: los españoles leen entre semana una media de 00:41 frente a 00:22 de los extranjeros (19 minutos más de media).

- Salir con la pareja el fin de semana: los adolescentes de nacionalidad española salen con su pareja el fin de semana una media de 00:26 mientras que los extranjeros sólo 00:09 (17 minutos más de media). 


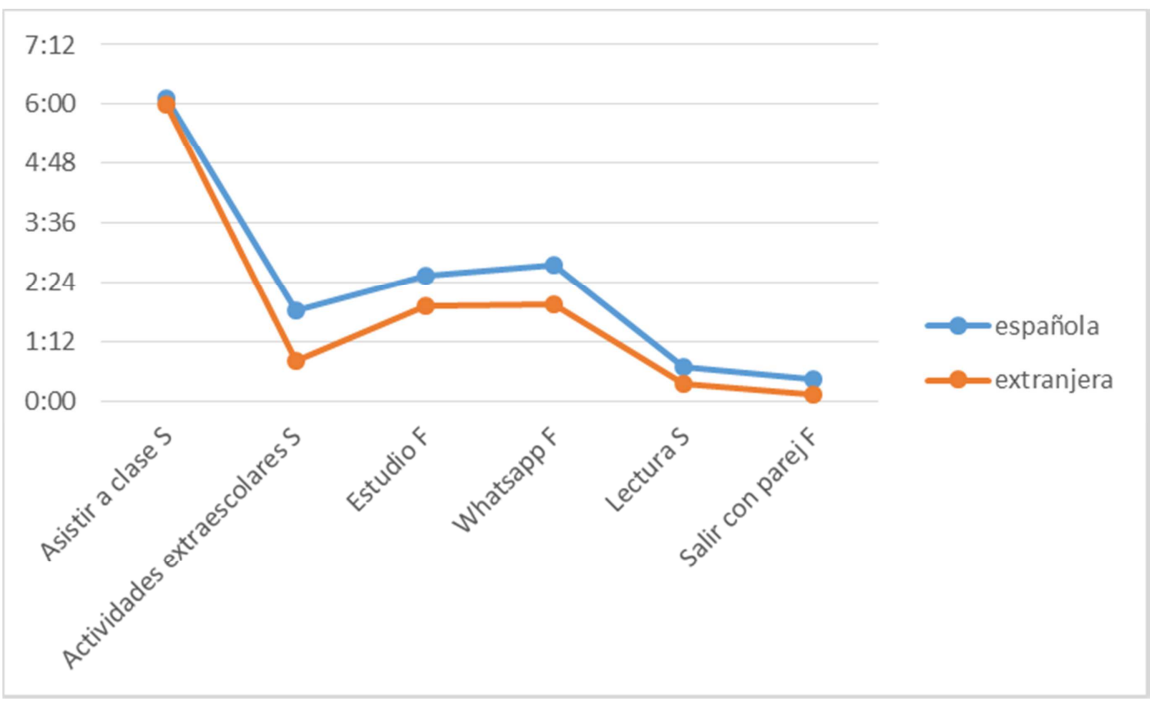

Gráfico 44: adolescentes españoles dedican más tiempo que extranjeros.

- Los adolescentes de nacionalidades extranjeras dedican más tiempo que los adolescentes españoles a las siguientes actividades (gráfico 45):

- Videojuegos/consolas entre semana: los adolescentes extranjeros dedican jugar a videojuegos 1:04 frente a 0:28 de los españoles (36 minutos más).

- Salir con los amigos: los adolescentes extranjeros salen con los amigos 2:10 horas frente a los 1:09 horas que salen los españoles (1:01 hora más).

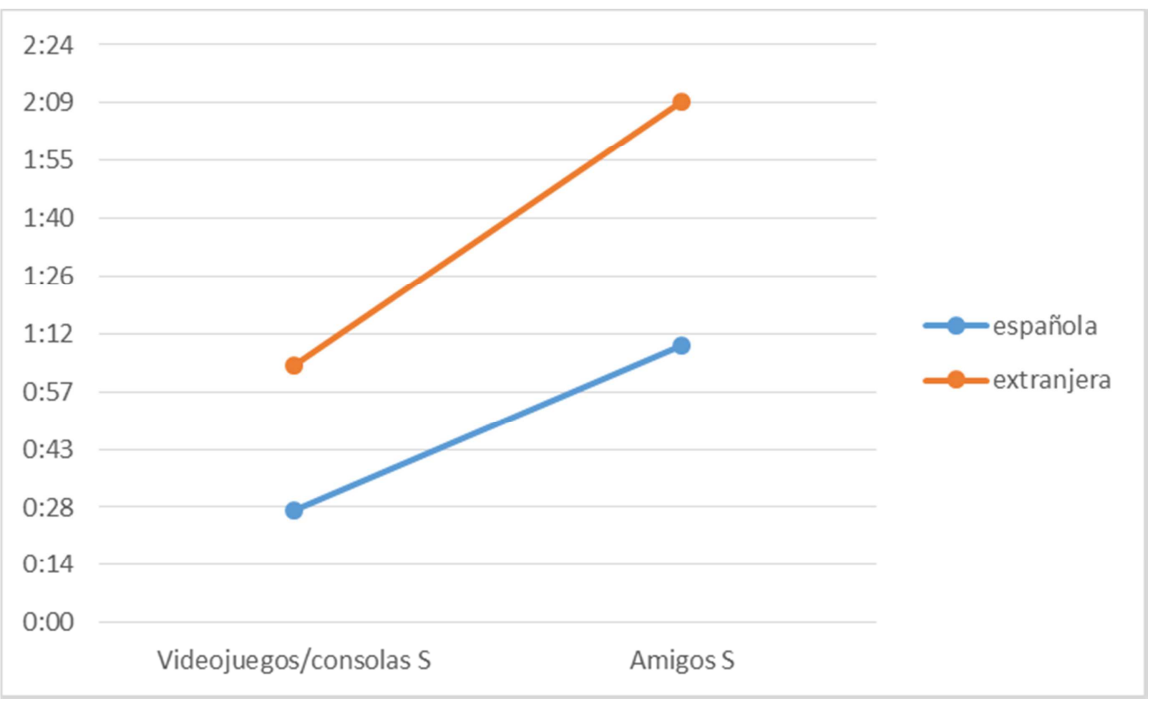

Gráfico 45: adolescentes extranjeros dedican más tiempo que españoles. 
2a PARTE

Capítulo 4.- Resultados

\begin{tabular}{|c|c|c|c|c|c|c|c|c|}
\hline & \multirow{2}{*}{\multicolumn{2}{|c|}{\begin{tabular}{|c} 
Media \\
española extranjera
\end{tabular}}} & \multirow[t]{2}{*}{$t$} & \multirow{2}{*}{ gl } & \multirow{2}{*}{$\begin{array}{c}\text { Sig. } \\
\text { (bilateral) }\end{array}$} & \multirow{2}{*}{$\begin{array}{l}\text { Diferencia } \\
\text { de medias }\end{array}$} & \multicolumn{2}{|c|}{$\begin{array}{c}95 \% \text { de int. de } \\
\text { confianza }\end{array}$} \\
\hline & & & & & & & Inferior & Superior \\
\hline Dormir S & $7: 44$ & $7: 33$ & 1,026 & 28,998 & 0,313 & $0: 11$ & $-0: 11$ & $0: 34$ \\
\hline Dormir F & 9:32 & $9: 46$ & $-0,934$ & 28,083 & 0,358 & $-0: 14$ & $-0: 45$ & $0: 16$ \\
\hline Asistir a clase $\mathrm{S}$ & $6: 08$ & $6: 00$ & 5,148 & 34,948 & 0,000 & $0: 07$ & $0: 04$ & $0: 10$ \\
\hline Asistir a clase $F$ & $0: 00$ & $0: 00$ & & & & & & \\
\hline Actividades extraesc. S & $1: 50$ & $0: 49$ & 5,342 & 30,531 & 0,000 & $1: 00$ & $0: 37$ & $1: 24$ \\
\hline Actividades extraesc. F & $0: 42$ & $0: 31$ & 1,064 & 27,617 & 0,296 & $0: 11$ & $-0: 10$ & $0: 32$ \\
\hline Estudio S & $2: 24$ & $2: 15$ & 0,486 & 32,087 & 0,631 & $0: 08$ & $-0: 26$ & $0: 42$ \\
\hline Estudio F & $2: 32$ & $1: 55$ & 2,185 & 28,664 & 0,037 & $0: 37$ & $0: 02$ & $1: 12$ \\
\hline WhatsApp S & $1: 47$ & $1: 31$ & 0,828 & 31,660 & 0,414 & $0: 15$ & $-0: 22$ & $0: 54$ \\
\hline WhatsApp F & $2: 46$ & $1: 58$ & 2,635 & 31,238 & 0,013 & $0: 47$ & $0: 10$ & $1: 24$ \\
\hline Redes sociales S & $1: 05$ & $1: 14$ & $-0,774$ & 31,153 & 0,445 & $-0: 09$ & $-0: 33$ & $0: 15$ \\
\hline Redes sociales F & $1: 35$ & $1: 50$ & $-0,952$ & 29,070 & 0,349 & $-0: 15$ & $-0: 47$ & $0: 17$ \\
\hline Internet S & $0: 53$ & $1: 07$ & $-1,148$ & 30,960 & 0,260 & $-0: 13$ & $-0: 38$ & $0: 10$ \\
\hline Internet F & $1: 15$ & $1: 20$ & $-0,261$ & 31,883 & 0,796 & $-0: 04$ & $-0: 41$ & $0: 31$ \\
\hline Videojuegos/consolas S & $0: 28$ & $1: 04$ & $-2,063$ & 31,492 & 0,047 & $-0: 36$ & $-1: 12$ & $-0: 00$ \\
\hline Videojuegos/consolas F & $1: 00$ & $1: 33$ & $-1,484$ & 33,822 & 0,147 & $-0: 32$ & $-1: 17$ & $0: 12$ \\
\hline Televisión S & $1: 25$ & $1: 42$ & $-1,707$ & 32,704 & 0,097 & $-0: 17$ & $-0: 37$ & $0: 03$ \\
\hline Televisión F & $2: 05$ & $2: 28$ & $-1,201$ & 34,302 & 0,238 & $-0: 22$ & $-1: 01$ & $0: 15$ \\
\hline Teléfono S & $0: 21$ & $0: 35$ & $-1,090$ & 31,467 & 0,284 & $-0: 13$ & $-0: 39$ & $0: 11$ \\
\hline Teléfono F & $0: 30$ & $0: 28$ & 0,190 & 32,288 & 0,850 & $0: 01$ & $-0: 19$ & $0: 23$ \\
\hline Deporte S & $1: 49$ & $1: 54$ & $-0,336$ & 32,670 & 0,739 & $-0: 04$ & $-0: 34$ & $0: 24$ \\
\hline Deporte F & $1: 30$ & $1: 42$ & $-0,816$ & 30,096 & 0,421 & $-0: 12$ & $-0: 42$ & $0: 18$ \\
\hline Trabajo doméstico S & $0: 38$ & $0: 46$ & $-1,138$ & 32,241 & 0,264 & $-0: 08$ & $-0: 24$ & $0: 06$ \\
\hline Trabajo doméstico F & $0: 50$ & $0: 59$ & $-0,879$ & 33,012 & 0,386 & $-0: 09$ & $-0: 31$ & $0: 12$ \\
\hline Trabajo remunerado S & $0: 06$ & $0: 25$ & $-1,719$ & 29,404 & 0,096 & $-0: 18$ & $-0: 41$ & $0: 03$ \\
\hline Trabajo remunerado $\mathrm{F}$ & $0: 10$ & $0: 12$ & $-0,203$ & 34,094 & 0,840 & $-0: 01$ & $-0: 14$ & $0: 11$ \\
\hline Lectura S & $0: 41$ & $0: 22$ & 3,063 & 28,491 & 0,005 & $0: 19$ & $0: 06$ & $0: 31$ \\
\hline Lectura F & $0: 51$ & $0: 38$ & 0,976 & 31,219 & 0,336 & $0: 12$ & $-0: 13$ & $0: 38$ \\
\hline Higiene personal S & $1: 11$ & $1: 15$ & $-0,379$ & 28,608 & 0,707 & $-0: 03$ & $-0: 25$ & $0: 17$ \\
\hline Higiene personal F & $1: 12$ & $1: 26$ & $-1,016$ & 28,691 & 0,318 & $-0: 14$ & $-0: 42$ & $0: 14$ \\
\hline Alimentación S & $1: 43$ & $1: 59$ & $-0,933$ & 27,760 & 0,359 & $-0: 15$ & $-0: 50$ & $0: 18$ \\
\hline Alimentación F & $1: 45$ & $1: 38$ & 0,572 & 25,973 & 0,573 & $0: 07$ & $-0: 19$ & $0: 35$ \\
\hline Amigos S & $1: 09$ & $2: 10$ & $-3,290$ & 30,056 & 0,003 & $-1: 00$ & $-1: 38$ & $-0: 23$ \\
\hline Amigos $\mathrm{F}$ & $3: 33$ & $4: 03$ & $-1,128$ & 30,307 & 0,268 & $-0: 30$ & $-1: 24$ & $0: 24$ \\
\hline Desplazamientos S & $0: 45$ & $1: 08$ & $-1,553$ & 24,378 & 0,133 & $-0: 23$ & $-0: 54$ & $0: 07$ \\
\hline Desplazamientos F & $0: 58$ & $0: 52$ & 0,388 & 23,686 & 0,701 & $0: 05$ & $-0: 25$ & $0: 37$ \\
\hline Salir con pareja S & $0: 15$ & $0: 07$ & 1,957 & 49,381 & 0,056 & $0: 07$ & $-0: 00$ & $0: 16$ \\
\hline Salir con parej F & $0: 26$ & 0:09 & 2,963 & 33,459 & 0,006 & $0: 17$ & $0: 05$ & $0: 29$ \\
\hline Tiempo en dormirse ayer & $0: 30$ & $0: 32$ & $-0,187$ & 33,409 & 0,853 & $-0: 01$ & $-0: 13$ & $0: 11$ \\
\hline
\end{tabular}

Tabla 43: Análisis t-Student uso del tiempo con respecto a la nacionalidad 


\subsection{5.- Centro educativo:}

Para analizar si existen diferencias en el uso del tiempo de los adolescentes por centro educativo, vamos a realizar una ANOVA de un factor eligiendo la opción de Tukey. De esta manera, podemos saber si hay diferencias significativas en el uso del tiempo de los adolescentes por centro (marcamos las actividades en las que hemos encontrado diferencias significativas en rojo en la tabla 44).

Debido al escaso número de adolescentes encuestados del centro público urbano 2 (sólo 56 individuos) y al factor curso (el centro público urbano 2 sólo tiene representación de 3o ESO, 1ㅇ y 2o de BACH), hemos tomado la decisión de agrupar las muestras de los dos centros públicos urbanos bajo la denominación de público urbano. De esta manera, cumplimos el objetivo de equilibrar la muestra del centro público urbano puesto que la cantidad de respuestas por curso de ambos centros se complementan (principalmente en $1 \circ$ y $2 \circ$ de $B A C H)$.

Analizamos con más detalle las actividades que, tal y como se ha reflejado en la tabla 44 , muestran diferencias significativas por centro:

- Dormir entre semana: tal y como refleja gráfica 46, los adolescentes del centro rural son los que más tiempo dedican a dormir. Los que menos tiempo dedican a esta actividad son los adolescentes de los centros privados.

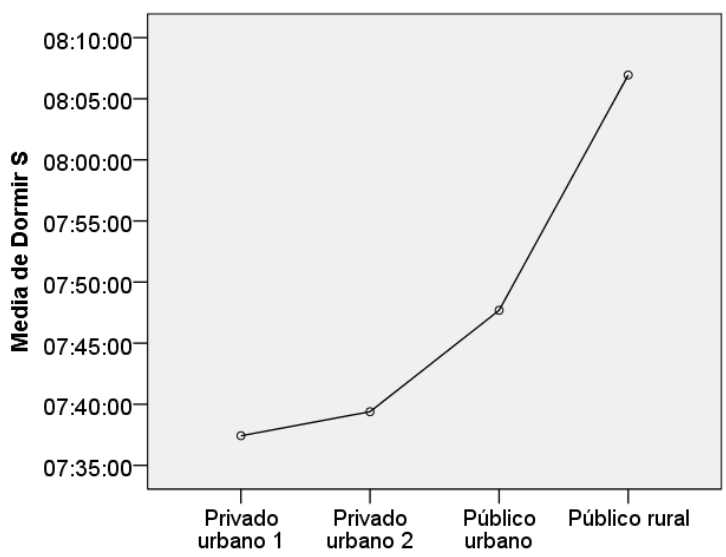

Gráfico 46: media de tiempo dedicado a dormir entre semana por centro. 
- Asistir a clase entre semana: como puede observarse en el gráfico 47, los adolescentes del centro privado urbano 2 son los que más tiempo dedican a ir a clase con relación al resto de los centros.

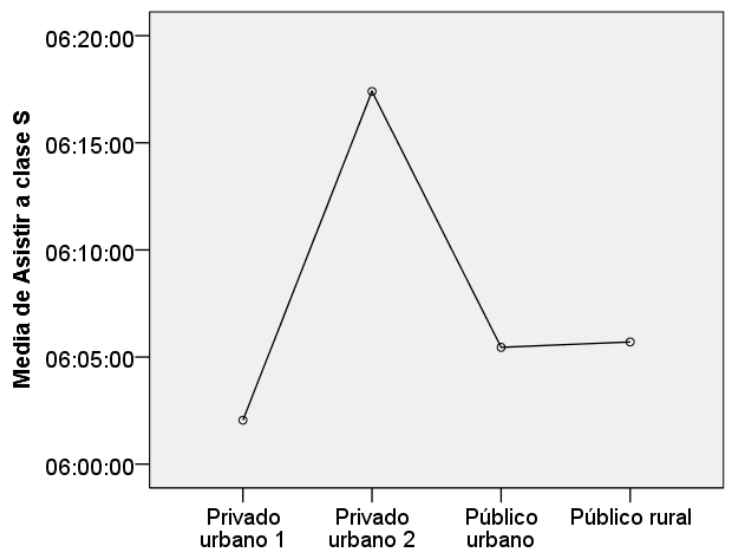

Gráfico 47: media de tiempo dedicado a asistir a clase entre semana por centro.

- Actividades extraescolares: la gráfica 48 pone de manifiesto que los adolescentes de los centros urbanos son notablemente los que más tiempo dedican a realizar actividades extraescolares, tanto entre semana, como durante el fin de semana. Durante el fin de semana, dedican más tiempo a estas actividades los adolescentes de los centros privados que aquellos de los públicos.
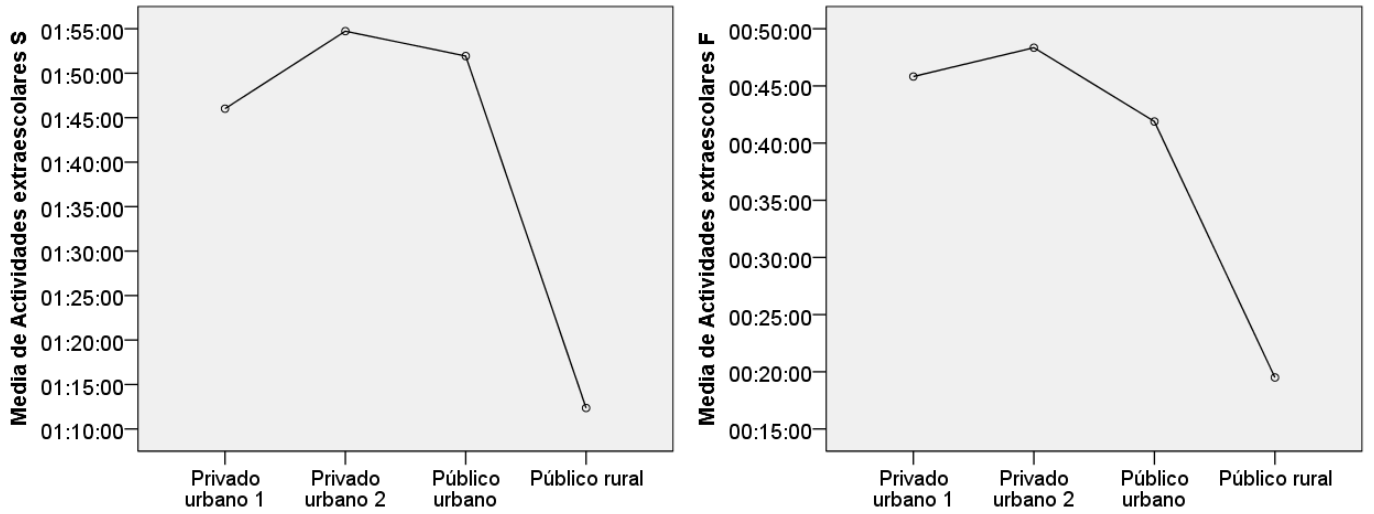

Gráfica 48: media de tiempo dedicado a realizar actividades extraescolares por centro. 
Capítulo 4.- Resultados

\begin{tabular}{|c|c|c|c|c|c|}
\hline & $\begin{array}{c}\text { Privado } \\
\text { urbano } 1\end{array}$ & $\begin{array}{c}\text { Privado } \\
\text { urbano } 2 \\
\end{array}$ & $\begin{array}{l}\text { Público } \\
\text { urbano }\end{array}$ & $\begin{array}{c}\text { Público } \\
\text { rural }\end{array}$ & Sig. \\
\hline Dormir S & $7: 37$ & $7: 39$ & $7: 47$ & 8:06 & 0,000 \\
\hline Dormir F & $9: 36$ & $9: 32$ & 9:30 & $9: 45$ & 0,435 \\
\hline Asistir a clase $\mathrm{S}$ & $6: 02$ & $6: 17$ & $6: 05$ & $6: 05$ & 0,000 \\
\hline \multicolumn{6}{|l|}{ Asistir a clase F } \\
\hline Actividades extraesc. S & $1: 46$ & $1: 54$ & $1: 51$ & $1: 12$ & 0,004 \\
\hline Actividades extraesc. F & $0: 45$ & $0: 48$ & $0: 41$ & $0: 19$ & 0,004 \\
\hline Estudio S & $2: 19$ & $2: 43$ & $2: 15$ & $2: 08$ & 0,000 \\
\hline Estudio F & $2: 21$ & $2: 57$ & $2: 23$ & $2: 01$ & 0,000 \\
\hline Whatsapp S & $1: 40$ & $1: 40$ & $1: 55$ & $1: 27$ & 0,034 \\
\hline Whatsapp F & $2: 32$ & $2: 46$ & $2: 50$ & $2: 22$ & 0,247 \\
\hline Redes sociales S & $0: 51$ & $1: 07$ & $1: 09$ & $0: 54$ & 0,020 \\
\hline Redes sociales F & $1: 20$ & $1: 37$ & $1: 42$ & $1: 15$ & 0,027 \\
\hline Internet S & $0: 49$ & $0: 55$ & $0: 54$ & $0: 48$ & 0,493 \\
\hline Internet F & $1: 07$ & $1: 19$ & $1: 18$ & $0: 56$ & 0,036 \\
\hline Videojuegos/consolas S & $0: 33$ & $0: 23$ & $0: 31$ & $0: 27$ & 0,093 \\
\hline Videojuegos/consolas F & $1: 06$ & $0: 54$ & $1: 05$ & $0: 52$ & 0,172 \\
\hline Televisión S & $1: 27$ & $1: 23$ & $1: 26$ & $1: 27$ & 0,891 \\
\hline Televisión F & $2: 07$ & $2: 10$ & $2: 03$ & $2: 01$ & 0,688 \\
\hline Teléfono S & $0: 21$ & $0: 25$ & $0: 20$ & $0: 15$ & 0,153 \\
\hline Teléfono F & $0: 29$ & $0: 36$ & $0: 28$ & $0: 26$ & 0,212 \\
\hline Deporte S & $1: 36$ & $1: 53$ & $1: 54$ & $1: 25$ & 0,003 \\
\hline Deporte F & $1: 41$ & $1: 26$ & $1: 31$ & $1: 23$ & 0,102 \\
\hline Trabajo doméstico S & $0: 37$ & $0: 38$ & $0: 38$ & $0: 37$ & 0,979 \\
\hline Trabajo doméstico F & $0: 44$ & $0: 50$ & $0: 51$ & $0: 57$ & 0,253 \\
\hline Trabajo remunerado $\mathrm{S}$ & $0: 05$ & 0:09 & $0: 05$ & $0: 07$ & 0,331 \\
\hline Trabajo remunerado F & $0: 05$ & $0: 15$ & $0: 08$ & $0: 22$ & 0,006 \\
\hline Lectura S & $0: 32$ & $0: 42$ & $0: 42$ & $0: 40$ & 0,073 \\
\hline Lectura F & $0: 42$ & $0: 49$ & $0: 54$ & $0: 41$ & 0,074 \\
\hline Higiene personal S & $1: 03$ & $1: 11$ & $1: 14$ & $1: 03$ & 0,134 \\
\hline Higiene personal F & $1: 07$ & $1: 13$ & $1: 15$ & $1: 04$ & 0,138 \\
\hline Alimentación S & $1: 39$ & $1: 40$ & $1: 49$ & $1: 37$ & 0,123 \\
\hline Alimentación F & $1: 38$ & $1: 39$ & $1: 53$ & $1: 30$ & 0,000 \\
\hline Amigos S & $1: 02$ & $1: 18$ & $1: 10$ & $1: 09$ & 0,209 \\
\hline Amigos F & $3: 08$ & $3: 31$ & $3: 42$ & $3: 33$ & 0,026 \\
\hline Desplazamientos S & $0: 46$ & $0: 48$ & $0: 44$ & $0: 37$ & 0,231 \\
\hline Desplazamientos F & $1: 01$ & $1: 02$ & $0: 56$ & $0: 41$ & 0,045 \\
\hline Salir con pareja S & 0:08 & $0: 12$ & $0: 13$ & $0: 11$ & 0,620 \\
\hline Salir con pareja F & $0: 16$ & $0: 23$ & $0: 30$ & $0: 27$ & 0,131 \\
\hline Tiempo en dormirse ayer & $0: 26$ & $0: 35$ & $0: 29$ & $0: 30$ & 0,004 \\
\hline
\end{tabular}

Tabla 44: medias de tiempo por centro educativo y nivel de significación 
- Tiempo dedicado a estudiar: los adolescentes que menos tiempo dedican a estudiar son los adolescentes del centro público rural (gráfica 49). Dentro de los centros urbanos, los que más tiempo dedican son los del centro privado urbano 2. Entendemos que esta práctica no es extensible a otros centros privados urbanos, puesto que en este el tiempo dedicado a estudiar por los adolescentes del centro privado urbano 1 es menor.
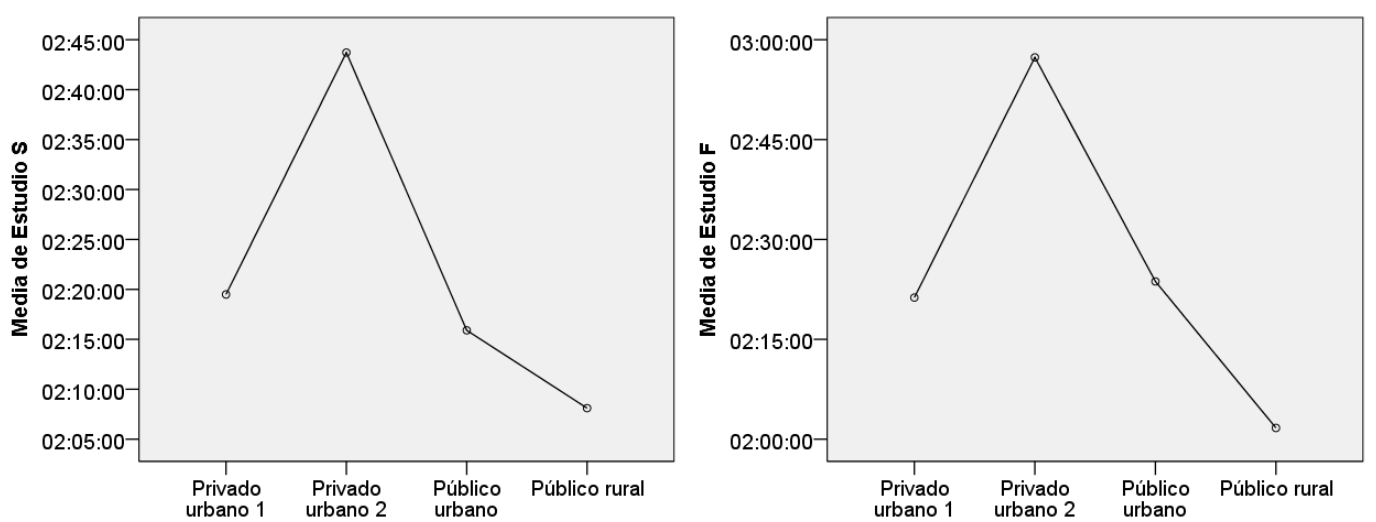

Gráfica 49: media de tiempo dedicado a estudiar por centro.

- Uso del WhatsApp entre semana: tal y como muestra la gráfica 50, los adolescentes que más dedican a esta actividad son los del centro público urbano. Los adolescentes del centro público rural son los que menos tiempo dedican a esta actividad.

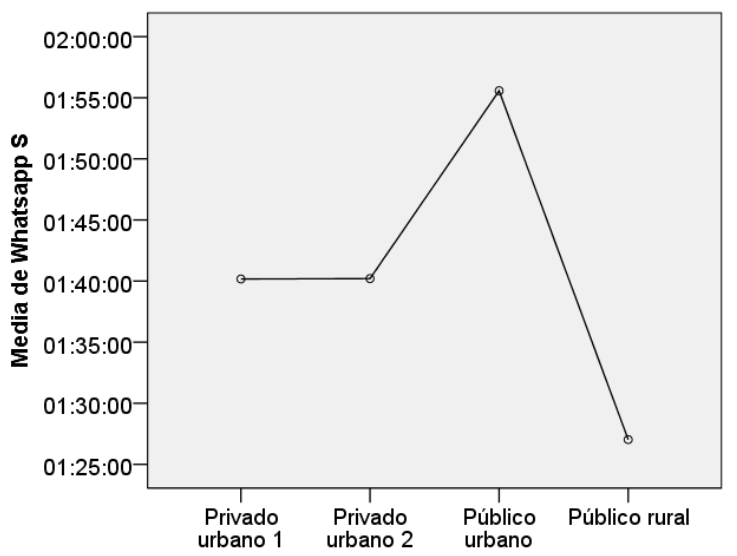

Gráfico 50: media de tiempo dedicado a uso de WhatsApp entre semana por centro. 
- Uso de redes sociales: los adolescentes del centro público urbano son los que más tiempo dedican a las redes sociales, tanto entre semana como durante el fin de semana (gráfica 51).
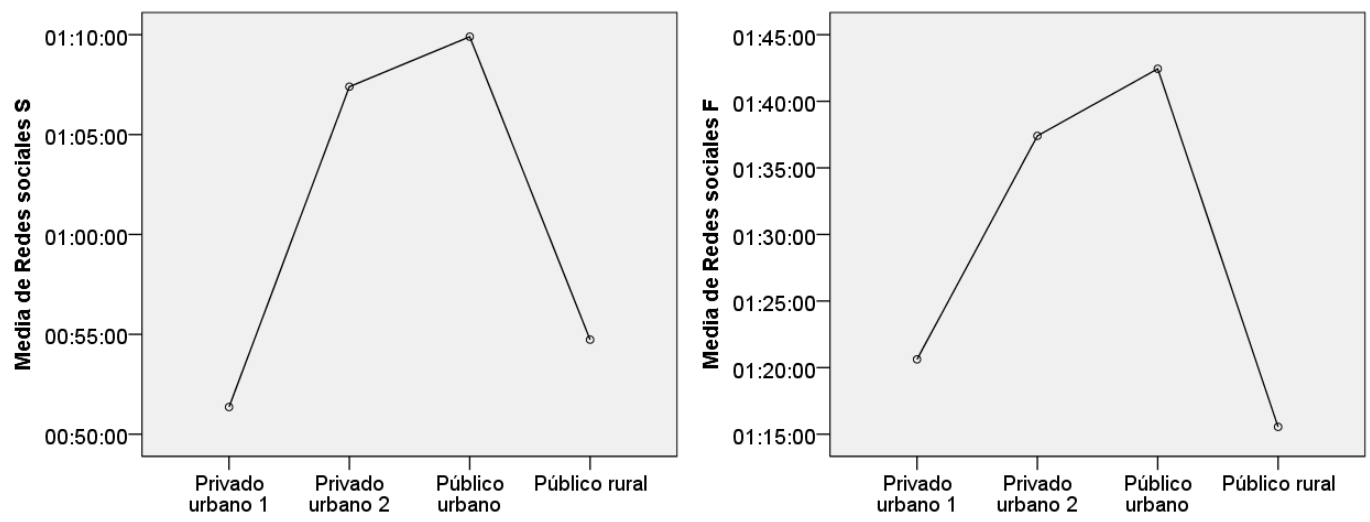

Gráfica 51: media de tiempo dedicado a redes sociales por centro.

- Internet en fin de semana: tal y como muestra la gráfica 52, los adolescentes del centro público rural manifiestan ser los que menos tiempo dedican a navegar por internet durante el fin de semana. En efecto, dedican menos de 1:00 hora al día.

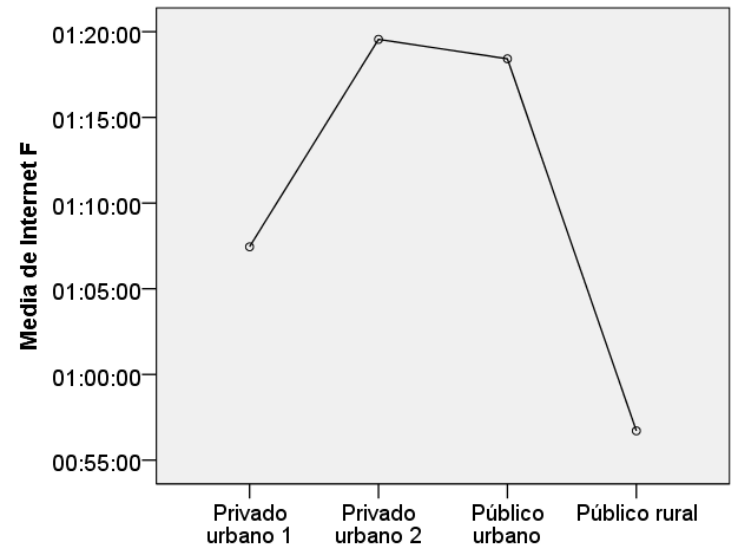

Gráfica 52: media de tiempo dedicado a internet en fin de semana por centro. 
- Deporte entre semana: según muestra la gráfica 53, los adolescentes de los centros urbanos dedican más tiempo a hacer deporte que los del centro rural entre semana. Los adolescentes del centro público rural dedican a esta actividad menos de 1:30 hora diaria.

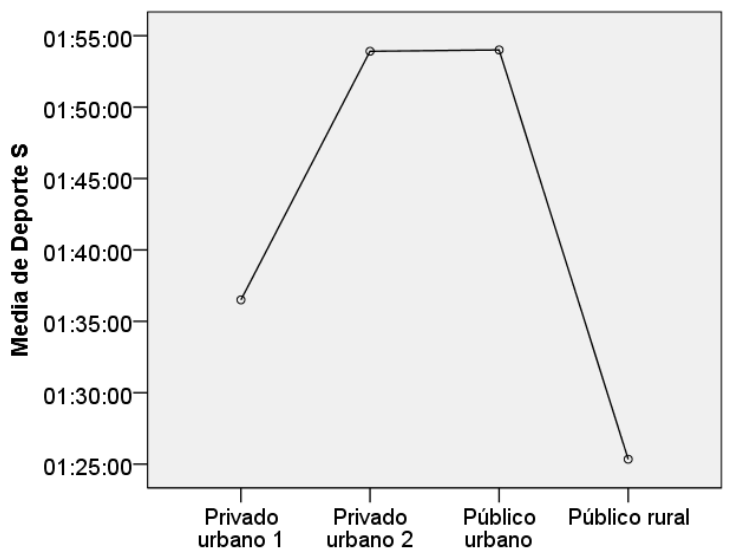

Gráfica 53: media de tiempo dedicado a hacer deporte entre semana por centro.

- Trabajo remunerado el fin de semana: como muestra la gráfica 54, los adolescentes del medio rural dedican más tiempo a realizar trabajo remunerado que el resto de centros urbanos.

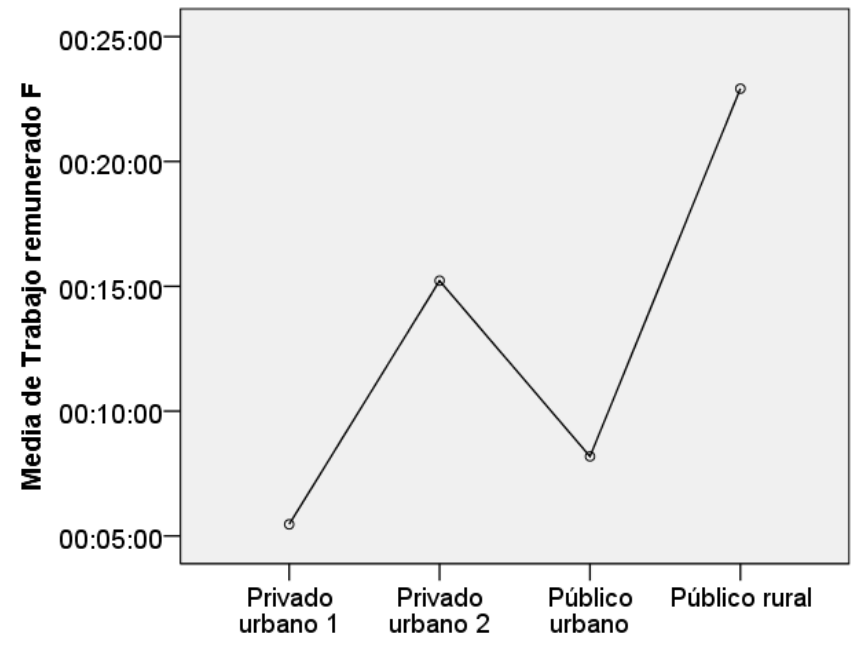

Gráfica 54: media de tiempo dedicado a trabajo remunerado el fin de semana por centro. 
- Alimentación el fin de semana: los adolescentes que menos tiempo dedican a alimentarse son los del centro rural (gráfica 55). Los que más tiempo dedican a esta actividad son los del centro público urbano.

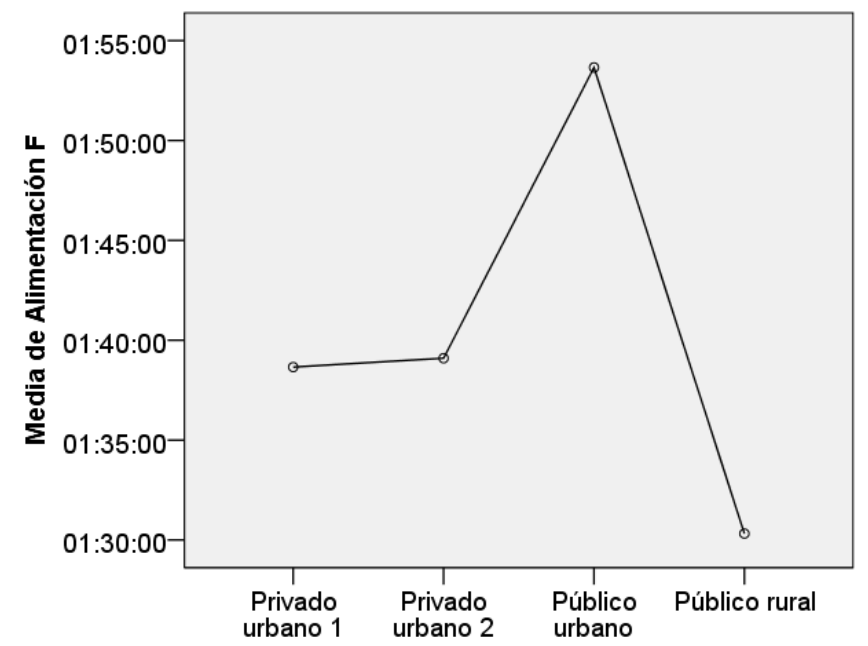

\section{Gráfica 55: media de tiempo dedicado a la alimentación el fin de semana por centro.}

- Salir con amigos el fin de semana: los adolescentes que más tiempo dedican a esta actividad son aquellos que asisten al centro público urbano (gráfica 56).

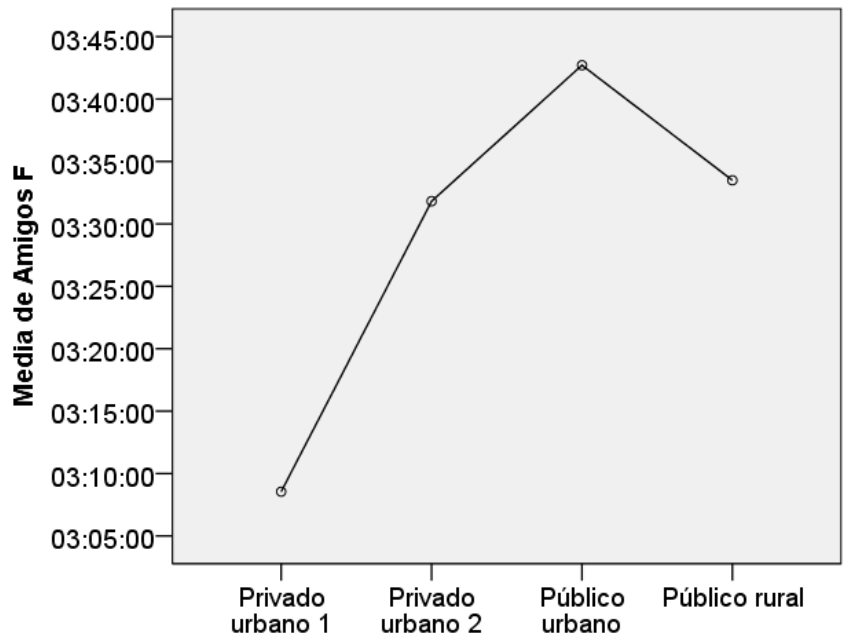

Gráfica 56: media de tiempo dedicado a la alimentación el fin de semana por centro 
- Desplazamientos en fin de semana: los adolescentes del entorno rural son los que menos tiempo dedican a desplazarse durante el fin de semana (gráfica 57).

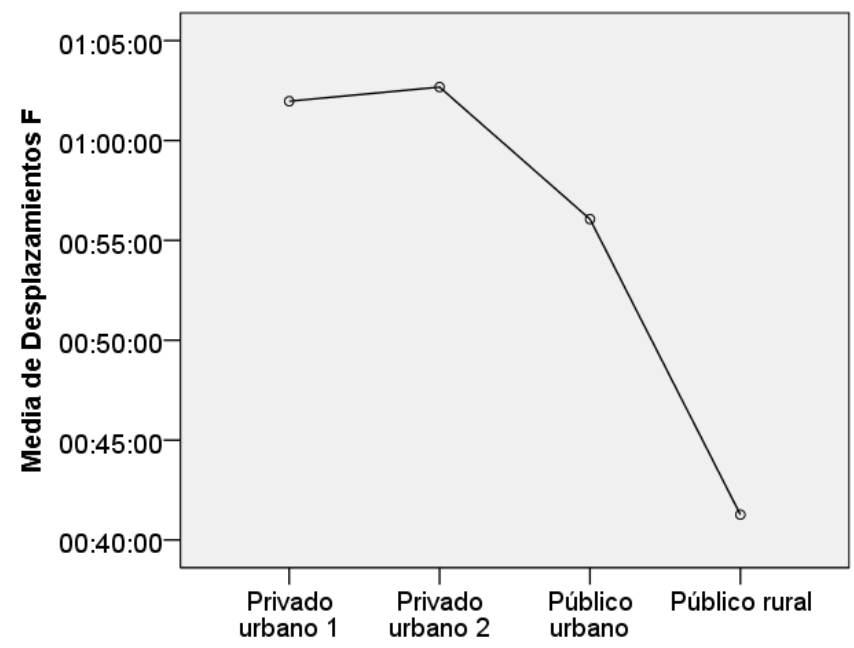

Gráfica 57: media de tiempo dedicado a la alimentación el fin de semana por centro.

- Tiempo en dormirse ayer: los adolescentes que manifiestan haber tardado más tiempo en dormirse el día previo a la realización de la encuesta son aquellos del centro privado 2 (gráfica 58).

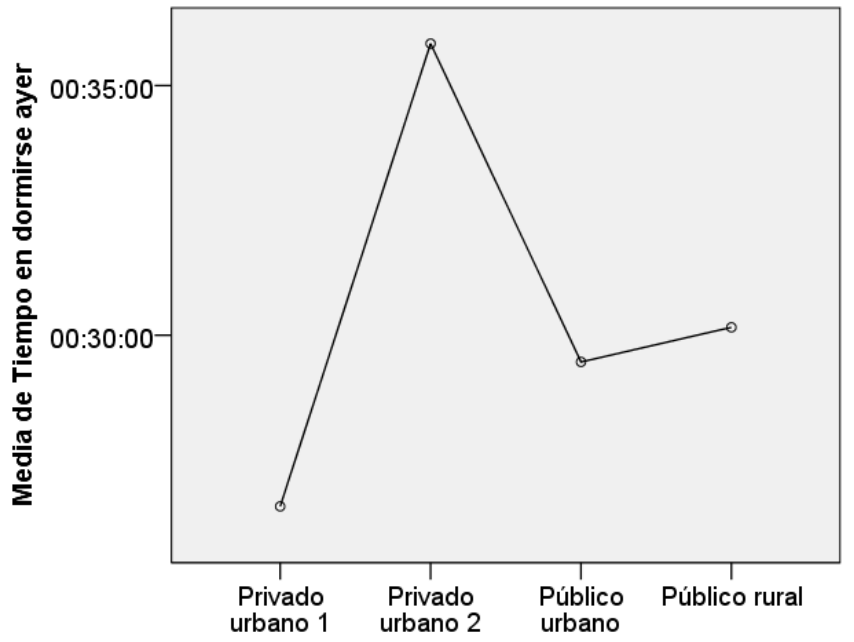

Gráfico 58: media de tiempo que tardaron en dormirse ayer por centro 


\subsection{6.- Entorno familiar:}

En cuanto al número de hermanos, utilizaremos para el análisis sólo aquellos casos cuya respuesta a esta cuestión haya sido 4 o inferior. El resto de las respuestas (adolescentes con más de 5 hermanos), las hemos marcado como perdidas debido a la baja frecuencia de las mismas.

En la tabla 45 podemos ver los resultados de la ANOVA que hemos realizado introduciendo el uso del tiempo de las distintas actividades y el número de hermanos. Las actividades marcadas en rojo, son las que presentan diferencias significativas por el número de hermanos, puesto que, como en casos anteriores, el nivel de significación obtenido tras el cálculo ha sido inferior a 0,05. Procedemos, tras mostrar los resultados obtenidos para todas las actividades en la tabla 45 , a analizar en detalle cada una de las actividades que han presentado diferencias significativas.

A continuación analizamos las actividades que muestran diferencias significativas.

- Uso de WhatsApp el fin de semana: la gráfica 59 muestra la evolución del tiempo medio dedicado al WhatsApp durante el fin de semana dependiendo del número de hermanos que tiene el adolescente. Los adolescentes que tienen 2 hermanos, muestran una tendencia a reducir el tiempo dedicado al WhatsApp. Sin embargo, los adolescentes que tienen 3 hermanos dedican bastante más tiempo a esta actividad, alrededor de 56 minutos más que los adolescentes con 1 hermano y 1:14 horas más que los adolescentes con 2 hermanos.

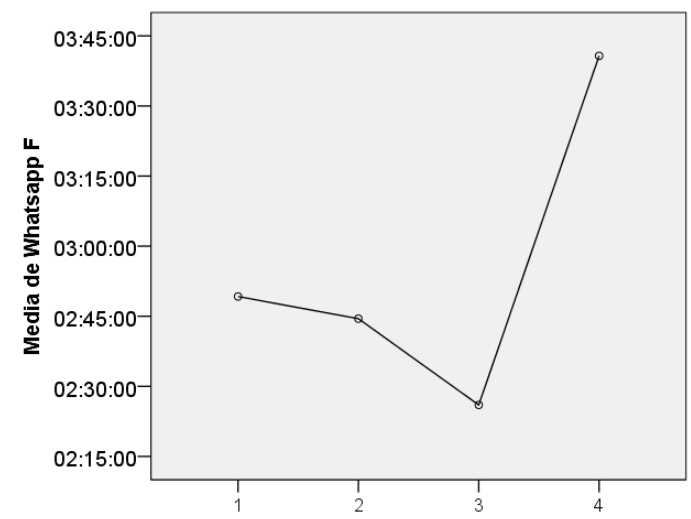

Gráfica 59: media de horas dedicadas a uso del WhatsApp dependiendo del número de hermanos el fin de semana 
2a PARTE

Capítulo 4.- Resultados

\begin{tabular}{|c|c|c|c|c|c|}
\hline & 1 & 2 & 3 & 4 & Sig. \\
\hline Dormir S & $7: 51$ & $7: 43$ & $7: 43$ & $7: 40$ & 0,267 \\
\hline Dormir F & $9: 32$ & $9: 35$ & $9: 28$ & $9: 12$ & 0,145 \\
\hline Asistir a clase S & $6: 08$ & $6: 07$ & $6: 08$ & $6: 13$ & 0,064 \\
\hline Asistir a clase $\mathbf{F}$ & $0: 00$ & $0: 00$ & $0: 00$ & $0: 00$ & \\
\hline Actividades extr. S & $1: 51$ & $1: 50$ & $1: 43$ & $1: 46$ & 0,796 \\
\hline Actividades extr. F & $0: 35$ & $0: 42$ & $0: 46$ & $0: 39$ & 0,401 \\
\hline Estudio S & $2: 30$ & $2: 22$ & $2: 21$ & $2: 34$ & 0,411 \\
\hline Estudio F & $2: 42$ & $2: 32$ & $2: 28$ & $2: 14$ & 0,326 \\
\hline WhatsApp S & $1: 44$ & $1: 48$ & $1: 39$ & $2: 01$ & 0,509 \\
\hline WhatsApp F & $2: 49$ & $2: 44$ & $2: 26$ & $3: 40$ & 0,012 \\
\hline Redes sociales S & $1: 02$ & $1: 06$ & $1: 02$ & $1: 09$ & 0,807 \\
\hline Redes sociales F & $1: 42$ & $1: 36$ & $1: 26$ & $1: 51$ & 0,351 \\
\hline Internet S & $0: 54$ & $0: 55$ & $0: 47$ & $0: 55$ & 0,295 \\
\hline Internet F & $1: 20$ & $1: 17$ & $1: 09$ & $1: 19$ & 0,442 \\
\hline Videojuegos/consolas S & $0: 28$ & $0: 29$ & $0: 29$ & $0: 20$ & 0,741 \\
\hline Videojuegos/consolas F & $0: 51$ & $1: 06$ & $0: 59$ & $0: 44$ & 0,094 \\
\hline Televisión S & $1: 24$ & $1: 27$ & $1: 23$ & $1: 30$ & 0,879 \\
\hline Televisión F & $2: 13$ & $2: 10$ & $1: 53$ & $2: 09$ & 0,117 \\
\hline Teléfono S & $0: 22$ & $0: 21$ & $0: 21$ & $0: 24$ & 0,947 \\
\hline Teléfono F & $0: 29$ & $0: 31$ & $0: 30$ & $0: 20$ & 0,498 \\
\hline Deporte S & $1: 53$ & $1: 49$ & $1: 51$ & $1: 45$ & 0,932 \\
\hline Deporte F & $1: 29$ & $1: 32$ & $1: 30$ & $1: 43$ & 0,645 \\
\hline Trabajo doméstico S & $0: 33$ & $0: 37$ & $0: 41$ & $0: 49$ & 0,031 \\
\hline Trabajo doméstico F & $0: 46$ & $0: 51$ & $0: 48$ & $1: 03$ & 0,132 \\
\hline Trabajo remunerado $\mathrm{S}$ & $0: 07$ & $0: 07$ & $0: 03$ & $0: 06$ & 0,392 \\
\hline Trabajo remunerado $\mathrm{F}$ & $0: 05$ & $0: 11$ & $0: 08$ & $0: 07$ & 0,317 \\
\hline Lectura S & $0: 41$ & $0: 40$ & $0: 37$ & $0: 55$ & 0,135 \\
\hline Lectura F & $0: 53$ & $0: 51$ & $0: 41$ & $1: 10$ & 0,020 \\
\hline Higiene personal S & $1: 11$ & $1: 09$ & $1: 14$ & $1: 30$ & 0,146 \\
\hline Higiene personal F & $1: 18$ & $1: 13$ & $1: 09$ & $1: 10$ & 0,433 \\
\hline Alimentación S & $1: 42$ & $1: 43$ & $1: 47$ & $1: 34$ & 0,694 \\
\hline Alimentación F & $1: 48$ & $1: 44$ & $1: 49$ & $1: 41$ & 0,638 \\
\hline Amigos S & $1: 03$ & $1: 10$ & $1: 11$ & $1: 17$ & 0,679 \\
\hline Amigos $\mathrm{F}$ & $3: 33$ & $3: 39$ & $3: 23$ & $3: 26$ & 0,460 \\
\hline Desplazamientos S & $0: 43$ & $0: 44$ & $0: 50$ & $0: 40$ & 0,404 \\
\hline Desplazamientos F & $0: 47$ & $0: 59$ & $1: 05$ & $0: 41$ & 0,013 \\
\hline Salir con pareja S & $0: 11$ & $0: 11$ & $0: 24$ & $0: 38$ & 0,012 \\
\hline Salir con pareja F & $0: 16$ & $0: 24$ & $0: 34$ & $0: 44$ & 0,036 \\
\hline Tiempo en dormirse ayer & $0: 29$ & $0: 31$ & $0: 28$ & $0: 25$ & 0,214 \\
\hline
\end{tabular}

Tabla 45: media de tiempo por número de hermanos y nivel de significación 
- Trabajo doméstico entre semana: la gráfica 60 refleja claramente que los adolescentes con más hermanos dedican más tiempo a realizar trabajo doméstico en el hogar entre semana. Los que menos tiempo dedican a esta actividad son los hijos únicos (sólo 33 minutos frente a los 49 minutos diarios dedicados por los adolescentes que tienen 3 hermanos).

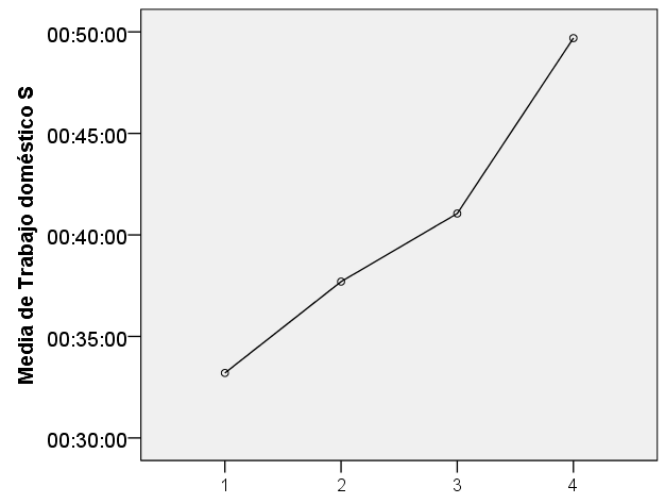

Gráfico 60: media de horas dedicadas a trabajo doméstico entre semana dependiendo del número de hermanos

- Lectura el fin de semana: la gráfica 61 muestra que el aumento del número de hermanos provoca en los adolescentes una disminución del tiempo dedicado a la lectura. Sin embargo, los adolescentes que tienen 3 hermanos dedican a leer el fin de semana notablemente más tiempo que los adolescentes con menos hermanos o hijos únicos.

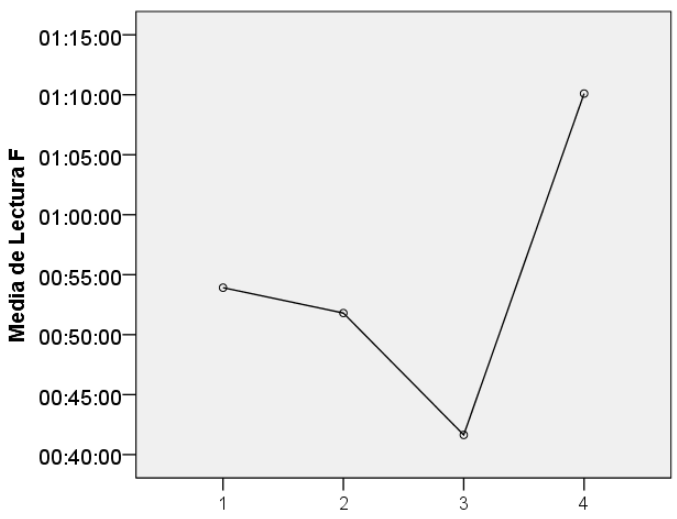

Gráfica 61: media de horas dedicadas leer el fin de semana dependiendo del número de hermanos 
- Salir con la pareja entre semana y el fin de semana: la gráfica 62 refleja un aumento del tiempo medido dedicado a salir con la pareja en relación al aumento del número de hermanos. Los que menos tiempo dedican a salir con la pareja son los hijos únicos.
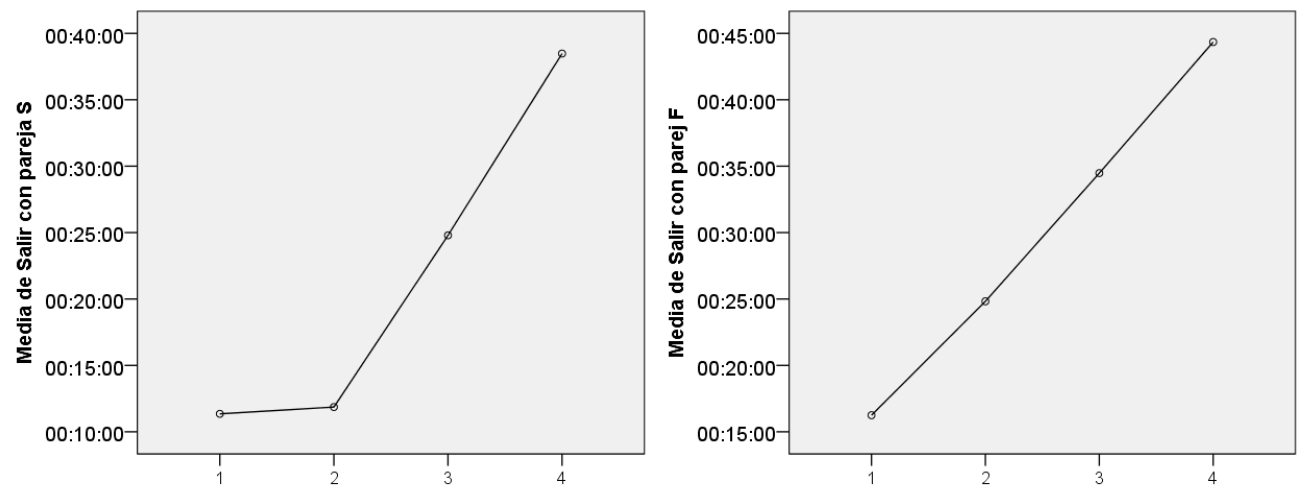

Gráfica 62: media de horas dedicadas a salir con la pareja entre semana y el fin de semana dependiendo del número de hermanos

En cuanto a la persona con la que viven el número de adolescentes que respondieron tutor y otros a esta pregunta no alcanzaron individualmente el 1\% (gráfico 12). Por la baja frecuencia de estas respuestas, hemos decidido marcarlas como perdidas, con el objetivo de que no distorsionen los resultados.

Realizamos el análisis de las respuestas a esta cuestión, por lo tanto, aceptando como válidas las respuestas "padre", "madre" y "ambos".

El resultado obtenido de la ANOVA es el que mostramos en la tabla 46, sombreando, como en los puntos anteriores, las actividades de uso del tiempo que presentan diferencias significativas en rojo.

A continuación, analizamos con más detalle las actividades más destacadas que han revelado mostrar diferencias significativas con respecto a la persona con quién viven los adolescentes. 
- Dormir entre semana: los adolescentes que más tiempo duermen son los que viven con ambos. Los que menos tiempo duermen son los que viven sólo con el padre (gráfica 63).

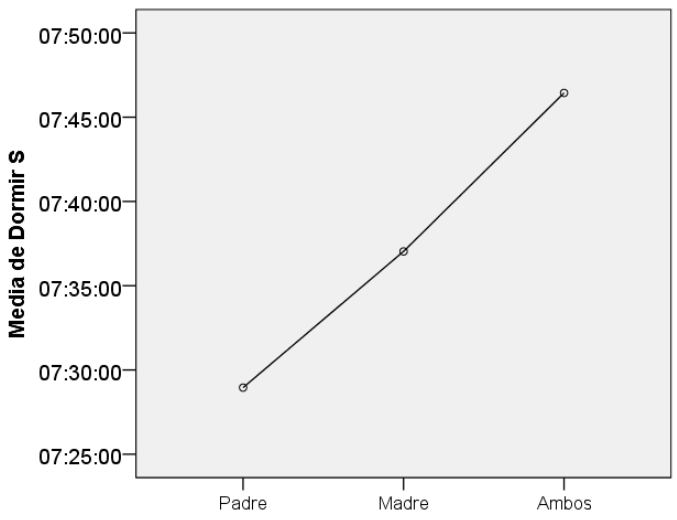

Gráfica 63: media de horas dedicadas a dormir entre semana dependiendo de la persona con quién vive

- Estudio entre semana y el fin de semana: la gráfica 64 pone de manifiesto que los adolescentes que menos tiempo dedican a estudiar, tanto entre semana como los fines de semana, son aquellos que viven únicamente con la madre. Entre semana, los que más tiempo dedican a estudiar son los que viven sólo con el padre. Durante el fin de semana, sin embargo, estudian más los que viven con ambos.
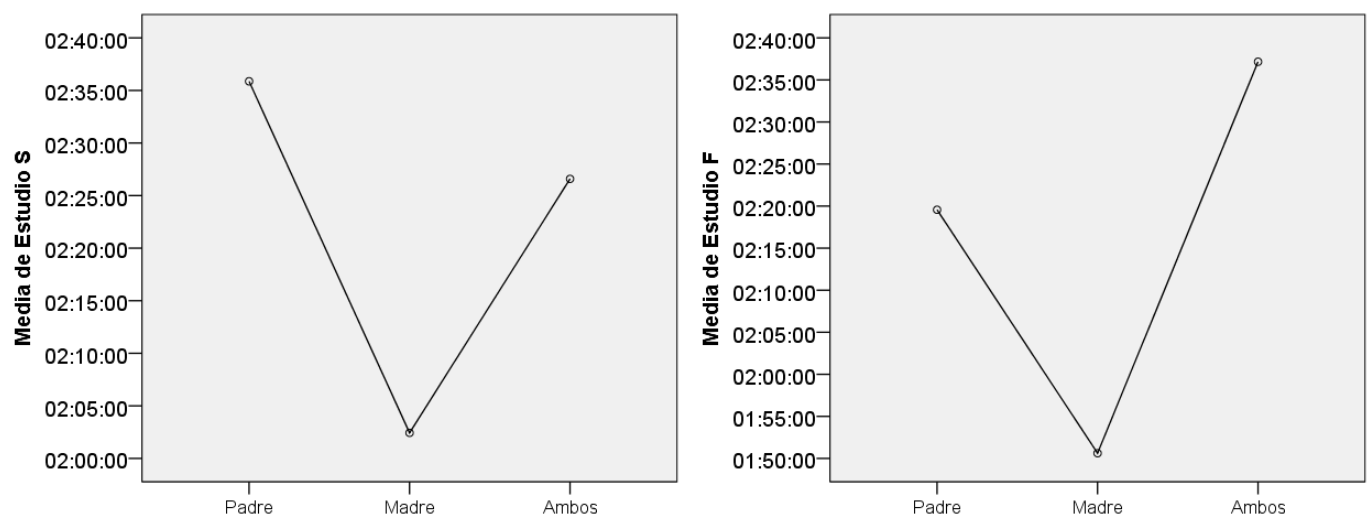

Gráfica 64: media de horas dedicadas a estudiar entre semana y el fin de semana dependiendo de la persona con quién vive 


\begin{tabular}{|c|c|c|c|c|}
\hline & Padre & Madre & Ambos & $\begin{array}{c}\text { Sig. } \\
\text { (bilateral) }\end{array}$ \\
\hline Dormir S & $7: 28$ & $7: 37$ & $7: 46$ & 0,050 \\
\hline Dormir F & 9:04 & $9: 31$ & $9: 33$ & 0,226 \\
\hline Asistir a clase $\mathrm{S}$ & $6: 05$ & $6: 09$ & $6: 08$ & 0,377 \\
\hline Asistir a clase $\mathrm{F}$ & $0: 00$ & $0: 00$ & $0: 00$ & \\
\hline Actividades extraesc. S & $1: 24$ & $1: 40$ & $1: 50$ & 0,281 \\
\hline Actividades extraesc. F & $0: 41$ & $0: 32$ & $0: 43$ & 0,145 \\
\hline Estudio S & $2: 35$ & $2: 02$ & $2: 26$ & 0,002 \\
\hline Estudio F & $2: 19$ & $1: 50$ & $2: 37$ & 0,000 \\
\hline Whatsapp S & $1: 34$ & $2: 00$ & $1: 45$ & 0,272 \\
\hline Whatsapp F & $2: 34$ & $3: 02$ & $2: 43$ & 0,320 \\
\hline Redes sociales S & $0: 47$ & $1: 08$ & $1: 05$ & 0,533 \\
\hline Redes sociales F & $1: 28$ & $1: 53$ & $1: 34$ & 0,115 \\
\hline Internet S & $0: 30$ & $1: 05$ & $0: 52$ & 0,006 \\
\hline Internet F & $0: 45$ & $1: 31$ & $1: 14$ & 0,010 \\
\hline Videojuegos/consolas S & $0: 11$ & $0: 47$ & $0: 26$ & 0,000 \\
\hline Videojuegos/consolas F & $0: 50$ & $1: 14$ & $0: 59$ & 0,130 \\
\hline Televisión S & $1: 16$ & $1: 27$ & $1: 25$ & 0,818 \\
\hline Televisión F & $2: 24$ & $2: 04$ & $2: 06$ & 0,663 \\
\hline Teléfono S & $0: 26$ & $0: 31$ & $0: 19$ & 0,002 \\
\hline Teléfono F & $0: 23$ & $0: 41$ & $0: 29$ & 0,031 \\
\hline Deporte S & $1: 43$ & $2: 03$ & $1: 48$ & 0,091 \\
\hline Deporte F & $1: 10$ & $1: 31$ & $1: 31$ & 0,412 \\
\hline Trabajo doméstico S & $0: 42$ & $0: 45$ & $0: 37$ & 0,030 \\
\hline Trabajo doméstico F & $0: 48$ & $0: 53$ & $0: 49$ & 0,626 \\
\hline Trabajo remunerado $\mathrm{S}$ & $0: 00$ & $0: 04$ & $0: 07$ & 0,404 \\
\hline Trabajo remunerado $\mathrm{F}$ & $0: 00$ & $0: 09$ & $0: 11$ & 0,531 \\
\hline Lectura S & $0: 43$ & $0: 36$ & $0: 41$ & 0,526 \\
\hline Lectura F & $0: 55$ & $0: 48$ & $0: 50$ & 0,848 \\
\hline Higiene personal S & $1: 30$ & $1: 13$ & $1: 11$ & 0,350 \\
\hline Higiene personal F & $1: 50$ & $1: 12$ & $1: 12$ & 0,007 \\
\hline Alimentación S & $1: 36$ & $1: 40$ & $1: 44$ & 0,712 \\
\hline Alimentación F & $1: 48$ & $1: 41$ & $1: 46$ & 0,697 \\
\hline Amigos S & $1: 04$ & $1: 05$ & $1: 11$ & 0,751 \\
\hline Amigos F & $3: 27$ & $3: 47$ & $3: 31$ & 0,417 \\
\hline Desplazamientos S & $0: 56$ & $0: 41$ & $0: 46$ & 0,330 \\
\hline Desplazamientos F & $0: 40$ & $0: 50$ & $0: 59$ & 0,103 \\
\hline Salir con pareja S & $0: 42$ & $0: 23$ & $0: 13$ & 0,056 \\
\hline Salir con pareja $F$ & $1: 13$ & $0: 35$ & $0: 24$ & 0,002 \\
\hline Tiempo en dormirse ayer & $0: 20$ & $0: 37$ & $0: 30$ & 0,011 \\
\hline
\end{tabular}

Tabla 46: media de tiempo con respecto a las personas con las que vive y nivel de significación 
- Internet entre semana y el fin de semana: la gráfica 65 muestra que los adolescentes que más tiempo dedican a navegar por Internet, tanto entre semana como durante el fin de semana, son los que viven con la madre.
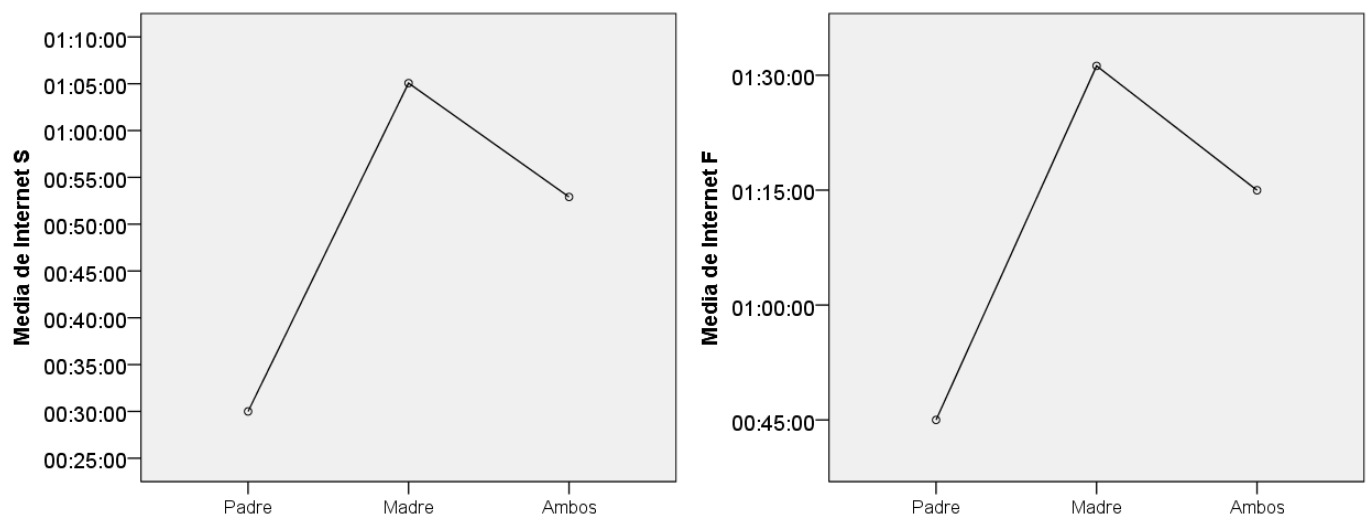

Gráfica 65: horas dedicadas a Internet dependiendo de la persona con quién vive

- Videojuegos/consolas entre semana: los adolescentes que viven sólo con la madre dedican más tiempo a esta actividad que los que viven sólo con el padre o con ambos. Los adolescentes que menos tiempo dedican a realizar esta actividad son los que viven con el padre. Aunque sólo se haya manifestado haber diferencias significativas en el tiempo dedicado a jugar a videojuegos/consolas entre semana, podemos ver en la gráfica 66 que el perfil se mantiene también para el fin de semana.
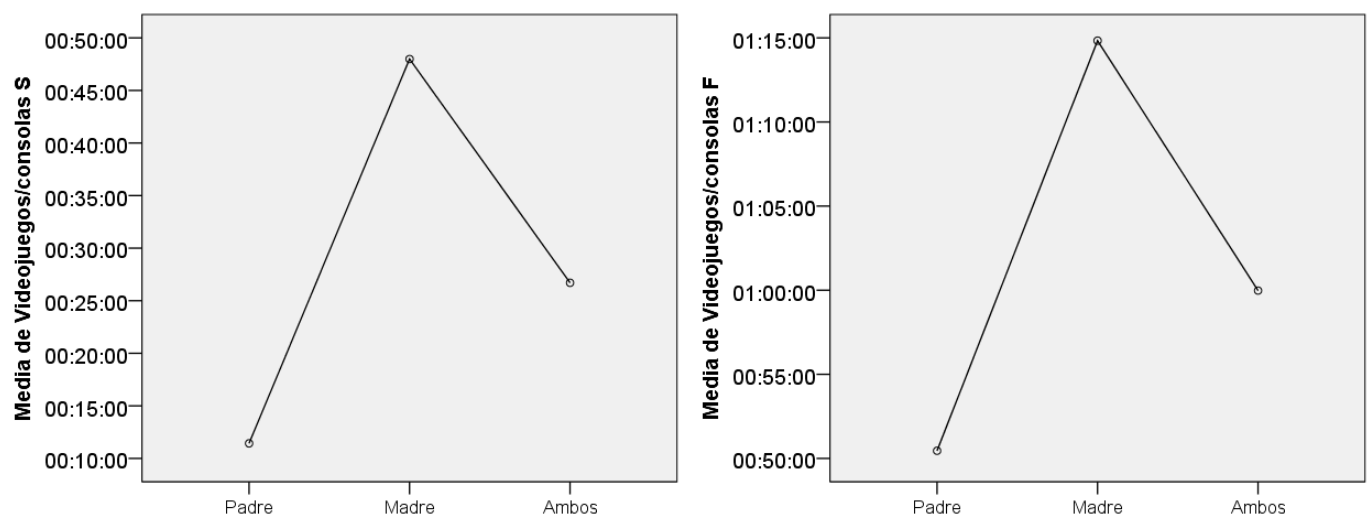

Gráfica 66: horas dedicadas a videojuegos/consolas dependiendo de la persona con quién vive 
- Teléfono entre semana y fin de semana: de nuevo son los adolescentes que viven exclusivamente con su madre los que demuestran dedicar más tiempo a esta actividad (gráfica 67).
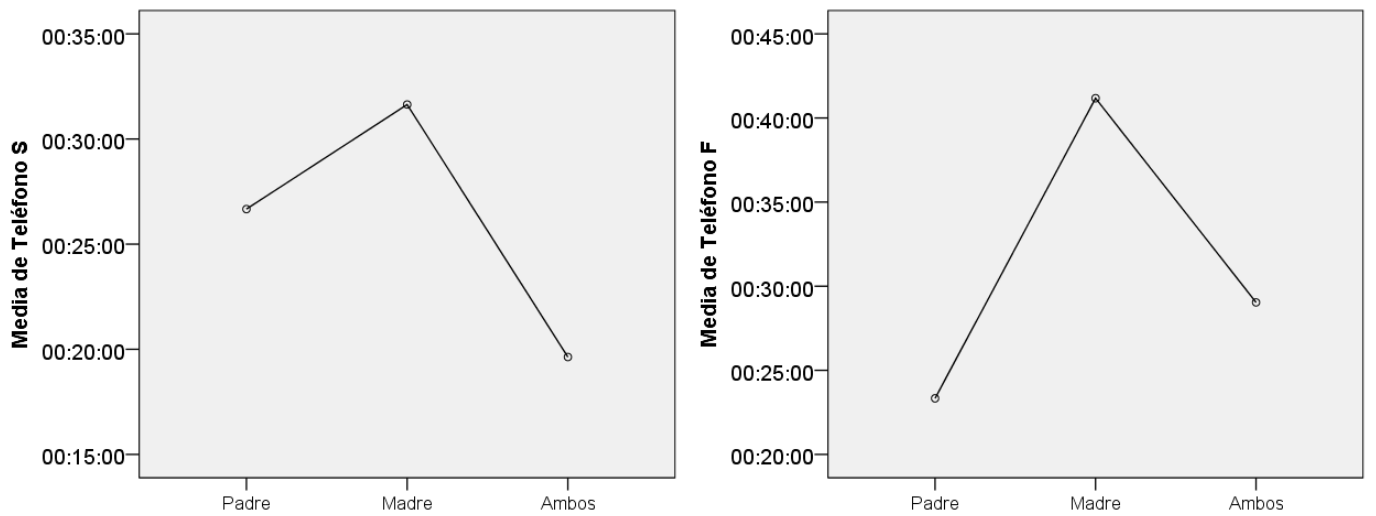

Gráfica 67: horas dedicadas al teléfono entre semana y el fin de semana dependiendo de la persona con quién vive

- Trabajo doméstico entre semana: los adolescentes que viven con la madre, dedican más tiempo a realizar trabajo doméstico entre semana (gráfica 68). Añadimos la gráfica del tiempo dedicado a esta actividad durante el fin de semana, puesto que el perfil es el mismo a la de entre semana, aunque no se encuentren diferencias significativas.
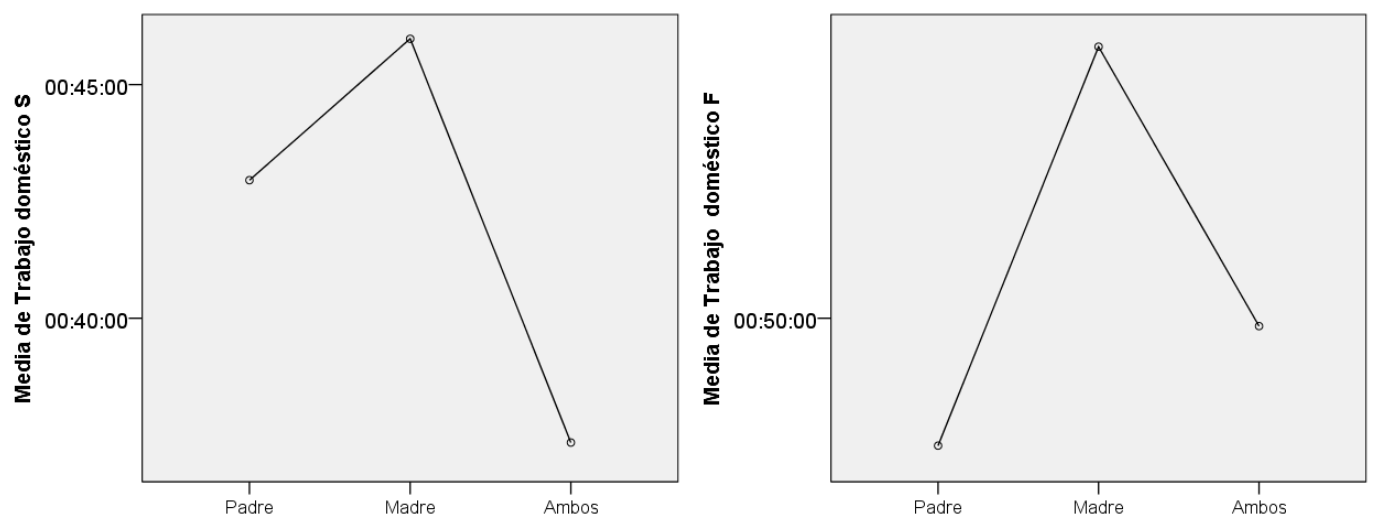

Gráfica 68: horas dedicadas al trabajo doméstico entre semana y el fin de semana dependiendo de la persona con quién vive 
- Higiene personal el fin de semana: la gráfica 69 pone de manifiesto que los adolescentes que viven con el padre dedican más tiempo a su higiene personal que el resto. Sólo se observan diferencias significativas en el tiempo dedicado a esta actividad en el fin de semana.

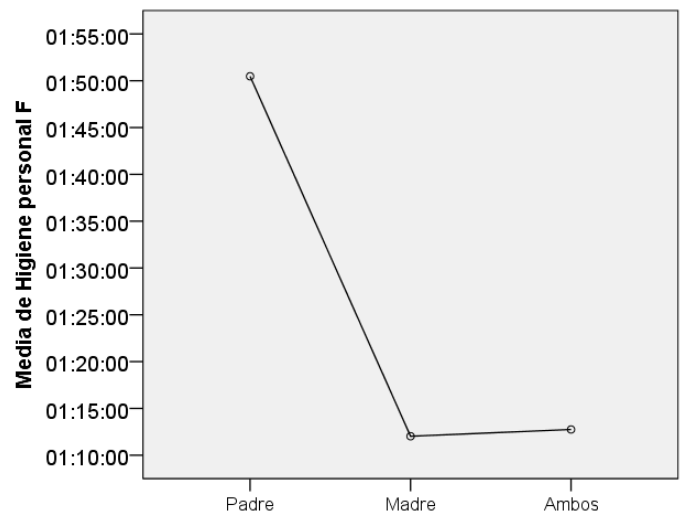

Gráfica 69: horas dedicadas a la higiene personal de la persona con quién vive

- Salir con la pareja el fin de semana: existen diferencias significativas en el tiempo dedicado a salir con la pareja durante el fin de semana en relación a las personas con quién vive el adolescente. La gráfica 70 muestra que los adolescentes que viven con su padre salen durante más tiempo con la pareja que el resto. El perfil de la gráfica del tiempo dedicado a esta actividad entre semana es el mismo que el del fin de semana aunque no hay diferencias significativas.
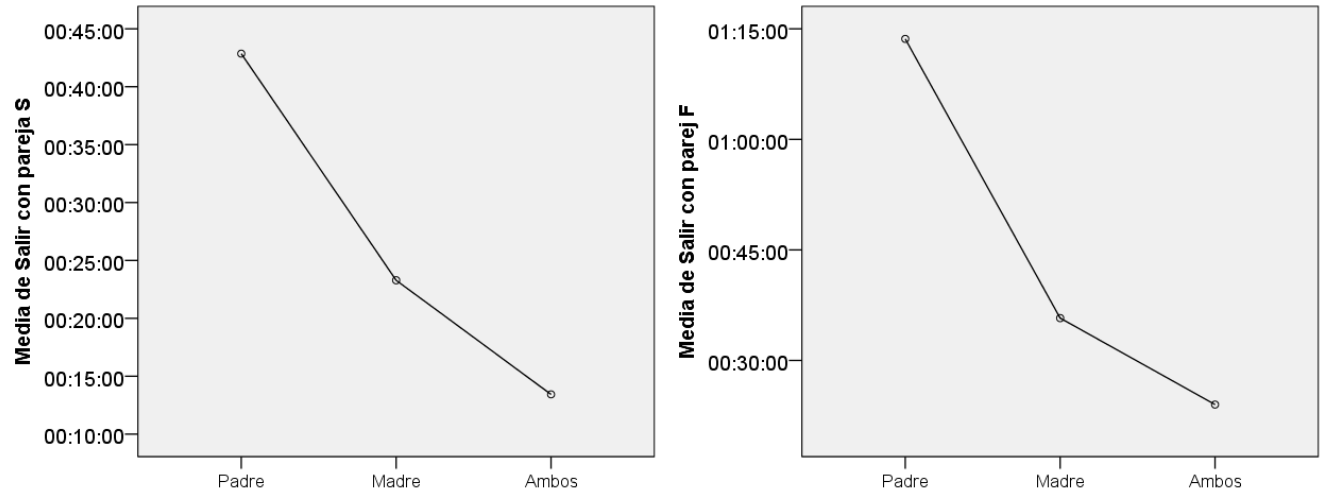

Gráfica 70: media de horas dedicadas a salir con la pareja entre semana y el fin de semana dependiendo de la persona con quién vive 
- $\quad$ Tiempo que tardan en dormirse: la gráfica 71 muestra que los adolescentes que más tiempo tardan en dormirse son los que viven con su madre. Como puede apreciarse en la gráfica 69, los adolescentes que menos tiempo tardan en dormirse son los que viven con el padre.

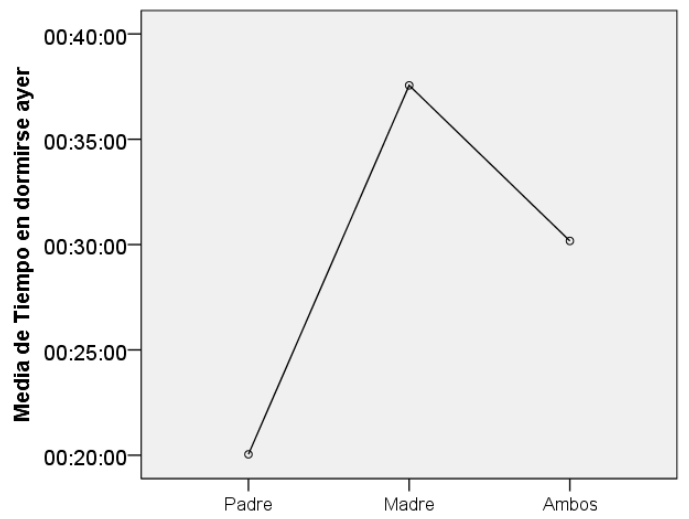

Gráfica 71: tiempo que tardaron en dormirse dependiendo de la persona con quién vive

Las diferencias de uso del tiempo de los adolescentes dependiendo de la persona que está en casa con ellos por las tardes la podemos ver en la tabla 47, sombreadas en rojo las actividades que presentan diferencias significativas con respecto a este factor.

- Dormir entre semana: los adolescentes que más tiempo duermen entre semana son aquellos cuyos padres o ambos están en casa por las tardes. La gráfica 72 muestra que los adolescentes que menos tiempo duermen son aquellos que pasan las tardes con otra compañía, seguido de los que están solos.

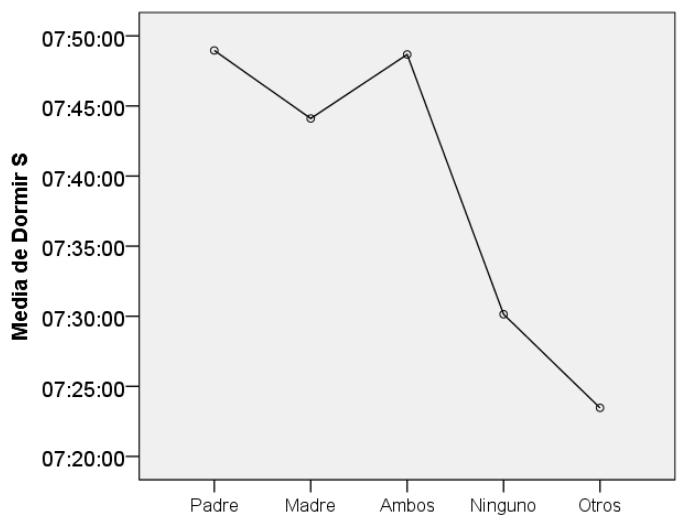

Gráfica 72: tiempo que duermen los adolescentes - quién está por las tardes en casa 
Capítulo 4.- Resultados

\begin{tabular}{|c|c|c|c|c|c|}
\hline & Padre & Madre & Ambos & Ninguno & $\begin{array}{c}\text { Sig. } \\
\text { (bilateral) }\end{array}$ \\
\hline Dormir S & $7: 48$ & $7: 44$ & $7: 48$ & $7: 30$ & 0,003 \\
\hline Dormir F & 9:32 & 9:34 & 9:33 & 9:24 & 0,570 \\
\hline Asistir a clase $\mathrm{S}$ & $6: 06$ & $6: 08$ & $6: 08$ & 6:09 & 0,485 \\
\hline Asistir a clase F & $0: 00$ & $0: 00$ & $0: 00$ & $0: 00$ & \\
\hline Actividades extraesc. S & $1: 41$ & $1: 46$ & $1: 50$ & $1: 51$ & 0,852 \\
\hline Actividades extraesc. F & $0: 48$ & $0: 38$ & $0: 47$ & $0: 36$ & 0,151 \\
\hline Estudio S & $2: 36$ & $2: 22$ & $2: 30$ & $2: 00$ & 0,000 \\
\hline Estudio F & $2: 35$ & $2: 23$ & $2: 43$ & $2: 29$ & 0,037 \\
\hline Whatsapp S & $1: 42$ & $1: 53$ & $1: 41$ & $1: 48$ & 0,515 \\
\hline Whatsapp F & $2: 47$ & $2: 49$ & $2: 36$ & $2: 56$ & 0,555 \\
\hline Redes sociales S & $1: 15$ & $1: 11$ & $0: 58$ & $0: 54$ & 0,035 \\
\hline Redes sociales F & $1: 48$ & $1: 41$ & $1: 28$ & $1: 30$ & 0,193 \\
\hline Internet S & $0: 48$ & $0: 58$ & $0: 49$ & $0: 57$ & 0,043 \\
\hline Internet F & $1: 05$ & $1: 16$ & $1: 18$ & $1: 21$ & 0,392 \\
\hline Videojuegos/consolas S & $0: 19$ & $0: 32$ & $0: 28$ & $0: 26$ & 0,204 \\
\hline Videojuegos/consolas F & $0: 59$ & $1: 00$ & $1: 04$ & $0: 56$ & 0,817 \\
\hline Televisión S & $1: 31$ & $1: 23$ & $1: 29$ & $1: 14$ & 0,256 \\
\hline Televisión F & $2: 18$ & $2: 00$ & $2: 12$ & $1: 44$ & 0,017 \\
\hline Teléfono S & $0: 22$ & $0: 22$ & $0: 20$ & $0: 17$ & 0,312 \\
\hline Teléfono F & $0: 29$ & $0: 32$ & $0: 29$ & $0: 22$ & 0,573 \\
\hline Deporte S & $1: 46$ & $1: 49$ & $1: 51$ & $1: 35$ & 0,549 \\
\hline Deporte F & $1: 40$ & $1: 25$ & $1: 33$ & $1: 25$ & 0,037 \\
\hline Trabajo doméstico S & $0: 39$ & $0: 38$ & $0: 38$ & $0: 32$ & 0,534 \\
\hline Trabajo doméstico F & $0: 56$ & $0: 49$ & $0: 51$ & $0: 45$ & 0,467 \\
\hline Trabajo remunerado $\mathrm{S}$ & $0: 03$ & 0:08 & $0: 07$ & 0:01 & 0,176 \\
\hline Trabajo remunerado F & $0: 07$ & $0: 12$ & $0: 12$ & $0: 04$ & 0,312 \\
\hline Lectura S & $0: 44$ & $0: 41$ & $0: 40$ & $0: 31$ & 0,345 \\
\hline Lectura F & $0: 56$ & $0: 48$ & $0: 52$ & $0: 48$ & 0,548 \\
\hline Higiene personal S & $1: 18$ & $1: 12$ & $1: 12$ & $0: 58$ & 0,096 \\
\hline Higiene personal F & $1: 14$ & $1: 16$ & $1: 12$ & $1: 00$ & 0,101 \\
\hline Alimentación S & $1: 44$ & $1: 47$ & $1: 43$ & $1: 28$ & 0,183 \\
\hline Alimentación F & $1: 41$ & $1: 47$ & $1: 47$ & $1: 27$ & 0,080 \\
\hline Amigos S & $1: 15$ & $1: 12$ & $1: 06$ & $1: 16$ & 0,475 \\
\hline Amigos F & $3: 20$ & $3: 42$ & $3: 27$ & $3: 27$ & 0,337 \\
\hline Desplazamientos S & $0: 46$ & $0: 46$ & $0: 45$ & $0: 45$ & 0,816 \\
\hline Desplazamientos F & $0: 50$ & $1: 01$ & $0: 58$ & $0: 50$ & 0,180 \\
\hline Salir con pareja S & $0: 35$ & $0: 14$ & $0: 11$ & $0: 07$ & 0,024 \\
\hline Salir con pareja F & $0: 31$ & $0: 24$ & $0: 26$ & $0: 25$ & 0,918 \\
\hline Tiempo en dormirse ayer & $0: 24$ & $0: 33$ & $0: 28$ & $0: 32$ & 0,004 \\
\hline
\end{tabular}

Tabla 47: tiempo en relación a las personas con quién pasa las tardes y nivel de significación 
- Estudio entre semana y el fin de semana: como puede apreciarse en la gráfica 73, los adolescentes que más tiempo dedican a estudiar entre semana son aquellos que pasan la tarde con el padre, seguido de los que están con ambos. Los que menos tiempo dedican a esta actividad son los que están solos por la tarde. Durante el fin de semana, los adolescentes que más estudian son los que están acompañados por ambos. Los que menos, los acompañados de su madre.
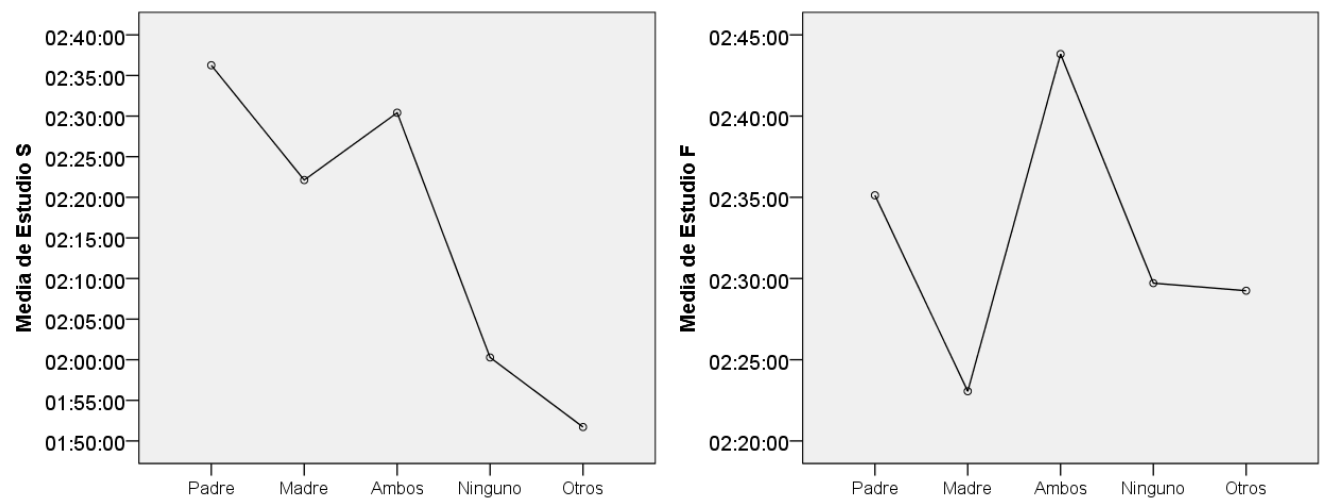

Gráfica 73: tiempo que estudian adolescentes dependiendo de quién está por la tarde en casa

- Uso de redes sociales entre semana: los adolescentes que más tiempo dedican a las redes sociales son los están acompañados por las tardes por su padre. Podemos observar que los que menos tiempo dedican a las redes sociales son los que pasan las tardes solos (gráfica 74).

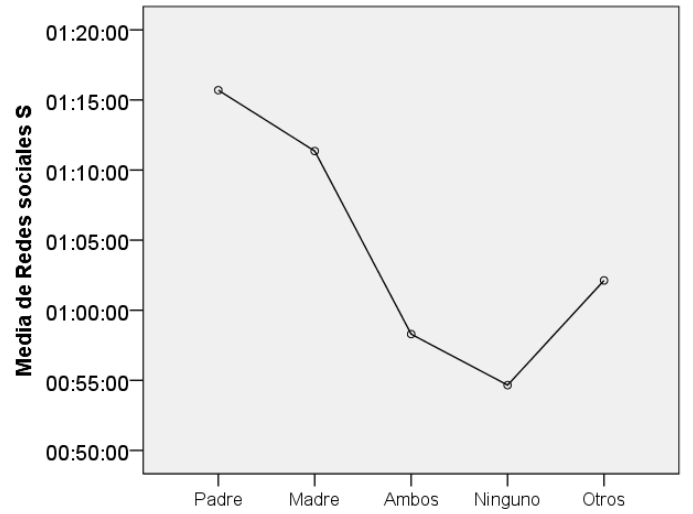

Gráfica 74: tiempo dedicado a redes sociales dependiendo de quién está por la tarde en casa 
- Internet entre semana: como se puede observar en la gráfica 75 los adolescentes que dedican más tiempo a navegar por internet son aquellos que están acompañados por las tardes exclusivamente de la madre (dedican casi 1:00 hora diaria) seguido de los que pasan las tardes solos.

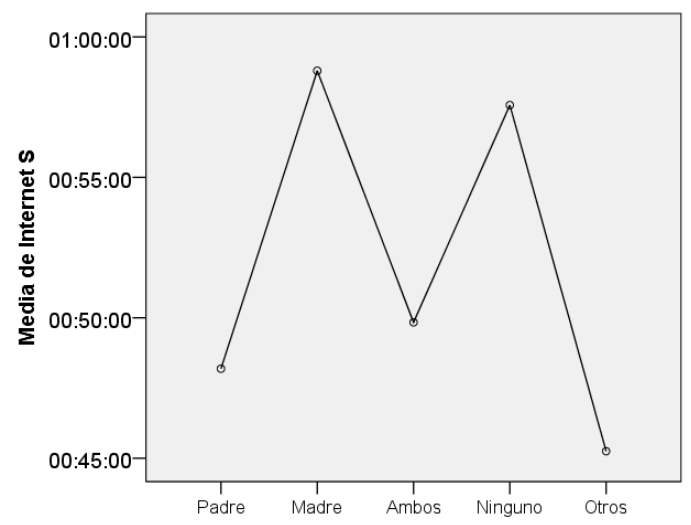

Gráfica 75: tiempo dedicado a internet dependiendo de quién está por la tarde en casa

- Televisión el fin de semana: los adolescentes que menos tiempo ven la televisión son aquellos que no tienen compañía por las tardes. Como muestra la gráfica 76, los adolescentes que más tiempo dedican a esta actividad son los que pasan la tarde con otros seguido de los que están exclusivamente con su padre.

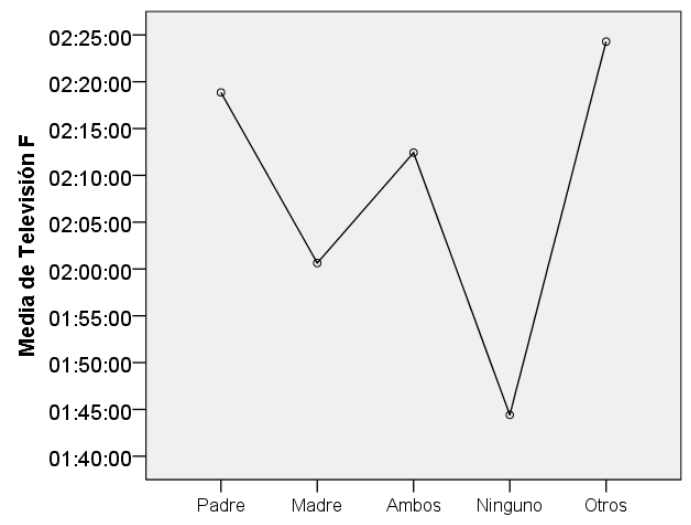

Gráfica 76: tiempo ver la televisión dependiendo de quién está por la tarde en casa 
- Deporte el fin de semana: los adolescentes que más tiempo dedican al realizar actividades deportivas son los que pasan la tarde con otros (gráfica 77), seguidos de aquellos que están acompañados por las tardes por su padre. Los que menos tiempo dedican a esta actividad son los que pasan la tarde con la madre o solos.

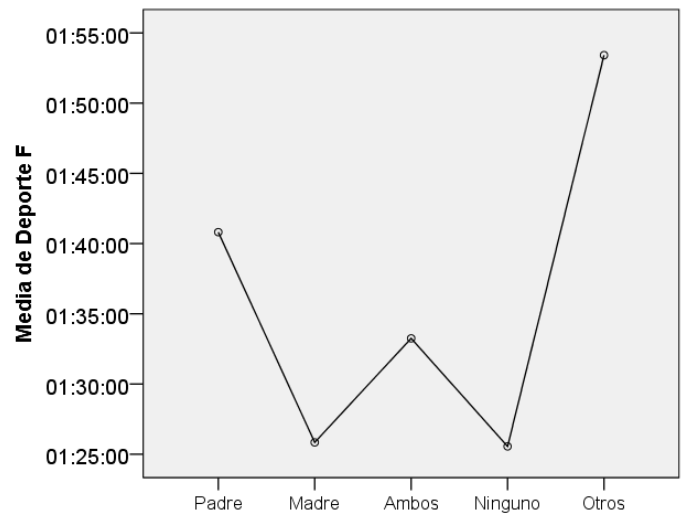

Gráfica 77: tiempo dedicado al deporte dependiendo de quién está por la tarde en casa

- Salir con pareja entre semana: los adolescentes que más tiempo dedican a salir con la pareja son aquellos que están acompañados por las tardes por su padre. Los que menos, los que pasan la tarde solos (gráfica 78).

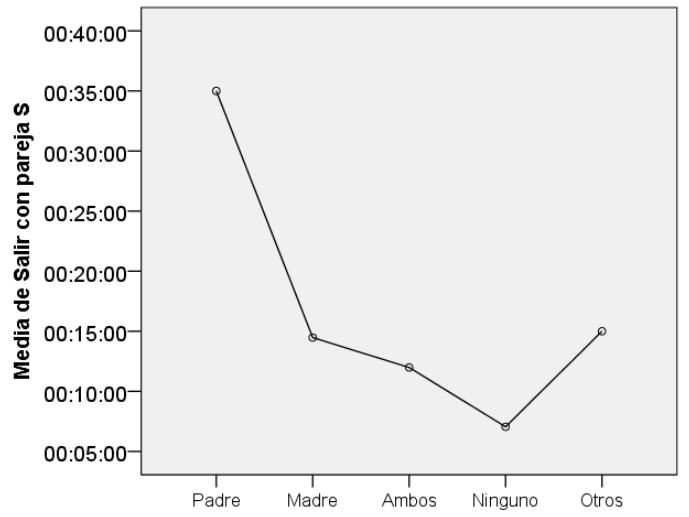

Gráfica 78: tiempo a salir con la dependiendo de quién está por la tarde en casa 
- $\quad$ Tiempo que tarda en dormirse: como puede apreciarse en el gráfico 79, los adolescentes que menos tiempo tardan en dormirse son aquellos que están acompañados por las tardes por su padre.

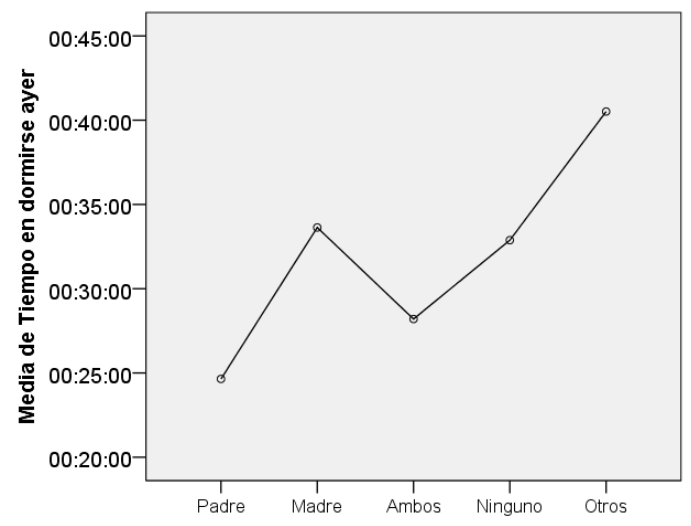

Gráfica 79: tiempo que tardan en dormirse dependiendo de quién está por la tarde en casa

En algunos casos, relacionamos el hecho de que los padres inscriban a sus hijos adolescentes en una serie de actividades extraescolares con el objetivo de evitar que pasen tiempo en casa solos. Sin embargo, el análisis de los datos de las respuestas de los adolescentes burgaleses no indica que haya diferencias significativas en cuanto al tiempo dedicado a realizar actividades extraescolares y el hecho de estar solos en casa durante las tardes (tabla 47).

A continuación, relacionamos el nivel de estudios alcanzado por el padre y por la madre con el uso del tiempo de los adolescentes en las diferentes actividades. El objetivo es conocer si existen diferencias significativas en cuanto al uso del tiempo de los adolescentes en relación al nivel de estudios de sus progenitores.

La tabla 48 muestra, sombreadas en rojo, las distintas actividades en las que se han encontrado diferencias significativas en relación al nivel de estudios alcanzado por el padre. 
2a PARTE

Capítulo 4.- Resultados

\begin{tabular}{|c|c|c|c|c|c|c|}
\hline & $\begin{array}{c}\text { Sin } \\
\text { estudios }\end{array}$ & $\begin{array}{l}\text { estudios } \\
\text { básicos }\end{array}$ & $\begin{array}{l}\text { formación } \\
\text { profesional }\end{array}$ & bachiller & $\begin{array}{c}\text { formación } \\
\text { universitaria }\end{array}$ & Sig. \\
\hline Dormir S & $7: 28$ & $7: 47$ & $7: 39$ & $7: 49$ & $7: 43$ & 0,141 \\
\hline Dormir F & $9: 15$ & 9:32 & $9: 30$ & $9: 42$ & $9: 33$ & 0,370 \\
\hline Asistir a clase $\mathrm{S}$ & $6: 07$ & $6: 07$ & $6: 08$ & $6: 06$ & $6: 10$ & 0,042 \\
\hline Asistir a clase $\mathrm{F}$ & $0: 00$ & $0: 00$ & $0: 00$ & $0: 00$ & $0: 00$ & \\
\hline Actividades extraesc. S & $1: 13$ & $1: 37$ & $1: 45$ & $1: 32$ & $2: 06$ & 0,000 \\
\hline Actividades extraesc. F & $0: 45$ & $0: 33$ & $0: 42$ & $0: 39$ & $0: 50$ & 0,021 \\
\hline Estudio S & $1: 39$ & $2: 22$ & $2: 26$ & $2: 26$ & $2: 27$ & 0,102 \\
\hline Estudio F & $1: 15$ & $2: 26$ & $2: 33$ & $2: 25$ & $2: 47$ & 0,000 \\
\hline Whatsapp S & 3:05 & $2: 01$ & $1: 45$ & $1: 42$ & $1: 36$ & 0,000 \\
\hline Whatsapp F & 3:57 & $3: 10$ & $2: 38$ & $2: 43$ & $2: 33$ & 0,003 \\
\hline Redes sociales S & $1: 20$ & $1: 15$ & $1: 06$ & $0: 54$ & $1: 01$ & 0,058 \\
\hline Redes sociales F & $1: 54$ & $1: 51$ & $1: 34$ & $1: 35$ & $1: 29$ & 0,100 \\
\hline Internet S & $0: 49$ & $0: 53$ & $0: 51$ & $0: 49$ & $0: 55$ & 0,774 \\
\hline Internet F & $1: 23$ & $1: 11$ & $1: 12$ & $1: 19$ & $1: 19$ & 0,500 \\
\hline Videojuegos/consolas S & $0: 47$ & $0: 30$ & $0: 31$ & $0: 31$ & $0: 22$ & 0,061 \\
\hline Videojuegos/consolas F & $0: 51$ & $0: 56$ & $1: 05$ & $1: 02$ & $0: 59$ & 0,754 \\
\hline Televisión S & $1: 42$ & $1: 34$ & $1: 25$ & $1: 25$ & $1: 18$ & 0,068 \\
\hline Televisión F & $1: 51$ & $2: 11$ & $2: 04$ & $2: 11$ & $2: 04$ & 0,771 \\
\hline Teléfono S & $0: 24$ & $0: 24$ & $0: 22$ & $0: 23$ & $0: 19$ & 0,568 \\
\hline Teléfono F & $0: 20$ & $0: 32$ & $0: 32$ & $0: 29$ & $0: 27$ & 0,471 \\
\hline Deporte S & $2: 01$ & $1: 40$ & $1: 51$ & $1: 42$ & $1: 54$ & 0,193 \\
\hline Deporte F & $1: 22$ & $1: 21$ & $1: 37$ & $1: 32$ & $1: 32$ & 0,125 \\
\hline Trabajo doméstico S & $0: 43$ & $0: 41$ & $0: 38$ & $0: 37$ & $0: 35$ & 0,242 \\
\hline Trabajo doméstico $\mathrm{F}$ & $0: 58$ & $0: 55$ & $0: 50$ & $0: 51$ & $0: 45$ & 0,109 \\
\hline Trabajo remunerado $\mathrm{S}$ & $0: 00$ & $0: 10$ & $0: 08$ & $0: 05$ & $0: 04$ & 0,107 \\
\hline Trabajo remunerado $\mathrm{F}$ & $0: 46$ & $0: 16$ & $0: 11$ & $0: 09$ & $0: 07$ & 0,003 \\
\hline Lectura S & $0: 39$ & $0: 44$ & $0: 38$ & $0: 37$ & $0: 40$ & 0,418 \\
\hline Lectura F & $0: 37$ & $0: 50$ & $0: 49$ & $0: 48$ & $0: 55$ & 0,498 \\
\hline Higiene personal S & $1: 30$ & $1: 19$ & $1: 08$ & $1: 07$ & $1: 07$ & 0,052 \\
\hline Higiene personal F & $1: 07$ & $1: 21$ & $1: 12$ & $1: 09$ & $1: 07$ & 0,017 \\
\hline Alimentación S & $1: 42$ & $1: 51$ & $1: 39$ & $1: 42$ & $1: 41$ & 0,316 \\
\hline Alimentación F & $1: 58$ & $1: 43$ & $1: 46$ & $1: 41$ & $1: 45$ & 0,800 \\
\hline Amigos S & $1: 00$ & $1: 04$ & $1: 20$ & $1: 13$ & $1: 04$ & 0,089 \\
\hline Amigos $\mathrm{F}$ & $4: 37$ & $3: 38$ & $3: 24$ & $3: 44$ & $3: 29$ & 0,128 \\
\hline Desplazamientos S & $0: 51$ & $0: 46$ & $0: 46$ & $0: 47$ & $0: 44$ & 0,914 \\
\hline Desplazamientos F & $0: 47$ & $1: 00$ & $0: 59$ & $0: 48$ & $0: 57$ & 0,362 \\
\hline Salir con pareja S & $0: 25$ & $0: 16$ & $0: 14$ & $0: 13$ & $0: 16$ & 0,964 \\
\hline Salir con pareja F & $1: 05$ & $0: 26$ & $0: 26$ & $0: 22$ & $0: 29$ & 0,175 \\
\hline Tiempo en dormirse ayer & $0: 39$ & $0: 30$ & $0: 31$ & $0: 34$ & $0: 28$ & 0,307 \\
\hline
\end{tabular}

Tabla 48: media de tiempo por el nivel de estudios del padre y nivel de significación 
- Asistir a clase entre semana: los adolescentes que más tiempo asisten a clase son aquellos cuyos padres han alcanzado formación universitaria. Como se puede observar en la gráfica 80 , la diferencia de tiempo es muy reducida, sin embargo el nivel de significación ha puesto de manifiesto la existencia de diferencias significativas.

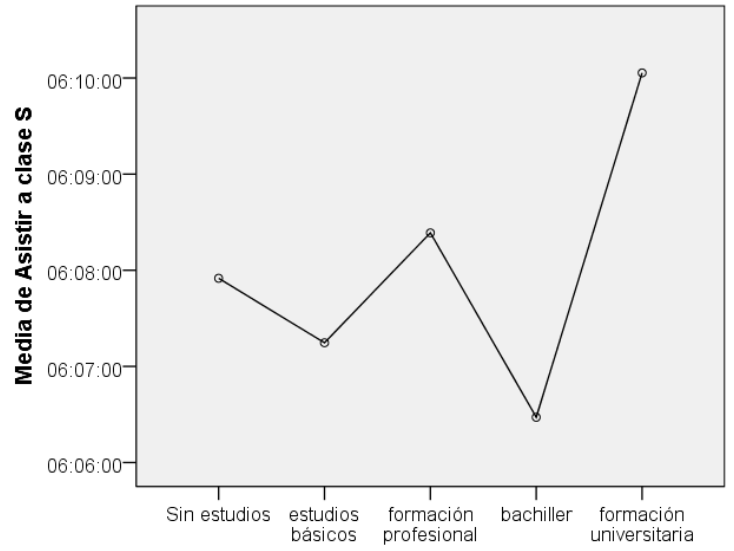

Gráfica 80: media de tiempo en asistir a clase - formación del padre

- $\quad$ Actividades extraescolares: la gráfica 81 muestra que los adolescentes que más tiempo dedican a realizar actividades extraescolares tanto entre semana como durante el fin de semana, son aquellos cuyo padre han alcanzado estudios universitarios. Los adolescentes que menos tiempo dedican a realizar actividades extraescolares entre semana son aquellos cuyos padres no tienen estudios.
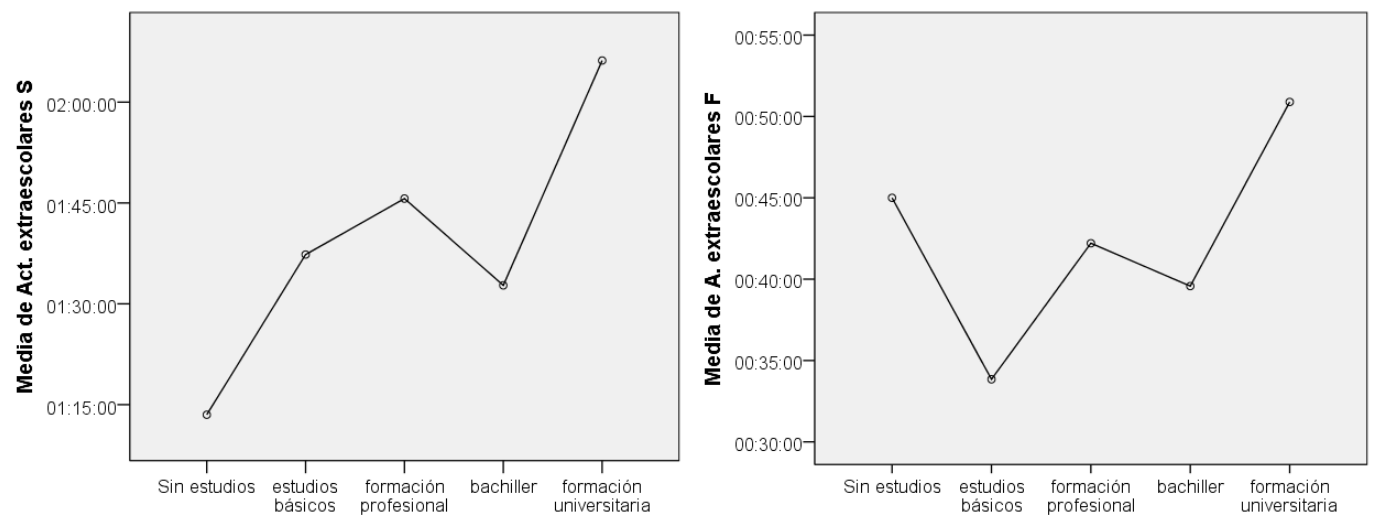

Gráfica 81: media de tiempo asistir a actividades extraescolares - formación académica padre 
- Estudio fin de semana: los adolescentes dedican a estudiar mayor cantidad de tiempo durante el fin de semana según aumentan el nivel académico alcanzado por el padre. Por lo tanto, como muestra la gráfica 82 , los adolescentes que más tiempo dedican a estudiar durante el fin de semana son aquellos cuyo padre tiene estudios universitarios.

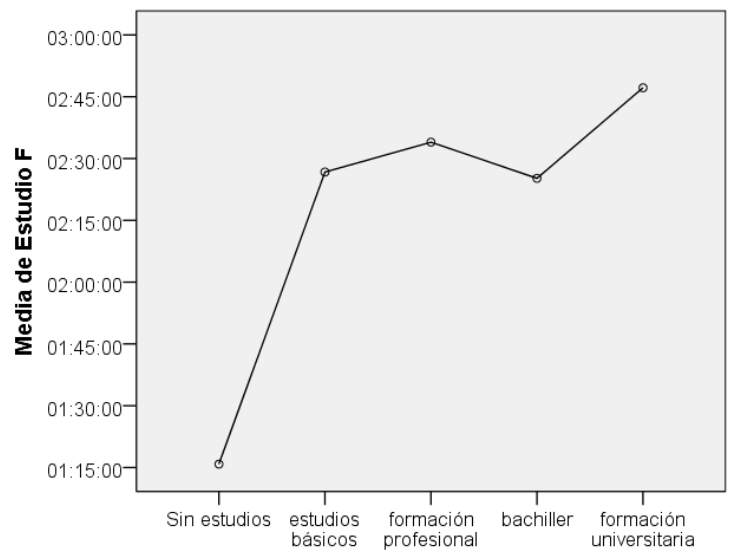

Gráfica 82: media de tiempo dedicado a estudiar - formación académica del padre

- WhatsApp: la gráfica 83 muestra que los adolescentes dedican menos tiempo al WhatsApp según va aumentando el nivel de estudios alcanzado por el padre. Los que menos tiempo dedican a esta actividad son aquellos cuyos padres han alcanzado estudios universitarios.
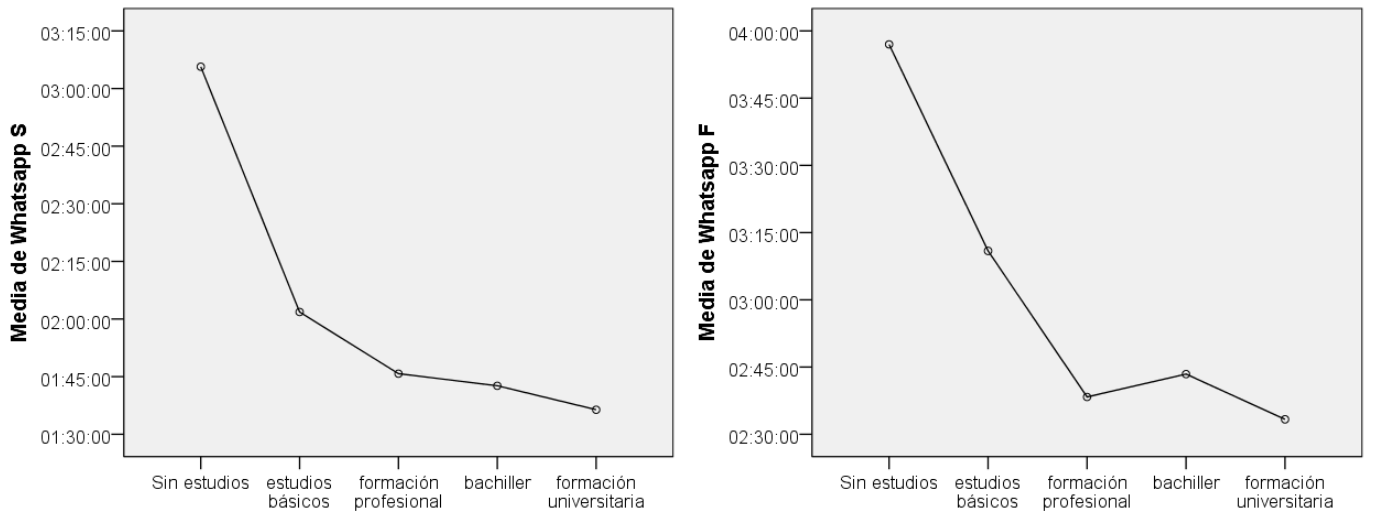

Gráfica 83: media de tiempo WhatsApp - formación académica del padre 
- Trabajo remunerado fin de semana: el tiempo que los adolescentes dedican a realizar trabajo remunerado disminuye al aumentar el nivel de estudios alcanzado por el padre (gráfica 84).

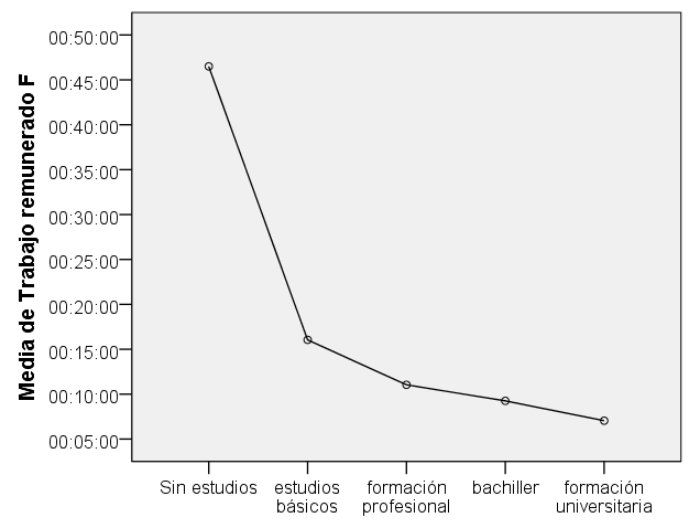

Gráfica 84: media de tiempo desempeñar trabajo remunerado - formación académica padre

- Higiene personal fin de semana: el tiempo dedicado a la higiene personal disminuye al aumentar el nivel de estudios del padre, excepto para los padres sin estudios, donde se localiza el menor tiempo dedicado por el adolescente a esta actividad (gráfica 85).

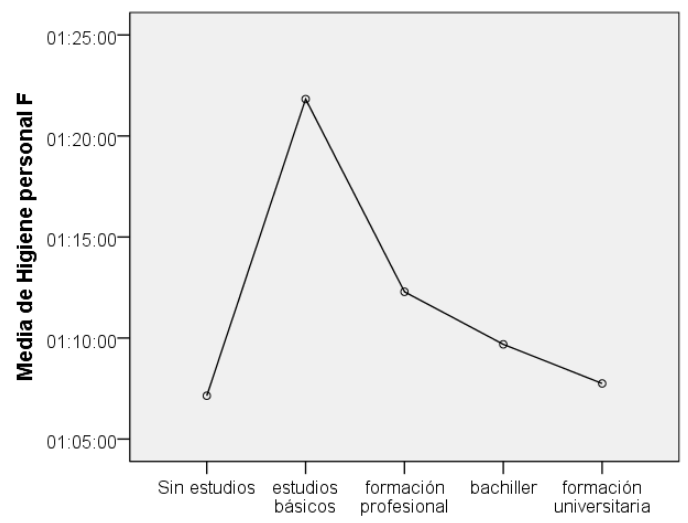

Gráfica 85: media de tiempo higiene personal el fin de semana-formación académica padre

La tabla 49 muestra, sombreadas en rojo, todas aquellas actividades en cuyo uso del tiempo se han encontrado diferencias significativas en relación al nivel de estudios alcanzado por la madre. 
2a PARTE

Capítulo 4.- Resultados

\begin{tabular}{|c|c|c|c|c|c|c|}
\hline & $\begin{array}{c}\text { Sin } \\
\text { estudios }\end{array}$ & $\begin{array}{l}\text { estudios } \\
\text { básicos }\end{array}$ & $\begin{array}{l}\text { formación } \\
\text { profesional }\end{array}$ & bachiller & $\begin{array}{c}\text { formación } \\
\text { universitaria }\end{array}$ & Sig. \\
\hline Dormir S & $7: 28$ & $7: 47$ & $7: 39$ & $7: 49$ & $7: 43$ & 0,141 \\
\hline Dormir F & $9: 15$ & 9:32 & $9: 30$ & $9: 42$ & $9: 33$ & 0,370 \\
\hline Asistir a clase $\mathrm{S}$ & $6: 07$ & $6: 07$ & $6: 08$ & $6: 06$ & $6: 10$ & 0,042 \\
\hline Asistir a clase $\mathrm{F}$ & $0: 00$ & $0: 00$ & $0: 00$ & $0: 00$ & $0: 00$ & \\
\hline Actividades extraesc. S & $1: 13$ & $1: 37$ & $1: 45$ & $1: 32$ & $2: 06$ & 0,000 \\
\hline Actividades extraesc. F & $0: 45$ & $0: 33$ & $0: 42$ & $0: 39$ & $0: 50$ & 0,021 \\
\hline Estudio S & $1: 39$ & $2: 22$ & $2: 26$ & $2: 26$ & $2: 27$ & 0,102 \\
\hline Estudio F & $1: 15$ & $2: 26$ & $2: 33$ & $2: 25$ & $2: 47$ & 0,000 \\
\hline Whatsapp S & 3:05 & $2: 01$ & $1: 45$ & $1: 42$ & $1: 36$ & 0,000 \\
\hline Whatsapp F & 3:57 & $3: 10$ & $2: 38$ & $2: 43$ & $2: 33$ & 0,003 \\
\hline Redes sociales S & $1: 20$ & $1: 15$ & $1: 06$ & $0: 54$ & $1: 01$ & 0,058 \\
\hline Redes sociales F & $1: 54$ & $1: 51$ & $1: 34$ & $1: 35$ & $1: 29$ & 0,100 \\
\hline Internet S & $0: 49$ & $0: 53$ & $0: 51$ & $0: 49$ & $0: 55$ & 0,774 \\
\hline Internet F & $1: 23$ & $1: 11$ & $1: 12$ & $1: 19$ & $1: 19$ & 0,500 \\
\hline Videojuegos/consolas S & $0: 47$ & $0: 30$ & $0: 31$ & $0: 31$ & $0: 22$ & 0,061 \\
\hline Videojuegos/consolas F & $0: 51$ & $0: 56$ & $1: 05$ & $1: 02$ & $0: 59$ & 0,754 \\
\hline Televisión S & $1: 42$ & $1: 34$ & $1: 25$ & $1: 25$ & $1: 18$ & 0,068 \\
\hline Televisión F & $1: 51$ & $2: 11$ & $2: 04$ & $2: 11$ & $2: 04$ & 0,771 \\
\hline Teléfono S & $0: 24$ & $0: 24$ & $0: 22$ & $0: 23$ & $0: 19$ & 0,568 \\
\hline Teléfono F & $0: 20$ & $0: 32$ & $0: 32$ & $0: 29$ & $0: 27$ & 0,471 \\
\hline Deporte S & $2: 01$ & $1: 40$ & $1: 51$ & $1: 42$ & $1: 54$ & 0,193 \\
\hline Deporte F & $1: 22$ & $1: 21$ & $1: 37$ & $1: 32$ & $1: 32$ & 0,125 \\
\hline Trabajo doméstico S & $0: 43$ & $0: 41$ & $0: 38$ & $0: 37$ & $0: 35$ & 0,242 \\
\hline Trabajo doméstico $\mathrm{F}$ & $0: 58$ & $0: 55$ & $0: 50$ & $0: 51$ & $0: 45$ & 0,109 \\
\hline Trabajo remunerado $\mathrm{S}$ & $0: 00$ & $0: 10$ & $0: 08$ & $0: 05$ & $0: 04$ & 0,107 \\
\hline Trabajo remunerado $\mathrm{F}$ & $0: 46$ & $0: 16$ & $0: 11$ & $0: 09$ & $0: 07$ & 0,003 \\
\hline Lectura S & $0: 39$ & $0: 44$ & $0: 38$ & $0: 37$ & $0: 40$ & 0,418 \\
\hline Lectura F & $0: 37$ & $0: 50$ & $0: 49$ & $0: 48$ & $0: 55$ & 0,498 \\
\hline Higiene personal S & $1: 30$ & $1: 19$ & $1: 08$ & $1: 07$ & $1: 07$ & 0,052 \\
\hline Higiene personal F & $1: 07$ & $1: 21$ & $1: 12$ & $1: 09$ & $1: 07$ & 0,017 \\
\hline Alimentación S & $1: 42$ & $1: 51$ & $1: 39$ & $1: 42$ & $1: 41$ & 0,316 \\
\hline Alimentación F & $1: 58$ & $1: 43$ & $1: 46$ & $1: 41$ & $1: 45$ & 0,800 \\
\hline Amigos S & $1: 00$ & $1: 04$ & $1: 20$ & $1: 13$ & $1: 04$ & 0,089 \\
\hline Amigos $\mathrm{F}$ & $4: 37$ & $3: 38$ & $3: 24$ & $3: 44$ & $3: 29$ & 0,128 \\
\hline Desplazamientos S & $0: 51$ & $0: 46$ & $0: 46$ & $0: 47$ & $0: 44$ & 0,914 \\
\hline Desplazamientos F & $0: 47$ & $1: 00$ & $0: 59$ & $0: 48$ & $0: 57$ & 0,362 \\
\hline Salir con pareja S & $0: 25$ & $0: 16$ & $0: 14$ & $0: 13$ & $0: 16$ & 0,964 \\
\hline Salir con pareja F & $1: 05$ & $0: 26$ & $0: 26$ & $0: 22$ & $0: 29$ & 0,175 \\
\hline Tiempo en dormirse ayer & $0: 39$ & $0: 30$ & $0: 31$ & $0: 34$ & $0: 28$ & 0,307 \\
\hline
\end{tabular}

Tabla 49: media de tiempo por el nivel de estudios de la madre y nivel de significación 
- Asistir a clase entre semana: el tiempo dedicado a esta actividad aumenta al aumentar el nivel de estudios alcanzado por la madre. Como se puede apreciar en la gráfica 86, los adolescentes cuyas madres tienen estudios universitarios dedican más tiempo a asistir a clase.

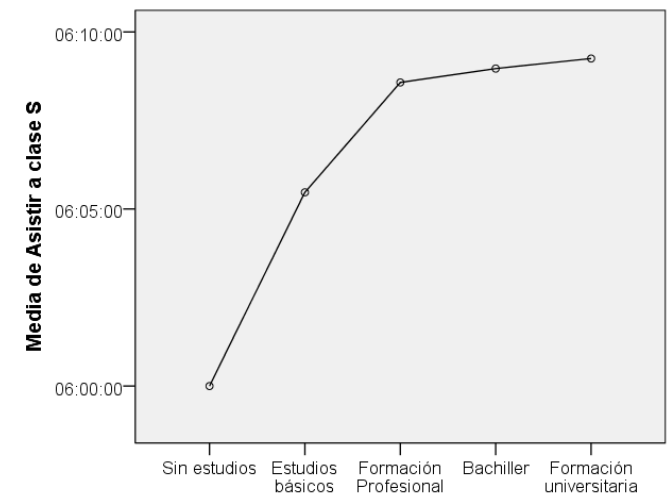

Gráfica 86: media de tiempo asistir a clase - formación académica de la madre

- Actividades extraescolares: los adolescentes cuyas madres han alcanzado mayor preparación académica, invierten más tiempo entre semana en esta actividad. Durante el fin de semana, los adolescentes que más tiempo dedican a realizar actividades extraescolares son aquellos cuyas madres no tienen estudios. Conviene recordar se da este mismo comportamiento en cuanto al nivel de estudios del padre. Los adolescentes cuyas madres han estudiado formación profesional dedican más tiempo a realizar actividades extraescolares el fin de semana que aquellas que han cursado bachiller (gráfica 87).
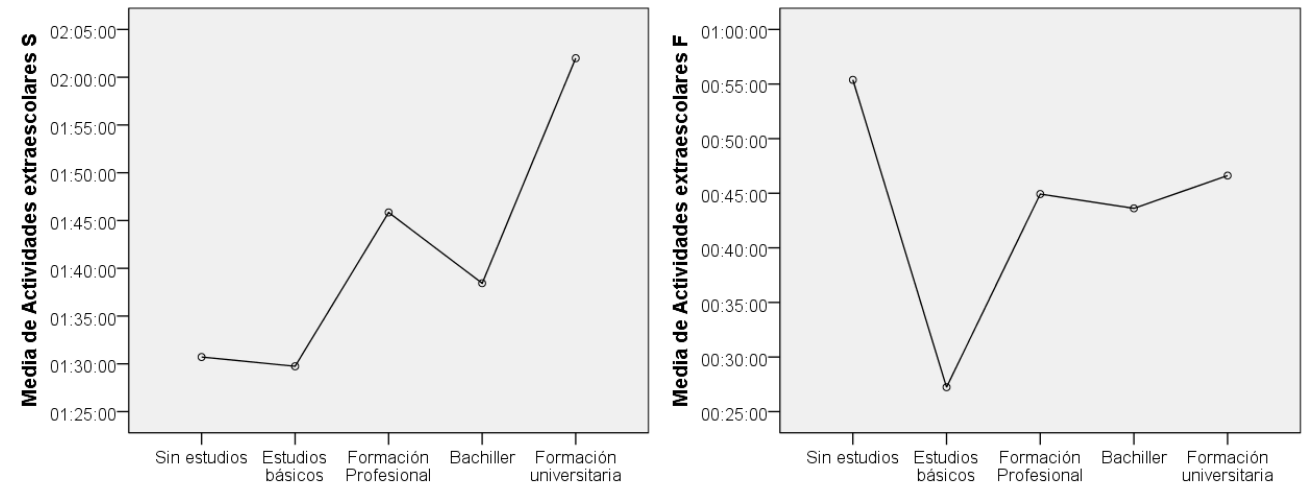

Gráfica 87: media de tiempo asistir a actividades extraescolares - formación académica madre 
- Estudio fin de semana: el tiempo dedicado al estudio aumenta con el nivel de estudios de la madre. Como se puede observar en la gráfica 88 , los adolescentes que más tiempo dedican al estudio son aquellos cuya madre ha alcanzado estudios universitarios.

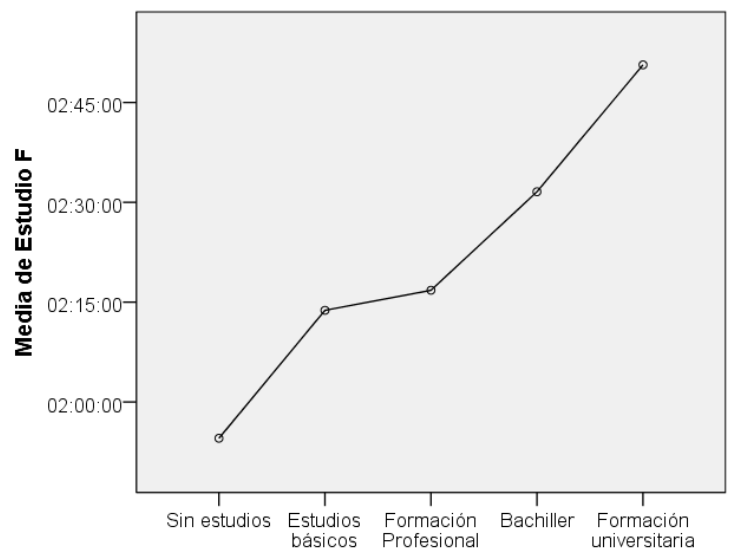

Gráfica 88: media de tiempo estudio - formación académica de la madre

- WhatsApp: los adolescentes que más tiempo dedican al WhatsApp son aquellos cuyas madres no tienen estudios. Como muestra la gráfica 89, el tiempo dedicado a esta actividad disminuye al aumentar el nivel de estudios de las madres (salvando un ligero incremento de tiempo para los adolescentes cuyas madres han estudiado bachiller).
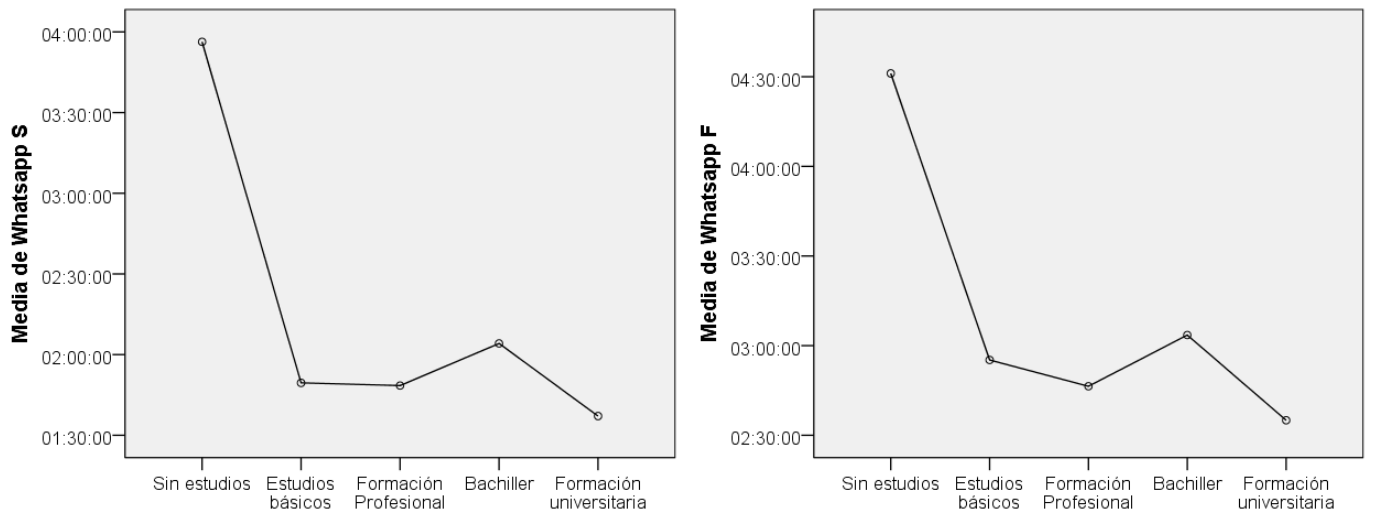

Gráfica 89: media de tiempo WhatsApp - formación académica de la madre 
- Internet fin de semana: los adolescentes que más tiempo dedican al navegar por internet son aquellos cuyas madres no han estudiado. Para el resto de opciones, el tiempo dedicado a esta actividad se mantiene prácticamente constante, independiente del nivel de estudios alcanzado por la madre (gráfica 90).

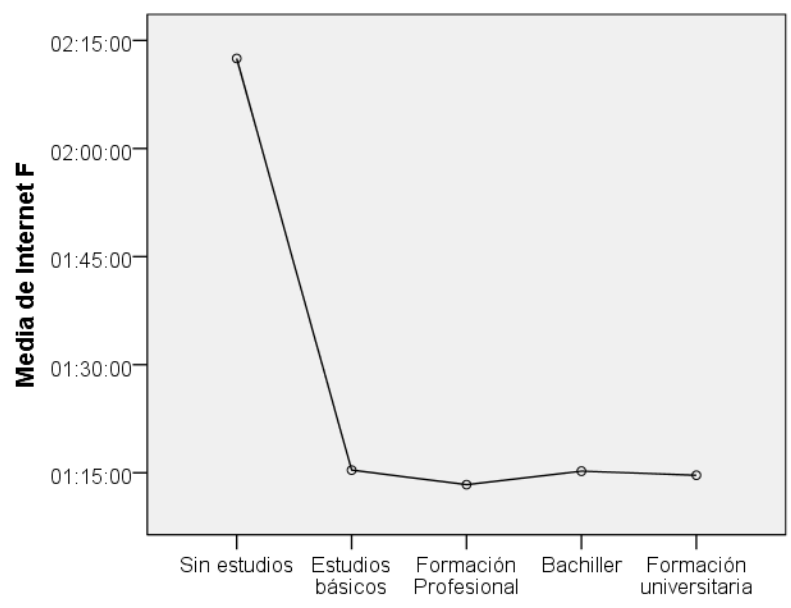

Gráfica 90: media de tiempo internet - formación académica de la madre

- Ver la televisión entre semana: el tiempo dedicado a esta actividad disminuye notablemente al aumentar el nivel de formación de la madre, llegando a sus valores más bajos para adolescentes cuyas madres han alcanzado estudios universitarios (gráfica 91).

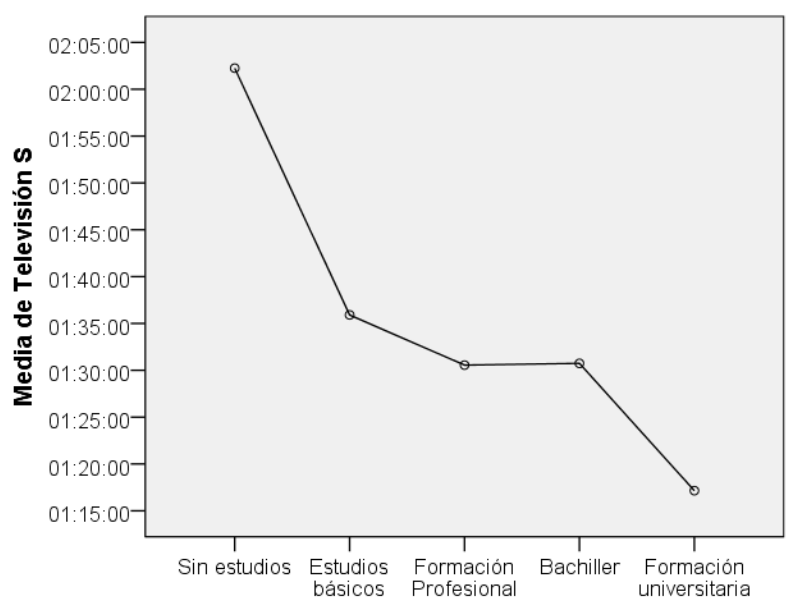

Gráfica 91: media de tiempo ver la televisión - formación académica de la madre 
- Deporte fin de semana: como muestra la gráfica 92, los adolescentes realizan deporte durante más tiempo al aumentar el nivel de estudios de la madre, exceptuándose para adolescentes cuyas madres son universitarias, donde se puede apreciar un ligero descenso de tiempo desempeñado en realizar actividades deportivas.

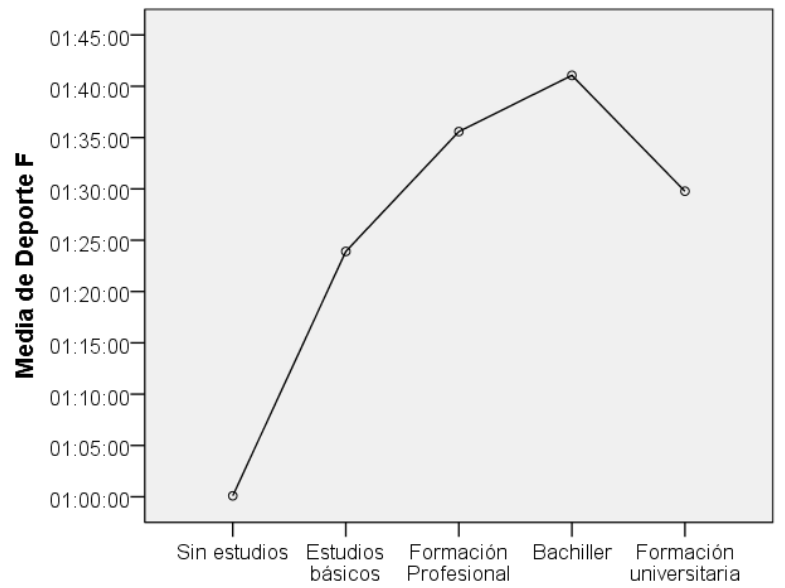

Gráfica 92: media de tiempo deporte - formación académica de la madre

- Trabajo remunerado en fin de semana: la gráfica 93 muestra que el tiempo dedicado a esta actividad disminuye al aumentar la formación de la madre, excepto para los adolescentes cuyas madres tienen estudios de bachillerato que aumenta ligeramente.

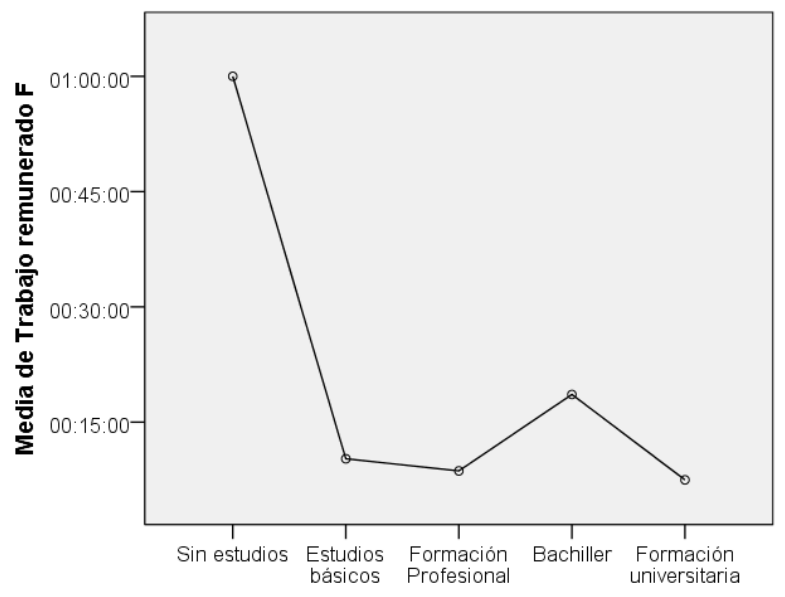

Gráfica 93: media de tiempo trabajo remunerado - formación académica de la madre 
- Tiempo dedicado a la lectura: en general, se puede concluir que el tiempo dedicado a esta actividad disminuye al aumentar la formación académica de la madre (gráfica 94). Existe un ligero aumento en el tiempo dedicado a esta actividad por las madres adolescentes cuyas madres han cursado estudios universitarios, pero el tiempo dedicado a leer es inferior al de adolescentes con madres sin estudios y con estudios básicos.
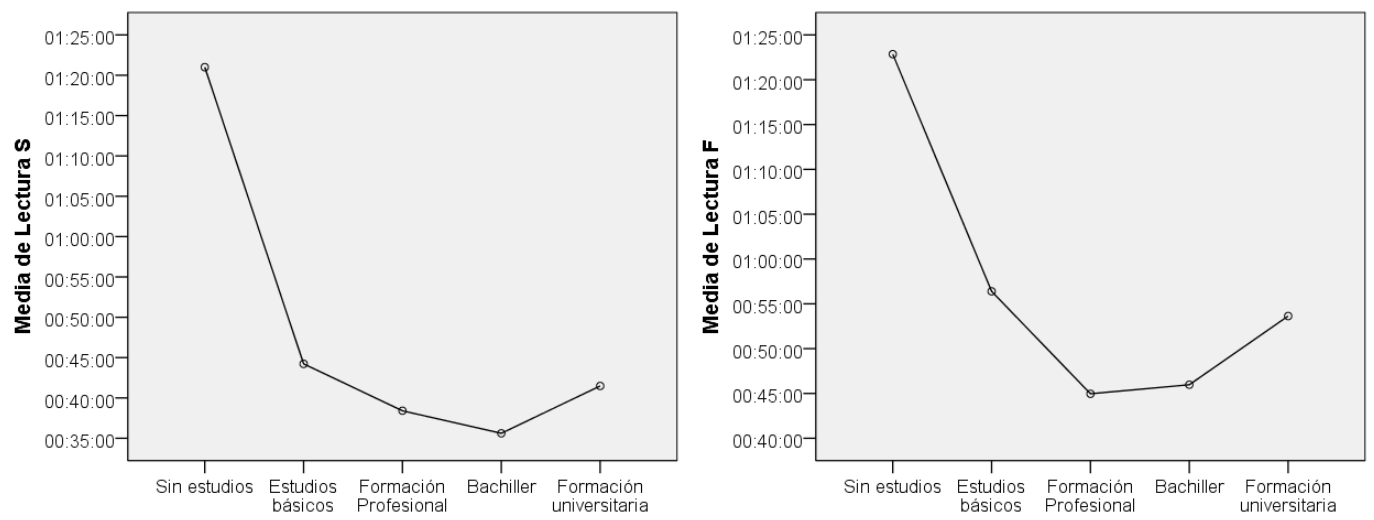

Gráfica 94: media de tiempo lectura -formación académica de la madre

- Higiene personal: el tiempo dedicado a la higiene personal disminuye, en general, al aumentar la formación de la madre (gráfica 95). Los adolescentes cuya madre no tiene estudios dedican 34 minutos más entre semana y 24 minutos más el fin de semana que aquellos cuyas madres tienen estudios universitarios.
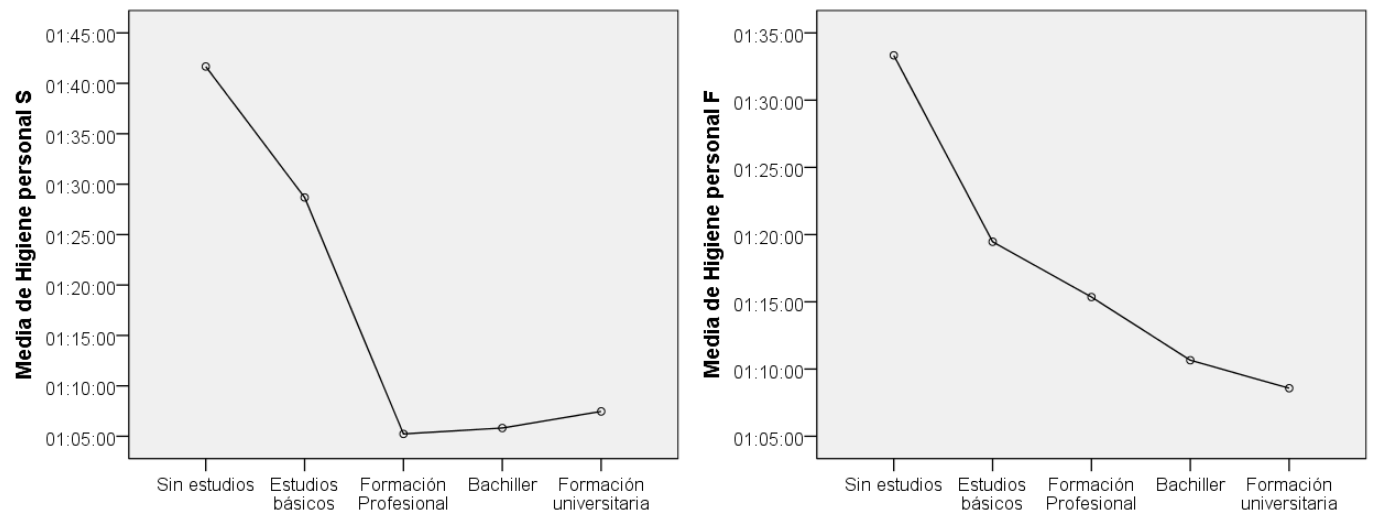

Gráfica 95: media de tiempo higiene personal - formación académica de la madre 
- $\quad$ Tiempo en dormirse ayer: no se observa una tendencia clara en cuanto a este punto (gráfica 96). Los adolescentes que más tiempo tardan en dormirse son aquellos cuya madre no ha cursado estudios. Estos tardan en dormirse 15 minutos más de media que aquellos cuyas madres tienen formación universitaria.

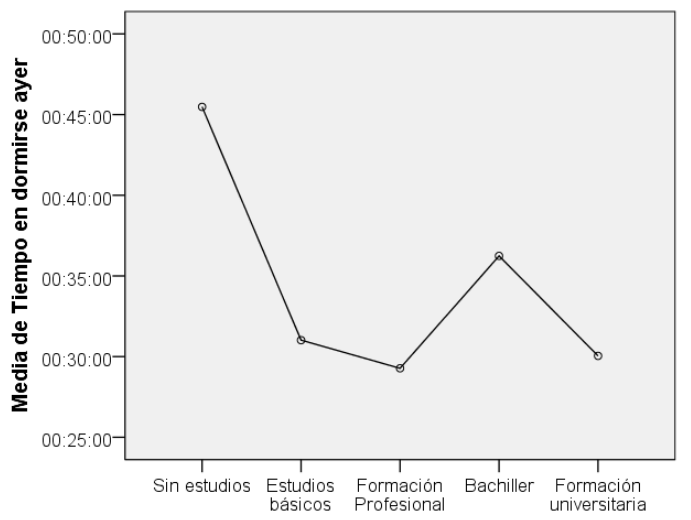

Gráfica 96: media de tiempo en dormirse - formación académica de la madre

\subsection{7.- Pareja}

Como último apartado de este punto de análisis de resultados, estudiamos el uso del tiempo de los adolescentes en función de si tienen o no pareja sentimental.

Para ello, realizamos el cálculo de la t-Student que se muestra en la tabla 50. Como en casos anteriores, hemos calculado la media de tiempo dedicada a cada una de las actividades en relación a si han afirmado tener o no pareja sentimental en el momento en el que responden a la encuesta. Se puede observar que 11 de las actividades estudiadas muestran diferencias significativas (sombreadas en rojo) en relación al estado sentimental del adolescente. 


\section{2a PARTE}

Capítulo 4.- Resultados

\begin{tabular}{|c|c|c|c|c|c|c|c|c|}
\hline & $\begin{array}{c}\text { ¿ Tiene } \\
\text { actua } \\
\text { no }\end{array}$ & $\begin{array}{l}\text { pareja } \\
\text { pente? } \\
\text { si }\end{array}$ & $\mathbf{t}$ & gl & $\begin{array}{c}\text { Sig. } \\
\text { (bilateral) }\end{array}$ & $\begin{array}{l}\text { Diferencia } \\
\text { de medias }\end{array}$ & $\begin{array}{r}95 \% \text { de } \\
\text { confia } \\
\text { Inferior }\end{array}$ & $\begin{array}{l}\text { itervalo de } \\
\text { Iza de la } \\
\text { Superior }\end{array}$ \\
\hline Dormir S & $7: 47$ & $7: 24$ & 5,842 & 269,291 & 0,000 & $0: 23$ & $0: 15$ & $0: 30$ \\
\hline Dormir F & 9:32 & $9: 32$ & 0,134 & 246,554 & 0,893 & $0: 00$ & $-0: 11$ & $0: 12$ \\
\hline Asistir a clase $\mathrm{S}$ & $6: 08$ & $6: 07$ & 1,159 & 281,613 & 0,247 & $0: 01$ & $-0: 00$ & $0: 03$ \\
\hline Asistir a clase $\mathrm{F}$ & $0: 00$ & $0: 00$ & & & & & & \\
\hline Actividades extraesc. S & $1: 49$ & $1: 40$ & 1,151 & 228,625 & 0,251 & $0: 08$ & $-0: 06$ & $0: 23$ \\
\hline Actividades extraesc. F & $0: 41$ & $0: 43$ & $-0,306$ & 205,810 & 0,760 & $-0: 01$ & $-0: 12$ & $0: 08$ \\
\hline Estudio S & $2: 24$ & $2: 15$ & 1,462 & 260,113 & 0,145 & $0: 09$ & $-0: 03$ & $0: 21$ \\
\hline Estudio F & $2: 32$ & $2: 28$ & 0,467 & 252,935 & 0,641 & $0: 04$ & $-0: 13$ & $0: 21$ \\
\hline Whatsapp S & $1: 41$ & $2: 18$ & $-4,187$ & 252,828 & 0,000 & $-0: 36$ & $-0: 54$ & $-0: 19$ \\
\hline Whatsapp F & $2: 37$ & $3: 31$ & $-4,272$ & 233,523 & 0,000 & $-0: 53$ & $-1: 18$ & $-0: 29$ \\
\hline Redes sociales S & $1: 03$ & $1: 20$ & $-2,700$ & 254,490 & 0,007 & $-0: 17$ & $-0: 30$ & $-0: 04$ \\
\hline Redes sociales $F$ & $1: 32$ & $1: 55$ & $-2,643$ & 245,278 & 0,009 & $-0: 22$ & $-0: 40$ & $-0: 05$ \\
\hline Internet S & $0: 54$ & $0: 50$ & 0,944 & 263,144 & 0,346 & $0: 04$ & $-0: 04$ & $0: 12$ \\
\hline Internet F & $1: 17$ & $1: 17$ & $-0,059$ & 224,365 & 0,953 & $-0: 00$ & $-0: 14$ & $0: 13$ \\
\hline Videojuegos/consolas S & $0: 28$ & $0: 28$ & $-0,059$ & 242,461 & 0,953 & $-0: 00$ & $-0: 10$ & 0:09 \\
\hline Videojuegos/consolas F & $1: 01$ & $0: 51$ & 1,500 & 253,522 & 0,135 & $0: 10$ & $-0: 03$ & $0: 24$ \\
\hline Televisión S & $1: 24$ & $1: 25$ & $-0,135$ & 280,695 & 0,893 & $-0: 00$ & $-0: 11$ & $0: 09$ \\
\hline Televisión F & $2: 05$ & $2: 06$ & $-0,052$ & 260,950 & 0,958 & $-0: 00$ & $-0: 15$ & $0: 14$ \\
\hline Teléfono S & $0: 18$ & $0: 36$ & $-4,436$ & 208,369 & 0,000 & $-0: 18$ & $-0: 26$ & $-0: 10$ \\
\hline Teléfono F & $0: 28$ & $0: 41$ & $-2,903$ & 222,447 & 0,004 & $-0: 13$ & $-0: 22$ & $-0: 04$ \\
\hline Deporte S & $1: 48$ & $1: 53$ & $-0,753$ & 254,212 & 0,452 & $-0: 05$ & $-0: 19$ & $0: 08$ \\
\hline Deporte F & $1: 30$ & $1: 33$ & $-0,461$ & 238,293 & 0,645 & $-0: 02$ & $-0: 15$ & $0: 09$ \\
\hline Trabajo doméstico S & $0: 37$ & $0: 38$ & $-0,149$ & 266,983 & 0,882 & $-0: 00$ & $-0: 06$ & $0: 05$ \\
\hline Trabajo doméstico F & $0: 50$ & $0: 49$ & 0,297 & 267,184 & 0,767 & $0: 01$ & $-0: 06$ & $0: 08$ \\
\hline Trabajo remunerado S & $0: 06$ & $0: 07$ & $-0,102$ & 237,468 & 0,918 & $-0: 00$ & $-0: 05$ & $0: 05$ \\
\hline Trabajo remunerado F & $0: 10$ & $0: 13$ & $-0,647$ & 215,277 & 0,519 & $-0: 02$ & $-0: 12$ & $0: 06$ \\
\hline Lectura S & $0: 43$ & $0: 32$ & 3,067 & 275,932 & 0,002 & $0: 10$ & $0: 03$ & $0: 17$ \\
\hline Lectura F & $0: 52$ & $0: 43$ & 1,930 & 282,078 & 0,055 & $0: 09$ & $-0: 00$ & $0: 18$ \\
\hline Higiene personal S & $1: 08$ & $1: 16$ & $-1,584$ & 253,553 & 0,115 & $-0: 07$ & $-0: 17$ & $0: 01$ \\
\hline Higiene personal F & $1: 12$ & $1: 16$ & $-1,084$ & 279,098 & 0,279 & $-0: 04$ & $-0: 11$ & $0: 03$ \\
\hline Alimentación S & $1: 43$ & $1: 39$ & 0,773 & 263,700 & 0,440 & $0: 04$ & $-0: 06$ & $0: 14$ \\
\hline Alimentación F & $1: 45$ & $1: 45$ & $-0,052$ & 243,028 & 0,958 & $-0: 00$ & $-0: 10$ & 0:09 \\
\hline Amigos S & $1: 09$ & $1: 12$ & $-0,426$ & 256,050 & 0,671 & $-0: 02$ & $-0: 16$ & $0: 10$ \\
\hline Amigos $\mathrm{F}$ & $3: 22$ & $4: 19$ & $-4,699$ & 234,833 & 0,000 & $-0: 57$ & $-1: 21$ & $-0: 33$ \\
\hline Desplazamientos S & $0: 45$ & $0: 44$ & 0,330 & 279,094 & 0,742 & $0: 01$ & $-0: 05$ & $0: 08$ \\
\hline Desplazamientos F & $0: 57$ & $1: 02$ & $-0,871$ & 245,843 & 0,385 & $-0: 04$ & $-0: 15$ & 0:05 \\
\hline Salir con pareja S & 0:00 & $1: 29$ & $-7,536$ & 180,204 & 0,000 & $-1: 29$ & $-1: 52$ & $-1: 05$ \\
\hline Salir con parej F & $0: 02$ & $2: 36$ & $-17,259$ & 177,411 & 0,000 & $-2: 34$ & $-2: 52$ & $-2: 17$ \\
\hline Tiempo en dormirse ayer & $0: 30$ & $0: 30$ & $-0,036$ & 285,060 & 0,971 & $-0: 00$ & $-0: 04$ & $0: 04$ \\
\hline
\end{tabular}

Tabla 50: análisis t-Student uso del tiempo con respecto a la su estado sentimental 
- Los adolescentes con pareja dedican más tiempo que los adolescentes sin pareja a las siguientes actividades (gráfica 97):

- Uso de WhatsApp: los adolescentes con pareja dedican al WhatsApp 36 minutos más de media entre semana y 53 minutos más de media el fin de semana.

- Redes sociales: entre semana dedican 17 minutos más de media y 22 minutos más el fin de semana.

- Hablar por teléfono: entre semana dedican 18 minutos más de media y 13 minutos más el fin de semana.

- Salir con amigos entre semana: los adolescentes con pareja dedican 57 minutos más de media a esta actividad que aquellos que no tienen pareja.

- Salir con pareja: como parece lógico, los adolescentes con pareja dedican 1:29 horas más de media entre semana a esta actividad y 2:34 horas más el fin de semana.

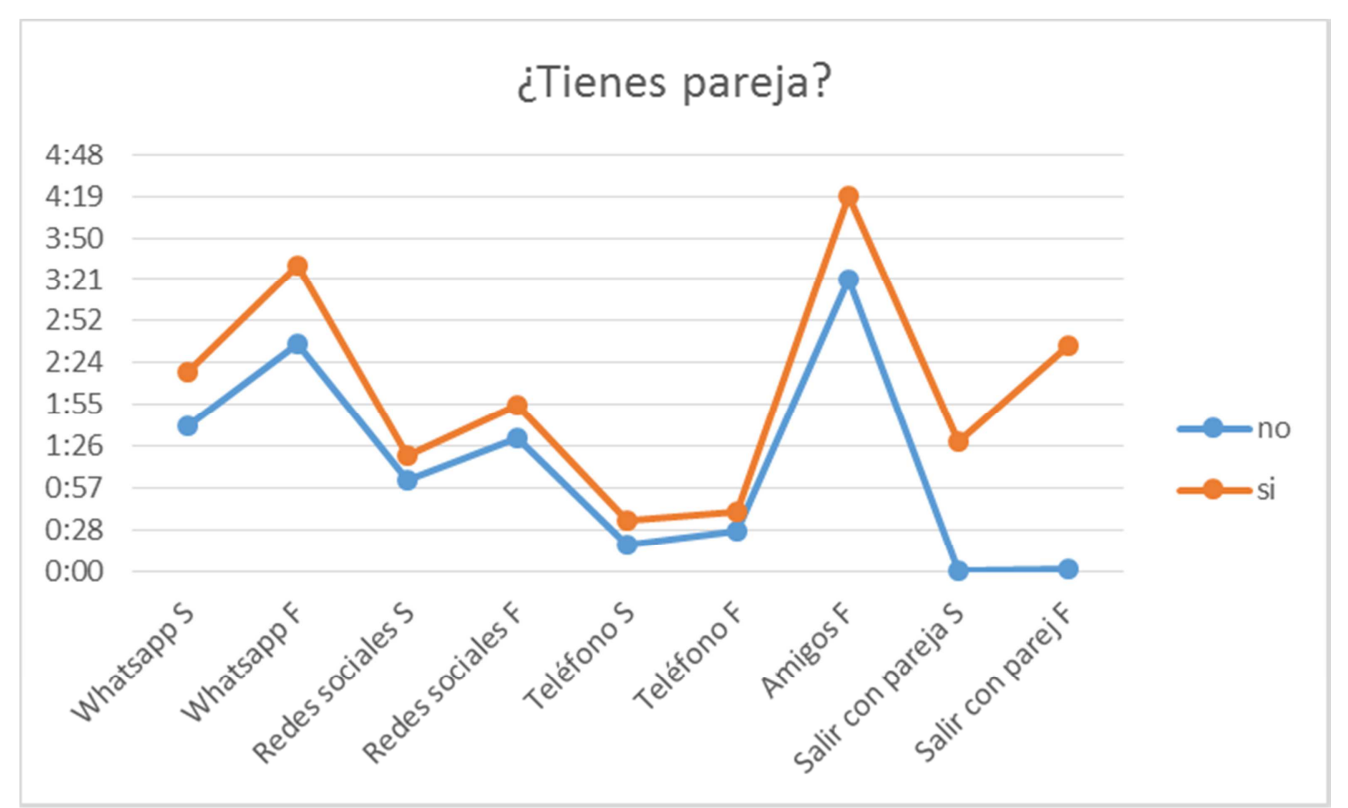

Gráfica 97: Tiempo medio dedicado a diferentes actividades - tienen pareja. 
- Los adolescentes que no tienen pareja dedican más tiempo que los adolescentes con pareja a las siguientes actividades (gráfica 98):

- Dormir entre semana: los adolescentes sin pareja duermen más tiempo entre semana que aquellos con pareja (23 minutos más de media).

- Lectura entre semana: los adolescentes sin pareja dedican 10 minutos de media al día a leer entre semana más que aquellos sin pareja.

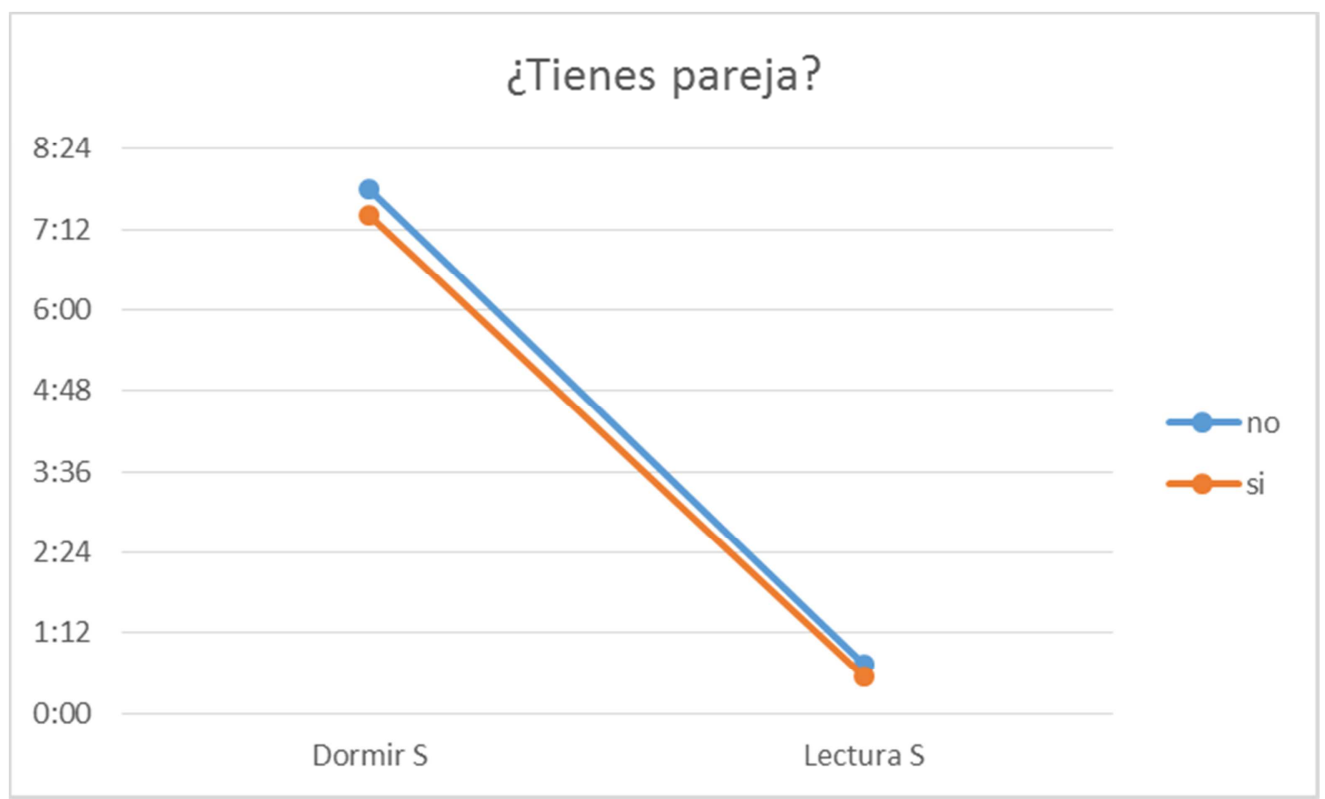

Gráfica 98: Tiempo medio dedicado a diferentes actividades -no tienen pareja.

\subsection{8.- Dormir la siesta y cansancio}

El objetivo de las siguientes cuestiones es saber si los adolescentes e encuentran cansados o si necesitan dormir la siesta como complemento al tiempo que duermen por las noches.

Como se puede observar en la tabla 51, no alcanza el $3 \%$ los adolescentes que afirman dormir la siesta siempre. De hecho más de la mitad, el $57 \%$ afirma rotundamente no dormir la siesta nunca. 


\begin{tabular}{|l|c|}
\cline { 2 - 2 } \multicolumn{1}{c|}{} & Frecuencia \\
\hline Nunca & $57,0 \%$ \\
\hline A veces & $34,0 \%$ \\
\hline Habitualmente & $6,5 \%$ \\
\hline Siempre & $2,6 \%$ \\
\hline Total & $100,0 \%$ \\
\hline
\end{tabular}

Tabla 51: duermen la siesta.

En la tabla 52 podemos ver el porcentaje de adolescentes burgaleses encuestados que afirma encontrarse a menudo cansado durante el día y con la sensación de no haber dormido lo suficiente. En este caso, el porcentaje que afirma nunca encontrarse cansado es bajo, solo del $18,4 \%$. Más de la mitad de los adolescentes manifiesta sentirse cansado sólo a veces.

\begin{tabular}{|l|c|}
\cline { 2 - 2 } \multicolumn{1}{c|}{} & Porcentaje \\
\hline Nunca & $18,4 \%$ \\
\hline A veces & $59,7 \%$ \\
\hline Habitualmente & $15,9 \%$ \\
\hline Siempre & $6,0 \%$ \\
\hline Total & $100,0 \%$ \\
\hline
\end{tabular}

Tabla 52: adolescentes cansados

Utilizaremos estos datos para analizar en capítulos siguientes si existen relaciones entre los adolescentes que se encuentran cansados y necesitan dormir la siesta y los que dedican más tiempo a las nuevas tecnologías.

\subsection{9.- Resumen del capítulo:}

Para finalizar este capítulo de estudio del uso del tiempo de los adolescentes en función de los factores sociodemográficos, hemos realizado la tabla 53 que recoge las conclusiones que hemos obtenido de cada punto estudiado. En ella se puede apreciar qué factores muestran diferencias significativas en cada actividad de uso del tiempo. 
Capítulo 4.- Resultados

\begin{tabular}{|c|c|c|c|c|c|c|c|c|c|c|}
\hline & Género & Edad & Nacion. & $\begin{array}{l}\text { Centro } \\
\text { educ. }\end{array}$ & № herm. & $\begin{array}{l}\text { Vive } \\
\text { con } \\
\end{array}$ & $\begin{array}{c}\text { Compañía } \\
\text { tardes }\end{array}$ & $\begin{array}{c}\text { Estudios } \\
\text { padre }\end{array}$ & $\begin{array}{c}\text { Estudios } \\
\text { madre }\end{array}$ & Pareja \\
\hline Dormir S & si & si & & si & & si & si & & & si \\
\hline Dormir F & & si & & & & & & & & \\
\hline Asistir a clase $\mathrm{S}$ & & & si & si & & & & si & si & \\
\hline \multicolumn{11}{|l|}{ Asistir a clase $F$} \\
\hline Actividades extr. S & si & & si & si & & & & si & si & \\
\hline Actividades extr. F & si & & & si & & & & si & si & \\
\hline Estudio S & si & si & & si & & si & si & & & \\
\hline Estudio F & si & si & si & si & & si & si & si & si & \\
\hline Whatsapp S & $\mathrm{si}$ & si & & si & & & & si & si & si \\
\hline Whatsapp F & si & si & si & & si & & & si & si & si \\
\hline Redes sociales S & si & si & & si & & & si & & & si \\
\hline Redes sociales F & si & si & & si & & & & & & si \\
\hline Internet S & si & si & & & & si & si & & & \\
\hline Internet F & si & si & & & & si & & & si & \\
\hline Videojuegos S & si & & si & & & si & & & & \\
\hline Videojuegos F & si & & & & & & & & & \\
\hline Televisión S & & & & & & & & & si & \\
\hline Televisión F & & & & & & & si & & & \\
\hline Teléfono S & si & & & & & si & & & & si \\
\hline Teléfono F & si & & & & & si & & & & si \\
\hline Deporte S & si & si & & si & & & & & & \\
\hline Deporte F & si & si & & & & & si & & si & \\
\hline Trabajo doméstico S & si & & & & si & si & & & & \\
\hline Trabajo doméstico F & si & & & & & & & & & \\
\hline \multicolumn{11}{|l|}{ Trabajo remunerado $\mathrm{S}$} \\
\hline Trabajo remunerado $\mathrm{F}$ & si & & & si & & & & si & si & \\
\hline Lectura S & si & si & si & si & & & & & si & si \\
\hline Lectura F & si & si & & & si & & & & si & \\
\hline Higiene personal S & si & si & & & & & & & si & \\
\hline Higiene personal F & si & & & & & si & & si & si & \\
\hline Alimentación S & & si & & & & & & & & \\
\hline Alimentación F & si & & & si & & & & & & \\
\hline Amigos S & & si & si & & & & & & & \\
\hline Amigos F & & si & & si & & & & & & si \\
\hline \multicolumn{11}{|l|}{ Desplazamientos S } \\
\hline Desplazamientos F & & si & & & si & & & & & \\
\hline Salir con pareja S & & si & & & si & & si & & & si \\
\hline Salir con parej F & & si & si & si & si & si & & & & si \\
\hline Tiempo en dormirse & si & & & si & & si & si & & si & \\
\hline
\end{tabular}

Tabla 53: tabla resumen factores que pueden afectar al uso del tiempo 


\section{3.- LA RELACIÓN DE LOS ADOLESCENTES CON LAS NUEVAS TECNOLOGÍAS:}

A continuación, nos centramos en realizar el análisis de las respuestas obtenidas en la tercera parte de la encuesta, dedicada a cuestiones sobre el uso de las nuevas tecnologías por los adolescentes. Estas preguntas tratan de buscar respuestas que arrojen luz sobre el nivel de tecnología que el adolescente tiene a su disposición. Adicionalmente, se pregunta al adolescente por la utilización de dicha tecnología en horarios lectivos.

En este capítulo estudiaremos la relación entre los diferentes dispositivos electrónicos y los adolescentes. En cada punto analizaremos primero el porcentaje de adolescentes que dispone de dicha tecnología. A continuación analizaremos el tiempo dedicado al uso de esa tecnología. Finalmente, trataremos de encontrar relación entre la posesión de estos dispositivos y los factores sociodemográficos analizados anteriormente en la estadística descriptiva (género, edad, nacionalidad, centro educativo y entorno familiar).

\subsection{1- Internet}

a) Internet en hogar

En el año 2015, el 95,5\% de los adolescentes encuestados de Burgos afirman disponer de conexión a internet en su hogar. Como se observa en la gráfica 99, tan sólo el 3\% de los adolescentes manifiesta no tenerla, mientras que el $1,5 \%$ no han respondido.

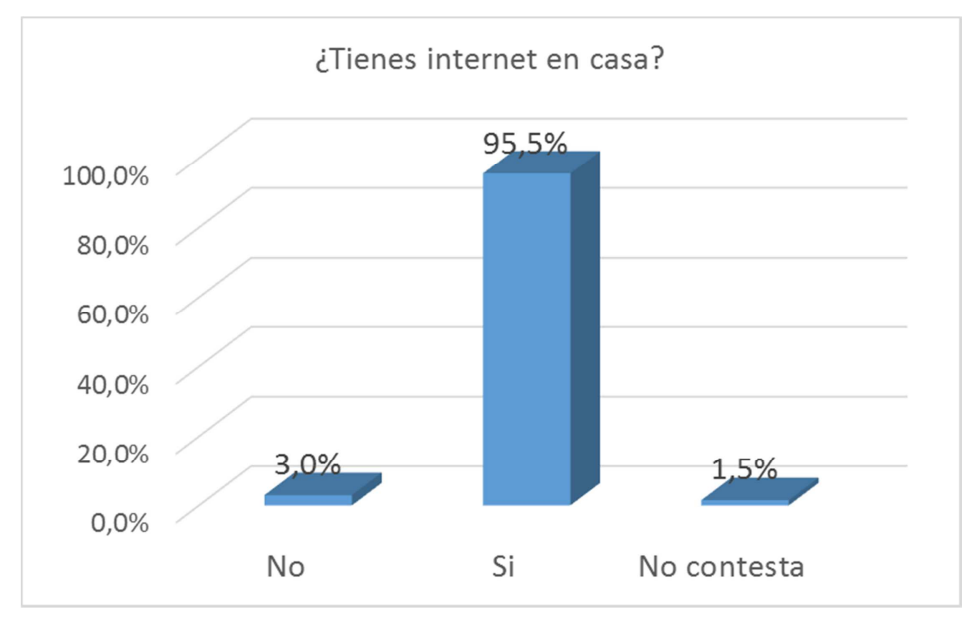

Gráfica 99: internet en casa 
Como puede observarse en la tabla 54, el porcentaje de adolescentes que tiene internet en casa por género es prácticamente el mismo. No se aprecian diferencias significativas puesto que el grado de significación es de 0,913, valor superior a 0,05.

\begin{tabular}{|l|cc|c|}
\cline { 2 - 4 } \multicolumn{1}{c|}{} & \multicolumn{2}{c|}{ Internet en casa } & Total \\
\cline { 1 - 4 } \multicolumn{1}{c|}{} & No & Si & \\
\hline Femenino & $3,1 \%$ & $96,9 \%$ & 751 \\
\hline Masculino & $3,0 \%$ & $97,0 \%$ & 675 \\
\hline Total & 43 & 1383 & 1426 \\
\hline
\end{tabular}

Tabla 54: Internet en casa - género

Realizamos una tabla cruzada con el objetivo de observar si existen diferencias con la edad en el hecho de tener conexión a Internet en casa. En la tabla 55 podemos observar que el porcentaje de adolescentes que tiene internet en casa es más elevado para los adolescentes más mayores (98,40\% de los hogares de adolescentes de 17 años) que para los adolescentes más jóvenes (94,50\% de los hogares de adolescentes de12 años). Tras realizar la chi-cuadrado de Pearson, observamos que el valor de significación es del 0,082 por lo que no podemos afirmar que existan diferencias significativas.

\begin{tabular}{|l|cc|c|}
\cline { 2 - 4 } \multicolumn{1}{c|}{} & \multicolumn{2}{c|}{ Internet en casa } & Total \\
\hline $\mathbf{1 2}$ & No & Si & \\
\hline $\mathbf{1 3}$ & $5,50 \%$ & $94,50 \%$ & 200 \\
\hline $\mathbf{1 4}$ & $3,32 \%$ & $96,68 \%$ & 271 \\
\hline $\mathbf{1 5}$ & $1,65 \%$ & $98,35 \%$ & 243 \\
\hline $\mathbf{1 6}$ & $4,13 \%$ & $95,87 \%$ & 218 \\
\hline $\mathbf{1 7}$ & $1,66 \%$ & $98,34 \%$ & 241 \\
\hline Total & $1,60 \%$ & $98,40 \%$ & 187 \\
\hline
\end{tabular}

Tabla 55: Internet en casa - edad.

Parece que el porcentaje de adolescentes que tiene internet en casa aumenta con el curso académico (tabla 56). El nivel significativo tiene un valor de 0,216 por lo que no podemos afirmar que estas diferencias sean significativas. 


\begin{tabular}{|c|c|c|c|}
\hline & \multicolumn{2}{|c|}{ ¿Tienes Internet en casa? } & \multirow{2}{*}{ Total } \\
\hline & No & Si & \\
\hline $1 \stackrel{0}{ } \mathrm{ESO}$ & $4,9 \%$ & $95,1 \%$ & 326 \\
\hline 2 ESO & $3,5 \%$ & $96,5 \%$ & 287 \\
\hline 3 ESO & $2,7 \%$ & $97,3 \%$ & 264 \\
\hline 4 ESO & $1,6 \%$ & $98,4 \%$ & 185 \\
\hline 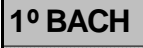 & $1,8 \%$ & $98,2 \%$ & 218 \\
\hline $2 \% \mathrm{BACH}$ & $2,1 \%$ & $97,9 \%$ & 146 \\
\hline Total & 43 & 1383 & 1426 \\
\hline
\end{tabular}

Tabla 56: Internet en casa - curso.

Tal y como muestra la tabla 57, aparentemente el porcentaje de adolescentes españoles que tiene Internet en casa $(97,05 \%)$ es superior al de adolescentes de nacionalidad distinta a la española $(94,12 \%)$. Sin embargo, el cálculo de chi-cuadrado desvela que el valor de significación es de 0,322 por lo que no podemos afirmar que estas diferencias sean significativas por nacionalidad. En este caso, el reducido número de extranjeros hace más complicado encontrar diferencias si existiesen.

\begin{tabular}{|c|c|c|c|}
\hline & \multicolumn{2}{|c|}{ Internet en casa } & \multirow{2}{*}{ Tota } \\
\hline & No & Si & \\
\hline Española & $2,95 \%$ & $97,05 \%$ & 1392 \\
\hline Extranjera & $5,88 \%$ & $94,12 \%$ & 34 \\
\hline Total & 43 & 1383 & 1426 \\
\hline
\end{tabular}

Tabla 57: Internet en casa - nacionalidad.

Según lo mostrado en la tabla 58, el porcentaje de adolescentes en cuyos hogares hay conexión a internet es prácticamente el mismo para todos los centros situados en la ciudad (entre el 97,2\% y el 97,5\%). Sin embargo, el porcentaje de hogares con conexión a internet del entorno rural $(88,3 \%)$ es inferior al del entorno urbano. El valor de significación en este caso es del 0,000 por lo que sí existen diferencias significativas. Sin_embargo, la prueba chi-cuadrado afirma que 1 casilla ha esperado un recuento menor que 5 , por lo que tomamos este nivel de significación con cautela. 


\begin{tabular}{|l|cc|c|}
\cline { 2 - 4 } \multicolumn{1}{c|}{} & \multicolumn{2}{c|}{ Internet en casa } & \multirow{2}{*}{ Total } \\
\hline Privado urbano 1 & $2,8 \%$ & Si & \\
\hline Privado urbano 2 & $2,5 \%$ & $97,2 \%$ & 217 \\
\hline Público urbano & $2,5 \%$ & $97,5 \%$ & 399 \\
\hline Público rural & $11,7 \%$ & $88,3 \%$ & 733 \\
\hline Total & 43 & 1383 & 77 \\
\hline
\end{tabular}

Tabla 58: Internet en casa - centro educativo

No hemos encontrado diferencias significativas entre el número de hermanos que tiene el adolescente y el hecho de tener Internet en casa.

Con respecto a las personas con las que vive el adolescente y su relación con la posibilidad de tener conexión a internet en casa, podemos observar en la tabla cruzada 59, que el número de valores esperados para varias de las casillas es inferior a 5, lo cual indica que el valor de la chi-cuadrado puede verse distorsionado.

\begin{tabular}{|l|cc|cc|c|}
\cline { 2 - 6 } \multicolumn{1}{c|}{} & \multicolumn{2}{c|}{ Internet en casa NO } & \multicolumn{2}{c|}{ Internet en casa SI } & Total \\
\hline Padre & Porcentaje & Valor esperado & Porcentaje & Valor esperado & \\
\hline Madre & $12,5 \%$ & 0,7 & $87,5 \%$ & 23,3 & 24 \\
\hline Ambos & $7,0 \%$ & 4,8 & $93,0 \%$ & 152,2 & 157 \\
\hline Tutor & $2,3 \%$ & 37,1 & $97,7 \%$ & 1187,9 & 1225 \\
\hline Otros & $0,0 \%$ & 0,1 & $100,0 \%$ & 2,9 & 3 \\
\hline Total & $11,1 \%$ & 0,3 & $88,9 \%$ & 8,7 & 9 \\
\hline
\end{tabular}

Tabla 59: Internet en casa-personas con las que vive y valor esperado

Por esta razón, vamos a establecer una comparativa entre los adolescentes que han contestado ambos y el resto de los adolescentes encuestados. A continuación, hacemos una tabla cruzada con la variable Internet en casa cuyo resultado se puede ver en la tabla 60. En esta tabla, el número de valores esperados es superior a 5 en todos los casos, por lo que entendemos que podemos tomar como válida la prueba chi-cuadrado. El valor de significación es de 0,000 (inferior a 0,05) por lo que afirmamos que existen diferencias significativas entre tener Internet en casa dependiendo de si el adolescente vive con ambos padres o con el resto. 


\begin{tabular}{|l|cc|c|}
\cline { 2 - 4 } \multicolumn{1}{c|}{} & \multicolumn{2}{c|}{ Internet en casa } & Total \\
\hline Ambos & No & Si & \\
\hline Resto & $2,3 \%$ & $97,7 \%$ & 1225 \\
\hline Total & $4,5 \%$ & $92,5 \%$ & 201 \\
\hline
\end{tabular}

Tabla 60: Internet en casa-personas con las que vive agrupado y valor esperado

También agrupamos la variable con quién pasas la tarde, que diferenciará entre los adolescentes que están acompañados por la tarde de su madre (porcentaje más alto de respuestas) o del resto (acompañados de otros adultos). Como podemos apreciar en la tabla 61 , los porcentajes son muy similares. El valor de significación $(0,849)$ indica que no se puede asegurar que existan diferencias significativas.

\begin{tabular}{|l|cc|c|}
\cline { 2 - 4 } \multicolumn{1}{c|}{} & \multicolumn{2}{c|}{ Internet en casa } & Total \\
\hline Madre & $2,9 \%$ & $97,1 \%$ & 619 \\
\hline Resto & $3,1 \%$ & $96,9 \%$ & 807 \\
\hline Total & 43 & 1383 & 1426 \\
\hline
\end{tabular}

Tabla 61: Internet en casa -personas que le acompañan por la tarde agrupado y valor esperado

La gráfica 100 muestra la comparativa por porcentaje de hogares en los que sí que hay conexión a Internet, en relación a los estudios alcanzados por los padres. Como se puede observar en dicha gráfica, parece que el porcentaje de hogares con internet más alto corresponde a aquellos cuyo padre o madre tiene estudios universitarios. Aunque según el valor de significación de chi-cuadrado estas diferencias no son significativas. 


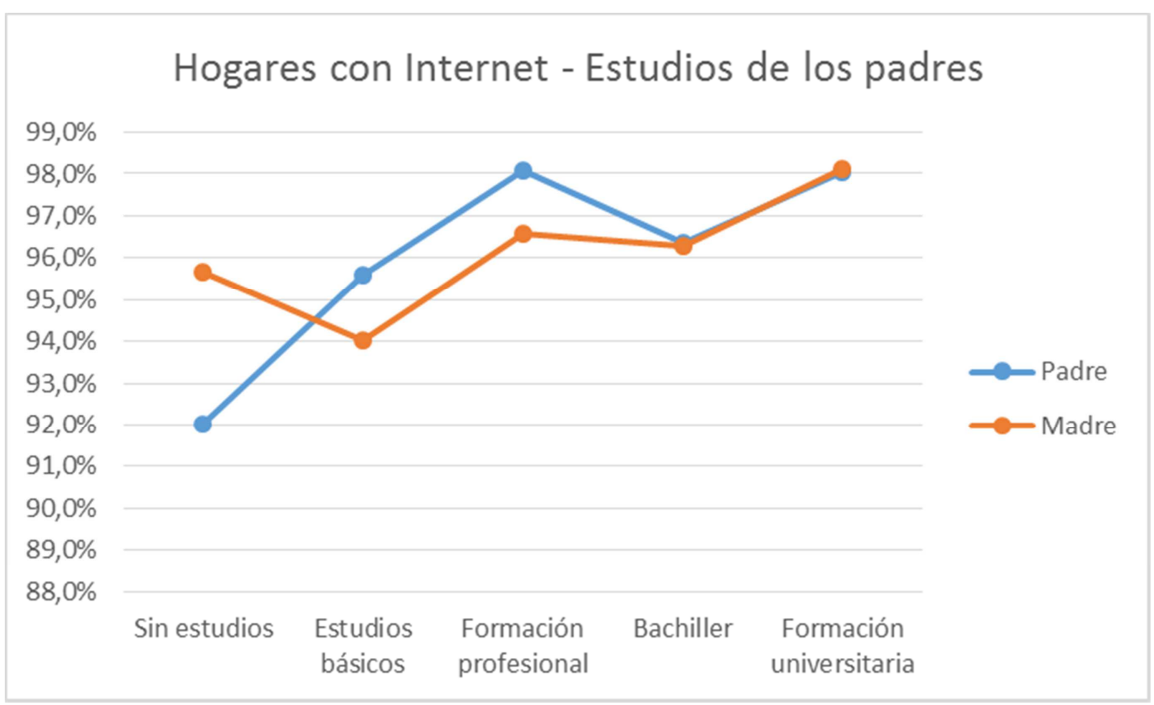

Gráfica 100: Hogares con Internet - nivel de estudios de padre y madre

Por último, analizamos si existe relación entre el estado sentimental del adolescente y el hecho de tener conexión a Internet en casa. Como se puede apreciar en la tabla 61.1, el porcentaje de adolescentes que tiene y no tiene pareja y que sí tiene internet en casa es prácticamente el mismo (96,59\% frente a 97,15\%). El valor de significación $(0,657)$ denota que no se puede asegurar que hay diferencias significativas.

\begin{tabular}{|l|cc|c|}
\cline { 2 - 4 } \multicolumn{1}{c|}{} & \multicolumn{2}{c|}{ Internet en casa } & \multirow{2}{*}{ Total } \\
\hline No & Si & \\
\hline Pareja no & $2,85 \%$ & $97,15 \%$ & 1159 \\
\hline Pareja si & $3,41 \%$ & $96,59 \%$ & 205 \\
\hline Total & 40 & 1324 & 1364 \\
\hline
\end{tabular}

Tabla 61.1: Internet en casa - pareja

\section{b) Porcentaje de adolescentes burgaleses que dedican tiempo a internet}

Utilizamos la información obtenida en la cuestión 15 para calcular el porcentaje de adolescentes que dedican tiempo a navegar por internet. El 16,77\% de los adolescentes burgaleses encuestados afirma no dedicar tiempo a navegar en la red. El 83,23\% sin embargo, afirma usar parte de su tiempo a navegar por internet. 
Con respecto al género, la tabla 62 pone de manifiesto que existen diferencias significativas en cuanto al uso de internet entre semana. El porcentaje de adolescentes que usa internet entre semana es ligeramente mayor entre el género masculino (casi 1\% más) que en el femenino.

\begin{tabular}{|c|c|c|c|}
\hline & \multicolumn{2}{|c|}{ Usan nternet entre semana } & \multirow{2}{*}{ Total } \\
\hline & No & Si & \\
\hline Femenino & $20,7 \%$ & $82,9 \%$ & 694 \\
\hline Masculino & $16,2 \%$ & $83,8 \%$ & 617 \\
\hline Total & 219 & 1092 & 1311 \\
\hline
\end{tabular}

Tabla 62: uso de internet por género entre semana.

La tabla 63 muestra que durante el fin de semana, el porcentaje de adolescentes masculinos que dedica tiempo a internet es también ligeramente mayor al femenino (casi $1,5 \%$ más).

\begin{tabular}{|l|cc|c|}
\cline { 2 - 4 } \multicolumn{1}{c|}{} & \multicolumn{2}{c|}{$\begin{array}{c}\text { Usan internet en fin de semana } \\
\text { No }\end{array}$} & Total \\
\hline Femenino & $19,6 \%$ & $80,4 \%$ & 673 \\
\hline Masculino & $19,0 \%$ & $81,0 \%$ & 600 \\
\hline Total & 246 & 1027 & 1273 \\
\hline
\end{tabular}

Tabla 63: uso de internet por género en fin de semana.

\section{c) Porcentaje del tiempo utilizado en internet dedicado a estudios y a ocio}

La cuestión 35 de la encuesta pide al adolescente que especifique qué porcentaje del tiempo que pasa conectado a Internet está destinado al estudio y qué porcentaje al ocio. Como puede apreciarse en la gráfica 101, los adolescentes manifiestan dedicar más tiempo a navegar por internet por ocio (61,02\%) que para apoyar en sus estudios $(38,98 \%)$. 


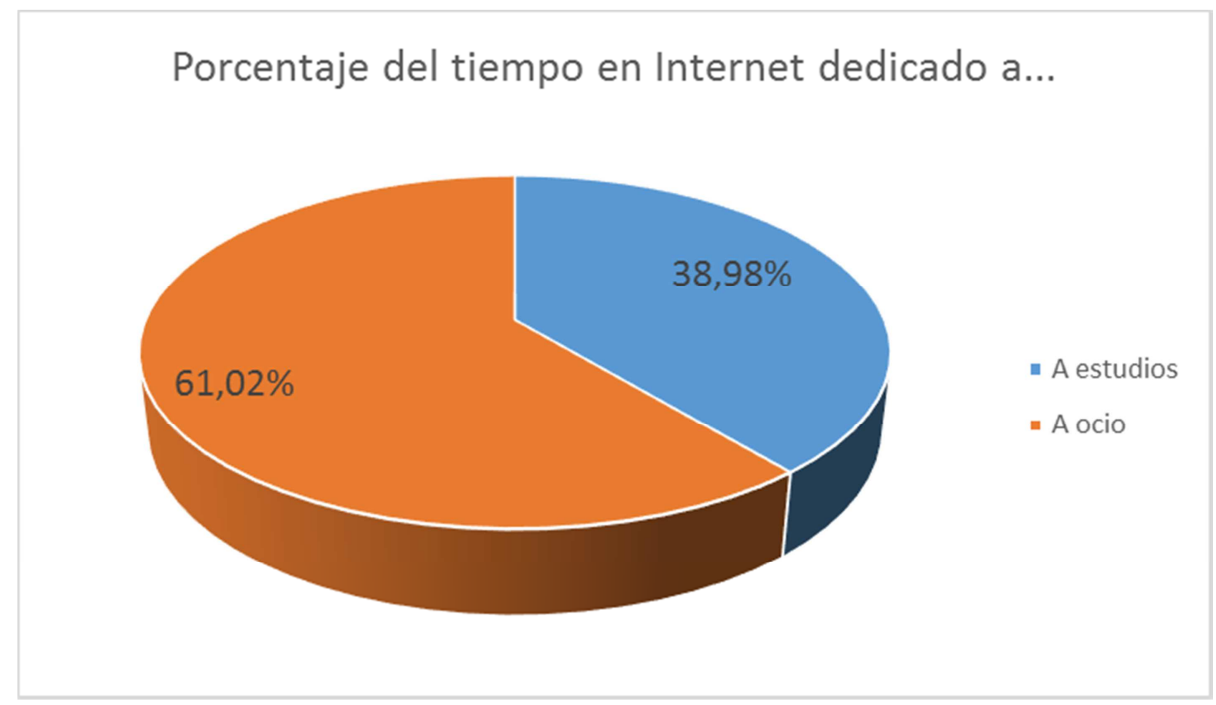

Gráfica 101: tiempo conectado a Internet dedicado a estudios y a ocio

Segmentamos el archivo en SPSS por género con el objetivo de calcular el porcentaje medio de tiempo dedicado a navegar en Internet para ocio o para estudiar. En la gráfica 102 podemos observar que tanto las chicas como los chicos dedican más tiempo a navegar por ocio que para sus estudios. Señalar que el porcentaje de adolescentes chicos dedicando tiempo en la red destinado al ocio es mayor que el de las chicas. El nivel de significación representa que existen diferencias significativas por género en cuanto al tiempo dedicado a navegar por internet por ocio o como apoyo a los estudios.

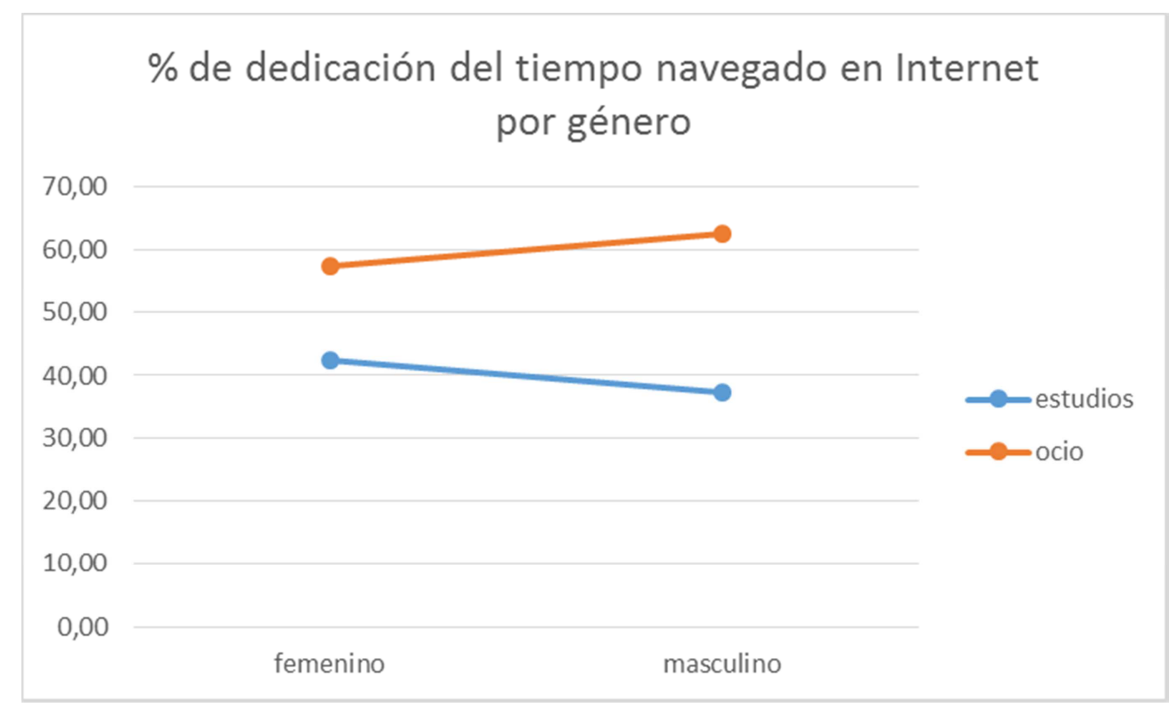

Gráfica 102: tiempo conectado a Internet dedicado a estudios y a ocio por género 
Con respecto a la edad, podemos observar en la gráfica 103 que los adolescentes más jóvenes dedican más tiempo en la Web para apoyar sus estudios. Sin embargo, el porcentaje de tiempo dedicado por los adolescentes a navegar en internet para ocio aumenta con la edad.

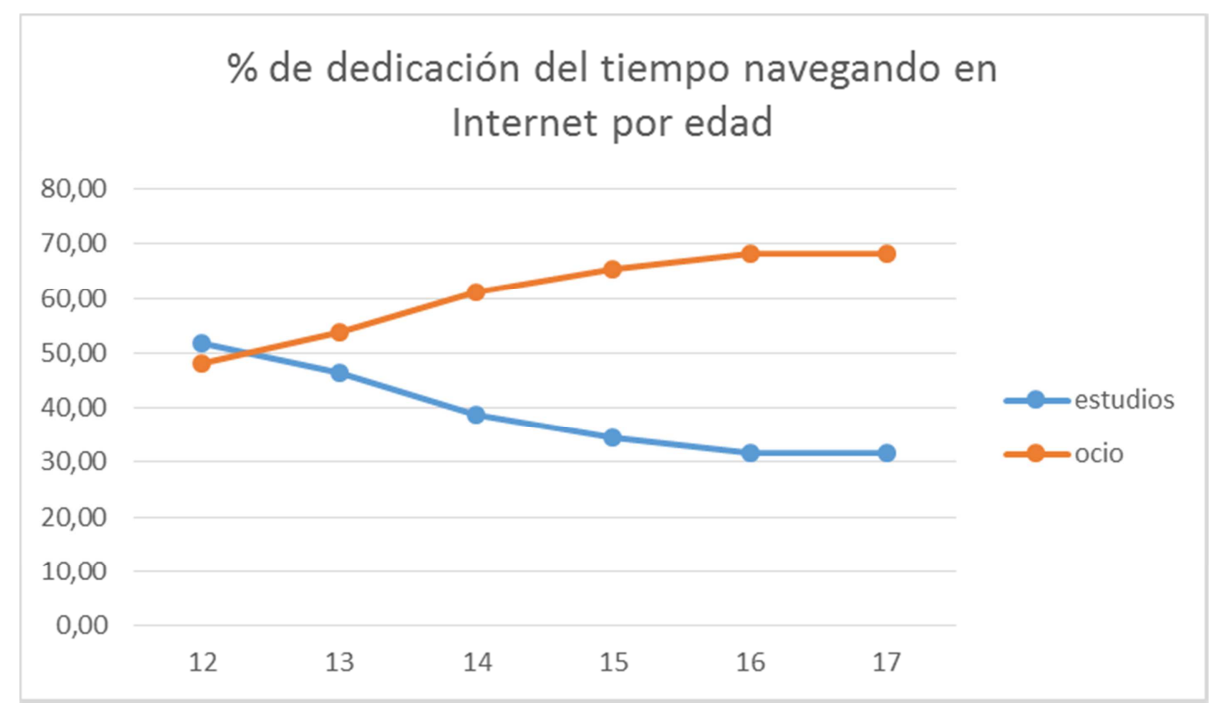

Gráfica 103: tiempo conectado a Internet dedicado a estudios y a ocio por edad.

Una vez analizados los datos sobre internet, pasamos a estudiar los resultados obtenidos de los análisis sobre las cuestiones relativas a las redes sociales.

\subsection{2- Redes sociales}

a) Porcentaje de adolescentes burgaleses que dedican tiempo a las redes sociales Según la información obtenida de la cuestión 15, el 81,14\% de los adolescentes burgaleses encuestados afirma invertir algo de su tiempo diario en las redes sociales. El 18,86\% manifiesta no dedicar ni un minuto al día a las redes sociales.

\section{b) Redes sociales preferidas por los adolescentes}

La pregunta 31 de la encuesta, pide a los adolescentes marcar con una $\mathrm{X}$ cada una de las redes sociales que utilizan. Las opciones disponibles para marcar en la encuesta son las redes sociales más utilizadas actualmente, según la literatura investigada. De cualquier manera, existe una última opción denominada "otros", 
donde los adolescentes han tenido la opción de especificar otras redes sociales que puedan utilizar.

Del mismo modo, se pide a los adolescentes que indiquen, el número de amigos que tienen en las distintas redes sociales, con el objetivo de estudiar la aceptación de cada una de ellas por los adolescentes.

Como se puede observar en el gráfico 104, la red social más utilizada por los adolescentes burgaleses es WhatsApp (89,7\% de los adolescentes), seguida de Instagram (68,9\%), Twitter (50,2\%) y Snapchat $(49,0 \%)$.

Analizamos el uso de cada una de las redes sociales por género, con el objetivo de concluir si alguna de ellas es más utilizada por el género masculino o femenino.

Los resultados obtenidos ponen de manifiesto que existen diferencias significativas en el uso de todas las redes sociales por género, puesto que el valor de significación obtenido para el uso de todas las redes sociales es inferior a 0,05.

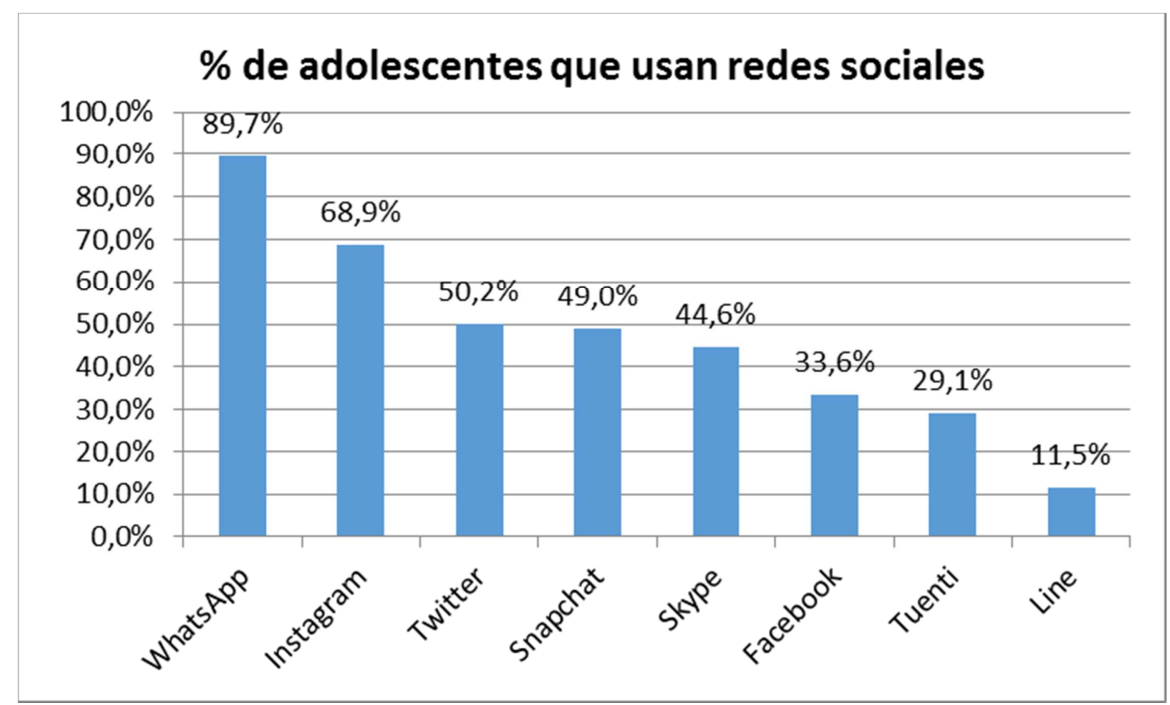

Gráfica 104: porcentaje de adolescentes que usan las diferentes redes sociales

Otro de los indicadores que nos proveen de información en relación a la aceptación de las distintas redes sociales por los adolescentes, es el que recoge el número de amigos que los jóvenes tienen en cada red social. Los adolescentes están interesados y en general anhelan tener un elevado número de amigos en sus redes sociales favoritas. La 
gráfica 105 muestra que la red social en la que los adolescentes afirman tener más amigos es en Instagram, (321 amigos de media), seguida de Twitter (294 amigos), de Tuenti (255 amigos) y Facebook (179 amigos).

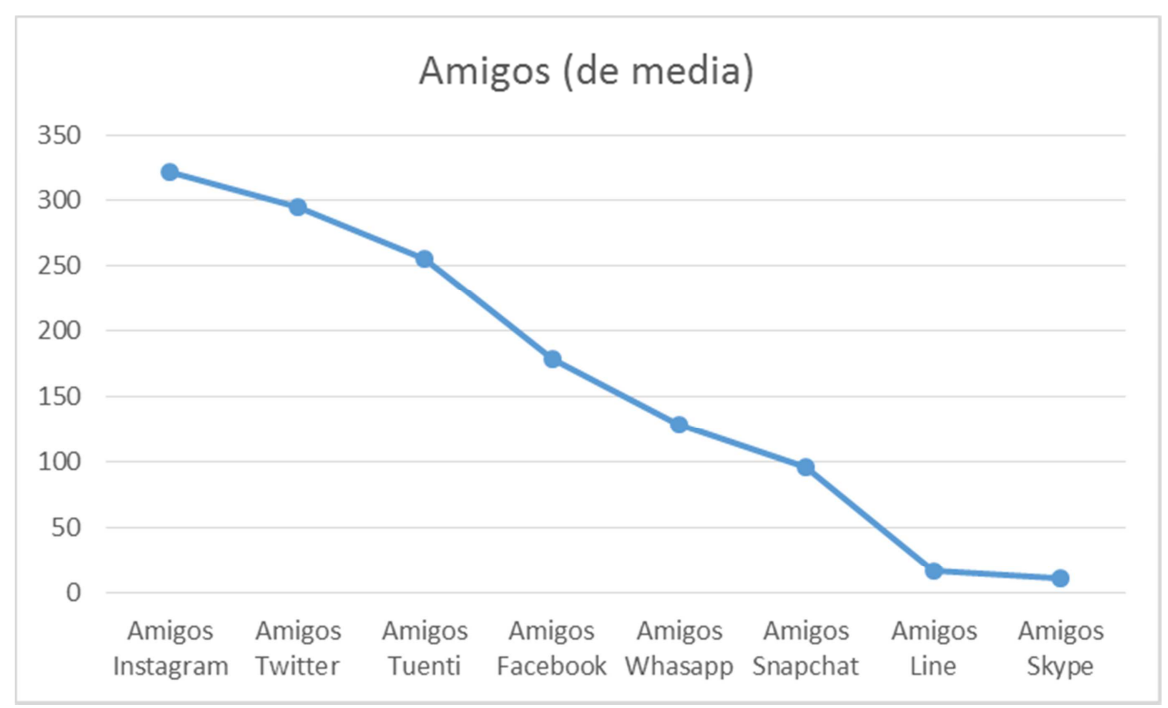

Gráfica 105: número de amigos que tienen los adolescentes burgaleses en cada red social

A continuación analizamos los datos obtenidos sobre el uso de los adolescentes de la televisión. Estamos muy interesados en conocer estos datos, puesto que la televisión es uno de los dispositivos tradicionales y nos interesa conocer el grado de aceptación de la misma por los adolescentes actuales.

\subsection{3- Televisión}

a) Porcentaje de adolescentes que dedica tiempo a ver la televisión

El 93,56\% de los adolescentes burgaleses encuestados afirma dedicar algo de su tiempo diario a ver la televisión o entre semana o durante el fin de semana. Sólo el 6,44\% manifiesta dedicar a esta actividad 0:00 minutos al día.

b) Disponibilidad de televisión en la habitación

Estamos notablemente interesados en conocer si los adolescentes encuestados tienen televisión en la habitación, para ver posteriormente cómo este hecho afecta en su uso del tiempo. Como puede apreciarse en la gráfica 106, el porcentaje de adolescentes que 
sí tiene televisión en la habitación $(17,0 \%)$ es muy inferior al de adolescentes que no tienen televisión en la habitación (81,4\%). El 1,7\% de los adolescentes, no ha contestado a esta pregunta (marcaremos estas respuestas como perdidas).

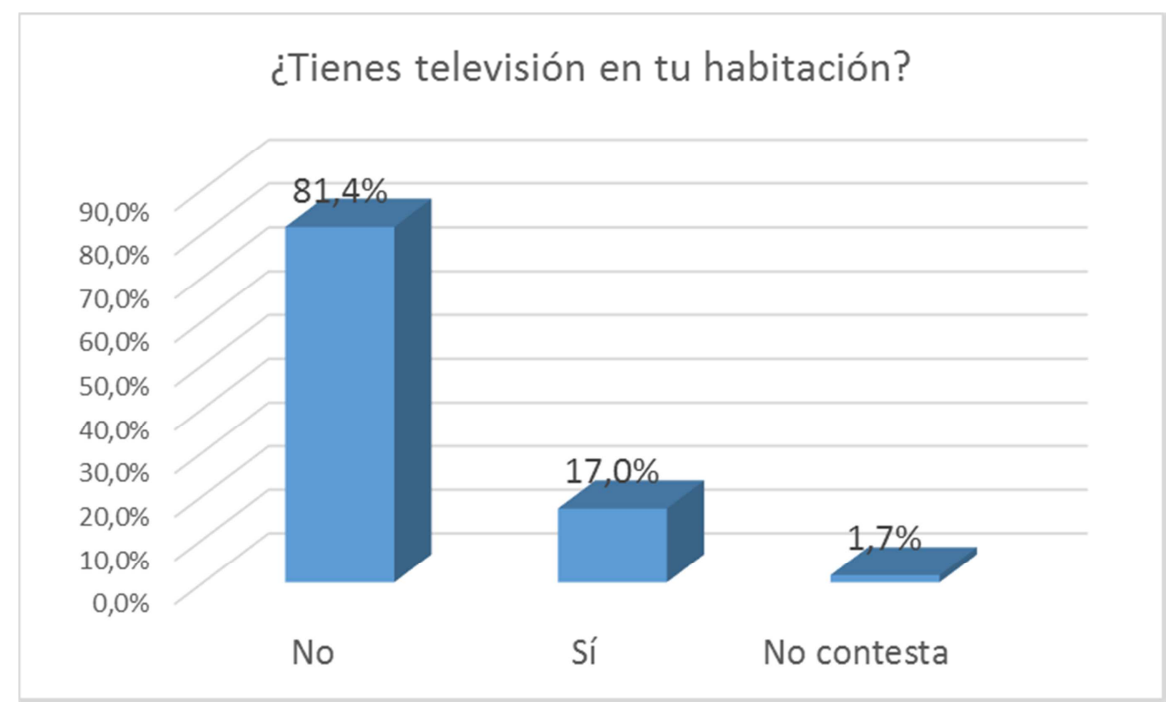

Gráfica 106: televisión en la habitación

Según los resultados obtenidos en la tabla 64 , el porcentaje de chicos que tienen televisión en la habitación (22,7\%) es superior al de chicas (12,4\%). El valor de significación es de 0,000 , lo cual indica que existen diferencias significativas por género.

\begin{tabular}{|c|c|c|c|}
\hline & $\begin{array}{c}\text { TV habitaci } \\
\text { NO }\end{array}$ & $\begin{array}{l}\text { habitación } \\
\text { SI }\end{array}$ & Total \\
\hline Femenino & $87,6 \%$ & $12,4 \%$ & 749 \\
\hline Masculino & $77,3 \%$ & $22,7 \%$ & 675 \\
\hline Total & 1178 & 246 & 1424 \\
\hline
\end{tabular}

Tabla 64: televisión en la habitación - género

Con respecto a la edad, se aprecia una tendencia a aumentar el porcentaje de adolescentes que tiene televisión en su habitación hasta la edad de 15 años, que prácticamente alcanza la cifra del $25 \%$. Sin embargo, este porcentaje disminuye a los 16 años y más aún a los 17 años (tabla 65). El valor de significación es de 0,041 por lo que sí existen diferencias significativas con la edad. 


\begin{tabular}{|l|cc|c|}
\cline { 2 - 4 } \multicolumn{1}{c|}{} & $\begin{array}{c}\text { TV habitación } \\
\text { NO }\end{array}$ & $\begin{array}{c}\text { TV habitación } \\
\text { SI }\end{array}$ & Total \\
\hline $\mathbf{1 2}$ & $86,5 \%$ & $13,5 \%$ & 200 \\
\hline $\mathbf{1 3}$ & $85,6 \%$ & $14,4 \%$ & 271 \\
\hline $\mathbf{1 4}$ & $81,9 \%$ & $18,1 \%$ & 243 \\
\hline $\mathbf{1 5}$ & $76,0 \%$ & $24,0 \%$ & 218 \\
\hline $\mathbf{1 7}$ & $80,9 \%$ & $19,1 \%$ & 241 \\
\hline Total & $84,9 \%$ & $15,1 \%$ & 187 \\
\hline
\end{tabular}

Tabla 65: televisión en la habitación - edad

No se aprecia una relación clara entre tener televisión en la habitación y el curso (tabla 66). Sin embargo, el nivel de significación $(0,012)$ afirma que sí existen diferencias significativas por curso.

\begin{tabular}{|c|c|c|c|}
\hline & $\begin{array}{c}\text { TV habitación } \\
\text { NO }\end{array}$ & $\begin{array}{c}\text { TV habitación } \\
\text { SI }\end{array}$ & Total \\
\hline 1 ESO & $86,2 \%$ & $13,8 \%$ & 326 \\
\hline 2 ESO & $81,8 \%$ & $18,2 \%$ & 286 \\
\hline 3 ESO & $76,0 \%$ & $24,0 \%$ & 263 \\
\hline $4^{\circ}$ ESO & $83,8 \%$ & $16,2 \%$ & 185 \\
\hline $1 \% \mathrm{BACH}$ & $82,1 \%$ & $17,9 \%$ & 218 \\
\hline $2^{\circ} \mathrm{BACH}$ & $88,4 \%$ & $11,6 \%$ & 146 \\
\hline Total & 1178 & 246 & 1424 \\
\hline
\end{tabular}

Tabla 66: televisión en la habitación - curso

A simple vista, se aprecian diferencias en los porcentajes de adolescentes que tienen televisión en la habitación por Nacionalidad. Según la tabla 67, el porcentaje de adolescentes extranjeros que tiene televisión en la habitación es superior $(30,3 \%)$ al de adolescentes españoles $(17,0 \%)$. El valor de significación es del 0,045, por lo que sí que existen diferencias significativas.

\begin{tabular}{|l|cc|c|}
\cline { 2 - 4 } \multicolumn{1}{c|}{} & $\begin{array}{c}\text { TV habitación } \\
\text { NO }\end{array}$ & $\begin{array}{c}\text { TV habitación } \\
\text { SI }\end{array}$ & Total \\
\hline Española & $83,0 \%$ & $17,0 \%$ & 1391 \\
\hline Extranjera & $69,7 \%$ & $30,3 \%$ & 33 \\
\hline Total & 1178 & 246 & 1424 \\
\hline
\end{tabular}

Tabla 67: televisión en la habitación - nacionalidad. 
La tabla 68 muestra que los adolescentes del centro rural son los que tienen menos disponibilidad de televisión en la habitación. El porcentaje de adolescentes que tiene televisión en la habitación que asisten a centros educativos urbanos es prácticamente el mismo para centros públicos y privados (entre $17,1 \%$ y $17,6 \%$ ). El valor de significación es de 0,930 por lo que no podemos afirmar que existan diferencias significativas.

\begin{tabular}{|l|cc|c|}
\cline { 2 - 4 } \multicolumn{1}{c|}{} & \multicolumn{2}{c|}{ TV habitación } & \multirow{2}{*}{ No } \\
\hline Privado urbano 1 & $82,4 \%$ & $17,6 \%$ & 216 \\
\hline Privado urbano 2 & $82,9 \%$ & $17,1 \%$ & 398 \\
\hline Público urbano & $82,5 \%$ & $17,5 \%$ & 733 \\
\hline Público rural & $84,4 \%$ & $15,6 \%$ & 77 \\
\hline Total & 1178 & 246 & 1424 \\
\hline
\end{tabular}

Tabla 68: televisión en la habitación - centro de estudios

No observamos una tendencia en los porcentajes obtenidos para este factor (tabla 69). El nivel de significación es de 0,353 por lo que se puede asegurar que haya diferencias significativas por el número de hermanos de los adolescentes.

\begin{tabular}{|l|cc|c|}
\cline { 2 - 4 } \multicolumn{1}{c|}{} & $\begin{array}{c}\text { TV habitación } \\
\text { NO }\end{array}$ & $\begin{array}{c}\text { TV habitación } \\
\text { SI }\end{array}$ & Total \\
\hline $\mathbf{1}$ & $86,5 \%$ & $13,5 \%$ & 193 \\
\hline $\mathbf{3}$ & $81,8 \%$ & $18,2 \%$ & 858 \\
\hline $\mathbf{4}$ & $83,3 \%$ & $16,7 \%$ & 245 \\
\hline Total & $78,2 \%$ & $21,8 \%$ & 55 \\
\hline
\end{tabular}

Tabla 69: televisión en la habitación - número de hermanos

Tal y como muestra la tabla 70, el porcentaje de adolescentes que viven con su padre y madre y tienen televisión en la habitación es inferior al porcentaje de los que viven con el resto de familiares. El valor de significación es de 0,001 por lo que se puede afirmar que existen diferencias significativas. 


\begin{tabular}{|l|cc|c|}
\cline { 2 - 4 } \multicolumn{1}{c|}{} & $\begin{array}{c}\text { TV habitación } \\
\text { NO }\end{array}$ & $\begin{array}{c}\text { TV habitación } \\
\text { SI }\end{array}$ & Total \\
\hline Ambos & $84,1 \%$ & $15,9 \%$ & 1224 \\
\hline Resto & $74,5 \%$ & $25,5 \%$ & 200 \\
\hline Total & 1178 & 246 & 1424 \\
\hline
\end{tabular}

Tabla 70: televisión en la habitación -personas con las que vive y valor esperado

No se puede asegurar que existan diferencias significativas en cuanto a la persona que acompaña a los adolescentes por las tardes y el hecho de tener televisión en la habitación. En la tabla 71 se puede observar que los porcentajes son prácticamente los mismos.

\begin{tabular}{|l|cc|c|}
\cline { 2 - 4 } \multicolumn{1}{c|}{} & $\begin{array}{c}\text { TV habitación } \\
\text { NO }\end{array}$ & $\begin{array}{c}\text { TV habitación } \\
\text { SI }\end{array}$ & Total \\
\hline Madre & $82,8 \%$ & $17,2 \%$ & 511 \\
\hline Resto & $82,7 \%$ & $17,3 \%$ & 913 \\
\hline Total & 1178 & 246 & 1424 \\
\hline
\end{tabular}

Tabla 71: televisión en la habitación - personas que le acompañan por la tarde y valor esperado

Como se puede observar en la gráfica 107, el porcentaje más elevado de adolescentes que tienen televisión en la habitación corresponde aquellos cuyos padres no tienen estudios. Los adolescentes cuyos padres han cursado estudios universitarios presentan los porcentajes más bajos.

El valor de significación tanto en relación a los estudios alcanzados por el padre como por la madre es de 0,000 lo cual pone de manifiesto que sí hay influencia entre el nivel educativo de los padres y el hecho de permitir que su hijo adolescente tenga televisión en la habitación. 


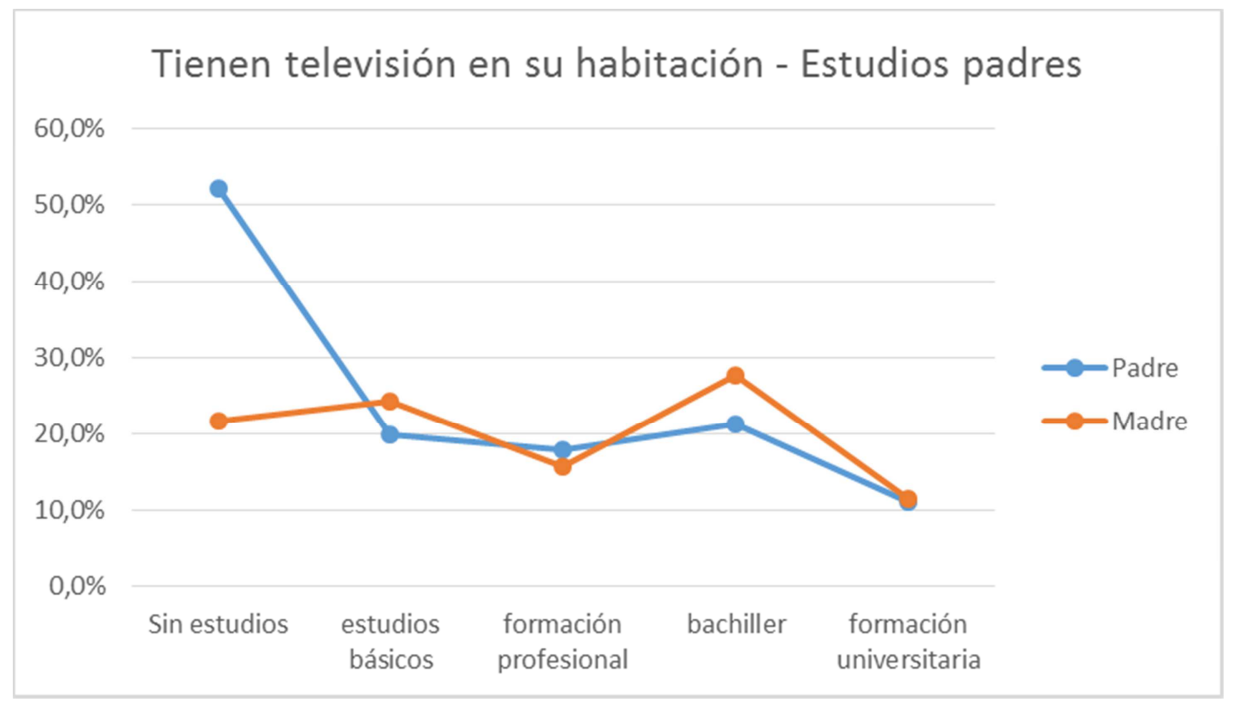

Gráfica 107: Televisión en su habitación - estudios de padre y madre

El porcentaje de adolescentes que tiene pareja y además posee televisión en la habitación es superior al porcentaje de los que no la tienen (tabla 72). El nivel de significación es de 0,000 lo cual implica que se puede afirmar que existen diferencias significativas.

\begin{tabular}{|l|cc|c|}
\cline { 2 - 4 } \multicolumn{1}{c|}{} & $\begin{array}{c}\text { TV habitación } \\
\text { NO }\end{array}$ & $\begin{array}{c}\text { TV habitación } \\
\text { SI }\end{array}$ & Total \\
\hline Pareja no & $85,1 \%$ & $14,9 \%$ & 1158 \\
\hline Pareja sí & $74,5 \%$ & $25,5 \%$ & 204 \\
\hline Total & 1138 & 224 & 1362 \\
\hline
\end{tabular}

Tabla 72: televisión en la habitación - pareja

A continuación procedemos a realizar el estudio de la relación entre los adolescentes y el uso y posesión de teléfono móvil.

\subsection{4- Teléfono móvil propio}

a) Porcentaje de adolescentes que tienen teléfono móvil propio

Como puede apreciarse en la gráfica 107, el porcentaje de adolescentes que tiene teléfono móvil propio es superior al $90 \%$. Sólo el 6,6\% manifiesta no tenerlo. El 1,8\% de los adolescentes, no ha contestado a esta pregunta (marcamos estas respuestas perdidas en SPSS por lo que no se las tiene en cuenta en los cálculos). 


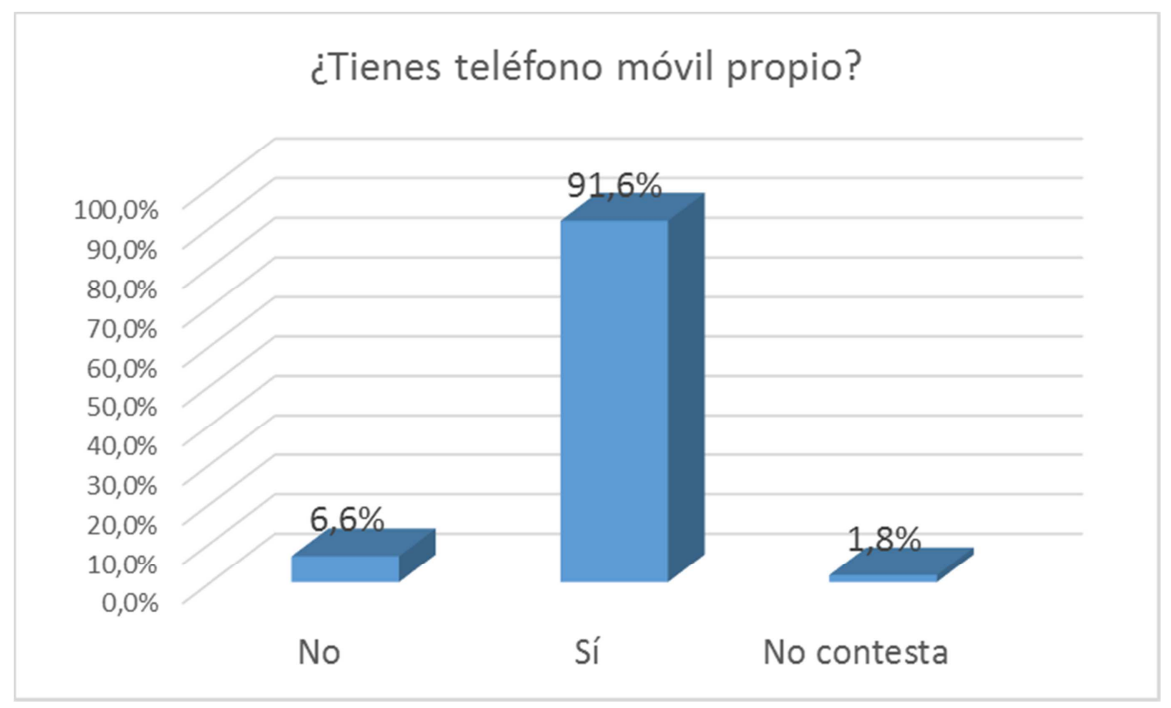

Gráfica 107: teléfono móvil propio

Una vez estudiados los porcentajes generales sobre este tema, procedemos a analizar los distintos factores que pueden afectar a la actividad de tener teléfono móvil propio.

Empezamos por analizar si existen diferencias por género en relación a la posesión de teléfono móvil propio. Como puede observarse en la tabla 73, el porcentaje de chicas que tiene teléfono móvil propio $(94,8 \%)$ es superior al de chicos $(91,5 \%)$. El valor de significación es del 0,014 por lo que podemos afirmar que sí existen diferencias significativas.

\begin{tabular}{|l|cc|c|}
\cline { 2 - 4 } \multicolumn{1}{c|}{} & $\begin{array}{c}\text { Móvil propio } \\
\text { NO }\end{array}$ & $\begin{array}{c}\text { Móvil propio } \\
\text { SI }\end{array}$ & Total \\
\hline Femenino & $5,2 \%$ & $94,8 \%$ & 749 \\
\hline Masculino & $8,5 \%$ & $91,5 \%$ & 673 \\
\hline Total & 96 & 1326 & 1422 \\
\hline
\end{tabular}

Tabla 73: teléfono móvil propio - género

La tabla 74 muestra el porcentaje de adolescentes que tiene teléfono móvil por edad. Como puede observarse, existe un evidente incremento de este porcentaje. El porcentaje de adolescentes de 17 años que tiene teléfono móvil es del 98,4\%, es decir, que prácticamente la totalidad de adolescentes de esta edad ya lo tienen. El valor de 
2a PARTE

Capítulo 4.- Resultados

significación $(0,000)$ pone de manifiesto la existencia de diferencias significativas con la edad.

\begin{tabular}{|l|cc|c|}
\cline { 2 - 4 } \multicolumn{1}{c|}{} & $\begin{array}{c}\text { Móvil propio } \\
\text { NO }\end{array}$ & $\begin{array}{c}\text { Móvil propio } \\
\text { SI }\end{array}$ & Total \\
\hline 12 & $18,5 \%$ & $81,5 \%$ & 200 \\
\hline 13 & $8,5 \%$ & $91,5 \%$ & 271 \\
\hline 14 & $7,8 \%$ & $92,2 \%$ & 243 \\
\hline 15 & $3,2 \%$ & $96,8 \%$ & 218 \\
\hline 16 & $2,5 \%$ & $97,5 \%$ & 241 \\
\hline Total & $1,6 \%$ & $98,4 \%$ & 184 \\
\hline
\end{tabular}

Tabla 74: teléfono móvil propio - edad

Con respecto al curso, se observa la misma tendencia que con la edad. La tabla 75 muestra que el porcentaje de adolescentes que tienen teléfono móvil propio de cursos superiores es mayor que el de los cursos más bajos. En 2o BACH, el porcentaje de adolescentes que tiene teléfono móvil propio alcanza la cifra de 99,3\%. El valor de chicuadrado $(0,000)$ denota que sí existen diferencias significativas por curso.

\begin{tabular}{|l|cc|c|}
\cline { 2 - 4 } \multicolumn{1}{c|}{} & $\begin{array}{c}\text { Móvil propio } \\
\text { NO }\end{array}$ & $\begin{array}{c}\text { Móvil propio } \\
\text { SI }\end{array}$ & Total \\
\hline 1 ESO & $15,6 \%$ & $84,4 \%$ & 326 \\
\hline 2 ESO & $8,7 \%$ & $91,3 \%$ & 287 \\
\hline 3 ESO & $3,8 \%$ & $96,2 \%$ & 264 \\
\hline 4 ESO & $2,2 \%$ & $97,8 \%$ & 185 \\
\hline 1 BACH & $2,3 \%$ & $97,7 \%$ & 218 \\
\hline 2 BACH & $0,7 \%$ & $99,3 \%$ & 142 \\
\hline Total & 96 & 1326 & 1422 \\
\hline
\end{tabular}

Tabla 75: teléfono móvil propio - curso

Con respecto a la nacionalidad, como se puede observar en la tabla 76 mostrada a continuación, parece que el porcentaje de adolescentes españoles que tiene teléfono móvil propio $(93,3 \%)$ es superior al porcentaje de adolescentes no españoles que lo poseen (91,2\%). Sin embargo, no podemos asegurar que las diferencias encontradas sean significativas. 


\begin{tabular}{|l|cc|c|}
\cline { 2 - 4 } \multicolumn{1}{c|}{} & $\begin{array}{c}\text { Móvil propio } \\
\text { NO }\end{array}$ & $\begin{array}{c}\text { Móvil propio } \\
\text { SI }\end{array}$ & Total \\
\hline Española & $6,7 \%$ & $93,3 \%$ & 1388 \\
\hline Extranjera & $8,8 \%$ & $91,2 \%$ & 34 \\
\hline Total & 96 & 1326 & 1422 \\
\hline
\end{tabular}

Tabla 76: teléfono móvil propio - nacionalidad

En la tabla 77 podemos ver los porcentajes de adolescentes que tienen teléfono móvil propio en relación al centro educativo al que asisten. No encontramos una tendencia definida. El factor de significación es del 0,096 lo cual indica que no podemos asegurar que existan diferencias significativas.

\begin{tabular}{|l|cc|c|}
\cline { 2 - 4 } \multicolumn{1}{c|}{} & $\begin{array}{c}\text { Móvil propio } \\
\text { NO }\end{array}$ & $\begin{array}{c}\text { Móvil propio } \\
\text { SI }\end{array}$ & Total \\
\hline Privado urbano 1 & $10,6 \%$ & $89,4 \%$ & 217 \\
\hline Privado urbano 2 & $6,0 \%$ & $94,0 \%$ & 399 \\
\hline Público urbano & $5,7 \%$ & $94,3 \%$ & 731 \\
\hline Público rural & $9,3 \%$ & $90,7 \%$ & 75 \\
\hline Total & 96 & 1270 & 1422 \\
\hline
\end{tabular}

Tabla 77: teléfono móvil propio - centro

A continuación analizamos si existen diferencias en el porcentaje de adolescentes que tienen teléfono móvil propio, dependiendo del número de hermanos que tienen. Como se puede apreciar en la tabla 78, el porcentaje de adolescentes que tiene teléfono móvil propio más alto corresponde a los hijos únicos. No se puede asegurar que haya diferencias significativas puesto que el nivel de significación es de 0,671.

\begin{tabular}{|l|cc|c|}
\cline { 2 - 4 } \multicolumn{1}{c|}{} & $\begin{array}{c}\text { Móvil propio } \\
\text { NO }\end{array}$ & $\begin{array}{c}\text { Móvil propio } \\
\text { SI }\end{array}$ & Total \\
\hline $\mathbf{1}$ & $5,2 \%$ & $94,8 \%$ & 192 \\
\hline $\mathbf{2}$ & $5,5 \%$ & $94,5 \%$ & 857 \\
\hline $\mathbf{3}$ & $7,3 \%$ & $92,7 \%$ & 246 \\
\hline $\mathbf{4}$ & $7,4 \%$ & $92,6 \%$ & 54 \\
\hline Total & 79 & 1270 & 1349 \\
\hline
\end{tabular}

Tabla 78: teléfono móvil propio - número de hermanos 
2a PARTE

Capítulo 4.- Resultados

En cuanto a con quién vive, el factor de significación es del 0,166 , por lo que no podemos afirmar que las personas con las que vive el adolescente creen diferencias significativas en relación a la posesión de teléfono móvil por el adolescente (tabla 79).

\begin{tabular}{|l|cc|c|}
\cline { 2 - 4 } \multicolumn{1}{c|}{} & $\begin{array}{c}\text { Móvil propio } \\
\text { NO }\end{array}$ & $\begin{array}{c}\text { Móvil propio } \\
\text { SI }\end{array}$ & Total \\
\hline Ambos & $7,1 \%$ & $92,9 \%$ & 1221 \\
\hline Resto & $4,5 \%$ & $95,5 \%$ & 201 \\
\hline Total & 96 & 1326 & 1422 \\
\hline
\end{tabular}

Tabla 79: teléfono móvil propio - personas con las que vive

La tabla 80 muestra porcentajes muy similares dependiendo de la persona que acompaña al adolescente por las tardes. No podemos afirmar que existan diferencias significativas puesto que el factor de significación es de 0,226.

\begin{tabular}{|l|cc|c|}
\cline { 2 - 4 } \multicolumn{1}{c|}{} & $\begin{array}{c}\text { Móvil propio } \\
\text { NO }\end{array}$ & $\begin{array}{c}\text { Móvil propio } \\
\text { SI }\end{array}$ & Total \\
\hline Madre & $7,8 \%$ & $92,2 \%$ & 511 \\
\hline Resto & $6,1 \%$ & $93,9 \%$ & 911 \\
\hline Total & 96 & 1326 & 1422 \\
\hline
\end{tabular}

Tabla 80: teléfono móvil propio - personas que le acompañan por la tarde

El porcentaje de adolescentes que tiene teléfono móvil propio aumenta al disminuir el nivel de estudios alcanzado por los padres. Consideramos muy remarcable que el $100 \%$ de los adolescentes encuestados cuyo padre no tiene estudios (25 adolescentes) tiene teléfono móvil propio. Del mismo modo, observamos que el $100 \%$ de los adolescentes cuya madre no tiene estudios ( 23 adolescentes) tiene teléfono móvil propio (gráfica 108).

El porcentaje de adolescentes con teléfono móvil más bajo, corresponde a aquellos cuyos padres han realizado estudios universitarios. El nivel de significación obtenido de la chi-cuadrado deja constancia de la existencia de diferencia significativas en relación al nivel de estudios del padre $(0,042)$. Sin embargo, el nivel de significación $(0,071)$ no nos permite afirmar que existan diferencias significativas. 


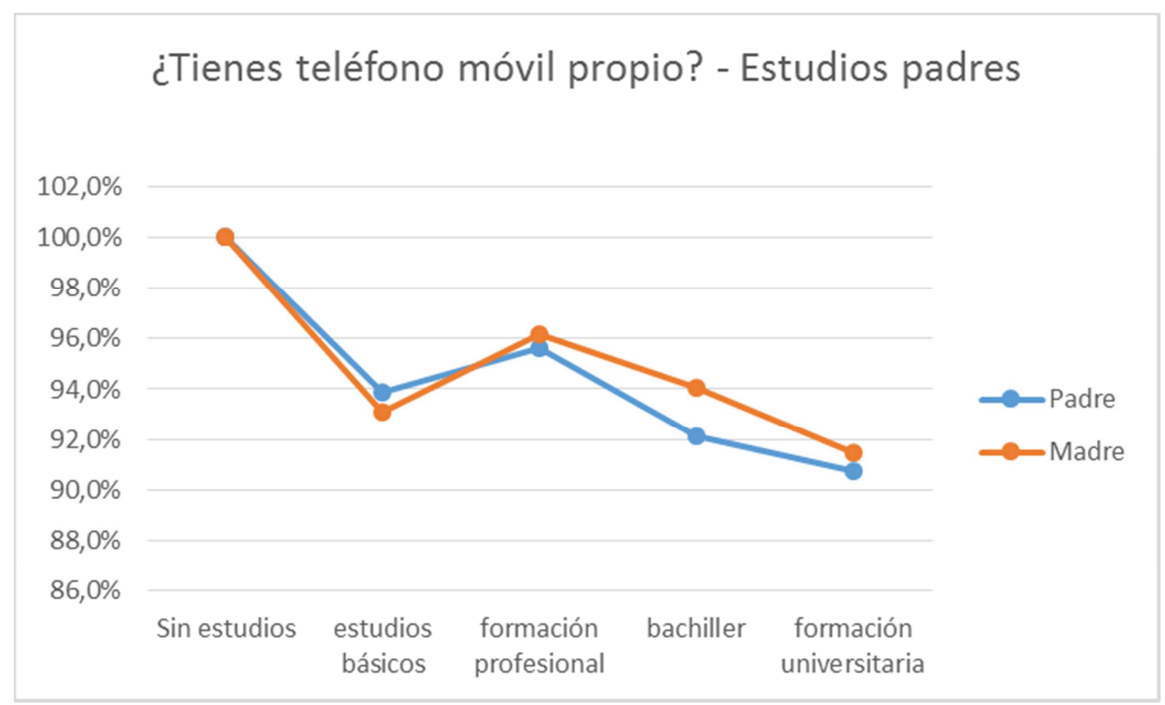

Gráfica 108: teléfono móvil propio - estudios de padre y madre

Con respecto a la pareja, el 98,5\% de los adolescentes que tienen pareja, tienen teléfono móvil. Sin embargo, el porcentaje de adolescentes que tiene teléfono móvil cae hasta el 92,3\% para los adolescentes que no tienen pareja (tabla 81). El valor de significación $(0,001)$, pone de manifiesto la existencia de diferencias significativas.

\begin{tabular}{|l|cc|c|}
\cline { 2 - 4 } \multicolumn{1}{c|}{} & $\begin{array}{c}\text { Móvil propio } \\
\text { NO }\end{array}$ & $\begin{array}{c}\text { Móvil propio } \\
\text { SI }\end{array}$ & Total \\
\hline Pareja no & $7,7 \%$ & $92,3 \%$ & 1157 \\
\hline Pareja sí & $1,5 \%$ & $98,5 \%$ & 203 \\
\hline Total & 92 & 1268 & 1360 \\
\hline
\end{tabular}

Tabla 81: teléfono móvil propio - pareja y valor esperado

b) Disponibilidad de Internet en tu móvil propio

Uno de los factores que provoca que el adolescente dedique más tiempo a su teléfono móvil radica en el hecho de que tenga en este dispositivo conexión a internet. Es por esta razón, que vamos a dedicar este punto al estudio de este factor.

Como puede apreciarse en la gráfica 109, el porcentaje de adolescentes que tienen internet en su teléfono móvil propio es prácticamente del $60 \%$. El 20,6\% manifiesta no tener internet en el teléfono móvil. El porcentaje de adolescentes que no responde a esta pregunta es elevado, aproximadamente el 19,5\% y corresponde a 282 encuestas. 
Para los estudios posteriores, hemos marcado las respuestas de no contesta como perdidos, aun a riesgo de sesgar la muestra.

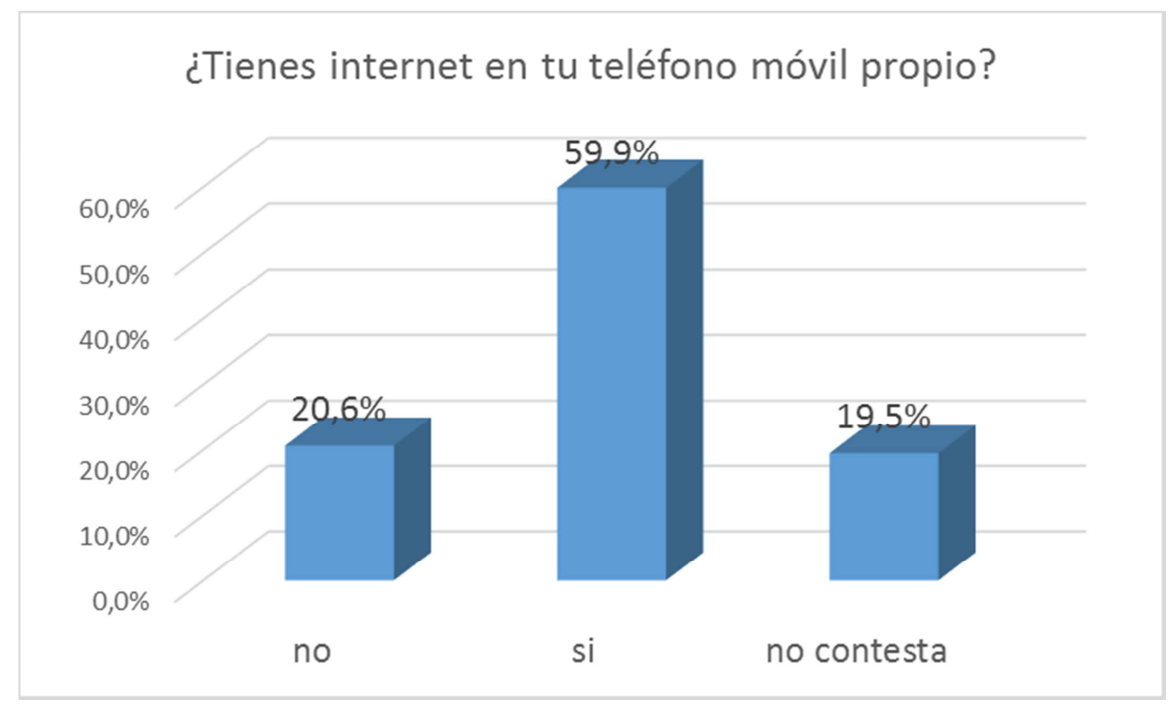

Gráfica 109: internet en teléfono móvil propio

Tal y como se muestra en la tabla 82 , el porcentaje de chicas que tiene Internet en su teléfono móvil propio $(77,0 \%)$ es superior al porcentaje de chicos que lo tiene $(71,6 \%)$. Existen diferencias significativas, puesto que el valor del nivel de significación es del 0,037 .

\begin{tabular}{|l|cc|c|}
\cline { 2 - 4 } \multicolumn{1}{c|}{} & $\begin{array}{c}\text { Internet Móvil propio } \\
\text { NO }\end{array}$ & $\begin{array}{c}\text { Internet Móvil propio } \\
\text { SI }\end{array}$ & Total \\
\hline Femenino & $23,0 \%$ & $77,0 \%$ & 595 \\
\hline Masculino & $28,4 \%$ & $71,6 \%$ & 571 \\
\hline Total & 299 & 867 & 1166 \\
\hline
\end{tabular}

Tabla 82: internet en teléfono móvil propio - género

La tabla 83 indica que el porcentaje de adolescentes que tiene Internet en su teléfono móvil propio aumenta, por regla general, con la edad, aunque bien es cierto que se observa un ligero decrecimiento a los 16 y 17 años. El nivel de significación es del 0,000 por lo que existen diferencias significativas por la edad. 


\begin{tabular}{|l|cc|c|}
\cline { 2 - 4 } \multicolumn{1}{c|}{} & $\begin{array}{c}\text { Internet movil } \\
\text { propio No }\end{array}$ & $\begin{array}{c}\text { Internet movil } \\
\text { propio Si }\end{array}$ & Total \\
\hline $\mathbf{1 2}$ & $38,9 \%$ & $61,1 \%$ & 131 \\
\hline $\mathbf{1 3}$ & $31,0 \%$ & $69,0 \%$ & 226 \\
\hline $\mathbf{1 4}$ & $27,2 \%$ & $72,8 \%$ & 232 \\
\hline $\mathbf{1 5}$ & $19,8 \%$ & $80,2 \%$ & 187 \\
\hline $\mathbf{1 6}$ & $20,1 \%$ & $79,9 \%$ & 209 \\
\hline $\mathbf{1 7}$ & $22,3 \%$ & $77,7 \%$ & 130 \\
\hline Total & 292 & 823 & 1115 \\
\hline
\end{tabular}

Tabla 83: internet en teléfono móvil propio - Edad.

Con respecto al curso, la tabla 84 muestra que existe un aumento del porcentaje de adolescentes que tienen internet en su teléfono móvil por curso. A partir de 3 으 de ESO, más del $80 \%$ de los adolescentes manifiesta tener internet en su teléfono móvil propio. El nivel de significación es del 0,000 por lo que podemos afirmar que sí existen diferencias significativas en cuanto a tener conexión a Internet en el teléfono móvil propio por curso.

\begin{tabular}{|l|cc|c|}
\cline { 2 - 4 } \multicolumn{1}{c|}{} & $\begin{array}{c}\text { Internet Móvil propio } \\
\text { NO }\end{array}$ & $\begin{array}{c}\text { Internet Móvil propio } \\
\text { SI }\end{array}$ & Total \\
\hline 1 ESO & $37,9 \%$ & $62,1 \%$ & 219 \\
\hline 2 ESO & $26,9 \%$ & $73,1 \%$ & 268 \\
\hline 3 ESO & $23,3 \%$ & $76,7 \%$ & 262 \\
\hline 4 ESO & $19,9 \%$ & $80,1 \%$ & 151 \\
\hline 1 BACH & $19,7 \%$ & $80,3 \%$ & 178 \\
\hline 2 BACH & $20,5 \%$ & $79,5 \%$ & 88 \\
\hline Total & 299 & 867 & 1166 \\
\hline
\end{tabular}

Tabla 84: internet en teléfono móvil propio - curso.

Con respecto a la nacionalidad, tal y como se puede ver en la tabla 85 , el porcentaje de adolescentes españoles que tienen Internet en su teléfono móvil propio $(74,4 \%)$ es ligeramente mayor que el porcentaje de adolescentes de otras nacionalidades $(71,9 \%)$.

Los datos obtenidos para chi-cuadrado certifican que no se puede asegurar que existan diferencias significativas por nacionalidad. 


\begin{tabular}{|l|cc|c|}
\cline { 2 - 4 } \multicolumn{1}{c|}{} & $\begin{array}{c}\text { Internet Móvil propio } \\
\text { NO }\end{array}$ & $\begin{array}{c}\text { Internet Móvil propio } \\
\text { SI }\end{array}$ & Total \\
\hline Española & $25,6 \%$ & $74,4 \%$ & 1134 \\
\hline Extranjera & $28,1 \%$ & $71,9 \%$ & 32 \\
\hline Total & 299 & 867 & 1166 \\
\hline
\end{tabular}

Tabla 85: internet en teléfono móvil propio - nacionalidad.

Tal y como muestra la tabla 86, el porcentaje de adolescentes del centro rural que tiene internet en su teléfono móvil es inferior al del resto. Podemos interpretar sea debido a que la accesibilidad a la conexión a internet en el medio rural aún sea técnicamente más compleja. El porcentaje de adolescentes con internet en su teléfono móvil propio del entorno urbano es similar en todos los centros (aproximadamente el $75 \%)$.

El factor de significación es de 0,075 , por lo que no podemos afirmar que existan diferencias significativas.

\begin{tabular}{|c|c|c|c|}
\hline & \multicolumn{2}{|c|}{ Internet en teléfono móvil propio } & \multirow{2}{*}{ Total } \\
\hline & No & Si & \\
\hline Privado urbano 1 & $24,5 \%$ & $75,5 \%$ & 216 \\
\hline Privado urbano 2 & $23,3 \%$ & $76,7 \%$ & 146 \\
\hline Público urbano & $25,1 \%$ & $74,9 \%$ & 728 \\
\hline Público rural & $38,2 \%$ & $61,8 \%$ & 76 \\
\hline Total & 299 & 867 & 1166 \\
\hline
\end{tabular}

Tabla 86: internet en teléfono móvil propio - centro educativo.

El mayor porcentaje de adolescentes que tiene Internet en su teléfono móvil propio corresponde al de los hijos únicos (tabla 87). Este porcentaje disminuye al aumentar el número de hermanos. Sin embargo, el valor de significación 0,095 indica que no se puede afirmar que existan diferencias significativas con respecto al número de hermanos. 


\begin{tabular}{|l|cc|c|}
\cline { 2 - 4 } \multicolumn{1}{c|}{} & $\begin{array}{c}\text { Internet Móvil propio } \\
\text { NO }\end{array}$ & $\begin{array}{c}\text { Internet Móvil propio } \\
\text { SI }\end{array}$ & Total \\
\hline $\mathbf{1}$ & $18,3 \%$ & $81,7 \%$ & 153 \\
\hline $\mathbf{2}$ & $24,9 \%$ & $75,1 \%$ & 711 \\
\hline $\mathbf{3}$ & $28,4 \%$ & $71,6 \%$ & 204 \\
\hline $\mathbf{4}$ & $32,6 \%$ & $67,4 \%$ & 46 \\
\hline Total & 278 & 836 & 1114 \\
\hline
\end{tabular}

Tabla 87: internet en teléfono móvil propio - número de hermanos.

Podemos observar que el porcentaje de adolescentes que tiene Internet en el móvil es inferior en el caso de que los adolescentes vivan con ambos padres (tabla 88). El nivel de significación $(0,138)$ nos indica que no podemos afirmar que existan diferencias significativas.

\begin{tabular}{|l|cc|c|}
\cline { 2 - 4 } \multicolumn{1}{c|}{} & $\begin{array}{c}\text { Internet Móvil propio } \\
\text { NO }\end{array}$ & $\begin{array}{c}\text { Internet Móvil propio } \\
\text { SI }\end{array}$ & Total \\
\hline Ambos & $26,4 \%$ & $73,6 \%$ & 1012 \\
\hline Resto & $20,8 \%$ & $79,2 \%$ & 154 \\
\hline Total & 299 & 867 & 116 \\
\hline
\end{tabular}

Tabla 88: internet en teléfono móvil propio - personas con las que vive

Con respecto a las personas que acompañan a los adolescentes por las tardes, la tabla 89 pone de manifiesto que el porcentaje de adolescentes que tienen Internet en su teléfono móvil propio es inferior en aquellos que viven con ambos padres. Sin embargo, no estamos en disposición de asegurar que haya diferencias significativas puesto que el nivel de significación es superior a 0,05.

\begin{tabular}{|l|cc|c|}
\cline { 2 - 4 } \multicolumn{1}{c|}{} & $\begin{array}{c}\text { Internet movil } \\
\text { propio No }\end{array}$ & $\begin{array}{c}\text { Internet movil } \\
\text { propio Si }\end{array}$ & Total \\
\hline Madre & $27,0 \%$ & $73,0 \%$ & 423 \\
\hline Resto & $24,9 \%$ & $75,1 \%$ & 743 \\
\hline Total & 299 & 867 & 1166 \\
\hline
\end{tabular}

Tabla 89: Internet en teléfono móvil propio - personas que le acompañan por la tarde

Con respecto al nivel de estudios de los padres, se puede apreciar en la gráfica 110 que los adolescentes cuyos padres no tienen estudios muestran el porcentaje mayor en 
conexión a Internet desde su teléfono móvil propio. Para el resto de los niveles de estudio de los padres, el valor prácticamente se mantiene. No podemos afirmar que existan diferencias significativas con respecto al nivel de estudios alcanzado por la madre ni por los alcanzados por el padre.

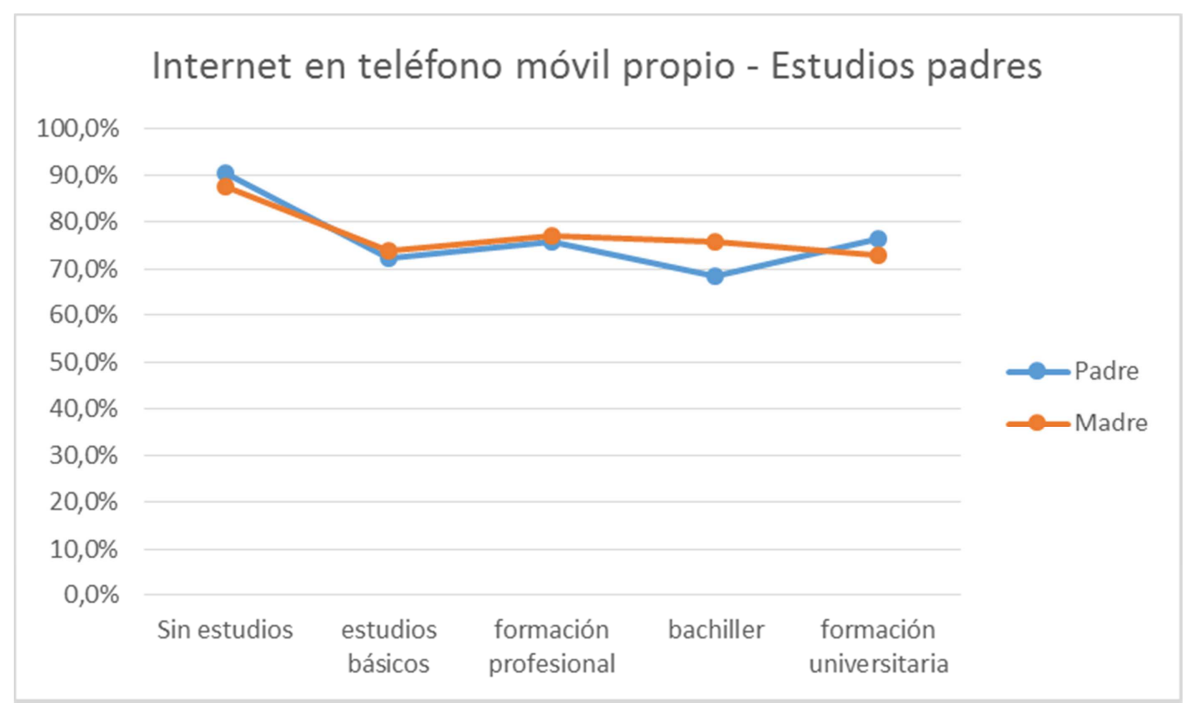

Gráfica 110: Internet en teléfono móvil propio - estudios de padre y madre

Se puede observar en la tabla 90 que el porcentaje de adolescentes que, teniendo pareja, tiene conexión a Internet en su teléfono móvil propio es mayor $(78,9 \%)$ frente al porcentaje de aquellos que no teniendo pareja, tienen Internet en su teléfono móvil propio $(73,4 \%)$. El valor del nivel de significación (superior a 0,05 ) no asegura que haya diferencias significativas.

\begin{tabular}{|l|cc|c|}
\cline { 2 - 4 } \multicolumn{1}{c|}{} & $\begin{array}{c}\text { Internet Móvil propio } \\
\text { NO }\end{array}$ & $\begin{array}{c}\text { Internet Móvil propio } \\
\text { SI }\end{array}$ & Total \\
\hline Pareja no & $26,6 \%$ & $73,4 \%$ & 946 \\
\hline Pareja sí & $21,1 \%$ & $78,9 \%$ & 175 \\
\hline Total & 289 & 832 & 1121 \\
\hline
\end{tabular}

Tabla 90: internet en teléfono móvil propio - pareja

c) El teléfono móvil como dispositivo de intercambio de mensajes de texto:

Como puede observarse en la tabla 91, la media de SMS que envían los adolescentes burgaleses es aproximadamente de 1,59 diario. La media de SMS que reciben 
diariamente es de 1,54. No profundizamos más en este estudio puesto que consideramos que el volumen de SMS intercambiados actualmente no es un tema de mucho interés, puesto que ha sido desbancado por otros servicios de mensajería instantánea.

\begin{tabular}{|l|ccc|}
\cline { 2 - 4 } \multicolumn{1}{c|}{} & $\mathbf{N}$ & Media & $\begin{array}{c}\text { Desviación } \\
\text { estándar }\end{array}$ \\
\hline Número de SMS que envías diariamente & 1240 & 1,59 & 29,289 \\
\hline Número de SMS que recibes diariamente & 1244 & 1,54 & 9,009 \\
\hline
\end{tabular}

Tabla 91 media de SMS enviados y recibidos

Estamos hablando, por ejemplo, de la aplicación WhatsApp. Ya hemos podido observar anteriormente (gráfica 104) que WhatsApp es actualmente, la red social más utilizada por los adolescentes.

Como podemos ver en la tabla 92, la media de WhatsApp enviados diariamente por un adolescente es de 94,9. La media de WhatsApp recibidos es de 363,2. Para realizar este cálculo, hemos decidido calcular la media recortada y eliminar el 5\% de los valores superiores. Esto es debido a que en algún caso los adolescentes han anotado un número muy elevado de WhatsApp.

\begin{tabular}{|l|ccc|}
\cline { 2 - 4 } \multicolumn{1}{c|}{} & N & Media & $\begin{array}{c}\text { Desviación } \\
\text { estándar }\end{array}$ \\
\hline Número de WhatsApp que envías diariamente & 1178 & 94,90 & 112,730 \\
\hline Número de WhatsApp que recibes diariamente & 1176 & 363,20 & 417,390 \\
\hline
\end{tabular}

Tabla 92: media de WhatsApp enviados y recibidos por los adolescentes burgaleses

\section{d) Teléfono móvil en entorno escolar}

A continuación pasamos a estudiar las respuestas de las cuestiones relacionadas con el uso del teléfono en el entorno educativo. Preguntados los adolescentes si utilizan su teléfono móvil durante las horas de clase, la tabla 93 afirma que el 11,13\% confirma utilizarlo. 


\begin{tabular}{|l|cc|}
\cline { 2 - 3 } \multicolumn{1}{c|}{} & Frecuencia & Porcentaje \\
\hline No & 1254 & $88,87 \%$ \\
\hline Si & 157 & $11,13 \%$ \\
\hline Total & 1411 & $100,00 \%$ \\
\hline
\end{tabular}

Tabla 93: uso del teléfono móvil durante las horas lectivas en el centro educativo

Con respecto al género, la tabla 94 muestra que el porcentaje de chicos que utilizan el teléfono en la clase es mayor que el de chicas.

\begin{tabular}{|c|c|c|c|}
\hline & \multicolumn{2}{|c|}{ Teléfono móvil en clase } & \multirow{2}{*}{ Total } \\
\hline & NO & sI & \\
\hline Femenino & $90,2 \%$ & $9,8 \%$ & 745 \\
\hline Masculino & $87,4 \%$ & $12,6 \%$ & 666 \\
\hline Total & 1254 & 157 & 1411 \\
\hline
\end{tabular}

Tabla 94: uso del teléfono móvil durante las horas de clase en el centro - género

A continuación pasamos a analizar los resultados obtenidos sobre la disposición de ordenador en la habitación de los adolescentes.

\subsection{5.- Ordenador en habitación}

a) Disponibilidad de ordenador en la habitación

Como puede apreciarse en la gráfica 111, más de la mitad de los adolescentes encuestados manifiestan no tener ordenador en la habitación, aproximadamente un $58,40 \%$. El $39,8 \%$ contesta que sí que tiene y el $1,8 \%$ no contesta.

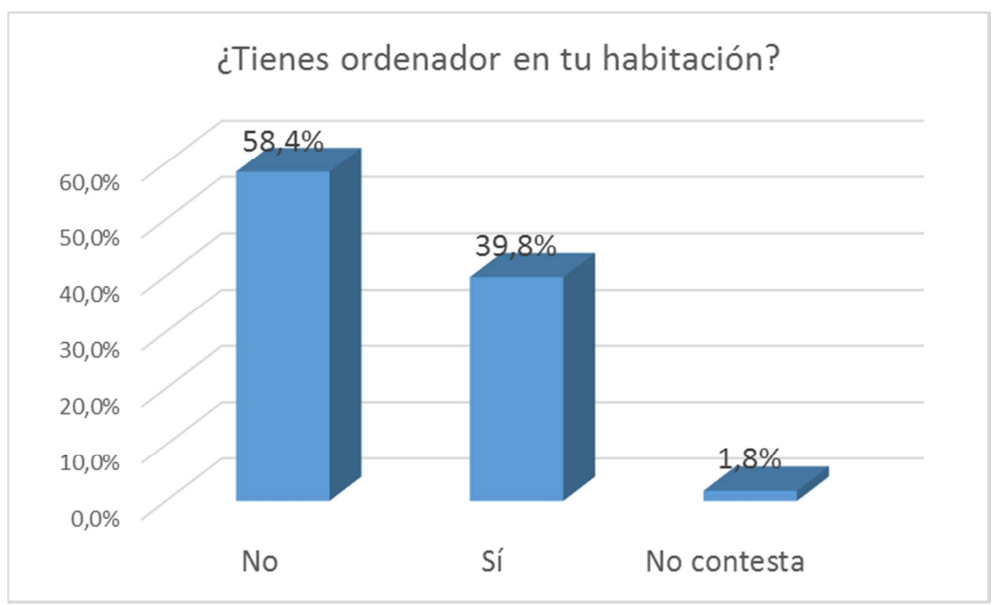

Gráfica 111: ordenador en la habitación 
A continuación estudiamos los distintos factores que pueden afectar a "tener ordenador en la habitación".

Tras realizar una tabla cruzada 95, introduciendo el género, observamos que los porcentajes obtenidos tanto para el género femenino como para el masculino son semejantes.

\begin{tabular}{|l|cc|c|}
\cline { 2 - 4 } \multicolumn{1}{c|}{} & $\begin{array}{c}\text { Ordenador } \\
\text { habitación NO }\end{array}$ & $\begin{array}{c}\text { Ordenador } \\
\text { habitación SI }\end{array}$ & Total \\
\hline Femenino & $59,0 \%$ & $41,0 \%$ & 749 \\
\hline Masculino & $60,0 \%$ & $40,0 \%$ & 673 \\
\hline Total & 846 & 576 & 1422 \\
\hline
\end{tabular}

Tabla 95: ordenador en la habitación - género

El coeficiente chi-cuadrado de Pearson es de 0,696 (valor superior a 0,05), por lo que no se puede considerar que haya diferencias significativas por género.

Observamos en la tabla 96 que el porcentaje de adolescentes que tiene ordenador en la habitación, aumenta de manera considerable con la edad. El aumento del porcentaje principal lo encontramos entre 15 y 16 años, donde el porcentaje ha aumentado un 8,6\% (aproximadamente desde el 39,9\% hasta el 48,5\%). Sí existen diferencias significativas en esta actividad con respecto a la edad. El coeficiente de chi-cuadrado de Pearson es de 0,000 .

\begin{tabular}{|c|c|c|c|}
\hline & $\begin{array}{l}\text { Ordenador er } \\
\text { habitación } \mathrm{Nc}\end{array}$ & $\begin{array}{l}\text { Ordenador en } \\
\text { habitación } \mathrm{Si}\end{array}$ & Total \\
\hline 12 & $68,0 \%$ & $32,0 \%$ & 200 \\
\hline 13 & $65,9 \%$ & $34,1 \%$ & 270 \\
\hline 14 & $61,3 \%$ & $38,7 \%$ & 243 \\
\hline 15 & $60,1 \%$ & $39,9 \%$ & 218 \\
\hline 16 & $51,5 \%$ & $48,5 \%$ & 241 \\
\hline 17 & $51,1 \%$ & $48,9 \%$ & 184 \\
\hline Total & 812 & 544 & 1356 \\
\hline
\end{tabular}

Tabla 96: ordenador en la habitación - Edad 
2a PARTE

Capítulo 4.- Resultados

Con respecto al curso, existen diferencias en los porcentajes obtenidos pero no se observa tendencia clara (tabla 97). El valor obtenido para el nivel de significación indica que existen diferencias significativas en tener ordenador en la habitación por curso $(0,000)$.

\begin{tabular}{|l|cc|c|}
\cline { 2 - 4 } \multicolumn{1}{c|}{} & $\begin{array}{c}\text { Ordenador } \\
\text { habitación NO }\end{array}$ & $\begin{array}{c}\text { Ordenador } \\
\text { habitación SI }\end{array}$ & Total \\
\hline 1 SO & $66,5 \%$ & $33,5 \%$ & 325 \\
\hline 2 ESO & $64,1 \%$ & $35,9 \%$ & 287 \\
\hline 3 ESO & $56,4 \%$ & $43,6 \%$ & 264 \\
\hline 1 ㅗㅇ $\mathrm{BACH}$ & $64,9 \%$ & $35,1 \%$ & 185 \\
\hline 2 BACH & $44,7 \%$ & $55,3 \%$ & 217 \\
\hline Total & $55,6 \%$ & $44,4 \%$ & 144 \\
\hline
\end{tabular}

Tabla 97: ordenador en la habitación - curso

Con respecto a la nacionalidad, los valores de la tabla cruzada 98 ponen de manifiesto que el porcentaje de adolescentes de nacionalidad diferente a la española $(55,9 \%)$ que tienen ordenador en la habitación es más alto que el de los de nacionalidad española $(40,1 \%)$. Sin embargo, el valor obtenido para el nivel de significación $(0,065)$ indica que no se puede asegurar que existan diferencias significativas con respecto a la nacionalidad.

\begin{tabular}{|l|cc|c|}
\cline { 2 - 4 } \multicolumn{1}{c|}{} & $\begin{array}{c}\text { Ordenador } \\
\text { habitación NO }\end{array}$ & $\begin{array}{c}\text { Ordenador } \\
\text { habitación SI }\end{array}$ & Total \\
\hline Española & $59,9 \%$ & $40,1 \%$ & 1388 \\
\hline Extranjera & $44,1 \%$ & $55,9 \%$ & 34 \\
\hline Total & 846 & 576 & 1422 \\
\hline
\end{tabular}

Tabla 98: ordenador en la habitación nacionalidad

La tabla 99 muestra los porcentajes de adolescentes que tienen ordenador en la habitación por centro. Como se puede observar, no existe una tendencia definida. Sí podemos comentar que el porcentaje más bajo lo encontramos entre los adolescentes del centro público situado en el entorno rural, aunque este porcentaje es semejante al 
hallado en el entorno privado urbano 2. El factor de significación es del 0,047 por lo que hay diferencias significativas.

\begin{tabular}{|c|c|c|c|}
\hline & \multicolumn{2}{|c|}{ Ordenador en la habitación } & \multirow{2}{*}{ Tota } \\
\hline & No & Si & \\
\hline Privado urbano 1 & $58,8 \%$ & $41,2 \%$ & 216 \\
\hline Privado urbano 2 & $64,5 \%$ & $35,5 \%$ & 397 \\
\hline Público urbano & $56,4 \%$ & $43,6 \%$ & 732 \\
\hline Público rural & $64,9 \%$ & $35,1 \%$ & 77 \\
\hline Total & 846 & 576 & 1422 \\
\hline
\end{tabular}

Tabla 99: ordenador en la habitación - centro educativo

Con respecto al número de hermanos, podemos observar en la tabla 100 que el porcentaje mayor de adolescentes que tienen ordenador en la habitación lo encontramos en adolescentes que tienen 1 hermano (44,4\%). Los hijos únicos que tienen ordenador en la habitación representan el 37,4\%, mientras que el porcentaje más reducido lo encontramos entre los adolescentes que tienen 3 hermanos (30,9\%). Podemos afirmar que existen diferencias significativas, puesto que el nivel de significación es del 0,013.

\begin{tabular}{|l|cc|c|}
\cline { 2 - 4 } \multicolumn{1}{c|}{} & $\begin{array}{c}\text { Ordenador } \\
\text { habitación NO }\end{array}$ & $\begin{array}{c}\text { Ordenador } \\
\text { habitación SI }\end{array}$ & Total \\
\hline $\mathbf{1}$ & $62,6 \%$ & $37,4 \%$ & 190 \\
\hline $\mathbf{2}$ & $55,6 \%$ & $44,4 \%$ & 859 \\
\hline $\mathbf{3}$ & $64,9 \%$ & $35,1 \%$ & 245 \\
\hline Total & $69,1 \%$ & $30,9 \%$ & 55 \\
\hline
\end{tabular}

Tabla 100: ordenador en la habitación - número de hermanos

El porcentaje de adolescentes que viven con ambos padres que tienen ordenador en la habitación es inferior al de los adolescentes que viven sólo con la madre, sólo con el padre o con un tutor (tabla 101). El valor de significación $(0,016)$ pone de manifiesto que existen diferencias significativas dependiendo de la persona con quién viven los adolescentes. 


\begin{tabular}{|l|cc|c|}
\cline { 2 - 4 } \multicolumn{1}{c|}{} & $\begin{array}{c}\text { Ordenador } \\
\text { habitación NO }\end{array}$ & $\begin{array}{c}\text { Ordenador } \\
\text { habitación SI }\end{array}$ & Total \\
\hline Ambos & $60,8 \%$ & $39,2 \%$ & 1221 \\
\hline Resto & $51,7 \%$ & $48,3 \%$ & 201 \\
\hline Total & 846 & 576 & 1422 \\
\hline
\end{tabular}

Tabla 101: ordenador en la habitación - personas con las que vive

El porcentaje de adolescentes que, estando acompañados únicamente por su madre durante las tardes, no tienen ordenador en la habitación es superior al porcentaje de adolescentes que, no teniéndolo, están acompañados por otras personas (tabla 102). El valor del nivel de significación es de 0,020, por lo que sí que existen diferencias significativas.

\begin{tabular}{|l|cc|c|}
\cline { 2 - 4 } \multicolumn{1}{c|}{} & $\begin{array}{c}\text { Ordenador } \\
\text { habitación NO }\end{array}$ & $\begin{array}{c}\text { Ordenador } \\
\text { habitación SI }\end{array}$ & Total \\
\hline Madre & $63,5 \%$ & $36,5 \%$ & 510 \\
\hline Resto & $57,2 \%$ & $42,8 \%$ & 912 \\
\hline Total & 846 & 576 & 1422 \\
\hline
\end{tabular}

Tabla 102: ordenador en la habitación - personas que le acompañan por la tarde

En la gráfica 112 observamos que el porcentaje mayor de adolescentes que tienen ordenador en la habitación corresponde a aquellos cuyo padre no tiene estudios. El porcentaje va disminuyendo al aumentar el nivel educativo del padre. De hecho, se encuentran diferencias significativas en este caso, puesto que el nivel de significación es del 0,05 .

Con respecto al nivel de estudios de la madre, podemos afirmar que el porcentaje de adolescentes que tiene ordenador en la habitación más bajo corresponde a aquellos adolescentes cuyas madres no han alcanzado ningún nivel de estudios. La gráfica 112 muestra que el porcentaje aumenta para los adolescentes con madres con estudios básicos y prácticamente se mantiene para el resto de casos. El nivel de significación es de 0,113 , por lo que no podemos asegurar que existan diferencias significativas. 


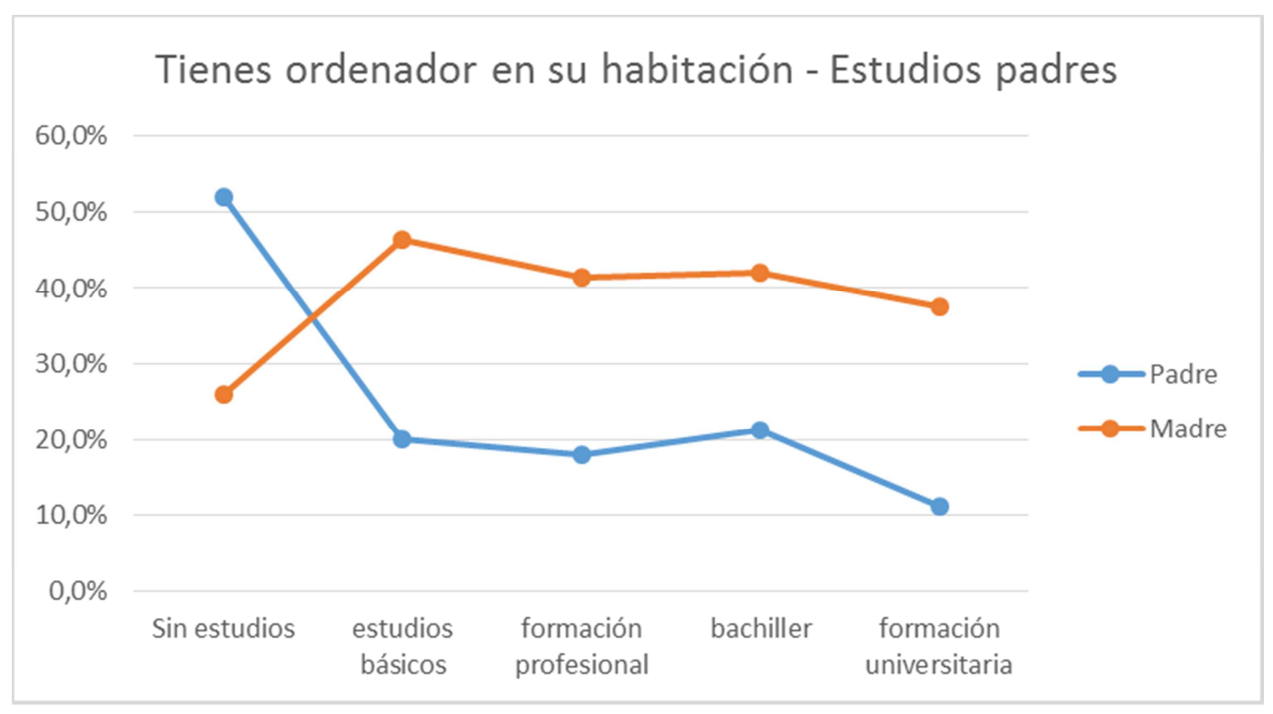

Gráfica 112: ordenador en la habitación - estudios de padre y madre

Como observamos en la tabla 103, dentro del grupo de adolescentes que sí tienen ordenador, predominan aquellos con pareja $(53,2 \%)$. Existen diferencias significativas, puesto que el nivel de significación es de 0,000.

\begin{tabular}{|l|cc|c|}
\cline { 2 - 4 } \multicolumn{1}{c|}{} & $\begin{array}{c}\text { Ordenador } \\
\text { habitación No }\end{array}$ & $\begin{array}{c}\text { Ordenador } \\
\text { habitación SI }\end{array}$ & Total \\
\hline Pareja no & $61,5 \%$ & $38,5 \%$ & 1155 \\
\hline Pareja sí & $46,8 \%$ & $53,2 \%$ & 205 \\
\hline Total & 806 & 554 & 1360 \\
\hline
\end{tabular}

Tabla 103: ordenador en la habitación - pareja y valor esperado

\subsection{6.- Tablet propia}

Como puede apreciarse en la gráfica 113 , el porcentaje de adolescentes que sí tiene tablet propia $(35,6 \%)$ es muy inferior al de adolescentes que no la tienen $(62,7 \%)$. El $1,7 \%$ de los adolescentes, no ha contestado a esta pregunta.

La tabla 104 muestra que el porcentaje de chicas de la muestra que tiene tablet propia $(38,2 \%)$ es superior al de chicos $(34,0 \%)$. Sin embargo, el nivel de significación es de 0,099 por lo que no podemos asegurar que existan diferencias significativas por género. 


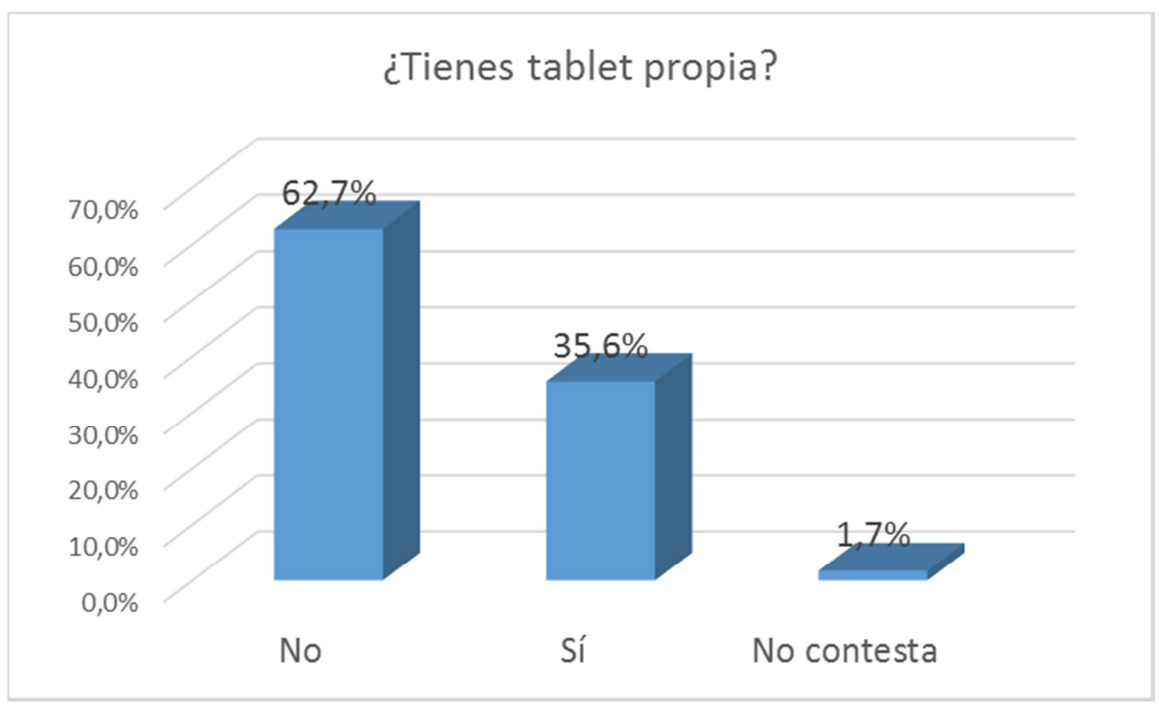

Gráfica 113: tablet propia

\begin{tabular}{|l|cc|c|}
\cline { 2 - 4 } \multicolumn{1}{c|}{} & Tablet propia NO & Tablet propia SI & Total \\
\hline Femenino & $61,8 \%$ & $38,2 \%$ & 749 \\
\hline Masculino & $66,0 \%$ & $34,0 \%$ & 674 \\
\hline Total & 908 & 515 & 1423 \\
\hline
\end{tabular}

Tabla 104: tablet propia - género

Observamos en la tabla 105 que el porcentaje de adolescentes que tiene tablet es mayor en los más jóvenes (57,5\% de los adolescentes de 12 años tienen tablet) que en los mayores (sólo el 28,9\% de los adolescentes de 17 años tienen tablet). El valor de significación obtenido tras realizar la chi-cuadrado es de 0,000 , lo cual indica que sí existen diferencias significativas por la edad.

\begin{tabular}{|l|cc|c|}
\cline { 2 - 4 } \multicolumn{1}{c|}{} & $\begin{array}{c}\text { Tablet propia } \\
\text { No }\end{array}$ & $\begin{array}{c}\text { Tablet propia } \\
\text { Si }\end{array}$ & Total \\
\hline 12 & $42,5 \%$ & $57,5 \%$ & 200 \\
\hline 13 & $55,0 \%$ & $45,0 \%$ & 269 \\
\hline 14 & $65,3 \%$ & $34,7 \%$ & 242 \\
\hline 15 & $66,1 \%$ & $33,9 \%$ & 218 \\
\hline 16 & $77,2 \%$ & $22,8 \%$ & 241 \\
\hline Total & $71,1 \%$ & $28,9 \%$ & 187 \\
\hline
\end{tabular}

Tabla 105: tablet propia -edad 
Obtenemos el mismo resultado para el curso que el obtenido con la edad. La tabla 106 pone de manifiesto que el porcentaje de adolescentes de cursos superiores que tiene tablet propia es inferior al porcentaje de cursos inferiores. De nuevo el nivel de significación es del 0,000 , por lo que podemos afirmar que existen diferencias significativas.

\begin{tabular}{|l|cc|c|}
\cline { 2 - 4 } \multicolumn{1}{c|}{} & Tablet propia NO & Tablet propia SI & Total \\
\hline 1 ESO & $48,6 \%$ & $51,4 \%$ & 325 \\
\hline 2 ESO & $56,6 \%$ & $43,4 \%$ & 286 \\
\hline 3 ESO & $69,6 \%$ & $30,4 \%$ & 263 \\
\hline 4 ESO & $70,3 \%$ & $29,7 \%$ & 185 \\
\hline 1 $\mathrm{BACH}$ & $76,1 \%$ & $23,9 \%$ & 218 \\
\hline 2 $\mathrm{BACH}$ & $74,7 \%$ & $25,3 \%$ & 146 \\
\hline Total & 908 & 515 & 1423 \\
\hline
\end{tabular}

Tabla 106: tablet propia - curso.

En la tabla 107 parece que el porcentaje de adolescentes de nacionalidad española que tienen tablet $(36,3 \%)$ es superior al de los adolescentes de otras nacionalidades $(32,4 \%)$. Sin embargo, el nivel de significación es de 0,637 por lo que no podemos asegurar que existan diferencias significativas.

\begin{tabular}{|l|cc|c|}
\cline { 2 - 4 } \multicolumn{1}{c|}{} & Tablet propia NO & Tablet propia SI & Total \\
\hline Española & $63,7 \%$ & $36,3 \%$ & 1389 \\
\hline Extranjera & $67,6 \%$ & $32,4 \%$ & 34 \\
\hline Total & 908 & 515 & 1423 \\
\hline
\end{tabular}

Tabla 107: tablet propia - nacionalidad.

Tal y como muestra la tabla 108, los porcentajes son diversos, habiendo diferencias remarcables principalmente en las respuestas aportadas por los adolescentes de los 2 centros privados urbanos (26,7\% para privado urbano 1 y $44,0 \%$ para privado urbano 2 ). El factor de significación es del 0,000, por lo que podemos afirmar que sí que existen diferencias significativas según el centro escolar al que acuden. 


\begin{tabular}{|l|cc|c|}
\cline { 2 - 4 } \multicolumn{1}{c|}{} & \multicolumn{2}{c|}{ Tablet propia } & \multirow{2}{*}{ Total } \\
\hline Privado urbano 1 & $73,3 \%$ & Si & \\
\hline Privado urbano 2 & $56,0 \%$ & $44,0 \%$ & 217 \\
\hline Público urbano & $64,8 \%$ & $35,2 \%$ & 398 \\
\hline Público rural & $67,5 \%$ & $32,5 \%$ & 731 \\
\hline Total & 908 & 515 & 1423 \\
\hline
\end{tabular}

Tabla 108: tablet propia - centro educativo.

Con respecto al número de hermanos, la tabla 109 pone de manifiesto que casi la mitad de los hijos únicos tiene tablet propia (49,2\%). El porcentaje de adolescentes que tiene tablet propia disminuye al aumentar el número de hermanos. El valor de significación es de 0,001 , lo cual indica que hay diferencias significativas.

\begin{tabular}{|l|cc|c|}
\cline { 2 - 4 } \multicolumn{1}{c|}{} & Tablet propia NO & Tablet propia SI & Total \\
\hline $\mathbf{1}$ & $50,8 \%$ & $49,2 \%$ & 193 \\
\hline $\mathbf{2}$ & $65,3 \%$ & $34,7 \%$ & 856 \\
\hline $\mathbf{3}$ & $65,9 \%$ & $34,1 \%$ & 246 \\
\hline $\mathbf{4}$ & $69,1 \%$ & $30,9 \%$ & 55 \\
\hline Total & 857 & 493 & 1350 \\
\hline
\end{tabular}

Tabla 109: tablet propia - número de hermanos.

Tal y como muestra la tabla 110, el porcentaje de adolescentes que tiene tablet propia que vive con su padre y madre es prácticamente el mismo que el de los adolescentes que viven con el resto de opciones posibles. El nivel de significación es del 0,906, por lo que no podemos asegurar que existan diferencias significativas.

\begin{tabular}{|l|cc|c|}
\cline { 2 - 4 } \multicolumn{1}{c|}{} & Tablet propia NO & Tablet propia SI & Total \\
\hline Ambos & $63,7 \%$ & $36,3 \%$ & 1222 \\
\hline Resto & $64,2 \%$ & $35,8 \%$ & 201 \\
\hline Total & 908 & 515 & 1423 \\
\hline
\end{tabular}

Tabla 110: tablet propia - personas con las que vive y valor esperado

Al igual que en el punto anterior, no se observan diferencias dependiendo de las personas que están en casa por las tardes (tabla 111), puesto que los porcentajes 
son muy similares $(35,6 \%$ los que pasan la tarde con su madre y $36,5 \%$ para aquellos que están acompañados por otras personas que no sean su madre). El nivel de significación es del 0,736 lo cual demuestra que no hay diferencias significativas.

\begin{tabular}{|l|cc|c|}
\cline { 2 - 4 } \multicolumn{1}{c|}{} & Tablet propia NO & Tablet propia SI & Total \\
\hline Madre & $64,4 \%$ & $35,6 \%$ & 511 \\
\hline Resto & $63,5 \%$ & $36,5 \%$ & 912 \\
\hline Total & 908 & 515 & 1423 \\
\hline
\end{tabular}

Tabla 111: tablet propia - personas que le acompañan por la tarde

En referencia al nivel de estudios de los padres los resultados obtenidos son muy similares para el padre y para la madre. Sólo se encuentran diferencias importantes para el caso de progenitores sin estudios. En el caso del padre sin estudios, el porcentaje de adolescentes con tablet es inferior al resto de adolescentes con padres con estudios.

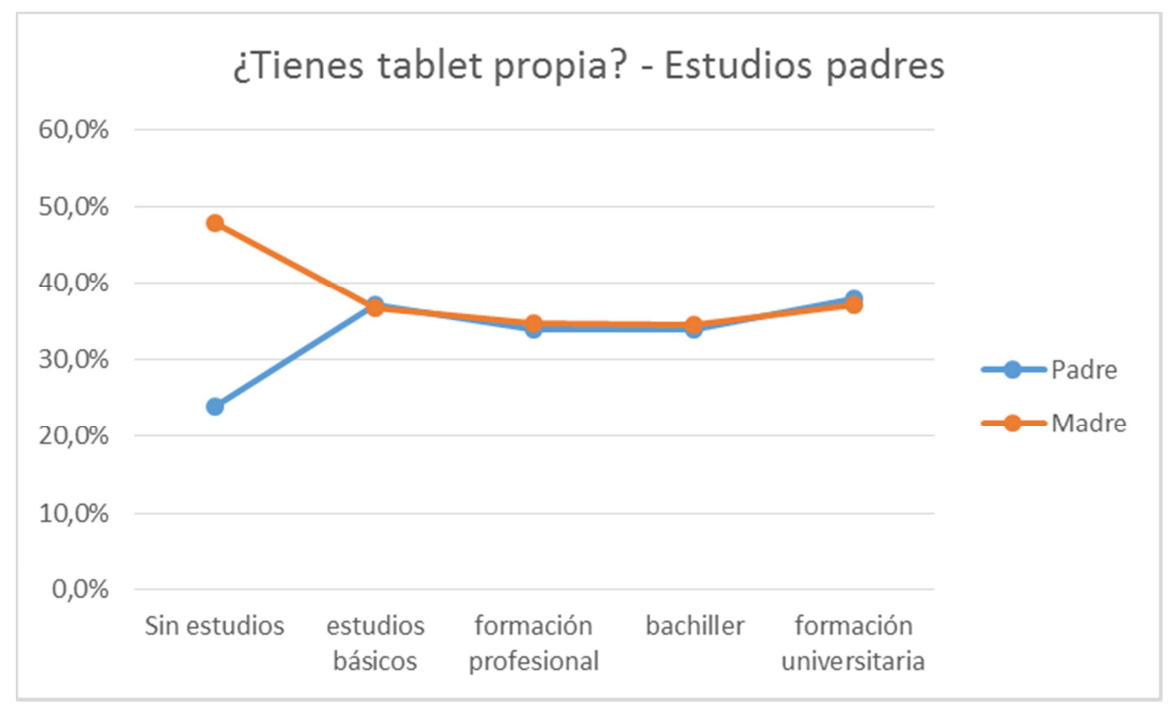

Gráfica 114: tablet propia - estudios de padre y madre

En el caso de madres sin estudios, el porcentaje de adolescentes con tablet propia es superior al del resto de adolescentes cuyas madres han estudiado (gráfica 114). Los porcentajes se mantienen constantes siendo ligeramente más 
alto el porcentaje de adolescentes que tienen tablet propia cuyos padres tienen estudios universitarios. Para ninguno de los 2 casos se encuentran diferencias significativas.

La tabla 112 muestra que aparentemente el porcentaje de adolescentes que tiene tablet pero no tiene pareja (36,9\%) es mayor que el que sí tiene pareja (33,7\%). Atendiendo al nivel de significación de 0,381, no podemos afirmar que existan diferencias significativas.

\begin{tabular}{|l|cc|c|}
\cline { 2 - 4 } \multicolumn{1}{c|}{} & Tablet propia NO & Tablet propia SI & Total \\
\hline Pareja no & $63,1 \%$ & $36,9 \%$ & 1156 \\
\hline Pareja sí & $66,3 \%$ & $33,7 \%$ & 205 \\
\hline Total & 866 & 495 & 1361 \\
\hline
\end{tabular}

Tabla 112: tablet propia - pareja y valor esperado

\subsection{7.- Videojuegos y consolas}

El análisis de los datos recogidos en la encuesta realizada a los adolescentes burgaleses muestra que del total de adolescentes que afirma dedicar tiempo a jugar a videojuegos y consolas entre semana, el $73,01 \%$ son chicos y el $26,99 \%$ son chicas (tabla 113 ). Durante el fin de semana, el porcentaje de chicos disminuye levemente, siendo de $71,45 \%$ frente a un $28,55 \%$ de chicas.

\begin{tabular}{|l|ccc|}
\cline { 2 - 4 } \multicolumn{1}{c|}{} & Masculino & Femenino & Total \\
\hline Videojuegos/consolas entre semana & $73,01 \%$ & $26,99 \%$ & 452 \\
\hline Videojuegos/consolas fin de semana & $71,45 \%$ & $28,55 \%$ & 655 \\
\hline
\end{tabular}

Tabla 113: adolescentes que dedican tiempo a jugar a videojuegos/consolas - género 


\subsection{8.- Nuevas tecnologías para la lectura}

El $17 \%$ de los adolescentes encuestados, ante la pregunta sobre el formato en que lee libros, contesta que no lee libros. El 83\%, sin embargo, afirma leer libros (gráfica 115).

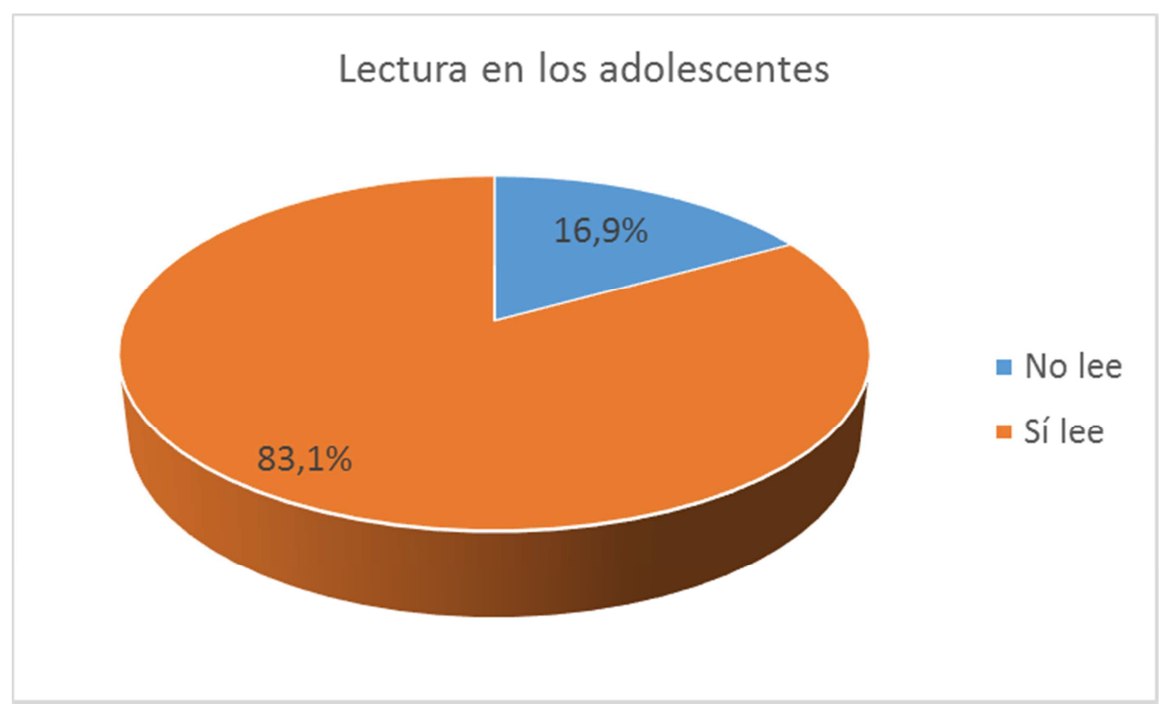

Gráfica 115: lectura de libros

Con respecto a al género, como puede apreciarse en la tabla 114, el porcentaje de chicos que no lee $(26,7 \%)$ es bastante superior al de chicas $(8,1 \%)$.

\begin{tabular}{|l|cc|c|}
\cline { 2 - 4 } \multicolumn{1}{c|}{} & No lee & Sí lee & Total \\
\hline Femenino & $8,1 \%$ & $91,9 \%$ & 743 \\
\hline Masculino & $26,7 \%$ & $73,3 \%$ & 671 \\
\hline Total & 239 & 1175 & 1414 \\
\hline
\end{tabular}

Tabla 114: lectura de libros - género

La gráfica 116 muestra las preferencias de los adolescentes en cuanto a los dispositivos de lectura. Aproximadamente tres de cada 4 adolescentes manifiestan seguir utilizando para la lectura el formato tradicional en papel (70,0\% de las respuestas obtenidas). El $10,6 \%$ de ellos afirma utilizar el libro electrónico u otro dispositivo digital como soporte para la lectura. El $19,4 \%$ de los adolescentes lee tanto en formato papel como en formato electrónico. 


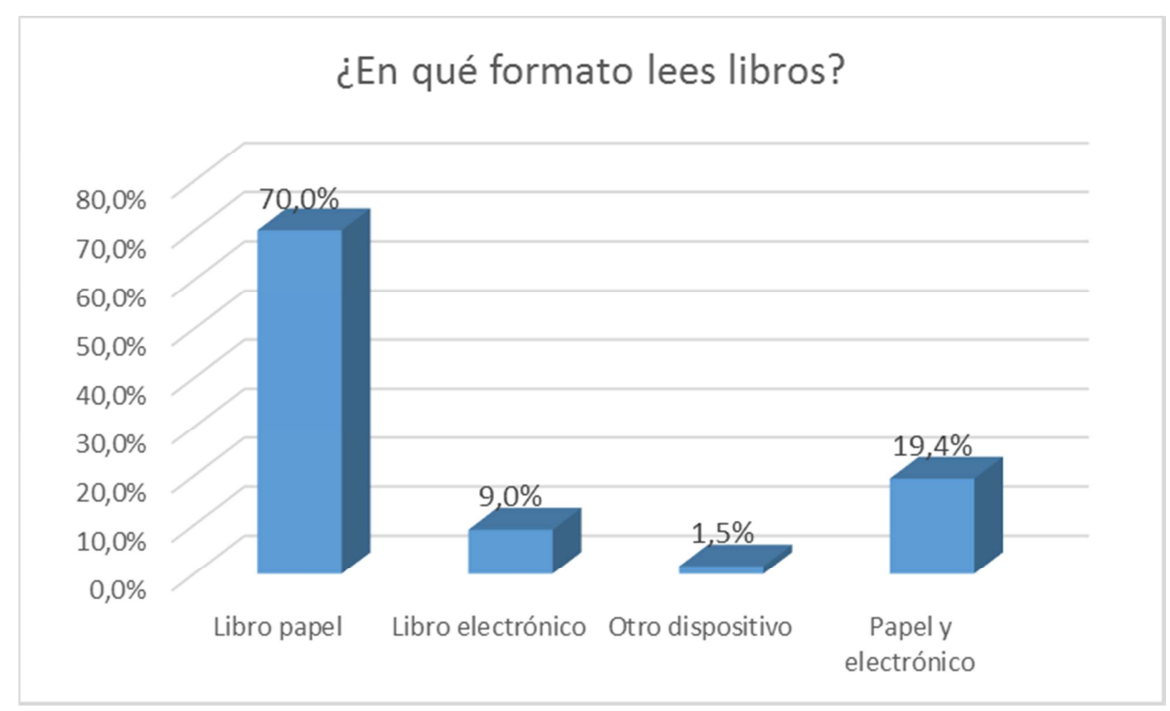

Gráfica 116: formatos de lectura preferidos

Para hacer el análisis del tipo de dispositivo utilizado por el adolescente con respecto a los distintos factores sociodemográficos que pueden afectar, hemos creado una nueva variable que agrupa los casos cuya respuesta es "libro electrónico" y "otro dispositivo". Se ha realizado esta agrupación de casos porque el recuento de los valores esperados obtenidos en alguna de las casillas de la tabla de contingencia resultaban ser menores de 5 .

Con respecto al género, la tabla 115 muestra que el porcentaje de adolescentes varones que prefieren el libro en papel $(77,4 \%)$ es superior al de las chicas $(64,7 \%)$. Las chicas utilizan más exclusivamente el formato electrónico que los chicos. Adicionalmente, podemos concluir que el porcentaje de chicas que simultanean la lectura en los distintos soportes digitales y en papel tradicional $(23,6 \%)$ es superior al de los $\operatorname{chicos}(13,6 \%)$.

\begin{tabular}{|l|ccc|c|}
\cline { 2 - 5 } \multicolumn{1}{c|}{} & Libro papel & $\begin{array}{c}\text { Formato } \\
\text { electrónico }\end{array}$ & $\begin{array}{c}\text { Electrónico } \\
\text { y papel }\end{array}$ & Total \\
\hline Femenino & $64,7 \%$ & $11,7 \%$ & $23,6 \%$ & 683 \\
\hline Masculino & $77,4 \%$ & $8,9 \%$ & $13,6 \%$ & 492 \\
\hline Total & 823 & 124 & 228 & 1175 \\
\hline
\end{tabular}

Tabla 115: formatos de lectura preferidos por los adolescentes - género 
Tras realizar el cálculo de la chi-cuadrado, el valor obtenido para el nivel de significación $(0,000)$, pone de manifiesto que existen diferencias significativas en el tipo de formato preferido para la lectura por los adolescentes por género.

La tabla 116 muestra que el porcentaje de adolescentes que no lee crece notablemente con la edad (pasa de ser el 6,1\% a los 12 años al 25\% a los 17 años).El nivel de significación indica que existen diferencias significativas por la edad.

\begin{tabular}{|l|cc|c|}
\cline { 2 - 4 } \multicolumn{1}{c|}{} & No lee & Sílee & Total \\
\hline 12 años & $6,1 \%$ & $93,9 \%$ & 198 \\
\hline 13 años & $7,8 \%$ & $92,2 \%$ & 270 \\
\hline 14 años & $16,2 \%$ & $83,8 \%$ & 241 \\
\hline 15 años & $21,3 \%$ & $78,7 \%$ & 216 \\
\hline 16 años & $26,3 \%$ & $73,7 \%$ & 240 \\
\hline 17 años & $25,0 \%$ & $75,0 \%$ & 184 \\
\hline Total & 227 & 1122 & 1349 \\
\hline
\end{tabular}

Tabla 116: lectura de libros - edad

El resultado obtenido, tras realizar una tabla cruzada con los datos resultantes, se muestra en la tabla 117. Queda patente en este caso, que existe una tendencia a disminuir el porcentaje de adolescentes que lee en papel con la edad, es decir, cuanto mayor es el adolescente menos libros en papel utiliza para leer. El valor del nivel de significación $(0,000)$ muestra que existen diferencias significativas.

\begin{tabular}{|l|ccc|c|}
\cline { 2 - 5 } \multicolumn{1}{c|}{} & Libro papel & $\begin{array}{c}\text { Electrónico y } \\
\text { papel }\end{array}$ & $\begin{array}{c}\text { Formato } \\
\text { electrónico }\end{array}$ & Total \\
\hline $\mathbf{1 2}$ años & $80,1 \%$ & $14,0 \%$ & $5,9 \%$ & 186 \\
\hline $\mathbf{1 3}$ años & $77,1 \%$ & $15,3 \%$ & $7,6 \%$ & 249 \\
\hline $\mathbf{1 4}$ años & $66,8 \%$ & $23,8 \%$ & $9,4 \%$ & 202 \\
\hline $\mathbf{1 5}$ años & $72,4 \%$ & $17,1 \%$ & $10,5 \%$ & 170 \\
\hline $\mathbf{1 6}$ años & $63,3 \%$ & $24,3 \%$ & $12,4 \%$ & 177 \\
\hline $\mathbf{1 7}$ años & $56,5 \%$ & $23,2 \%$ & $20,3 \%$ & 138 \\
\hline Total & 789 & 216 & 117 & 1122 \\
\hline
\end{tabular}

Tabla 117: formatos de lectura preferidos por los adolescentes - edad 
A continuación, mostramos en la tabla 118 un resumen de todo este capítulo, marcando en amarillo las actividades que muestran diferencias significativas, con respecto a alguno de los factores estudiados.

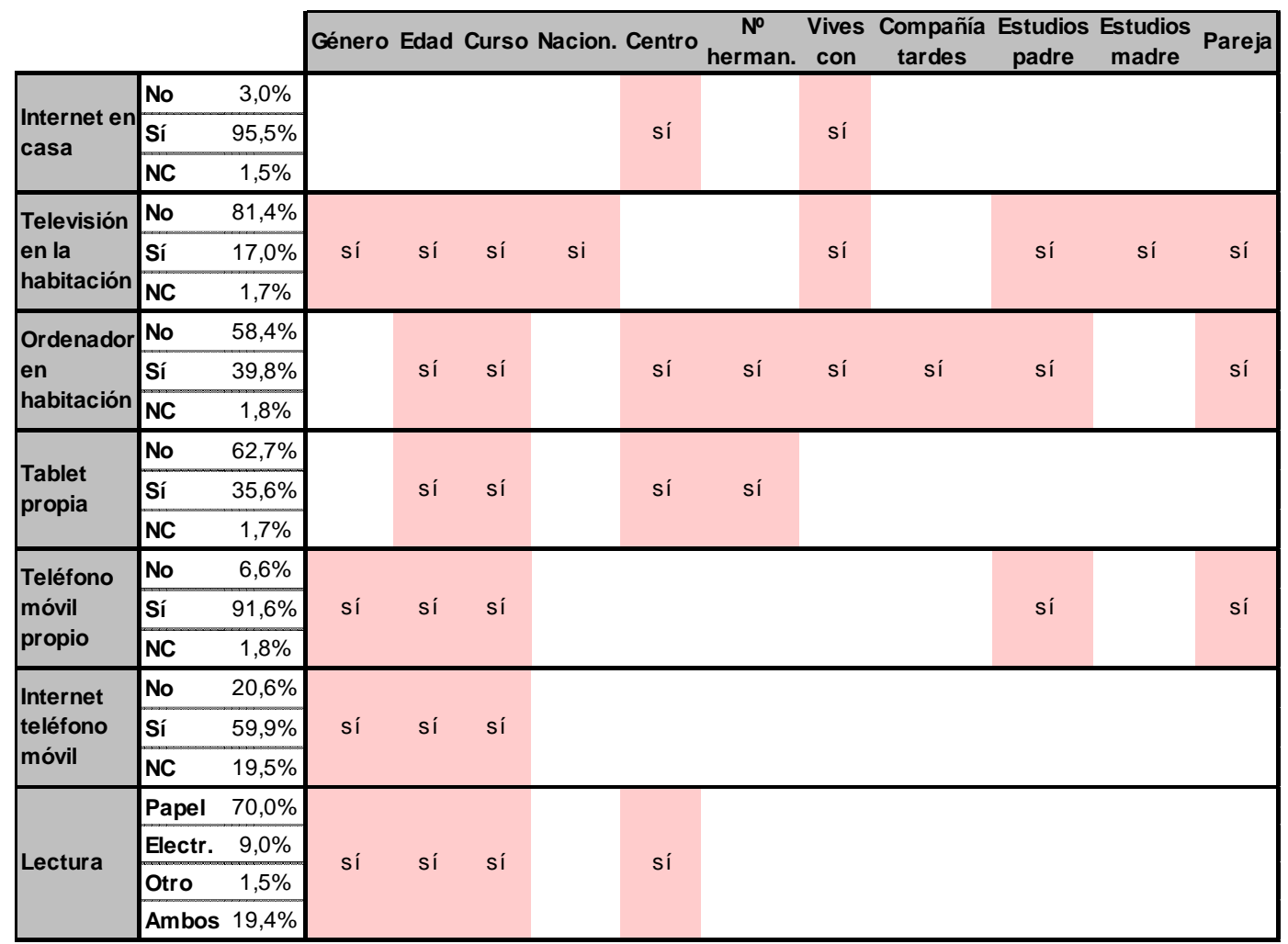

Tabla 118: factores que marcan diferencias significativas en cuanto al uso de TIC

\subsection{9- Edad de iniciación en las nuevas tecnologías}

Las cuestiones 24, 2526 y 27 preguntan al adolescente sobre su edad de inicio en el uso de los dispositivos electrónicos, además de indagar sobre la edad a la que dispusieron de ellos como propios. El adolescente tiene la opción de indicar esta información en la encuesta por edad o curso, puesto que en algunos casos, los adolescentes recuerdan con más fiabilidad el curso al que les sucedió alguno de estos eventos por los que preguntamos.

La pregunta 24 de la encuesta tiene por objetivo indagar en la edad de iniciación de los adolescentes en el uso de los dispositivos tecnológicos. Marcamos como perdidos los casos cuya respuesta es "No contesta" y "No tengo" (esta última ya la hemos analizado en las preguntas de la 16 a la 21). En la tabla 119 se muestra la edad media a la que los 
adolescentes encuestados se iniciaron en el uso de estos dispositivos tecnológicos. Puede observarse que los niños afirman iniciarse más jóvenes a los videojuegos $(8,28)$. Después al ordenador (9,22 años), a internet (9,33 años) y finalmente al teléfono móvil (11,2 años). Tenemos que tomar estas cifras con cautela, puesto que como veremos a continuación, la edad de inicio es cada vez más temprana, por lo que los adolescentes más jóvenes, se habrán iniciado antes que estas medias.

\begin{tabular}{|l|ccccc|}
\cline { 2 - 6 } \multicolumn{1}{c|}{} & \multicolumn{2}{|c}{ N } & Mínimo & Máximo & Media $\begin{array}{c}\text { Desviación } \\
\text { estándar }\end{array}$ \\
\hline ¿A qué edad o curso empezaste a usar el ordenador/tablet? & 1303 & 1 & 16 & 9,22 & 2,467 \\
\hline ¿A qué edad o curso empezaste a utilizar Internet? & 1319 & 3 & 16 & 9,33 & 2,319 \\
\hline ¿A qué edad o curso empezaste a utilizar los videojuegos? & 1167 & 3 & 17 & 8,28 & 2,405 \\
\hline ¿A qué edad o curso empezaste a utilizar el teléfono móvil? & 1294 & 3 & 16 & 11,20 & 1,882 \\
\hline
\end{tabular}

Tabla 119: edad de iniciación a la utilización de los diferentes dispositivos tecnológicos

Con respecto a esta cuestión, también es posible que encontremos diferencias por alguno de los factores sociodemográficos que estamos estudiando, por lo que vamos a analizarlos a continuación:

Analizamos si existen diferencias por género en la edad de iniciación a la utilización de estos dispositivos electrónicos. Los resultados obtenidos se muestran en la tabla 120. Las chicas empiezan a utilizar el ordenador/tablet y el teléfono móvil antes que los chicos. Ellos sin embargo, son más precoces en la utilización de Internet y de los videojuegos aunque las diferencias no son significativas con el tamaño de muestra que tenemos.

\begin{tabular}{|l|rr|rr|rr|rr|rr|}
\cline { 2 - 10 } \multicolumn{1}{c|}{} & \multicolumn{2}{c|}{$\mathbf{N}$} & Mínimo & \multicolumn{2}{c|}{ Máximo } & \multicolumn{2}{c|}{ Media } & \multicolumn{2}{c|}{$\begin{array}{c}\text { Desviación } \\
\text { estándar }\end{array}$} \\
\hline ¿A qué edad empezaste a utilizar...? & mas. fem. & mas. fem. & mas. fem. & mas. & fem. & mas. & fem. \\
\hline Ordenador/tablet & 615 & 688 & 1 & 1 & 16 & 15 & 9,24 & 9,21 & 2,545 & 2,397 \\
\hline Internet & 632 & 687 & 3 & 3 & 15 & 16 & 9,28 & 9,37 & 2,264 & 2,369 \\
\hline Videojuegos & 617 & 550 & 3 & 3 & 16 & 17 & 8,25 & 8,30 & 2,475 & 2,325 \\
\hline Teléfono móvil & 607 & 687 & 3 & 3 & 16 & 16 & 11,39 & 11,03 & 1,902 & 1,849 \\
\hline
\end{tabular}

Tabla 120: edad de inicio de utilización de dispositivos tecnológicos - género 
Podemos observar en la gráfica 117, que la edad de inicio a la utilización de dispositivos electrónicos aumenta cuando aumenta la edad del adolescente. Esto implica que los adolescentes más jóvenes se inician antes en la utilización de estos dispositivos tecnológicos.

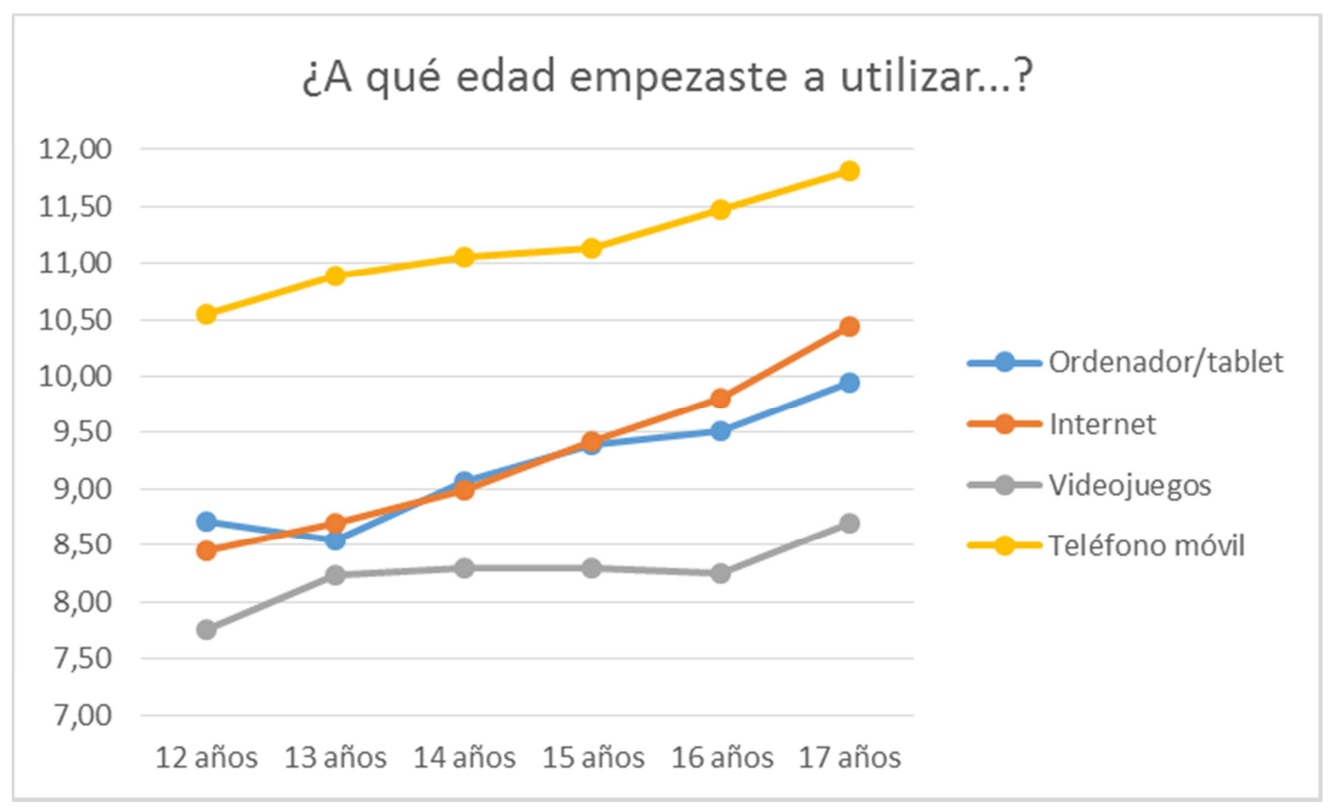

Gráfica 117: edad de inicio de utilización de dispositivos tecnológicos con respecto a la edad

De hecho, el porcentaje de adolescentes que se han iniciado en las nuevas tecnologías antes de los 6 años puede observarse en la tabla 121. Casi el 10\% de los adolescentes encuestados afirma haberse iniciado en el uso de los videojuegos antes de los 6 años de edad. El 6,5\% de los adolescentes empezaron a utilizar su ordenador o tablet antes de los 6 años.

\begin{tabular}{|l|c|}
\cline { 2 - 2 } \multicolumn{1}{c|}{} & $\begin{array}{c}\text { \%adolescentes } \\
\text { antes de } \mathbf{6} \text { años }\end{array}$ \\
\hline ¿A qué edad o curso empezaste a usar el ordenador/tablet? & $6,49 \%$ \\
\hline ¿A qué edad o curso empezaste a utilizar Internet? & $5,32 \%$ \\
\hline ¿A qué edad o curso empezaste a utilizar los videojuegos? & $9,25 \%$ \\
\hline ¿A qué edad o curso empezaste a utilizar el teléfono móvil? & $1,10 \%$ \\
\hline
\end{tabular}

Tabla 121: adolescentes que se ha iniciado en las nuevas tecnologías antes de los 6 años 
La edad media a la que los adolescentes han tenido, por primera vez, cada uno de los dispositivos, es la que se muestra en la tabla 122. Los adolescentes encuestados manifiestan haber tenido el ordenador a los 11,21 años de media, el teléfono móvil a los 11,26 años de media y la tablet a los 11,79 años de media.

\begin{tabular}{|l|cccccc|}
\cline { 2 - 7 } \multicolumn{1}{c|}{} & N & Mínimo & Máximo & Media & $\begin{array}{c}\text { Desviación } \\
\text { estándar }\end{array}$ \\
\hline ¿A qué edadtuviste tu primer móvil propio? & 1291 & 3 & 17 & 11,26 & 1,843 \\
\hline ¿A qué edad tuviste tu primer ordenador propio? & 754 & 3 & 17 & 11,21 & 2,508 \\
\hline ¿A qué edad tuviste tu primera tablet propia? & 557 & 3 & 17 & 11,79 & 2,321 \\
\hline
\end{tabular}

Tabla 122: edad media a la que poseen los primeros dispositivos electrónicos

Si analizamos los datos, segmentando por género (tabla 123), podemos observar que las chicas manifestaron tener su primer teléfono móvil propio más jóvenes que los chicos, al igual que la primera tablet propia.

Sin embargo, los chicos afirmaron tener su primer ordenador propio antes que las chicas aunque estas diferencias no sean significativas al $95 \%$.

\begin{tabular}{|c|c|c|c|c|c|}
\hline & $\mathbf{N}$ & Mínimo & Máximo & Media & $\begin{array}{c}\begin{array}{c}\text { Desviación } \\
\text { estándar }\end{array} \\
\end{array}$ \\
\hline ¿A qué edad tuviste tu primer...? & mas. fem. & mas. fem. & mas. fem. & mas. fem. & mas. fem. \\
\hline Teléfono móvil propio & $607 \quad 684$ & 3 & 16 & $11,38 \quad 11,15$ & $1,8921,794$ \\
\hline Ordenador propio & 403 & 3 & 17 & $11,16 \quad 11,25$ & $2,5522,472$ \\
\hline Tablet propia & $253 \quad 304$ & 3 & 17 & $11,9211,68$ & $2,3962,256$ \\
\hline
\end{tabular}

Tabla 123: edad media a la que poseen los primeros dispositivos electrónicos - género

Los resultados obtenidos con respecto a la edad, son similares a los obtenidos para la edad de inicio en la utilización de los dispositivos electrónicos. La edad media en que el adolescente manifiesta tener su primer aparato electrónico crece con la edad, lo cual indica que la edad media a la que los adolescentes más jóvenes han dispuesto de su primer dispositivo electrónico ha sido más temprana que la de los adolescentes más mayores. Esta tendencia queda plasmada en la gráfica 118. 


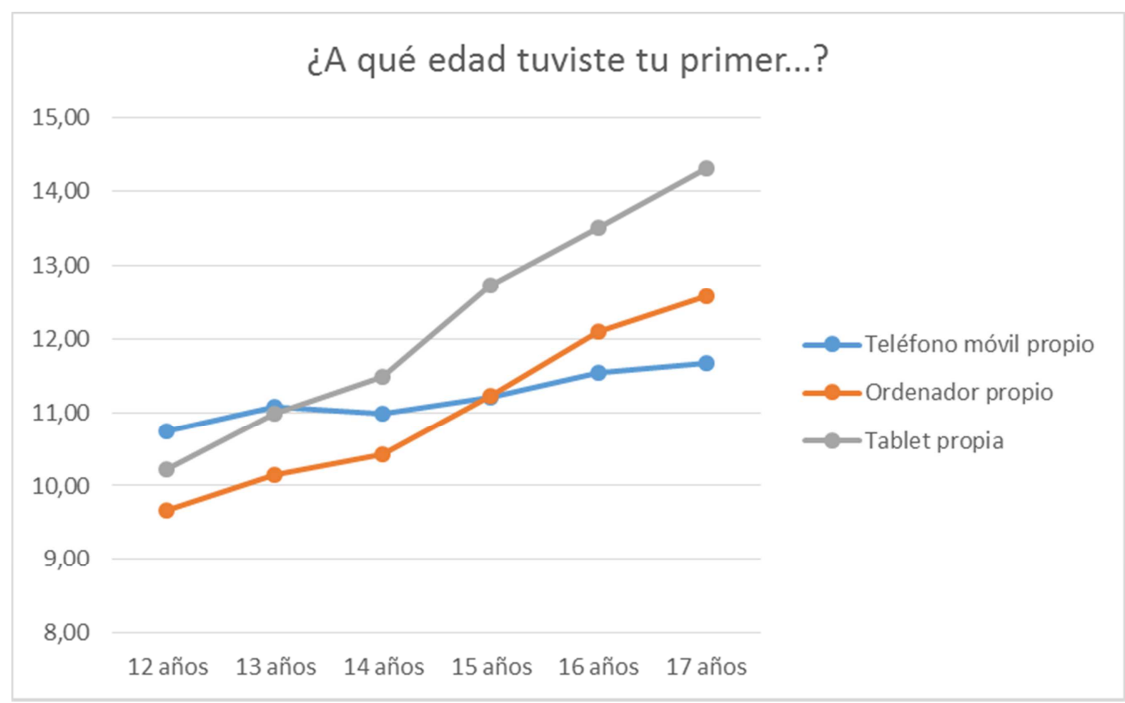

Gráfica 118: evolución de la edad media de posesión del primer dispositivo electrónico - edad.

Por lo tanto, la edad media a la que los adolescentes actuales han empezado a utilizar los diferentes dispositivos electrónicos e internet se sitúa entre 8 y 11 años, no encontrándose grandes diferencias por género.

La edad a la que los adolescentes afirman haber tenido su primer dispositivo electrónico es de 11 años. Tanto la edad de inicio como de posesión de tecnología propia aumenta con la edad de los adolescentes, lo cual quiere decir que los adolescentes cada vez acceden antes 


\section{4.- USO DEL TIEMPO Y NUEVAS TECNOLOGÍAS}

Con el objetivo de estudiar si existe influencia en la posesión de los distintos dispositivos electrónicos por los adolescentes en su uso del tiempo, vamos a realizar comparaciones dos a dos utilizando la prueba t-Student con cada una de las distintas tecnologías y sombrearemos en rojo (como hemos hecho en capítulos anteriores), las actividades en las que encontremos diferencias significativas con el fin de analizarlas posteriormente. Las nuevas tecnologías que vamos a analizar son las siguientes:

- internet en casa

- televisión en tu habitación

- ordenador en tu habitación

- tablet propia

- teléfono móvil propio

- internet en tu teléfono móvil propio

\subsection{1.- Uso del tiempo y la disposición de conexión a Internet}

La tabla 124 muestra el resultado de la t-Student realizada entre el uso del tiempo del adolescentes y el factor tener internet en casa. Como puede observarse, se encuentran diferencias significativas en 3 actividades (nivel de significación es inferior a 0,05):

- tiempo destinado a internet el fin de semana: los adolescentes que tienen internet en casa se conectan 24 minutos más que los que no tienen (0:51 horas frente a 1:16).

- tiempo dedicado a ver la televisión entre semana: los adolescentes que no tienen internet en casa ven la televisión 33 minutos más que los que sí tienen (1:58 frente a 1:24 horas).

- tiempo dedicado a hacer deporte entre semana: los adolescentes que tienen internet en casa hacen menos deporte (47minutos menos) que los que sí que tienen (1:48 frente a 2:36 horas al día). 


\section{2a PARTE}

Capítulo 4.- Resultados

\begin{tabular}{|c|c|c|c|c|c|c|c|c|}
\hline & \multicolumn{2}{|c|}{$\begin{array}{c}\text { Internet en } \\
\text { casa }\end{array}$} & \multirow{2}{*}{$\mathbf{t}$} & \multirow{2}{*}{ gl } & \multirow{2}{*}{$\begin{array}{c}\text { Sig. } \\
\text { (bilateral) }\end{array}$} & \multirow{2}{*}{$\begin{array}{l}\text { Diferencia } \\
\text { de medias }\end{array}$} & \multicolumn{2}{|c|}{$\begin{array}{c}\text { 95\% int.confianza } \\
\text { diferencia }\end{array}$} \\
\hline & No & $\mathbf{S i}$ & & & & & Inferior & Superior \\
\hline Dormir S & $7: 45$ & $7: 44$ & 0,034 & 42,480 & 0,973 & $0: 00$ & $-0: 17$ & $0: 17$ \\
\hline Dormir F & $9: 32$ & $9: 33$ & $-0,057$ & 39,220 & 0,955 & $-0: 00$ & $-0: 25$ & $0: 24$ \\
\hline Asistir a clase $\mathrm{S}$ & $6: 11$ & $6: 08$ & 1,135 & 38,761 & 0,264 & $0: 03$ & $-0: 02$ & $0: 08$ \\
\hline Asistir a clase F & $0: 00$ & $0: 00$ & & & & & & \\
\hline Actividades extr. S & $1: 42$ & $1: 48$ & $-0,339$ & 32,309 & 0,737 & $-0: 06$ & $-0: 45$ & $0: 32$ \\
\hline Actividades extr. F & $0: 36$ & $0: 42$ & $-0,569$ & 29,767 & 0,573 & $-0: 05$ & $-0: 27$ & $0: 15$ \\
\hline Estudio S & $2: 13$ & $2: 24$ & $-0,874$ & 41,571 & 0,387 & $-0: 10$ & $-0: 36$ & $0: 14$ \\
\hline Estudio F & $2: 01$ & $2: 32$ & $-1,826$ & 40,372 & 0,075 & $-0: 31$ & $-1: 05$ & $0: 03$ \\
\hline Whatsapp S & $2: 05$ & $1: 46$ & 0,858 & 40,513 & 0,396 & $0: 19$ & $-0: 25$ & $1: 03$ \\
\hline Whatsapp F & $2: 34$ & $2: 45$ & $-0,492$ & 39,608 & 0,625 & $-0: 11$ & $-0: 57$ & $0: 34$ \\
\hline Redes sociales S & $0: 54$ & $1: 05$ & $-1,279$ & 44,420 & 0,208 & $-0: 11$ & $-0: 29$ & $0: 06$ \\
\hline Redes sociales F & $1: 15$ & $1: 36$ & $-1,673$ & 41,726 & 0,102 & $-0: 21$ & $-0: 46$ & $0: 04$ \\
\hline Internet S & $0: 41$ & $0: 54$ & $-1,635$ & 39,944 & 0,110 & $-0: 12$ & $-0: 28$ & $0: 03$ \\
\hline Internet F & $0: 51$ & $1: 16$ & $-2,551$ & 40,857 & 0,015 & $-0: 24$ & $-0: 44$ & $-0: 05$ \\
\hline Videojuegos/consolas S & $0: 42$ & $0: 28$ & 1,206 & 40,624 & 0,235 & $0: 13$ & $-0: 09$ & $0: 36$ \\
\hline Videojuegos/consolas F & $0: 56$ & $1: 01$ & $-0,390$ & 41,561 & 0,698 & $-0: 05$ & $-0: 33$ & $0: 22$ \\
\hline Televisión S & $1: 58$ & $1: 24$ & 2,155 & 39,289 & 0,037 & $0: 33$ & $0: 02$ & $1: 05$ \\
\hline Televisión F & $2: 36$ & $2: 05$ & 1,649 & 39,509 & 0,107 & $0: 31$ & $-0: 07$ & $1: 09$ \\
\hline Teléfono S & $0: 39$ & $0: 21$ & 1,835 & 35,914 & 0,075 & $0: 17$ & $-0: 01$ & $0: 37$ \\
\hline Teléfono F & $0: 44$ & $0: 30$ & 1,160 & 34,915 & 0,254 & $0: 14$ & $-0: 11$ & $0: 40$ \\
\hline Deporte S & $2: 36$ & $1: 48$ & 2,289 & 38,940 & 0,028 & $0: 47$ & $0: 05$ & $1: 30$ \\
\hline Deporte F & $1: 20$ & $1: 31$ & $-1,018$ & 38,538 & 0,315 & $-0: 11$ & $-0: 33$ & $0: 11$ \\
\hline Trabajo doméstico S & $0: 51$ & $0: 37$ & 1,870 & 40,690 & 0,069 & $0: 13$ & $-0: 01$ & $0: 28$ \\
\hline Trabajo doméstico F & $0: 57$ & $0: 50$ & 0,811 & 40,569 & 0,422 & $0: 07$ & $-0: 11$ & $0: 27$ \\
\hline Trabajo remunerado $\mathrm{S}$ & $0: 11$ & $0: 06$ & 0,683 & 37,381 & 0,499 & $0: 04$ & $-0: 09$ & $0: 18$ \\
\hline Trabajo remunerado $\mathrm{F}$ & $0: 12$ & $0: 10$ & 0,168 & 37,811 & 0,867 & $0: 01$ & $-0: 13$ & $0: 15$ \\
\hline Lectura S & $0: 43$ & $0: 40$ & 0,375 & 36,551 & 0,710 & 0:02 & $-0: 11$ & $0: 16$ \\
\hline Lectura F & $1: 01$ & $0: 50$ & 1,069 & 39,411 & 0,291 & $0: 10$ & $-0: 09$ & $0: 31$ \\
\hline Higiene personal S & $1: 29$ & $1: 10$ & 1,967 & 40,703 & 0,056 & $0: 19$ & $-0: 00$ & $0: 38$ \\
\hline Higiene personal F & $1: 29$ & $1: 12$ & 1,824 & 36,919 & 0,076 & $0: 17$ & $-0: 01$ & $0: 36$ \\
\hline Alimentación S & $2: 00$ & $1: 43$ & 1,293 & 37,677 & 0,204 & $0: 17$ & $-0: 09$ & $0: 44$ \\
\hline Alimentación F & $1: 42$ & $1: 45$ & $-0,257$ & 37,010 & 0,798 & $-0: 02$ & $-0: 25$ & $0: 19$ \\
\hline Amigos S & $1: 45$ & $1: 10$ & 2,023 & 36,484 & 0,050 & $0: 34$ & $-0: 00$ & $1: 09$ \\
\hline Amigos $\mathrm{F}$ & $3: 31$ & $3: 33$ & $-0,070$ & 39,469 & 0,945 & $-0: 01$ & $-0: 59$ & $0: 55$ \\
\hline Desplazamientos S & $0: 38$ & $0: 45$ & $-1,242$ & 40,446 & 0,222 & $-0: 07$ & $-0: 18$ & $0: 04$ \\
\hline Desplazamientos F & $0: 53$ & $0: 58$ & $-0,612$ & 38,628 & 0,544 & $-0: 05$ & $-0: 22$ & $0: 12$ \\
\hline Salir con pareja S & $0: 31$ & $0: 14$ & 0,857 & 37,725 & 0,397 & $0: 17$ & $-0: 23$ & $0: 57$ \\
\hline Salir con pareja F & $0: 24$ & $0: 26$ & $-0,131$ & 33,669 & 0,897 & $-0: 01$ & $-0: 29$ & $0: 25$ \\
\hline Tiempo en dormirse ayer & $0: 27$ & $0: 30$ & $-0,989$ & 45,612 & 0,328 & $-0: 03$ & $-0: 12$ & $0: 04$ \\
\hline
\end{tabular}

Tabla 124: resultado de t-Student: uso del tiempo - tener internet en casa 


\subsection{2.- Uso del tiempo y televisión en la habitación:}

La tabla 125 muestra el resultado de la t-Student que relaciona ambos conceptos. El resultado más llamativo de esta tabla es que no se encuentran diferencias significativas entre tener o no televisión en la habitación y el tiempo que dedican a verla.

El gráfico 119 muestra las actividades en las cuáles los adolescentes que tienen televisión en la habitación dedican más tiempo y que se han encontrado diferencias significativas. Son las siguientes:

- Actividades relacionadas con las nuevas tecnologías: WhatsApp entre semana, redes sociales, internet entre semana, videoconsolas, teléfono fin de semana.

- Deporte fin semana: los que tienen televisión en la habitación dedican al deporte 11 minutos más que los que no la tienen (1:40 frente 1:29 horas al día).

- Higiene personal entre semana: aquellos que la tienen dedican a higiene personal 13 minutos más que los que no la tienen (1:09 frente a 1:22 horas/día).

- Amigos fin de semana: los adolescentes que tienen televisión en la habitación están con los amigos el fin de semana 25 minutos más que los que no la tienen (3:29 frente a 3:55 horas al día).

- Tiempo en dormirse ayer: los adolescentes que tienen televisión en la habitación tardan de media 6 minutos más en dormirse que los que no la tienen.

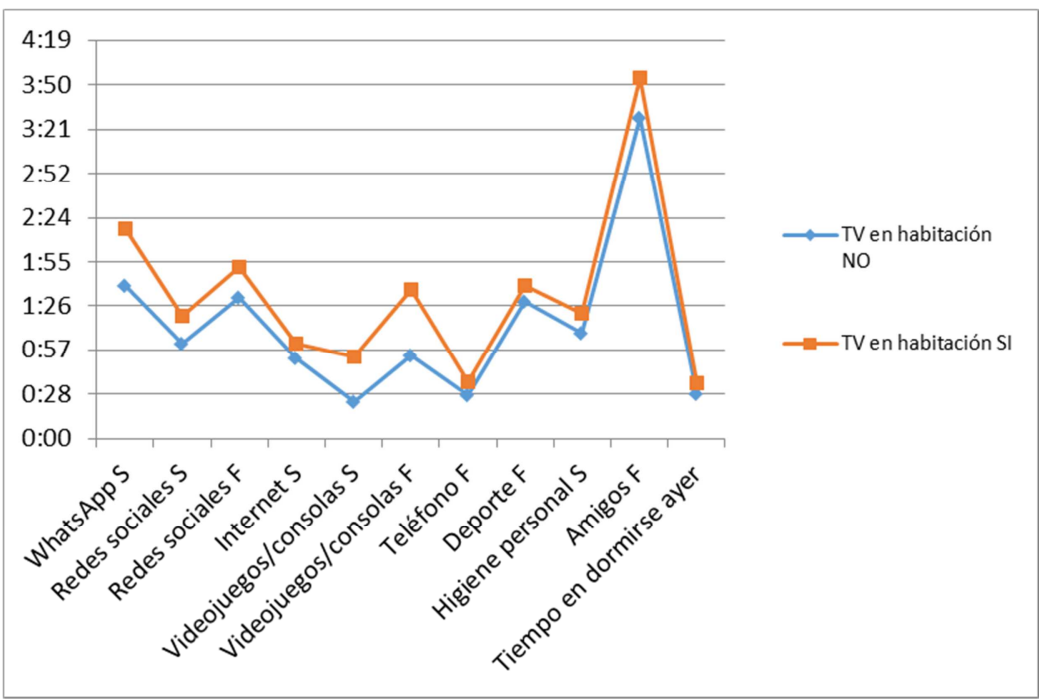

Gráfica 119: media de tiempo dedicado a actividades -tener televisión en la habitación 


\section{2a PARTE}

Capítulo 4.- Resultados

\begin{tabular}{|c|c|c|c|c|c|c|c|c|}
\hline & \multicolumn{2}{|c|}{$\begin{array}{c}\text { TV en } \\
\text { habitación }\end{array}$} & \multirow[t]{2}{*}{$t$} & \multirow[t]{2}{*}{ gl } & \multirow{2}{*}{$\begin{array}{c}\text { Sig. } \\
\text { (bilateral) }\end{array}$} & \multirow{2}{*}{$\begin{array}{l}\text { Diferencia } \\
\text { de medias }\end{array}$} & \multicolumn{2}{|c|}{$\begin{array}{l}\text { 95\% int.confianza } \\
\text { diferencia }\end{array}$} \\
\hline & No & $\mathrm{Si}$ & & & & & Inferior & Superior \\
\hline Dormir S & $7: 46$ & $7: 37$ & 2,272 & 306,445 & 0,024 & $0: 09$ & $0: 01$ & $0: 16$ \\
\hline Dormir F & 9:33 & $9: 32$ & 0,185 & 291,169 & 0,854 & $0: 01$ & $-0: 10$ & $0: 12$ \\
\hline Asistir a clase $\mathrm{S}$ & $6: 08$ & 6:06 & 2,546 & 335,765 & 0,011 & $0: 02$ & $0: 00$ & $0: 04$ \\
\hline Asistir a clase $\mathrm{F}$ & $0: 00$ & $0: 00$ & & & & & & \\
\hline Actividades extr. S & $1: 52$ & $1: 30$ & 3,146 & 280,560 & 0,002 & $0: 22$ & $0: 08$ & $0: 36$ \\
\hline Actividades extr. F & $0: 42$ & $0: 39$ & 0,736 & 267,716 & 0,463 & $0: 03$ & $-0: 05$ & $0: 12$ \\
\hline Estudio S & $2: 25$ & $2: 13$ & 2,337 & 343,253 & 0,020 & $0: 12$ & $0: 02$ & $0: 23$ \\
\hline Estudio F & $2: 35$ & $2: 14$ & 2,644 & 318,860 & 0,009 & $0: 20$ & $0: 05$ & $0: 36$ \\
\hline WhatsApp S & $1: 40$ & $2: 17$ & $-3,912$ & 278,954 & 0,000 & $-0: 37$ & $-0: 55$ & $-0: 18$ \\
\hline WhatsApp F & $2: 42$ & $2: 59$ & $-1,458$ & 289,746 & 0,146 & $-0: 17$ & $-0: 40$ & $0: 05$ \\
\hline Redes sociales S & $1: 02$ & $1: 20$ & $-2,933$ & 306,170 & 0,004 & $-0: 17$ & $-0: 29$ & $-0: 05$ \\
\hline Redes sociales F & $1: 32$ & $1: 52$ & $-2,381$ & 297,377 & 0,018 & $-0: 19$ & $-0: 36$ & $-0: 03$ \\
\hline Internet S & $0: 52$ & $1: 02$ & $-2,349$ & 293,220 & 0,019 & $-0: 09$ & $-0: 18$ & $-0: 01$ \\
\hline Internet F & $1: 14$ & $1: 24$ & $-1,736$ & 274,766 & 0,084 & $-0: 10$ & $-0: 22$ & $0: 01$ \\
\hline Videojuegos/consolas S & $0: 24$ & $0: 53$ & $-5,156$ & 261,055 & 0,000 & $-0: 29$ & $-0: 40$ & $-0: 18$ \\
\hline Videojuegos/consolas F & $0: 54$ & $1: 37$ & $-5,163$ & 260,903 & 0,000 & $-0: 42$ & $-0: 59$ & $-0: 26$ \\
\hline Televisión S & $1: 24$ & $1: 31$ & $-1,346$ & 328,883 & 0,179 & $-0: 07$ & $-0: 17$ & $0: 03$ \\
\hline Televisión F & $2: 07$ & $1: 59$ & 1,206 & 323,292 & 0,229 & $0: 08$ & $-0: 05$ & $0: 21$ \\
\hline Teléfono S & $0: 20$ & $0: 26$ & $-1,704$ & 269,108 & 0,090 & $-0: 05$ & $-0: 12$ & $0: 00$ \\
\hline Teléfono F & $0: 28$ & $0: 37$ & $-2,049$ & 268,059 & 0,041 & $-0: 08$ & $-0: 17$ & $-0: 00$ \\
\hline Deporte S & $1: 47$ & $1: 57$ & $-1,467$ & 297,145 & 0,143 & $-0: 09$ & $-0: 22$ & $0: 03$ \\
\hline Deporte F & $1: 29$ & $1: 40$ & $-2,076$ & 289,340 & 0,039 & $-0: 11$ & $-0: 22$ & $-0: 00$ \\
\hline Trabajo doméstico S & $0: 38$ & $0: 39$ & $-0,454$ & 302,478 & 0,650 & $-0: 01$ & $-0: 07$ & $0: 04$ \\
\hline Trabajo doméstico F & $0: 50$ & $0: 49$ & 0,376 & 307,635 & 0,707 & 0:01 & $-0: 05$ & $0: 08$ \\
\hline Trabajo remunerado S & $0: 07$ & $0: 05$ & 1,006 & 431,510 & 0,315 & 0:01 & $-0: 01$ & $0: 05$ \\
\hline Trabajo remunerado F & $0: 10$ & $0: 11$ & $-0,068$ & 296,161 & 0,946 & $-0: 00$ & $-0: 07$ & $0: 06$ \\
\hline Lectura S & $0: 42$ & $0: 32$ & 3,331 & 357,339 & 0,001 & $0: 10$ & $0: 04$ & $0: 16$ \\
\hline Lectura F & $0: 53$ & $0: 38$ & 3,511 & 354,801 & 0,001 & $0: 14$ & $0: 06$ & $0: 23$ \\
\hline Higiene personal S & $1: 09$ & $1: 22$ & $-2,567$ & 280,219 & 0,011 & $-0: 13$ & $-0: 23$ & $-0: 03$ \\
\hline Higiene personal F & $1: 11$ & $1: 20$ & $-1,775$ & 272,572 & 0,077 & $-0: 08$ & $-0: 17$ & $0: 00$ \\
\hline Alimentación S & $1: 44$ & $1: 43$ & 0,083 & 306,301 & 0,934 & $0: 00$ & $-0: 09$ & $0: 10$ \\
\hline Alimentación F & $1: 45$ & $1: 45$ & $-0,042$ & 274,783 & 0,967 & $-0: 00$ & $-0: 10$ & $0: 10$ \\
\hline Amigos S & $1: 09$ & $1: 17$ & $-1,153$ & 301,666 & 0,250 & $-0: 07$ & $-0: 21$ & 0:05 \\
\hline Amigos $\mathrm{F}$ & $3: 29$ & $3: 55$ & $-2,306$ & 294,177 & 0,022 & $-0: 25$ & $-0: 47$ & $-0: 03$ \\
\hline Desplazamientos S & $0: 45$ & $0: 47$ & $-0,597$ & 272,037 & 0,551 & $-0: 02$ & $-0: 10$ & $0: 05$ \\
\hline Desplazamientos F & $0: 57$ & $1: 00$ & $-0,468$ & 288,504 & 0,640 & $-0: 02$ & $-0: 12$ & $0: 07$ \\
\hline Salir con pareja S & $0: 12$ & $0: 26$ & $-1,649$ & 230,804 & 0,100 & $-0: 13$ & $-0: 28$ & $0: 02$ \\
\hline Salir con pareja F & $0: 24$ & $0: 36$ & $-1,897$ & 258,781 & 0,059 & $-0: 12$ & $-0: 24$ & $0: 00$ \\
\hline Tiempo en dormirse ayer & $0: 29$ & $0: 36$ & $-2,287$ & 306,135 & 0,023 & $-0: 06$ & $-0: 11$ & $-0: 00$ \\
\hline
\end{tabular}

Tabla 125: resultado de t-Student: uso del tiempo - tener televisión en la habitación 
El gráfico 120 muestra las actividades en las cuáles los adolescentes que no tienen televisión en la habitación dedican más tiempo y que se han encontrado diferencias significativas. Son las siguientes:

- Dormir entre semana: los adolescentes que no tienen televisión duermen 9 minutos más que los que sí que tienen.

- Actividades extraescolares entre semana: los que no tienen televisión en la habitación dedican 22 minutos más al día a realizar actividades extraescolares que los que no tienen.

- Estudio: los adolescentes que no tienen televisión en la habitación estudian más tiempo que los que la tienen, aproximadamente 12 minutos más entre semana y 20 minutos más durante el fin de semana.

- Lectura: los adolescentes que no tienen televisión en la habitación leen durante más tiempo, alrededor de 10 minutos más entre semana y 14 minutos más durante el fin de semana.

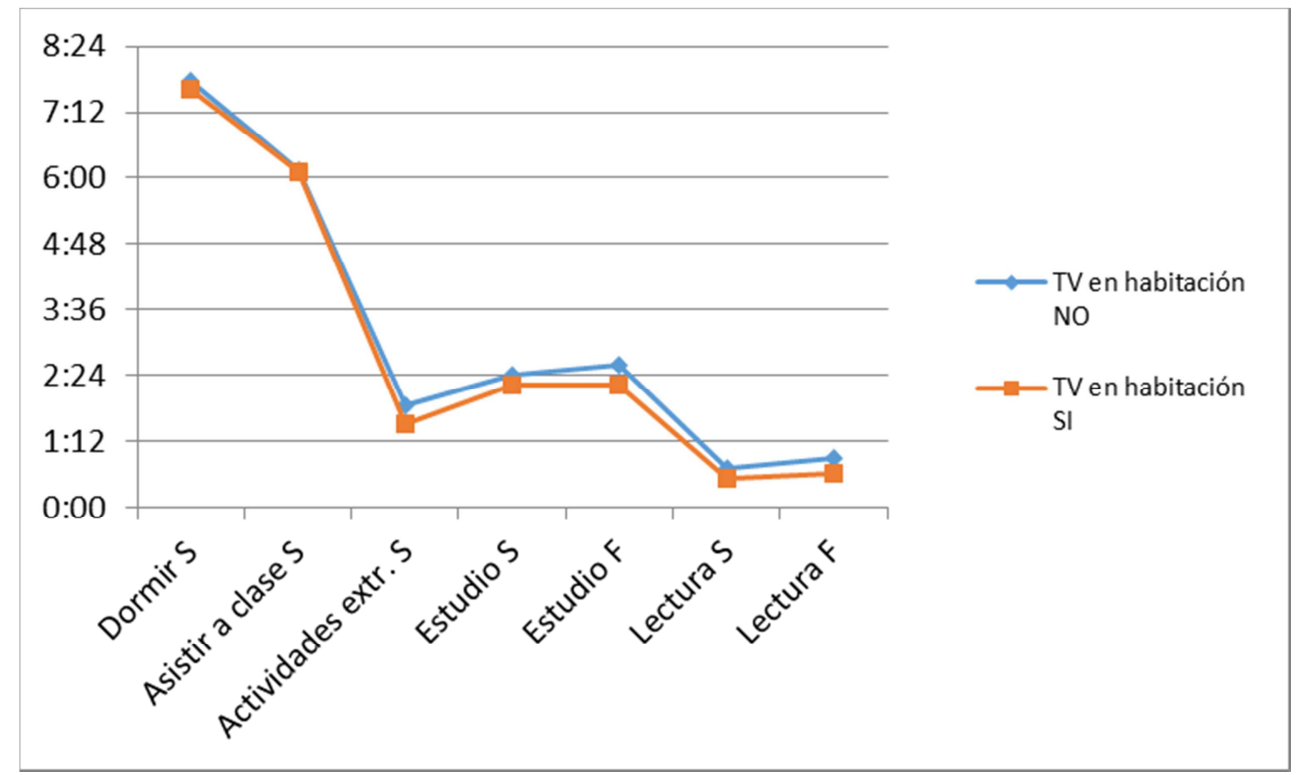

Gráfica 120: media de tiempo dedicado a actividades -no tener televisión en la habitación 


\subsection{3.- Uso del tiempo y ordenador en la habitación:}

A continuación, centramos la atención en analizar si el hecho de tener ordenador en la habitación influye en el tiempo medio que los adolescentes dedican a realizar las distintas actividades estudiadas (resultado en tabla 126).

En la gráfica 121, podemos observar que los que sí tienen ordenador en la habitación dedican más tiempo que los que no tienen a las siguientes actividades:

- WhatsApp: dedican una media de 20 minutos más al día entre semana y de 18 minutos más al día durante el fin de semana.

- Redes sociales entre semana: los adolescentes que tienen ordenador en la habitación dedican 11 minutos más a esta actividad.

- Internet: los adolescentes dedican 11 minutos más entre semana y 10 minutos más durante el fin de semana.

- Videojuegos/consolas: los que tienen ordenador en la habitación juegan durante 7 minutos más entre semana y 13 minutos más durante el fin de semana.

- Teléfono: los adolescentes que tienen ordenador en la habitación dedican más tiempo al teléfono, aproximadamente 5 minutos más entre semana y 8 minutos más durante el fin de semana.

- Higiene personal entre semana: dedican 8 minutos más a la higiene personal.

- Amigos fin de semana: los adolescentes que tienen ordenador en la habitación salen de media, 19 minutos más al día durante el fin de semana.

- Salir con pareja: los adolescentes que tienen ordenador en la habitación salen con su pareja durante más tiempo, alrededor de 9 minutos más entre semana y 11 minutos más durante el fin de semana. 
2a PARTE

Capítulo 4.- Resultados

\begin{tabular}{|c|c|c|c|c|c|c|c|c|}
\hline & \multicolumn{2}{|c|}{$\begin{array}{c}\text { ordenador en } \\
\text { habitación }\end{array}$} & \multirow[t]{2}{*}{$\mathbf{t}$} & \multirow[t]{2}{*}{ gl } & \multirow{2}{*}{$\begin{array}{c}\text { Sig. } \\
\text { (bilateral) }\end{array}$} & \multirow{2}{*}{$\begin{array}{r}\text { Diferencia } \\
\text { de medias }\end{array}$} & \multicolumn{2}{|c|}{$\begin{array}{l}\text { 95\% int.confianza } \\
\text { diferencia }\end{array}$} \\
\hline & No & Si & & & & & Inferior & Superior \\
\hline Dormir S & $7: 50$ & $7: 36$ & 4,836 & 1151,448 & 0,000 & $0: 14$ & $0: 08$ & $0: 20$ \\
\hline Dormir F & $9: 36$ & $9: 28$ & 1,980 & 1045,702 & 0,048 & $0: 08$ & $0: 00$ & $0: 16$ \\
\hline Asistir a clase $\mathrm{S}$ & $6: 09$ & $6: 07$ & 1,900 & 1202,065 & 0,058 & $0: 01$ & $-0: 00$ & $0: 03$ \\
\hline Asistir a clase $F$ & $0: 00$ & $0: 00$ & & & & & & \\
\hline Actividades extr. S & $1: 48$ & $1: 48$ & 0,130 & 943,535 & 0,897 & $0: 00$ & $-0: 10$ & $0: 11$ \\
\hline Actividades extr. F & $0: 42$ & $0: 41$ & 0,410 & 910,627 & 0,682 & $0: 01$ & $-0: 05$ & $0: 08$ \\
\hline Estudio S & $2: 27$ & $2: 18$ & 1,925 & 1161,379 & 0,054 & $0: 08$ & $-0: 00$ & $0: 17$ \\
\hline Estudio $\mathrm{F}$ & $2: 31$ & $2: 30$ & 0,180 & 1056,405 & 0,857 & $0: 01$ & $-0: 10$ & $0: 12$ \\
\hline Whatsapp S & $1: 38$ & $1: 59$ & $-3,173$ & 963,985 & 0,002 & $-0: 20$ & $-0: 33$ & $-0: 07$ \\
\hline Whatsapp F & $2: 37$ & $2: 56$ & $-2,185$ & 1033,626 & 0,029 & $-0: 18$ & $-0: 35$ & $-0: 01$ \\
\hline Redes sociales S & $1: 00$ & $1: 11$ & $-2,439$ & 990,227 & 0,015 & $-0: 11$ & $-0: 20$ & $-0: 02$ \\
\hline Redes sociales F & $1: 34$ & $1: 38$ & $-0,736$ & 1089,895 & 0,462 & $-0: 04$ & $-0: 16$ & $0: 07$ \\
\hline Internet S & $0: 49$ & $1: 00$ & $-3,628$ & 957,975 & 0,000 & $-0: 11$ & $-0: 17$ & $-0: 05$ \\
\hline Internet F & $1: 12$ & $1: 22$ & $-2,319$ & 991,918 & 0,021 & $-0: 10$ & $-0: 18$ & $-0: 01$ \\
\hline Videojuegos/consolas S & $0: 25$ & $0: 33$ & $-2,362$ & 978,000 & 0,018 & $-0: 07$ & $-0: 14$ & $-0: 01$ \\
\hline Videojuegos/consolas F & $0: 56$ & $1: 09$ & $-2,586$ & 930,991 & 0,010 & $-0: 13$ & $-0: 23$ & $-0: 03$ \\
\hline Televisión S & $1: 27$ & $1: 24$ & 0,654 & 1090,896 & 0,513 & $0: 02$ & $-0: 05$ & $0: 10$ \\
\hline Televisión F & $2: 10$ & $2: 00$ & 1,867 & 1147,926 & 0,062 & $0: 09$ & $-0: 00$ & $0: 20$ \\
\hline Teléfono S & $0: 19$ & $0: 25$ & $-2,531$ & 902,863 & 0,012 & $-0: 05$ & $-0: 10$ & $-0: 01$ \\
\hline Teléfono F & $0: 27$ & $0: 35$ & $-2,636$ & 883,933 & 0,009 & $-0: 08$ & $-0: 14$ & $-0: 02$ \\
\hline Deporte S & $1: 51$ & $1: 46$ & 1,059 & 1162,004 & 0,290 & $0: 05$ & $-0: 04$ & $0: 14$ \\
\hline Deporte F & $1: 31$ & $1: 29$ & 0,600 & 1141,914 & 0,549 & $0: 02$ & $-0: 05$ & $0: 10$ \\
\hline Trabajo doméstico S & $0: 40$ & $0: 36$ & 1,900 & 1159,875 & 0,058 & $0: 04$ & $-0: 00$ & $0: 08$ \\
\hline Trabajo doméstico F & $0: 53$ & $0: 46$ & 2,747 & 1204,136 & 0,006 & $0: 07$ & $0: 02$ & $0: 12$ \\
\hline Trabajo remunerado S & $0: 06$ & $0: 05$ & 0,675 & 1208,014 & 0,500 & $0: 01$ & $-0: 02$ & $0: 04$ \\
\hline Trabajo remunerado $\mathrm{F}$ & $0: 11$ & $0: 10$ & 0,358 & 1095,302 & 0,720 & $0: 00$ & $-0: 04$ & $0: 06$ \\
\hline Lectura S & $0: 40$ & $0: 41$ & $-0,146$ & 1065,530 & 0,884 & $-0: 00$ & $-0: 05$ & $0: 04$ \\
\hline Lectura F & $0: 49$ & $0: 52$ & $-0,962$ & 1043,113 & 0,336 & $-0: 03$ & $-0: 10$ & $0: 03$ \\
\hline Higiene personal S & $1: 08$ & $1: 16$ & $-2,200$ & 1048,187 & 0,028 & $-0: 08$ & $-0: 15$ & $-0: 00$ \\
\hline Higiene personal F & $1: 11$ & $1: 15$ & $-1,014$ & 1133,265 & 0,311 & $-0: 03$ & $-0: 09$ & $0: 02$ \\
\hline Alimentación S & $1: 44$ & $1: 44$ & 0,081 & 1065,053 & 0,935 & $0: 00$ & $-0: 07$ & $0: 08$ \\
\hline Alimentación F & $1: 44$ & $1: 46$ & $-0,442$ & 1034,811 & 0,659 & $-0: 01$ & $-0: 08$ & $0: 05$ \\
\hline Amigos S & $1: 12$ & $1: 09$ & 0,540 & 1150,069 & 0,589 & $0: 02$ & $-0: 07$ & $0: 12$ \\
\hline Amigos $\mathrm{F}$ & $3: 26$ & $3: 45$ & $-2,392$ & 1073,420 & 0,017 & $-0: 19$ & $-0: 35$ & $-0: 03$ \\
\hline Desplazamientos S & $0: 47$ & $0: 43$ & 1,365 & 1039,832 & 0,172 & $0: 03$ & $-0: 01$ & $0: 09$ \\
\hline Desplazamientos F & $1: 01$ & $0: 53$ & 2,004 & 1104,108 & 0,045 & $0: 07$ & $0: 00$ & $0: 14$ \\
\hline Salir con pareja S & $0: 11$ & $0: 20$ & $-2,109$ & 775,044 & 0,035 & $-0: 09$ & $-0: 17$ & $-0: 00$ \\
\hline Salir con parej F & $0: 21$ & $0: 33$ & $-2,505$ & 856,445 & 0,012 & $-0: 11$ & $-0: 20$ & $-0: 02$ \\
\hline Tiempo en dormirse ayer & $0: 29$ & $0: 33$ & $-1,951$ & 1103,705 & 0,051 & $-0: 03$ & $-0: 07$ & $0: 00$ \\
\hline
\end{tabular}

Tabla 126: t-Student uso del tiempo - tener ordenador en la habitación 


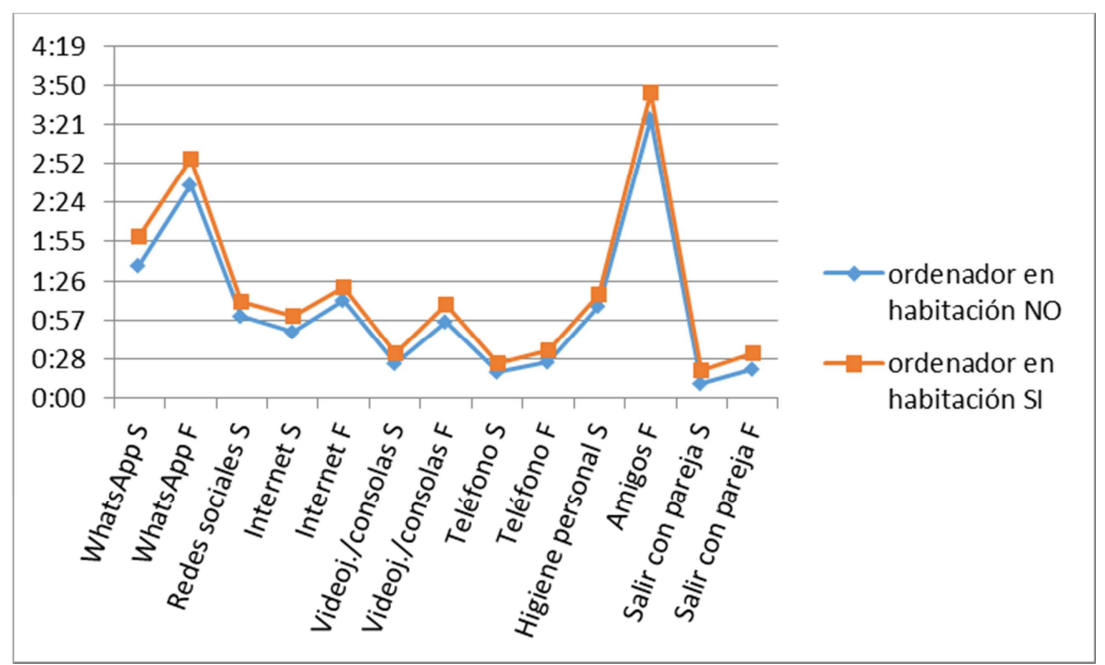

Gráfica 121: media de tiempo dedicado a actividades- ordenador en la habitación

En la gráfica 122, podemos observar que los que no tienen ordenador en la habitación dedican más tiempo que los que no lo tienen a las siguientes actividades:

- Dormir: aproximadamente 14 minutos al día entre semana y 8 minutos durante el fin de semana.

- Trabajo doméstico el fin de semana: los adolescentes que no tienen televisión en la habitación dedican 7 minutos más en fin de semana.

- Desplazamientos el fin de semana: los adolescentes que no tienen televisión en la habitación dedican a los desplazamientos en fin de semana 7 minutos más.

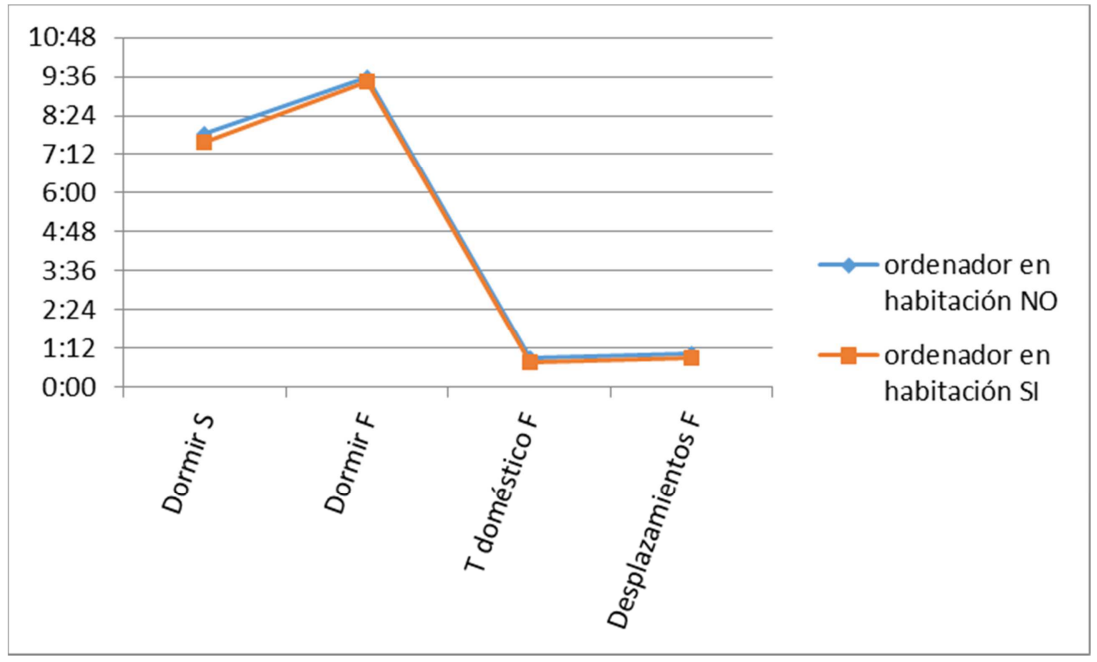

Gráfica 122: media de tiempo dedicado a actividades - no ordenador en la habitación 
2a PARTE

Capítulo 4.- Resultados

\subsection{4.- Uso del tiempo y tablet propia}

\begin{tabular}{|c|c|c|c|c|c|c|c|c|}
\hline & \multicolumn{2}{|c|}{ tablet propia } & \multirow[t]{2}{*}{$\mathbf{t}$} & \multirow[t]{2}{*}{ gl } & \multirow{2}{*}{$\begin{array}{c}\text { Sig. } \\
\text { (bilateral) }\end{array}$} & \multirow{2}{*}{$\begin{array}{l}\text { Diferencia } \\
\text { de medias }\end{array}$} & \multicolumn{2}{|c|}{$\begin{array}{l}\text { 95\% int.confianza } \\
\text { diferencia }\end{array}$} \\
\hline & No & Si & & & & & Inferior & Superior \\
\hline Dormir S & $7: 43$ & $7: 46$ & $-1,160$ & 979,538 & 0,246 & $-0: 03$ & $-0: 09$ & $0: 02$ \\
\hline Dormir F & $9: 31$ & $9: 36$ & $-1,305$ & 910,457 & 0,192 & $-0: 05$ & $-0: 14$ & $0: 02$ \\
\hline Asistir a clase $\mathrm{S}$ & $6: 08$ & $6: 08$ & $-0,535$ & 949,978 & 0,593 & $-0: 00$ & $-0: 02$ & $0: 01$ \\
\hline Asistir a clase $\mathrm{F}$ & $0: 00$ & $0: 00$ & & & & & & \\
\hline Actividades extr. S & $1: 45$ & $1: 53$ & $-1,328$ & 714,229 & 0,185 & $-0: 07$ & $-0: 19$ & $0: 03$ \\
\hline Actividades extr. F & $0: 42$ & $0: 41$ & 0,185 & 752,263 & 0,853 & $0: 00$ & $-0: 06$ & $0: 07$ \\
\hline Estudio S & $2: 23$ & $2: 24$ & $-0,356$ & 1008,539 & 0,722 & $-0: 01$ & $-0: 10$ & $0: 07$ \\
\hline Estudio F & $2: 34$ & $2: 27$ & 1,116 & 977,394 & 0,265 & $0: 06$ & $-0: 05$ & $0: 18$ \\
\hline WhatsApp S & $1: 47$ & $1: 46$ & 0,145 & 985,406 & 0,885 & $0: 00$ & $-0: 11$ & $0: 13$ \\
\hline WhatsApp F & $2: 43$ & $2: 47$ & $-0,458$ & 915,327 & 0,647 & $-0: 04$ & $-0: 21$ & $0: 13$ \\
\hline Redes sociales S & $1: 02$ & $1: 10$ & $-1,743$ & 873,978 & 0,082 & $-0: 08$ & $-0: 17$ & $0: 01$ \\
\hline Redes sociales F & $1: 33$ & $1: 39$ & $-0,958$ & 943,737 & 0,338 & $-0: 06$ & $-0: 18$ & $0: 06$ \\
\hline Internet S & $0: 52$ & $0: 55$ & $-1,054$ & 956,426 & 0,292 & $-0: 03$ & $-0: 09$ & $0: 02$ \\
\hline Internet F & $1: 15$ & $1: 16$ & $-0,056$ & 963,530 & 0,955 & $-0: 00$ & $-0: 08$ & $0: 08$ \\
\hline Videojuegos/consolas S & $0: 29$ & $0: 28$ & 0,050 & 1004,643 & 0,960 & $0: 00$ & $-0: 06$ & $0: 06$ \\
\hline Videojuegos/consolas F & $1: 00$ & $1: 02$ & $-0,421$ & 938,938 & 0,674 & $-0: 02$ & $-0: 12$ & $0: 07$ \\
\hline Televisión S & $1: 22$ & $1: 31$ & $-2,227$ & 1032,531 & 0,026 & $-0: 09$ & $-0: 17$ & $-0: 01$ \\
\hline Televisión F & $2: 00$ & $2: 15$ & $-2,610$ & 987,047 & 0,009 & $-0: 14$ & $-0: 24$ & $-0: 03$ \\
\hline Teléfono S & $0: 19$ & $0: 25$ & $-2,718$ & 859,274 & 0,007 & $-0: 06$ & $-0: 11$ & $-0: 01$ \\
\hline Teléfono F & $0: 27$ & $0: 36$ & $-2,662$ & 759,780 & 0,008 & $-0: 08$ & $-0: 14$ & $-0: 02$ \\
\hline Deporte S & $1: 47$ & $1: 53$ & $-1,100$ & 971,989 & 0,272 & $-0: 05$ & $-0: 14$ & $0: 04$ \\
\hline Deporte F & $1: 29$ & $1: 34$ & $-1,183$ & 961,531 & 0,237 & $-0: 04$ & $-0: 13$ & $0: 03$ \\
\hline Trabajo doméstico S & $0: 39$ & $0: 35$ & 2,126 & 1008,125 & 0,034 & $0: 04$ & $0: 00$ & $0: 08$ \\
\hline Trabajo doméstico $\mathrm{F}$ & $0: 50$ & $0: 50$ & $-0,148$ & 900,070 & 0,882 & $-0: 00$ & $-0: 06$ & $0: 05$ \\
\hline Trabajo remunerado $\mathrm{S}$ & $0: 07$ & $0: 05$ & 1,329 & 1166,052 & 0,184 & $0: 02$ & $-0: 01$ & $0: 05$ \\
\hline Trabajo remunerado $\mathrm{F}$ & $0: 11$ & $0: 10$ & 0,394 & 935,162 & 0,694 & $0: 01$ & $-0: 04$ & $0: 06$ \\
\hline Lectura S & $0: 39$ & $0: 43$ & $-1,422$ & 946,101 & 0,155 & $-0: 03$ & $-0: 09$ & $0: 01$ \\
\hline Lectura F & $0: 50$ & $0: 51$ & $-0,333$ & 1022,172 & 0,739 & $-0: 01$ & $-0: 08$ & $0: 05$ \\
\hline Higiene personal S & $1: 07$ & $1: 17$ & $-2,787$ & 941,172 & 0,005 & $-0: 10$ & $-0: 17$ & $-0: 03$ \\
\hline Higiene personal F & $1: 08$ & $1: 21$ & $-3,988$ & 843,628 & 0,000 & $-0: 13$ & $-0: 19$ & $-0: 06$ \\
\hline Alimentación S & $1: 40$ & $1: 50$ & $-2,516$ & 912,741 & 0,012 & $-0: 10$ & $-0: 18$ & $-0: 02$ \\
\hline Alimentación F & $1: 42$ & $1: 52$ & $-2,651$ & 901,546 & 0,008 & $-0: 10$ & $-0: 17$ & $-0: 02$ \\
\hline Amigos S & $1: 09$ & $1: 13$ & $-0,726$ & 990,444 & 0,468 & $-0: 03$ & $-0: 13$ & $0: 06$ \\
\hline Amigos F & $3: 39$ & $3: 22$ & 2,058 & 1024,733 & 0,040 & $0: 16$ & $0: 00$ & $0: 32$ \\
\hline Desplazamientos S & $0: 43$ & $0: 50$ & $-2,256$ & 782,612 & 0,024 & $-0: 06$ & $-0: 12$ & $-0: 00$ \\
\hline Desplazamientos F & $0: 54$ & $1: 04$ & $-2,493$ & 835,143 & 0,013 & $-0: 09$ & $-0: 17$ & $-0: 02$ \\
\hline Salir con pareja S & $0: 16$ & $0: 12$ & 1,083 & 1120,411 & 0,279 & $0: 04$ & $-0: 03$ & $0: 11$ \\
\hline Salir con pareja F & $0: 25$ & $0: 27$ & $-0,313$ & 840,363 & 0,755 & $-0: 01$ & $-0: 10$ & $0: 07$ \\
\hline Tiempo en dormirse ayer & $0: 31$ & $0: 30$ & 0,506 & 1138,734 & 0,613 & $0: 00$ & $-0: 02$ & $0: 04$ \\
\hline
\end{tabular}

Tabla 127: t-Student uso del tiempo - tener tablet propia 
En la tabla 127 se pueden observar los resultados obtenidos tras realizar la t-Student entre el uso del tiempo de los adolescentes y el hecho de tener o no tablet propia. Se sombrean, las actividades cuyo uso del tiempo ha mostrado diferencias significativas con el hecho de que el adolescente tenga tablet propia.

En la gráfica 123, podemos observar que los que sí tienen tablet propia dedican más tiempo a las siguientes actividades que los que no la tienen:

- Ver la televisión: los adolescentes que tienen tablet propia dedican 9 minutos más a ver la televisión entre semana y 14 minutos más durante el fin de semana.

- Teléfono: aquellos adolescentes que tienen tablet propia utilizan 6 minutos más entre semana y 8 durante el fin de semana al teléfono.

- Higiene personal: aquellos adolecentes que tienen tablet propia dedican 10 minutos entre semana y 13 durante el fin de semana a su higiene personal.

- Alimentación: los adolescentes que tienen tablet propia invierten en comer 10 minutos más que los que no la tienen.

- Desplazamientos: aquellos que tienen tablet se desplazan, entre semana, 6 minutos al día más que los que no la tienen y 9 minutos más el fin de semana.

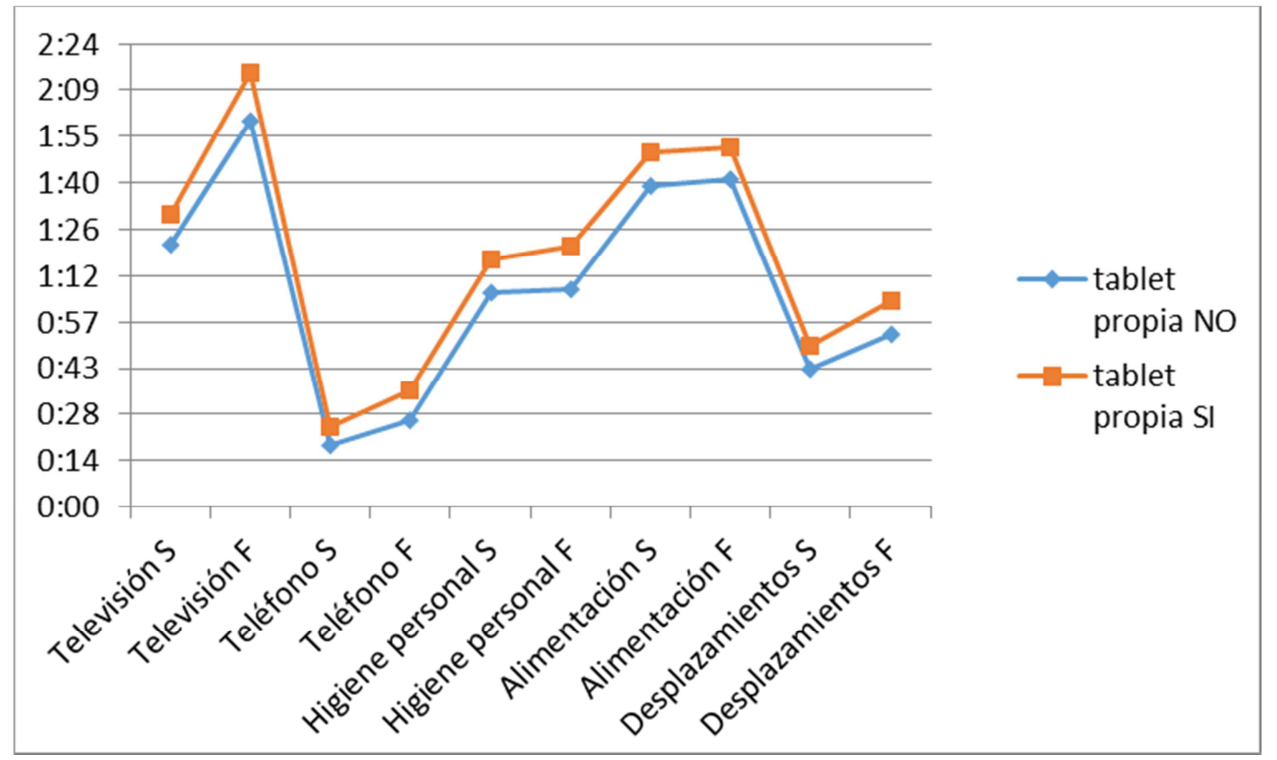

Gráfica 123: media de tiempo dedicado a actividades - tablet propia 
Los adolescentes que NO tienen tablet propia dedican más tiempo a las actividades que se muestran en la gráfica 124 y que se explican a continuación:

- Trabajo doméstico entre semana: los adolescentes que no tienen tablet propia dedican 4 minutos más que los que sí tienen tablet.

- Salir con amigos el fin de semana: los adolescentes que no tienen tablet propia dedican 16 minutos más a esta actividad con respecto a los que sí que tienen.

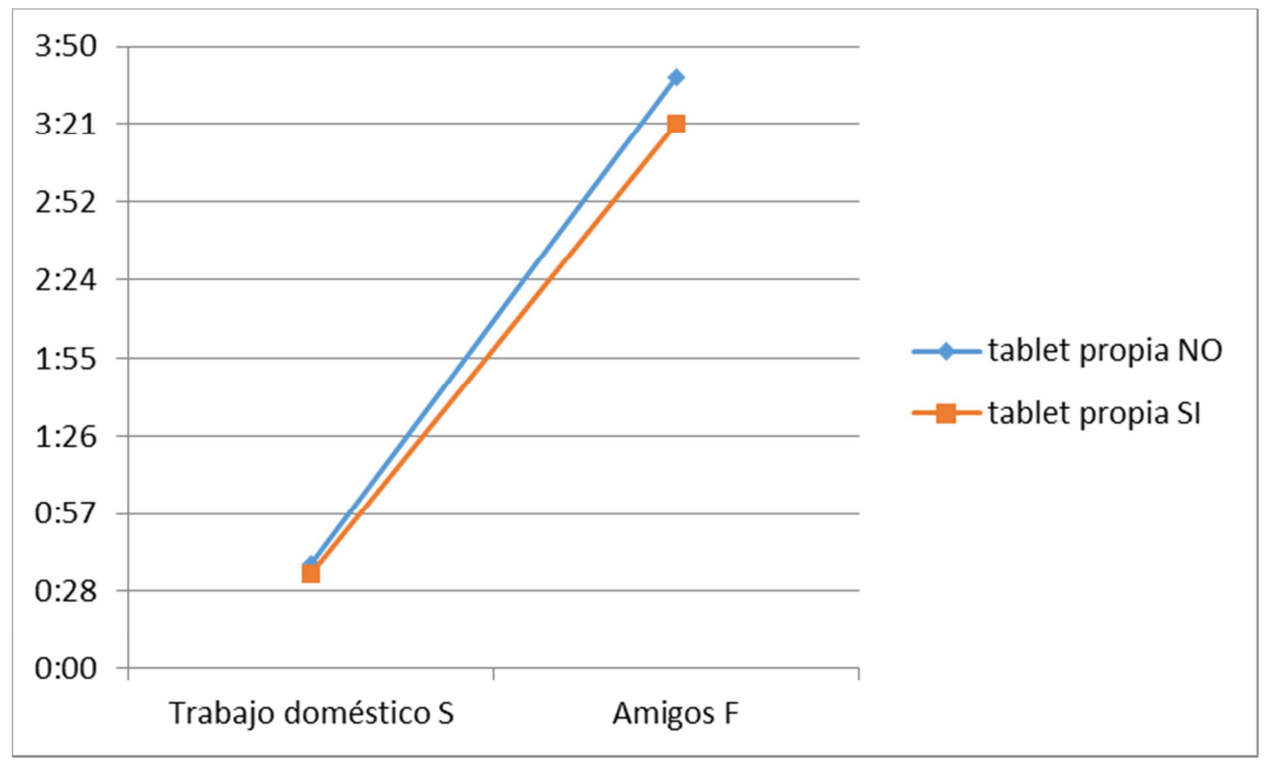

Gráfica 124: media de tiempo dedicado a actividades - no tablet propia

\subsection{5.- Uso del tiempo y teléfono móvil propio}

Son varias las actividades cuyo uso del tiempo medio muestra diferencia significativa por el hecho de tener teléfono móvil propio. Además la diferencia de medias, también es importarte. Como puede observarse en la tabla 128, los adolescentes que tienen teléfono móvil propio duermen de media casi media hora menos entre semana que los que no lo tienen. Además, dedican una media de 12 minutos menos a la lectura entre semana. 


\section{2a PARTE}

Capítulo 4.- Resultados

\begin{tabular}{|c|c|c|c|c|c|c|c|c|}
\hline & \multicolumn{2}{|c|}{\begin{tabular}{|c} 
teléfono móvil \\
propio
\end{tabular}} & \multirow[t]{2}{*}{$\mathbf{t}$} & \multirow[t]{2}{*}{ gl } & \multirow{2}{*}{$\begin{array}{c}\text { Sig. } \\
\text { (bilateral) }\end{array}$} & \multirow{2}{*}{$\begin{array}{l}\text { Diferencia } \\
\text { de medias }\end{array}$} & \multicolumn{2}{|c|}{$\begin{array}{c}95 \% \text { int.confianza } \\
\text { diferencia }\end{array}$} \\
\hline & No & Si & & & & & Inferior & Superior \\
\hline Dormir S & $8: 11$ & $7: 42$ & 4,514 & 98,563 & 0,000 & $0: 28$ & $0: 16$ & $0: 41$ \\
\hline Dormir F & 9:38 & 9:32 & 0,719 & 102,951 & 0,474 & $0: 05$ & $-0: 09$ & $0: 21$ \\
\hline Asistir a clase $\mathrm{S}$ & $6: 07$ & $6: 08$ & $-0,463$ & 99,762 & 0,644 & $-0: 00$ & $-0: 04$ & $0: 02$ \\
\hline Asistir a clase F & $0: 00$ & $0: 00$ & & & & & & \\
\hline Actividades extr. S & $1: 24$ & $1: 50$ & $-3,357$ & 100,539 & 0,001 & $-0: 26$ & $-0: 41$ & $-0: 10$ \\
\hline Actividades extr. F & $0: 38$ & $0: 42$ & $-0,618$ & 83,258 & 0,538 & $-0: 04$ & $-0: 17$ & 0:09 \\
\hline Estudio S & $2: 26$ & $2: 23$ & 0,295 & 100,137 & 0,769 & $0: 02$ & $-0: 16$ & $0: 22$ \\
\hline Estudio F & $2: 11$ & $2: 33$ & $-1,918$ & 107,443 & 0,058 & $-0: 21$ & $-0: 42$ & $0: 00$ \\
\hline WhatsApp S & $0: 26$ & $1: 53$ & $-10,475$ & 118,684 & 0,000 & $-1: 26$ & $-1: 43$ & $-1: 10$ \\
\hline WhatsApp F & $0: 37$ & $2: 54$ & $-16,069$ & 153,391 & 0,000 & $-2: 17$ & $-2: 33$ & $-2: 00$ \\
\hline Redes sociales S & $0: 27$ & $1: 08$ & $-8,056$ & 137,342 & 0,000 & $-0: 41$ & $-0: 51$ & $-0: 30$ \\
\hline Redes sociales F & $0: 36$ & $1: 40$ & $-9,253$ & 134,669 & 0,000 & $-1: 04$ & $-1: 18$ & $-0: 50$ \\
\hline Internet S & $0: 53$ & $0: 53$ & $-0,144$ & 100,132 & 0,885 & $-0: 00$ & $-0: 12$ & $0: 11$ \\
\hline Internet F & $1: 14$ & $1: 16$ & $-0,183$ & 104,409 & 0,855 & $-0: 01$ & $-0: 17$ & $0: 14$ \\
\hline Videojuegos/consolas S & $0: 34$ & $0: 28$ & 0,829 & 98,115 & 0,409 & 0:06 & $-0: 08$ & $0: 20$ \\
\hline Videojuegos/consolas F & $1: 11$ & $1: 00$ & 1,084 & 103,289 & 0,281 & $0: 10$ & $-0: 08$ & $0: 29$ \\
\hline Televisión S & $1: 21$ & $1: 26$ & $-0,519$ & 99,915 & 0,605 & $-0: 05$ & $-0: 24$ & $0: 14$ \\
\hline Televisión F & $1: 54$ & $2: 06$ & $-1,234$ & 102,331 & 0,220 & $-0: 12$ & $-0: 32$ & $0: 07$ \\
\hline Teléfono S & $0: 15$ & $0: 21$ & $-1,533$ & 88,841 & 0,129 & $-0: 06$ & $-0: 13$ & $0: 01$ \\
\hline Teléfono F & $0: 20$ & $0: 31$ & $-1,786$ & 92,075 & 0,077 & $-0: 10$ & $-0: 21$ & $0: 01$ \\
\hline Deporte S & $1: 27$ & $1: 51$ & $-3,051$ & 107,174 & 0,003 & $-0: 24$ & $-0: 39$ & $-0: 08$ \\
\hline Deporte F & $1: 16$ & $1: 32$ & $-2,036$ & 99,092 & 0,044 & $-0: 15$ & $-0: 30$ & $-0: 00$ \\
\hline Trabajo doméstico S & $0: 38$ & $0: 38$ & 0,104 & 93,157 & 0,917 & $0: 00$ & $-0: 08$ & $0: 09$ \\
\hline Trabajo doméstico F & $0: 39$ & $0: 51$ & $-2,388$ & 97,989 & 0,019 & $-0: 11$ & $-0: 20$ & $-0: 01$ \\
\hline Trabajo remunerado S & $0: 17$ & $0: 05$ & 1,855 & 82,243 & 0,067 & $0: 11$ & $-0: 00$ & $0: 23$ \\
\hline Trabajo remunerado F & $0: 21$ & $0: 09$ & 1,514 & 82,654 & 0,134 & $0: 11$ & $-0: 03$ & $0: 27$ \\
\hline Lectura S & $0: 52$ & $0: 40$ & 2,076 & 92,978 & 0,041 & $0: 12$ & $0: 00$ & $0: 24$ \\
\hline Lectura F & $1: 00$ & $0: 50$ & 1,509 & 102,080 & 0,134 & $0: 10$ & $-0: 03$ & $0: 23$ \\
\hline Higiene personal S & $1: 15$ & $1: 11$ & 0,561 & 89,591 & 0,576 & $0: 04$ & $-0: 12$ & $0: 21$ \\
\hline Higiene personal F & $1: 16$ & $1: 13$ & 0,439 & 89,023 & 0,661 & 0:03 & $-0: 11$ & $0: 17$ \\
\hline Alimentación S & $1: 53$ & $1: 43$ & 1,041 & 78,878 & 0,301 & 0:09 & $-0: 08$ & $0: 27$ \\
\hline Alimentación F & $1: 42$ & $1: 45$ & $-0,409$ & 82,496 & 0,684 & $-0: 03$ & $-0: 18$ & $0: 12$ \\
\hline Amigos S & $1: 02$ & $1: 11$ & $-0,946$ & 98,700 & 0,346 & $-0: 08$ & $-0: 27$ & 0:09 \\
\hline Amigos $\mathrm{F}$ & $2: 37$ & $3: 38$ & $-3,628$ & 96,755 & 0,000 & $-1: 00$ & $-1: 33$ & $-0: 27$ \\
\hline Desplazamientos S & $0: 46$ & $0: 45$ & 0,095 & 77,525 & 0,925 & $0: 00$ & $-0: 13$ & $0: 14$ \\
\hline Desplazamientos F & $1: 00$ & $0: 58$ & 0,221 & 82,460 & 0,826 & $0: 01$ & $-0: 15$ & $0: 19$ \\
\hline Salir con pareja S & $0: 01$ & $0: 15$ & $-6,235$ & 1063,686 & 0,000 & $-0: 14$ & $-0: 19$ & $-0: 09$ \\
\hline Salir con pareja F & $0: 13$ & $0: 27$ & $-2,287$ & 104,794 & 0,024 & $-0: 13$ & $-0: 25$ & $-0: 01$ \\
\hline Tiempo en dormirse ayer & $0: 30$ & $0: 30$ & $-0,205$ & 99,146 & 0,838 & $-0: 00$ & $-0: 08$ & 0:07 \\
\hline
\end{tabular}

Tabla 128: t-Student uso del tiempo - tener teléfono móvil propio 
En la gráfica 125, podemos observar que los que sí tienen teléfono móvil propio dedican más tiempo a las siguientes actividades que los que no la tienen:

- Actividades extraescolares entre semana: los adolescentes que tienen teléfono móvil propio dedican a hacer actividades extraescolares 26 minutos más que los que no tienen.

- WhatsApp: los adolescentes que tienen teléfono móvil propio dedican más tiempo al WhatsApp que los que no tienen. Las diferencias son muy reseñables, aproximadamente 1:27 horas más entre semana y 2:17 horas más durante el fin de semana.

- Redes sociales: los adolescentes que tienen teléfono móvil propio dedican más tiempo a las redes sociales que los que no lo tienen (0:41 minutos diarios entre semana y 1:04 minutos diarios durante el fin de semana).

- Deporte: nos llama la atención que se aprecien diferencias significativas en el tiempo dedicado a realizar deporte tanto entre semana como durante el fin de semana con respecto a poseer teléfono móvil propio o no, realizando más deporte los adolescentes que tienen teléfono móvil propio (alrededor de 24 minutos diarios más entre semana y 16 minutos más durante el fin de semana.

- Trabajo doméstico en fin de semana: aquellos que tienen teléfono móvil invierten 12 minutos más en las labores domésticas que los que no lo tienen

- Salir con amigos el fin de semana: los adolescentes que tienen teléfono móvil salen durante más tiempo el fin de semana con los amigos. La diferencia es remarcable, puesto que es superior a 1 hora de media.

- Salir con la pareja: salen más tiempo con la pareja aquellos que tienen teléfono móvil, aproximadamente 14 minutos más diarios de media. 


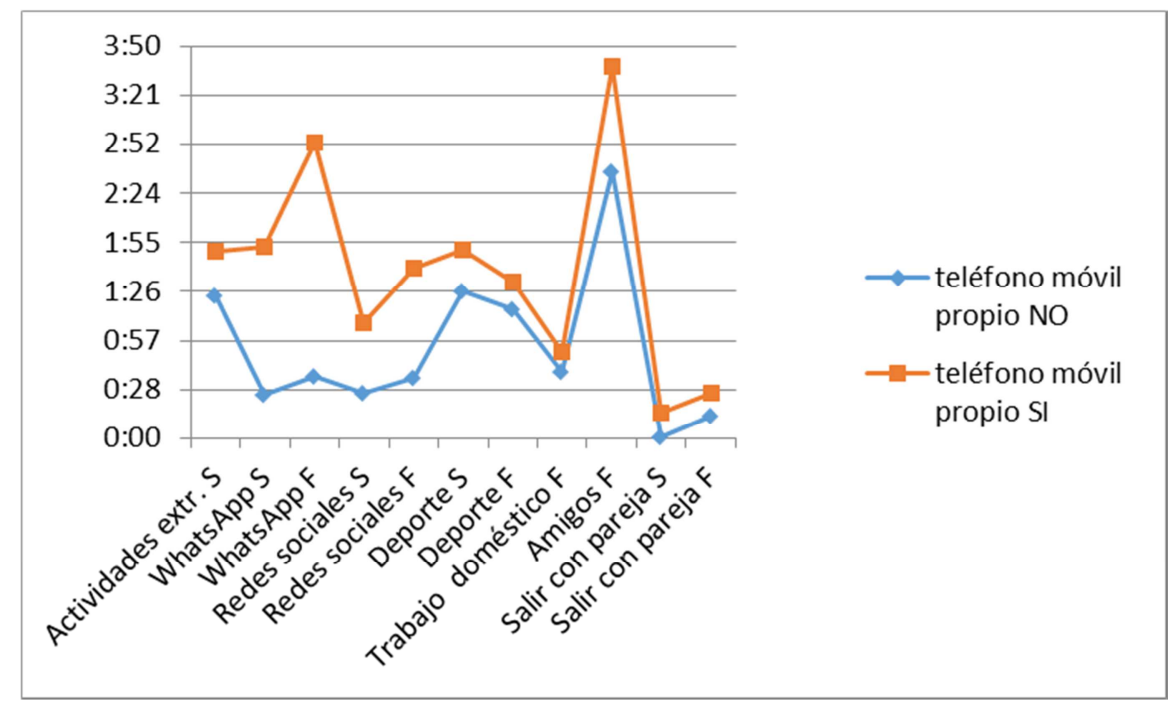

Gráfica 125: media de tiempo dedicado a actividades - tener móvil propio

En la gráfica 126, podemos observar que los que no tienen teléfono móvil propio dedican más tiempo a las siguientes actividades que los que no la tienen:

- Dormir entre semana: aquellos que no tienen teléfono móvil propio duermen, entre semana, 29 minutos más que aquellos que sí tienen.

- Leer entre semana: dedican 12 minutos al día más a esta actividad aquellos que no tienen teléfono móvil propio.

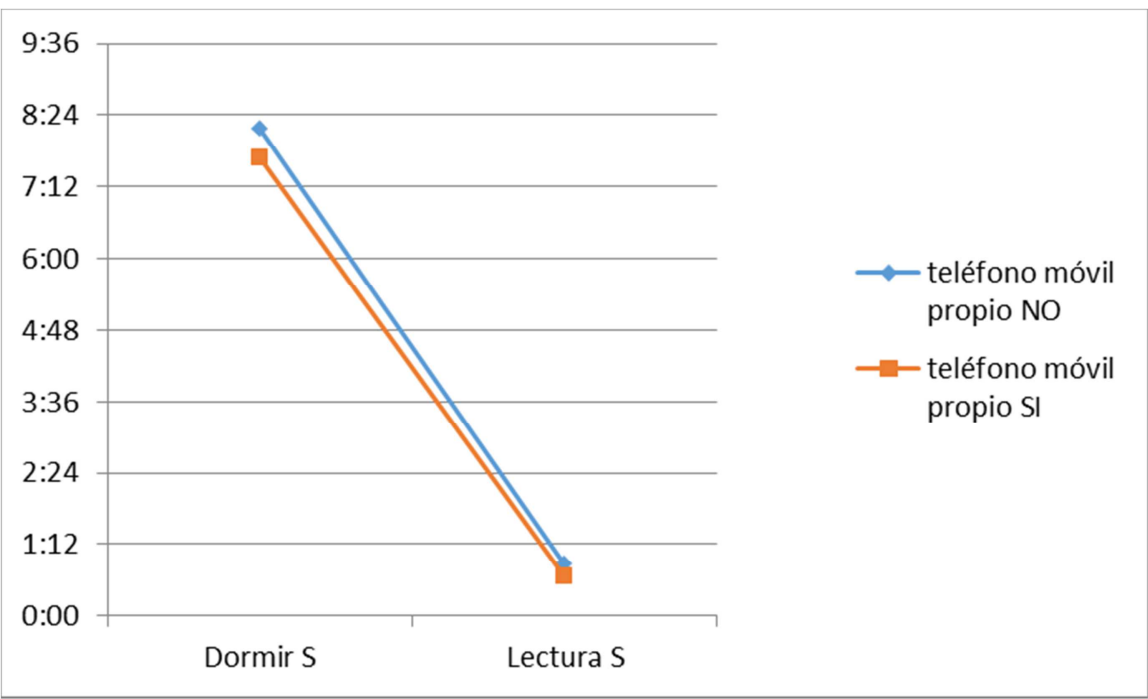

Gráfica 126: ti media de tiempo dedicado a actividades - no tener móvil propio 
No se aprecian diferencias significativas en el tiempo que dedican los adolescentes a hablar por teléfono en relación a si poseen su propio teléfono.

\subsection{6.- Uso del tiempo y conexión a Internet en móvil}

En la tabla 129 se muestra la t-Student que relaciona el uso del tiempo con el hecho de tener internet en el teléfono móvil propio del adolescente.

Como se puede observar en la tabla 129 , sólo hay 1 actividad a la cual dedica más tiempo el adolescente que no tiene internet en el móvil y que ha reflejado la existencia de diferencias significativas. Esta actividad es dormir entre semana. Los adolescentes que no tienen conexión a internet en su teléfono móvil dedican a dormir 7:54 horas diarias frente a las 7:41 horas diarias de los adolescentes que sí tienen conexión a internet en su teléfono móvil propio, es decir, 13 minutos de diferencia.

En la gráfica 127, podemos observar que los que sí tienen internet en su teléfono móvil propio dedican más tiempo a las siguientes actividades que los que no la tienen:

- WhastApp: los adolescentes qué tienen internet en su teléfono móvil propio dedican a utilizar la aplicación WhatsApp 45 minutos más entre semana y 56 minutos de media más durante el fin de semana que aquellos que no la utilizan.

- Redes sociales: aquellos adolescentes que tienen internet en su teléfono móvil propio, utilizan las redes sociales 15 minutos más entre semana y 27 minutos más entre semana que aquellos que no lo tienen.

- Salir con amigos el fin de semana: los que tienen internet en el teléfono móvil, salen con los amigos el fin de semana, una media de 40 minutos más diarios.

- Salir con pareja el fin de semana: salen 10 minutos más con la pareja durante el fin de semana aquellos adolescentes que tienen internet en el teléfono móvil propio. 


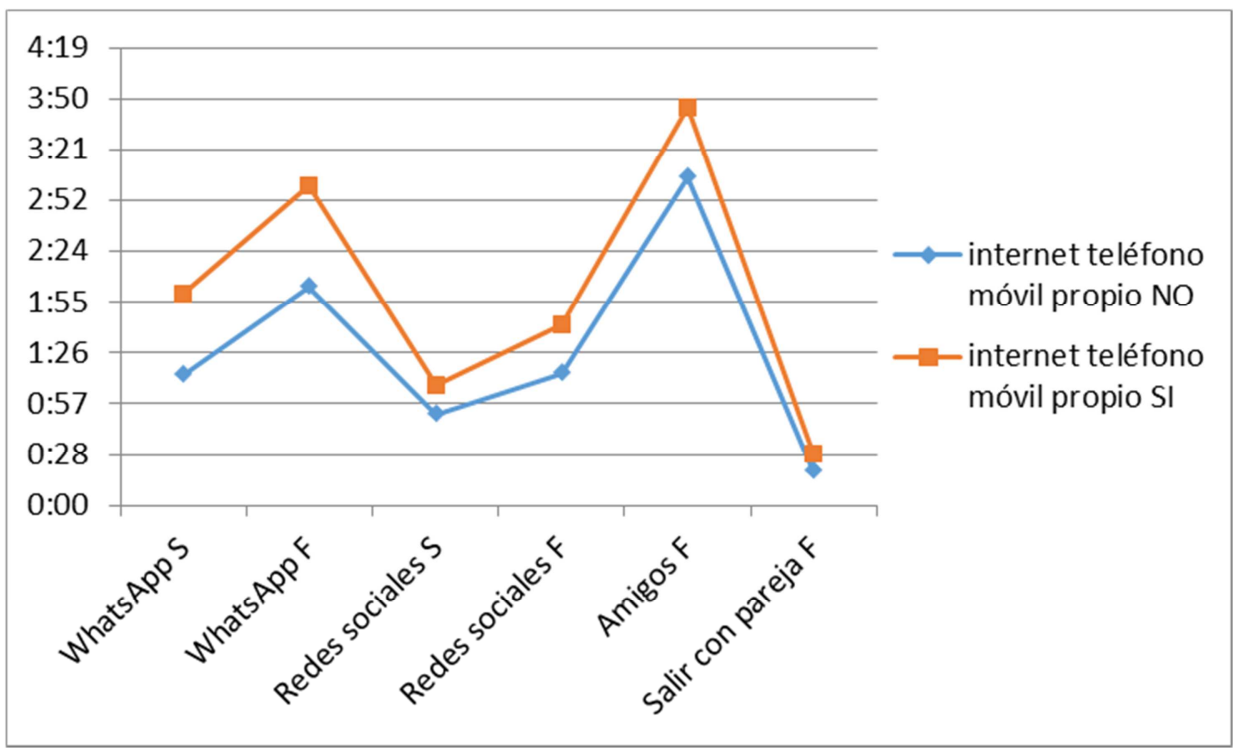

Gráfica 127: media de tiempo dedicado a actividades - internet en el móvil propio

Los resultados obtenidos de los estudios anteriores muestran que no existe una relación clara que indique que los adolescentes que poseen estas tecnologías dedican menos tiempo a hacer deporte (tabla 129.1).

\begin{tabular}{|c|c|cc|}
\cline { 3 - 4 } \multicolumn{2}{c|}{} & Deporte S & Deporte F \\
\hline \multirow{2}{*}{ TV habitación } & no & $1: 47$ & $1: 29$ \\
\cline { 2 - 4 } & si & $1: 57$ & $1: 40$ \\
\hline \multirow{2}{*}{ Internet en casa } & no & $2: 36$ & $1: 20$ \\
\cline { 2 - 4 } ordenador en habitación & si & $1: 48$ & $1: 31$ \\
\hline \multirow{2}{*}{ ¿Tienes tablet propia? } & no & $1: 51$ & $1: 31$ \\
\cline { 2 - 4 } & si & $1: 46$ & $1: 29$ \\
\hline \multirow{2}{*}{ Teléfono movil propio } & no & $1: 47$ & $1: 29$ \\
\cline { 2 - 4 } & si & $1: 53$ & $1: 34$ \\
\cline { 2 - 4 } & no & $1: 27$ & $1: 16$ \\
\hline \multirow{2}{*}{ Internet en teléfono móvil propio } & si & $1: 51$ & $1: 32$ \\
\cline { 3 - 4 } & no & $1: 41$ & $1: 29$ \\
\hline
\end{tabular}

Tabla 129.1: tiempo a deporte - acceso a las nuevas tecnologías 
2a PARTE

Capítulo 4.- Resultados

\begin{tabular}{|c|c|c|c|c|c|c|c|c|}
\hline & \multicolumn{2}{|c|}{$\begin{array}{c}\text { internet teléfono } \\
\text { móvil propio }\end{array}$} & \multirow[t]{2}{*}{$t$} & \multirow[t]{2}{*}{ gl } & \multirow{2}{*}{$\begin{array}{c}\text { Sig. } \\
\text { (bilateral) }\end{array}$} & \multirow{2}{*}{$\begin{array}{l}\text { Diferencia } \\
\text { de medias }\end{array}$} & \multicolumn{2}{|c|}{$\begin{array}{l}\text { 95\% int.confianza } \\
\text { diferencia }\end{array}$} \\
\hline & No & Si & & & & & Inferior & Superior \\
\hline Dormir S & $7: 54$ & $7: 41$ & 3,701 & 451,767 & 0,000 & $0: 13$ & $0: 06$ & $0: 20$ \\
\hline Dormir F & $9: 40$ & $9: 32$ & 1,553 & 469,742 & 0,121 & $0: 07$ & $-0: 02$ & $0: 17$ \\
\hline Asistir a clase $\mathrm{S}$ & $6: 07$ & $6: 06$ & 1,015 & 473,451 & 0,311 & $0: 00$ & $-0: 00$ & $0: 02$ \\
\hline Asistir a clase F & $0: 00$ & $0: 00$ & & & & & & \\
\hline Actividades extr. S & $1: 41$ & $1: 50$ & $-1,453$ & 493,744 & 0,147 & $-0: 09$ & $-0: 21$ & $0: 03$ \\
\hline Actividades extr. F & $0: 40$ & $0: 42$ & $-0,458$ & 482,061 & 0,647 & $-0: 01$ & $-0: 09$ & $0: 06$ \\
\hline Estudio S & $2: 20$ & $2: 16$ & 0,554 & 437,571 & 0,580 & $0: 03$ & $-0: 08$ & $0: 14$ \\
\hline Estudio F & $2: 20$ & $2: 25$ & $-0,798$ & 467,524 & 0,425 & $-0: 05$ & $-0: 19$ & $0: 08$ \\
\hline WhatsApp S & $1: 14$ & $2: 00$ & $-6,553$ & 582,495 & 0,000 & $-0: 45$ & $-0: 59$ & $-0: 32$ \\
\hline WhatsApp F & $2: 04$ & $3: 01$ & $-5,450$ & 484,944 & 0,000 & $-0: 56$ & $-1: 16$ & $-0: 36$ \\
\hline Redes sociales S & $0: 52$ & $1: 08$ & $-2,817$ & 485,588 & 0,005 & $-0: 15$ & $-0: 26$ & $-0: 04$ \\
\hline Redes sociales F & $1: 15$ & $1: 42$ & $-3,738$ & 520,946 & 0,000 & $-0: 27$ & $-0: 41$ & $-0: 13$ \\
\hline Internet S & $0: 55$ & $0: 52$ & 0,629 & 473,606 & 0,529 & $0: 02$ & $-0: 05$ & $0: 10$ \\
\hline Internet F & $1: 16$ & $1: 14$ & 0,279 & 499,461 & 0,781 & $0: 01$ & $-0: 08$ & $0: 11$ \\
\hline Videojuegos/consolas S & $0: 34$ & $0: 28$ & 1,241 & 458,530 & 0,215 & $0: 05$ & $-0: 03$ & $0: 13$ \\
\hline Videojuegos/consolas F & $1: 10$ & $1: 01$ & 1,330 & 497,799 & 0,184 & $0: 08$ & $-0: 04$ & $0: 20$ \\
\hline Televisión S & $1: 21$ & $1: 26$ & $-0,930$ & 497,969 & 0,353 & $-0: 04$ & $-0: 14$ & $0: 05$ \\
\hline Televisión F & $2: 03$ & $2: 06$ & $-0,376$ & 471,566 & 0,707 & $-0: 02$ & $-0: 15$ & $0: 10$ \\
\hline Teléfono S & $0: 18$ & $0: 22$ & $-1,516$ & 539,745 & 0,130 & $-0: 03$ & $-0: 08$ & $0: 01$ \\
\hline Teléfono F & $0: 25$ & $0: 31$ & $-1,740$ & 500,839 & 0,082 & $-0: 06$ & $-0: 13$ & $0: 00$ \\
\hline Deporte S & $1: 41$ & $1: 49$ & $-1,404$ & 494,158 & 0,161 & $-0: 07$ & $-0: 19$ & $0: 03$ \\
\hline Deporte F & $1: 29$ & $1: 35$ & $-1,126$ & 478,452 & 0,261 & $-0: 05$ & $-0: 15$ & $0: 04$ \\
\hline Trabajo doméstico S & $0: 36$ & $0: 38$ & $-0,991$ & 509,719 & 0,322 & $-0: 02$ & $-0: 07$ & $0: 02$ \\
\hline Trabajo doméstico F & $0: 50$ & $0: 50$ & $-0,036$ & 482,853 & 0,971 & $-0: 00$ & $-0: 06$ & $0: 06$ \\
\hline Trabajo remunerado $\mathrm{S}$ & $0: 06$ & $0: 05$ & 0,771 & 434,423 & 0,441 & $0: 01$ & $-0: 02$ & $0: 05$ \\
\hline Trabajo remunerado $\mathrm{F}$ & $0: 10$ & $0: 08$ & 0,500 & 380,680 & 0,617 & $0: 01$ & $-0: 05$ & $0: 08$ \\
\hline Lectura S & $0: 39$ & $0: 40$ & $-0,419$ & 486,628 & 0,675 & $-0: 01$ & $-0: 07$ & $0: 04$ \\
\hline Lectura F & $0: 52$ & $0: 49$ & 0,594 & 480,557 & 0,553 & $0: 02$ & $-0: 06$ & $0: 11$ \\
\hline Higiene personal S & $1: 10$ & $1: 10$ & $-0,155$ & 455,713 & 0,877 & $-0: 00$ & $-0: 09$ & $0: 07$ \\
\hline Higiene personal F & $1: 14$ & $1: 12$ & 0,418 & 400,153 & 0,676 & $0: 01$ & $-0: 06$ & $0: 09$ \\
\hline Alimentación S & $1: 50$ & $1: 43$ & 1,235 & 399,568 & 0,218 & $0: 06$ & $-0: 03$ & $0: 16$ \\
\hline Alimentación F & $1: 52$ & $1: 46$ & 1,248 & 393,474 & 0,213 & $0: 06$ & $-0: 03$ & $0: 15$ \\
\hline Amigos S & $1: 14$ & $1: 07$ & 1,163 & 460,722 & 0,245 & $0: 07$ & $-0: 05$ & $0: 19$ \\
\hline Amigos $\mathrm{F}$ & $3: 06$ & $3: 46$ & $-4,123$ & 472,078 & 0,000 & $-0: 40$ & $-0: 59$ & $-0: 20$ \\
\hline Desplazamientos S & $0: 47$ & $0: 42$ & 1,356 & 414,820 & 0,176 & $0: 04$ & $-0: 02$ & $0: 11$ \\
\hline Desplazamientos F & $0: 56$ & $0: 54$ & 0,473 & 413,258 & 0,636 & $0: 02$ & $-0: 06$ & $0: 10$ \\
\hline Salir con pareja S & $0: 17$ & $0: 14$ & 0,579 & 390,458 & 0,563 & $0: 03$ & $-0: 08$ & $0: 15$ \\
\hline Salir con pareja F & $0: 19$ & $0: 29$ & $-2,105$ & 560,213 & 0,036 & $-0: 10$ & $-0: 20$ & $-0: 00$ \\
\hline Tiempo en dormirse ayer & $0: 28$ & $0: 29$ & $-0,178$ & 458,324 & 0,859 & $-0: 00$ & $-0: 05$ & $0: 04$ \\
\hline
\end{tabular}

Tabla 129: t-Student uso del tiempo - tener internet en teléfono móvil propio 


\subsection{7- Uso de nuevas tecnologías antes de dormir y consecuencias}

Queremos cerrar este capítulo que relaciona el uso del tiempo de los adolescentes con el uso de nuevas tecnologías, enfocándonos en un momento del día determinado que tiene actualmente gran interés: el momento de acostarse y dormirse.

El 60,3\% de los adolescentes afirma llevarse el ordenador, teléfono móvil o tablet a la cama cuando se va a dormir. Los resultados, que pueden apreciarse en la tabla 130, afirman que los adolescentes que se llevan los aparatos electrónicos a la cama duermen entre semana menos horas que los que no se los llevan (7:33 frente a 8:01 horas/día). El nivel de significación $(0,000)$ representa que existen diferencias significativas. Sin embargo, no se puede asegurar que existan para dormir durante el fin de semana. La diferencia de medias durante el fin de semana es menor (escasamente de 0:04 horas).

\begin{tabular}{|c|c|c|c|c|c|c|c|c|}
\hline & \multicolumn{2}{|c|}{ TICs cama } & \multirow{2}{*}{$\mathbf{t}$} & \multirow{2}{*}{ gl } & \multirow{2}{*}{$\begin{array}{c}\text { Sig. } \\
\text { (bilateral) }\end{array}$} & \multirow{2}{*}{$\begin{array}{l}\text { Diferencia } \\
\text { de medias }\end{array}$} & \multicolumn{2}{|c|}{$95 \%$ de inter.confianza } \\
\hline & No & Si & & & & & Inferior & Superior \\
\hline Dormir S & $8: 01$ & $7: 33$ & 9,965 & 1158,189 & 0,000 & $0: 28$ & $0: 23$ & $0: 34$ \\
\hline Dormir F & $9: 36$ & $9: 31$ & 1,150 & 1116,519 & 0,250 & $0: 04$ & $-0: 03$ & $0: 13$ \\
\hline Tiempo en dormirse ayer & $0: 23$ & $0: 35$ & $-7,075$ & 1355,620 & 0,000 & $-0: 12$ & $-0: 15$ & $-0: 08$ \\
\hline
\end{tabular}

Tabla 130: t-Student tiempo a dormir y tiempo que tardan en dormirse - llevarse los dispositivos electrónicos a la cama

Del mismo modo, podemos observar en la tabla 130 que los adolescentes que se llevan los dispositivos electrónicos a la cama, tardaron 12 minutos más en dormirse el día previo a cumplimentar la encuesta que los que no se los llevan. El nivel de significación es de nuevo de 0,000 , por lo que se puede afirmar que existen diferencias significativas.

Más de la mitad de los adolescentes (53\%) afirma conectarse a internet después de haberse acostado. Al igual que en el punto anterior, realizamos la t-Student para constatar si el hecho de conectarse a internet desde la cama tiene consecuencias en el tiempo dedicado a dormir y en el tiempo que tardan en dormirse los adolescentes. La tabla 131 muestra que sí existen diferencias significativas entre semana (la diferencia de medias es de 26 minutos al día). Sin embargo, no se puede asegurar que existan diferencias significativas durante el fin de semana (sólo 03 minutos al día de diferencia de medias). 


\begin{tabular}{|l|cccccccc|}
\cline { 2 - 9 } \multicolumn{1}{c|}{} & \multicolumn{2}{c}{ Internet tras acostarte } & \multirow{2}{*}{ No } & Si & t & gl & \multicolumn{3}{c|}{$\begin{array}{c}\text { Sig. } \\
\text { (bilateral) }\end{array}$} & De medias & Inferior & Superior \\
\hline Dormir S & $7: 58$ & $7: 32$ & 9,210 & 1324,679 & 0,000 & $0: 26$ & $0: 20$ & $0: 31$ \\
\hline Dormir F & $9: 35$ & $9: 31$ & 0,893 & 1277,392 & 0,372 & $0: 03$ & $-0: 04$ & $0: 11$ \\
\hline Tiempo en dormirse ayer & $0: 23$ & $0: 37$ & $-7,835$ & 1323,817 & 0,000 & $-0: 13$ & $-0: 16$ & $-0: 10$ \\
\hline
\end{tabular}

Tabla 131: t-Student tiempo a dormir y tiempo que tardan en dormirse - conectarse tras haberse acostado

Asimismo, se encuentran diferencias significativas entre el hecho de conectarse a internet tras acostarse y el tiempo que tardaron en dormirse la noche previa a la cumplimentación de la encuesta. Los adolescentes que sí se conectan a internet tardaron 13 minutos más en dormirse. El nivel de significación, como puede apreciarse en la tabla 131, es de 0,000 .

No se observa, sin embargo diferencias en la hora a la que levantó el adolescente el día de la encuesta en relación a si se había conectado a internet tras acostarse. Recordamos que las encuestas se realizaron en días lectivos. La tabla 132 muestra que no se puede asegurar que existan diferencias significativas.

\begin{tabular}{|c|c|c|c|c|c|c|c|c|}
\hline & \multicolumn{2}{|c|}{ Internet tras acostarte } & \multirow{2}{*}{$t$} & \multirow{2}{*}{ gl } & \multirow{2}{*}{$\begin{array}{c}\text { Sig. } \\
\text { (bilateral) }\end{array}$} & \multirow{2}{*}{$\begin{array}{l}\text { Diferencia } \\
\text { de medias }\end{array}$} & \multicolumn{2}{|c|}{$95 \%$ de int. de confianza } \\
\hline & No & $\mathrm{Si}$ & & & & & Inferior & Superior \\
\hline Hora de levantarse & $7: 20$ & $7: 21$ & $-0,490$ & 1250,610 & 0,624 & $-0: 00$ & $-0: 03$ & $0: 02$ \\
\hline
\end{tabular}

Tabla 132: hora levantarse - llevarse los dispositivos electrónicos a la cama

El análisis del tiempo que tardaron en dormirse los adolescentes burgaleses el día previo a responder la encuesta, en relación a las redes sociales que utilizan, afirma que los adolescentes que tienen perfil en cualquier red social tardaron más tiempo en dormirse que los que no tienen (tabla 133). La mayor diferencia de tiempo la encontramos entre los adolescentes que tienen perfil en WhatsApp, puesto que tardaron 8 minutos más en dormirse que los que no lo tienen.

Se encuentran diferencias significativas en cuanto al tiempo que tardan en dormirse y las diferentes redes sociales que utilizan. Estas diferencias se han hallado para los usuarios de Twitter, Facebook, Line y Snapchat. 
2a PARTE

Capítulo 4.- Resultados

\begin{tabular}{|c|c|c|c|c|c|c|c|c|c|c|c|c|c|c|c|c|}
\hline & \multicolumn{2}{|c|}{ Twitter } & \multicolumn{2}{|c|}{ Tuenti } & \multicolumn{2}{|c|}{ Instagram } & \multicolumn{2}{|c|}{ Facebook } & \multicolumn{2}{|c|}{ Whatsapp } & \multicolumn{2}{|c|}{ Line } & \multicolumn{2}{|c|}{ Skype } & \multicolumn{2}{|c|}{ Snachap } \\
\hline & no & si & no & si & no & si & no & si & no & si & no & si & no & si & no & si \\
\hline Tiempo en dormirse ayer & $0: 27$ & $0: 33$ & $0: 30$ & $0: 31$ & $0: 28$ & $0: 31$ & $0: 29$ & $0: 32$ & $0: 23$ & $0: 31$ & $0: 29$ & $0: 34$ & $0: 30$ & $0: 31$ & $0: 27$ & $0: 33$ \\
\hline
\end{tabular}

Tabla 133: tiempo en dormirse - uso de las distintas redes sociales

Nos interesa saber si se encuentra relación en los adolescentes entre llevarse los dispositivos electrónicos a la cama y sentirse cansados durante el día o tener la sensación de no haber descansado lo suficiente. Tal y como muestra la tabla 134, el porcentaje de adolescentes que se llevan los dispositivos a la cama y que está siempre o habitualmente cansado $(26,0 \%)$ es superior a aquellos que no se llevan las TIC a la cama (16,34\%). El nivel de significación obtenido es de 0,000 por lo que podemos afirmar que sí existen diferencias significativas.

\begin{tabular}{|c|c|c|c|c|c|c|}
\hline & \multicolumn{4}{|c|}{ ¿Estás cansado durante el día? } & \multirow{2}{*}{ Total } \\
\hline & & Nunca & A veces & Habitualmente & Siempre & \\
\hline \multirow{3}{*}{$\begin{array}{c}\text { TICS a } \\
\text { la cama }\end{array}$} & No & $22,0 \%$ & $62,4 \%$ & $11,3 \%$ & $4,4 \%$ & 550 \\
\hline & Si & $16,3 \%$ & $57,6 \%$ & $19,0 \%$ & $7,0 \%$ & 838 \\
\hline & Total & 258 & 826 & 221 & 83 & 1388 \\
\hline
\end{tabular}

Tabla 134: estar cansado durante el día-llevar los dispositivos a la cama

Del mismo modo, calculamos en la tabla 135 la relación entre conectarse a internet después de acostarse y estar cansado durante el día. Como se puede observar, el porcentaje de adolescentes que se encuentran siempre o habitualmente cansados y se conectan a internet tras haberse acostado $(26,5 \%)$ es superior al porcentaje de aquellos que nunca se conectan (16,9\%). De nuevo, el nivel de significación es 0,000 por lo que se puede concluir que sí se encuentran diferencias significativas.

\begin{tabular}{|c|c|c|c|c|c|c|}
\hline & \multicolumn{4}{|c|}{ Cansado durante el día } & \multirow{2}{*}{ Total } \\
\hline & & Nunca & $A$ veces & Habitualmente & Siempre & \\
\hline \multirow{3}{*}{$\begin{array}{c}\text { Internet tras } \\
\text { acostarte }\end{array}$} & No & $21,5 \%$ & $61,7 \%$ & $13,0 \%$ & $3,8 \%$ & 652 \\
\hline & Si & $16,1 \%$ & $57,4 \%$ & $18,6 \%$ & $7,9 \%$ & 735 \\
\hline & Total & 258 & 824 & 222 & 83 & 1387 \\
\hline
\end{tabular}

Tabla 135: estar cansado durante el día-conectarse a internet después de haberse acostado 
A continuación, pasamos a analizar si el uso de las TIC mientras estudian y las consecuencias de esta práctica.

\subsection{8.- Uso de TIC mientras estudia}

Como se puede apreciar en la tabla 136, los resultados de la encuesta ponen de manifiesto lo siguiente:

- $\quad$ El 10,19\% de los adolescentes siempre mira las redes sociales mientras estudia.

- $\quad$ El 8,29\% de los adolescentes siempre mira el WhatsApp mientras estudia.

- $\quad$ El 8,04\% de los adolescentes estucha música mientras estudia.

\begin{tabular}{|l|c|c|c|}
\cline { 2 - 4 } \multicolumn{1}{c|}{} & $\begin{array}{c}\text { Redes sociales } \\
\text { mientras estudia }\end{array}$ & $\begin{array}{c}\text { WhatsApp } \\
\text { mientras estudia }\end{array}$ & $\begin{array}{c}\text { Escucha música } \\
\text { mientras estudia }\end{array}$ \\
\hline Nunca & $38,31 \%$ & $30,55 \%$ & $48,44 \%$ \\
\cline { 2 - 4 } A veces & $36,15 \%$ & $44,44 \%$ & $31,65 \%$ \\
\hline Habitualmente & $15,35 \%$ & $16,73 \%$ & $11,88 \%$ \\
\cline { 2 - 4 } Siempre & $10,19 \%$ & $8,29 \%$ & $8,04 \%$ \\
\hline
\end{tabular}

Tabla 136: TIC mientras estudia

Nos interesa conocer este dato, porque pone sobre la mesa el esfuerzo que los adolescentes deben realizar para impedir que las TIC interfieran en sus estudios. La tabla 137 pone de manifiesto que más 1 de cada 5 adolescentes burgaleses encuestados es consciente de que tiene la necesidad de apartar o esconder su teléfono móvil mientras estudia para evitar perder la concentración.

\begin{tabular}{|l|c|}
\cline { 2 - 2 } \multicolumn{1}{c|}{} & $\begin{array}{c}\text { Esconder TICs } \\
\text { mientras estudia }\end{array}$ \\
\hline Nunca & $35,14 \%$ \\
\cline { 2 - 2 } A veces & $27,50 \%$ \\
\hline Habitualmente & $17,07 \%$ \\
\hline Siempre & $20,29 \%$ \\
\hline
\end{tabular}

Tabla 137: tienen que apartar el móvil mientras estudian para evitar distracciones 
2a PARTE

Capítulo 4.- Resultados

Como se puede observar en la tabla 138, de los adolescentes que han repetido curso, el $15,72 \%$ se conecta a las redes sociales. Sin embargo, el porcentaje que se conecta y no ha repetido curso, es menor $(9,04 \%)$. El valor obtenido para el nivel de significación es de 0,000 por lo que podemos afirmar que en este caso sí existen diferencias significativas.

\begin{tabular}{|l|cccc|c|}
\cline { 2 - 6 } \multicolumn{1}{c|}{} & \multicolumn{4}{c|}{ Redes sociales mientras estudias } & \multirow{2}{*}{ Total } \\
\hline No & Nunca & A veces & Habitualmente & Siempre & \\
\hline Si & $40,48 \%$ & $35,14 \%$ & $15,33 \%$ & $9,04 \%$ & 1161 \\
\hline Total & $53,51 \%$ & $41,48 \%$ & $15,28 \%$ & $15,72 \%$ & 229 \\
\hline
\end{tabular}

Tabla 138: uso de redes sociales mientras estudia - repetir algún curso

La tabla 139 muestra que el comportamiento en cuanto al uso del WhatsApp mientras estudia es muy similar al anterior. El porcentaje de adolescentes que afirma que nunca se conecta a WhatsApp mientras estudia y que además, no ha repetido ningún curso $(32,60 \%)$ es superior al porcentaje de los que sí que han suspendido (20,26\%). El nivel de significación hallado es de 0,003 por lo que podemos afirmar que existen diferencias significativas.

\begin{tabular}{|l|cccc|c|}
\cline { 2 - 6 } \multicolumn{1}{c|}{} & \multicolumn{4}{c|}{ WhatsApp mientras estudias } & Total \\
\hline No & Nunca & A veces & Habitualmente & Siempre & \\
\hline Si & $32,60 \%$ & $43,32 \%$ & $16,17 \%$ & $7,91 \%$ & 1175 \\
\hline Total & $40,26 \%$ & $50,43 \%$ & $19,40 \%$ & $9,91 \%$ & 232 \\
\hline
\end{tabular}

Tabla 139: uso WhatsApp mientras estudia - repetir algún curso

Con respecto al hecho de escuchar música mientras estudian, como se puede observar en la tabla 140, el porcentaje de adolescentes que ha repetido curso y que escucha música cuando estudia es superior al porcentaje que no ha repetido curso. De nuevo se demuestra que existen diferencias significativas puesto que el nivel de significación es del 0,001 . 


\begin{tabular}{|l|cccc|c|}
\cline { 2 - 6 } \multicolumn{1}{c|}{} & \multicolumn{4}{c|}{ Música mientras estudias } & Total \\
\hline No & Nunca & A veces & Habitualmente & Siempre & \\
\hline Si & $49,87 \%$ & $32,11 \%$ & $10,76 \%$ & $7,26 \%$ & 1171 \\
\hline Total & $60,69 \%$ & $29,87 \%$ & $17,32 \%$ & $12,12 \%$ & 231 \\
\hline
\end{tabular}

Tabla 140: escuchar música mientras estudia - repetir algún curso

\subsection{9.- Uso adictivo a las TIC}

La pregunta 36 de la encuesta va dirigida a conocer cuál es la percepción del adolescente sobre la relación de sus amigos con las TIC. Como puede observarse en la tabla 141, el porcentaje de adolescentes que piensa que sus amigos están enganchados al teléfono móvil es el más relevante de la tabla. Más de la mitad de los adolescentes encuestados $(57,4 \%)$ considera que sus amigos están enganchados al teléfono móvil. El resto de valores obtenidos para la opción sí en el resto de TIC, no son tan relevantes como esta anterior.

\begin{tabular}{|l|ccccc|}
\cline { 2 - 6 } \multicolumn{1}{c|}{} & \multicolumn{4}{c|}{ ¿Consideras que tus amigos están enganchados a...? } \\
\cline { 2 - 6 } \multicolumn{1}{c|}{} & $\begin{array}{c}\text { Teléfono } \\
\text { móvil }\end{array}$ & $\begin{array}{c}\text { Redes } \\
\text { sociales }\end{array}$ & WhatsApp & Videojuegos & Televisión \\
\hline No & $42,6 \%$ & $94,6 \%$ & $92,1 \%$ & $96,0 \%$ & $97,0 \%$ \\
\hline Si & $57,4 \%$ & $5,4 \%$ & $7,9 \%$ & $4,0 \%$ & $3,0 \%$ \\
\hline Total & $100,0 \%$ & $100,0 \%$ & $100,0 \%$ & $100,0 \%$ & $100,0 \%$ \\
\hline
\end{tabular}

Tabla 141: adiciones de los amigos según los adolescentes

Sufrir adición a las TIC implica no saber cumplir los límites de utilización. Las cuestiones 42, 43 y 44 preguntan al adolescente si pasa más tiempo del que se ha propuesto conectado a internet o en redes sociales o en WhatsApp.

Los resultados obtenidos en esta cuestión pueden darnos indicios sobre la dificultad que presentan los adolescentes para conseguir controlar sus impulsos en cuanto a las nuevas tecnologías. La tabla 142 muestra que prácticamente el 15\% de los adolescentes dedica más tiempo a internet del que se había propuesto. Del mismo modo, el $11,36 \%$ a las redes sociales y el $16,62 \%$ a WhatsApp. 


\begin{tabular}{|l|c|c|c|}
\cline { 2 - 4 } \multicolumn{1}{c|}{} & $\begin{array}{c}\text { Más tiempo del } \\
\text { propuesto a } \\
\text { Internet }\end{array}$ & $\begin{array}{c}\text { Más tiempo del } \\
\text { propuesto a } \\
\text { redes sociales }\end{array}$ & $\begin{array}{c}\text { Más tiempo del } \\
\text { propuesto a } \\
\text { WhatsApp }\end{array}$ \\
\hline Nunca & $29,43 \%$ & $41,71 \%$ & $32,09 \%$ \\
\cline { 2 - 4 } A veces & $38,00 \%$ & $32,36 \%$ & $34,10 \%$ \\
\cline { 2 - 4 } Habitualmente & $17,93 \%$ & $14,57 \%$ & $17,19 \%$ \\
\cline { 2 - 4 } Siempre & $14,64 \%$ & $11,36 \%$ & $16,62 \%$ \\
\hline
\end{tabular}

Tabla 142: pasa más tiempo en internet, redes sociales y WhatsApp del que se había propuesto

\section{5.- CONTROL PARENTAL}

En esta parte del análisis de resultados vamos a tratar de obtener información sobre el control parental con respecto al uso de las TIC por parte de los adolescentes. También queremos cuantificar el grado de interés de los padres por conocer los usos de Internet y las TIC por parte de sus hijos.

\subsection{1.- Normas en casa}

Como muestra la tabla 143 , el $43,45 \%$ manifiesta no tener nunca normas en casa sobre el uso de dispositivos electrónicos y acceso a internet. Casi 1 de cada 5 afirma tener normas siempre.

\begin{tabular}{|l|cc|}
\cline { 2 - 3 } \multicolumn{1}{c|}{} & Frecuencia & Porcentaje \\
\hline Nunca & 604 & $43,45 \%$ \\
\cline { 2 - 3 } & 348 & $25,04 \%$ \\
\cline { 2 - 3 } A veces & 164 & $11,80 \%$ \\
\cline { 2 - 3 } Siempre & 274 & $19,71 \%$ \\
\hline Total & 1390 & $100,00 \%$ \\
\hline
\end{tabular}

Tabla 143: tiene normas en casa sobre el uso de dispositivos electrónicos y acceso a internet

Con respecto al género, podemos observar en la tabla 144 que, aparentemente, el porcentaje de adolescentes masculinos que nunca tienen normas es superior al femenino.

Sin embargo, el porcentaje de adolescentes femeninas que siempre tiene normas es ligeramente superior al masculino. Sin embargo, el nivel de significación según el 
valor de chi-cuadrado es de 0,083 por lo que no podemos afirmar que existan diferencias significativas.

\begin{tabular}{|l|cccc|c|}
\cline { 2 - 6 } \multicolumn{1}{c|}{} & Nunca & A veces & Habitualmente & Siempre & Total \\
\hline Femenino & $40,63 \%$ & $27,50 \%$ & $11,76 \%$ & $20,11 \%$ & 731 \\
\cline { 2 - 6 } Masculino & $46,59 \%$ & $22,31 \%$ & $11,84 \%$ & $19,27 \%$ & 659 \\
\hline Total & 604 & 348 & 164 & 274 & 1390 \\
\hline
\end{tabular}

Tabla 144: normas en casa sobre el uso de dispositivos electrónicos y acceso a internet - género

Con respecto a la edad, podemos afirmar que el porcentaje de adolescentes que afirma tener siempre normas en casa para el uso de dispositivos electrónicos disminuye con la edad (tabla 145), al igual que aumenta el porcentaje que nunca tiene normas con la edad.

El nivel de significación es de 0,000 por lo que podemos afirmar que existen diferencias significativas por la edad.

\begin{tabular}{|l|cccc|c|}
\cline { 2 - 6 } \multicolumn{1}{c|}{} & Nunca & A veces & Habitualmente & Siempre & Total \\
\hline $\mathbf{1 2}$ & $33,33 \%$ & $25,52 \%$ & $8,85 \%$ & $32,29 \%$ & 192 \\
\cline { 2 - 6 } $\mathbf{1 3}$ & $36,19 \%$ & $24,25 \%$ & $15,30 \%$ & $24,25 \%$ & 268 \\
\cline { 2 - 6 } $\mathbf{1 4}$ & $40,85 \%$ & $21,70 \%$ & $15,32 \%$ & $22,13 \%$ & 235 \\
\cline { 2 - 6 } $\mathbf{1 6}$ & $35,10 \%$ & $32,69 \%$ & $11,54 \%$ & $20,67 \%$ & 208 \\
\cline { 2 - 6 } $\mathbf{1 7}$ & $54,66 \%$ & $25,85 \%$ & $8,05 \%$ & $11,44 \%$ & 236 \\
\hline Total & $55,14 \%$ & $22,16 \%$ & $11,35 \%$ & $11,35 \%$ & 185 \\
\hline
\end{tabular}

Tabla 145: normas en casa sobre el uso de dispositivos electrónicos y acceso a internet - edad

Con respecto al uso del tiempo, la tabla 146 estudia el uso del tiempo de las actividades en las cuales se han encontrado (mediante la prueba ANOVA de un factor) diferencias significativas en relación a tener normas en casa para las nuevas tecnologías. 
Los adolescentes que tienen normas dedican más tiempo a las siguientes actividades:

- Dormir entre semana y fin de semana: los adolescentes que tienen normas para el uso de internet y para los dispositivos tecnológicos duermen durante más tiempo.

- Actividades extraescolares entre semana y fin de semana: los adolescentes que siempre tienen normas dedican más tiempo a estas actividades.

- Deporte entre semana y fin de semana: los adolescentes que tienen normas dedican más tiempo entre semana (18 minutos) y el fin de semana (13 minutos) diarios a realizar deporte que aquellos que no tienen normas.

- Trabajo doméstico fin de semana: los adolescentes con normas dedican 7 minutos más al día a esta labor.

- Trabajo remunerado fin de semana: los adolescentes que habitualmente tienen normas dedican 15 minutos más al trabajo remunerado.

- Lectura en fin de semana: los adolescentes que tienen normas leen durante más tiempo (12 minutos diarios de diferencia)

- Salir con amigos entre semana: los adolescentes que tienen normas siempre salen durante 4 minutos más diarios 
2a PARTE

Capítulo 4.- Resultados

\begin{tabular}{|c|c|c|c|c|c|}
\hline & nunca & a veces & habitualmente & siempre & Sig. \\
\hline Dormir S & $7: 41$ & $7: 46$ & 7:38 & $7: 53$ & 0,010 \\
\hline Dormir F & 9:26 & $9: 43$ & $9: 29$ & 9:38 & 0,007 \\
\hline Asistir a clase $\mathrm{S}$ & $6: 07$ & $6: 08$ & $6: 07$ & $6: 10$ & 0,270 \\
\hline Asistir a clase F & 0:00 & $0: 00$ & $0: 00$ & $0: 00$ & \\
\hline Actividades extr. S & $1: 44$ & $1: 41$ & $2: 04$ & $1: 57$ & 0,039 \\
\hline Actividades extr. F & $0: 36$ & $0: 45$ & $0: 39$ & $0: 51$ & 0,017 \\
\hline Estudio S & $2: 22$ & $2: 20$ & $2: 35$ & $2: 24$ & 0,277 \\
\hline Estudio F & $2: 34$ & $2: 26$ & $2: 32$ & $2: 31$ & 0,713 \\
\hline Whatsapp S & $1: 53$ & $1: 54$ & $1: 43$ & $1: 22$ & 0,001 \\
\hline Whatsapp F & $2: 42$ & $2: 56$ & $2: 39$ & $2: 39$ & 0,425 \\
\hline Redes sociales S & $1: 13$ & $1: 10$ & $0: 53$ & $0: 47$ & 0,000 \\
\hline Redes sociales F & $1: 37$ & $1: 42$ & $1: 32$ & $1: 23$ & 0,178 \\
\hline Internet S & $0: 55$ & $0: 49$ & $1: 01$ & $0: 51$ & 0,141 \\
\hline Internet F & $1: 16$ & $1: 07$ & $1: 25$ & $1: 19$ & 0,056 \\
\hline Videojuegos/consolas S & $0: 32$ & $0: 22$ & $0: 31$ & $0: 25$ & 0,061 \\
\hline Videojuegos/consolas F & $1: 05$ & $0: 50$ & $1: 12$ & $1: 02$ & 0,046 \\
\hline Televisión S & $1: 23$ & $1: 25$ & $1: 31$ & $1: 23$ & 0,633 \\
\hline Televisión F & $2: 03$ & $2: 07$ & $2: 13$ & $2: 05$ & 0,686 \\
\hline Teléfono S & $0: 21$ & $0: 20$ & $0: 21$ & $0: 24$ & 0,669 \\
\hline Teléfono F & $0: 30$ & $0: 29$ & $0: 35$ & $0: 30$ & 0,623 \\
\hline Deporte S & $1: 44$ & $1: 44$ & $2: 00$ & $2: 02$ & 0,009 \\
\hline Deporte F & $1: 29$ & $1: 26$ & $1: 31$ & $1: 42$ & 0,042 \\
\hline Trabajo doméstico S & $0: 37$ & $0: 35$ & $0: 41$ & $0: 41$ & 0,184 \\
\hline Trabajo doméstico F & $0: 46$ & $0: 47$ & $1: 02$ & $0: 53$ & 0,002 \\
\hline Trabajo remunerado $\mathrm{S}$ & $0: 05$ & 0:06 & $0: 08$ & $0: 05$ & 0,762 \\
\hline Trabajo remunerado $\mathrm{F}$ & $0: 05$ & $0: 13$ & $0: 20$ & $0: 10$ & 0,002 \\
\hline Lectura S & $0: 40$ & $0: 37$ & $0: 45$ & $0: 43$ & 0,239 \\
\hline Lectura F & $0: 46$ & $0: 47$ & $0: 55$ & $0: 58$ & 0,042 \\
\hline Higiene personal S & $1: 12$ & $1: 05$ & $1: 21$ & $1: 08$ & 0,058 \\
\hline Higiene personal F & $1: 13$ & $1: 11$ & $1: 25$ & $1: 06$ & 0,009 \\
\hline Alimentación S & $1: 40$ & $1: 44$ & $1: 52$ & $1: 42$ & 0,373 \\
\hline Alimentación F & $1: 42$ & $1: 50$ & $1: 50$ & $1: 43$ & 0,286 \\
\hline Amigos S & $1: 03$ & $1: 23$ & $1: 21$ & $1: 07$ & 0,005 \\
\hline Amigos $\mathrm{F}$ & $3: 39$ & $3: 39$ & $3: 24$ & $3: 11$ & 0,043 \\
\hline Desplazamientos S & $0: 45$ & $0: 42$ & $0: 53$ & $0: 43$ & 0,115 \\
\hline Desplazamientos $\mathrm{F}$ & $0: 56$ & $0: 55$ & 1:09 & $0: 55$ & 0,120 \\
\hline Salir con pareja S & $0: 16$ & $0: 15$ & $0: 15$ & 0:09 & 0,593 \\
\hline Salir con parej F & $0: 31$ & $0: 26$ & $0: 21$ & $0: 15$ & 0,038 \\
\hline Tiempo en dormirse ayer & $0: 28$ & $0: 33$ & $0: 34$ & $0: 32$ & 0,061 \\
\hline
\end{tabular}

Tabla 146: uso del tiempo - normas en casa sobre nuevas tecnologías 
2a PARTE

Capítulo 4.- Resultados

Los adolescentes que nunca tienen normas, dedican más tiempo a las siguientes actividades:

- Actividades relacionadas con las nuevas tecnologías:

$\checkmark \quad$ WhatsApp entre semana: dedican 31 minutos más diarios

$\checkmark$ Redes sociales entre semana: dedican 26 minutos más al día

$\checkmark$ Videojuegos/consolas: dedican 3 minutos más al día

- Amigos el fin de semana: dedican 28 minutos más diarios a esta actividad

- Salir con la pareja: los adolescentes que nunca tienen normas sobre el uso de internet y de los dispositivos electrónicos dedican 16 minutos más a salir con la pareja.

\subsection{2.- Conocimiento por los padres del nic/alias/nombre en las redes sociales}

La tabla 147 muestra que el 40,78\% de los adolescentes afirma que sus padres no conocen su nombre en las redes sociales. No llega al 30\% que siempre lo conocen.

\begin{tabular}{|l|cc|}
\cline { 2 - 3 } \multicolumn{1}{c|}{} & Frecuencia & Porcentaje \\
\hline Nunca & 564 & $40,78 \%$ \\
\cline { 2 - 3 } A veces & 264 & $19,09 \%$ \\
\cline { 2 - 3 } Habitualmente & 164 & $11,86 \%$ \\
\cline { 2 - 3 } Siempre & 391 & $28,27 \%$ \\
\hline Total & 1383 & $100,00 \%$ \\
\hline
\end{tabular}

Tabla 147: padres conocen nombre en las redes sociales

Tal y como se puede observar en la tabla 148, el porcentaje de adolescentes femeninas cuyos padres conocen sus nombres en la red es superior al masculino. Más diferencias se encuentran entre los que nunca revelan su nombre en las redes a sus padres $(46,59 \%$ de los chicos frente al 35,50\% de las chicas).

\begin{tabular}{|l|cccc|c|}
\cline { 2 - 6 } \multicolumn{1}{c|}{} & Nunca & A veces & Habitualmente & Siempre & Total \\
\hline Femenino & $35,50 \%$ & $20,99 \%$ & $12,98 \%$ & $30,52 \%$ & 724 \\
\cline { 2 - 6 } Masculino & $46,59 \%$ & $17,00 \%$ & $10,62 \%$ & $25,80 \%$ & 659 \\
\hline Total & 564 & 264 & 164 & 391 & 1383 \\
\hline
\end{tabular}

Tabla 148: padres conocen nombre en las redes sociales - género 
Según el valor de chi-cuadrado, el nivel de significación es del 0,001 por lo que hay diferencias significativas por género.

Con respecto a la edad, podemos observar que la transparencia con los padres en cuanto al nombre utilizado por los adolescentes en las redes va disminuyendo con la edad (tabla 149).

Según el resultado de chi-cuadrado, el nivel de significación es del 0,000 por lo que hay diferencias significativas por edad.

\begin{tabular}{|l|cccc|c|}
\cline { 2 - 6 } \multicolumn{1}{c|}{} & Nunca & A veces & Habitualmente & Siempre & Total \\
\hline 12 & $28,21 \%$ & $16,41 \%$ & $10,77 \%$ & $44,62 \%$ & 195 \\
\cline { 2 - 6 } 13 & $41,83 \%$ & $13,69 \%$ & $14,83 \%$ & $29,66 \%$ & 263 \\
\cline { 2 - 6 } 14 & $39,91 \%$ & $23,61 \%$ & $7,73 \%$ & $28,76 \%$ & 233 \\
\cline { 2 - 6 } 15 & $33,98 \%$ & $23,79 \%$ & $13,11 \%$ & $29,13 \%$ & 206 \\
\cline { 2 - 6 } & $51,06 \%$ & $17,02 \%$ & $12,34 \%$ & $19,57 \%$ & 235 \\
\hline \multirow{2}{*}{17} & $42,16 \%$ & $21,62 \%$ & $14,05 \%$ & $22,16 \%$ & 185 \\
\hline Total & 526 & 252 & 160 & 379 & 1317 \\
\hline
\end{tabular}

Tabla 149: padres conocen nombre en las redes sociales - edad

En la tabla 150 realizamos un ANOVA para relacionar el uso del tiempo de los adolescentes con el hecho de que sus padres conozcan su nombre o nic en las redes sociales.

Los adolescentes cuyos padres siempre conocen su nic en las redes dedican más tiempo a las siguientes actividades (con diferencias significativas):

- Dormir entre semana: los adolescentes cuyos padres siempre conocen su nic duermen 15 minutos más

- Estudiar entre semana: estudian una media de 10 minutos diarios más.

- Deporte entre semana y fin de semana: estos adolescentes, cuyos padres conocen su nic, hacen más deporte que aquellos cuyos padres no lo conocen (aproximadamente 16 minutos entre semana y 9 minutos el fin de semana).

- Lectura entre semana: dedican a leer entre semana 10 minutos diarios más.

- Alimentación el fin de semana: dedican 11 minutos al día más a esta actividad. 
Capítulo 4.- Resultados

\begin{tabular}{|c|c|c|c|c|c|}
\hline & nunca & a veces & habitualmente & siempre & Sig. \\
\hline Dormir S & $7: 39$ & $7: 40$ & $7: 47$ & $7: 54$ & 0,000 \\
\hline Dormir F & 9:35 & 9:27 & $9: 28$ & 9:37 & 0,324 \\
\hline Asistir a clase $\mathrm{S}$ & $6: 09$ & $6: 07$ & $6: 07$ & $6: 07$ & 0,054 \\
\hline Asistir a clase $\mathrm{F}$ & $0: 00$ & $0: 00$ & $0: 00$ & $0: 00$ & \\
\hline Actividades extr. S & $1: 44$ & $1: 51$ & $1: 47$ & $1: 52$ & 0,658 \\
\hline Actividades extr. F & $0: 36$ & $0: 45$ & $0: 54$ & $0: 41$ & 0,010 \\
\hline Estudio S & $2: 24$ & $2: 15$ & $2: 08$ & $2: 34$ & 0,002 \\
\hline Estudio F & $2: 42$ & $2: 24$ & $2: 18$ & $2: 28$ & 0,027 \\
\hline Whatsapp S & $1: 44$ & $1: 52$ & $1: 51$ & $1: 45$ & 0,748 \\
\hline Whatsapp F & $2: 45$ & $2: 59$ & $2: 53$ & $2: 34$ & 0,199 \\
\hline Redes sociales S & $1: 08$ & $1: 08$ & $1: 10$ & $0: 59$ & 0,354 \\
\hline Redes sociales F & $1: 36$ & $1: 48$ & $1: 44$ & $1: 24$ & 0,038 \\
\hline Internet S & $0: 57$ & $0: 51$ & $0: 41$ & $0: 55$ & 0,019 \\
\hline Internet F & $1: 22$ & $1: 17$ & $0: 58$ & $1: 11$ & 0,005 \\
\hline Videojuegos/consolas S & $0: 29$ & $0: 27$ & $0: 28$ & $0: 29$ & 0,972 \\
\hline Videojuegos/consolas F & $1: 06$ & $0: 55$ & $0: 57$ & $1: 00$ & 0,388 \\
\hline Televisión S & $1: 26$ & $1: 21$ & $1: 28$ & $1: 24$ & 0,700 \\
\hline Televisión F & $2: 06$ & $2: 03$ & $2: 14$ & $2: 04$ & 0,687 \\
\hline Teléfono S & $0: 21$ & $0: 22$ & $0: 20$ & $0: 22$ & 0,937 \\
\hline Teléfono F & $0: 29$ & $0: 33$ & $0: 30$ & $0: 30$ & 0,759 \\
\hline Deporte S & $1: 42$ & $1: 49$ & $1: 51$ & $1: 58$ & 0,047 \\
\hline Deporte F & $1: 24$ & $1: 32$ & $1: 46$ & $1: 33$ & 0,011 \\
\hline Trabajo doméstico S & $0: 36$ & $0: 37$ & $0: 39$ & $0: 40$ & 0,579 \\
\hline Trabajo doméstico F & $0: 47$ & $0: 51$ & $0: 50$ & $0: 54$ & 0,189 \\
\hline Trabajo remunerado S & 0:06 & $0: 05$ & $0: 07$ & $0: 05$ & 0,918 \\
\hline Trabajo remunerado $\mathrm{F}$ & $0: 10$ & 0:07 & $0: 13$ & $0: 11$ & 0,556 \\
\hline Lectura S & $0: 38$ & $0: 37$ & $0: 34$ & $0: 48$ & 0,002 \\
\hline Lectura F & $0: 49$ & $0: 48$ & $0: 48$ & $0: 53$ & 0,725 \\
\hline Higiene personal S & $1: 12$ & $1: 09$ & $1: 10$ & $1: 09$ & 0,913 \\
\hline Higiene personal F & $1: 11$ & $1: 15$ & $1: 13$ & $1: 13$ & 0,807 \\
\hline Alimentación S & $1: 40$ & $1: 38$ & $1: 47$ & $1: 50$ & 0,109 \\
\hline Alimentación F & $1: 42$ & $1: 39$ & $1: 50$ & $1: 53$ & 0,025 \\
\hline Amigos S & $1: 12$ & $1: 04$ & $1: 29$ & $1: 06$ & 0,032 \\
\hline Amigos $\mathrm{F}$ & 3:39 & $3: 46$ & $3: 48$ & $3: 13$ & 0,006 \\
\hline Desplazamientos S & $0: 45$ & $0: 42$ & $0: 47$ & $0: 47$ & 0,659 \\
\hline Desplazamientos F & $0: 58$ & $1: 03$ & $0: 49$ & $0: 57$ & 0,273 \\
\hline Salir con pareja S & $0: 18$ & $0: 10$ & $0: 12$ & $0: 11$ & 0,344 \\
\hline Salir con parej F & $0: 31$ & $0: 28$ & $0: 23$ & $0: 20$ & 0,255 \\
\hline Tiempo en dormirse ayer & $0: 31$ & $0: 31$ & $0: 29$ & $0: 30$ & 0,899 \\
\hline
\end{tabular}

Tabla 150: uso del tiempo - padres conocen nic en las redes 
Los adolescentes cuyos padres nunca conocen su nic en las redes dedican más tiempo a las siguientes actividades (con diferencias significativas):

- Estudiar el fin de semana: estudian una media de 14 minutos más al día

- Redes sociales el fin de semana: dedican 12 minutos más diarios.

- Internet entre semana y fin de semana: invierten en navegar más tiempo (2 minutos más entre semana y 11 minutos más el fin de semana).

- Salir con amigos: 6 minutos más entre semana y 26 minutos más el fin de semana.

\subsection{3.- Comunicación con padres sobre riesgos de acceso a internet}

La respuesta más repetida a esta cuestión, por los adolescentes burgaleses, es a veces $(35,67 \%)$. Según observamos en la tabla 151 , casi un cuarto de los adolescentes nunca ha hablado con sus padres sobre los riesgos de los contenidos existentes en internet, aproximadamente la misma cantidad que los que siempre hablan de ello.

\begin{tabular}{|l|cc|}
\cline { 2 - 3 } \multicolumn{1}{c|}{} & Frecuencia & Porcentaje \\
\hline Nunca & 324 & $23,21 \%$ \\
\cline { 2 - 3 } A veces & 498 & $35,67 \%$ \\
\cline { 2 - 3 } Habitualmente & 249 & $17,84 \%$ \\
\cline { 2 - 3 } Siempre & 325 & $23,28 \%$ \\
\hline Total & 1396 & $100,00 \%$ \\
\hline
\end{tabular}

Tabla 151: hablan con sus padres sobre los riesgos de acceso a los contenidos de internet

Como puede observarse en la tabla 152, el porcentaje de chicas que hablan habitualmente o siempre con sus padres sobre este tema $(48,08 \%)$ es ampliamente superior al de chicos $(36,74 \%)$. El valor de significación $(0,001)$ de chi-cuadrado pone de manifiesto que sí existen diferencias significativas con respecto al género.

El porcentaje de adolescentes que habla siempre con sus padres sobre los riesgos de la red disminuye con la edad, excepto a los 17 años que hay un pico de aumento (tabla 153). El valor de significación $(0,000)$ de chi-cuadrado pone de manifiesto que sí existen diferencias significativas con respecto a la edad. 


\begin{tabular}{|l|cccc|c|}
\cline { 2 - 6 } \multicolumn{1}{c|}{} & Nunca & A veces & Habitualmente & Siempre & Total \\
\hline Femenino & $19,26 \%$ & $35,66 \%$ & $19,81 \%$ & $25,27 \%$ & 732 \\
\cline { 2 - 6 } Masculino & $27,56 \%$ & $35,69 \%$ & $15,66 \%$ & $21,08 \%$ & 664 \\
\hline Total & 324 & 498 & 249 & 325 & 1396 \\
\hline
\end{tabular}

Tabla 152: hablan con sus padres sobre los riesgos de internet - género.

\begin{tabular}{|l|cccc|c|}
\cline { 2 - 6 } \multicolumn{1}{c|}{} & Nunca & A veces & Habitualmente & Siempre & Total \\
\hline $\mathbf{1 2}$ & $19,90 \%$ & $31,12 \%$ & $18,37 \%$ & $30,61 \%$ & 196 \\
\cline { 2 - 6 } 13 & $17,23 \%$ & $35,21 \%$ & $16,48 \%$ & $31,09 \%$ & 267 \\
\cline { 2 - 6 } 14 & $23,65 \%$ & $35,68 \%$ & $17,01 \%$ & $23,65 \%$ & 241 \\
\cline { 2 - 6 } 15 & $22,33 \%$ & $40,78 \%$ & $14,56 \%$ & $22,33 \%$ & 206 \\
\cline { 2 - 6 } 16 & $28,81 \%$ & $36,44 \%$ & $20,76 \%$ & $13,98 \%$ & 236 \\
\hline 17 & $20,00 \%$ & $40,54 \%$ & $22,16 \%$ & $17,30 \%$ & 185 \\
\hline Total & 293 & 486 & 241 & 311 & 1331 \\
\hline
\end{tabular}

Tabla 153: hablan con sus padres sobre los riesgos de acceso a los contenidos de internet - edad

Con respecto al uso del tiempo, la tabla 154 representa las actividades de uso del tiempo y su relación con el hecho de que los padres hayan hablado con sus hijos de los riesgos de internet. A continuación, comentamos las principales actividades en cuyo uso del tiempo se han encontrado diferencias significativas.

Los adolescentes que hablan siempre con sus padres de los riesgos de internet, dedican significativamente más tiempo que aquellos que nunca hablan a las siguientes actividades:

- Actividades extraescolares entre semana: dedican 24 minutos más

- Lectura entre semana: 13 minutos diarios más.

Los adolescentes que nunca hablan con sus padres de los riesgos de internet, dedican significativamente más tiempo que aquellos que siempre hablan a las siguientes actividades:

- Videojuegos/consolas: 16 minutos más entre semana y 22 minutos más el fin de semana.

- Amigos fin de semana: dedican 41 minutos más a salir con sus amigos. 


\begin{tabular}{|c|c|c|c|c|c|}
\hline & nunca & a veces & habitualmente & siempre & Sig. \\
\hline Dormir S & $7: 41$ & $7: 44$ & $7: 41$ & $7: 51$ & 0,084 \\
\hline Dormir F & 9:36 & 9:32 & $9: 31$ & 9:33 & 0,903 \\
\hline Asistir a clase $\mathrm{S}$ & $6: 07$ & $6: 09$ & $6: 09$ & $6: 06$ & 0,065 \\
\hline Asistir a clase F & $0: 00$ & $0: 00$ & $0: 00$ & $0: 00$ & \\
\hline Actividades extr. S & $1: 28$ & $1: 53$ & $1: 57$ & $1: 52$ & 0,001 \\
\hline Actividades extr. F & $0: 34$ & $0: 44$ & $0: 43$ & $0: 45$ & 0,115 \\
\hline Estudio S & $2: 21$ & $2: 27$ & $2: 20$ & $2: 23$ & 0,632 \\
\hline Estudio F & $2: 25$ & $2: 36$ & $2: 37$ & $2: 26$ & 0,361 \\
\hline Whatsapp S & $1: 53$ & $1: 44$ & $1: 47$ & $1: 41$ & 0,556 \\
\hline Whatsapp F & $2: 50$ & $2: 41$ & $2: 49$ & $2: 41$ & 0,795 \\
\hline Redes sociales S & $1: 08$ & $1: 09$ & $1: 02$ & $0: 57$ & 0,176 \\
\hline Redes sociales F & $1: 29$ & $1: 41$ & $1: 32$ & $1: 33$ & 0,469 \\
\hline Internet S & $0: 57$ & $0: 55$ & $0: 50$ & $0: 49$ & 0,268 \\
\hline Internet F & $1: 21$ & $1: 17$ & $1: 13$ & $1: 09$ & 0,244 \\
\hline Videojuegos/consolas S & $0: 39$ & $0: 28$ & $0: 24$ & $0: 23$ & 0,002 \\
\hline Videojuegos/consolas F & $1: 19$ & $0: 57$ & $0: 52$ & $0: 57$ & 0,001 \\
\hline Televisión S & $1: 27$ & $1: 27$ & $1: 17$ & $1: 26$ & 0,391 \\
\hline Televisión F & 2:06 & $2: 10$ & $1: 59$ & $2: 02$ & 0,470 \\
\hline Teléfono S & $0: 23$ & $0: 21$ & $0: 20$ & $0: 22$ & 0,830 \\
\hline Teléfono F & $0: 29$ & $0: 31$ & $0: 30$ & $0: 30$ & 0,974 \\
\hline Deporte S & $1: 45$ & $1: 52$ & $1: 45$ & $1: 52$ & 0,513 \\
\hline Deporte F & $1: 26$ & $1: 32$ & $1: 29$ & $1: 35$ & 0,390 \\
\hline Trabajo doméstico S & $0: 33$ & $0: 39$ & $0: 38$ & $0: 40$ & 0,093 \\
\hline Trabajo doméstico F & $0: 45$ & $0: 49$ & $0: 50$ & $0: 55$ & 0,121 \\
\hline Trabajo remunerado S & $0: 08$ & $0: 06$ & $0: 05$ & $0: 07$ & 0,860 \\
\hline Trabajo remunerado $\mathrm{F}$ & $0: 10$ & $0: 10$ & $0: 12$ & $0: 11$ & 0,896 \\
\hline Lectura S & $0: 36$ & $0: 39$ & $0: 38$ & $0: 49$ & 0,004 \\
\hline Lectura F & $0: 45$ & $0: 48$ & $0: 52$ & $0: 58$ & 0,068 \\
\hline Higiene personal S & $1: 12$ & $1: 11$ & $1: 04$ & $1: 12$ & 0,458 \\
\hline Higiene personal F & $1: 15$ & $1: 11$ & $1: 15$ & $1: 10$ & 0,479 \\
\hline Alimentación S & $1: 44$ & $1: 47$ & $1: 36$ & $1: 44$ & 0,337 \\
\hline Alimentación F & $1: 44$ & $1: 46$ & $1: 41$ & $1: 49$ & 0,496 \\
\hline Amigos S & $1: 08$ & $1: 16$ & $1: 10$ & $1: 08$ & 0,562 \\
\hline Amigos $\mathrm{F}$ & $3: 48$ & 3:39 & 3:36 & 3:07 & 0,002 \\
\hline Desplazamientos S & $0: 40$ & $0: 49$ & $0: 40$ & $0: 48$ & 0,019 \\
\hline Desplazamientos F & $0: 55$ & $1: 01$ & $0: 53$ & $0: 59$ & 0,444 \\
\hline Salir con pareja S & 0:09 & $0: 18$ & $0: 13$ & $0: 13$ & 0,336 \\
\hline Salir con parej F & $0: 20$ & $0: 27$ & $0: 32$ & $0: 26$ & 0,365 \\
\hline Tiempo en dormirse ayer & $0: 31$ & $0: 30$ & $0: 32$ & $0: 29$ & 0,703 \\
\hline
\end{tabular}

Tabla 154: uso del tiempo - hablan con los padres sobre los riesgos de acceso a internet 
2a PARTE

Capítulo 4.- Resultados

\subsubsection{1.- Interés de los padres por los contenidos que utilizan sus hijos en internet}

Podemos observar en la tabla 155 que el interés de los padres por los contenidos que sus hijos van a utilizar en internet en bastante bajo. El porcentaje de padres que siempre preguntan por los contenidos que van a utilizar es escasamente del $12,1 \%$. El $72,44 \%$ afirma que no preguntan a sus hijos por lo contenidos nunca o sólo a veces.

\begin{tabular}{|l|cc|}
\cline { 2 - 3 } \multicolumn{1}{c|}{} & Frecuencia & Porcentaje \\
\hline Nunca & 511 & $36,58 \%$ \\
\cline { 2 - 3 } A veces & 501 & $35,86 \%$ \\
\cline { 2 - 3 } Habitualmente & 213 & $15,25 \%$ \\
\hline Siempre & 172 & $12,31 \%$ \\
\hline Total & 1397 & $100,00 \%$ \\
\hline
\end{tabular}

Tabla 155: padres les preguntan por los contenidos que utilizan o van a utilizar en internet.

Con respecto al género, la tabla 156 muestra que de nuevo el porcentaje de chicas que manifiesta que los padres se interesan por su gestión de la red. El 41,93\% de los adolescentes masculinos afirman que sus padres nunca les preguntan sobre este tema. El porcentaje en las chicas es 10 puntos inferior. El valor de significación es de 0,001, por lo que se puede afirmar que existen diferencias significativas.

\begin{tabular}{|l|cccc|}
\cline { 2 - 5 } \multicolumn{1}{c|}{} & Nunca & A veces & Habitualmente & Siempre \\
\hline Femenino & $31,74 \%$ & $36,65 \%$ & $16,89 \%$ & $14,71 \%$ \\
\cline { 2 - 5 } Masculino & $41,93 \%$ & $34,99 \%$ & $13,42 \%$ & $9,65 \%$ \\
\hline Total & 511 & 501 & 213 & 172 \\
\hline
\end{tabular}

Tabla 156: padres les preguntan por los contenidos que utilizan en internet - género

Los adolescentes confirman que los padres se interesan menos por los contenidos que utilizan en la red con la edad. Vemos en la tabla 157, cómo disminuyen los porcentajes de siempre con la edad. Existen diferencias significativas, puesto que el valor de significación es de 0,001. 


\begin{tabular}{|l|cccc|}
\cline { 2 - 5 } \multicolumn{1}{c|}{} & Nunca & A veces & Habitualmente & Siempre \\
\hline $\mathbf{1 2}$ & $31,12 \%$ & $29,08 \%$ & $19,39 \%$ & $20,41 \%$ \\
\cline { 2 - 5 } 13 & $35,07 \%$ & $29,85 \%$ & $15,30 \%$ & $19,78 \%$ \\
\cline { 2 - 5 } 14 & $39,26 \%$ & $35,12 \%$ & $13,22 \%$ & $12,40 \%$ \\
\cline { 2 - 5 } 16 & $35,27 \%$ & $40,10 \%$ & $14,98 \%$ & $9,66 \%$ \\
\hline 17 & $37,77 \%$ & $42,06 \%$ & $14,59 \%$ & $5,58 \%$ \\
\hline Total & $39,04 \%$ & $41,71 \%$ & $13,37 \%$ & $5,88 \%$ \\
\hline
\end{tabular}

Tabla 157: padres les preguntan por los contenidos que utilizan en internet - edad

En la tabla 158 mostramos el resultado del estudio realizado sobre el uso del tiempo en las distintas actividades en relación a si sus padres les han preguntado por los contenidos que van a utilizar o utilizan en internet.

Los adolescentes que siempre hablan con sus padres sobre los contenidos que ven en la red, dedican significativamente más tiempo a las siguientes actividades que aquellos que nunca hablan:

- Dormir entre semana: 15 minutos más de media diaria.

- Teléfono entre semana: 11 minutos más de media diaria

- Trabajo doméstico: tanto entre semana como durante el fin de semana dedican 10 minutos más a esta actividad.

- Lectura: 15 minutos más entre semana y 23 minutos más el fin de semana.

Los adolescentes que nunca hablan con sus padres sobre los contenidos que ven en la red, dedican significativamente más tiempo a las siguientes actividades que aquellos que siempre hablan:

- Actividades relacionadas con las nuevas tecnologías:

$\checkmark$ WhatsApp el fin de semana: aunque la diferencia es escasamente de 3 minutos.

$\checkmark$ Redes entre semana: invierten 13 minutos más.

$\checkmark$ Internet fin de semana: dedican 4 minutos más.

$\checkmark$ Videojuegos: 15 minutos más entre semana y 28 minutos fin de semana.

- Salir con los amigos el fin de semana: dedican 29 minutos más. 
Capítulo 4.- Resultados

\begin{tabular}{|c|c|c|c|c|c|}
\hline & nunca & a veces & habitualmente & siempre & Sig. \\
\hline Dormir S & $7: 43$ & $7: 43$ & $7: 42$ & $7: 58$ & 0,008 \\
\hline Dormir F & $9: 37$ & $9: 29$ & $9: 29$ & $9: 39$ & 0,242 \\
\hline Asistir a clase $\mathrm{S}$ & $6: 07$ & $6: 09$ & $6: 08$ & $6: 07$ & 0,341 \\
\hline Asistir a clase $\mathrm{F}$ & $0: 00$ & $0: 00$ & $0: 00$ & $0: 00$ & \\
\hline Actividades extr. S & $1: 42$ & $1: 52$ & $1: 50$ & $1: 54$ & 0,403 \\
\hline Actividades extr. F & $0: 39$ & $0: 45$ & $0: 44$ & $0: 39$ & 0,475 \\
\hline Estudio S & $2: 20$ & $2: 24$ & $2: 22$ & $2: 31$ & 0,536 \\
\hline Estudio F & $2: 27$ & $2: 39$ & $2: 26$ & $2: 21$ & 0,161 \\
\hline Whatsapp S & $1: 45$ & $1: 48$ & $1: 55$ & $1: 29$ & 0,141 \\
\hline Whatsapp F & $2: 33$ & $2: 56$ & $2: 57$ & $2: 30$ & 0,029 \\
\hline Redes sociales S & $1: 03$ & $1: 12$ & $1: 03$ & $0: 50$ & 0,024 \\
\hline Redes sociales F & $1: 30$ & $1: 42$ & $1: 37$ & $1: 25$ & 0,213 \\
\hline Internet S & $0: 57$ & $0: 51$ & $0: 52$ & $0: 48$ & 0,201 \\
\hline Internet F & $1: 22$ & $1: 15$ & $1: 00$ & $1: 18$ & 0,007 \\
\hline Videojuegos/consolas S & $0: 35$ & $0: 26$ & $0: 25$ & $0: 20$ & 0,011 \\
\hline Videojuegos/consolas F & $1: 15$ & $0: 54$ & $0: 56$ & $0: 47$ & 0,000 \\
\hline Televisión S & $1: 27$ & $1: 26$ & $1: 21$ & $1: 21$ & 0,676 \\
\hline Televisión F & $2: 07$ & $2: 10$ & $1: 57$ & $1: 58$ & 0,289 \\
\hline Teléfono S & $0: 17$ & $0: 22$ & $0: 21$ & $0: 28$ & 0,024 \\
\hline Teléfono F & $0: 27$ & $0: 31$ & $0: 31$ & $0: 37$ & 0,217 \\
\hline Deporte S & $1: 46$ & $1: 50$ & $1: 47$ & $2: 01$ & 0,238 \\
\hline Deporte F & $1: 31$ & $1: 31$ & $1: 28$ & $1: 36$ & 0,751 \\
\hline Trabajo doméstico S & $0: 33$ & $0: 39$ & $0: 42$ & $0: 43$ & 0,002 \\
\hline Trabajo doméstico F & $0: 44$ & $0: 52$ & $0: 55$ & $0: 54$ & 0,008 \\
\hline Trabajo remunerado S & $0: 06$ & $0: 07$ & $0: 05$ & 0:06 & 0,942 \\
\hline Trabajo remunerado $\mathrm{F}$ & $0: 10$ & $0: 09$ & $0: 12$ & $0: 12$ & 0,812 \\
\hline Lectura S & $0: 35$ & $0: 41$ & $0: 46$ & $0: 50$ & 0,001 \\
\hline Lectura F & $0: 41$ & $0: 52$ & $0: 55$ & $1: 04$ & 0,000 \\
\hline Higiene personal S & $1: 12$ & $1: 08$ & $1: 11$ & $1: 13$ & 0,816 \\
\hline Higiene personal F & $1: 13$ & $1: 10$ & $1: 16$ & $1: 12$ & 0,635 \\
\hline Alimentación S & $1: 41$ & $1: 46$ & $1: 42$ & $1: 48$ & 0,556 \\
\hline Alimentación F & $1: 42$ & $1: 45$ & $1: 50$ & $1: 50$ & 0,385 \\
\hline Amigos S & $1: 14$ & $1: 09$ & $1: 16$ & $0: 58$ & 0,223 \\
\hline Amigos F & $3: 35$ & $3: 47$ & $3: 11$ & 3:06 & 0,001 \\
\hline Desplazamientos S & $0: 42$ & $0: 50$ & $0: 44$ & $0: 47$ & 0,078 \\
\hline Desplazamientos F & $0: 56$ & $1: 03$ & $0: 51$ & $0: 55$ & 0,094 \\
\hline Salir con pareja S & $0: 18$ & $0: 09$ & $0: 10$ & $0: 21$ & 0,071 \\
\hline Salir con parej F & $0: 25$ & $0: 25$ & $0: 24$ & $0: 31$ & 0,858 \\
\hline Tiempo en dormirse ayer & $0: 30$ & $0: 32$ & $0: 27$ & $0: 31$ & 0,424 \\
\hline
\end{tabular}

Gráfica 158: uso del tiempo - los padres les preguntan por los contenidos que utilizan internet 


\subsubsection{2.- Cuentan a sus padres los contenidos que ven en internet}

El porcentaje de adolescentes que siempre cuenta a sus padres lo que ve en la red es de un $12,63 \%$. Como muestra la tabla 159 , es bastante superior el porcentaje de aquellos que nunca dan explicaciones a sus padres sobre lo que ven $(33,33 \%)$ o que sólo lo hacen a veces $(36,62 \%)$.

\begin{tabular}{|l|cc|}
\cline { 2 - 3 } \multicolumn{1}{c|}{} & Frecuencia & Porcentaje \\
\hline Nunca & 467 & $33,33 \%$ \\
\cline { 2 - 3 } A veces & 513 & $36,62 \%$ \\
\cline { 2 - 3 } Habitualmente & 244 & $17,42 \%$ \\
\hline Siempre & 177 & $12,63 \%$ \\
\hline Total & 1401 & $100,00 \%$ \\
\hline
\end{tabular}

Tabla 159: cuentan a sus padres los contenidos que ven en internet

Podemos observar en la tabla 160 que existen diferencias por género. El valor de significación, obtenido de la chi-cuadrado de hecho es del 0,000. El porcentaje de chicos que nunca les cuenta a sus padres los contenidos que visita en la web es del $40,00 \%$, cifra muy superior a la femenina $(27,31 \%)$.

\begin{tabular}{|l|cccc|}
\cline { 2 - 5 } \multicolumn{1}{c|}{} & Nunca & A veces & Habitualmente & Siempre \\
\hline Femenino & $27,31 \%$ & $39,40 \%$ & $18,89 \%$ & $14,40 \%$ \\
\hline Masculino & $40,00 \%$ & $33,53 \%$ & $15,79 \%$ & $10,68 \%$ \\
\hline Total & 467 & 513 & 244 & 177 \\
\hline
\end{tabular}

Tabla 160: cuentan a sus padres los contenidos que ven en internet - género

Con respecto a la edad, la tabla 161 muestra claramente que el porcentaje de adolescentes que les cuenta a sus padres lo que visita en la red siempre disminuye notablemente con la edad. De hecho pasa de ser un $22,11 \%$ a los 12 años a un $8,02 \%$ a los 17 , encontrándose años como los 16 con cifras incluso inferiores (5,13\%).

La tabla 162 recoge la ANOVA realizada entre el uso del tiempo en las distintas actividades y el hecho de que les cuenten a sus padres los contenidos a los que acceden en internet. 


\begin{tabular}{|l|cccc|}
\cline { 2 - 5 } \multicolumn{1}{c|}{} & Nunca & A veces & Habitualmente & Siempre \\
\hline 12 & $22,11 \%$ & $33,17 \%$ & $22,61 \%$ & $22,11 \%$ \\
\cline { 2 - 5 } 13 & $29,00 \%$ & $34,20 \%$ & $18,96 \%$ & $17,84 \%$ \\
\cline { 2 - 5 } 14 & $38,17 \%$ & $38,17 \%$ & $12,03 \%$ & $11,62 \%$ \\
\cline { 2 - 5 } 15 & $31,22 \%$ & $42,93 \%$ & $13,66 \%$ & $12,20 \%$ \\
\hline 16 & $40,60 \%$ & $33,76 \%$ & $20,51 \%$ & $5,13 \%$ \\
\hline Total & $34,76 \%$ & $39,04 \%$ & $18,18 \%$ & $8,02 \%$ \\
\hline
\end{tabular}

Tabla 161: cuentan a sus padres los contenidos que ven en internet - edad

Los comentarios principales que podemos hacer a la tabla 162 son los siguientes. Los adolescentes que siempre les cuentan a sus padres los contenidos que ven en la red, dedican significativamente más tiempo que los que no lo cuentan nunca a las siguientes actividades:

- Dormir entre semana: dedican 20 minutos más de media.

- Trabajo doméstico: dedican 7 minutos más entre semana y 8 minutos más el fin de semana.

- Lectura: dedican 15 minutos más entre semana y 17 minutos más el fin de semana.

- Alimentación el fin de semana: dedican 5 minutos más de media.

Los adolescentes que nunca les cuentan a sus padres los contenidos que ven en la red, dedican significativamente más tiempo que los que no lo cuentan siempre a las siguientes actividades:

- Relacionadas con las nuevas tecnologías:

$\checkmark \quad$ WhatsApp el fin de semana: 5 minutos más.

$\checkmark$ Redes sociales: 31 minutos más entre semana y 32 el fin de semana.

$\checkmark \quad$ Internet entre semana: 10 minutos más diarios de media.

$\checkmark$ Videojuegos/consolas el fin de semana: 27 minutos diarios más.

- Salir con amigos: dedican 13 minutos más entre semana y 48 minutos más el fin de semana. 


\begin{tabular}{|c|c|c|c|c|c|}
\hline & nunca & a veces & habitualmente & siempre & Sig. \\
\hline Dormir S & $7: 40$ & $7: 41$ & $7: 49$ & $8: 00$ & 0,000 \\
\hline Dormir F & $9: 34$ & $9: 33$ & $9: 28$ & $9: 35$ & 0,760 \\
\hline Asistir a clase $\mathrm{S}$ & $6: 09$ & $6: 08$ & $6: 07$ & $6: 07$ & 0,239 \\
\hline Asistir a clase $F$ & $0: 00$ & $0: 00$ & $0: 00$ & $0: 00$ & \\
\hline Actividades extr. S & $1: 50$ & $1: 49$ & $1: 51$ & $1: 38$ & 0,557 \\
\hline Actividades extr. F & $0: 42$ & $0: 43$ & $0: 44$ & $0: 36$ & 0,706 \\
\hline Estudio S & $2: 23$ & $2: 22$ & $2: 19$ & $2: 34$ & 0,272 \\
\hline Estudio F & $2: 29$ & $2: 34$ & $2: 28$ & $2: 27$ & 0,832 \\
\hline Whatsapp S & $1: 53$ & $1: 47$ & $1: 36$ & $1: 36$ & 0,149 \\
\hline Whatsapp F & $2: 40$ & $2: 59$ & $2: 30$ & $2: 35$ & 0,045 \\
\hline Redes sociales S & $1: 14$ & $1: 06$ & $1: 01$ & $0: 43$ & 0,000 \\
\hline Redes sociales F & $1: 40$ & $1: 39$ & $1: 35$ & $1: 08$ & 0,006 \\
\hline Internet S & $0: 58$ & $0: 54$ & $0: 47$ & $0: 48$ & 0,050 \\
\hline Internet F & $1: 20$ & $1: 16$ & $1: 11$ & $1: 07$ & 0,246 \\
\hline Videojuegos/consolas S & $0: 34$ & $0: 27$ & $0: 26$ & $0: 21$ & 0,052 \\
\hline Videojuegos/consolas F & $1: 14$ & $0: 56$ & $0: 56$ & $0: 47$ & 0,001 \\
\hline Televisión S & $1: 30$ & $1: 26$ & $1: 17$ & $1: 23$ & 0,180 \\
\hline Televisión F & $2: 12$ & $2: 06$ & $1: 56$ & $1: 59$ & 0,180 \\
\hline Teléfono S & $0: 19$ & $0: 22$ & $0: 26$ & $0: 17$ & 0,073 \\
\hline Teléfono F & $0: 30$ & $0: 33$ & $0: 29$ & $0: 25$ & 0,448 \\
\hline Deporte S & $1: 45$ & $1: 49$ & $1: 57$ & $1: 51$ & 0,349 \\
\hline Deporte F & $1: 29$ & $1: 32$ & $1: 27$ & $1: 36$ & 0,615 \\
\hline Trabajo doméstico S & $0: 33$ & $0: 40$ & $0: 41$ & $0: 40$ & 0,019 \\
\hline Trabajo doméstico F & $0: 43$ & $0: 55$ & $0: 52$ & $0: 51$ & 0,002 \\
\hline Trabajo remunerado S & 0:09 & $0: 05$ & $0: 05$ & $0: 06$ & 0,283 \\
\hline Trabajo remunerado $\mathrm{F}$ & $0: 11$ & 0:09 & $0: 11$ & $0: 11$ & 0,889 \\
\hline Lectura S & $0: 33$ & $0: 41$ & $0: 48$ & $0: 48$ & 0,000 \\
\hline Lectura F & $0: 42$ & $0: 50$ & $0: 59$ & $0: 59$ & 0,002 \\
\hline Higiene personal S & $1: 13$ & $1: 11$ & $1: 10$ & $1: 03$ & 0,329 \\
\hline Higiene personal F & $1: 12$ & $1: 15$ & $1: 13$ & $1: 06$ & 0,409 \\
\hline Alimentación S & $1: 39$ & $1: 45$ & $1: 48$ & $1: 48$ & 0,401 \\
\hline Alimentación F & $1: 39$ & $1: 49$ & $1: 51$ & $1: 44$ & 0,047 \\
\hline Amigos S & $1: 16$ & $1: 15$ & $0: 57$ & $1: 03$ & 0,029 \\
\hline Amigos $\mathrm{F}$ & $3: 40$ & $3: 44$ & $3: 23$ & $2: 52$ & 0,000 \\
\hline Desplazamientos S & $0: 42$ & $0: 47$ & $0: 48$ & $0: 46$ & 0,392 \\
\hline Desplazamientos F & $0: 51$ & $1: 04$ & $0: 59$ & $0: 56$ & 0,035 \\
\hline Salir con pareja S & $0: 12$ & $0: 16$ & $0: 16$ & 0:09 & 0,611 \\
\hline Salir con parej $\mathbf{F}$ & $0: 24$ & $0: 28$ & $0: 30$ & $0: 21$ & 0,526 \\
\hline Tiempo en dormirse ayer & $0: 33$ & $0: 30$ & $0: 27$ & $0: 29$ & 0,091 \\
\hline
\end{tabular}

Tabla 162: uso del tiempo -cuentan a sus padres los contenidos que ven en internet 


\subsection{4.- Conclusiones control parental:}

Como conclusión a este último bloque de preguntas podemos afirmar que en todos los casos, el control que se ejerce por parte de los padres es mayor sobre el género femenino que sobre el masculino. Los padres muestras más interés por las prácticas de sus hijas en la web.

Se observa además, que la comunicación con las adolescentes es más fluida que con los chicos. Las cifras, también apuntan a que las chicas son más comunicativas en este sentido que los chicos. El resultado del valor de significación es inferior en las 5 preguntas a 0,05 por lo que podemos afirmar que el género marca diferencias significativas en todas ellas.

Con respecto a la edad, las respuestas a todas las preguntas afirman que el control que ejercen los padres sobre sus hijos en las redes, el interés mostrado por los padres en saber y por los hijos en mantenerles informados, disminuye con la edad. El factor de significación afirma la existencia de diferencias significativas.

\section{6.- RENDIMIENTO ACADÉMICO}

En este apartado analizaremos el uso del tiempo y las TIC en relación con el rendimiento escolar. La gráfica 128 muestra las respuestas a las preguntas 50,51 y 52 de la encuesta. Como puede verse en ella:

- el $16,6 \%$ de los adolescentes ha repetido algún curso escolar.

- casi del $60 \%$ ha suspendido alguna asignatura la evaluación pasada (la media de asignaturas suspensas por adolescente es de 1,76).

- el $51,2 \%$ de los adolescentes burgaleses encuestados tiene actualmente apoyo escolar (academia o profesor particular).

La nota media que obtuvo el curso pasado fue de 6,70 (pregunta 53 de la encuesta). La nota media que espera sacar este curso es de 6,92(pregunta 54 de la encuesta). 


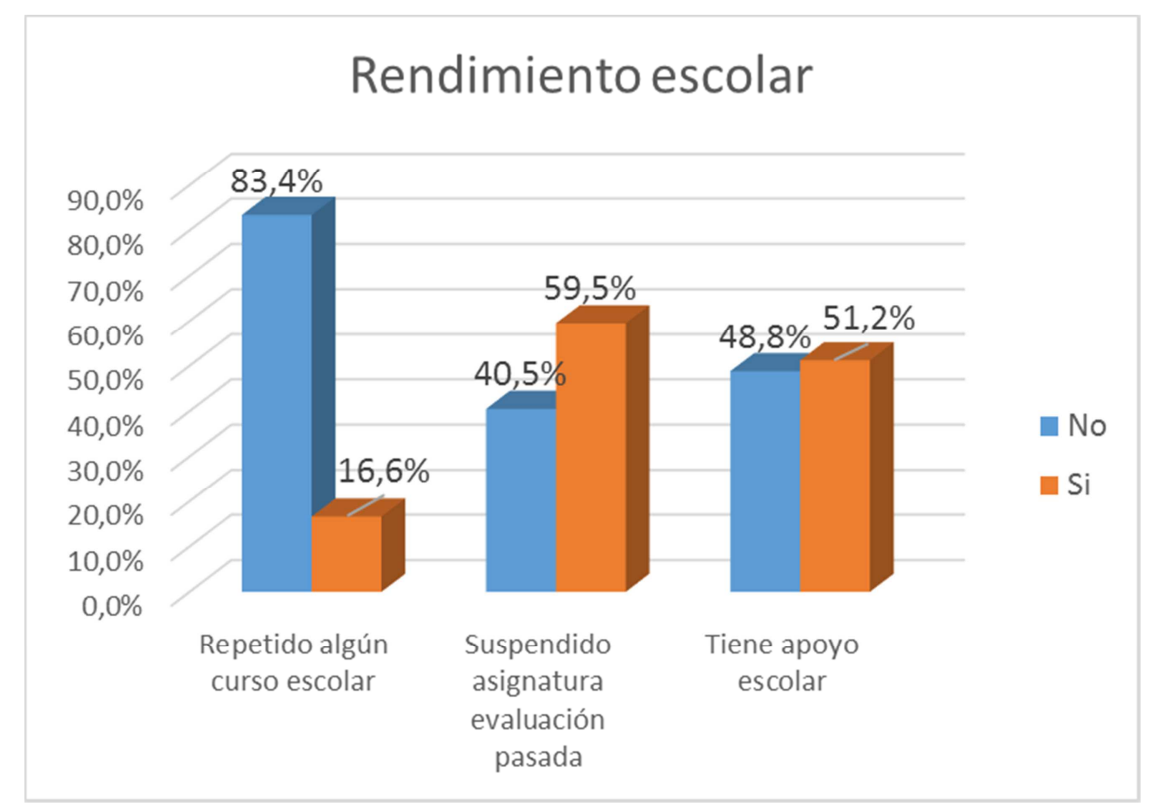

Gráfica 128: resultados académicos de los adolescentes burgaleses encuestados

La tabla 163 representa las diferencias entre el uso del tiempo en las diferentes actividades y si el adolescente ha repetido algún curso.

Los adolescentes que han repetido algún curso escolar dedican más tiempo (de manera significativa) que los que nunca han repetido a las siguientes actividades (tabla 163):

- Actividades relacionadas con las nuevas tecnologías:

$\checkmark$ WhatsApp: 42 minutos más entre semana y 48 minutos más el fin de semana.

$\checkmark$ Redes sociales: 27 minutos más entre semana y 34 minutos más el fin de semana.

$\checkmark$ Videojuegos/consolas: 24 minutos más ente semana y 27 minutos más el fin de semana.

$\checkmark$ Televisión entre semana: 26 minutos más

- Trabajo doméstico entre semana: 9 minutos más.

- Higiene personal: 17 minutos más entre semana y 10 minutos más el fin de semana.

- Amigos: 20 minutos más entre semana y 56 minutos más el fin de semana

- Salir con pareja: 18 minutos más entre semana y 28 el fin de semana. 


\section{2a PARTE}

Capítulo 4.- Resultados

\begin{tabular}{|c|c|c|c|c|c|c|c|c|}
\hline & \multicolumn{2}{|c|}{$\begin{array}{l}\text { Repetido algún } \\
\text { curso escolar }\end{array}$} & \multirow[t]{2}{*}{$t$} & \multirow[t]{2}{*}{ gl } & \multirow{2}{*}{$\begin{array}{c}\text { Sig. } \\
\text { (bilateral) }\end{array}$} & \multirow{2}{*}{$\begin{array}{r}\text { Diferencia } \\
\text { de medias }\end{array}$} & \multicolumn{2}{|c|}{$\begin{array}{l}\text { 95\% de intervalo de } \\
\text { confianza de la diferencia }\end{array}$} \\
\hline & no & si & & & & & Inferior & Superior \\
\hline Dormir S & $7: 46$ & $7: 36$ & 2,364 & 271,585 & 0,019 & $0: 10$ & $0: 01$ & $0: 18$ \\
\hline Dormir F & 9:35 & 9:25 & 1,608 & 264,102 & 0,109 & 0:09 & $-0: 02$ & $0: 21$ \\
\hline Asistir a clase $\mathrm{S}$ & $6: 08$ & $6: 07$ & 1,538 & 305,272 & 0,125 & $0: 01$ & $-0: 00$ & $0: 03$ \\
\hline Asistir a clase $\mathrm{F}$ & $0: 00$ & 0:00 & & & & & & \\
\hline Actividades extr. S & $1: 53$ & $1: 23$ & 4,114 & 279,251 & 0,000 & $0: 29$ & $0: 15$ & $0: 43$ \\
\hline Actividades extr. F & $0: 45$ & $0: 25$ & 5,235 & 334,411 & 0,000 & $0: 20$ & $0: 12$ & $0: 28$ \\
\hline Estudio S & $2: 26$ & $2: 08$ & 3,368 & 325,684 & 0,001 & $0: 18$ & $0: 07$ & $0: 29$ \\
\hline Estudio F & $2: 40$ & $1: 45$ & 7,281 & 304,628 & 0,000 & $0: 54$ & $0: 40$ & 1:09 \\
\hline Whatsapp S & $1: 40$ & $2: 22$ & $-4,482$ & 250,417 & 0,000 & $-0: 41$ & $-1: 00$ & $-0: 23$ \\
\hline Whatsapp F & $2: 37$ & $3: 25$ & $-3,656$ & 239,511 & 0,000 & $-0: 47$ & $-1: 12$ & $-0: 21$ \\
\hline Redes sociales S & 1:01 & $1: 28$ & $-3,936$ & 252,269 & 0,000 & $-0: 27$ & $-0: 41$ & $-0: 13$ \\
\hline Redes sociales F & $1: 30$ & $2: 04$ & $-3,693$ & 250,743 & 0,000 & $-0: 33$ & $-0: 51$ & $-0: 15$ \\
\hline Internet S & $0: 52$ & $1: 01$ & $-1,874$ & 240,443 & 0,062 & $-0: 08$ & $-0: 18$ & $0: 00$ \\
\hline Internet F & $1: 15$ & $1: 20$ & $-0,810$ & 249,868 & 0,419 & $-0: 04$ & $-0: 17$ & $0: 07$ \\
\hline Videojuegos/consolas S & $0: 24$ & $0: 48$ & $-4,508$ & 249,832 & 0,000 & $-0: 24$ & $-0: 34$ & $-0: 13$ \\
\hline Videojuegos/consolas F & $0: 57$ & $1: 24$ & $-3,346$ & 250,054 & 0,001 & $-0: 27$ & $-0: 43$ & $-0: 11$ \\
\hline Televisión S & $1: 21$ & $1: 47$ & $-4,059$ & 259,050 & 0,000 & $-0: 26$ & $-0: 38$ & $-0: 13$ \\
\hline Televisión F & $2: 03$ & $2: 17$ & $-1,732$ & 266,325 & 0,084 & $-0: 13$ & $-0: 29$ & $0: 01$ \\
\hline Teléfono S & $0: 19$ & $0: 30$ & $-2,647$ & 241,020 & 0,009 & $-0: 10$ & $-0: 17$ & $-0: 02$ \\
\hline Teléfono F & $0: 28$ & $0: 39$ & $-2,093$ & 232,951 & 0,037 & $-0: 10$ & $-0: 19$ & $-0: 00$ \\
\hline Deporte S & $1: 49$ & $1: 49$ & 0,002 & 276,222 & 0,999 & $0: 00$ & $-0: 13$ & $0: 13$ \\
\hline Deporte F & $1: 31$ & $1: 28$ & 0,607 & 258,461 & 0,545 & 0:03 & $-0: 08$ & $0: 15$ \\
\hline Trabajo doméstico S & $0: 36$ & $0: 45$ & $-2,573$ & 260,244 & 0,011 & $-0: 08$ & $-0: 15$ & $-0: 02$ \\
\hline Trabajo doméstico F & $0: 49$ & $0: 55$ & $-1,624$ & 259,457 & 0,106 & $-0: 06$ & $-0: 15$ & $0: 01$ \\
\hline Trabajo remunerado $\mathrm{S}$ & $0: 06$ & $0: 08$ & $-0,510$ & 253,981 & 0,611 & $-0: 01$ & $-0: 07$ & $0: 04$ \\
\hline Trabajo remunerado $\mathrm{F}$ & 0:09 & $0: 19$ & $-1,868$ & 221,465 & 0,063 & $-0: 09$ & $-0: 19$ & $0: 00$ \\
\hline Lectura S & $0: 41$ & $0: 35$ & 1,766 & 291,273 & 0,078 & 0:06 & $-0: 00$ & $0: 13$ \\
\hline Lectura F & $0: 53$ & $0: 35$ & 4,078 & 315,868 & 0,000 & $0: 17$ & 0:09 & $0: 26$ \\
\hline Higiene personal S & 1:08 & $1: 25$ & $-3,334$ & 255,937 & 0,001 & $-0: 17$ & $-0: 27$ & $-0: 07$ \\
\hline Higiene personal F & $1: 11$ & $1: 21$ & $-2,509$ & 271,165 & 0,013 & $-0: 10$ & $-0: 19$ & $-0: 02$ \\
\hline Alimentación S & $1: 44$ & $1: 42$ & 0,262 & 252,265 & 0,793 & 0:01 & $-0: 09$ & $0: 12$ \\
\hline Alimentación F & $1: 46$ & $1: 40$ & 1,153 & 252,247 & 0,250 & 0:06 & $-0: 04$ & $0: 17$ \\
\hline Amigos S & 1:08 & $1: 28$ & $-2,866$ & 270,609 & 0,004 & $-0: 20$ & $-0: 34$ & $-0: 06$ \\
\hline Amigos F & 3:24 & $4: 20$ & $-4,743$ & 272,402 & 0,000 & $-0: 56$ & $-1: 19$ & $-0: 32$ \\
\hline Desplazamientos S & $0: 46$ & $0: 41$ & 1,346 & 247,657 & 0,179 & $0: 05$ & $-0: 02$ & $0: 13$ \\
\hline Desplazamientos F & $0: 59$ & $0: 50$ & 1,777 & 279,261 & 0,077 & $0: 08$ & $-0: 00$ & $0: 17$ \\
\hline Salir con pareja S & $0: 11$ & $0: 29$ & $-2,608$ & 220,795 & 0,010 & $-0: 17$ & $-0: 30$ & $-0: 04$ \\
\hline Salir con parej F & $0: 22$ & $0: 50$ & $-3,523$ & 211,273 & 0,001 & $-0: 28$ & $-0: 44$ & $-0: 12$ \\
\hline Tiempo en dormirse ayer & $0: 30$ & $0: 31$ & $-0,379$ & 304,035 & 0,705 & $-0: 00$ & $-0: 06$ & $0: 04$ \\
\hline
\end{tabular}

Tabla 163: uso del tiempo - repetido curso 
Los adolescentes que nunca han repetido curso dedican más tiempo significativamente que los que sí han repetido a las siguientes actividades:

- Dormir entre semana: 10 minutos más.

- Actividades extraescolares: entre semana, dedican a estas actividades 30 minutos más de media y 20 el fin de semana.

- Estudio: los adolescentes que no han repetido curso, dedican entre semana 18 minutos más y 55 el fin de semana que aquellos que sí que han repetido.

- Lectura fin de semana: dedican 18 minutos más diarios de media.

A continuación analizamos el uso del tiempo de los adolescentes en relación a si han suspendido alguna asignatura la evaluación pasada. Podemos ver los resultados de este cálculo de t-Student en la tabla 164.

Los adolescentes que sí han suspendido ninguna asignatura la evaluación pasada dedican más tiempo que los que no suspendieron nada a las siguientes actividades:

- Actividades relacionadas con las nuevas tecnologías:

$\checkmark$ WhatsApp: 20 minutos más de media entre semana y 19 el fin de semana.

$\checkmark$ Redes sociales: 18 minutos de media más entre semana y 24 el fin de semana

$\checkmark$ Internet: 12 minutos más entre semana y 13 el fin de semana.

$\checkmark$ Televisión: 20 minutos más entre semana y 14 minutos más el fin de semana

$\checkmark$ Teléfono: 5 minutos más entre semana y 7 durante el fin de semana.

- Deporte fin de semana: 8 minutos más de media.

- Trabajo doméstico: 4 minutos más diarios entre semana y 7 el fin de semana.

- Trabajo remunerado: 4 minutos más diarios entre semana y 7 el fin de semana.

- Higiene personal: dedican 11 minutos más entre semana y 6 minutos más el fin de semana.

- Salir con amigos: 13 minutos más entre semana y 32 el fin de semana.

- Salir con pareja el fin de semana: dedican 9 minutos a esta actividad más que los que no han suspendido ninguna asignatura la evaluación pasada. 


\section{2a PARTE}

Capítulo 4.- Resultados

\begin{tabular}{|c|c|c|c|c|c|c|c|c|}
\hline & \multicolumn{2}{|c|}{$\begin{array}{c}\text { asign. suspensa } \\
\text { evaluación pasada }\end{array}$} & \multirow[t]{2}{*}{$t$} & \multirow{2}{*}{ gl } & \multirow{2}{*}{$\begin{array}{c}\text { Sig. } \\
\text { bilateral }\end{array}$} & \multirow{2}{*}{$\begin{array}{c}\text { Diferencia } \\
\text { medias }\end{array}$} & \multicolumn{2}{|c|}{$\begin{array}{l}95 \% \text { de interv. } \\
\text { confianza }\end{array}$} \\
\hline & No & Sí & & & & & Inferior & Superior \\
\hline Dormir S & $7: 48$ & $7: 42$ & 2,129 & 1257,116 & 0,033 & $0: 06$ & $0: 00$ & $0: 11$ \\
\hline Dormir F & $9: 37$ & $9: 30$ & 1,538 & 1194,789 & 0,124 & $0: 06$ & $-0: 01$ & $0: 14$ \\
\hline Asistir a clase $\mathrm{S}$ & $6: 08$ & $6: 08$ & $-0,127$ & 1200,104 & 0,899 & $-0: 00$ & $-0: 01$ & $0: 01$ \\
\hline Asistir a clase $\mathrm{F}$ & $0: 00$ & $0: 00$ & & & & & & \\
\hline Actividades extr. S & $1: 54$ & $1: 43$ & 2,042 & 1046,155 & 0,041 & $0: 11$ & $0: 00$ & $0: 21$ \\
\hline Actividades extr. F & $0: 44$ & $0: 40$ & 1,082 & 953,751 & 0,279 & $0: 03$ & $-0: 03$ & $0: 11$ \\
\hline Estudio S & $2: 21$ & $2: 24$ & $-0,806$ & 1226,815 & 0,420 & $-0: 03$ & $-0: 12$ & $0: 05$ \\
\hline Estudio F & $2: 37$ & $2: 26$ & 1,846 & 1205,063 & 0,065 & $0: 10$ & $-0: 00$ & $0: 22$ \\
\hline Whatsapp S & $1: 34$ & $1: 54$ & $-3,378$ & 1279,641 & 0,001 & $-0: 20$ & $-0: 31$ & $-0: 08$ \\
\hline Whatsapp F & $2: 33$ & $2: 52$ & $-2,338$ & 1207,818 & 0,020 & $-0: 19$ & $-0: 35$ & $-0: 03$ \\
\hline Redes sociales S & $0: 54$ & $1: 12$ & $-4,113$ & 1242,015 & 0,000 & $-0: 18$ & $-0: 26$ & $-0: 09$ \\
\hline Redes sociales F & $1: 21$ & $1: 45$ & $-4,163$ & 1228,143 & 0,000 & $-0: 24$ & $-0: 35$ & $-0: 12$ \\
\hline Internet S & $0: 46$ & $0: 58$ & $-3,803$ & 1252,747 & 0,000 & $-0: 11$ & $-0: 16$ & $-0: 05$ \\
\hline Internet F & $1: 08$ & $1: 21$ & $-3,135$ & 1213,418 & 0,002 & $-0: 13$ & $-0: 21$ & $-0: 04$ \\
\hline Videojuegos/consolas S & $0: 25$ & $0: 31$ & $-1,805$ & 1282,037 & 0,071 & $-0: 05$ & $-0: 11$ & $0: 00$ \\
\hline Videojuegos/consolas F & $0: 57$ & $1: 04$ & $-1,394$ & 1170,339 & 0,164 & $-0: 06$ & $-0: 16$ & $0: 02$ \\
\hline Televisión S & $1: 14$ & $1: 34$ & $-5,094$ & 1296,058 & 0,000 & $-0: 20$ & $-0: 27$ & $-0: 12$ \\
\hline Televisión F & $1: 57$ & $2: 11$ & $-2,642$ & 1199,507 & 0,008 & $-0: 13$ & $-0: 24$ & $-0: 03$ \\
\hline Teléfono S & $0: 18$ & $0: 23$ & $-2,237$ & 1187,202 & 0,025 & $-0: 04$ & $-0: 09$ & $-0: 00$ \\
\hline Teléfono F & $0: 26$ & $0: 33$ & $-2,284$ & 1163,194 & 0,023 & $-0: 06$ & $-0: 12$ & $-0: 00$ \\
\hline Deporte S & $1: 45$ & $1: 52$ & $-1,343$ & 1197,409 & 0,179 & $-0: 06$ & $-0: 15$ & $0: 02$ \\
\hline Deporte F & $1: 26$ & $1: 34$ & $-2,073$ & 1215,658 & 0,038 & $-0: 08$ & $-0: 16$ & $-0: 00$ \\
\hline Trabajo doméstico S & $0: 35$ & $0: 39$ & $-2,151$ & 1217,114 & 0,032 & $-0: 04$ & $-0: 08$ & $-0: 00$ \\
\hline Trabajo doméstico $\mathrm{F}$ & $0: 45$ & $0: 52$ & $-2,747$ & 1224,659 & 0,006 & $-0: 07$ & $-0: 12$ & $-0: 02$ \\
\hline Trabajo remunerado S & $0: 04$ & $0: 08$ & $-2,484$ & 1228,898 & 0,013 & $-0: 04$ & $-0: 07$ & $-0: 00$ \\
\hline Trabajo remunerado F & $0: 06$ & $0: 13$ & $-2,482$ & 1209,117 & 0,013 & $-0: 06$ & $-0: 11$ & $-0: 01$ \\
\hline Lectura S & $0: 41$ & $0: 40$ & 0,188 & 1209,445 & 0,851 & $0: 00$ & $-0: 04$ & $0: 05$ \\
\hline Lectura F & $0: 53$ & $0: 48$ & 1,486 & 1203,645 & 0,138 & $0: 05$ & $-0: 01$ & $0: 12$ \\
\hline Higiene personal S & $1: 04$ & $1: 15$ & $-3,182$ & 1212,526 & 0,002 & $-0: 10$ & $-0: 17$ & $-0: 04$ \\
\hline Higiene personal F & $1: 09$ & $1: 15$ & $-2,163$ & 1203,226 & 0,031 & $-0: 06$ & $-0: 12$ & $-0: 00$ \\
\hline Alimentación S & $1: 43$ & $1: 44$ & $-0,343$ & 1220,010 & 0,732 & $-0: 01$ & $-0: 09$ & $0: 06$ \\
\hline Alimentación F & $1: 49$ & $1: 42$ & 1,917 & 1136,639 & 0,055 & $0: 07$ & $-0: 00$ & $0: 14$ \\
\hline Amigos S & $1: 03$ & $1: 16$ & $-2,713$ & 1226,164 & 0,007 & $-0: 13$ & $-0: 22$ & $-0: 03$ \\
\hline Amigos $\mathrm{F}$ & $3: 13$ & $3: 45$ & $-4,033$ & 1207,982 & 0,000 & $-0: 31$ & $-0: 46$ & $-0: 16$ \\
\hline Desplazamientos S & $0: 47$ & $0: 44$ & 0,898 & 1139,398 & 0,369 & $0: 02$ & $-0: 02$ & $0: 07$ \\
\hline Desplazamientos F & $0: 58$ & $0: 57$ & 0,283 & 1141,882 & 0,777 & $0: 01$ & $-0: 06$ & $0: 08$ \\
\hline Salir con pareja S & $0: 10$ & $0: 17$ & $-1,681$ & 980,255 & 0,093 & $-0: 06$ & $-0: 14$ & $0: 01$ \\
\hline Salir con pareja F & $0: 20$ & $0: 29$ & $-2,248$ & 1166,708 & 0,025 & $-0: 09$ & $-0: 17$ & $-0: 01$ \\
\hline Tiempo en dormirse ayer & $0: 29$ & $0: 31$ & $-1,472$ & 1214,384 & 0,141 & $-0: 02$ & $-0: 06$ & $0: 00$ \\
\hline
\end{tabular}

Tabla 164: uso del tiempo - asignatura suspensa la evaluación pasada

Los adolescentes que no han suspendido ninguna asignatura la evaluación pasada dedican más tiempo que los que sí que suspendieron a las siguientes actividades: 
- Dormir entre semana: 6 minutos de media al día más

- Asistir a actividades extraescolares entre semana: los adolescentes que manifiestan no haber suspendido ninguna asignatura la evaluación previa a la realización de la encuesta, dedican 11 minutos diarios más de media a realizar actividades extraescolares que aquellos que sí han suspendido.

Otro de los puntos que entendemos interesantes analizar, es ver la relación entre el tiempo destinado a internet para ocio o para soporte académico y su relación con el rendimiento académico. En la tabla 165 podemos observar que los adolescentes que han repetido algún curso dedican un porcentaje mayor de su tiempo en internet al ocio $(67,9 \%)$ que aquellos que no han repetido ningún curso $(59,7 \%)$.

\begin{tabular}{|l|l|cc|}
\cline { 3 - 4 } \multicolumn{2}{l|}{} & $\begin{array}{c}\text { \%de uso de internet a } \\
\text { estudios }\end{array}$ & $\begin{array}{c}\% \text { de uso internet a } \\
\text { ocio }\end{array}$ \\
\hline $\begin{array}{l}\text { Repetido } \\
\text { curso }\end{array}$ & No & $40,3 \%$ & $59,7 \%$ \\
\cline { 2 - 4 } & Si & $32,1 \%$ & $67,9 \%$ \\
\hline
\end{tabular}

Tabla 165: tiempo a internet para educación y para ocio - curso repetido

Del mismo modo, tal y como muestra la tabla 166, aquellos adolescentes que han suspendido alguna asignatura la evaluación pasada, dedican más tiempo a internet por ocio $(63,4 \%)$ que los que no han suspendido ninguna asignatura $(57,6 \%)$.

\begin{tabular}{|l|l|cc|}
\cline { 3 - 4 } \multicolumn{2}{c|}{} & $\begin{array}{c}\text { \%de uso de internet a } \\
\text { estudios }\end{array}$ & $\begin{array}{c}\% \text { de uso internet a } \\
\text { ocio }\end{array}$ \\
\hline $\begin{array}{l}\text { Suspendido } \\
\text { asignatura }\end{array}$ & No & $42,4 \%$ & $57,6 \%$ \\
\hline
\end{tabular}

Tabla 166: tiempo a internet para educación y para ocio - asignatura suspensa

Por lo tanto, podemos concluir que los adolescentes burgaleses cuyo rendimiento académico es bueno (no han repetido ningún curso o no han suspendido ninguna asignatura la evaluación pasada), dedican más tiempo a navegar como apoyo a su educación que aquellos que obtienen peores notas. 
Además del uso de internet, queremos analizar si el hecho de poseer tecnología afecta al rendimiento escolar del adolescente. Analizamos si uno de los dispositivos de moda entre los adolescentes actualmente (el teléfono móvil) puede afectar en el rendimiento académico (has repetido curso). Como muestra la tabla 167, el porcentaje de adolescentes que tiene móvil propio y ha repetido algún curso escolar es muy similar al porcentaje de aquellos que también han repetido pero no tienen teléfono móvil propio. El nivel de significación $(0,847)$ es muy superior a 0,05 por lo que no podemos afirmar que existan diferencias significativas.

\begin{tabular}{|c|l|cc|c|}
\cline { 3 - 4 } \multicolumn{2}{c|}{} & \multicolumn{3}{c|}{ ¿Has repetido algún curso escolar? } \\
\cline { 3 - 5 } \multicolumn{2}{c|}{} & No & Si & Total \\
\hline \multirow{2}{*}{$\begin{array}{c}\text { ¿Tienes teléfono } \\
\text { móvil propio? }\end{array}$} & No & $84,2 \%$ & $15,8 \%$ & 95 \\
\cline { 2 - 5 } & Si & $83,4 \%$ & $16,6 \%$ & 1311 \\
\cline { 2 - 5 } & Total & 1174 & 232 & 1406 \\
\hline
\end{tabular}

Tabla 167: repetir un curso escolar y tener teléfono móvil

A continuación analizamos la relación entre control parental y rendimiento académico.

\subsection{1.- Control parental y rendimiento escolar}

Nos interesa saber si el control parental (pregunta 45 de la encuesta) afecta al rendimiento académico de los adolescentes (pregunta 50 de la encuesta). Para ello, calculamos el porcentaje de adolescentes que teniendo normas han repetido o no curso escolar. Como muestra la tabla 168, el porcentaje de adolescentes que repite curso disminuye al aumentar el control parental. El porcentaje de adolescentes que han repetido curso y que nunca tienen normas sobre el uso de dispositivos e internet $(47,8 \%)$ es mayor que el porcentaje que repite aun teniendo siempre normas (13\%). El factor de significación es de 0,046 (inferior a 0,05) por lo que podemos afirmar que existen diferencias significativas.

\begin{tabular}{|c|c|c|c|c|c|c|}
\hline & \multicolumn{4}{|c|}{ Normas sobre uso de dispositivos e internet } & \multirow{2}{*}{ Tota } \\
\hline & & Nunca & A veces & Habitualmente & Siempre & \\
\hline \multirow{3}{*}{$\begin{array}{c}\text { Repetido } \\
\text { curso }\end{array}$} & No & $42,6 \%$ & $24,5 \%$ & $11,8 \%$ & $21,0 \%$ & 1157 \\
\hline & $\mathbf{S i}$ & $47,8 \%$ & $27,4 \%$ & $11,7 \%$ & $13,0 \%$ & 230 \\
\hline & Total & 603 & 347 & 164 & 273 & 1387 \\
\hline
\end{tabular}

Tabla 168: tener normas en casa en internet - repetir curso 
Comparamos a continuación la nota media obtenida el año pasado y la espera este año por el adolescente en relación a tener normas en casa con el uso de internet. Como podemos ver en la gráfica 129 , no se observa una tendencia clara en cuanto a la relación. Sí que podemos observar que el valor de nota media más alta (tanto el año pasado como la esperada este año) corresponde a una situación en que los adolescentes siempre tienen normas con respecto al uso de internet. Sin embargo, estos porcentajes se asemejan bastante a los que obtenemos para los adolescentes que manifiestan nunca tener normas.

El factor de significación no confirma la existencia de diferencias significativas en la nota del año pasado ni en la esperada este año en relación a tener normas en casa sobre el uso de internet (nivel de significación de 0,116 y de 0,222 respectivamente).

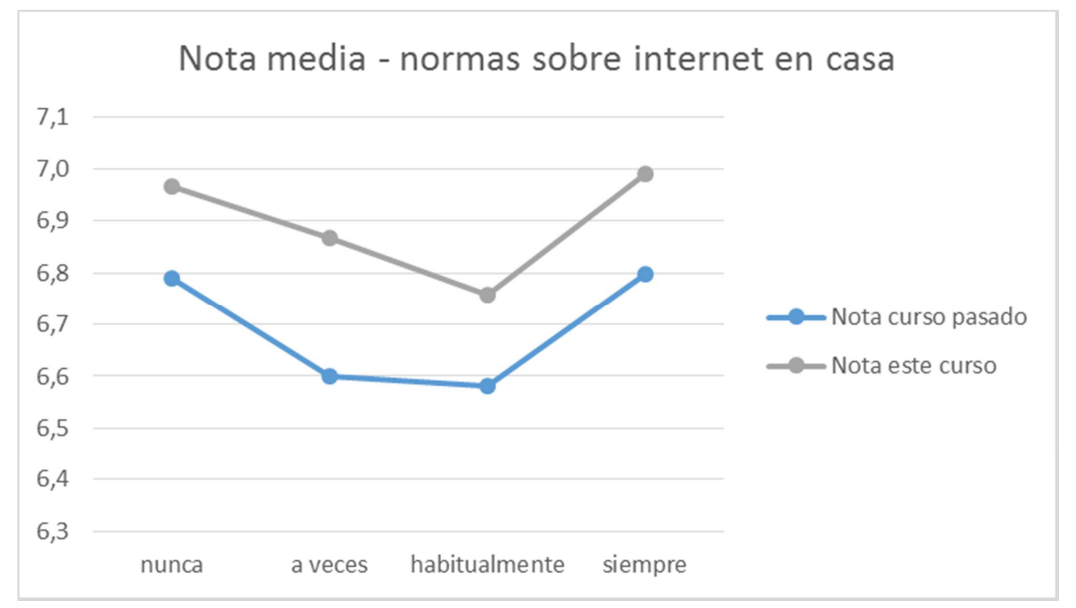

Gráfico 129: relación nota media y normas sobre internet en casa

\subsection{2.- Satisfacción con el rendimiento académico}

El último bloque de preguntas de la encuesta trata de medir la satisfacción tanto de los padres como del adolescente en relación a su rendimiento escolar. Además, preguntamos a los adolescentes sobre el fin predominante de su estudio: estudiar para aprobar o para aprender.

La tabla 169 refleja el porcentaje de adolescentes que ha repetido curso y su satisfacción personal en relación a sus logros académicos. Como puede observarse, el porcentaje de 
adolescentes que está habitualmente satisfecho o siempre con sus logros académicos es más alto para los adolescentes que no han repetido curso. Encontramos el mayor porcentaje de adolescentes que nunca están satisfechos, entre aquellos que han repetido curso alguna vez. El nivel de significación es de 0,000 por lo que sí que existen diferencias significativas.

\begin{tabular}{|l|cccc|c|}
\cline { 2 - 6 } \multicolumn{1}{c|}{} & \multicolumn{4}{c|}{ Satisfecho con sus logros académicos } & \multirow{2}{*}{ Total } \\
\hline No & Nunca & A veces & Habitualmente & Siempre & \\
\hline Si & $12,35 \%$ & $35,08 \%$ & $36,54 \%$ & $16,04 \%$ & 1166 \\
\hline Total & $28,19 \%$ & $46,70 \%$ & $15,42 \%$ & $9,69 \%$ & 227 \\
\hline
\end{tabular}

Tabla 169: repetir curso escolar- satisfacción con rendimiento escolar

Del mismo modo, comparamos los logros académicos de los adolescentes con la satisfacción de los padres. Como se puede observar en la tabla 170, de los adolescentes que han repetido curso, el porcentaje de padres que nunca están satisfechos es del $21,05 \%$ y el $53,51 \%$ sólo a veces. Los porcentajes de padres satisfechos habitualmente y siempre son mucho más elevados para los adolescentes que no han repetido curso. Existen diferencias significativas, puesto que el nivel de significación es inferior a 0,05.

\begin{tabular}{|l|cccc|c|}
\cline { 2 - 6 } \multicolumn{1}{c|}{} & \multicolumn{3}{c|}{ Padres satisfechos con logros académicos } & \multirow{2}{*}{ Total } \\
\hline No & Nunca & A veces & Habitualmente & Siempre & \\
\hline Si & $8,43 \%$ & $30,32 \%$ & $37,39 \%$ & $23,85 \%$ & 1174 \\
\hline Total & $21,05 \%$ & $53,51 \%$ & $16,67 \%$ & $8,77 \%$ & 228 \\
\hline
\end{tabular}

Tabla 170: relación repetir curso escolar-satisfacción de los padres

Con respecto al uso del tiempo, vamos a realizar una t-Student para tratar de encontrar las posibles diferencias significativas entre el uso del tiempo de los adolescentes y satisfacción académica. El resultado se puede observar en la tabla 171. 


\begin{tabular}{|c|c|c|c|c|c|}
\hline & nunca & a veces & habitualmente & siempre & Sig. \\
\hline Dormir S & $7: 34$ & $7: 39$ & $7: 46$ & $8: 03$ & 0,000 \\
\hline Dormir F & $9: 36$ & $9: 24$ & 9:39 & $9: 41$ & 0,006 \\
\hline Asistir a clase $\mathrm{S}$ & $6: 09$ & $6: 08$ & $6: 08$ & $6: 06$ & 0,170 \\
\hline Asistir a clase F & $0: 00$ & $0: 00$ & $0: 00$ & $0: 00$ & \\
\hline Actividades extr. S & $1: 53$ & $1: 48$ & $1: 43$ & $1: 48$ & 0,615 \\
\hline Actividades extr. $F$ & $0: 45$ & $0: 41$ & $0: 44$ & $0: 34$ & 0,268 \\
\hline Estudio S & $2: 13$ & $2: 23$ & $2: 29$ & $2: 18$ & 0,090 \\
\hline Estudio F & $2: 19$ & $2: 32$ & $2: 38$ & $2: 25$ & 0,160 \\
\hline Whatsapp S & $2: 06$ & $1: 55$ & $1: 42$ & $1: 17$ & 0,000 \\
\hline Whatsapp F & $2: 58$ & $2: 49$ & $2: 43$ & $2: 25$ & 0,164 \\
\hline Redes sociales S & $1: 19$ & $1: 11$ & $1: 03$ & $0: 44$ & 0,000 \\
\hline Redes sociales F & $1: 47$ & $1: 43$ & $1: 35$ & $1: 05$ & 0,000 \\
\hline Internet S & $0: 57$ & $0: 57$ & $0: 51$ & $0: 47$ & 0,104 \\
\hline Internet F & $1: 12$ & $1: 22$ & $1: 12$ & $1: 13$ & 0,202 \\
\hline Videojuegos/consolas S & $0: 38$ & $0: 26$ & $0: 27$ & $0: 26$ & 0,101 \\
\hline Videojuegos/consolas F & $1: 01$ & $1: 00$ & $1: 00$ & $1: 05$ & 0,904 \\
\hline Televisión S & $1: 27$ & $1: 37$ & $1: 13$ & $1: 21$ & 0,000 \\
\hline Televisión F & $1: 58$ & $2: 19$ & $2: 01$ & $1: 51$ & 0,001 \\
\hline Teléfono S & $0: 25$ & $0: 23$ & $0: 18$ & $0: 18$ & 0,060 \\
\hline Teléfono F & $0: 37$ & $0: 33$ & $0: 23$ & $0: 27$ & 0,004 \\
\hline Deporte S & $2: 02$ & $1: 54$ & $1: 41$ & $1: 45$ & 0,014 \\
\hline Deporte F & $1: 31$ & $1: 36$ & $1: 24$ & $1: 35$ & 0,078 \\
\hline Trabajo doméstico S & $0: 43$ & $0: 39$ & $0: 36$ & $0: 36$ & 0,174 \\
\hline Trabajo doméstico F & $0: 51$ & $0: 55$ & $0: 46$ & $0: 46$ & 0,011 \\
\hline Trabajo remunerado $\mathrm{S}$ & $0: 06$ & 0:09 & $0: 06$ & $0: 02$ & 0,113 \\
\hline Trabajo remunerado F & $0: 13$ & $0: 13$ & 0:09 & 0:02 & 0,056 \\
\hline Lectura S & $0: 32$ & $0: 42$ & $0: 42$ & $0: 41$ & 0,079 \\
\hline Lectura F & $0: 40$ & $0: 53$ & $0: 50$ & $0: 54$ & 0,077 \\
\hline Higiene personal S & $1: 13$ & $1: 16$ & $1: 06$ & $1: 02$ & 0,021 \\
\hline Higiene personal F & $1: 16$ & $1: 14$ & $1: 09$ & $1: 09$ & 0,275 \\
\hline Alimentación S & $1: 43$ & $1: 41$ & $1: 47$ & $1: 42$ & 0,683 \\
\hline Alimentación F & $1: 42$ & $1: 38$ & $1: 50$ & $1: 50$ & 0,038 \\
\hline Amigos S & $1: 20$ & $1: 17$ & $1: 06$ & $0: 58$ & 0,023 \\
\hline Amigos $\mathrm{F}$ & $4: 03$ & $3: 45$ & $3: 28$ & $2: 44$ & 0,000 \\
\hline Desplazamientos S & $0: 40$ & $0: 47$ & $0: 45$ & $0: 45$ & 0,391 \\
\hline Desplazamientos F & $0: 54$ & $0: 57$ & $1: 02$ & $0: 51$ & 0,210 \\
\hline Salir con pareja S & $0: 18$ & $0: 13$ & $0: 08$ & $0: 22$ & 0,080 \\
\hline Salir con parej $\mathbf{F}$ & $0: 40$ & $0: 29$ & $0: 19$ & $0: 19$ & 0,006 \\
\hline Tiempo en dormirse ayer & $0: 34$ & $0: 29$ & $0: 32$ & $0: 26$ & 0,037 \\
\hline
\end{tabular}

Tabla 171: uso del tiempo - satisfacción académica del propio adolescente 
Los adolescentes que siempre están satisfechos con su rendimiento académico general dedican más tiempo, de manera significativa que aquellos que nunca lo están, a las siguientes actividades:

- Dormir: entre semana duermen 29 minutos diarios más y el fin de semana 5 minutos más.

- Alimentación el fin de semana: dedican 8 minutos más al día de media a esta actividad.

Los adolescentes que nunca están satisfechos con su rendimiento académico general dedican más tiempo, de manera significativa que aquellos que siempre lo están, a las siguientes actividades:

- Actividades relacionadas con las nuevas tecnologías:

$\checkmark$ WhatsApp entre semana: dedican 49 minutos al día más.

$\checkmark$ Redes sociales: dedican 35 minutos más entre semana y 42 el fin de semana.

$\checkmark$ Televisión: dedican 6 minutos más entre semana y 7 el fin de semana.

$\checkmark$ Teléfono fin de semana: dedican 10 minutos diarios más

- Deporte entre semana: dedican 17 minutos más de media.

- Trabajo doméstico en fin de semana: dedican a esta actividad 5 minutos más

- Salir con amigos: salen durante 22 minutos más entre semana y 1:19 el fin de semana.

- Salir con pareja el fin de semana: desarrollan esta actividad durante 21 minutos más

- Tiempo en dormirse ayer: los adolescentes que nunca están satisfechos con su rendimiento académico, tardaron 8 minutos más en dormirse que aquellos que siempre están satisfechos.

A continuación relacionamos el rendimiento escolar de los adolescentes con la satisfacción tanto de los padres como de los propios adolescentes. Encontramos diferencias significativas en cuanto a la relación entre haber repetido curso y la 
satisfacción de los padres y la personal del propio adolescente (el valor de nivel de significación es de 0,000 en ambos casos):

- El porcentaje de padres cuyos hijos han repetido curso que nunca están satisfechos es de $21,1 \%$.

- El porcentaje de adolescentes que han repetido curso y que no están satisfechos con ellos mismos es de $28,2 \%$.

Concluimos esta parte del estudio analizando si los adolescentes están más preocupados por aprobar o por aprender. A la mayoría de los adolescentes burgaleses encuestados les preocupa más aprobar (54,3\%) que aprender (35,9\%). El 10\% de ellos afirma que le importan ambas (gráfico 130).

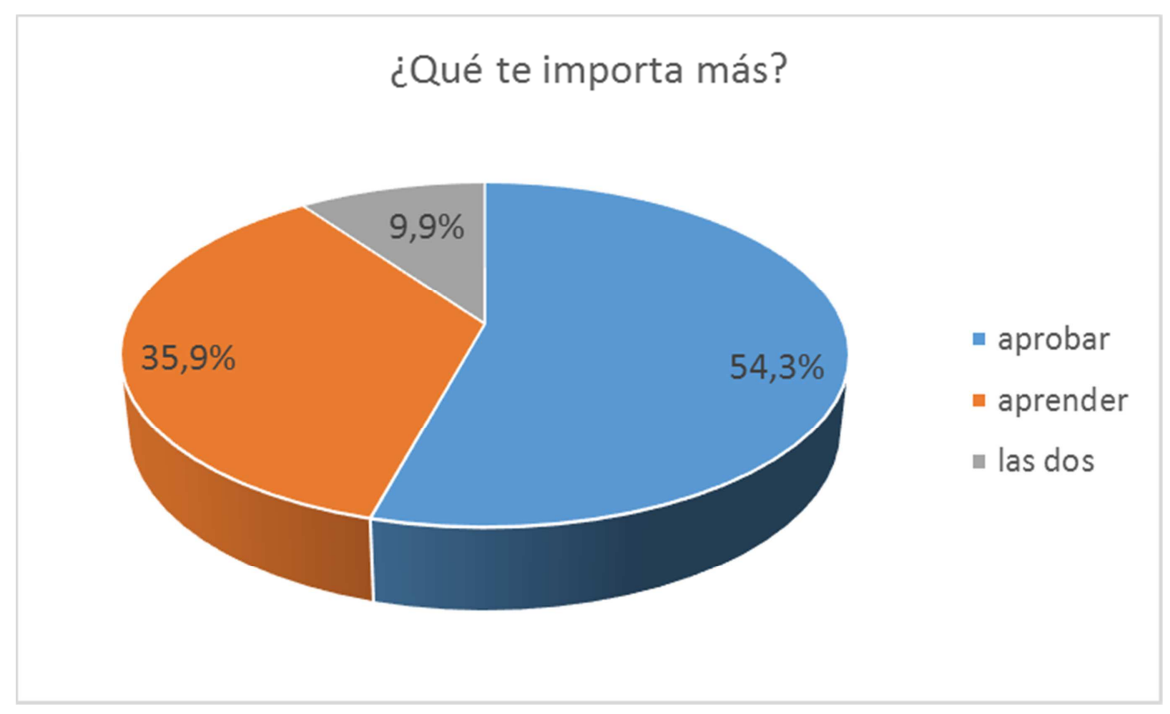

Gráfica 130: ¿qué te importa más?

El resultado de la prueba t-Student muestra en la tabla 172 los distintos usos del tiempo de los adolescentes burgaleses encuestados dependiendo de si su mayor importancia es aprobar o aprender. Como se puede observar en la gráfica 131, los adolescentes que anteponen su interés de aprobar al de aprender, dedican significativamente más tiempo al uso de nuevas tecnologías (WhatsApp, redes sociales, internet entre semana y televisión). 


\section{2a PARTE}

Capítulo 4.- Resultados

Además, invierten más cantidad de tiempo en su higiene personal y en mantener las relaciones sociales: salen más con los amigos durante el fin de semana y también dedican más tiempo a la pareja entre semana. Asimismo, tardan significativamente más tiempo en dormirse.

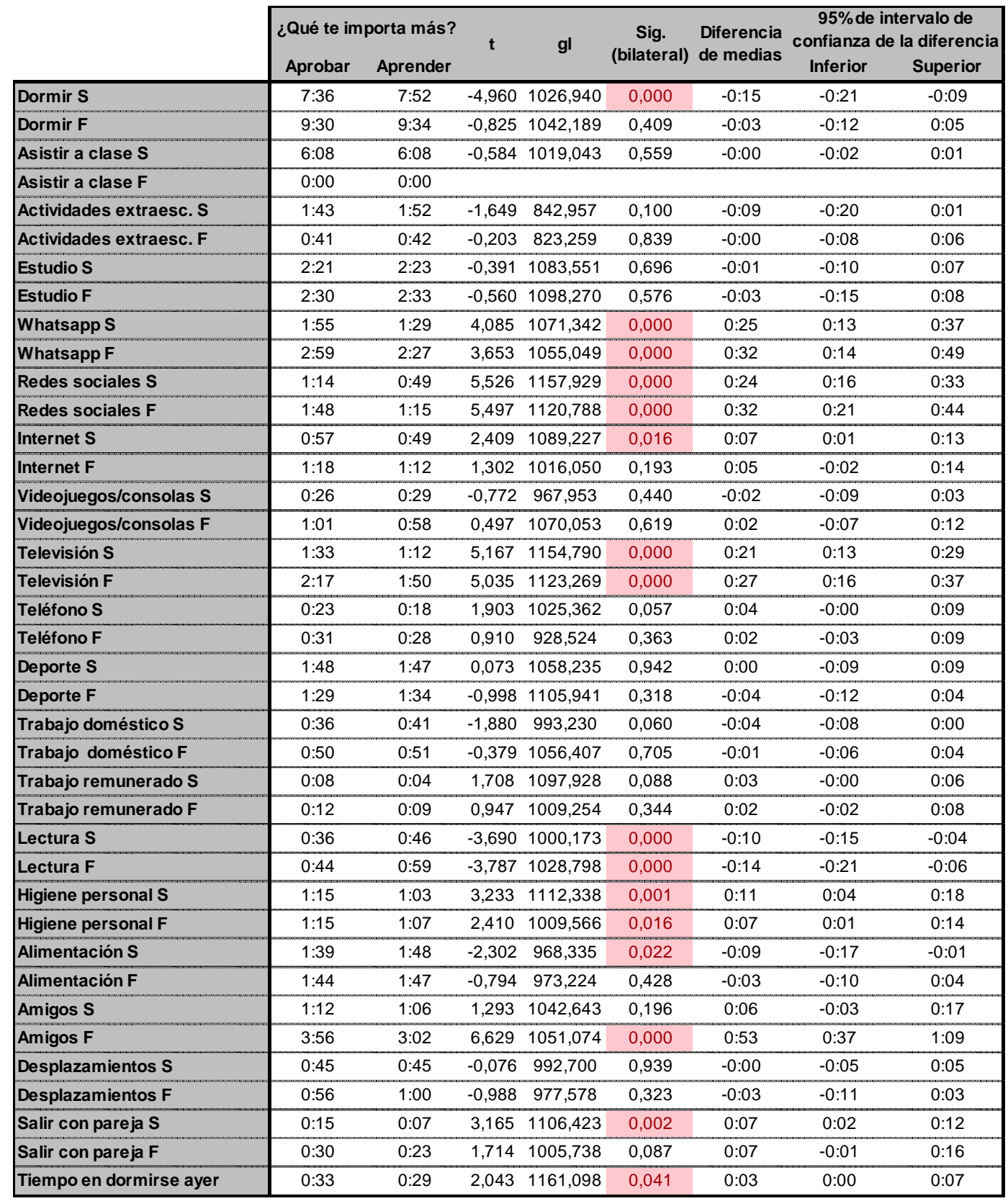

Tabla 172: $t$-Student uso del tiempo - estudiar para aprobar o aprender 
La gráfica 131 muestra la media de tiempo dedicada por los adolescentes cuya principal preocupación es aprobar a las distintas actividades.

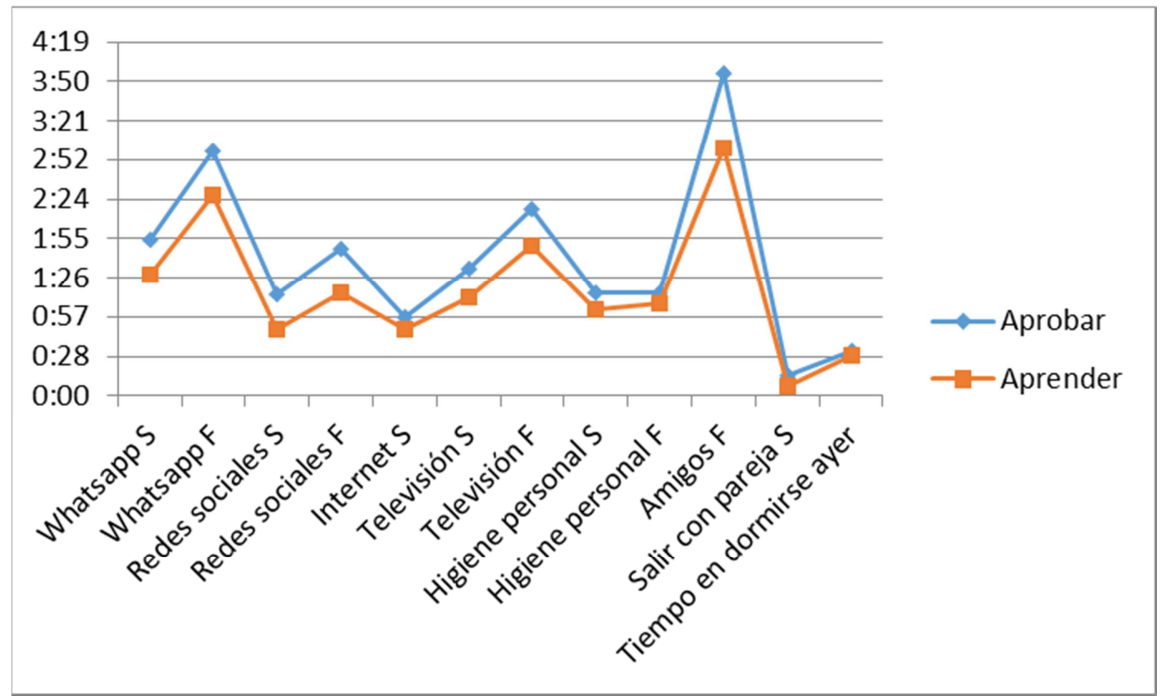

Gráfica 131: diferencias significativas

Sin embargo, aquellos adolescentes cuya preocupación mayor es aprender frente a aprobar, dedican más tiempo a dormir entre semana, a la lectura y a la alimentación también entre semana (gráfica 132).

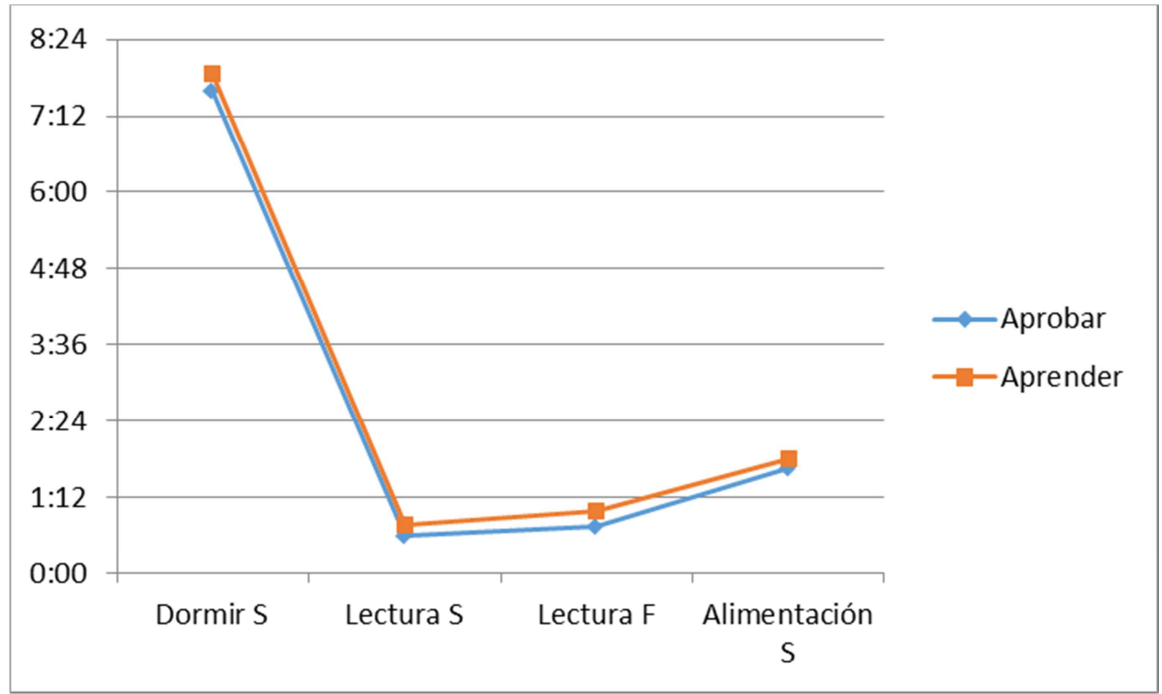

Gráfica 132: resultados obtenidos a la pregunta: ¿qué te importa más? 
Tras haber estudiado el uso del tiempo de los adolescentes, su relación con las nuevas tecnologías y la interrelación de ambas actividades, todo ello bajo un grado de supervisión parental, podemos afirmar que hemos llegado al fin último de este análisis de resultados que radicaba en determinar la influencia del uso del tiempo y de las nuevas tecnologías con los resultados académicos y de satisfacción de los adolescentes. Por esta razón, damos por concluido el capítulo de resultados, procediendo a continuación a realizar la discusión. 
$3^{a}$ Parte:

\section{DISCUSIÓN Y}

CONCLUSIONES 

Capítulo 5:

Discusión 



\section{3a PARTE: DISCUSIÓN Y CONCLUSIONES}

\section{Capítulo 5.- DISCUSIÓN}

Una vez concluido el capítulo de análisis de resultados, procedemos a realizar su discusión. En esta parte, confeccionamos la comparativa entre las conclusiones obtenidas tras el estudio de los distintos artículos analizados en la revisión bibliográfica y los hallazgos obtenidos tras realizar el análisis de los resultados obtenidos en la encuesta realizada a los adolescentes burgaleses. Con el objetivo de seguir la misma estructura que nos ha acompañado en los anteriores capítulos de este trabajo, hemos segmentado el capítulo de discusión en dos grandes bloques. En el primero se discute sobre el uso del tiempo de los adolescentes, para posteriormente continuar, en el segundo, con la discusión sobre el uso y la gestión de las nuevas tecnologías por parte de los adolescentes.

\section{1.- USO DEL TIEMPO DE LOS ADOLESCENTES}

En esta primera parte de la discusión nos centramos en realizar la comparativa entre las conclusiones obtenidas de las investigaciones estudiadas y los resultados de nuestra encuesta relacionados con las pautas de uso del tiempo de los adolescentes.

Hilbrecht et al. (2008) confirman que las pautas del uso del tiempo varían dependiendo del país, la cultura, demografía o factores históricos. En nuestro estudio, tras realizar el análisis de los resultados, hemos observado diferentes comportamientos en cuanto al uso del tiempo de los adolescentes burgaleses. Vamos a desarrollar la discusión de diferentes actividades de uso del tiempo, atendiendo a:
A.- Nacionalidad
B.- Género
C.- Edad
D.- Nivel socioeconómico de la familia.
D.- Centro educativo o entorno 
Las actividades que destacamos las relacionadas con el tiempo dedicado a:

1. dormir

2. alimentación

3. higiene y cuidado personal

4. estudio

5. actividades extraescolares

6. deporte

7. realizar trabajo remunerado

8. trabajo domestico

\subsection{1.- Tiempo dedicado a dormir:}

Con respecto al tiempo dedicado a dormir, el análisis de datos de la encuesta realizada a los adolescentes de Burgos, afirma que duermen una media de 7:44 horas/día entre semana y 9:33 horas al día los fines de semana (tabla 32). Según la National Sleep Foundation (2010), se recomienda que los adolescentes duerman entre 8:30 y 9:15 horas al día.

Observamos que los adolescentes burgaleses duermen, entre semana, menos tiempo del recomendado anteriormente, sin embargo, durante el fin de semana, duermen más de lo recomendado. Entre semana, muestran 46 minutos de déficit de tiempo dedicado a dormir con respecto a la cantidad mínima pautada, mientras que durante el fin de semana muestran dormir 18 minutos más de lo máximo recomendado.

Yang et al. (2005) manifiestan que pocos adolescentes cumplen estas recomendaciones. Los adolescentes burgaleses encuestados tampoco.

Olds, Blunden, et al. (2010) afirman en su estudio que los adolescentes duermen más tiempo los días festivos que los días lectivos, tendencia que los resultados muestran que siguen los adolescentes burgaleses.

Destacamos aspectos que nos aportan variabilidad en relación a dormir. 


\subsubsection{1.- Nacionalidad:}

La literatura estudiada confirma que, como regla general, el tiempo medio que los adolescentes de diversas nacionalidades analizadas destinan a dormir se circunscribe al intervalo comprendido entre 7 y 9 horas diarias (Carskadon, 1990; Flammer \& Alsaker, 1999; Carskadon et al., 2004, Albares Tendero et al., 2008). El tiempo medio que duermen los adolescentes burgaleses entre semana, como hemos visto en la tabla 32 , está dentro de este rango anterior. El fin de semana, lo supera en 33 minutos.

En la tabla 173 recogemos estudios realizados en los últimos 10 años que muestran el tiempo medio que duermen los adolescentes en diferentes países del mundo. Añadimos a este cuadro comparativo los resultados obtenidos en nuestra encuesta, en el que se puede apreciar que los adolescentes españoles duermen menos que los de otras nacionalidades. Los datos obtenidos para los adolescentes burgaleses encuestados están en línea con los recogidos en otras regiones de España.

\begin{tabular}{|c|c|c|c|c|c|}
\hline PAÍS & ESTUDIO & Edad & Entre semana & Fin de semana & Comentarios \\
\hline $\begin{array}{l}\text { España } \\
\text { (Cuenca) }\end{array}$ & $\begin{array}{c}\text { García-Jiménez et } \\
\text { al., } 2004\end{array}$ & & $\begin{array}{l}\text { 8:00 } \\
\text { o más }\end{array}$ & & $\begin{array}{c}\text { 31,3\% duerme } \\
\text { entre 6:00 y 7:00 } \\
\text { horas/día }\end{array}$ \\
\hline \multirow{2}{*}{$\begin{array}{l}\text { Canadá } \\
\text { (Ontario) }\end{array}$} & \multirow{2}{*}{$\begin{array}{l}\text { Hilbrecht et al., } \\
2008\end{array}$} & 12-14 años & $8: 28$ & & \\
\hline & & 15-19 años & $7: 21$ & & \\
\hline $\begin{array}{l}\text { China (Wuhan } \\
\text { y Hunan) }\end{array}$ & $\begin{array}{l}\text { Jaung, } \\
2008\end{array}$ & & $7: 52$ & & \\
\hline Australia & $\begin{array}{l}\text { Olds, Maher et al., } \\
2010\end{array}$ & 16-17 años & 9:00 & $9: 30-10: 00$ & \\
\hline $\begin{array}{l}\text { España } \\
\text { (Andalucía } \\
\text { Occidental) }\end{array}$ & $\begin{array}{c}\text { Delgado et al., } \\
2011\end{array}$ & & $7: 36$ & $\begin{array}{c}81,9 \% \text { más de } \\
9: 00\end{array}$ & $\begin{array}{c}56,3 \% \text { duermen } \\
\text { 8:00 horas al día o } \\
\text { más }\end{array}$ \\
\hline \begin{tabular}{|l} 
España \\
(Burgos)
\end{tabular} & $\begin{array}{c}\text { Presente estudio, } \\
2015\end{array}$ & & $7: 44$ & $9: 33$ & \\
\hline
\end{tabular}

Tabla 173: artículos referidos al tiempo que dedican a dormir los adolescentes

\subsubsection{2- Género:}

La tabla 34 muestra el tiempo dedicado a dormir por los adolescentes burgaleses encuestados entre semana y el fin de semana diferenciado por género. Se puede concluir que el género masculino duerme más tiempo entre semana (14 minutos más). El tiempo dedicado a dormir el fin de semana es prácticamente el mismo independientemente del género. 
En la tabla 174 mostramos, en relación a este tema, los resultados de otras investigaciones que versan sobre el tiempo que dedican a dormir los adolescentes por género, no llegamos a obtener unanimidad sobre el género que dedica más tiempo a dormir. Los adolescentes burgaleses masculinos dedican más tiempo a dormir entre semana, al igual que los de Canadá. Sin embargo, durante el fin de semana, son los adolescentes de género femenino quienes dedican más tiempo a dormir, tanto en Cuenca (España), en Australia como en nuestro estudio realizado a los adolescentes burgaleses.

\begin{tabular}{|l|ccc|}
\hline PAís & ESTUDIO & $\begin{array}{c}\text { GÉNERO QUE } \\
\text { MÁS DUERME }\end{array}$ & OBSERVACIONES \\
\hline España (Cuenca) & $\begin{array}{c}\text { García-Jiménez et } \\
\text { al., 2004 }\end{array}$ & femenino & en fin de semana \\
\hline Canadá (Ontario) & $\begin{array}{c}\text { Hilbrecht et al., } \\
2008\end{array}$ & masculino & 0:20 más de 12 a 14 años \\
\hline Australia & $\begin{array}{c}\text { Olds, Maher, et al., } \\
2010\end{array}$ & femenino & en fin de semana \\
\hline España (Burgos) & $\begin{array}{c}\text { Presente estudio, } \\
2015\end{array}$ & masculino & 0:14 más entre semana \\
\hline
\end{tabular}

Tabla 174: estudios tiempo dedicado a dormir - género

\subsubsection{3.- Edad:}

Los estudios de Carskadon (1990), Flammer y Alsaker (1999), Albares Tendero et al. (2008), Olds, Blunden et al. (2010) y Oliva Delgado et al. (2011) confirman que, como regla general, se puede afirmar que se encuentra una disminución paulatina de las horas de sueño con relación al crecimiento de los adolescentes. Como se puede observar en la tabla 35, esta afirmación, también es válida para los adolescentes burgaleses, puesto que duermen menos tiempo con la edad, tanto entre semana, como durante el fin de semana.

El tiempo dedicado a dormir por los adolescentes australianos disminuye aproximadamente 12 minutos por año los días lectivos y 4 minutos por año los días no lectivos (Olds, Maher, et al., 2010). La tabla 175 muestra el decremento de tiempo que los encuestados dedican a dormir por año (sin establecer un tiempo medio que disminuye el tiempo dedicado a dormir por año, puesto que no es estable). 


\begin{tabular}{|c|c|c|c|c|}
\hline & \multicolumn{2}{|c|}{$\begin{array}{c}\text { Olds, Maher, et al., } 2010 \\
\text { (Australia) }\end{array}$} & \multicolumn{2}{|c|}{$\begin{array}{c}\text { Presente estudio, } 2015 \\
\text { (Burgos, España) }\end{array}$} \\
\hline & \multicolumn{2}{|c|}{ Diferencia de medias } & \multicolumn{2}{|c|}{ Diferencia de medias } \\
\hline & Dormir S & Dormir F & Dormir S & Dormir F \\
\hline 12 años & \multirow{6}{*}{$\begin{array}{l}\text { aprox. }-0: 12 \\
\text { por año }\end{array}$} & \multirow{6}{*}{$\begin{array}{c}\text { aprox. -0:04 } \\
\text { por año }\end{array}$} & & \\
\hline 13 años & & & $-0: 18$ & $-0: 08$ \\
\hline 14 años & & & $-0: 10$ & $-0: 04$ \\
\hline 15 años & & & $-0: 16$ & $-0: 06$ \\
\hline 16 años & & & $+0: 07$ & $+0: 08$ \\
\hline 17 años & & & $-0: 26$ & $-0: 30$ \\
\hline
\end{tabular}

Tabla 175: estudios sobre la diferencia de medias de tiempo dedicado a dormir - edad

Albares Tendero et al. (2008) afirma que la diferencia de tiempo que duerme un adolescente de 13 y 18 años es de 2:00 horas al día. Sin embargo, la diferencia de tiempo que dedica a dormir un adolescente burgalés de 18 años, con respecto a uno de 13 años es de escasamente 36 minutos, por lo que demuestra que no sigue la misma pauta, como se aprecia en la tabla 176.

\begin{tabular}{|l|cc|}
\cline { 2 - 3 } \multicolumn{1}{c|}{} & $\begin{array}{c}\text { Albares Tendero et al., 2008 } \\
\text { (Barcelona, España) }\end{array}$ & $\begin{array}{c}\text { Presente estudio, 2015 } \\
\text { (Burgos, España) }\end{array}$ \\
\hline 13 años & $9: 00$ & $8: 27$ \\
\hline 18 años & $7: 00$ & $7: 50$ \\
\hline Diferencia & $2: 00$ & $0: 36$ \\
\hline
\end{tabular}

Tabla 176: estudios sobre tiempo dedicado a dormir por adolescentes de 13 y 18 años

Oliva Delgado et al. (2011) afirman que las horas dedicadas a dormir por los adolescentes de Andalucía Occidental (España) sufren un decremento con la edad, siendo esta disminución más notable en las chicas que en los chicos. Esta misma tendencia se cumple para los adolescentes burgaleses encuestados, tal y como hemos recogido en la tabla 35, siendo más grande la diferencia en el fin de semana que entre semana.

\subsubsection{4.- Centro educativo:}

La investigación de Oliva Delgado et al. (2011) recoge que los adolescentes de Andalucía (España) de zonas rurales, duermen entre semana más tiempo que los de las zonas 
urbanas. Durante el fin de semana, sin embargo, duermen más los adolescentes de las zonas urbanas. Podemos afirmar que los adolescentes participantes que vienen en un entorno rural duermen más tiempo tanto entre semana como durante el fin de semana (tabla 44).

Una vez estudiados los principales factores sociodemográficos que afectan al tiempo dedicado a dormir por los adolescentes, nos adentramos en la discusión sobre la hora de acostarse y de levantarse.

La tabla 177 recoge diversos estudios de la última década, sobre la hora a la que se acuestan los adolescentes en España. Como se puede observar, los adolescentes burgaleses son de los más tardíos en acostarse (siendo media a las 23:25).

\begin{tabular}{|c|c|c|c|c|}
\hline PAÍS & ESTUDIO & HORA DE ACOSTARSE & $\begin{array}{l}\text { DÍA DE LA } \\
\text { SEMANA }\end{array}$ & COMENARIOS \\
\hline $\begin{array}{l}\text { España } \\
\text { (Cuenca) }\end{array}$ & $\begin{array}{c}\text { García-Jiménez et al., } \\
2004\end{array}$ & $23: 00$ & entre semana & 15-16 años \\
\hline Europa & $\begin{array}{l}\text { Garitaonandia et al., } \\
2005\end{array}$ & $23: 15$ & entre semana & \\
\hline \begin{tabular}{|l} 
España \\
(Andalucía)
\end{tabular} & $\begin{array}{l}\text { Delgado et al., } \\
2011\end{array}$ & $\frac{76,5 \% \text { antes de media noche }}{19,2 \% \text { entre las } 00: 00 \text { y 01:00 }}$ & - entre semana & \\
\hline \begin{tabular}{|l} 
España \\
(Burgos) \\
\end{tabular} & $\begin{array}{c}\text { Presente estudio, } \\
2015 \\
\end{array}$ & $23: 25$ & entre semana & \\
\hline
\end{tabular}

Tabla 177: estudios hora a la que se han acostado los adolescentes

Oliva Delgado et al. (2011) afirma que chicos se acuestan ligeramente más tarde que las chicas, aunque las diferencias no son excesivamente notables por género. Olds, Maher, et al. (2010) no encuentra diferencias notables por género. Ocurre lo mismo entre los adolescentes burgaleses encuestados no se observa diferencia en la hora de acostarse por género, puesto que la las chicas se acostaron de media el día previo a hacer la encuesta a las 23:25 y los chicos a las 23:26 (escasamente 1 minuto de diferencia).

En la investigación de Olds, Maher, et al. (2010) afirman que los adolescentes australianos se acuestan 17 minutos más tarde de media cada año. Los adolescentes burgaleses siguen esta misma tendencia. Se acuestan de media 15 
minutos más tarde cada año (media calculada para el intervalo de edad entre 12 y 17 años).

Oliva Delgado et al. (2011) encuentran además, diferencias en la hora de acostarse por zona de residencia y afirma que los adolescentes de entornos rurales se acuestan más temprano entre semana. En contraposición, no hemos encontrado diferencias significativas en nuestro estudio en la hora de acostarse en relación al entorno rural o urbano. Sin embargo, sí hemos podido constatar en este análisis, que los adolescentes de los centros públicos (tanto en entorno rural como urbano) se acuestan más tarde que aquellos de los centros urbanos privados.

Los adolescentes de Cuenca (España) se levantan de media a las 7:59 entre semana (García-Jiménez et al., 2004). Los adolescentes de Burgos se levantaron a las 7:20 de media, es decir, 39 minutos antes.

Olds, Maher, et al. (2010) no encuentran diferencias en la hora de levantarse por género entre semana, pero sí en días no lectivos, donde las adolescentes se levantan una media de 15 minutos más tarde. Según nuestra encuesta, sí existen diferencias significativas por género en la hora de levantarse los adolescentes de Burgos (las chicas se levantaron 5 minutos antes que los chicos).

\subsection{2.- Tiempo dedicado a la alimentación:}

\subsubsection{1.- Nacionalidad:}

Los adolescentes canadienses de Ontario dedican una media de 40 minutos al día a comer entre semana (Hilbrecht et al., 2008). Los adolescentes burgaleses invierten en alimentación una media de tiempo de 1:44 horas al día entre semana y de 1:45 horas al día los fines de semana, menos tiempo que los franceses (1:54 horas al día) pero más que los adolescentes húngaros (0:58 horas al día), belgas (entre 1:00 y 1:15), americanos y canadienses. El tiempo destinado a comer por los adolescentes burgaleses está en línea con la media de los adolescentes europeos (media de $1: 12$ horas/día). 


\subsubsection{2.- Género:}

Existe una ligera diferenciación en el tiempo dedicado a las comidas por género. Las chicas burgalesas encuestadas dedican más tiempo a su alimentación que los chicos, principalmente durante el fin de semana, donde la diferencia es de 14 minutos (tabla 34). Esta afirmación no está en línea con las conclusiones alcanzadas por Hilbrecht et al. (2008), que afirmaban que los adolescentes de género masculino de Ontario (Canadá) dedican ligeramente más tiempo a las comidas que los de género femenino.

\subsection{3.- Tiempo dedicado a la higiene y el cuidado personal:}

\subsubsection{1- Nacionalidad:}

Duckett et al. (1989) concluye en su estudio que el tiempo dedicado por los adolescentes europeos a su cuidado personal no varía en exceso dependiendo del país al que pertenecen.

Flammer \& Alsaker (1999) realizaron un estudio en 12 países (Bulgaria, antigua Checoslovaquia, Finlandia, Francia, Alemania, Hungría, Polonia, Rusia, Suiza, Estados Unidos, Noruega y Rumania) que puso de manifiesto que el tiempo medio dedicado por los adolescentes a su cuidado personal es de entre 0:30 y 0:48 horas al día. Los adolescentes belgas dedican aproximadamente 0:45 horas al día, mientras que los holandeses dedican más tiempo, llegando a 1:00 hora al día en el fin de semana (Stevens et al., 2003). Sin embargo, el tiempo medio dedicado por los adolescentes burgaleses a esta actividad es de 1:11, por lo que podemos afirmar que los valores no son los mismos para todas las nacionalidades. Como muestra la tabla 32 , no se encuentran diferencias en el tiempo dedicado a esta actividad por los adolescentes de Burgos entre semana, cuya media es 1:11 horas y la media el fin de semana es 1:13 horas.

\subsubsection{2- Género:}

Carpenter et al, (1989), Duckett et al. (1989), Flammer y Alsaker (1999) ponen de manifiesto que las adolescentes de los países desarrollados dedicaban más tiempo al cuidado personal que los chicos, principalmente en la adolescencia. En la tabla 178 recogemos estudios que informan que las adolescentes dedican más tiempo a su 
cuidado personal. Este mismo comportamiento se reproduce entre las adolescentes encuestadas. Las chicas de Burgos dedican de media 1:20 horas al día a la higiene personal, mientras que los chicos dedican sólo 1:00 hora al día, por lo tanto, la diferencia de medias es de 20 minutos al día.

\begin{tabular}{|l|ccc|}
\hline PAís & ESTUDIO & $\begin{array}{c}\text { DEDICAN MÁS TIEMPO A } \\
\text { HIGIENE PERSONAL }\end{array}$ & $\begin{array}{c}\text { CUÁNTO TIEMPO } \\
\text { MÁS DEDICAN }\end{array}$ \\
\hline $\begin{array}{l}\text { Bélgica y } \\
\text { Holanda }\end{array}$ & $\begin{array}{c}\text { Stevens et al., } \\
2003\end{array}$ & femenino & 12 minutos \\
\hline $\begin{array}{l}\text { Canadá } \\
\text { (Ontario) }\end{array}$ & $\begin{array}{c}\text { Hilbrecht et al., } \\
2008\end{array}$ & femenino & 17 minutos \\
\hline $\begin{array}{l}\text { España } \\
\text { (Burgos) }\end{array}$ & $\begin{array}{c}\text { Presente estudio, } \\
2015\end{array}$ & femenino & 20 minutos \\
\hline
\end{tabular}

Tabla 178: estudios sobre tiempo dedicado a la higiene personal - género

Cabe destacar la variabilidad del tiempo dedicado a la higiene personal, dependiendo del día de la semana. Las chicas de Burgos encuestadas dedican más tiempo a la higiene personal el fin de semana (1:25 horas al día) que durante la semana (1:19 horas al día). Los chicos sin embargo, dedican más tiempo a la higiene personal entre semana (1:02 horas al día) que durante el fin de semana (0:58 horas al día), como se recoge en la tabla 32. Esta misma tendencia siguen los adolescentes canadienses de Ontario. Para Hilbrecht et al. (2008), las chicas dedican más tiempo a esta actividad que los chicos durante el fin de semana. Entre semana, los chicos dedican más tiempo que las chicas a la higiene personal.

\subsubsection{3- Edad:}

La tabla 35 muestra la tendencia del uso del tiempo de los adolescentes con la edad y nos permite afirmar que entre semana, el tiempo dedicado a esta actividad comienza a disminuir a partir de los 13 años, encontrándose diferencias significativas. El fin de semana, sin embargo, aumenta hasta los 15 años. A partir de esta edad, se aprecia una disminución de tiempo dedicado a esta tarea. No podemos afirmar que existan diferencias significativas en el tiempo dedicado a esta actividad en fin de semana con la edad. Hilbrecht et al. (2008) afirman que los adolescentes canadienses de Ontario 
invierten más tiempo en higiene personal en fin de semana con la edad. Este aumento de tiempo es mayor en los chicos que en las chicas (donde la cifra prácticamente se mantiene).

\subsection{4.- Tiempo dedicado al estudio}

\subsubsection{1- Nacionalidad:}

Fuligni y Stevenson (1995), Juster et al. (2003) afirman que el tiempo dedicado a realizar las tareas del colegio por los adolescentes norteamericanos no es suficiente. Según Larson y Verma (1999), comentan que se podía hacer una clasificación en torno al tiempo dedicado por los adolescentes a esta actividad por continente, tal y como se refleja en la siguiente tabla 179.

\begin{tabular}{|l|c|}
\cline { 2 - 2 } \multicolumn{1}{c|}{} & $\begin{array}{c}\text { tiempo semanal dedicado a } \\
\text { estudiar y hacer tareas escolares }\end{array}$ \\
\hline Adolescentes americanos & $3-4: 30$ \\
\hline Adolescentes europeos & $4-5: 30$ \\
\hline Adolescentes asiáticos & $5: 30-7: 30$ \\
\hline
\end{tabular}

Tabla 179: tiempo a estudiar y a hacer tarea escolar por continente. Fuente: (Larson \& Verma, 1999)

Kalenkoski y Pabilonia (2012) afirman que el tiempo dedicado por los adolescentes a hacer tareas escolares está cuantificado en 49 minutos diarios. El promedio de horas dedicadas a estudiar y a realizar las tareas escolares por los adolescentes burgaleses es notablemente superior al mencionado en el estudio anterior, siendo 2:23 horas diarias entre semana y 2:31 horas diarias el fin de semana (tabla 32). Esta cifra es notablemente superior a la media de horas dedicadas a estudiar por el resto de países analizados.

El tiempo que los encuestados dedican a estudiar y a hacer tareas escolares, es considerablemente superior al tiempo de estudio mínimo recomendado para alcanzar el éxito académico, estipulado en 5 horas a la semana por Cooper y Valentine (2001). 
Entre las respuestas obtenidas en el cuestionario se puede observar que los adolescentes burgaleses participantes dedican ligeramente más tiempo a estudiar el fin de semana (2:31 horas al día) frente a durante la semana (2:23 horas al día) mientras que en otros países como Argentina la preocupación es palpable al detectar que la mitad de los adolescentes no invierte ni un sólo minuto en estudiar los fines de semana (Kornblit et al., 2006).

\subsubsection{2.- Género:}

Los estudios que hemos analizado manifiestan que son las adolescentes de género femenino quienes dedican más tiempo a estudiar y a realizar las tareas escolares. En Norteamérica, numerosos estudios constatan que las adolescentes de 9 ㅇ a 12 음 grado dedican más tiempo a realizar la tarea del colegio que los chicos (Gager et al., 1999; Wight et al., 2009; Shanahan \& Flaherty, 2001). Hilbrecht et al. (2008) afirman que las adolescentes canadienses de Ontario, dedican más tiempo a estudiar que los chicos. Entre semana, las adolescentes de 12 a 14 años dedican 23 minutos al día más, mientras que entre las adolescentes de 15 a 19 años sólo 10 minutos al día más. Las adolescentes afroamericanas, manifiestan realizar la tarea del colegio más a menudo que los chicos (Xu, 2010).

Con respecto a los adolescentes encuestados se aprecia, en la tabla 34, también una diferencia por género. Las chicas estudian durante más tiempo que los chicos, tanto entre semana (0:19 horas al día más) como durante el fin de semana (0:38 horas al día más). Por lo tanto, se cumple la misma tendencia para las adolescentes burgalesas que para las de Ontario (Canadá), norteamericanas y afroamericanas.

\subsubsection{3- Edad:}

Gager et al. (1999) afirmaron que el tiempo dedicado al estudio por los adolescentes norteamericanos aumenta entre 9 o grado y $12 \circ$ grado. Del mismo modo, Hilbrecht et al. (2008) afirman que los adolescentes de Ontario estudian más tiempo con la edad. Con respecto a los adolescentes encuestados, los adolescentes más mayores estudian durante más tiempo. La diferencia principal se encuentra durante el fin de semana, 
donde la diferencia de tiempo dedicado a estudiar entre los 17 y 12 años es de 1:13 en fin de semana.

\subsection{5.- Tiempo dedicado a actividades extraescolares:}

\subsubsection{1.- Nacionalidad}

Según Larson et al. (2001), el origen de los adolescentes influye en el tiempo dedicado a realizar actividades extraescolares. Los adolescentes americanos dedican una media de 15 minutos al día a realizar actividades extraescolares no deportivas (Larson \& Verma, 1999). Los adolescentes norteamericanos de origen africano dedican 10 minutos al día y el tiempo medio que invierten los adolescentes de origen europeo a realizar actividades extraescolares es de 15 minutos diarios. Mahoney et al. (2006) afirma que los adolescentes norteamericanos entre 15 y 18 años dedican una media de 5 horas semanales a realizar estas actividades. Estos resultados están más en línea con los obtenidos para los adolescentes burgaleses encuestados, que invierten en realizar actividades extraescolares no deportivas 1:48 horas al día entre semana y 0:41 horas al día el fin de semana, como figura en la tabla 32. Es importante destacar que el tiempo es ampliamente superior al encontrado en los estudios mencionados anteriormente.

\subsubsection{2.- Género:}

En Norteamérica, los adolescentes varones de secundaria (principalmente de 12ํgrado) dedican más tiempo a realizar actividades extraescolares que las mujeres (Gager et al., 1999; Shanahan \& Flaherty, 2001). En relación al tiempo destinado a realizar extraescolares por los adolescentes burgaleses encuestados, la tabla 34 muestra que esta afirmación depende del día de la semana estudiado. Los días lectivos, las chicas dedican más tiempo a esta actividad que los chicos (1:55 horas al día frente a 1:41 horas al día). Sin embargo, durante el fin de semana, los chicos dedican más tiempo que las chicas a realizar extraescolares (0:46 frente a 0:37 horas al día).

\subsubsection{3.- Nivel socioeconómico de los padres - entorno familiar:}

Lareau (2003) y Dumais (2008) afirman que puede existir una relación entre el nivel socioeconómico al que pertenecen los padres y el tiempo destinado por los hijos 
adolescentes a realizar actividades extraescolares. Los padres de clase media apuntan a sus hijos a más actividades extraescolares que los de clase baja, con el objetivo de fomentar su desarrollo cultural, según Dumais (2008). En el cuestionario se recoge el nivel de estudios que han alcanzado los padres. En la gráfica 79, podemos observar que los adolescentes que más tiempo dedican a actividades extraescolares son aquellos cuyos padres han alcanzado estudios universitarios, excepto durante el fin de semana, donde los encuestados que más tiempo dedican a esta actividad son aquellos cuyas madres no tienen estudios.

El aumento del tiempo destinado a realizar estas actividades se puede interpretar como un esfuerzo de los padres para supervisar, controlar y racionalizar el tiempo libre (Larson \& Verma, 1999). Sin embargo, no apreciamos diferencias significativas en los adolescentes burgaleses en cuanto al tiempo dedicado a realizar actividades extraescolares y el hecho de estar solos en casa durante las tardes tal y como se puede ver en la tabla 47.

Según los estudios analizados la revisión bibliográfica, la participación en actividades extraescolares ayuda a los adolescentes a desarrollar competencias reconocidas en el sistema educativo y se traduce en beneficios educativos. El análisis de los datos obtenidos de la encuesta realizada a los adolescentes burgaleses confirma este dato. Como se puede observar en la tabla 163, los adolescentes burgaleses encuestados que no han repetido curso el año previo a la encuesta, dedican más tiempo a realizar actividades extraescolares, tanto entre semana como durante el fin de semana.

\subsection{6.- Tiempo dedicado al deporte}

\subsubsection{1.- Nacionalidad:}

Flammer \& Alsaker, (1999) afirman que los adolescentes noruegos son los que más deporte realizan en Europa, aproximadamente 1:26 horas al día. Apuntan, también, que los alemanes dedican 52 minutos al día a esta actividad y los búlgaros sólo 21 minutos diarios. Lee (1994) afirma que los adolescentes asiáticos dedican menos tiempo a actividades deportivas que los europeos y norteamericanos. Los adolescentes 
burgaleses encuestados dedican a hacer deporte de media más tiempo que los estudios analizados, aproximadamente 1:43 horas al día, como se observa en la tabla 32 . Por lo tanto, son los adolescentes burgaleses los que dedican más tiempo a realizar deporte, por encima de alemanes, búlgaros, coreanos y japoneses.

Los adolescentes burgaleses practican más deporte entre semana, con una media de 1:49 horas al día, siendo la media de los fines de semana 1:31 horas al día. Sin embargo, tal y como afirman Wight et al. (2009), esta pauta no la siguen los adolescentes norteamericanos de entre 15 y 17 años, puesto que dedican más tiempo a realizar deporte durante el fin de semana que entre semana.

\subsubsection{2.- Género:}

Los adolescentes burgaleses dedican más tiempo a realizar actividades deportivas que las adolescentes (Wight et al., 2009), aproximadamente 11 minutos al día más entre semana y 30 minutos más durante el fin de semana (tabla 34).

La tabla 180 recopila los estudios analizados en la revisión bibliográfica que tratan sobre la influencia del género en el tiempo dedicado a la práctica de deporte. Como puede observarse, los estudios manifiestan que es el género masculino el que dedica más tiempo a hacer deporte.

\begin{tabular}{|c|c|c|c|c|c|c|}
\hline PAÍS & ESTUDIO & $\begin{array}{l}\text { Género hace } \\
\text { más deporte }\end{array}$ & $\begin{array}{l}\text { Tiempo me } \\
\text { Femenino }\end{array}$ & $\begin{array}{l}\text { dio deporte } \\
\text { Masculino }\end{array}$ & $\begin{array}{l}\text { Diferencia } \\
\text { por género }\end{array}$ & Observaciones \\
\hline EEUU & $\begin{array}{c}\text { Robinson \& } \\
\text { Bianchi, } 1997\end{array}$ & masculino & $0: 53$ & $1: 13$ & $0: 20$ & $\begin{array}{c}\text { entre } 12 \text { y } 17 \\
\text { años }\end{array}$ \\
\hline Mundial & $\begin{array}{c}\text { Larson \& } \\
\text { Verma, } 1999\end{array}$ & masculino & & & $0: 12-0: 17$ & \\
\hline $\begin{array}{l}\text { Canadá } \\
\text { (Ontario) }\end{array}$ & $\begin{array}{c}\text { Hilbrecht, } \\
\text { Zuzanek \& } \\
\text { Mannell, } 2008\end{array}$ & masculino & & & & $\begin{array}{c}\text { diferencia mayor } \\
\text { durante el fin de } \\
\text { semana }\end{array}$ \\
\hline EEUU & $\begin{array}{l}\text { Wight et al., } \\
2009\end{array}$ & masculino & $0: 29$ & $0: 59$ & $0: 30$ & $\begin{array}{c}\text { entre } 15-17 \\
\text { años }\end{array}$ \\
\hline Alemania & $\begin{array}{c}\text { Bucksch, } \\
\text { Inchley, Hamrik, } \\
\text { Finne \& Kolip, } \\
2014\end{array}$ & masculino & & & & \\
\hline $\begin{array}{l}\text { España } \\
\text { (Burgos) }\end{array}$ & $\begin{array}{c}\text { Presente } \\
\text { estudio, } 2015\end{array}$ & masculino & $1: 36$ & $1: 52$ & $0: 16$ & \\
\hline
\end{tabular}

Tabla 180: estudios sobre tiempo dedicado a hacer deporte por los adolescentes - género 
Encontramos diferencia por género, también, en el tiempo dedicado a hacer deporte dependiendo del día de la semana. Entre semana, los chicos hacen deporte durante 8 minutos más al día que el fin de semana mientras que la diferencia es mayor en las chicas, puesto que hacen 27 minutos al día más deporte entre semana que el fin de semana. Las investigaciones de Wight et al. (2009) exponen que los adolescentes norteamericanos, dedican más tiempo al deporte durante los fines de semana (20 minutos más los chicos y 10 minutos más las chicas). Por lo que podemos decir que las diferencias coinciden en lo relativos hacia la tendencia, si bien cuantitativamente hay diferencia en la nacionalidad.

\subsubsection{3.- Edad:}

Robinson y Bianchi (1997) afirman que los adolescentes hacen menos deporte en la medida que se incrementa la edad. Esta tendencia, así mismo, se produce en Japón, donde el tiempo dedicado a hacer deporte pasa de 0:30 horas diarias entre aquellos de 10 y 15 años a escasamente 7 minutos al día entre los de 16 y 19 años, según los estudios de NHK Public Opinion Research Division (1996). Lo mismo ocurre con el género femenino, pasando de 10 minutos diarios las más pequeñas a sólo 3 minutos diarios las mayores.

Analizados los datos de la tabla 32, podemos afirmar que el tiempo dedicado a hacer deporte por los adolescentes burgaleses tanto entre semana como durante el fin de semana decrece a partir de los 15 años.

En Estados Unidos, la participación en actividades deportivas está asociada con alcanzar estudios universitarios y a bajos niveles de abandono escolar (Eitle, 2005) y a promover su compromiso con su propia educación y su autoconfianza (Jordan, 1999). Como puede observarse en la tabla 163, tras relacionar el tiempo dedicado por los adolescentes al deporte y su rendimiento escolar, podemos afirmar que los resultados dados por los adolescentes burgaleses encuestados no nos llevan a las mismas conclusiones. Los adolescentes que han repetido algún curso practican deporte durante el mismo tiempo que aquellos que no han repetido. 
Cuando les preguntamos si han suspendido alguna asignatura en la pasada evaluación, las respuestas nos indican que dedican más tiempo a hacer deporte aquellos que han suspendido que los que no suspendieron alguna vez, como se observa en la tabla 164.

\subsection{7.- Tiempo dedicado a realizar trabajo remunerado:}

Marsh y Kleitman (2005) afirman que compaginar el trabajo remunerado con los estudios en secundaria, tiene efectos negativos en la educación. Del mismo modo, Kalenkoski y Pabilonia (2012) tratan de demostrar que compaginar los estudios de secundaria con un trabajo, trae consigo un empeoramiento de las notas obtenidas por el adolescente. Los datos recogidos de la encuesta, aunque son escasos, nos llevan a afirmaciones similares. La tabla 163 pone de manifiesto que los adolescentes que trabajan durante más tiempo, afirman haber repetido algún curso escolar. Por otra parte, los resultados de la tabla 164, muestran que los adolescentes que han suspendido alguna asignatura la evaluación previa a la cumplimentación del cuestionario, afirman trabajar durante más tiempo.

Por su parte Porterfield y Winkler (2007), manifiestan y justifican que obtienen mejores notas en matemáticas los adolescentes que emplean más tiempo a desempeñar trabajo remunerado.

Con respecto a la cantidad de trabajo realizado, Mortimer et al. (1999) cifran en 20 horas semanales la cantidad límite para que el trabajo no afecte al rendimiento académico del adolescente, ni le ponga en riesgo, pudiendo entrañar conductas negativas en el colegio, delincuencia y consumo de sustancias. Los resultados obtenidos por los adolescentes burgaleses, tal y como se indican en la tabla 32 , se alejan de los datos, siendo 6 minutos de media entre semana y de 10 minutos de media durante el fin de semana.

\subsubsection{1.- Nacionalidad:}

Según los datos recogidos por el Bureau of Labor Statistics, el 36,5\% de los adolescentes estadounidenses trabaja. En Argentina el porcentaje se sitúa en un 25\%, según estudios de Kornblit et al. (2006). La tasa de empleo en países subdesarrollados es 
considerablemente superior a la de países desarrollados, sobre todo en los adolescentes de más edad (Larson \& Verma, 1999). La tasa de empleo de adolescentes en Burgos es la más baja en relación a los estudios analizados. El porcentaje de adolescentes encuestados que afirma dedicar algo de tiempo a desempeñar un trabajo remunerado entre semana es del $8,0 \%$ entre semana y del $9,6 \%$ durante el fin de semana, lo que es ligeramente mayor.

El tiempo dedicado por los adolescentes estadounidenses de entre 14 y 16 años a trabajar es de 0:48 horas al día (Flammer \& Alsaker, 1999). En Corea, estudios de Lee (1994), han constatado que los adolescentes de entre 14 y 16 años no trabajan, puesto que han declarado dedicar 0 minutos/día al desempeño laboral. El tiempo medio que dedican a trabajos remunerados los adolescentes burgaleses encuestados, como se observa en la tabla 32, es muy bajo, escasamente de 0:06 minutos diarios entre semana y de 0:10 minutos diarios el fin de semana.

\subsubsection{2.- Género:}

Analizados los estudios de Gager et al. (1999), Statistics Canada, (2006) y Hilbrecht et al. (2008), corroboran que durante la adolescencia, el género femenino trabaja más que el masculino. Sin embargo, esta afirmación no se cumple para los adolescentes burgaleses encuestados, tal y como se muestra en la tabla 34 , ya que los adolescentes varones burgaleses trabajan, tanto entre semana, como durante el fin de semana más tiempo que las chicas.

Por otra parte, Vernon (2005) afirma que no encuentra excesiva diferencia en cuanto al tiempo destinado a trabajar por los jóvenes de 15-19 años por género.

\subsubsection{3.- Edad:}

Los jóvenes dedican poco tiempo a actividades que reportan ingresos (Larson \& Verma, 1999), aunque el tiempo trabajado por los adolescentes aumenta en los de más edad. Según los datos de la CPS recogidos en 2003 y 2004, el porcentaje de adolescentes que tienen un trabajo a los 18 años es mayor que a los 16 años, siendo ligeramente mayor el 
porcentaje en las chicas que en los chicos. No observamos una tendencia clara en el tiempo dedicado a desempeñar trabajo remunerado en los encuestados, tal vez, porque el tiempo que manifiestan trabajar es muy bajo, lo que se recoge en la tabla 35.

\subsubsection{4.- Entorno familiar:}

Porterfield y Winkler (2007) afirman que los adolescentes que trabajan durante más tiempo son aquellos cuyos padres han alcanzado un menor nivel educativo. Los resultados encontrados muestran que la mayor cantidad de adolescentes trabaja más de 20 horas semanales en los hogares cuyos padres no han terminado el bachillerato. Las tablas 48 y 49 muestran la cantidad de tiempo destinada a trabajo remunerado en relación al nivel educativo alcanzado por el padre y por la madre. Se puede observar que sigue la misma tendencia que la encontrada en el estudio anterior, es decir, el tiempo dedicado a realizar trabajos remunerados disminuye al aumentar los estudios de los padres. Esta diferencia se hace más evidente durante el fin de semana. Con respecto al nivel educativo alcanzado por el padre, es preciso comentar que los adolescentes cuyo padre tiene estudios universitarios dedican 39 minutos menos a trabajar que aquellos con padre sin estudios. Por otra parte, los adolescentes hijos de madres universitarias dedican 53 minutos menos a trabajar que aquellos cuya madre no ha estudiado.

\subsection{8.- Tiempo dedicado al trabajo doméstico}

\subsubsection{1.- Nacionalidad:}

El tiempo medio destinado por los adolescentes norteamericanos de 12 a 17 años para realizar trabajos del hogar es de 36 minutos al día (Robinson \& Bianchi, 1997). En Corea del Sur, en los estudios de Lee (1994), son 6 minutos diarios el tiempo dedicado. Los adolescentes europeos de 10 a 16 años dedican entre 12 y 42 minutos al día, según investigaciones de Flammer \& Alsaker (1999). No se encuentran estudios que verifiquen que los adolescentes de países desarrollados dediquen más de 1 hora/día a las labores del hogar (Larson \& Verma, 1999). 
En la tabla 32, puede apreciarse la media de tiempo dedicado por los adolescentes burgaleses encuestados, que se aproxima al último estudio recién mencionado, ya que nuestros participantes destinan a esta actividad 38 minutos al día entre semana y 50 minutos al día durante el fin de semana.

\subsubsection{2.- Género:}

Tal y como muestra la tabla 34, las adolescentes burgalesas dedican notablemente más tiempo a realizar tareas del hogar que sus pares de género masculino. Encontramos este mismo comportamiento por género en los estudios analizados en la revisión bibliográfica (Larson \& Verma, 1999; Gager et al., 1999).

\subsubsection{3.- Edad:}

Gager et al. (1999) afirman que el tiempo dedicado a las labores del hogar disminuye durante los años de adolescencia un $25 \%$ en las chicas y hasta un $40 \%$ en los chicos. Así mismo, en Estados Unidos, tal y como exponen Shanahan \& Flaherty (2001), el tiempo destinado a esta actividad por los adolescentes disminuye con los años.

La tabla 35 muestra la evolución del tiempo dedicado por los encuestados al trabajo doméstico atendiendo a la edad y género. Se observa que entre los 12 y 17 años, el tiempo dedicado por los varones decrece tanto entre semana, como durante el fin de semana, lo que reafirma las investigaciones aludidas. Respecto al género femenino, durante el fin de semana el tiempo dedicado a trabajos domésticos aumenta ligeramente.

\subsection{9- Tiempo dedicado a las nuevas tecnologías de información y comunicación:}

El uso de las nuevas tecnologías es uno de los puntos clave de la presente investigación y objeto de este estudio, por lo que vamos a abordarlo con mayor extensión, configurando un apartado expreso. 


\section{2.- USO DE LAS NUEVAS TECNOLOGÍAS}

\subsection{1.- La relación de los adolescentes con las nuevas tecnologías}

Para Madden et al. (2013), en Norteamérica, el 93\% de los adolescentes tiene ordenador o acceso al mismo en casa. En España, la encuesta sobre Equipamiento y Uso de Tecnologías de Información y Comunicación en los Hogares realizada por el INE en 2014, pone de manifiesto que el $74,8 \%$ de los hogares españoles tienen algún tipo de ordenador. Actualmente, no es necesario tener un ordenador para conectarse a internet, a las redes sociales o jugar a videojuegos, sino que existen otros muchos dispositivos que permiten conectarse como el teléfono móvil, la tablet, etc. Esta razón nos ha llevado a omitir preguntas relativas a este aspecto en el cuestionario. Esto no impide que podamos extraer otra información de nuestros resultados y compararlo con otros estudios realizados.

\subsubsection{1.- Edad de inicio en las nuevas tecnologías:}

En Estados Unidos, los adolescentes menores de 20 años manifiestan haber accedido a internet por primera vez a una edad de media 9 años (Li et al., 2015). En España, el estudio realizado por INTECO y Fundación Orange (2009) expone que la edad media de inicio en internet es de 10 años. Ambos estudios son coincidentes con los resultados de los adolescentes burgaleses que sitúan la media de edad de inicio en internet en 9,33 años, como se puede comprobar en la tabla 119.

Munoz-Miralles et al. (2014) confirman en sus estudios que los niños actuales acceden a las TIC, cada vez, a una edad más temprana, datos coincidentes con nuestros resultados ya que los adolescentes más jóvenes, afirman haber empezado a utilizar las nuevas tecnologías antes, como se puede ver en la gráfica 114, que muestra la edad media de inicio en las distintas tecnologías de los adolescentes burgaleses encuestados por edad.

La edad de inicio en las nuevas tecnologías, en la actualidad, no se sitúa en la adolescencia, ni tan siquiera en la niñez. Genc (2014) afirma que los bebés de pocos meses de edad pasan 1 hora diaria viendo la televisión. Los niños, empiezan a los 2 años a jugar con el smartphone y la tablet. Nuestros resultados confirman que un porcentaje 
de los adolescentes se ha iniciado en las nuevas tecnologías desde muy jóvenes. En la tabla 121 puede observarse el porcentaje de los adolescentes que se ha iniciado en las nuevas tecnologías antes de los 6 años.

\subsubsection{2.- Tiempo dedicado por los adolescentes a las nuevas tecnologías:}

En la última década, las nuevas tecnologías se han convertido en una parcela cada vez más importante de la vida de los adolescentes.

Strasburger et al. (2010) afirman que los adolescentes destinan más tiempo a las nuevas tecnologías que a asistir al colegio. La media del tiempo medio invertido en realizar actividades relacionadas con las nuevas tecnologías por los adolescentes burgaleses es, para días entre semana, de 5:59 horas. El tiempo medio que los adolescentes dedican a asistir al colegio es de 6:08. Esto nos lleva a afirmar que los adolescentes burgaleses pasan más tiempo en el colegio que utilizando las nuevas tecnologías, pese a la pequeña diferencia, ya que son escasos 9 minutos. En relación al fin de semana es de 9:13 horas diarias de media. Podemos considerar que lo elevado de esta cifra puede deberse al hecho de simultanear la realización de varias actividades relacionadas con la utilización de las nuevas tecnologías.

En el mismo estudio realizado por Strasburger et al. (2010), manifiestan que el uso de nuevas tecnologías es la actividad a la que más tiempo dedican los adolescentes después de dormir. Resultados de la presente investigación nos ubica en tercer lugar el tiempo dedicado a las nuevas tecnologías por los adolescentes burgaleses, inmediatamente después de dormir y asistir a clase.

Tras llevar a cabo el análisis de los resultados de la encuesta realizada a los adolescentes burgaleses, concluimos que la media de tiempo que dedican a las nuevas tecnologías, considerando los 7 días de la semana, es de 6:54 horas al día. Para Rideout et al. (2010), esta media de tiempo es inferior al dedicado por los adolescentes de Estados Unidos en 2009 a la misma actividad, si bien hay que considerar que los 7 días de la semana rondaba las 7:38 horas diarias. Así mismo, esta media de tiempo para los adolescentes de más edad se aproxima a las 11 horas diarias. 
Strasburger (2014) afirma que el tiempo medio de un adolescente estadounidense frente a una pantalla es superior a 7 horas diarias. Dado que el tiempo dedicado por los adolescentes burgaleses a las nuevas tecnologías es de 6:54 horas diarias, podemos afirmar que, aun siendo ligeramente inferior, el tiempo dedicado a esta actividad es equiparable entre adolescentes burgaleses y los estadounidenses.

Los participantes en la encuesta exceden el tiempo frente a una pantalla recomendado por la AAP, baremado en 2 horas al día, al igual que ocurre con los adolescentes australianos (Houghton et al., 2015) y los noruegos (Overby et al., 2013). Rideout et al. (2010) y Tremblay et al. (2012) que afirman que el tiempo medio que dedican a las nuevas tecnologías tanto los niños como los jóvenes es de 4 ó 5 veces más que el tiempo recomendado por la AAP. Los resultados del cuestionario arrojan que los encuestados dedican a las nuevas tecnologías 3,5 veces más de tiempo que lo recomendado por la AAP. Lo que pone de manifiesto que los adolescentes burgaleses encuestados dedican menos tiempo a las nuevas tecnologías en relación a las investigaciones referidas.

\subsubsection{3.- Control parental:}

El estudio de Lam (2015) afirma que el control que ejercen los padres sobre el uso de las nuevas tecnologías por parte de sus hijos es bajo. Según los resultados obtenidos en nuestra encuesta, el $43,45 \%$ de los adolescentes burgaleses encuestados ha manifestado no tener normas en casa para el uso de dispositivos electrónicos y de acceso a internet, como se observa en la tabla 143.

Munoz-Miralles et al. (2014) mantiene que el control parental con respecto al uso de las TIC, por parte de sus hijos adolescentes, disminuye con la edad. Los adolescentes, al hacerse mayores tienen más independencia y esto dificulta el control de su uso de las TIC. Este resultado coincide con lo encontrado en el presente estudio, donde el porcentaje de adolescentes que afirma tener siempre normas en casa para el uso de dispositivos electrónicos disminuye con la edad (tabla 145). 
El control de los padres del uso de las TIC se asocia a alcanzar un mejor rendimiento académico por parte de los adolescentes, según investigaciones de Munoz-Miralles et al. (2014). Como muestra la tabla 168, el porcentaje de adolescentes que tiene normas en casa con respecto al uso de las TIC y que no ha repetido curso es de $89,01 \%$, lo que es muy superior al $10,99 \%$ de adolescentes que aun teniendo normas, han repetido curso.

\subsubsection{4.- Efectos positivos y negativos del uso de internet en los adolescentes:}

\subsubsection{1-Efectos positivos y beneficios:}

O'Keeffe et al. (2011) afirman que internet aporta al adolescente recursos necesarios para su formación académica que pueden ayudarle a obtener resultados más satisfactorios. Las tablas 165 y 166 muestran que los adolescente burgaleses encuestados que no han repetido curso o suspendido alguna asignatura han obtenido afirman dedicar mayor porcentaje del tiempo a navegar por internet para apoyar su educación, en relación a los que han repetido algún curso o suspendido alguna asignatura.

\subsubsection{2-.- Riesgos/efectos negativos del uso de las TIC:}

Hale \& Guan (2015) y Arora et al. (2014) afirman que el tiempo pasado frente a una pantalla por el adolescente afecta a la cantidad de tiempo destinado a dormir y al tiempo necesario a dormirse.

Cain y Gradisar (2010) manifiestan en su estudio que el uso en exceso de medios electrónicos por los adolescentes antes de acostarse o durante la noche se relaciona con tener dificultades para dormir y muestra un impacto negativo en la duración del sueño.

De igual manera, Lemola et al. (2015) puntualizan que los efectos más negativos del uso de las TIC son los relacionados con las dificultades para conciliar el sueño. En nuestro caso, al preguntar si llevan los aparatos electrónicos a la cama y si se conectan a ellos antes de dormirse y relacionarlo con el tiempo que tardaron en dormirse el día previo a la realización de la encuesta, los resultados obtenidos confirman las investigaciones anteriormente mencionadas. Los adolescentes que se llevaron los dispositivos 
electrónicos a la cama el día previo a la cumplimentación del cuestionario, tardaron 12 minutos más en dormirse que los que no los llevaron.

Del mismo modo, encontramos diferencias en relación al tiempo que tardaron en dormirse la noche anterior a la encuesta y el hecho de conectarse a internet después de acostarse. La diferencia de medias muestra que los que sí que se conectan tardaron 13 minutos más en dormirse (tabla 131).

Lemola et al. (2015) afirman que la duración del sueño está afectada por el uso de las nuevas tecnologías, pero no de manera contundente. Los resultados de nuestro cuestionario, como puede apreciarse en la tabla 130, muestran que los adolescentes que se llevan los aparatos electrónicos a la cama duermen entre semana menos tiempo que los que no se los llevan, alrededor de 28 minutos menos (7:33 frente a 8:01 horas diarias) por lo que podemos afirmar que la duración del sueño está afectada por el hecho de disponer de dispositivos electrónicos a la cama entre semana. Sin embargo, no podemos asegurar que existan diferencias significativas durante el fin de semana.

En la tabla 131 se relaciona el tiempo dedicado a dormir por los adolescentes y el hecho de conectarse a internet tras haberse acostado. Los resultados demuestran que sí existen diferencias entre semana (la diferencia de medias es de 26 minutos al día). Sin embargo, este análisis pone de manifiesto, como en el caso anterior, que no podemos asegurar que existan diferencias significativas durante el fin de semana.

Lee (2015) afirma en su estudio que revisar frecuentemente el Smartphone y las redes sociales como Facebook no dañan el desarrollo académico de los jóvenes afroamericanos. Como se puede apreciar en la tabla 136, el porcentaje de adolescentes que siempre compagina redes sociales y estudio ronda el $10 \%$.

La práctica de actividad física (moderate-to-vigorous physical activity MVPA) y el tiempo frente a una pantalla (ordenador, tablet, televisión, etc...), están asociadas con una serie de resultados sobre la salud física. Los resultados del estudio llevado a cabo por Bucksch et al. (2014) en los adolescentes alemanes, destacan la necesidad de establecer estrategias dirigidas a reducir el tiempo frente a una pantalla y a promocionar la 
inversión de tiempo en actividades físicas. Sin embargo, los resultados de nuestro estudio muestran que no existe una relación clara que indique que los adolescentes que poseen estas tecnologías dedican menos tiempo a hacer deporte.

Munoz-Miralles et al. (2014) afirman que los adolescentes que pueden sufrir adicción a las nuevas tecnologías. Por su parte, Labrador et al. (2013) han tratado de establecer un criterio de medición de esta adicción. En el presente trabajo queremos conocer si hay indicios entre los adolescentes burgaleses de adiciones a las TIC. Para ello, hemos elaborado la tabla 142 que recoge los porcentajes de adolescentes que dedican más tiempo a las TIC del que se habían propuesto, lo cual estimamos que puede considerarse como un indicio de adicción. Este porcentaje ronda entre el $11 \%$ y el $16 \%$ de los adolescentes, dependiendo de la tecnología.

Se considera importante en el presente estudio profundizar en el uso de las nuevas tecnologías analizando los diferentes dispositivos electrónicos y aplicaciones de mayor uso, como son: Internet, Redes sociales, Televisión, Teléfono móvil y Videojuegos.

\subsection{2.- Internet}

\subsubsection{1.- Disponibilidad de conexión a internet en los hogares:}

La tabla 181 recoge un resumen de estudios recientes sobre la posibilidad de conexión a internet en el hogar. En los resultados obtenidos en la encuesta realizada a los adolescentes burgaleses, puede observarse que tienen internet en mayor medida, lo que puede ser debido a que estudio es el más reciente de todos.

\begin{tabular}{|l|cc|}
\hline PAís & ESTUDIO & $\begin{array}{c}\text { \%ADOLESCENTES CONEXIÓN A } \\
\text { INTERNET EN CASA }\end{array}$ \\
\hline Grecia & Siomos, Dafouli et al., 2008 & $70,8 \%$ \\
\hline EEUU & Strasburger, Hogan, et al 2013 & $84,0 \%$ \\
\hline España & $\begin{array}{c}\text { encuesta sobre Equipamiento y Uso de } \\
\text { Tecnologías de Información y } \\
\text { Comunicación en los Hogares INE, 2014 }\end{array}$ & $74,5 \%$ \\
\hline $\begin{array}{l}\text { España } \\
\text { (Burgos) }\end{array}$ & Presente estudio 2015 & $95,5 \%$ \\
\hline
\end{tabular}

Tabla 181: estudios adolescentes que tienen conexión a internet en su casa 
El porcentaje de adolescentes españoles de edades comprendidas entre 10 y 15 años, que se conectan a internet, es del 92\%, según la encuesta sobre Equipamiento y Uso de Tecnologías de Información y Comunicación en los Hogares realizada por el INE en el año 2014. Munoz-Miralles et al. (2014) afirman que el 98,6\% de los adolescentes barceloneses accede a internet. Con respecto a los adolescentes burgaleses, la encuesta confirma que el porcentaje de adolescentes burgaleses que manifiesta dedicar algo de tiempo a internet entre semana o durante el fin de semana es del $90,0 \%$, datos que se aproximan a los estudios mencionados.

El 44,8\% de los adolescentes barceloneses utiliza internet durante 2 o más horas al día, datos de Munoz-Miralles et al. (2014). La media de tiempo que dedican los adolescentes burgaleses a navegar por internet es bastante inferior a esta cifra; aproximadamente de 0:54 horas diarias entre semana y de 1:15 horas diarias durante el fin de semana. Sin embargo, estos datos se aproximan más al estudio realizado por Noriega et al. (2015) que indica que casi el $72 \%$ de los chicos y el $80 \%$ de las chicas adolescentes de la Comunidad Autónoma de Cantabria, manifiestan utilizar internet entre semana durante menos de 2 horas al día.

En Estados Unidos, aproximadamente el $28 \%$ de los adolescentes tienen acceso a internet en su propio dormitorio (Strasburger et al., 2013). Hay que destacar que hoy en día con las redes wifi si hay conexión en la casa, también lo hay en la habitación del adolescente. En relación a los adolescentes encuestados, el 39,8\% tiene ordenador en su habitación, sin especificar si tiene conexión a internet en dicho ordenador. El 35,6\% tiene tablet propia, lo que implica el uso en su habitación y, por tanto, la posibilidad de conectarse a internet en cualquier momento.

\subsubsection{2.- Uso de internet en relación a los distintos factores sociodemográficos:}

La encuesta sobre Equipamiento y Uso de Tecnologías de Información y Comunicación en los Hogares realizada por el INE (2014), concluye que en España no se encuentran diferencias significativas en el uso de internet por género. Sin embargo, los datos de nuestra encuesta que se pueden ver en la tabla 62 , ponen de manifiesto que el 
porcentaje de adolescentes femeninas que dedica algo de su tiempo a navegar por internet es mayor que el porcentaje de adolescentes varones.

Los resultados de la encuesta sobre Equipamiento y Uso de Tecnologías de Información y Comunicación en los Hogares realizada por el INE (2014) exponen que el porcentaje de adolescentes usuarios de internet en España aumenta con la edad, llegando a ser de un 95,2\% para los adolescentes de 15 años. Nuestros resultados ponen de manifiesto, del mismo modo, que el porcentaje de adolescentes que tiene acceso a internet en casa aumenta al aumentar la edad, siendo de 95,9\% para los adolescentes de 15 años

\subsubsection{3.- Dispositivos de acceso a internet:}

Madden et al. (2013) afirman que el $50 \%$ de los adolescentes se conecta a internet desde su smartphone. La encuesta sobre Equipamiento y Uso de Tecnologías de Información y Comunicación en los Hogares, realizada por el INE (2014) ha destacado que el $74 \%$ de los adolescentes de entre 12 y 17 años, manifiesta conectarse a internet en el teléfono móvil, tablet u otros dispositivos móviles, al menos de manera ocasional. En España, Cánovas et al. (2014) afirman que el 60\% de los menores españoles de entre 11 y 14 años navega y busca información a través de internet desde su smartphone. Los resultados de nuestro estudio, están en línea con este último estudio, siendo el 59,9\% de los adolescentes burgaleses encuestados los que tiene conexión a internet desde su teléfono móvil propio.

Madden et al. (2013) ponen de manifiesto que existen diferencias en el dispositivo de conexión a internet por género, es decir, el 34\% de las adolescentes se conecta a internet desde su teléfono móvil, frente al $24 \%$ de los adolescentes masculinos. Con respecto a los resultados obtenidos en nuestra encuesta (reflejados en la tabla 82) el porcentaje de chicas que tiene Internet en su teléfono móvil propio $(77,0 \%)$ es superior al porcentaje de chicos $(71,6 \%)$.

\subsubsection{4.- Efectos positivos y negativos del uso de internet en los adolescentes:}

El $81 \%$ de los adolescentes de Barcelona (España) considera que los contenidos de la red son de su interés, y les sirven, entre otras utilidades, como soporte para realizar los 
trabajos de clase (Castellana Rosell et al., 2007). La media de tiempo dedicada por los adolescentes burgaleses a navegar por la red como apoyo a sus tareas escolares es del $38,98 \%$ del tiempo total que pasan conectados, datos recogidos en la gráfica 98.

Para Rey-López et al. (2010), el tiempo destinado por los adolescentes a navegar en internet por ocio, ha aumentado durante los últimos años. Las causas principales son el aumento de puntos de conexión a internet y la popularización de las redes sociales (Noriega et al., 2015). Según nuestro estudio, los adolescentes burgaleses reconocen destinar el $61,02 \%$ del tiempo total que navegan por internet para su propio ocio.

Estudios de Young, (1996), Labrador et al, (2013) y Rial et al, (2014), confirman que el mal uso o uso intensivo de internet puede provocar cuantiosas consecuencias negativas en los adolescentes. Al igual que numerosas investigaciones han tratado de estudiar sobre la posible adicción a internet.

Hale y Guan (2015) y Arora et al. (2014) en sus estudios afirman que el tiempo pasado frente a una pantalla por el adolescente afecta a la cantidad de tiempo destinado a dormir y al tiempo necesario a dormirse. Sin embargo, no encontramos diferencias significativas en el tiempo que tardan los adolescentes burgaleses en dormirse en relación al hecho de tener o no Internet en casa.

Los adolescentes que mayor uso hacen de internet, muestran hábitos problemáticos a la hora de dormir y problemas relacionados con el sueño. Se pone de manifiesto que la presencia de conexión a internet en las habitaciones de los adolescentes canadienses de Otawa, representan un riesgo ante la calidad o eficiencia del sueño del mismo (Chaput et al, 2014). Se puede concluir de los datos de la encuesta realizada a los adolescentes burgaleses (tabla 126) que aquellos que tienen ordenador en la habitación duermen menos, tanto entre semana como durante el fin de semana. Asimismo, encontramos diferencias en el tiempo que duermen entre semana si tienen televisión en la habitación (duermen 9 minutos diarios menos de media.) No se encuentran diferencias significativas en el tiempo que duermen en función de tener conexión a internet disponible en casa. 


\subsubsection{5.- Control parental}

Con respecto al control parental sobre el uso de internet, el $18,92 \%$ de los adolescentes burgaleses encuestados manifiesta que siempre tiene normas para el uso de dispositivos electrónicos y de acceso a internet. Sin embargo, el 43,45\% de los adolescentes encuestados ha manifestado que nunca tiene normas en casa sobre este tema. Esta cifra es ligeramente inferior a la encontrada para los adolescentes barceloneses, que cuantifica en $47,2 \%$ los que se conectan a internet sin control paterno (Munoz-Miralles et al., 2014). Los resultados de estudios realizados a adolescentes gallegos aportan cifras aún superiores: el $54 \%$ de los adolescentes afirma que sus padres no ejercen sobre su uso de internet control alguno.

Strasburger (2014) comenta haber detectado una falta de interés o de preocupación por parte de los padres en conocer las actividades relacionadas con las nuevas tecnologías en las que sus hijos invierten su tiempo. Podemos realizar afirmaciones similares tras analizar las respuestas a la cuestión 48 que pregunta a los adolescentes si sus padres les preguntan por los contenidos que utilizan en la red. El 35,29\% de los padres no preguntan a sus hijos sobre los contenidos a los que acceden en la red. El 34,60\% manifiesta que sólo lo hacen "a veces". Por lo tanto, el hábito de preguntar a los hijos sobre los contenidos que visitan en la red, queda limitado al $26,59 \%$ de los adolescentes que respondieron que reciben estas preguntas de sus progenitores "habitualmente" 0 " siempre".

\subsection{3.- Redes sociales}

\subsubsection{1.- Cifras de adolescentes conectados a redes sociales}

El 97\% de los adolescentes españoles de edades comprendidas entre 14 y 17 años tiene algún perfil en alguna red social, según el VI Estudio Redes Sociales de IAB Spain (2014). Los adolescentes burgaleses encuestados superan esta cifra. El porcentaje de ellos que afirma tener un perfil en al menos 1 de las redes sociales del listado aportado en la encuesta es del $97,73 \%$. Sólo el $2,27 \%$ ha confirmado que no utiliza las redes sociales. 
El 71\% de los adolescentes de 16 años tienen varios perfiles en más de una red social (Bravo \& Rasco, 2013). De los adolescentes burgaleses que usan redes sociales, el 90,91\% manifiesta tener perfil en más de una de las redes sociales propuestas. El 9,09\% afirma tener perfil en sólo 1 de ellas.

Lenhart (2015) afirma que el 92\% de los adolescentes manifiesta participar a diario en redes sociales. El porcentaje de adolescentes burgaleses encuestado que afirma dedicar algo de tiempo al día a las redes sociales es menor al apuntado por Lenhart (2015). El 81,14\% de los adolescentes afirma dedicar diariamente tiempo a las redes sociales.

Las redes sociales ocupan una gran parte del tiempo que los adolescentes dedican a internet. De hecho, casi el 70,7\% del tiempo invertido por los adolescentes andaluces de entre 10 y 18 años a navegar por internet está destinado a las redes sociales (Bringué \& Sádaba, 2009). El tiempo que dedican los adolescentes burgaleses a las redes sociales es de 1:05 horas al día entre semana y de 1:36 horas al día el fin de semana. Este tiempo es superior al tiempo que éstos mismos afirman dedicar a internet, que es de 0:53 horas al día entre semana 1:15 horas al día el fin de semana. El tiempo destinado a redes sociales por los adolescentes burgaleses representa el 54,9\% con respecto al tiempo global dedicado a internet y redes sociales, por lo que podemos afirmar que el porcentaje es inferior al de los adolescentes andaluces.

\subsubsection{2.- Redes sociales utilizadas por los adolescentes:}

En la tabla 11 observamos el ranking de redes más utilizadas por los adolescentes según diferentes investigaciones. Destacamos que estos estudios son posteriores al año 2013, dado que de ser más antiguos correrían el riesgo de quedarse obsoletos.

Esta tabla 182 muestra que la red más utilizada por los adolescentes es Facebook. En España, en primer lugar encontramos Tuenti o Facebook. Sin embargo, el análisis de los datos recogidos de los adolescentes burgaleses muestra que la red más utilizada en WhatsApp seguida de Instagram, aunque es cierto que existe cierta discusión sobre la inclusión de WhatsApp como red social. 
Los adolescentes catalanes utilizan en algún caso Skype para hacer videollamadas. Sin embargo, no es una práctica muy extendida, puesto que la mayoría reconoce que le gusta más hablar en persona que por las redes sociales (Navarro et al., 2014). Según nuestra encuesta, los adolescentes burgaleses sitúan Skype como quinta red social más utilizada. Sólo un 44,61\% de los adolescentes afirma utilizarla.

\begin{tabular}{|c|c|c|c|c|c|c|c|c|c|c|c|}
\hline \multirow[b]{2}{*}{ PAÍS } & \multirow[b]{2}{*}{ ESTUDIO } & \multicolumn{10}{|c|}{ RANKING DE REDES SOCIALES MÁS UTILIZADAS POR LOS ADOLESCENTES } \\
\hline & & 1 & 2 & 3 & 4 & 5 & 6 & 7 & 8 & 9 & 10 \\
\hline España & $\begin{array}{c}\text { Jiménez, de } \\
\text { Ayala López, } \\
\text { et al., } 2013\end{array}$ & Tuenti & Facebook & Twitter & My Space & Fotolog & & & & & \\
\hline $\begin{array}{l}\text { Andalucí } \\
\text { a } \\
\text { (España) }\end{array}$ & $\begin{array}{c}\text { Bravo y } \\
\text { Rasco, } 2013\end{array}$ & Tuenti & Facebook & & & & & & & & \\
\hline $\begin{array}{l}\text { Cataluña } \\
\text { (España) }\end{array}$ & $\begin{array}{c}\text { Navarro, } \\
\text { González et } \\
\text { al., } 2014\end{array}$ & Facebook & & & & & & & & & \\
\hline Mundial & $\begin{array}{c}\text { Webempres } \\
\text { a20.com } \\
(2014)\end{array}$ & Facebook & Youtube & QQ & Qzone & WeChat & Twitter & Whats App & SinaWibo & $\mathrm{Hi} 5$ & Tagged \\
\hline España & $\begin{array}{l}\text { VI Estudio } \\
\text { Redes } \\
\text { Sociales de } \\
\text { IAB Spain, } \\
2014 \\
\end{array}$ & Facebook & Youtube & Twitter & Instagram & Tuenti & Spotify & Google+ & Badoo & Linkedln & Pinterest \\
\hline \multirow[t]{2}{*}{ USA } & $\begin{array}{l}\text { Lenhart, } \\
2015\end{array}$ & Facebook & Instagram & Snapchat & t Twitter & Google+ & Vine & Tumblr & & & \\
\hline & $\begin{array}{c}\text { Navarro, } \\
2015\end{array}$ & Facebook & Youtube & Google+ & Twitter & Instagram & Tumblr & Pinterest & Linkedln & My Space & Reddit \\
\hline \begin{tabular}{|l} 
Burgos \\
(España)
\end{tabular} & $\begin{array}{c}\text { Presente } \\
\text { estudio }\end{array}$ & Whats App & Instagram & Twitter & Snapchat & t Skype & Facebook & Tuenti & Line & & \\
\hline
\end{tabular}

Tabla 182: comparativa de ranking de uso de redes sociales por los adolescentes

\subsubsection{3.- Efectos positivos y negativos del uso de las redes sociales}

Las redes sociales son una herramienta de ayuda en el proceso de búsqueda de amistad (Mazur \& Richards, 2011). Los adolescentes contabilizan el número de sus seguidores (Bravo \& Rasco, 2013). Algunos acumulan numerosos amigos, y en ciertos casos, a muchos de ellos no los conocen en persona (Navarro et al., 2014). La gráfica 102 muestra la media de amigos que los adolescentes burgaleses afirman tener en las redes.

Los adolescentes, en ocasiones, consideran que pasan excesivo tiempo conectados a las redes sociales. Pierden la noción del tiempo y se olvidan del resto de sus planes por estar conectados a ellas (Navarro et al., 2014). Para Vilca \& Vallejos (2015), los adolescentes de edades comprendidas entre 14 y 18 de Perú presentan 7 síntomas de adicción a las redes sociales: pérdida de control, síndrome de abstinencia, disminución 
del rendimiento académico, modificación estado de ánimo, dependencia, pérdida de interés en otras actividades y conflictos en el ámbito social. En nuestro estudio, hemos preguntado a los adolescentes burgaleses si consideran que están conectados a las redes sociales más tiempo del que se proponen. El 46,93\% considera que, tanto a veces, como habitualmente, están conectados a la red, más tiempo del que se habían propuesto (tabla 142). El 11,36\% de ellos afirma que siempre que se conecta, lo hace más tiempo del que se había propuesto.

Para Navarro et al. (2014), los adolescentes, utilizan los dispositivos tecnológicos como apoyo para realizar las tareas y trabajos escolares. Esto hace que corran el riesgo de terminar conectados a las redes sociales mientras están estudiando. En este caso, suelen dejar de prestar atención a los deberes para finalmente focalizarse en las redes sociales. Las adolescentes catalanas reconocen realizar ambas actividades a la vez, incluso en algún caso a escondidas de sus padres. En nuestro estudio, el $38,31 \%$ de los adolescentes burgaleses encuestados afirma que nunca tiene abiertas las redes sociales mientras estudia. El $36,15 \%$ contesta que a veces y el $25,54 \%$ responde que habitualmente o siempre, tal y como se recoge en la tabla 136.

Andreassen, et al. (2012) afirman que los altos niveles de utilización de Facebook están asociados con una hora más tardía de dormirse y también de levantarse. Esto se cumple para los adolescentes burgaleses que han participado en nuestra encuesta. La tabla 133 muestra que los adolescentes que tienen perfil en Facebook tardaron en dormirse el día previo a la cumplimentación de la encuesta 3 minutos más que aquellos que no tienen.

\subsubsection{4.- Control parental:}

Los adolescentes andaluces manifiestan que no muestran restricciones en el uso de las redes sociales. Además, afirman que el control parental es bastante escaso (Bravo \& Rasco, 2013). A nivel global, el estudio elaborado por OCU en 2013, con motivo del Día de internet encontró que, de los 400 padres y madres a los que encuestaron, el $27 \%$ admitió no tener información sobre el uso que sus hijos de entre 10 y 16 años hacen de las redes sociales. El item 46 del cuestionario pregunta sobre si sus padres o tutores 
conocen su nic/alias/nombre en las redes sociales en las que participan. El 38,33\% de los adolescentes afirman que sus padres conocen habitualmente o siempre sus nics en las redes sociales. El $38,95 \%$ de los adolescentes burgaleses encuestados afirma que sus padres nunca conocen su nombre en las redes sociales. Por lo tanto, este último valor es superior al de las investigaciones referidas.

\subsection{4.- Televisión}

Estudios de Strasburger et al. (2013), de la Piscina et al. (2011) y Navarro et al. (2014) comentan que la introducción de las nuevas tecnologías en la sociedad ha cambiado radicalmente el panorama de los medios y la TV sigue siendo el medio predominante. EI análisis de los resultados de nuestra encuesta, pone de manifiesto que los adolescentes burgaleses dedican más tiempo al WhatsApp que a ver la televisión (tabla 32), por lo que podemos aportar datos que permitan discrepar.

La televisión ha sido, por lo tanto, desbancada por el WhatsApp para los adolescentes burgaleses. Es necesario que tengamos en cuenta que en algunos casos, los adolescentes están utilizando el WhatsApp simultáneamente a la realización de otras actividades, como puede ser ver la televisión.

\subsubsection{1.- Cifras de adolescentes y televisión}

La siguiente tabla 183 recoge datos de estudios sobre el porcentaje de adolescentes que ve la televisión. Los adolescentes burgaleses encuestados, dedican a ver la televisión una cantidad de horas bastante inferior a la encontrada en estos estudios, larededor de 1:25 horas al día entre semana y 2:06 horas al día durante el fin de semana.

Las cifras mencionadas anteriormente son incluso inferiores a las obtenidas por los adolescentes cántabros, que afirman que durante los días lectivos, el 86\% de ellos dedica a ver la televisión menos de 2:00 diarias (Noriega et al., 2015). El autor afirma que durante el fin de semana, el número de horas que los 
Capítulo 5.- Discusión

adolescentes dedican a ver la televisión es mayor, al igual que ocurre con los adolescentes burgaleses que durante el fin de semana, dedican a ver la televisión, como ya hemos comentado anteriormente, 2:06 horas al día de media.

\begin{tabular}{|c|c|c|c|}
\hline PAÍS & ESTUDIO & $\begin{array}{c}\text { HORAS DIARIAS TV } \\
\text { ENTRE SEMANA }\end{array}$ & $\begin{array}{c}\text { HORAS DIARIAS TV } \\
\text { FN DE SEMANA }\end{array}$ \\
\hline España & Gabelas (2005) & $3: 30$ & \\
\hline España & Bercedo Sanz et al. (2005) & 3:00 & 3:12 \\
\hline Ontario (Canadá) & Hilbrecht et al., (2008) & $1: 12$ y $1: 30$ & $2: 24$ y $3: 00$ \\
\hline País Vasco (España) & $\begin{array}{c}\text { Samaniego, Barandiaran, \& } \\
\text { Navarro (2010) }\end{array}$ & $2: 15$ y $2: 30$ & 7:00 \\
\hline País Vasco (España) & $\begin{array}{l}\text { De la Piscina, Zarandona et } \\
\text { al. (2011) }\end{array}$ & más de 4:00 & \\
\hline USA & Strasburger et al. (2013) & más de 4:00 & \\
\hline Cantabria (España) & $\begin{array}{c}\text { Borge, Canser, Pablos, } \\
\text { Lanza, Guerra, Ruiz \& Rivas, }\end{array}$ & $86 \% 2: 00$ & \\
\hline Burgos (España) & Presente estudio (2015) & $1: 25$ & $2: 06$ \\
\hline
\end{tabular}

Tabla 183: estudios tiempo que los adolescentes dedican a ver la televisión

Investigaciones existentes han identificado una diferenciación por género en cuanto al número de horas de visualización de televisión. El género femenino dedica, independientemente del día de la semana, menos horas a ver la televisión que el masculino (Noriega et al., 2015). Los datos recogidos de los adolescentes burgaleses no muestran diferencias significativas por género en el tiempo dedicado a ver la televisión.

Para Noriega et al. (2015), el porcentaje de adolescentes que ven la televisión durante más de 2 horas diarias aumenta con la edad, excepto para el intervalo entre 16 y 17 años donde decrece. El análisis de los resultados de la encuesta realizada a los adolescentes burgaleses confirma la tendencia. El tiempo que los adolescentes burgaleses dedica a ver la televisión aumenta con la edad, hasta los 15 años. A partir de los 16 años, se observa que existe una disminución, como figura en la tabla 35.

\subsubsection{2.- Televisión en la habitación}

En Estados Unidos, la media de adolescentes de edades comprendidas entre 8 y 18 años, que tiene TV en su habitación es del 71\% (Rideout et al., 2010; Zamorano et al, 2014). 
Cameron et al. (2013) afirma que el porcentaje en países europeos es inferior (desde el $65 \%$ en Hungría hasta el $28 \%$ en España). Esta misma conclusión se recoge en el estudio de De la Piscina et al. (2011) que manifiestan que sólo 1 de cada 4 adolescentes vascos, tiene televisión en su habitación. El porcentaje de nuestros encuestados, que tiene televisión en la habitación es inferior al encontrado para otros países extranjeros. Las cifras son incluso inferiores a las encontradas en otros estudios realizados en España. Sólo el 17\% de los adolescentes burgaleses tiene televisión en la habitación.

\subsubsection{3.- Efectos positivos y negativos de ver la televisión}

No se han encontrado estudios que pongan de manifiesto las ventajas para el adolescente de ver la televisión. Nuestro estudio no nos permite aportar luz sobre ventajas o efectos positivos en los adolescentes de ver la televisión.

Gilbert-Diamond et al. (2014), Chaput et al. (2014) y Zamorano et al (2014) vaticinan que los adolescentes son muy propensos a aumentar el tiempo dedicado a ver la televisión y corren riesgo de perder el control del tiempo dedicado a esta actividad. Sin embargo, los resultados obtenidos de la encuesta realizada a los adolescentes burgaleses, ponen de manifiesto que el hecho de tener televisión en la habitación no marca diferencias significativas en el tiempo que dedican a verla (tabla 125).

Chaput et al (2014) afirman que el número de horas que duermen los adolescentes canadienses de Otawa no está relacionado con la presencia o no de pantallas en su habitación, aunque sí con la calidad del sueño, que se ve perjudicada por la existencia de televisión en la habitación del adolescente. Los datos de nuestro estudio muestran que los adolescentes que no tienen televisión en la habitación duermen durante más tiempo. Destacamos que se encuentran diferencias significativas entre el tiempo que dedican a dormir entre semana y el hecho de tener televisión en la habitación.

El tiempo que un adolescente con dispositivos electrónicos en su habitación dedica a realizar ejercicio físico es prácticamente el mismo que el de un adolescente que no los posee, como afirma Chaput et al, (2014). Según nuestro estudio, los adolescentes 
burgaleses que tienen televisión en la habitación dedican más tiempo a hacer deporte que los que no la tienen (aproximadamente 9 minutos más entre semana y 11 minutos más durante el fin de semana). Tal y como podemos observar en la tabla 125 , este incremento de tiempo no pone de manifiesto que existan diferencias significativas entre semana, pero sí durante el fin de semana, con un nivel de significación de 0,039.

\subsection{5.- Teléfono móvil}

\subsubsection{1-Edad de posesión del primer teléfono móvil:}

Hemos encontrado estudios que afirman que, en España, la edad media a la que los adolescentes tienen su primer teléfono móvil ronda los 11-13 años (Chóliz et al., 2009; Instituto Nacional de Tecnologías de la Comunicación, 2011; INTECO y Fundación Orange en 2013; Munoz-Miralles et al., 2014). Los resultados obtenidos del análisis de las respuestas a la encuesta muestran que los adolescentes burgaleses han tenido su primer teléfono móvil a la edad de 11,26 años, como se recoge en la tabla 122, por lo que podemos considerarlos que se encuentra muy cercano al límite inferior.

\subsubsection{2.- Porcentaje de adolescentes que posee teléfono móvil:}

La tabla 184 muestra los porcentajes de varios estudios sobre los adolescentes y el teléfono móvil. Se observa que el porcentaje de adolescentes burgaleses encuestados que tiene teléfono móvil es similar que el encontrado por el estudio realizado por Barrio Fernández (2014). Sin embargo, el porcentaje obtenido en nuestra muestra es bastante superior al encontrado por Madden et al. (2013) en Estados Unidos. Es probable que esto se deba a que este estudio se realizó 2 años antes, y la expansión del teléfono móvil en la sociedad ha sido vertiginosa en los últimos años. 
3a PARTE

Capítulo 5.- Discusión

\begin{tabular}{|c|c|c|c|c|c|}
\hline ESTUDIO & PAís & \% TIENE MÓVIL & $\begin{array}{c}\text { \% TIENE } \\
\text { SMARTPHONE }\end{array}$ & $\begin{array}{c}\text { \% NO TIENE } \\
\text { MOVIL }\end{array}$ & OBSERVACIONES \\
\hline EEUU & $\begin{array}{c}\text { Madden, } \\
\text { Lenhart et al. } \\
(2013)\end{array}$ & $78,0 \%$ & $47,0 \%$ & & $\begin{array}{c}\text { entre } 12 \text { y } 17 \\
\text { años }\end{array}$ \\
\hline $\begin{array}{c}\text { Cantabria } \\
\text { (España) }\end{array}$ & $\begin{array}{l}\text { Barrio } \\
\text { Fernández } \\
(2014)\end{array}$ & $92,9 \%$ & $80,9 \%$ & $7,0 \%$ & \\
\hline $\begin{array}{c}\text { Burgos } \\
\text { (España) }\end{array}$ & $\begin{array}{l}\text { Presente } \\
\text { estudio } \\
(2015)\end{array}$ & $91,6 \%$ & & $6,6 \%$ & $\begin{array}{c}\text { entre } 12 \text { y } 17 \\
\text { años }\end{array}$ \\
\hline
\end{tabular}

Tabla 184: adolescentes que poseen teléfono móvil

\subsubsection{3.- Uso del teléfono móvil en relación a los distintos factores sociodemográficos:}

El estudio llevado a cabo por Madden et al. (2013) no encontró diferencias significativas por género en relación al uso del teléfono móvil por los adolescentes.

Según la encuesta sobre Equipamiento y Uso de Tecnologías de Información y Comunicación en los Hogares realizada por el INE (2014), la disponibilidad de teléfono móvil en las adolescentes de género femenino supera en más de tres puntos a la de los adolescentes de género masculino. Este mismo resultado se recoge del análisis de los datos de la encuesta realizada a los adolescentes burgaleses. El porcentaje de posesión de teléfono móvil es mayor en las chicas, aproximadamente 3,3\%, como se recoge en la tabla 73.

La encuesta sobre Equipamiento y Uso de Tecnologías de Información y Comunicación en los Hogares realizada por el INE (2014) muestra el porcentaje de adolescentes que tiene teléfono móvil a las distintas edades. Comparamos los porcentajes con los obtenidos en nuestro estudio, expuesto en la tabla 185. Los porcentajes de adolescentes que tienen teléfono móvil en Burgos son superiores a los de la encuesta del INE, independiente mente de la edad. 


\begin{tabular}{|l|cc|}
\cline { 2 - 3 } \multicolumn{1}{c|}{} & \multicolumn{2}{|c|}{ \%adolescentes que tiene móvil } \\
\hline Edad & $\begin{array}{c}\text { Encuesta } \\
\text { burgaleses }\end{array}$ & Encuesta INE \\
\hline 10 & \multicolumn{2}{|c|}{} \\
\hline 11 & $81,5 \%$ & $64,3 \%$ \\
\hline 12 & $91,5 \%$ & \\
\hline 13 & $92,2 \%$ & $85,6 \%$ \\
\hline 14 & $96,8 \%$ & $90,3 \%$ \\
\hline 15 & $97,5 \%$ & \\
\hline 17 & $98,4 \%$ & \\
\hline
\end{tabular}

Tabla 185: comparativa de resultados en encuesta INE y encuesta realizada a jóvenes burgaleses en relación - edad primer teléfono móvil

\subsubsection{4.- Evolución del teléfono móvil y actuales usos:}

\section{A.- Mensajes:}

Según Lenhart, (2012), los adolescentes de entre 13 y 17 años enviaron una media de 3364 mensajes de texto al mes. La tabla 91, muestra la media de SMS que envían los adolescentes burgaleses que es aproximadamente de 1,5, lo que significa que al mes envían una media de 45 SMS. Estas cifras no se corresponden con el estudio realizado por Lenhart (2012), que puede deberse a que hemos preguntado exclusivamente por el número de SMS enviados y recibidos, mientras que en 2012 el WhatsApp, Line o aplicaciones similares no estaban tan extendidas.

\section{B.- WhatsApp:}

Fuentes oficiales de WhatsApp confirman que en Abril de 2015, el número de usuarios activos de WhatsApp era superior a los 800 millones. Cada día se registra en WhatsApp 1 millón de usuarios nuevos, siendo la aplicación más utilizada por los adolescentes españoles de entre 11 y 14 años, desbancando a los SMS. El 76\% de los adolescentes lo utiliza habitualmente y el 65\% participa en grupos (Cánovas et al., 2014). Según nuestros datos, el $86,8 \%$ de los adolescentes burgaleses encuestados de entre 12 y 14 años tiene perfil de WhatsApp, el $10,5 \%$ no lo tiene y el $2,8 \%$ no responde.

En Estados Unidos, el 90\% de los adolescentes de edades comprendidas entre 13 y 17 años se comunican a través de mensajes de textos. Las aplicaciones más utilizadas para 
este tipo de comunicación son Kik o WhatsApp (Lenhart, 2015). El 90,9\% de los adolescentes burgaleses encuestados, entre 13 y 17 años, tiene perfil en WhatsApp (similar a los datos estadounidenses), el 5,6\% no tiene perfil y el 3,5\% no ha respondido a esta pregunta.

Un usuario medio envía y recibe al mes una media de 1000 mensajes de WhatsApp Según Lenhart (2015), un adolescente envía y recibe diariamente 30 mensajes de media. La tabla 92 muestra el número de WhatsApp enviados y recibidos por los adolescentes, siendo los burgaleses los que aportan mayor dato. Los datos de la presente investigación constatan que la media de WhatsApp que los adolescentes burgaleses envían es de 95. El número de WhatsApp que reciben de media cada día es de 363. Esta cifra se aleja mucho del estudio de Lenhart (2015), pero como ya hemos comentado en el análisis de los resultados, consideramos que la discrepancia en los datos sea debida a que el número de WhatsApp que los adolescentes han afirmado que envían o reciben en algunos casos es una cifra muy alta. Es importante destacar el elevado número de mensajes que se intercambian.

Un usuario chequea el WhatsApp una media de 23 veces al día y dedica a la semana una media de 3:15 horas (Cristianmonroy.com, 2015). El tiempo medio que dedica un adolescente burgalés al WhatsApp es de 2:03 horas al día.

\section{C.- Conexión a internet desde el smartphone:}

El $68 \%$ de los adolescentes se conectan a internet desde sus dispositivos móviles como mínimo una vez al día (Lenhart, 2015). La tendencia en los adolescentes españoles es similar. No podemos aportar datos del porcentaje de adolescentes que se conectan a internet desde su teléfono móvil, pero sí podemos mostar el porcentaje de los que tienen internet en el teléfono móvil. El 59,9\% de los adolescentes burgaleses, según nuestro estudio, tienen teléfono móvil propio con conexión a internet. El 20,6\% manifiesta no tenerlo, mientras que casi el $20 \%$ no ha contestado, datos recogidos en la gráfica 107. 


\subsubsection{5- Efectos positivos y negativos del uso del teléfono móvil:}

Para Adachi-Mejia et al. (2014), el 62,9 \% de los adolescentes de entre 12 y 20 años se lleva el teléfono móvil a la cama y el $56,8 \%$ lo tiene conectado mientras duerme. Los resultados obtenidos de la encuesta realizada a los adolescentes burgaleses muestra que el 60,33\% de los adolescentes llevan consigo el teléfono móvil y/o ordenador y/o tablet cuando se van a la cama. Aproximadamente el $40 \%$ de ellos afirman no llevárselo.

En Bélgica, según estudios de Brunborg et al. (2011) y Dijk, (2014), más del 55\% de los adolescentes envían y/o reciben mensajes de texto después de "apagar las luces". Según Chóliz et al. (2009) el 80\% de los adolescentes no apaga el teléfono móvil para dormir. El $36,7 \%$ de los adolescentes, envía al menos un mensaje por el móvil después de haberse ido a la cama. Casi el $8 \%$ de los adolescentes manifiesta haber sido despertado durante dos o más veces por semana por un mensaje del móvil (Adachi-Mejia et al., 2014). En nuestro estudio hemos preguntado por los que se conectan a internet después de acostarse y los datos que obtenemos es que $53,05 \%$ de los adolescentes lo hace (tabla 131).

Los adolescentes que tienen un smartphone, usan más las tecnologías antes de dormirse y se duermen más tarde que los adolescentes que tienen teléfonos convencionales. Lemola et al. (2015), sin embargo, no encontraron relación entre la posesión de un smartphone y padecer trastornos del sueño. Como puede apreciarse en la tabla 130, los adolescentes burgaleses encuestados que se llevan a la cama el teléfono móvil y/u ordenador y/o tablet tardan más tiempo de media en dormirse pasando de 0:35 a 0:23 horas diarias.

Los adolescentes que juegan en el móvil o lo utilizan para navegar por internet o enviar/recibir mensajes pueden tener problemas para madrugar (Fossum et al., 2014). Como se puede apreciar en la tabla 132, no se encuentran diferencias en la hora a la que se levantan los adolescentes burgaleses en relación a si se llevan a la cama el teléfono móvil y/u ordenador y/o tablet tardan más tiempo de media en dormirse. La hora media de levantarse es la misma (7:20). 
Se observa que, en los niños, existe una asociación significativa entre el uso consistente del teléfono móvil y la fatiga (Zheng et al., 2015).

Varios estudios, afirman que los adolescentes que envían y/o reciben mensajes de texto después de "apagar las luces reportan mayores niveles de cansancio (Brunborg et al., 2011; Dijk, 2014). El análisis de los datos recogidos en las encuestas realizadas a los adolescentes burgaleses manifiesta que el porcentaje de adolescentes que se lleva los dispositivos electrónicos a la cama y que está cansado es más alto que el que no se los lleva (tabla 134).

Según Chóliz, (2012), los síntomas que aparecen en los adolescentes, en relación al uso del teléfono móvil que hacen plantearnos si pueden llegar a sufrir adicción al mismo son los siguientes: utilización en exceso, problemas con los padres o dificultad para controlar el uso. El 16,62\% de los adolescentes burgaleses encuestados afirma que siempre se conecta a WhatsApp más tiempo del que tenía previsto y el 17,19\% afirma que lo hace habitualmente (tabla 142). Foerster et al (2015), también, afirman que la pérdida de control del uso de móvil puede considerarse un indicio de padecer adicción al teléfono móvil.

Bercedo Sanz et al. (2005) afirman que el $46,4 \%$ de los adolescentes llevan móvil al instituto. En nuestro estudio hemos preguntado si utilizan el teléfono en clase, matiz que ha provocado que el porcentaje hallado en nuestra encuesta diste tanto del encontrado por Bercedo Sanz et al. (2005). Tal y como se puede observar en la tabla 93, el porcentaje de adolescentes burgaleses que utilizan su teléfono móvil en clase es del $11,13 \%$. Hay que destacar que existe en los centros prohibición de uso en clase de dispositivos móviles, a no ser que fuera con motivos académicos.

Existe un debate sobre si el uso del teléfono móvil por el adolescente puede impactar negativamente en los resultados académicos del mismo. Lepp (2014) demuestra que el uso de teléfonos móviles y de los mensajes no está relacionado con el rendimiento académico. Tras analizar los resultados obtenidos en este estudio y recogidos en la tabla 167, podemos observar que tampoco existen diferencias significativas entre la pertenencia de teléfono móvil propio y haber repetido curso. 


\subsection{6.- Videojuegos y consolas}

El 64,4\% de los adolescentes de Barcelona juegan a videojuegos (Munoz-Miralles et al., 2014). La cifra es similar a la obtenida en la encuesta realizada a los adolescentes burgaleses, que arroja un 66,3\% en dedicar tiempo a jugar a videojuegos/consolas entre semana. El porcentaje disminuye los fines de semana, siendo del $50 \%$.

La tabla 186 recoge los estudios principales analizados sobre el tiempo utilizado por los adolescentes a los videojuegos. Como se puede observar los adolescentes que más tiempo dedican a esta actividad son los adolescentes burgaleses. Tal vez pueda deberse a que es el estudio más reciente.

\begin{tabular}{|c|c|c|c|c|}
\hline ESTUDIO & PAÍS & $\begin{array}{c}\text { Entre } \\
\text { semana }\end{array}$ & $\begin{array}{c}\text { Fin de } \\
\text { semana }\end{array}$ & COMENTARIOS \\
\hline \multirow{2}{*}{$\begin{array}{c}\text { Pasquier et al. } \\
\text { (1998) }\end{array}$} & Bélgica & $0: 20$ & $0: 30$ & \\
\hline & Holanda & & $0: 46$ & \\
\hline \begin{tabular}{|c|} 
Livingstone \& Bovill \\
(1999)
\end{tabular} & Inglaterra & & & $64 \%$ media de $0: 45$ \\
\hline \begin{tabular}{|c|} 
Munoz-Miralles et al. \\
$(2014)$ \\
\end{tabular} & $\begin{array}{l}\text { Barcelona } \\
\text { (España) }\end{array}$ & & & $36,5 \% 3: 00$ o más semana \\
\hline \multirow{3}{*}{$\begin{array}{l}\text { Barrio Fernández } \\
\qquad(2014)\end{array}$} & \multirow{3}{*}{$\begin{array}{c}\text { Cantabria } \\
\text { (España) }\end{array}$} & & & $36 \%$ 6:00 o más semana \\
\hline & & & & $3 \%$ entre 7 y 9 horas semana \\
\hline & & & & $4,3 \%$ más de 10 horas semana \\
\hline \multirow{2}{*}{$\begin{array}{c}\text { Presente estudio } \\
\text { (2015) }\end{array}$} & \multirow{2}{*}{$\begin{array}{l}\text { Burgos } \\
\text { (España) }\end{array}$} & \multirow{2}{*}{$0: 28$} & \multirow{2}{*}{$1: 01$} & $22,7 \%$ más de 1 hora día \\
\hline & & & & $11 \%$ más de 2 horas día \\
\hline
\end{tabular}

Tabla 186: estudios tiempo dedicado por los adolescentes a los videojuegos y consolas

Según Bercedo Sanz et al. (2005), los adolescentes cántabros, comenzaron a jugar a los videojuegos de promedio a la edad de 8,8 años. Esta cifra es muy similar a la hallada en nuestro estudio. Los adolescentes burgaleses encuestados fijan la media de edad a la que empezaron a jugar a videojuegos en 8,3 años.

\subsubsection{1.- Uso de los videojuegos en relación a los distintos factores sociodemográficos}

El estudio llevado a cabo por Barrio Fernández (2014) certifica que el porcentaje de usuarios chicos de videojuegos es superior al de chicas. En el caso de los adolescentes de Barcelona, las diferencias por género son muy notables. El 75,7\% los chicos manifiestan jugar a videojuegos frente a 31,3\% las chicas (Munoz-Miralles et al., 2014). Los datos 
aportados en nuestro estudio ratifican estas afirmaciones, como se observa en la tabla 113. Entre semana, el $73,01 \%$ de los adolescentes que afirman jugar a videojuegos son chicos y el $26,99 \%$ son chicas. El fin de semana el porcentaje disminuye levemente ( $71,45 \%$ de los chicos frente al $28,55 \%$ de las chicas).

Ohannessian (2009) afirma que los chicos juegan más a menudo a videojuegos que las chicas y Barrio Fernández (2014) afirma, también, que el tiempo invertido en jugar a videojuegos por los chicos es mayor que el invertido por las chicas. Entre el $90 \%$ y el $95 \%$ de las adolescentes cántabras juegan a videojuegos durante menos de 1 hora al día, cifra inferior a la encontrada para el género masculino (Noriega et al., 2015). El análisis de los resultados obtenidos para los adolescentes burgaleses manifiesta que los chicos dedican notablemente más tiempo a jugar a videojuegos/consolas que las chicas. Entre semana, los chicos dedican una media de 0:40 horas más y durante el fin de semana la diferencia es de 1:27 horas (tabla 34).

Munoz-Miralles et al. (2014) afirma que el tiempo dedicado a jugar a los videojuegos por los adolescentes de Barcelona disminuye con la edad. Noriega et al. (2015) demuestran, sin embargo, que el tiempo dedicado a jugar a videojuegos por los jóvenes de género masculino, de edades comprendidas entre 10 y 17 años de Cantabria, aumenta con la edad. En el género femenino se aprecia, no obstante, el efecto contrario, puesto que las chicas, dedican menos tiempo a jugar con los años. La tabla 35 nos permite comentar que no encontramos ninguna tendencia a aumentar o disminuir en el tiempo que dedican los adolescentes burgaleses encuestados a jugar a videojuegos/consolas con la edad ni entre semana ni durante el fin de semana.

Una de las preocupaciones principales relacionadas con el uso de videojuegos es su posible capacidad adictiva (King et al., 2013). Los datos de nuestro cuestionario aportan que el $4 \%$ de los adolescentes burgaleses encuestados considera que sus amigos están enganchados a los videojuegos (tabla 141). 


\section{3.- SATISFACCIÓN ACADÉMICA Y BIENESTAR PERSONAL:}

Lepp (2014) afirma que el resultado académico de los adolescentes está relacionado con la satisfacción personal del mismo. Este mismo comportamiento lo encontramos entre los adolescentes burgaleses encuestados, como muestra la tabla 169, el porcentaje de adolescentes que está habitualmente satisfecho o siempre con sus logros académicos es más alto para los adolescentes que no han repetido curso. Encontramos el mayor porcentaje de adolescentes que nunca están satisfechos, entre aquellos que han repetido curso alguna vez.

En este capítulo hemos realizado la discusión de los resultados más relevantes del presente estudio, teniendo siempre como objeto de comparación investigaciones tanto nacionales como internacionales, bajo la premisa de considerar y seleccionar las que son más recientes.

El próximo capítulo recoge las conclusiones fruto del presente estudio y que nos permiten aportar evidencias objetivas del uso del tiempo de los adolescentes en relación a las nuevas tecnologías. 


\section{Capítulo 6:}

\section{Conclusiones}





\section{Capítulo 6.- CONCLUSIONES:}

Vivimos en una sociedad sometida a vertiginosos cambios a nivel tecnológico. Los adolescentes, como nativos digitales, son proclives a experimentar y utilizar las nuevas tecnologías y aplicaciones.

Justificación de lo comentado, es preciso, mencionar que WhatsApp utilizado aproximadamente por el $90 \%$ de los adolescentes burgaleses encuestados, fue fundada hace escasamente 6 años. A su vez Instagram que lanzó su versión abierta al público para Android hace sólo 3 años, es utilizada alrededor del 69\% de los adolescentes burgaleses.

El presente estudio pone de manifiesto el lugar que ocupan las nuevas tecnologías en el tiempo disponible por los adolescentes. Diferentes investigaciones han demostrado que el tiempo dedicado a las TIC ocupa el segundo lugar en Estados Unidos después de dormir y, el tercero, entre los adolescentes burgaleses encuestados, si bien en nuestro caso después de dormir y asistir a clase.

Consideramos que es trascendental estudiar este tema, teniendo en cuenta que la velocidad a la que cambia el panorama tecnológico y las tendencias de uso, provoca que los estudios puedan quedar obsoletos más pronto que otras investigaciones.

La extensa literatura existente sobre el uso del tiempo dedicado por los adolescentes a dormir demuestra el interés que suscita este tema entre la comunidad científica. Las nuevas tecnologías son un aspecto más, que puede poner en riesgo el descanso del adolescente y con ello disminuir sus capacidades, así como incidir en su salud. Los adolescentes duermen, por norma general, menos tiempo del recomendado entre semana y más durante el fin de semana. Por lo que se puede estimar que es un periodo en que tratan de suplir las carencias de sueño de los días lectivos.

En nuestro estudio constatamos que los adolescentes de 17 años duermen 56 minutos menos que los de 12 años, es decir, a medida que incrementa la edad, disminuye el tiempo dedicado al descanso nocturno. 
La influencia de las TIC en el tiempo dedicado a dormir por el adolescente, queda constatada en aquellos que tienen ordenador en la habitación, puesto que duermen 12 minutos menos de media al día que los que no lo tienen. También en los que se conectan a internet después de haberse acostado, ya que duermen 26 minutos menos y tardan en dormirse 13 minutos más que aquellos que no se conectan.

La preocupación internacional por el escaso tiempo dedicado a estudiar por los adolescentes, queda expuesto en abundantes estudios que muestran que es inferior a 1 hora diaria. Sin embargo, los adolescentes burgaleses superan ampliamente esta cifra, puesto que invierten en esta actividad una media de 2:25 horas al día.

Del mismo modo, el tiempo dedicado por los adolescentes burgaleses a realizar actividades extraescolares es de 1:28 horas al día, dato superior a los encontrados en las investigaciones referidas en este trabajo.

La tasa de empleo de nuestra muestra es más baja que los estudios analizados, lo cual puede verse influido por la mayor tendencia en otros países, como Estados Unidos, a trabajar durante la adolescencia.

Algunas de las actividades de uso del tiempo de los adolescentes muestran diferencias por género. El género femenino dedica más tiempo al uso de nuevas tecnologías que suponen comunicarse (WhatsApp, redes sociales y teléfono), higiene personal, trabajo doméstico, estudiar y leer que el género masculino, que, por su parte invierte más tiempo en practicar actividades deportivas, internet y en jugar a videojuegos y consolas.

La edad es otra variable que marca diferencias. Los adolescentes de 12 años dedican más tiempo que los de 17 años a actividades como dormir, hacer deporte, leer y salir con los amigos entre semana. Sin embargo, los adolescentes de 17 años invierten más tiempo en estudiar, usar el WhatsApp y las redes sociales y salir con los amigos en fin de semana y con la pareja.

El uso de las nuevas tecnologías y su interacción con el uso del tiempo de los adolescentes es un aspecto esencial en la presente investigación. El porcentaje de 
hogares con conexión a internet ha crecido de manera asombrosa en los últimos 10 años. En la actualidad, la edad de inicio en las nuevas tecnologías se sitúa en la niñez, rebajando la edad que estaba en la adolescencia. Los niños empiezan antes de los dos años a jugar con el smartphone o la Tablet, dado que es un recurso accesible y cercano para ellos y sus padres. Actualmente, la edad de inicio a internet entre los adolescentes se sitúa entre los 9 y 10 años. Debemos destacar que los más jóvenes se inician en las nuevas tecnologías con menos edad, por lo que la edad de inicio decrece con el paso de los años.

Consideramos importante subrayar que los adolescentes actuales no sólo usan las nuevas tecnologías, sino que poseen cada vez, en mayor medida, diferentes dispositivos tecnológicos como teléfono móvil, ordenador o tablet. Más del $90 \%$ de los adolescentes burgaleses encuestados tiene teléfono móvil. La edad media de los más jóvenes de nuestra investigación muestra que los adolescentes de 12 años tuvieron su propio primer ordenador a los 9,7 años de edad. A los 10,2 años tuvieron su primera tablet y a los 10,7 años su primer teléfono móvil propio.

El tiempo medio que los adolescentes actuales pasan frente a una pantalla es aproximadamente de 7 horas al día, 2:03 horas diarias a WhatsApp, 1:13 horas diarias a redes sociales, 0:59 horas diarias a internet, 0:37 horas diarias a videojuegos/consolas, 1:36 horas diarias a televisión y 0:23 horas diarias al teléfono. Este tiempo se excede considerablemente de las recomendaciones emitidas por la AAP, siendo de 2 horas diarias su limitación a realizar estas actividades.

Actualmente, el dispositivo de acceso a internet no se limita al ordenador. La tecnología preferida por los adolescentes para conectarse a internet es el smartphone. Existen diferencias por género en cuanto al tiempo invertido en el uso de nuevas tecnologías. Las chicas anteponen el uso del teléfono móvil y las redes sociales, mientras que los chicos prefieren utilizar las consolas y dedicar su tiempo a los videojuegos y a conectarse a internet. 
Internet se presenta como un aliado para el adolescente en la consecución de relaciones sociales. Más del $97 \%$ de los adolescentes burgaleses tiene al menos un perfil en una red social. Entre las favoritas por los adolescentes destacan Facebook, WhatsApp e Instagram. WhatsApp, hoy en día, merece una mención especial por su peso específico actual entre los adolescentes encuestados.

No hay consenso en cuanto al papel que juega actualmente la televisión. Por un lado, se sigue pensando que es el dispositivo preferido por los adolescentes, sin embargo, por otro lado, cada vez más adolescentes utilizan otros dispositivos tecnológicos y aplicaciones. En nuestro estudio, el tiempo medio dedicado a ver la televisión se estima en 1:36 horas al día, frente a las 2:03 horas diarias destinadas al uso de WhatsApp.

Es preciso tener en cuenta que en muchos casos los adolescentes solapan las actividades tecnológicas, es decir, utilizan el WhatsApp mientras ven la televisión. Un dato destacable es que los adolescentes que tienen televisión en su habitación no dedican más tiempo a verla que aquellos que no la tienen.

El 40\% del tiempo dedicado por los adolescentes a navegar en internet, está destinado a apoyar sus estudios, lo que mantiene los beneficios de Internet como herramienta de apoyo en su entorno académico.

El 70\% de los adolescentes encuestados que afirman leer libros, prefieren el formato papel observándose diferencias por género, representadas en el $11,7 \%$ de las adolescentes que leen en formato digital frente al 8,9\% de los chicos. El uso del libro en formato papel va perdiendo adeptos entre los adolescentes con la edad, más proclives a utilizar los distintos formatos electrónicos.

El mal uso de internet y de los dispositivos tecnológicos puede provocar riesgos en los adolescentes tales como posibilidad de reducir la duración del sueño, dado que los adolescentes que se llevan los dispositivos a la cama tardan 12 minutos de media más en dormirse. Así mismo, pueden sufrir comportamientos adictivos a dichas tecnologías o de perder la noción del tiempo dedicado a las mismas, distraerle de sus tareas escolares 
y empeorar su rendimiento escolar o poner en riesgo su privacidad. El $15 \%$ de los adolescentes burgaleses admite que se conecta a internet más tiempo del que se había propuesto, el $11 \%$ a las redes sociales y el $16 \%$ a WhatsApp.

Los datos obtenidos de nuestra investigación no muestran indicios de que el uso de las nuevas tecnologías disminuya el tiempo dedicado a realizar actividades deportivas.

El control de los padres sobre la gestión de las nuevas tecnologías de los adolescentes, mejora el rendimiento académico de los mismos, es decir, a mayor control se genera mejor rendimiento escolar. La investigación aporta datos que arrojan un bajo control parental con respecto al uso de las nuevas tecnologías por los adolescentes. Los adolescentes afirman que sus padres muestran desconocimiento y despreocupación por estar al corriente sobre los contenidos que manejan sus hijos en las redes, aun siendo una actividad muy relevante en su vida cotidiana como demuestra este estudio. Además, este control disminuye en la medida que se incrementa la edad de los adolescentes. Se observa, sin embargo, un mayor control parental sobre el género femenino. Los padres dedican más tiempo a hablar con sus hijas sobre los riesgos de internet que con sus hijos y se interesan más por los contenidos a los que ellas acceden en la red. Del mismo modo se observa, que las chicas son más comunicativas con sus padres sobre los contenidos que ven en la red.

Es importante comentar las principales limitaciones de nuestra investigación que están relacionadas con la selección de la muestra, la aceleración y cambio permanente en el uso de diferentes tipos de redes sociales y nuevas tecnologías.

La muestra del estudio es de la provincia de Burgos, de centros educativos que han permitido encuestar a alumnos de 12 a 17 años, en un determinado momento del curso escolar, aspecto que puede variar los datos, si se realizase a principios de curso. Hubo, cierta presión en la toma de datos para que se recogiesen al finalizar el segundo trimestre. 
Las apreciaciones sobre los distintos cursos considerados están influidas por el sistema educativo, es decir, aspectos metodológicos, evaluativos, recursos, etc., por lo que las inferencias a otras comunidades autónomas y países, ha de tenerlo presente y se ha de realizar con cautela.

El uso del tiempo de los adolescentes y su aproximación a las nuevas tecnologías se modifica con rapidez. Cada poco tiempo surgen nuevos dispositivos y aplicaciones a los que los adolescentes se adaptan. Esta es una tendencia consideramos que se mantendrá en el tiempo, por lo que limita la transferencia de resultados.

Los nuevos tipos de familia (nuclear, monoparental, reconstruida, etc.), así como otros aspectos socio demográficos dificultan e influyen en los hábitos de las personas en general y, concretamente de los adolescentes, al coincidir con una edad que conlleva a su vez muchos cambios.

A lo largo de la realización de este trabajo han surgido nuevas inquietudes que podrán convertirse en futuras líneas de investigación, como:

- Profundizar en las actividades extraescolares realizadas por los adolescentes y el tiempo dedicado a las mismas. Entender si las realizan por gusto o por imposición parental y ver cómo la realización de distintas actividades extraescolares se relaciona con el rendimiento académico, la satisfacción personal y sus resultados a largo plazo.

- Analizar si los adolescentes están conformes con las actividades extraescolares ofertadas en su entorno, si las consideran insuficientes, con el objetivo de solicitar el establecimiento de un plan de acción o/ y estratégico.

- Establecer las relaciones entre la dedicación de tiempo a las distintas actividades extraescolares y el nivel socioeconómico y educativo de los padres, con el objetivo de analizar si la elección de las mismas se aproxima a la teoría de la reproducción o de la movilidad o a ambas. 
- Elaborar recomendaciones dirigidas a los educadores, padres y profesores sobre la inversión de tiempo de los adolescentes en las diversas actividades extraescolares.

- La realización de estudios longitudinales puede posibilitar ver la evolución del adolescente a lo largo del tiempo y permitirá establecer análisis causales (relaciones causa-efecto) según las diferentes actividades realizadas a lo largo de la vida. Por esta razón, es conveniente realizar estudios con un grupo focal de adolescentes a los que seguir en su evolución desde la etapa de primero de secundaria hasta los primeros años de su inserción laboral (desde los 12 años a los 30 años), lo que supondría un trabajo de 18 años, pudiendo aportar datos en diferentes etapas.

- Las actividades a las que dedican su tiempo vienen derivadas de sus preferencias, creencias y la influencia del entorno. Establecer relaciones entre la gestión del tiempo de los adolescentes y capacidad de planificación, de hacer lo planificado, cumplir los plazos, evitar interrupciones, asertividad, orden, evaluar-revisar, multitarea, etc.

- Investigar sobre las técnicas de los padres para gestionar el uso de las nuevas tecnologías por sus hijos.

- Estudiar las necesidades formativas de los responsables de educar a los adolescentes. Los padres, miembros integrantes del grupo de inmigrantes digitales, necesitan ser formados con el objetivo de tomar las riendas y establecer los hábitos de uso de las nuevas tecnologías por los adolescentes.

- Profundizar en el estudio del desempeño de los centros educativos, como órganos colaboradores en el proceso de formación de los adolescentes en las TIC. Actualmente, podemos observar que la tendencia es informatizar las aulas, pero consideramos necesario analizar el estado de maduración tanto de las aulas como de los educadores sobre esta materia. Es necesario conocer si los educadores han recibido el apoyo necesario para adquirir las competencias requeridas para impartir esta docencia apoyada en las nuevas tecnologías. 
La investigación en el uso del tiempo, consideramos que es un tema que se mantendrá en el tiempo, puesto que los hábitos y la forma de vida van cambiando. Todo ello nos deriva a una continua revisión de los estudios e investigaciones más relevantes.

Estimamos que esta investigación pueda ser de utilidad y servir de base para un mejor uso del tiempo y de las nuevas tecnologías por los adolescentes. Es importante que pueda servir como informe para los padres, profesores y educadores en su labor diaria y que pueda ayudar a percibir y prevenir variaciones con respecto a lo deseable en el uso del tiempo y de las nuevas tecnologías por parte de los adolescentes. 


\section{Referencias}

\section{bibliográficas}





\section{Referencias bibliográficas:}

Adachi-Mejia, A. M., Edwards, P. M., Gilbert-Diamond, D., Greenough, G. P. \& Olson, A. L. (2014). Txt me I'm only sleeping: adolescents with mobile phones in their bedroom. Family \& community health, 37(4), 252-257.

Albares Tendero, J., Estivill Sancho, E., Pascual Domenech, M. \& Roure Miro, N. (2008). Sleeping habits and drug and alcohol abuse in adolescents. [Habitos de sueno y consumo de toxicos de los adolescentes.]. Atencion primaria / Sociedad Espanola de Medicina de Familia y Comunitaria, 40(11), 581-581.

Andreassen, C. S., Torsheim, T., Brunborg, G. S. \& Pallesen, S. (2012). Development of a Facebook addiction scale 1, 2. Psychological reports, 110(2), 501-517.

Aptekar, L. (1988). Colombian street children: their mental health and how they can be served. International Journal of Mental Health, 17(3), 81-104.

Arora, T., Broglia, E., Thomas, G. N. \& Taheri, S. (2014). Associations between specific technologies and adolescent sleep quantity, sleep quality, and parasomnias. Sleep Medicine, 15(2), 240-247. doi: 10.1016/j.sleep.2013.08.799

Aschaffenburg, K. \& Maas, I. (1997). Cultural and educational careers: The dynamics of social reproduction. American Sociological Review, 62(4), 573-587. doi: $10.2307 / 2657427$

Asociación para la Investigación de Medios de Comunicación AIMC/EGM Audiencia Infantil/Juvenil en Medios en España (2006). Recuperado de http://aimc.es

Bae, D. \& Wickrama, K. A. S. (2014). Family Socioeconomic Status and Academic Achievement Among Korean Adolescents Linking Mechanisms of Family Processes and Adolescents' Time Use. The Journal of Early Adolescence, 35(7), 1014-1038. doi: 10.1177/0272431614549627

Bajovic, M. (2013). Violent video gaming and moral reasoning in adolescents: is there an association?. Educational media international, 50(3), 177-191.

Barker, V. (2009). Older adolescents' motivations for social network site use: The influence of gender, group identity, and collective self-esteem. CyberPsychology \& Behavior, 12(2), 209-213.

Barrio Fernández, A. (2014). Los adolescentes y el uso de los teléfonos móviles y de videojuegos. International Journal of Developmental and Educational Psychology.

Beranuy, M., Chamarro, A., Graner, C. \& Carbonell, X (2009). Validación de dos escalas breves para evaluar la Adicción a Internet y el Abuso de móvil. Psicothema, 21, 480-485.

Bercedo Sanz, A., Redondo Figuero, C., Pelayo Alonso, R., Gomez Del Rio, Z., Hernandez Herrero, M. \& Cadenas Gonzalez, N. (2005). Mass media consumption in 
adolescence. [Consumo de los medios de comunicacion en la adolescencia.]. Anales de pediatria (Barcelona, Spain : 2003), 63(6), 516-525.

Bianchi, S. M. \& Robinson, J. (1997). Did you do today? Children's use of time, family composition, and the acquisition of social capital. Journal of Marriage and the Family, 59(2), 332-344.

Bickham, D. S., Hswen, Y. \& Rich, M. (2015). Media use and depression: exposure, household rules, and symptoms among young adolescents in the USA. International journal of public health, 60(2), 147-155.

Biddle, S. J., Gorely, T., Marshall, S. J. \& Cameron, N. (2009). The prevalence of sedentary behavior and physical activity in leisure time: a study of Scottish adolescents using ecological momentary assessment. Preventive medicine, 48(2), 151-155.

Blader, J. C., Koplewicz, H. S., Abikoff, H. \& Foley, C. (1997). Sleep problems of elementary school children - A community survey. Archives of Pediatrics \& Adolescent Medicine, 151(5), 473-480.

Blades, M., Blumberg, F. C. \& Oates, C. (2015). The importance of digital games for children and young people. Zeitschrift für Psychologie.

Blumberg, F. C., Blades, M., Oates, C. (2013). Youth and new media: The appeal and educational ramifications of digital game play for children and adolescents. Zeitschrift für Psychologie, 221(2), 67-71

Blunden, S., Hoban, T. F. \& Chervin, R. D. (2006). Sleepiness in Children. Sleep Medicine Clinics, 1(1), 105-118.

Boergers, J., Gable, C. J. \& Owens, J. A. (2014). Later School Start Time Is Associated with Improved Sleep and Daytime Functioning in Adolescents. Journal of Developmental and Behavioral Pediatrics, 35(1), 11-17.

Noriega, M. J., Jaén, P., Santamaría, A., Amigo, M. T., Antolin, O., Casuso, I.,... De-Rufino, P. M., (2015). Hábitos sedentarios en adolescentes escolarizados de Cantabria. Retos, 27, 3-7.

Borja, R. R. (2005)." Blogs" Catching on as Tool for Instruction: Teachers Use Interactive Web Pages to Hone Writing Skills. Education Week, 25(15), 1-17.

Bourdieu, P. (1973). Cultural reproduction and social reproduction. Knowledge, Education and Cultural Change: papers in the sociology of education, 71-112. London: Tavistock.

Brand, M., Laier, C. \& Young, K. S. (2014). Internet addiction: coping styles, expectancies, and treatment implications. Frontiers in Psychology, 5. doi: 10.3389/fpsyg.2014.01256

Bravo, C. B. \& Rasco, F. A. (2013). Interacciones de los jóvenes andaluces en las redes sociales. Comunicar, 20(40), 25-30. 
Briere, M., Poussevin, C., Vayleux, E., Lefranc, J., Cayrol, B., Garre, J. B. \& Gohier, B. (2012). Teenagers and mobile phone, which place during hospitalization?. Annales medico-psychologiques 170(8), 587-590.

Bringué, X. \& Sádaba, C. C. (2009). La generación interactiva en España. Niños y adolescentes ante las pantallas. Ariel y Fundación Telefónica.

Broh, B. A. (2002). Linking extracurricular programming to academic achievement: Who benefits and why? Sociology of education, 69-95.

Brunborg, G. S., Mentzoni, R. A., Molde, H., Myrseth, H., Skouveroe, K. J. M., Bjorvatn, B. \& Pallesen, S. (2011). The relationship between media use in the bedroom, sleep habits and symptoms of insomnia. Journal of sleep research, 20(4), 569-575.

Bryce, J. \& Fraser, J. (2014). The role of disclosure of personal information in the evaluation of risk and trust in young peoples' online interactions. Computers in Human Behavior, 30, 299-306. doi: 10.1016/j.chb.2013.09.012

Buckingham, D. (2005). Educación en medios: Alfabetización, aprendizaje y cultura contemporánea. Barcelona: Paidós.

Bucksch, J., Inchley, J., Hamrik, Z., Finne, E. \& Kolip, P. (2014). Trends in television time, non-gaming PC use and moderate-to-vigorous physical activity among German adolescents 2002-2010. BMC public health, 14(1), 351.

Bunge, M. (2000). La investigación científica: su estrategia y su filosofía. Siglo XXI.

Cabero Almenara, J., Cairncross, F. C., Schramm, W., Millerson, G. \& Fuenzalida, V. (2007). Nuevas tecnologías aplicadas a la educación: CEPAL, Santiago (Chile).

Cain, N. \& Gradisar, M. (2010). Electronic media use and sleep in school-aged children and adolescents: A review. Sleep Medicine, 11(8), 735-742. doi: 10.1016/j.sleep.2010.02.006

Calamaro, C. J., Mason, T. B. \& Ratcliffe, S. J. (2009). Adolescents living the 24/7 lifestyle: effects of caffeine and technology on sleep duration and daytime functioning. Pediatrics, 123(6), e1005-e1010.

Cameron, A. J., Stralen, M. M., Brug, J., Salmon, J., Bere, E., ChinAPaw, M. J. M., ... \& Velde, S. J. (2013). Television in the bedroom and increased body weight: potential explanations for their relationship among European schoolchildren. Pediatric obesity, 8(2), 130-141.

Cánovas, G (2015). Cariño, he conectado a los niños. Guía sobre salud digital para familias y educadores. Madrid: Mensajero.

Cánovas, G, García de Pablo, A., Oliaga San Atilano, A., Aboy Ferrer, I. \& Protégeles. (2014). Menores de Edad y Conectividad Móvil en España: Tablets y Smartphones. España: Centro de Seguridad en Internet para los Menores en España: PROTEGELES recuperdado de www.protegeles.com. 
Cao, F. \& Su, L. (2007). Internet addiction among Chinese adolescents: prevalence and psychological features. Child Care Health and Development, 33(3), 275-281. doi: 10.1111/j.1365-2214.2006.00715.x

Caplan, S. E. (2002). Problematic Internet use and psychosocial well being: Development of a theory-based cognitive-behavioral measurement instrument. Computers in Human Behavior, 18, 553-575.

Carpenter, C J., Huston, A. C. \& Spera, L. (1989). Children's use of time in their everyday activities during middle childhood. The ecological context of children's play, 165190.

Carskadon, M. A. (1990). Patterns of sleep and sleepiness in adolescents. Pediatrician, 17(1), 5-12.

Carskadon, M. A., Acebo, C. \& Jenni, O. G. (2004). Regulation of adolescent sleep: implications for behavior. Annals of the New York Academy of Sciences, 1021(1), 276-291.

Carskadon, M. A., Harvey, K., Duke, P., Anders, T. F., Litt, I. F. \& Dement, W. C. (1980). Pubertal changes in daytime sleepiness. Sleep, 2(4), 453-460.

Castellana Rosell, M., Sánchez-Carbonell, X., Graner Jordana, C. \& Beranuy Fargues, M. (2007). El adolescente ante las tecnologías de la información y la comunicación: Internet, móvil y videojuegos. Papeles del psicólogo, 28(3), 196-204.

Ceci, S. J. \& Williams, W. M. (1997). Schooling, intelligence, and income. American Psychologist, 52(10), 1051.

Chamarro, A., Carbonell, X., Maria Manresa, J., Munoz-Miralles, R., Ortega-González, R., Rosa Lopez-Morrón, M., . . .Toran-Monserrat, P. (2014). The questionnaire of experiences associated with Video games (CERV): an instrument to detect the problematic use of video games in Spanish adolescents. Adicciones, 26(4), 303311.

Chandra, A., Martino, S. C., Collins, R. L., Elliott, M. N., Berry, S. H., Kanouse, D. E. \& Miu, A. (2008). Does watching sex on television predict teen pregnancy? Findings from a national longitudinal survey of youth. Pediatrics, 122(5), 1047-1054.

Chaput, J. P., Leduc, G., Boyer, C., Bélanger, P., LeBlanc, A. G., Borghese, M. M. \& Tremblay, M. S. (2014). Electronic screens in children's bedrooms and adiposity, physical activity and sleep: Do the number and type of electronic devices matter?. Can J Public Health, 105(4), e273-e279.

Choi, W. S., Patten, C. A., Gillin, J. C., Kaplan, R. M. \& Pierce, J. P. (1997). Cigarette smoking predicts development of depressive symptoms among US adolescents. Annals of Behavioral Medicine, 19(1), 42-50. doi: 10.1007/bf02883426

Chóliz, M. (2012). Mobile-phone addiction in adolescence: the test of mobile phone dependence (TMD). Prog Health Sci, 2(1), 33-44. 
Chóliz, M., Villanueva, V. \& Chóliz, M.C. (2009). Ellos, ellas y su móvil: Uso, abuso (¿`y dependencia?) del teléfono móvil en la adolescencia. Revista Española de Drogodependencias, 34(1), 74-88.

Coleman, J. S. (1961). The adolescent society.

Connolly, T. M., Boyle, E. A., MacArthur, E., Hainey, T. \& Boyle, J. M. (2012). A systematic literature review of empirical evidence on computer games and serious games. Computers \& Education, 59(2), 661-686.

Cookingham, L. M. \& Ryan, G. L. (2015). The Impact of Social Media on the Sexual and Social Wellness of Adolescents. Journal of Pediatric and Adolescent Gynecology, 28(1), 2-5. doi: 10.1016/j.jpag.2014.03.001

Cooper, H. \& Valentine, J. C. (2001). Using research to answer practical questions about homework. Educational Psychologist, 36(3), 143-153.

Crowley, S. J., Acebo, C. \& Carskadon, M. A. (2007). Sleep, circadian rhythms, and delayed phase in adolescence. Sleep medicine, 8(6), 602-612.

Csikszentmihalyi, M (2011). Fluir (Flow): Una psicología de la felicidad. Editorial Kairos.

Dahl, R. E. \& Lewin, D. S. (2002). Pathways to adolescent health sleep regulation and behavior. Journal of adolescent health, 31(6), 175-184.

Danner, F. \& Phillips, B. (2008). Adolescent sleep, school start times, and teen motor vehicle crashes. Journal of clinical sleep medicine: JCSM: official publication of the American Academy of Sleep Medicine, 4(6), 533-535.

Davie, R., Panting, C. \& Charlton, T. (2004). Mobile phone ownership and usage among pre-adolescents. Telematics and Informatics, 21(4), 359-373.

De Gracia Blanco, M., Vigo Anglada, M., Fernández Pérez, M. J. \& Marcó Arbonés, M. (2002). Problemas conductuales relacionados con el uso de Internet: Un estudio exploratorio.

De Gracia, M., Vigo, M., Fernández, M. J. \& Marcó, M. (2002). Problemas conductuales relacionados con el uso de Internet: un estudio exploratorio. Anales de Psicología, 18, 273-292.

de la Piscina, T. R., Zarandona, E., Basterretxea, J. I. \& Idoiaga, P. (2011). Estudio sobre la alfabetización audiovisual de los adolescentes vascos: Recopilatorio de actitudes críticas y acríticas. Zer-Revista de Estudios de Comunicación, 11(21).

Dijk, D. J. (2014). Not so fast: sleep and media use. Journal of sleep research, 23(4), 363363.

DiMaggio, P. (1982). Cultural Capital and School Success: The Impact of Status Culture Participation on the Grades of U.S. High School Students. American Sociological Review, 47(2), 189-201. doi: 10.2307/2094962 
DiMaggio, P., Hargittai, E., Neuman, W.R. \& Robinson, J. P. (2001) Social implications of the internet. Annual Review of Sociology, 27, 307-336. doi: 10.1146/annurev.soc.7.1.307

Duckett, E., Raffaelli, M. \& Richards, M. H. (1989). "Taking care": Maintaining the self and the home in early adolescence. Journal of Youth and Adolescence, 18(6), 549-565.

Dumais, S. A. (2002). Cultural capital, gender, and school success: The role of habitus. Sociology of Education, 75(1), 44-68. doi: 10.2307/3090253

Dumais, S. A. (2008). Adolescents' Time Use and Academic Achievement: A Test of the Reproduction and Mobility Models*. Social Science Quarterly, 89(4), 867-886.

Durkee, T., Kaess, M., Carli, V., Parzer, P., Wasserman, C., Floderus, B., . . W Wasserman, D. (2012). Prevalence of pathological internet use among adolescents in Europe: demographic and social factors. Addiction, 107(12), 2210-2222. doi: 10.1111/j.1360-0443.2012.03946.x

Durkin, K., Boyle, J., Hunter, S. \& Conti-Ramsden, G. (2015). Video games for children and adolescents with special educational needs. Zeitschrift für Psychologie.

Echeburúa, E., Labrador, F. J. \& Becoña, E. (2009). Adicción a las nuevas tecnologías en jóvenes y adolescente. Madrid: Pirámide.[Links].

Eisenmann, J. C., Ekkekakis, P. \& Holmes, M. (2006). Sleep duration and overweight among Australian children and adolescents. Acta Paediatrica, 95(8), 956-963.

Eitle, T. M. (2005). Do gender and race matter? Explaining the relationship between sports participation and achievement. Sociological Spectrum, 25(2), 177-195.

Eitle, T. M. \& Eitle, D. J. (2002). Race, cultural capital, and the educational effects of participation in sports. Sociology of education, 123-146.

Ekinci, Ö., Celik, T., Savas, N. \& Toros, F. (2014). Association Between internet Use and Sleep Problems in Adolescents. Noropsikiyatri arsivi-archives of neuropsychiatry, 51(2), 122-128.

Ellison, N. B. (2007). Social network sites: Definition, history, and scholarship. Journal of Computer-Mediated Communication, 13(1), 210-230.

Asociación Mexicana de internet [AMIPCI] (2008). Estudio AMIPCI de nuevas tecnologías de internet en México. Recuperado de https://www.amipci.org.mx/estudios/nuevas_tecnologias/2008_Nvas_Tecnolog ias_Internet_Mx.pdf

OCU (2013). Estudio elaborado por OCU con motivo del Día de internet. Recuperado de http://www.marketingdirecto.com/actualidad/digital/el-60-de-losadolescentes-utiliza-tuenti-como-red-social-principal/\#sthash.mYaEGoby.dpuf

EU Kids Online realizado en el marco del Safer internet Programme de la Comisión Europea. 
EU NET ADB (2012). Investigación sobre conductas adictivas a internet y entre los adolescentes europeos. Estudio Europeo sobre Tecnoadiciones. Asociación Protégeles. Recuperado de http://lineasdeayuda.es.

Farb, A. F. \& Matjasko, J. L. (2012). Recent advances in research on school-based extracurricular activities and adolescent development. Developmental Review, 32(1), 1-48. doi: 10.1016/j.dr.2011.10.001

Feldman, A. F. \& Matjasko, J. L. (2005). The role of school-based extracurricular activities in adolescent development: A comprehensive review and future directions. Review of educational research, 75(2), 159-210.

Feng, Y. \& Xie, W. (2014). Teens' concern for privacy when using social networking sites: An analysis of socialization agents and relationships with privacy-protecting behaviors. Computers in Human Behavior, 33, 153-162.

Flammer, A. \& Alsaker, F. D. (1999). The adolescent experience: European and American adolescents in the 1990s. Psychology Press

Flammer, A., Alsaker, F. D. \& Noack, P. (1999). Time use by adolescents in an international perspective. I: The case of leisure activities. Adolescent Experience, 33-60.

Flynn, J. (2014). The effect of mobile phone attachment on an attention task among secondary school and college students.

Foerster, M., Roser, K., Schoeni, A. \& Röösli, M. (2015). Problematic mobile phone use in adolescents: derivation of a short scale MPPUS-10. International journal of public health, 60(2), 277-286.

Fossum, I. N., Nordnes, L. T., Storemark, S. S., Bjorvatn, B. \& Pallesen, S. (2014). The association between use of electronic media in bed before going to sleep and insomnia symptoms, daytime sleepiness, morningness, and chronotype. Behavioral sleep medicine, 12(5), 343-357.

Fuligni, A. J. \& Stevenson, H. W. (1995). Time Use and Mathematics Achievement among American, Chinese, and Japanese High-School-Students. Child Development, 66(3), 830-842.

Fuster, H., Oberst, U., Griffiths, M. D., Carbonell, X., Chamarro, A., y Talarn, A. (2012). Psychological motivation in online role-playing games: A study of Spanish World of Warcraft players. Anales de Psicología, 28, 274-280.

Gager, C. T., Cooney, T. M. \& Call, K. T. (1999). The effects of family characteristics and time use on teenagers' household labor. Journal of Marriage and the Family, 982-994.

Gangwisch, J. E., Babiss, L. A., Malaspina, D., Turner, J. B., Zammit, G. K. \& Posner, K. (2010). Earlier parental set bedtimes as a protective factor against depression and suicidal ideation. Sleep, 33(1), 97-106. 
Garaigordobil, M. (2011). Prevalencia y consecuencias del cyberbullying: una revisión. International Journal of Psychology and Psychological Therapy, 11(2), 233-254.

García-Jiménez, M. A., Salcedo-Aguilar, F., Rodríguez-Almonacid, F.M., RedondoMartínez, M. P., Monterde-Aznar, M. L., Marcos-Navarro, A. I. \& TorrijosMartinez, M. P. (2004). Prevalencia de los trastornos del sueño en adolescentes de Cuenca, España. Rev Neurol, 39(1), 18-24.

Garitaonandia, C., Fernández, E. \& Oleaga, J. A. (2005). Las tecnologías de la información y de la comunicación y su uso por los niños y los adolescentes. Doxa Comunicación, 3, 45-64.

Garmendia, M., Garitaonandia, C., Martínez, G. \& Casado, M. A. (2011). Riesgos y seguridad en internet: Los menores españoles en el contexto europeo. Universidad del País Vasco/Euskal Herriko Unibertsitatea, Bilbao: EU Kids Online.

Genc, Z. (2014). Parents' Perceptions about the Mobile Technology Use of Preschool Aged Children. Third Annual International Conference Early Childhood Care and Education, 146, 55-60. doi: 10.1016/j.sbspro.2014.08.086

Gentile, D. A., Reimer, R. A., Nathanson, A. I., Walsh, D. A. \& Eisenmann, J. C. (2014). Protective effects of parental monitoring of children's media use: a prospective study. JAMA pediatrics, 168(5), 479-484.

Ghassemzadeh, L., Shahraray, M. \& Moradi, A. R. (2008). Prevalence of Internet addiction and comparison of Internet addicts and non-addicts in Iranian high schools. CyberPsychology \& Behavior, 11, 731-733.

Gilbert-Diamond, D., Li, Z., Adachi-Mejia, A. M., McClure, A. C. \& Sargent, J. D. (2014). Association of a television in the bedroom with increased adiposity gain in a nationally representative sample of children and adolescents. JAMA pediatrics, 168(5), 427-434.

Goldberg, I. (1995). Internet Addictive Disorder (IAD). Diagnostic Criteria [Electronic Version], retrie.

Gómez Salgado, P., Rial Boubeta, A., Brana Tobio, T., Varela Mallou, J. \& Barreiro Couto, C. (2014). Evaluation and early detection of problematic Internet use in adolescents. Psicothema, 26(1), 21-26. doi: 10.7334/psicothema2013.109

Gozal, D. \& Kheirandish-Gozal, L. (2007). Neurocognitive and behavioral morbidity in children with sleep disorders. Current Opinion in Pulmonary Medicine, 13(6), 505-509. doi: 10.1097/MCP.0b013e3282ef6880.

Graner, P., Fargues, M. B., Sánchez-Carbonell, X., Lusar, A. C. \& Rosell, M. C. (2007). ¿ं Que uso hacen los jóvenes y adolescentes de internet y del móvil?. In Comunicación e xuventude: Actas do Foro Internacional (pp. 71-90). Colexio Profesional de Xornalistas de Galicia.

Greenberger, E. \& Steinberg, L. (1986). When teenagers work: The psychological and social costs of adolescent employment: Basic Books. 
Greydanus, D. E. \& Greydanus, M. M. (2012). Internet use, misuse, and addiction in adolescents: current issues and challenges. International journal of adolescent medicine and health, 24(4), 283-289. doi: 10.1515/ijamh.2012.041

Griffiths, M. D. (2005). Videogame addiction: An overview of the literature. Psicologia Conductual, 13(3), 445-462.

Gross, E.F. (2004). Adolescent Internet use: What we expect, what teens report. Journal of Applied Developental Psycology, 25(6), 633-649. Doi: 10.1016/j.appdev.2004.09.005

Hale, L. \& Guan, S. (2015). Screen time and sleep among school-aged children and adolescents: A systematic literature review. Sleep Medicine Reviews, 21, 50-58. doi: 10.1016/j.smrv.2014.07.007

Haythornthwaite, C. (2001). Introduction. The internet in Everyday Life. American Behavioral Scientist, 45(3), 363-382.

Hernández, A. C., del Valle, C. S., Adams, P., Garay Cruz, L. M. , García Hernández, C., López, L., . . . Zamorano Rojas, A. D. (2010). Educación y tecnologías de la información y la comunicación. Perfiles Educativos, 32(130), 172-178.

Hilbrecht, M., Zuzanek, J. \& Mannell, R. C. (2008). Time use, time pressure and gendered behavior in early and late adolescence. Sex Roles, 58(5-6), 342-357.

Hofferth, S. L. \& Sandberg, J. F. (2001). How American children spend their time. Journal of Marriage and the Family, 63(2), 295-308.

Hogan, M. J \& Strasburger, V. C. (2008). Media and prosocial behavior in children and adolescents. Handbook of moral and character education. Mahwah, NJ: Lawrence Erlbaum, 537-553.

Holmen, T. L., Barrett-Connor, E., Holmen, J. \& Bjermer, L. (2000). Health problems in teenage daily smokers versus nonsmokers, Norway, 1995-1997 - The NordTrondelag health study. American Journal of Epidemiology, 151(2), 148-155.

Holtz, P. \& Appel, M. (2011). Internet use and video gaming predict problem behavior in early adolescence. Journal of Adolescence, 34(1), 49-58. doi: 10.1016/j.adolescence.2010.02.004

Houghton, S., Hunter, S. C., Rosenberg, M., Wood, L., Zadow, C., Martin, K., \& Shilton, T. (2015). Virtually impossible: limiting Australian children and adolescents daily screen based media use. Bmc Public Health, 15(1), 5. doi: 10.1186/1471-2458$15-5$

Cristian Monroy (2015). Estadísticas y datos interesantes sobre el uso de Whatsapp recuperado de http://www.cristianmonroy.com/2015/06/47-estadisticas-ydatos-interesantes-sobre-WhatsApp.html\#sthash.Vw54uV9A.dpuf

Webempresa (2014). Ranking de las 30 redes sociales más utilizadas en el mundo recuperado de http://www.webempresa20.com 
Huang, Z., Wang, M., Qian, M., Zhong, J. \& Tao, R. (2007). Chinese Internet Addiction Inventory: Developing a measure of problematic Internet use for Chinese college students. Cyberpsychology \& Behavior, 10(6), 805-811. doi: 10.1089/cpb.2007.9950

IAB Spain (2015). VI Estudio Redes Sociales. Recuperado de http://www.iabspain.net/wpcontent/uploads/downloads/2015/01/Estudio_Anual_Redes_Sociales_2015.pdf

Instituto Nacional de Estadística [INE] (2013). Encuesta sobre Equipamiento y Uso de Tecnologías de Información y Comunicación en los Hogares. Madrid, España: INE. Recuperado de http://www.ine.es/prensa/np864.pdf

Instituto Nacional de Tecnologías de la Comunicación [INTECO] (2009). Estudio sobre hábitos seguros en el uso de las TIC por niños y adolescentes y e-confianza de sus padres. Madrid, España: INTECO. Recuperado de www.inteco.es/Seguridad/Observatorio/Estudios_e_Informes/Estudios_e_Inf ormes_1/Estudio_ninos

Instituto Nacional de Tecnologías de la Comunicación [INTECO] (2011). Estudio sobre hábitos seguros en el uso de smartphones por los niños y adolescentes españoles. Madrid, España: INTECO. Recuperado de http://www.observatoriodelainfancia.es/oia/esp/documentos_ficha.aspx?id=33 79

Instituto Nacional de Tecnologías de la Comunicación, 2011

Ito, Mizuko, Horst, Heather, Bittanti, Matteo, Boyd, Danah, Herr-Stephenson, Becky, Lange, Patricia G, . . . Robinson, Laura. (2008). Living and Learning with New Media: Summary of Findings from the Digital Youth Project. John D. and Catherine T. MacArthur Foundation.

Jago, R., Sebire, S. J., Gorely, T., Cillero, I. H. \& Biddle, S. J. (2011). I'm on it 24/7 at the moment": a qualitative examination of multi-screen viewing behaviours among UK 10-11 year olds. Int J Behav Nutr Phys Act, 8, 85.

James, S. (2009). Is Technology Networking Changing Childhood?-A National Poll by Common Sense Media, San Francisco.

Jaung, M. (2008). Sleep Patterns, School-Related Stress, and Road Traffic Injury among Middle School Students in Rural China. The Ohio State University.

Jenaro, C., Flores, N., Gómez-Vela, M., González-Gil, F. \& Caballo, C. (2007). Problematic internet and cell-phone use: Psychological, behavioral, and health correlates. Addiction research \& theory, 15(3), 309-320.

Jenkins, H. (2009). Confronting the challenges of participatory culture: Media education for the 21st century: Mit Press.

Jiménez, A. G., de Ayala López, M. C. L. \& García, B. C. (2013). Hábitos de uso en internet y en las redes sociales de los adolescentes españoles. Comunicar, 21(41), 195204. 
Johnson, E. O., Roth, T. \& Breslau, N. (2006). The association of insomnia with anxiety disorders and depression: Exploration of the direction of risk. Journal of Psychiatric Research, 40(8), 700-708. doi: 10.1016/j.jpsychires.2006.07.008

Jordan, W. J. (1999). Black high school students' participation in school-sponsored sports activities: Effects on school engagement and achievement. Journal of Negro Education, 68(1), 54-71.

Juste, R. P., González, A. G. \& Díaz, J. Q. (2012). Métodos y diseños de investigación en educación. Editorial UNED.

Juster, F. T., Ono, H. \& Stafford, F. P. (2003). An assessment of alternative measures of time use. Sociological Methodology, Vol 33, 33, 19-54. doi: 10.1111/j.00811750.2003.t01-1-00126.x

Kalenkoski, C. M. \& Pabilonia, S. W. (2012). Time to work or time to play: The effect of student employment on homework, sleep, and screen time. Labour Economics, 19(2), 211-221.

Kalmijn, M. \& Kraaykamp, G. (1996). Race, cultural capital, and schooling: An analysis of trends in the United States. Sociology of Education, 69(1), 22-34. doi: $10.2307 / 2112721$

Kaufman, J. \& Gabler, J. (2004). Cultural capital and the extracurricular activities of girls and boys in the college attainment process. Poetics, 32(2), 145-168.

Kerlinger. F. (2001) Investigación del comportamiento. Métodos de investigación en Ciencias Sociales. México: Mc. Graw Hill.

King, D. L., Delfabbro, P. H. \& Griffiths, M. D. (2013). Trajectories of problem video gaming among adult regular gamers: an 18-month longitudinal study. Cyberpsychology, Behavior, and Social Networking, 16(1), 72-76.

Kingston, P. W. (2001). The unfulfilled promise of cultural capital theory. Sociology of education, 88-99.

Kirmilgray, K., Eagleston, J. R., Gibson, E. \& Thoresen, C. E. (1984). Sleep disturbance in adolescents: sleep quality, sleep habits, beliefs about sleep, and daytime functioning. Journal of Youth and Adolescence, 13(5), 375-384. doi: $10.1007 / \mathrm{bf02088636}$

Ko, C. H., Yen, J. y., Chen, C. C., Chen, S. H. \& Yen, C. F. (2005). Proposed diagnostic criteria of Internet addiction for adolescents. The Journal of nervous and mental disease, 193(11), 728-733.

Kornblit, A., Diz, A. M. \& Adaszko, D. (2006). Salud y enfermedad desde la perspectiva de los jóvenes. Un estudio en jóvenes escolarizados en el nivel medio de todo el país. Documentos de Trabajo (Universidad de Buenos Aires. Facultad de Ciencias Sociales)(47), 1.

Kuriyama, K., Stickgold, R. \& Walker, M. P. (2004). Sleep-dependent learning and motorskill complexity. Learning \& Memory, 11(6), 705-713. doi: 10.1101/Im.76304 
Labrador, F., y Villadangos, S. (2010). Menores y nuevas tecnologias: conductas indicadoras de posible problema de adiccion. Psicothema, 22, 180-188.

Labrador, Francisco J., Villadangos, Silvia M., Crespo, Maria \& Becona, Elisardo. (2013). Design and validation of the new technologies problematic use questionnaire. Anales De Psicologia, 29(3), 836-847. doi: 10.6018/analesps.29.3.159291.

Lam, L. T. (2015). Parental mental health and Internet Addiction in adolescents. Addictive behaviors, 42, 20-23.

Landhuis, C. E., Poulton, R., Welch, D. \& Hancox, R. J. (2008). Childhood sleep time and long-term risk for obesity: a 32-year prospective birth cohort study. Pediatrics, 122(5), 955-960.

Lareau, A. (2003). Unequal childhoods: Race, class and family life. Berkeley: University of CaliforniaPress.

Larson, R. W. (2001). How U.S. children and adolescents spend time: What it does (and doesn't) tell us about their development. Current Directions in Psychological Science, 10(5), 160-164.

Larson, R. W. \& Verma, S. (1999). How children and adolescents spend time across the world: work, play, and developmental opportunities. Psychological bulletin, 125(6), 701-736.

Larson, R. W., Richards, M. H., Sims, B. \& Dworkin, J. (2001). How urban African American young adolescents spend their time: Time budgets for locations, activities, and companionship. American Journal of Community Psychology, 29(4), 565-597.

Lee, M. (1994). Cultural differences in the daily manifestation of adolescent depression: A comparative study of American and Korean high school seniors. University of Illinois at Urbana-Champaign, Doctoral dissertation.

Lee, M. (1994). Cultural differences in the daily manifestations of adolescent depression: A comparative study of American and Korean high school seniors. Unpublished doctoral dissertation. University of Illinois, Urbana.

Lee, M. \& Larson, R. (2000). The Korean 'examination hell': Long hours of studying, distress, and depression. Journal of Youth and Adolescence, 29(2), 249-271.

Lemola, S., Perkinson-Gloor, N., Brand, S., Dewald-Kaufmann, J. F. \& Grob, A. (2015). Adolescents' electronic media use at night, sleep disturbance, and depressive symptoms in the smartphone age. Journal of youth and adolescence, 44(2), 405418. doi: 10.1007/s10964-014-0176-x

Lenhart, A. (2012). Teens, smartphones \& texting. Pew internet \& American Life Project.

Lenhart, A., 2015. Teen, Social Media and Technology Overview 2015. smartphone facilitate shifts in communication landscape for teens. Pew Research Center's Teens Relationships Survey. 
Lenhart, A., Ling, R., Campbell, S. \& Purcell, K. (2010). Teens and mobile phones: Text messaging explodes as teens embrace it as the centerpiece of their communication strategies with friends. Pew internet \& American Life Project.

Lepp, A., Barkley, J. E. \& Karpinski, A. C. (2014). The relationship between cell phone use, academic performance, anxiety, and satisfaction with life in college students. Computers in Human Behavior, 31, 343-350.

Li, W., O'Brien, J. E., Snyder, S. M. \& Howard, M. O. (2015). Characteristics of Internet Addiction/Pathological Internet Use in US University Students: A QualitativeMethod Investigation. Plos One, 10(2). doi: 10.1371/journal.pone.0117372

Livingstone, S. M. \& Bovill, M. (1999). Young people, new media: London School of Economics and Political Science London.

Livingstone, S. \& Bober, M. (2004). UK Children Go Online: Surveying the experiences of young people and their parents.

Lopes, A. S., Silva, K. S., Barbosa Filho, V. C., Bezerra, J., de Oliveira, E. S. \& Nahas, M. V. (2014). Trends in screen time on week and weekend days in a representative sample of Southern Brazil students. Journal of Public Health, fdt133.

Lopez-Fernandez, O., Freixa-Blanxart, M. \& Honrubia-Serrano, M. L. (2013). The problematic Internet entertainment use scale for adolescents: prevalence of problem Internet use in Spanish high school students. Cyberpsychology, Behavior, and Social Networking, 16(2), 108-118. doi:10.1089/cyber.2012.0250.

Lorenci, M. (2012). Anuario SGAE de las Artes Escenicas, musicales y audiovisuales. Fundacion Autor: Madrid.

Loucaides, C. A., Jago, R. \& Theophanous, M. (2011). Physical activity and sedentary behaviours in Greek-Cypriot children and adolescents: a cross-sectional study. Int J Behav Nutr Phys Act, 8(1), 90-101.

Lu, H. Y. (2008). Sensation-seeking, Internet dependency, and online interpersonal deception. CyberPsychology \& Behavior, 11, 227-231.

Madden, M., Lenhart, A., Duggan, M., Cortesi, S. \& Gasser, U. (2013). Teens and technology 2013: Pew Internet \& American Life Project Washington, DC.

Mahoney, J. L., Harris, A. L. \& Eccles, J. S. (2006). Organized Activity Participation, Positive Youth Development, and the Over-Scheduling Hypothesis. Society for Research in Child Development, 20(4).

Maras, D., Flament, M. F., Murray, M., Buchholz, A., Henderson, K. A., Obeid, N. \& Goldfield, G. S. (2015). Screen time is associated with depression and anxiety in Canadian youth. Preventive Medicine, 73, 133-138. doi: 10.1016/j.ypmed.2015.01.029

Marsh, H. W. (1991). Employment during high school: Character building or a subversion of academic goals? Sociology of Education, 64(3), 172-189. doi: $10.2307 / 2112850$. 
Marsh, H. W. \& Kleitman, S. (2005). Consequences of employment during high school: Character building, subversion of academic goals, or a threshold? American Educational Research Journal, 42(2), 331-369. doi: 10.3102/00028312042002331

Mazur, E. \& Richards, L. (2011). Adolescents' and emerging adults' social networking online: Homophily or diversity?. Journal of Applied Developmental Psychology, 32(4), 180-188.

Mc Millan, J.H., Schumacher, S. (2010). Investigación Educativa. Pearson-Addison Wesley. Madrid.

Meerkerk, G. J., Van Den Eijnden, R. J., Vermulst, A. A. \& Garretsen, H. F. (2009). The Compulsive Internet Use Scale (CIUS): Some psychometric properties. Cyberpsychology Behavior, 12(1), 1-6.

Montañés, M. C. \& Silvestre, V. V. (2011). Evaluación de la adicción al móvil en la adolescencia. Revista española de drogodependencias, (2), 165-183.

Morales, J. M. R. (2011). Ciudadanía digital: una introducción a un nuevo concepto de ciudadano. UOC.

Morales, P. (2011). El análisis factorial en la construcción e interpretación de test, escalas y cuestionarios. Universidad Pontificia Comillas, Madrid. Recuperado de http://upcomillas.es/personal/peter/investigación

Mortimer, J. T., Harley, C. \& Aronson, P. J. (1999). How do prior experiences in the workplace set the stage for transitions to adulthood. Transitions to adulthood in a changing economy: No work, no family, no future, 131-159.

Muñoz, F. G. (2009). El impacto de las pantallas: televisión, ordenador y videojuegos. Pediatria Integral, 13, 881-890.

Munoz-Miralles, R., Ortega-Gonzalez, R., Batalla-Martinez, C., Rosa Lopez-Moron, M., Maria Manresa, J. \& Toran-Monserrat, P. (2014). Access and use of new information and telecommunication technologies among teenagers at high school, health implications. JOITIC Study. Atencion Primaria, 46(2), 77-88. doi: 10.1016/j.aprim.2013.06.001

National Center for Educational Statistics. (1998). National Educational Longitudinal Study (NELS: 88/94) Methodology Report. U. S. Department of Education, Office of Educational Research and Improvement, Publication.

National Sleep Foundation (2006). Sleep in America Pool. Recuperado de https://sleepfoundation.org/sites/default/files/2006_summary_of_findings.pdf

Navarro, H., González, Z. \& Massana, E. (2014). El consumo multipantalla. Estudio sobre el uso de medios tradicionales y nuevos por parte de niños, jóvenes, adultos y personas mayores en Cataluña. Quaderns del CAC, 38, 91-100.

Navarro, J. (2015). Preferencias de los jóvenes de 16 a 19 años en el uso de redes sociales tomando como referencia los datos Cristian Monroy de Global Web Index. 
Recuperado de http://www.emprendemania.com/2015/03/las-10-redes-socialesmas-usadas-entre-los-adolescentes.html

NHK Public Opinion Research Division, (1996). Japanese time use in 1995

O'Brien, E. M. \& Mindell, J. A. (2005). Sleep and risk-taking behavior in adolescents. Behavioral sleep medicine, 3(3), 113-133.

O'Brien, L. M. \& Gozal, D. (2004). Neurocognitive dysfunction and sleep in children: From human to rodent. Pediatric Clinics of North America, 51(1), 187-+. doi: 10.1016/s0031-3955(03)00184-6

Ohannessian, C. M (2009). Media use and adolescent psychological adjustment: an examination of gender differences. Journal of child and family studies, 18(5), 582-593

O'Keeffe, G. S., Clarke-Pearson, K. \& Council, Commun Media. (2011). Clinical ReportThe Impact of Social Media on Children, Adolescents, and Families. Pediatrics, 127(4), 800-804. doi: 10.1542/peds.2011-0054

Olds, T., Blunden, S., Petkov, J. \& Forchino, F. (2010). The relationships between sex, age, geography and time in bed in adolescents: a meta-analysis of data from 23 countries. Sleep medicine reviews, 14(6), 371-378.

Olds, T., Maher, C., Blunden, S. \& Matricciani, L. (2010). Normative Data on the Sleep Habits of Australian Children and Adolescents. Sleep, 33(10), 1381-1388.

Oliva Delgado, A., Reina Flores, M. C., Pertegal Vega, M. A. \& Antolin-Suarez, L. (2011). Sleep routines and adolescent adjustment. Behavioral Psychology-Psicologia Conductual, 19(3), 541-556.

ONG Protégeles, 2005.

Ortega, F. B., Chillón, P., Ruiz, J. R., Delgado, M., Albers, U., Álvarez-Granda, J. L., . . . Castillo, M. J. (2010). Sleep patterns in Spanish adolescents: associations with TV watching and leisure-time physical activity. European journal of applied physiology, 110(3), 563-573.

Overby, N. C., Klepp, K. \& Bere, E. (2013). Changes in screen time activity in Norwegian children from 2001 to 2008: two cross sectional studies. Bmc Public Health, 13. doi: 10.1186/1471-2458-13-80

Owens, J. A., Belon, K. \& Moss, P. (2010). Impact of Delaying School Start Time on Adolescent Sleep, Mood, and Behavior. Archives of Pediatrics \& Adolescent Medicine, 164(7), 608-614.

Palfrey, J. G \& Gasser, U. (2010). Response to FCC Notice of Inquiry 09-94: Empowering Parents and Protecting Children in an Evolving Media Landscape. Berkman Center Research Publication(2010-02), 10-19.

Pasquier, D., Buzzi, C., D'Haenens, L. \& Sjöberg, U. (1998). Family lifestyles and media use patterns: An analysis of domestic media among Flemish, French, Italian and 
Swedish children and teenagers. European Journal of Communication, 13(4), 503-519.

Pichel Mira, R. (2014). El uso problemático de Internet entre los adolescentes: estado de la cuestión y retos inmediatos.

Porterfield, S. L. \& Winkler, A. E. (2007). Teen time use and parental education: Evidence from the CPS, MTF, and ATUS. Monthly Labor Review, 130(5), 37-56.

Randler, C., Bilger, S. \& Díaz-Morales, J. F. (2009). Associations among sleep, chronotype, parental monitoring, and pubertal development among German adolescents. The Journal of psychology, 143(5), 509-520.

Rey-Lopez, J. P., Vicente-Rodriguez, G., Ortega, F. B., Ruiz, J. R., Martinez-Gomez, D., De Henauw, S., . . . Grp, Helena Study. (2010). Sedentary patterns and media availability in European adolescents: The HELENA study. Preventive Medicine, 51(1), 50-55. doi: 10.1016/j.ypmed.2010.03.013

Rial, A., Gomez, P., Brana, T. \& Varela, J. (2014). Attitudes, perceptions and Internet and social networks use among Galician (Spain) teens. Anales De Psicologia, 30(2), 642-655.

Rideout, V. J., Foehr, U. G. \& Roberts, D. F. (2010). Generation $M^{2}$ : Media in the Lives of 8-to 18-Year-Old. Henry J. Kaiser Family Foundation.

Roberts, D. F. \& Foehr, U. G. (2004). Kids and media in America: Cambridge University Press.

Roberts, R. E., Roberts, C. R. \& Duong, H. T. (2009). Sleepless in adolescence: prospective data on sleep deprivation, health and functioning. Journal of adolescence, 32(5), 1045-1057.

Robinson, J. P. (1985). The validity and reliability of diaries versus alternative time use measures. Time, goods, and well-being, 3, 33-62.

Robinson, J. P. (1999). The time-diary method: Structure and uses. In W. E. Pentland, A.S.

Robinson, J. P. \& Bianchi, S. . (1997). The children's hours. American Demographics, 19(12), 2024.

Romer, D., Jamieson, P. E., Bushman, B. J., Bleakley, A., Wang, A., Langleben, D. \& Jamieson, K. H. (2014). Parental desensitization to violence and sex in movies. Pediatrics, 134(5), 877-884.

Rothmund, T., Gollwitzer, M., Bender, J. \& Klimmt, C. (2015). Short-and long-term effects of video game violence on interpersonal trust. Media Psychology, 18(1), 106-133.

Salcedo Aguilar, F., Rodríguez Almonacid, F. M., Monterde Aznar, M. L., García Jiménez, M. A., Redondo Martínez, P. \& Marcos Navarro, A. I. (2005). Sleeping habits and sleep disorders during adolescence: Relation to school performance. Atencion Primaria, 35(8), 408-414. doi: 10.1157/13074792 
Samaniego, M. C. M., Barandarian, A. A. \& Navarro, S. P. (2010). El perfil de consumo televisivo en adolescentes, jóvenes y adultos: implicaciones para la educación. Revista de educación, (352), 545-566.

Sánchez-Martinez, M. \& Otero Puime, A. (2010). Internet and associated factors in adolescents in the Community of Madrid. Atencion Primaria, 42(2), 79-85. doi: 10.1016/j.aprim.2009.05.004

Sanz, A. B. (2008). Los medios de comunicación. Atención al adolescente (203-212).

Schoenhals, M., Tienda, M. \& Schneider, B. (1998). The educational and personal consequences of adolescent employment. Social Forces, 77(2), 723-761.

Shanahan, M. J. \& Flaherty, B. P. (2001). Dynamic patterns of time use in adolescence. Child Development, 72(2), 385-401.

Shapira, N. A., Goldsmith, T.D., Keck, P.E., Khosla, U.M. y McElroy, S. M. (2000). Psychiatric features of individuals with problematic Internet use. Journal of Affective Disorders, 57(1-3), 267-272. doi: 10.1016/S0165-0327(99)00107-X

Shek, D. T. \& Yu, L. (2012). Internet addiction phenomenon in early adolescents in Hong Kong. The Scientific World Journal, 2012.

Shochat, T., Flint-Bretler, O. \& Tzischinsky, O. (2010). Sleep patterns, electronic media exposure and daytime sleep-related behaviours among Israeli adolescents. Acta Paediatrica, 99(9), 1396-1400.

Siomos, K. E., Dafouli, E. D., Braimiotis, D. A., Mouzas, O. D. \& Angelopoulos, N. V. (2008). Internet Addiction among Greek Adolescent Students. Cyberpsychology \& Behavior, 11(6), 653-657. doi: 10.1089/cpb.2008.0088

Sivertsen, B., Skogen, J. C., Jakobsen, R. \& Hysing, M. (2015). Sleep and use of alcohol and drug in adolescence. A large population-based study of Norwegian adolescents aged 16 to 19 years. Drug and Alcohol Dependence, 149, 180-186. doi: 10.1016/j.drugalcdep.2015.01.045

Škařupová, K., Ólafsson, K. \& Blinka, L. (2015). Excessive Internet Use and its association with negative experiences: Quasi-validation of a short scale in 25 European countries. Computers in Human Behavior, 53, 118-123.

Smith, P. K. \& Collage, G. (2006). Ciberacoso: naturaleza y extensión de un nuevo tipo de acoso dentro y fuera de la escuela. In Congreso Educación Palma de Mallorca.

Smoll, F. L. \& Smith, R. E. (1996). Children and youth in sport: a biopsychosocial perspective [Edited by Smoll, FL; Smith, RE]: Brown \& Benchmark.

Sorbring, E., Hallberg, J., Bohlin, M. \& Skoog, T. (2015). Parental attitudes and young people's online sexual activities. Sex Education, 15(2), 129-143.

Steinberg, L. \& Cauffman, E. (1995). The impact of employment on adolescent development. Annals of child development, 11(1), 131-166.

Stevens, F, Van Den Broek, A \& Vandeweyer, J. (2003). Time use of adolescents in Belgium and the Netherlands (Vol. 35): Steunpunt re-creatief Vlaanderen. 
Strasburger, V. C. (2014). Children, Adolescents, and Media in the U.S.: What are the Next Steps to Take? J Child Adolesc Behav, 2(143), 2.

Strasburger, V. C., Jordan, A. B. \& Donnerstein, E. (2010). Health Effects of Media on Children and Adolescents. Pediatrics, 125(4), 756-767. doi: 10.1542/peds.20092563

Strasburger, V.C., Hogan, M. J., Mulligan, D. A., Ameenuddin, N., Christakis, D. A., Cross, C., . . . Commun, MediaCouncil. (2013). Children, Adolescents, and the Media. Pediatrics, 132(5), 958-961. doi: 10.1542/peds.2013-2656

Subrahmanyam, K. \& Greenfield, P. (2008). Online communication and adolescent relationships. Future of Children, 18(1), 119-146.

Sureda, J., Mut, B., Comas, R., Casero, A., Oliver, M. \& Salvà, F. (2008). Les TIC i els menors a les Illes Balears. Equipament i usos de les tecnologies de la informació i la comunicació per part dels menors de les Illes Balears d'entre, 6 .

Tonioni, F., D'Alessandris, L., Lai, C., Martinelli, D., Corvino, S., Vasale, M., . . Bria, P. (2012). Internet addiction: hours spent online, behaviors and psychological symptoms. General Hospital Psychiatry, 34(1), 80-87. doi: 10.1016/j.genhosppsych.2011.09.013

Tremblay, M. S, LeBlanc, A. G, Carson, V., Choquette, L., Connor Gorber, S., Dillman, C., . . . Janssen, I. (2012). Canadian physical activity guidelines for the early years (aged 0-4 years). Applied Physiology, Nutrition, and Metabolism, 37(2), 345-356.

Tsitsika, A, Tzavela, E, Mavromati, F \& Consortium, EU NET ADB. (2012). Research on Internet addictive behaviours among European adolescents. Eunetadb. eu.

Turner, N. E., Paglia-Boak, A., Ballon, B., Cheung, J. T., Adlaf, E. M., Henderson, J., ... \& Mann, R. E. (2012). Prevalence of problematic video gaming among Ontario adolescents. International Journal of Mental Health and Addiction, 10(6), 877889. doi:10.1007/s11469-012-9382-5.

Tyler, T. R. (2002). Is the internet changing social life? It seems the more things change, the more they stay the same. Journal of Social Issues, 58(1), 195-205

Usher, K., Woods, C., Casella, E., Glass, N., Wilson, R., Mayner, L., . . Irwin, P. (2014). Australian health professions student use of social media. Collegian, 21(2), 95101. doi: 10.1016/j.colegn.2014.02.004

Valkenburg, P. M. \& Peter, J. (2009). Social consequences of the internet for adolescents a decade of research. Current Directions in Psychological Science, 18(1), 1-5.

Valmaña, E. L. \& García-Martínez, J. (2009). Las tecnologías de la información y la comunicación (TIC). Educa Nova: colección de artículos técnicos de educación(2), 110-129.

Van den Bulck, J. (2004). Television viewing, computer game playing, and Internet use and self-reported time to bed and time out of bed in secondary-school children. SLEEP-NEW YORK THEN WESTCHESTER-, 27(1), 101-104. 
Van den Bulck, J. (2007). Adolescent use of mobile phones for calling and for sending text messages after lights out: Results from a prospective cohort study with a one-year follow-up. Sleep, 30(9), 1220-1223.

Vernon, M. K. (2005). Time use as a way of examining contexts of adolescent development in the United States. Loisir et Societe, 28(2), 549-570.

Vicente-Rodríguez, G., Rey-López, J. P., Martín-Matillas, M., Moreno, L. A., Wärnberg, J., Redondo, C., ... \& AVENA Study Group. (2008). Television watching, videogames, and excess of body fat in Spanish adolescents: the AVENA study. Nutrition, 24(7), 654-662.

Vilca, L. W. \& Vallejos, M. (2015). Construction of the Risk of Addiction to Social Networks Scale (C r. ARS). Computers in Human Behavior, 48, 190-198.

Wartberg, L., Kammerl, R., Bröning, S., Hauenschild, M., Petersen, K. U. \& Thomasius, R. (2015). Gender-related consequences of internet use perceived by parents in a representative quota sample of adolescents. Behaviour \& Information Technology, 34(4), 341-348.

Wight, V. R., Price, J., Bianchi, S. M. \& Hunt, B. R. (2009). The time use of teenagers. Social Science Research, 38(4), 792-809.

Wolfson, A. R. \& Carskadon, M. A. (1998). Sleep schedules and daytime functioning in adolescents. Child Development, 69(4), 875-887. doi: 10.1111/j.14678624.1998.tb06149.x

Wong, M. M., Brower, K. J., Fitzgerald, H. E. \& Zucker, R. A. (2004). Sleep problems in early childhood and early onset of alcohol and other drug use in adolescence. Alcoholism-Clinical and Experimental Research, 28(4), 578-587. doi: 10.1097/01.alc.0000121651.75952.39

Xu, J. Z. (2010). Gender and homework management reported by African American students. Educational Psychology, 30(7), 755-770.

Yang, C. K., Kim, J. K., Patel, S. R. \& Lee, J. H. (2005). Age-related changes in sleep/wake patterns among Korean teenagers. Pediatrics, 115(1), 250-256. doi: 10.1542/peds.2004-0815G

Yang, S., Lu, Y., Wang, B. \& Zhao, L. (2014). The benefits and dangers of flow experience in high school students' internet usage: The role of parental support. Computers in Human Behavior, 41, 504-513.

Young, K. S. (1998). Caught in the net: How to recognize the signs of internet addiction-and a winning strategy for recovery: John Wiley \& Sons.

Zamorano, M. M., Abad, M. E. M., Torres, N. N., Hernández, A. H. \& Puerta, E. V. (2014). Nuevas recomendaciones de la Academia Americana de Pediatría: Incluir dos preguntas sobre el uso de la televisión y los videojuegos en las revisiones de salud. Canarias pediátrica, 38(3), 129-131. 
Zheng, F., Gao, P., He, M., Li, M., Tan, J., Chen, D., ... \& Zhang, L. (2015). Association between mobile phone use and self-reported well-being in children: a questionnaire-based cross-sectional study in Chongqing, China. BMJ open, 5(5), e007302

Zhu, Y., Zhang, H. \& Tian, M. (2015). Molecular and functional imaging of Internet addiction. BioMed research international, 2015. 


\section{Anexos}





\section{Anexos:}

\section{Anexo 1: Encuesta administrada a los adolescents burgaleses}

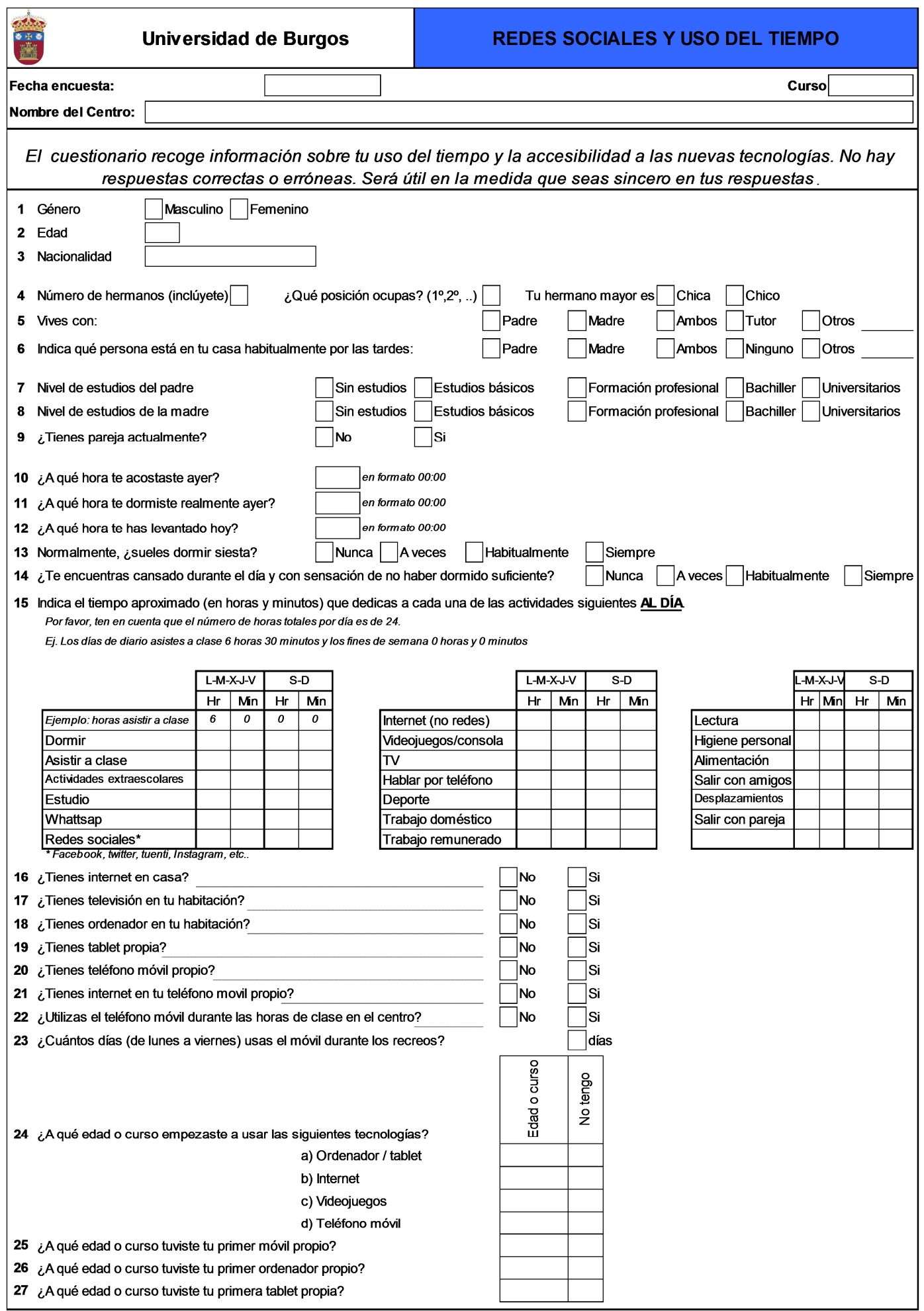


Anexos

28 ¿En qué formato lees libros?
29 ¿Llevas contigo el teléfono movil y/o ordenador y/o tablet cuando te vas a la cama?
30 ¿Te conectas a internet después de haberte acostado?
Si tu respuesta es sí, a) ¿cuántos días a la semana?
b) ¿durante cuánto tiempo te conectas cada vez?

31 Marca cuáles de las siguientes aplicaciones y/o redes sociales usas e indica el número de amigos que tienes aproximadamente en cada una de ellas.

$\square$ Twitter № amigos _ $\square$ Instagram № amigos _ $\square$ Whatsapp $\square$ Skype
$\square$ Tuenti № amigos _ $\square$ Facebook № amigos _
mero aproximado de Whastap que diariamente:

32 Indica el

34 Indica el número aproximado de mails que diariamente:

35 Indica, mediante un número, el porcentaje del tiempo que estás conectado a internet, es dedicado al tus estudios o dedicado al ocio (la suma debe ser 100\%): Por ejemplo, del $100 \%$ del tiempo que me conecto a internet, un $75 \%$ es para apoyar a mis estudios y un $25 \%$ es por ocio

$\square \%$ tiempo conectado dedicado a estudios $\square \%$ tiempo dedicado a internet por ocio

36 Indica a qué actividades consideras que tus compañeros y/o amigos están enganchados (puedes marcar más de una opción):

$\square$ Teléfono móvil $\square$ Redes sociales $\square$ Wattsap $\square$ Videojuegos $\square$ Televisión $\square$ Otras ¿Cuáles?

37 ¿Tienes abiertas las redes sociales mientras estudias?

38 ¿Miras el Whatsap mientras estudias?

39 ¿Escuchas música mientras estudias?

40 ¿Tienes que apartar/esconder el teléfono móvil y dispositivos con Internet de tu vista mientras estás estudiando o realizando la tarea escolar para que no te distraigan?

41 ¿Consideras que podrías sacar más provecho a tu rendimiento escolar y mejorar tu resultado académico si disminuyeses el tiempo

41 dedicado a internet como ocio?

42 ¿Estás conectado a internet más tiempo del que te habías propuesto?

43 ¿Estás conectado a las redes sociales más tiempo del que te habías propuesto?

44 ¿Estás conectado a whatsap más tiempo del que te habías propuesto?

45 ¿Tienes normas en casa para el uso de dispositivos electrónicos y de acceso a internet?

46 ¿Tus padres/tutores conocen tu nic/alias/nombre en las redes sociales en las que participas?

47 ¿Has hablado con tus padres o tutores sobre los riesgos de acceso a los contenidos en internet?

48 ¿Tus padres te preguntan sobre los contenidos que has utilizado $y / o$ vas a utilizar en la red?

49 ¿Le cuentas a tus padres los contenidos que ves en internet?

50 ¿Has repetido algún curso escolar?

51 ¿Has suspendido alguna asignatura la evaluación pasada? $\square$ Si Cuántas asignaturas suspendiste?

52 ¿Tienes actualmente apoyo escolar (academia, profesor particular, etc..)? $\square$ No $\square \mathrm{Si}$

53 Indica del 1 al 10, la nota media que obtuviste en el curso pasado

54 Indica del 1 al 10, la nota media que esperas sacar en este curso

55 ¿Cuál es la asignatura que más te gusta?

56 ¿Están tus padres satisfechos con tus logros académicos?

57 ¿Te comparan con otras personas (hermanos, primos, compañeros, amigos, etc...)? $\square$ Nunca $\square$ A veces

59 ¿Estás tú satisfech@, en general, con tus logros académicos?

$\square$ Nunca $\square$ A veces

59 ¿Cuál de estas dos cosas te importa más?

$\square$ Aprobar

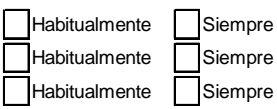

$\square$ Aprender 


\section{Anexo 2: internet Addiction Test (IAT) by Dr. Kimberly Young}

It consists of 20 items that measures mild, moderate and severe level of internet Addiction.

To begin, answer the following questions by using this scale:

\begin{tabular}{|l|l|}
\hline Does not apply & 0 \\
\hline Rarely & 1 \\
\hline Occasionally & 2 \\
\hline Frequently & 3 \\
\hline Often & 4 \\
\hline Always & 5 \\
\hline
\end{tabular}

\begin{tabular}{|c|c|c|c|c|c|c|c|}
\hline & QUESTION & \multicolumn{6}{|c|}{ SCALE } \\
\hline 1 & Do you find that you stay online longer than you intended? & & 2 & 3 & 4 & & 0 \\
\hline 2 & Do you neglect household chores to spend more time online? & 1 & 2 & 3 & 4 & 5 & 0 \\
\hline 3 & Do you prefer the excitment of the internet to intimacy with your partner? & 1 & 2 & 3 & 4 & 5 & 0 \\
\hline 4 & Do you form new relationships with fellow online users? & 1 & 2 & 3 & 4 & 5 & 0 \\
\hline 5 & Do others in your life complain to you about the amount of time you spend online? & 1 & 2 & 3 & 4 & 5 & 0 \\
\hline 6 & $\begin{array}{l}\text { Does your work suffer because of the amount of time you spend online? (E.g., } \\
\text { postponing things, not meeting deadlines, etc.) }\end{array}$ & 1 & 2 & 3 & 4 & 5 & 0 \\
\hline 7 & Do you check your email before something else you need to do? & 1 & 2 & 3 & 4 & 5 & 0 \\
\hline 8 & Does your job performance or productivity suffer because of the internet? & 1 & 2 & 3 & 4 & 5 & 0 \\
\hline 9 & Do you become defensive or secretive when anyone asks you what you do online? & 1 & 2 & 3 & 4 & 5 & 0 \\
\hline 10 & Do you block disturbing thoughts about your life with soothing thoughts of the & 1 & 2 & 3 & 4 & 5 & 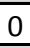 \\
\hline 11 & Do you find yourself anticipating when you will go online again? & 1 & 2 & 3 & 4 & 5 & 0 \\
\hline 12 & Do you fear that life without the internet would be boring, empty or joyless? & 1 & 2 & 3 & 4 & 5 & $\pi$ \\
\hline 13 & Do you snap, yell, or act annoyed if someone bothers you while you are online? & 1 & 2 & 3 & 4 & 5 & 0 \\
\hline 14 & Do you lose sleep due to late night internet use? & 1 & 2 & 3 & 4 & 5 & 0 \\
\hline 15 & $\begin{array}{l}\text { Do you feel preoccupied with the internet when not online, or fantasize about } \\
\text { being online? }\end{array}$ & 1 & 2 & 3 & 4 & 5 & 0 \\
\hline 16 & Do you find yourself saying "Just a few more minutes" when online? & 1 & 2 & 3 & 4 & 5 & 0 \\
\hline 17 & Do you try to cut down on the amount of time you spend online and fail? & 1 & 2 & 3 & 4 & 5 & \\
\hline 18 & Do you try and hide how long you've been online? & 1 & 2 & 3 & 4 & 5 & 0 \\
\hline 19 & Do you choose to spend more time online over spending time out with others? & 1 & 2 & 3 & 4 & 5 & 0 \\
\hline 20 & $\begin{array}{l}\text { Do you feel depressed, moody, or nervous when you are not online, and do these } \\
\text { feelings go awhile when you go back online? }\end{array}$ & 1 & 2 & 3 & 4 & 5 & 0 \\
\hline
\end{tabular}

Total up the scores for each item. The higher your score, the greater level of addiction is. 20-49 points:

You are an average on-line user. You may surf the Web a bit too long at times, but you have control over your usage.

\section{$50-79$ points:}

You are experiencing occasional or frequent problems because of the internet. You should consider their full impact on your life.

\section{$80-100$ points:}

Your internet usage is causing significant problems in your life. You should elevate the impact of the internet on your life and address the problems directly caused by you internet usage. 


\section{Anexo 3: Cuestionario de Experiencias Relacionadas con los Videojuegos (CERV)} Cuestionario CERV

A continuación encontrarás algunas afirmaciones sobre tu uso de los videojuegos. Lee atentamente cada frase e indica la frecuencia. Señala la respuesta que más se aproxime a tu realidad.

\begin{tabular}{|c|c|c|c|c|}
\hline & $\begin{array}{c}\text { Nuncal } \\
\text { Casi } \\
\text { nunca }\end{array}$ & $\begin{array}{l}\text { Algunas } \\
\text { veces }\end{array}$ & $\begin{array}{l}\text { Bastantes } \\
\text { veces }\end{array}$ & $\begin{array}{l}\text { Casi } \\
\text { siempn }\end{array}$ \\
\hline 1. ¿Hasta quê punto te sientes inquieto por temas relacionados con los videojuegos? & a & $b$ & c & d \\
\hline 2. ¿Cuando te aburres, usas los videojuegos corno una forma de distracción? & a & $b$ & c & d \\
\hline $\begin{array}{l}\text { 3. Con que frecuencia abandonas lo que estas haciendo para estar más tiempo jugando a } \\
\text { videojuegos? }\end{array}$ & a & b & c & d \\
\hline $\begin{array}{l}\text { 4. ¿Te han criticado tus amigos o familiares por invertir demasiado tiempoy dinero en los } \\
\text { videojuegos o te han dicha que tienes un problema, aunque creas que no es cierto? }\end{array}$ & a & b & c & d \\
\hline $\begin{array}{l}\text { 5. ¿Has tenido el riesgo de perder una relación importante, un trabajo o una oportunidad } \\
\text { académica por el uso de los videojuegos? }\end{array}$ & a & $b$ & c & d \\
\hline $\begin{array}{l}\text { 6. ¿Piensas que tu rendimiento acadèmico se ha visto afectado negativarnente por el uso de } \\
\text { los videojuegos? }\end{array}$ & a & $b$ & c & d \\
\hline $\begin{array}{l}\text { 7. ¿Mientes a tus familiares o amigos con respecto a la frecuencia y duración del tiempo que } \\
\text { inviertes en los videojuegos? }\end{array}$ & a & b & c & d \\
\hline 8. ¿Cuando tienes problemas, usar los videojuegos te ayuda a evadirte? & a & b & c & d \\
\hline $\begin{array}{l}\text { 9. ¿Con qué frecuencia bloqueas los pensamientos molestos sabre tu vida y los sustituyes por } \\
\text { pensarnientos agradables de los videojuegos? }\end{array}$ & a & $b$ & c & d \\
\hline 10. ¿Piensas que la vida sin videojuegos es aburrida, vaciay triste? & a & b & c & d \\
\hline 11. ¿Te enfadas o te irritas, cuando alguien te molesta mientras juegas con algún videojuego? & a & $\mathrm{b}$ & c & d \\
\hline 12. ¿Sutres alteraciones de suefio debido a aspectos relacionados con los videojuegos? & a & $b$ & c & d \\
\hline 13. ¿Cuando no juegas con videojuegos te sientes agitado o preocupado? & a & $b$ & c & d \\
\hline $\begin{array}{l}\text { 14. ¿Sientes la necesidad de invertir cada ver más tiempo en los videojuegos para sentirte } \\
\text { satisfecha? }\end{array}$ & a & $b$ & c & d \\
\hline 15. ¿Quitas importancia al tiempo que has estado jugando convideojuegos? & a & $b$ & $c$ & d \\
\hline 16. ¿Dejas de salir con tus amigos para pasar más tiempo jugando con videojuegos? & a & $b$ & c & d \\
\hline 17. ¿Cuando utilizas los videojuegos, te pasa el tiempo sin darte cuenta? & a & b & c & d \\
\hline
\end{tabular}




\section{Relación de tablas}

y gráficas 



\section{Relación de tablas y gráficas:}

\section{Tablas:}

Tabla 1: Actividades de ocio por frecuencia (1982-2007). Fuente: Instituto de la Juventud (INJUVE) 2000; y EJ077, EJ100, EJ124.

Tabla 2: estudios sobre el tiempo que dedican los adolescentes a dormir por nacionalidad.

Tabla 3: estudios sobre el tiempo dedicado por los adolescentes a dormir por género.

Tabla 4: estudios del tiempo dedicado por los adolescentes a su higiene personal por género.

Tabla 5: estudios sobre el tiempo dedicado por los adolescentes a hacer deporte por género.

Tabla 6: tiempo medio de exposición a las TIC de los adolescentes norteamericanos entre 8 y 18 años Fuente: Rideout et al. (2010)

Tabla 7: estudios sobre el porcentaje de adolescentes que tienen conexión a internet en sus hogares.

Tabla 8: estudios relacionados con la Adicción a internet desde el año 1999.

Tabla 9: Ranking de las 30 redes sociales más utilizadas en el mundo

Tabla 10: Redes sociales en que los adolescentes tienen un perfil por grupo de edad, género y clase social. Fuente: Jiménez et al. (2013)

Tabla 11: estudios que definen un ranking de redes sociales preferidas por los adolescentes

Tabla 12: adolescentes y televisión

Tabla 13: adolescentes y telefonía movil

Tabla 14: género

Tabla 15: edad

Tabla 16: curso

Tabla 17: edad-curso

Tabla 18: nacionalidad

Tabla 19: Clasificación de los centros

Tabla 20: Centro de estudios - Género 
Tabla 21: chi-cuadrado Centro de estudios - Género

Tabla 22: centro de estudios - curso

Tabla 23: chi-cuadrado centro de estudios - curso

Tabla 24: centro de estudios - nacionalidad

Tabla 25: adolescentes con pareja por género

Tabla 26: chi-cuadrado adolescentes con pareja por género

Tabla 27: adolescentes con pareja por edad.

Tabla 28: chi-cuadrado pareja por edad

Tabla 29: Número de valores extremos superiores e inferiores eliminados de la base de datos

Tabla 30: hora de acostarse, dormirse y levantarse

Tabla 31: hora de acostarse, dormirse y levantarse por género

Tabla 32: Valores estadísticos principales del uso del tiempo por parte de los adolescentes

Tabla 33: tiempo que tardan los adolescentes en dormirse

Tabla 34: Análisis t-Student del uso del tiempo con respecto al género.

Tabla 35: media de tiempo por edad y nivel de significación.

Tabla 36: diferencia de medias del tiempo dedicado a dormir en fin de semana.

Tabla 37: dormir por género y edad

Tabla 38: diferencia de medias de tiempo dedicado a estudiar

Tabla 39: diferencia de medias del tiempo dedicado al WhatsApp

Tabla 40: niveles de significación de las diferencias dos a dos

Tabla 41: media de tiempo por curso y nivel de significación.

Tabla 42: diferencias significativas de tiempo que tardan en dormirse por curso

Tabla 43: Análisis t-Student uso del tiempo con respecto a la nacionalidad

Tabla 44: media de tiempo por centro educativo y nivel de significación

Tabla 45: media de tiempo por número de hermanos y nivel de significación

Tabla 46: media de tiempo con respecto a las personas con las que vive y nivel de significación 
Tabla 47: media de tiempo en relación a las personas con quién pasa las tardes y nivel de significación

Tabla 48: media de tiempo por el nivel de estudios del padre y nivel de significación

Tabla 49: media de tiempo por el nivel de estudios de la madre y nivel de significación.

Tabla 50: análisis t-Student uso del tiempo con respecto a la su estado sentimental

Tabla 51: duermen la siesta.

Tabla 52: adolescentes cansados

Tabla 53: tabla resumen factores que pueden afectar al uso del tiempo

Tabla 54: Internet en casa - género

Tabla 55: Internet en casa - edad.

Tabla 56: Internet en casa - curso.

Tabla 57: Internet en casa - nacionalidad.

Tabla 58: Internet en casa - centro educativo

Tabla 59: Internet en casa - personas con las que vive y valor esperado

Tabla 60: Internet en casa-personas que le acompañan por la tarde y valor esperado

Tabla 61: Internet en casa - pareja

Tabla 62: uso de internet por género entre semana.

Tabla 63: uso de internet por género en fin de semana.

Tabla 64: televisión en la habitación - género

Tabla 65: televisión en la habitación - edad

Tabla 66: televisión en la habitación - curso.

Tabla 67: televisión en la habitación - nacionalidad.

Tabla 68: televisión en la habitación - centro de estudios

Tabla 69: televisión en la habitación - número de hermanos

Tabla 70: televisión en la habitación -personas con las que vive y valor esperado

Tabla 71: televisión en la habitación - personas que le acompañan por la tarde y valor esperado

Tabla 72: televisión en la habitación - pareja

Tabla 73: teléfono móvil propio - género 
Tabla 74: teléfono móvil propio - edad

Tabla 75: teléfono móvil propio - curso.

Tabla 76: teléfono móvil propio - nacionalidad

Tabla 77: teléfono móvil propio - centro.

Tabla 78: teléfono móvil propio - número de hermanos.

Tabla 79: teléfono móvil propio - personas con las que vive

Tabla 80: teléfono móvil propio - personas que le acompañan por la tarde

Tabla 81: teléfono móvil propio - pareja y valor esperado

Tabla 82: internet en teléfono móvil propio - género

Tabla 83: internet en teléfono móvil propio - Edad.

Tabla 84: internet en teléfono móvil propio - curso.

Tabla 85: internet en teléfono móvil propio - nacionalidad.

Tabla 86: internet en teléfono móvil propio - centro educativo.

Tabla 87: internet en teléfono móvil propio - número de hermanos.

Tabla 88: internet en teléfono móvil propio - personas con las que vive

Tabla 89: Internet en teléfono móvil propio - personas que le acompañan por la tarde

Tabla 90: internet en teléfono móvil propio - pareja

Tabla 91 media de SMS enviados y recibidos

Tabla 92: media de WhatsApp enviados y recibidos por los adolescentes burgaleses encuestados

Tabla 93: uso del teléfono móvil durante las horas lectivas en el centro educativo

Tabla 94: uso del teléfono móvil durante las horas de clase en el centro - género.

Tabla 95: ordenador en la habitación - género

Tabla 96: ordenador en la habitación - Edad.

Tabla 97: ordenador en la habitación - curso.

Tabla 98: ordenador en la habitación nacionalidad

Tabla 99: ordenador en la habitación - centro educativo

Tabla 100: ordenador en la habitación - número de hermanos

Tabla 101: ordenador en la habitación - personas con las que vive 
Tabla 102: ordenador en la habitación - personas que le acompañan por la tarde

Tabla 103: ordenador en la habitación - pareja y valor esperado

Tabla 104: tablet propia - género

Tabla 105: tablet propia -edad

Tabla 106: tablet propia - curso.

Tabla 107: tablet propia - nacionalidad.

Tabla 108: tablet propia - centro educativo.

Tabla 109: tablet propia - número de hermanos.

Tabla 110: tablet propia - personas con las que vive y valor esperado

Tabla 111: tablet propia - personas que le acompañan por la tarde

Tabla 112: tablet propia - pareja y valor esperado

Tabla 113: adolescentes que dedican tiempo a jugar a videojuegos/consolas - género.

Tabla 114: lectura de libros - género.

Tabla 115: formatos de lectura preferidos por los adolescentes - género.

Tabla 116: lectura de libros - edad

Tabla 117: formatos de lectura preferidos por los adolescentes - edad.

Tabla 118: factores que marcan diferencias significativas en cuanto al uso de TIC

Tabla 119: edad de iniciación a la utilización de los diferentes dispositivos tecnológicos

Tabla 120: edad de inicio de utilización de dispositivos tecnológicos - género.

Tabla 121: adolescentes que se ha iniciado en las nuevas tecnologías antes de los 6 años

Tabla 122: edad media a la que poseen los primeros dispositivos electrónicos

Tabla 123: edad media a la que poseen los primeros dispositivos electrónicos - género.

Tabla 124: resultado de t-Student: uso del tiempo - tener internet en casa.

Tabla 125: resultado de t-Student: uso del tiempo - tener televisión en la habitación.

Tabla 126: t-Student uso del tiempo - tener ordenador en la habitación

Tabla 127: t-Student uso del tiempo - tener tablet propia

Tabla 129: t-Student uso del tiempo - tener internet en teléfono móvil propio

Tabla 129.1: tiempo a deporte - acceso a las nuevas tecnologías 
Tabla 130: $t$-Student tiempo a dormir y tiempo que tardan en dormirse - se llevan los dispositivos electrónicos a la cama.

Tabla 131: t-Student tiempo a dormir y tiempo que tardan en dormirse - conectarse tras haberse acostado.

Tabla 132: hora levantarse - llevan los dispositivos electrónicos a la cama.

Tabla 133: tiempo en dormirse - uso de las distintas redes sociales.

Tabla 134: estar cansado durante el día-llevar los dispositivos a la cama

Tabla 135: estar cansado durante el día-conectarse a internet después de haberse acostado

Tabla 136: TIC mientras estudia.

Tabla 137: tienen que apartar el móvil mientras estudian para evitar distracciones

Tabla 138: uso de redes sociales mientras estudia - repetir algún curso.

Tabla 139: uso WhatsApp mientras estudia - repetir algún curso.

Tabla 140: escuchar música mientras estudia - repetir algún curso.

Tabla 141: adiciones de los amigos según los adolescentes.

Tabla 142: pasa más tiempo en internet, redes sociales y WhatsApp del que se había propuesto

Tabla 143: tiene normas en casa sobre el uso de dispositivos electrónicos y acceso a internet

Tabla 144: normas en casa sobre el uso de dispositivos electrónicos y acceso a internet género

Tabla 145: normas en casa sobre el uso de dispositivos electrónicos y acceso a internet edad

Tabla 146: uso del tiempo - normas en casa sobre nuevas tecnologías

Tabla 147: padres conocen nombre en las redes sociales.

Tabla 148: padres conocen nombre en las redes sociales - género.

Tabla 149: padres conocen nombre en las redes sociales - edad

Gráfica 150: uso del tiempo - padres conocen nic en las redes

Tabla 151: hablan con sus padres sobre los riesgos de acceso a los contenidos de internet

Tabla 152: hablan con sus padres sobre los riesgos de acceso a los contenidos de internet - género. 
Tabla 153: hablan con sus padres sobre los riesgos de acceso a los contenidos de internet - edad

Gráfica 154: uso del tiempo - hablan con los padres sobre los riesgos de acceso a internet

Tabla 155: padres les preguntan por los contenidos que utilizan o van a utilizar en internet.

Tabla 156: Tabla 155: padres les preguntan por los contenidos que utilizan en internetgénero

Gráfica 158: uso del tiempo - los padres les preguntan por los contenidos que utilizan internet

Tabla 159: cuentan a sus padres los contenidos que ven en internet

Tabla 160: cuentan a sus padres los contenidos que ven en internet - género.

Tabla 161: cuentan a sus padres los contenidos que ven en internet - edad

Tabla 162: uso del tiempo-cuentan a sus padres los contenidos que ven en internet

Tabla 163: uso del tiempo - repetido curso

Tabla 164: uso del tiempo - asignatura suspensa la evaluación pasada

Gráfica 165: tiempo a internet para educación y para ocio - curso repetido

Gráfica 166: tiempo a internet para educación y para ocio-asignatura suspensa

Tabla 167: repetir un curso escolar y tener teléfono móvil

Tabla 168: tener normas en casa en internet - repetir curso

Tabla 169: repetir curso escolar- satisfacción con rendimiento escolar

Tabla 170: relación repetir curso escolar- satisfacción de los padres.

Tabla 171: uso del tiempo - satisfacción académica del propio adolescente

Tabla 172: t-Student uso del tiempo - estudiar para aprobar o aprender

Tabla 173: artículos referidos al tiempo que dedican a dormir los adolescentes

Tabla 174: estudios tiempo dedicado a dormir - género.

Tabla 175: estudios sobre la diferencia de medias de tiempo dedicado a dormir - edad

Tabla 176: estudios sobre tiempo dedicado a dormir por adolescentes de 13 y 18 años

Tabla 177: estudios hora a la que se han acostado los adolescentes

Tabla 178: estudios sobre tiempo dedicado a la higiene personal - género 
Tabla 179: tiempo dedicado a estudiar y a hacer tareas escolares por continente. Fuente: (Larson \& Verma, 1999)

Tabla 180: estudios sobre tiempo dedicado a hacer deporte por los adolescentes - género Tabla 181: estudios adolescentes que tienen conexión a internet en su casa Tabla 182: comparativa de ranking de uso de redes sociales por los adolescentes Tabla 183: estudios tiempo que los adolescentes dedican a ver la televisión. Tabla 184: adolescentes que poseen teléfono móvil Tabla 185: comparativa de resultados en encuesta INE y encuesta realizada a jóvenes burgaleses en relación - edad primer teléfono móvil.

Tabla 186: estudios tiempo dedicado por los adolescentes a los videojuegos y consolas

\section{Gráficos:}

Gráfico 1: Tiempo dedicado por los adolescentes entre semana a diferentes actividades. Fuente: Bureau of Labor Statistics. American Time Use Survey (media de horas al día 2008-2010)

Gráfico 2: distribución de actividades por grupo de edad, 2009-2010. Fuente: datos obtenidos en la Encuesta de Empleo del Tiempo realizada por el INE 2009-2010.

Gráfico 3: hogares españoles que disponen de cada dispositivo electrónico. Fuente: Encuesta sobre Equipamiento y Uso de Tecnologías de Información y Comunicación en los Hogares (2014)

Gráfico 4: Evolución del equipamiento TIC en los hogares. Total nacional (\% hogares). Fuente: Encuesta sobre Equipamiento y Uso de Tecnologías de Información y Comunicación en los Hogares (2006 a 2014)

Gráfico 5: Servicios de internet usados en los últimos 3 meses (2013). Fuente: Encuesta sobre el Equipamiento y Uso de Tecnologías de la Información y Comunicación en los Hogares y Encuesta de uso de TIC y comercio electrónico en las empresas (INE).

Gráfico 6: utilización de las redes sociales por los adolescentes estadounidenses de 13 a 17 años Fuente: Lenhart (2015)

Gráfico 7: redes sociales usadas por los adolescentes españoles de 14 a 17 años. Datos obtenidos en Diciembre 2014. Fuente: VI Estudio Redes Sociales de IAB Spain

Gráfico 8: emprendemanía (2015). Jóvenes entre 16 y 19 años que tienen perfil y que usan la cuenta en las distintas redes sociales. Emprendemanía (2015) 
Gráfico 9: nacional - extranjero

Gráfico 10: centro educativo

Gráfico 11: número de hermanos

Gráfico 12: personas con las que vive el adolescente.

Gráfico 13: personas que acompañan al adolescente por las tardes

Gráfico 14: nivel de estudios del padre y de la madre

Gráfico 15: adolescentes con pareja

Gráfico 16: Media de tiempo dedicado por los adolescentes burgaleses entre semana

Gráfico 17: Media de tiempo dedicado por los adolescentes burgaleses el fin de semana

Gráfico 18: Tiempo dedicado a diferentes actividades -chicas dedican más tiempo que chicos.

Gráfico 19: Tiempo dedicado a diferentes actividades -chicos dedican más tiempo que chicas.

Gráfica 20: media de horas dedicadas a dormir por edad (entre semana y fin de semana).

Gráfica 21: media de tiempo dedicado a estudiar por edad (entre semana y fin de semana).

Gráfica 22: media de tiempo dedicado a WhatsApp por edad (entre semana y fin de semana).

Gráfica 23: media de tiempo dedicados a redes sociales por edad

Gráfica 24: media de horas dedicadas a Internet por edad (entre semana y fin de semana).

Gráfica 25: media de horas dedicadas al deporte por edad.

Gráfica 26: media de tiempo dedicado a la lectura por edad (entre semana y fin de semana).

Gráfico 27: media de tiempo dedicado a la higiene personal por edad entre semana

Gráfica 28: media de tiempo dedicado a la alimentación por edad entre semana

Gráfica 29: media de horas dedicadas a salir con los amigos con la edad

Gráfico 30: media de horas dedicadas a salir con la pareja con la edad

Gráfico 31: media de tiempo hasta dormirse el día previo a la realización de la encuesta

Gráfico 32: media de horas dedicadas a dormir por curso (entre semana y fin de semana). 
Gráfico 33: media de horas dedicadas a estudiar por curso (entre semana y fin de semana).

Gráfico 34: media de horas a uso del WhatsApp por curso (entre semana y fin de semana).

Gráfico 35: media de horas a uso de redes sociales por curso (entre semana y fin de semana).

Gráfico 36: media de horas dedicadas a internet por curso (entre semana y fin de semana).

Gráfica 37: media de horas dedicadas a videojuegos y consolas por curso

Gráfico 38: media de horas dedicadas al teléfono por curso

Gráfico 39: media de horas dedicadas al deporte por curso

Gráfico 40: media de horas dedicadas al deporte por curso

Gráfico 41: media de tiempo dedicado a la alimentación entre semana.

Gráfico 42: media de tiempo dedicado a la salir con los amigos entre semana.

Gráfica 43: tiempo medio que los adolescentes tardan en dormirse por curso

Gráfico 44: adolescentes españoles dedican más tiempo que extranjeros.

Gráfico 45: adolescentes extranjeros dedican más tiempo que españoles.

Gráfico 46: media de tiempo dedicado a dormir entre semana por centro.

Gráfico 47: media de tiempo dedicado a asistir a clase entre semana por centro.

Gráfica 48: media de tiempo dedicado a realizar actividades extraescolares por centro.

Gráfica 49: media de tiempo dedicado a estudiar por centro.

Gráfico 50: media de tiempo dedicado a uso de WhatsApp entre semana por centro.

Gráfica 51: media de tiempo dedicado a redes sociales por centro.

Gráfica 52: media de tiempo dedicado a internet en fin de semana por centro.

Gráfica 53: media de tiempo dedicado a hacer deporte entre semana por centro.

Gráfica 54: media de tiempo dedicado a trabajo remunerado el fin de semana por centro.

Gráfica 55: media de tiempo dedicado a la alimentación el fin de semana por centro.

Gráfica 56: media de tiempo dedicado a la alimentación el fin de semana por centro.

Gráfica 57: media de tiempo dedicado a la alimentación el fin de semana por centro. 
Gráfico 58: media de tiempo que tardaron en dormirse ayer por centro.

Gráfica 59: media de horas dedicadas a uso del WhatsApp dependiendo del número de hermanos el fin de semana.

Gráfico 60: media de horas dedicadas a trabajo doméstico entre semana dependiendo del número de hermanos.

Gráfica 61: media de horas dedicadas leer el fin de semana dependiendo del número de hermanos.

Gráfica 62: media de horas dedicadas a salir con la pareja entre semana y el fin de semana dependiendo del número de hermanos.

Gráfica 63: media de horas dedicadas a dormir entre semana dependiendo de la persona con quién vive

Gráfica 64: media de horas dedicadas a estudiar entre semana y el fin de semana dependiendo de la persona con quién vive

Gráfica 65: media de horas dedicadas a Internet entre semana y el fin de semana dependiendo de la persona con quién vive

Gráfica 66: media de horas dedicadas a videojuegos/consolas entre semana y el fin de semana dependiendo de la persona con quién vive

Gráfica 67: media de horas dedicadas al teléfono entre semana y el fin de semana dependiendo

de la persona con quién vive el adolescente

Gráfica 68: media de horas dedicadas al trabajo doméstico entre semana y el fin de semana dependiendo de la persona con quién vive

Gráfica 69: media de horas dedicadas a la higiene personal entre semana y el fin de semana dependiendo de la persona con quién vive

Gráfica 70: media de horas dedicadas a salir con la pareja entre semana y el fin de semana dependiendo de la persona con quién vive

Gráfica 71: media de tiempo que tardaron en dormirse el día previo a realizar la encuesta dependiendo de la persona con quién vive

Gráfica 72: media de tiempo que duermen los adolescentes dependiendo de quién está por las tardes en casa.

Gráfica 73: media de tiempo que estudian los adolescentes dependiendo de quién está por las tardes en casa. 
Gráfica 74: media de tiempo que dedican a redes sociales los adolescentes dependiendo de quién está por las tardes en casa.

Gráfica 75: media de tiempo que dedican a internet los adolescentes dependiendo de quién está por las tardes en casa.

Gráfica 76: media de tiempo que ven la televisión los adolescentes dependiendo de quién está por las tardes en casa.

Gráfica 77: media de tiempo que hacen deporte los adolescentes dependiendo de quién está por las tardes en casa.

Gráfica 78: media de tiempo que dedican a salir con la pareja los adolescentes dependiendo de quién está por las tardes en casa.

Gráfica 79: media de tiempo que tardan en dormirse dependiendo de quién está por las tardes en casa.

Gráfica 80: media de tiempo en asistir a clase -formación del padre.

Gráfica 81: media de tiempo asistir a actividades extraescolares - formación académica del padre

Gráfica 82: media de tiempo dedicado a estudiar - formación académica del padre

Gráfica 83: media de tiempo WhatsApp - formación académica del padre

Gráfica 84: media de tiempo desempeñar trabajo remunerado - formación académica del padre

Gráfica 85: media de tiempo higiene personal el fin de semana - formación académica del padre

Gráfica 86: media de tiempo asistir a clase - formación académica de la madre

Gráfica 87: media de tiempo asistir a actividades extraescolares - formación académica de la madre

Gráfica 88: media de tiempo estudio - formación académica de la madre

Gráfica 89: media de tiempo WhatsApp - formación académica de la madre

Gráfica 90: media de tiempo internet - formación académica de la madre

Gráfica 91: media de tiempo ver la televisión - formación académica de la madre

Gráfica 92: media de tiempo deporte - formación académica de la madre

Gráfica 93: media de tiempo trabajo remunerado - formación académica de la madre

Gráfica 94: media de tiempo lectura -formación académica de la madre 
Gráfica 95: media de tiempo higiene personal - formación académica de la madre Gráfica 96: media de tiempo en dormirse - formación académica de la madre Gráfica 97: Tiempo medio dedicado a diferentes actividades - tienen pareja. Gráfica 98: Tiempo medio dedicado a diferentes actividades -no tienen pareja. Gráfica 99: internet en casa Gráfica 100: Hogares con Internet - nivel de estudios de padre y madre Gráfica 101: tiempo conectado a Internet dedicado a estudios y a ocio Gráfica 102: tiempo conectado a Internet dedicado a estudios y a ocio por género Gráfica 103: tiempo conectado a Internet dedicado a estudios y a ocio por edad. Gráfica 104: porcentaje de adolescentes que usan las diferentes redes sociales Gráfica 105: número de amigos que tienen los adolescentes burgaleses en cada red social

Gráfica 106: televisión en la habitación

Gráfica 107: teléfono móvil propio

Gráfica 108: teléfono móvil propio - estudios de padre y madre

Gráfica 109: internet en teléfono móvil propio

Gráfica 110: Internet en teléfono móvil propio - estudios de padre y madre

Gráfica 111: ordenador en la habitación

Gráfica 112: ordenador en la habitación - estudios de padre y madre

Gráfica 113: tablet propia

Gráfica 114: tablet propia - estudios de padre y madre

Gráfica 115: lectura de libros

Gráfica 116: formatos de lectura preferidos

Gráfica 117 evolución de la edad media de inicio de utilización de dispositivos tecnológicos con respecto a la edad.

Gráfica 118: evolución de la edad media de posesión del primer dispositivo electrónico edad.

Gráfica 119: media de tiempo dedicado a actividades -tener televisión en la habitación 
Gráfica 120: media de tiempo dedicado a actividades -no tener televisión en la habitación

Gráfica 121: media de tiempo dedicado a actividades- ordenador en la habitación

Gráfica 122: media de tiempo dedicado a actividades - no ordenador en la habitación

Gráfica 123: media de tiempo dedicado a actividades - tablet propia

Gráfica 124: media de tiempo dedicado a actividades - no tablet propia

Gráfica 125: media de tiempo dedicado a actividades - tener móvil propio

Gráfica 126: ti media de tiempo dedicado a actividades - no tener móvil propio

Gráfica 127: media de tiempo dedicado a actividades - internet en el móvil propio

Gráfica 128: resultados académicos de los adolescentes burgaleses encuestados.

Gráfico 129: relación nota media y normas sobre internet en casa.

Gráfica 130: ¿qué te importa más?

Gráfica 131: diferencias significativas

Gráfica 132: resultados obtenidos a la pregunta: ¿qué te importa más? 
